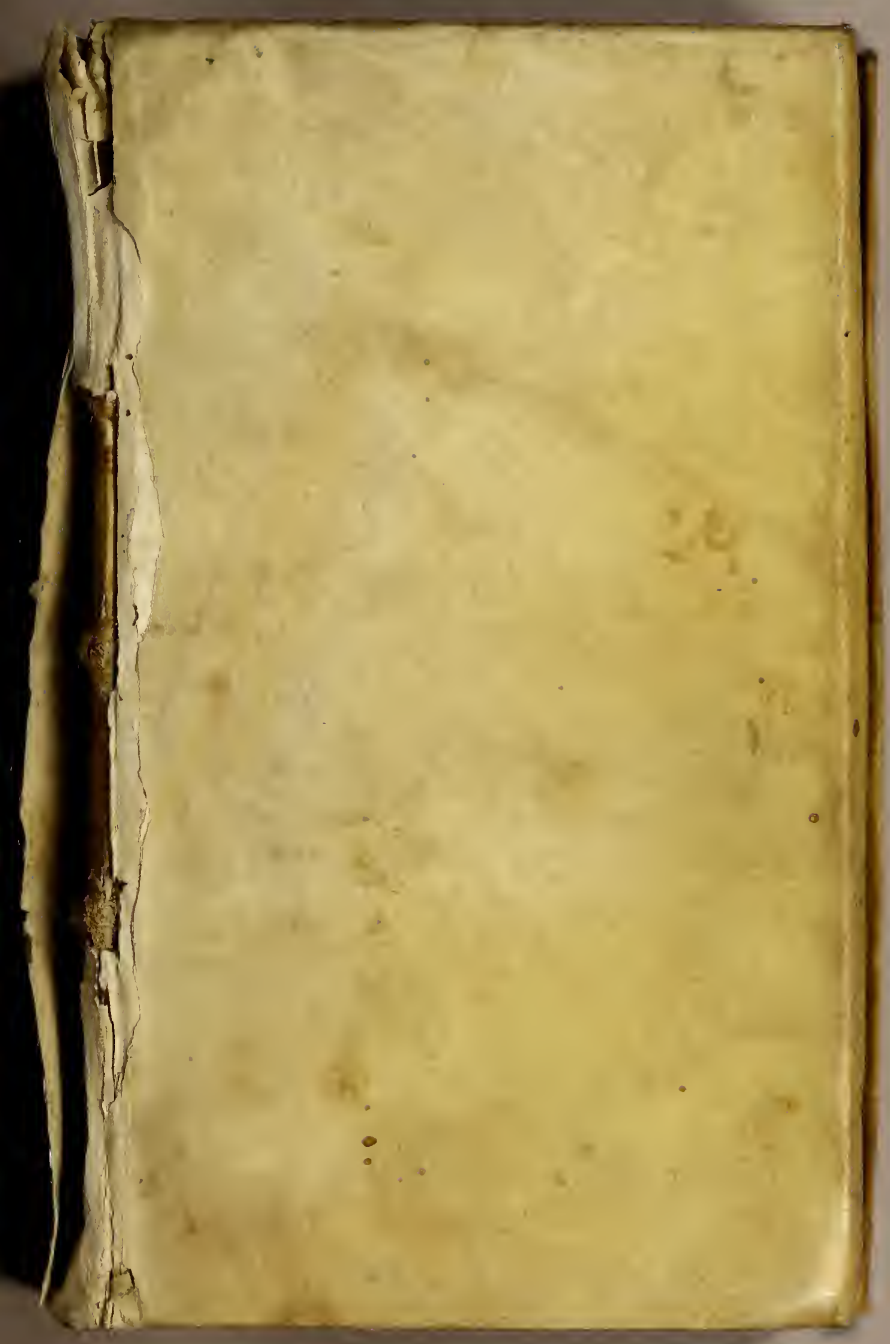




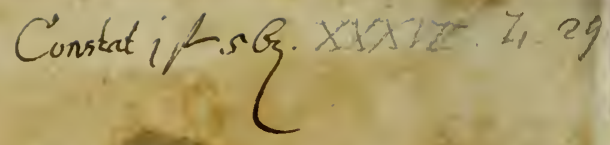

Acquired Doith the assistance of the

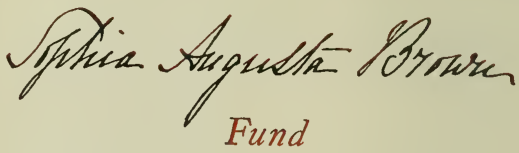
John Carter Brown Library 



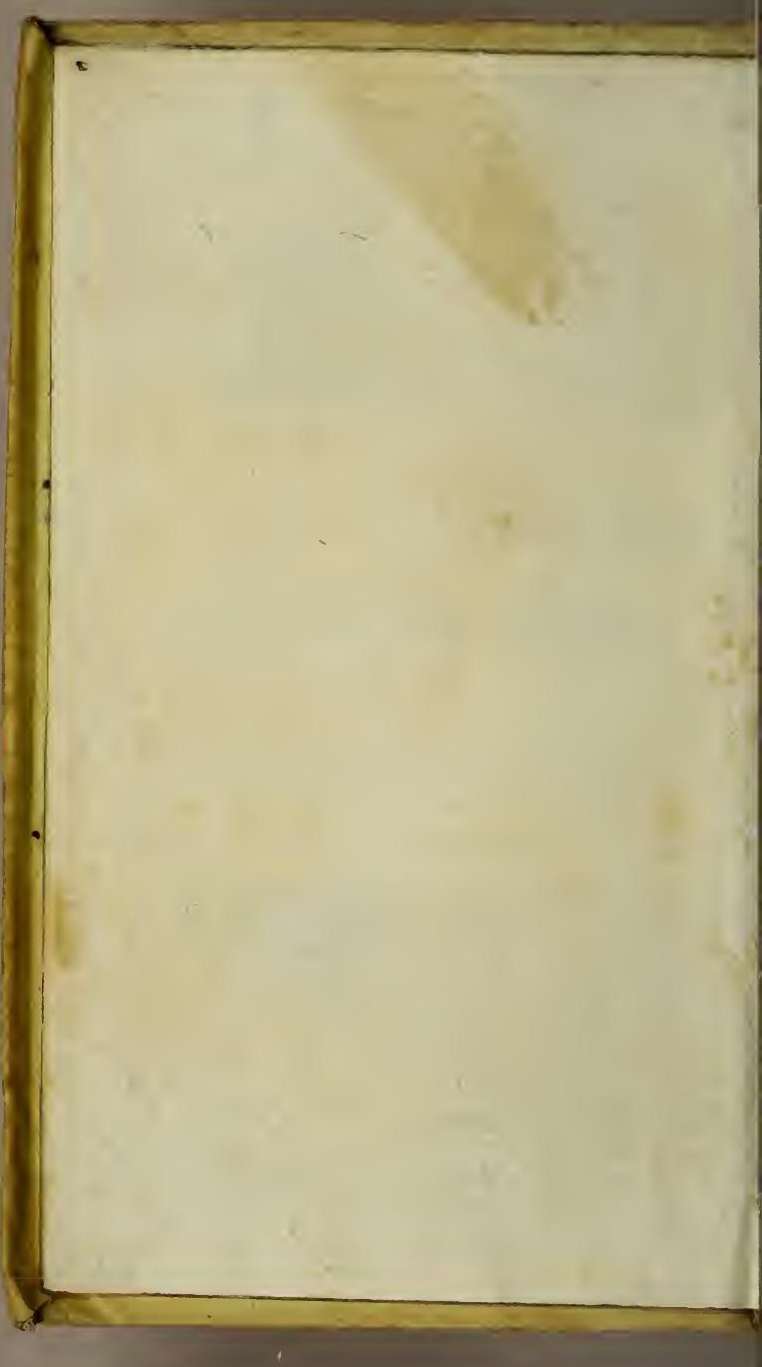




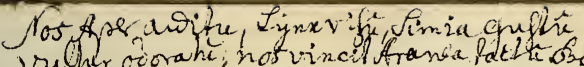

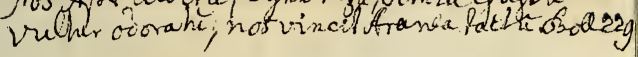




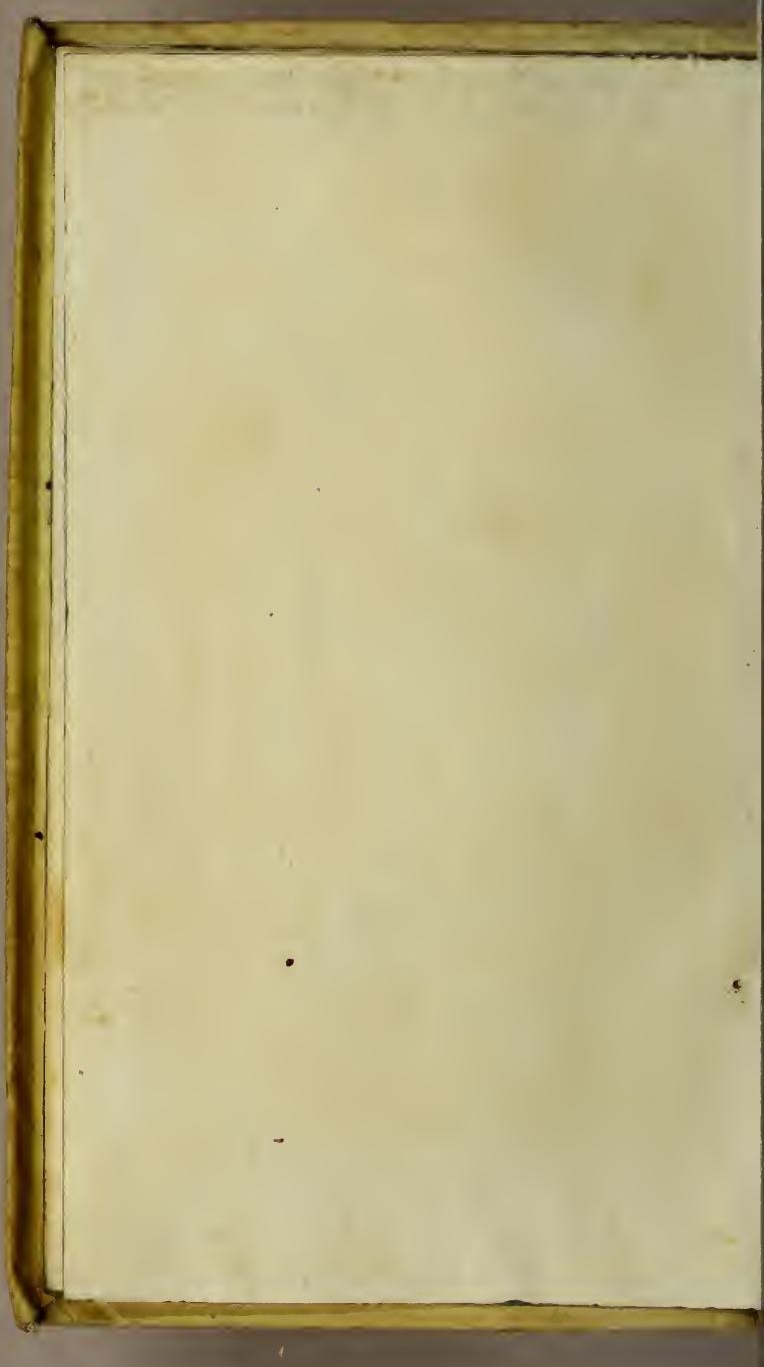




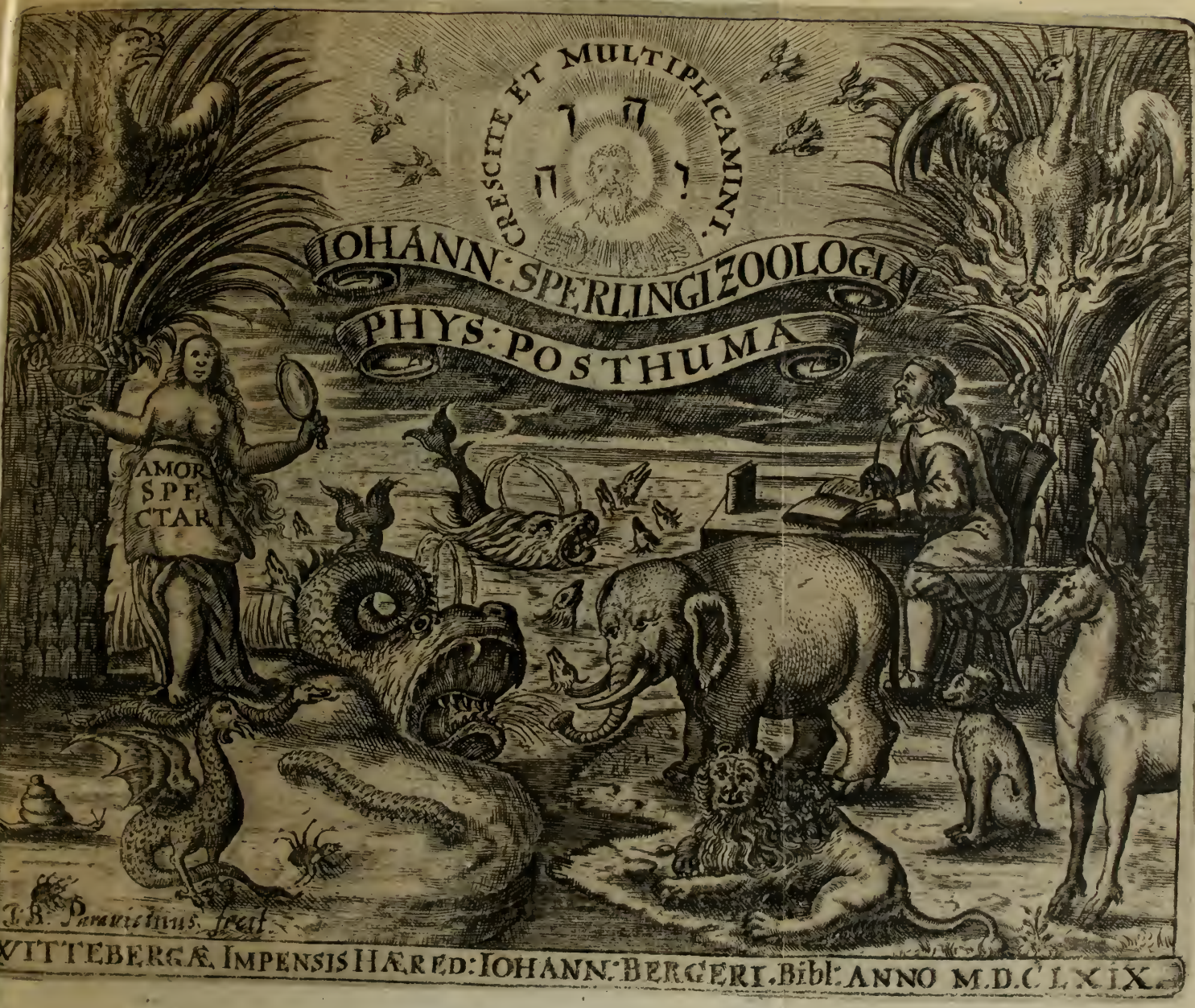




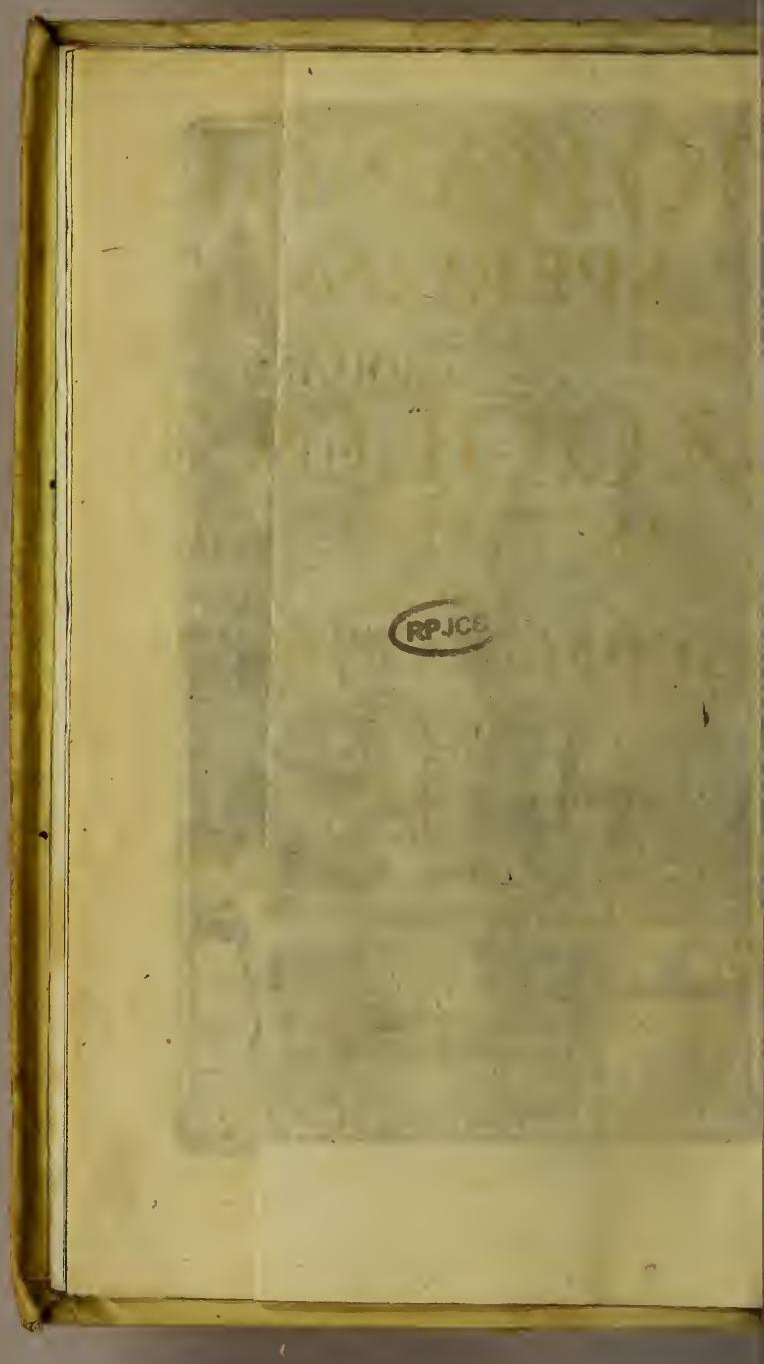




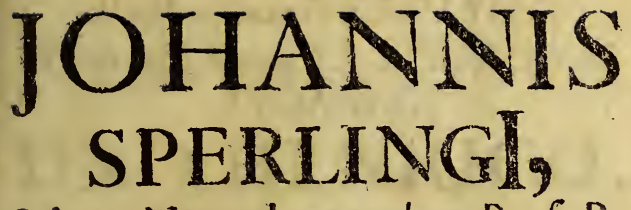

Scicnto Narural. quondam Prof. P. relcberrimi,

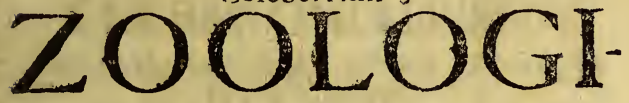

\section{AM PHYSICAM}

Recenfuit

GEORG. CASP.KIRCHMAJER, Eloqv.P.P. Wittcb.

Addiditque Difertationes

De

Baflifco, Unicormu, Pbonice, Behe. mocb, Leviathan, Jracone, aranea \& ave Paradifi.

Editio Altera, priori longè emendatior. คํำ VVIT TEBERGA,

Impenfis Hrredum JOH. BER GERI, Literis J OH. H $A \mathrm{KEN}$, Guamis Puchai med, Gis ac 


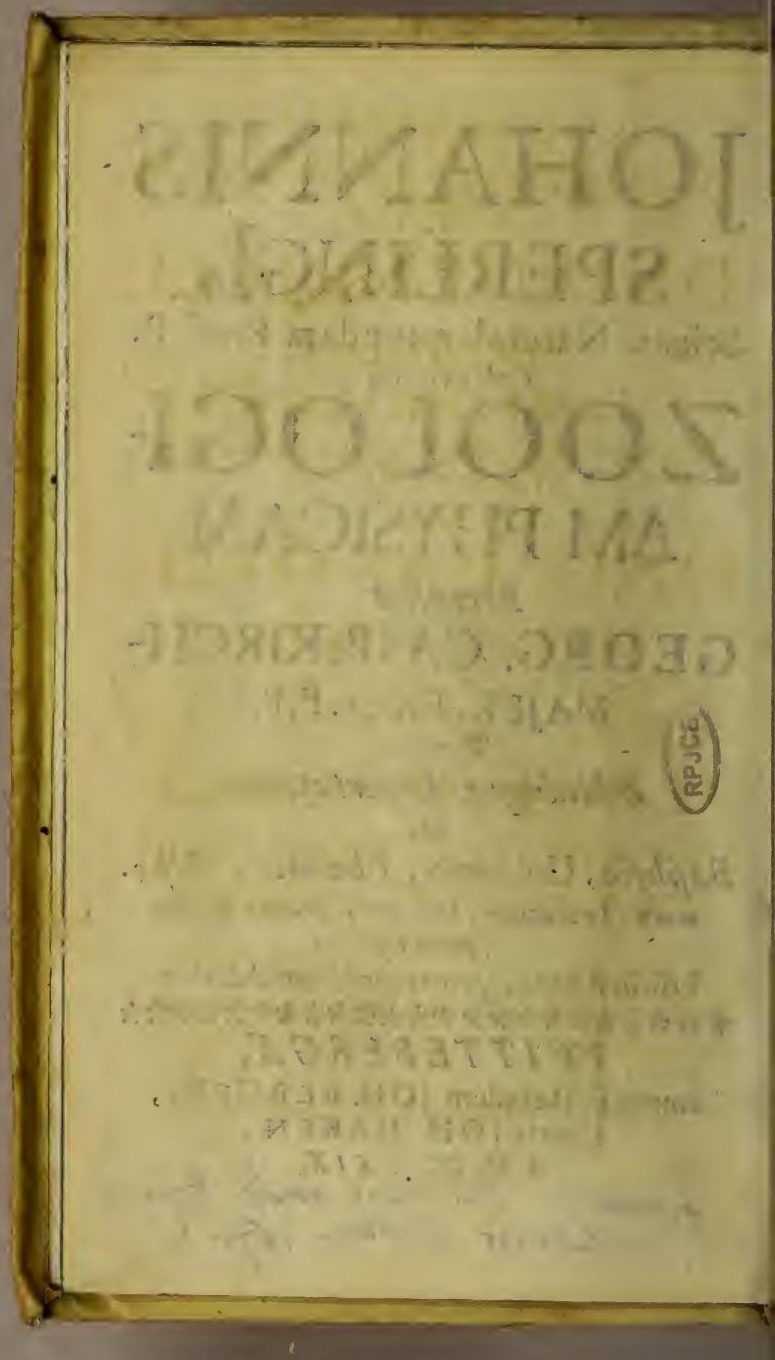




\section{Illuftrisfinis $H E R O I B U S$,}

Generofisfimisg FRATRIBUS $F$ C - DOMINIS,

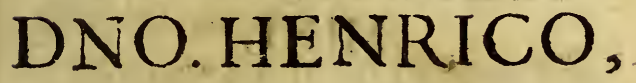

\section{SECUNDO,}

LIB. BAR ONI à FRISEN,

Putzkavii, Schönfeld. Jeffenx ac Crauppx DYNASTE:

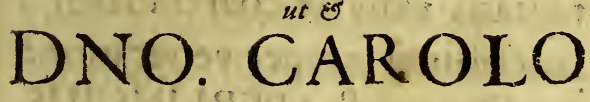

\section{LIB. BAR. à FRISEN,}

DYNASTA in Rörha . Cotta \&e. SERENISSIM. POTENTISS.g. ELEOT:SAXONIA, IN CONSILIO SANCTIORE SENATORIBLIS ET COMITIBUS EXCELLENTISS

ILLI qvidem in Intimis DIRECTORI ; HUIC verò PRASSIDI in Proto-Syncdrio Eccleliaftico Dresd. EMINENTISS. DOMINIS mCIS GRATICSIS, NUMEN FROPITIUM. 


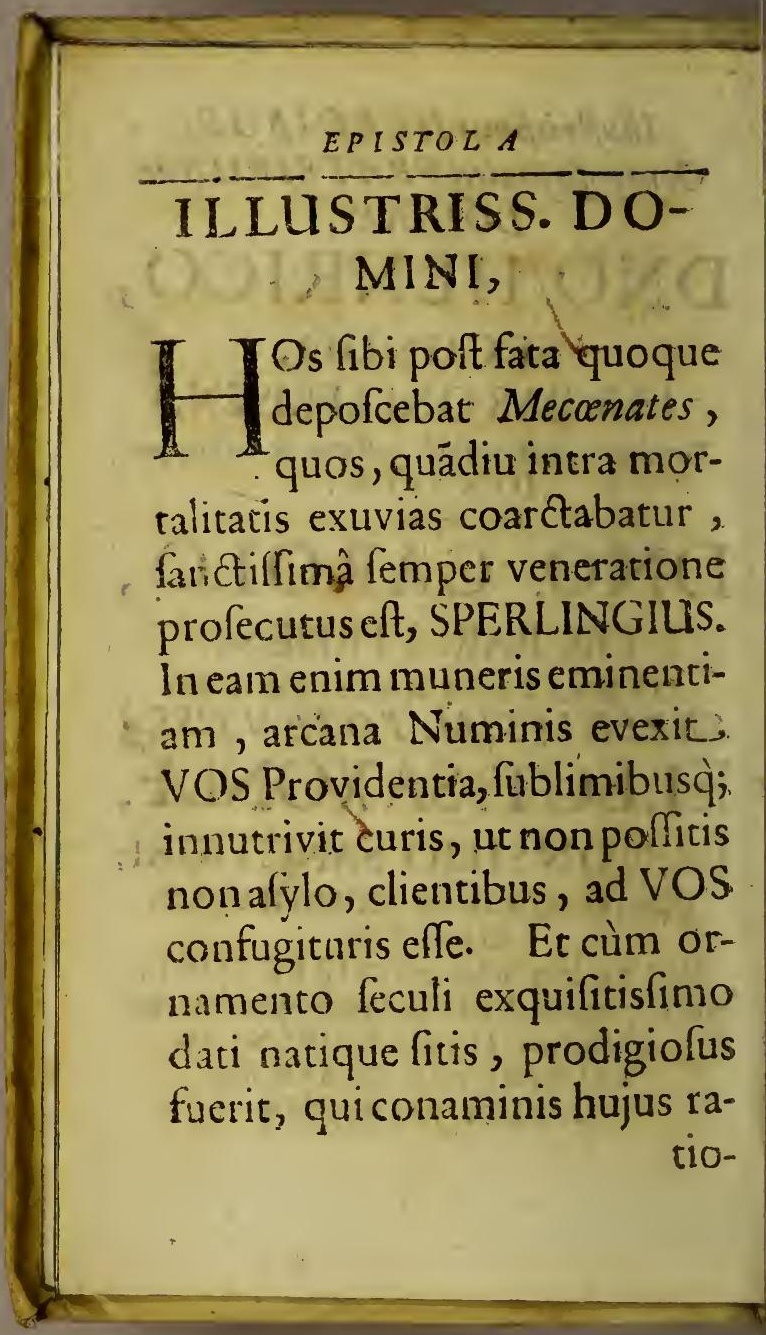




\section{DEDICATORIA.}

cionem, aut interpretamentum aliquod popofcerit.

Ac deFRISLORLIM quidem Angustisfina Nomine, atǵ univergo or bi, de reconditisfinâ a fapientiâ, controverfarm movente. judicio, quis vel dixerit fatis, vel fcriplerit? Pofitum Timanthi, ingeniofisfino pictorum, inter laudes fuit, quòd, cùm fufficiente affectui paterno luctu, Aga memnona, Iphigeniam immolationi teftinatam, deploratu. rum, delineare omninò nequiviffet, pepls, conturbatiffimi. parentis vultrui, objecto, vel adumbraret faltem, quem hullo exprimi penicillo poffe judicar

$$
\text { )o. } 4 \text { ret, }
$$


ret, mørorem. Mihi, fummo. rum Nominum MECOENATES, æmúlo conatu, quanquá alieniorefcopo, fequendus Timanthes eft. Vellem equidem \& VOBIS, HEROES, humillimü fignificare cultum meum, \&VESTRAS, COLLIMNÆ SACRI ELECTORATUS SAXONI$\mathrm{Cl}$, exprimere laudum meritisf 1 marum iliadas. Sed peplum asfumendum VOBISq;appendendum effe, animadverto: plus ut infinuafle, quàm elumbi fcriptione diduxiffe videar. Quod fupereft igitur, fulcipite, DOMINI, hoc, V OBIS, Sperlingiano nomine, à Sperlingii (dum viveret) 


\section{DEDICATORIA.}

ret) difcipulo, devotè confecratumlibamentum! non ut apocham, quâ devinctus liberetur; jed/Jngrapbam; quâ mancipe. tur magis. Ita vivite ad arbitrium, diuciffimè felices, $D E O$, PATRIA, V ORIS, bonisq; $a_{\text {- }}$ mnibus, donec cœlum, unde orti eftis, repetatis, quod precor :

\section{ILLUSTRISSIMI NOMI- NIS, VIRTUTU UG, VESTRARUM,}

Witleberg.Pri- EXCELLENTISSIMI HEdie Idus fan.

- ROES, A.O.R.M.DC.LXIX:

Devorisfimus admirator arque cliens Georgius Calpar Kirchmajer.

$$
\text { ) } 0 \text { ( } 5 \text {. PRAE- }
$$




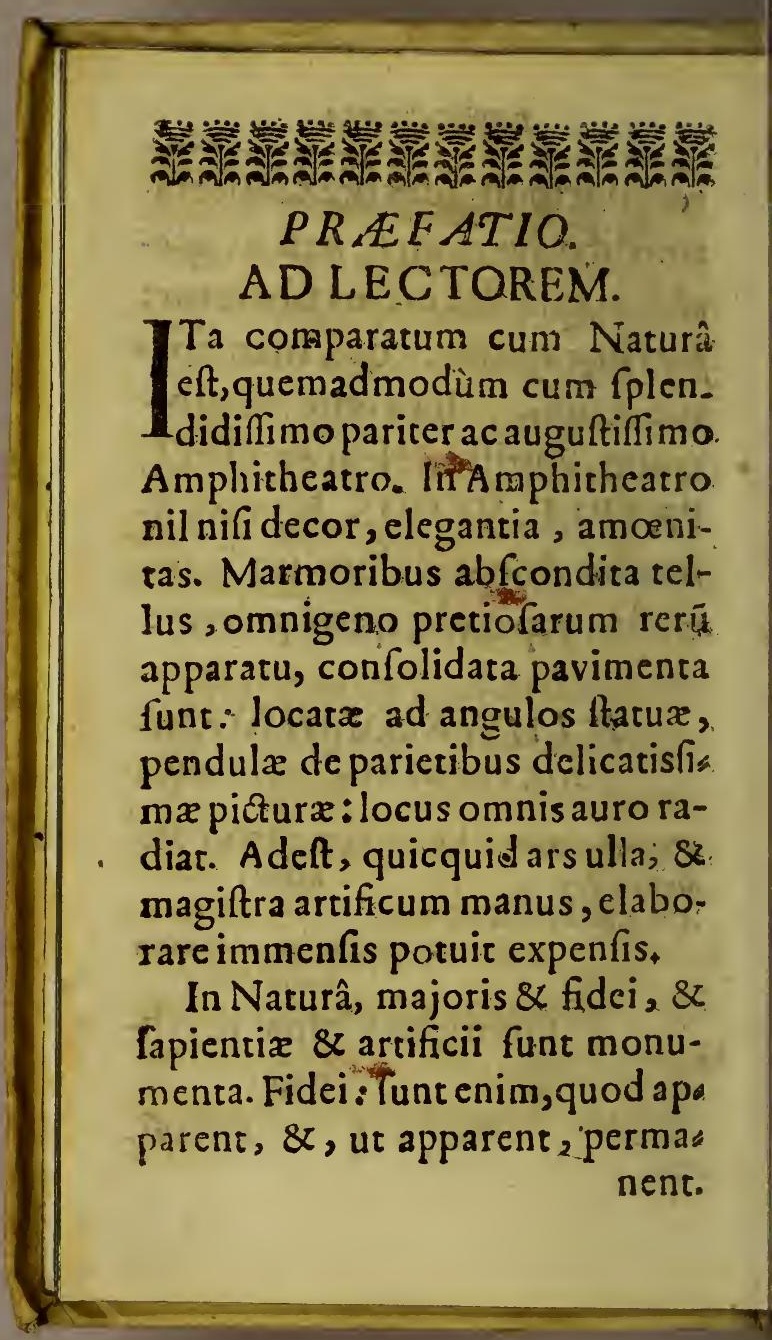


nent. Adulterina funt, caduca funt, qua ingeniofis pecunix expilandz vaframentis, folers opificum curiofitas confinxit. Sapicntix : ab optimo enim maximoque rerum Cófmoplafte, illi rerû. naturalium promanârunt thefauii: Artificiiluculentioris efle eap dem, nemo, fi voletetiam, addu. bitare poterit.

Ars potens, Natura potention, Deus potentis $2 m u s$. In hoc igitur profcenio, decor, elegantia,amc: nitasque major longè. Non marmorcâ duntaxat crưttá, fed omnimodo mineralium, metallorum gemmarumque nicore exfplendeicit. Non fictis illis ftatuis, \& $x \omega-$ Qoís roegótross; fed multifariorumgenerum animantibus, homi. nibus: (4). 


\section{PRAFATIO.}

nibus, brutis, greffilibus partim, partim natatilibus, volatilibus, reprilibusque, ad abundantiam e: tiam luperbit. Non pictis iftusmodifiguris ac colaturis, fed naturali vigore, virore, variisque alis coloribus, elegantiffima fimulacra oftentantibus, floribus, her. bis ac arboribus renidet.

Ex Amphitheatro patulus in omnes mundicardines, profpectus eft. Supera, media, infima, \& quicquid five antrorfum, five re. trorfum delitefcit, contemplari expeditè licer. Idem in Natu. ra obtinet. Quisquis in hanc fenel ett admiffus, admiranda.ex eâdem Deifpeculacur, miratur \& rimatur opera. Suprà fc, cœlum,

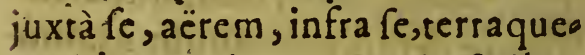
um illum globum, In colo, ftellas, lucio 
lucidifimasillas fuperioris mun difaculas: in aëre, genus oinne volanium, in matre magna inerrantes buves, oves, \& quotquot grefflium repiliumáue fpecies, Natura promaconda in apricum profert.

Tua, Pate alme, Sapientia, omnia pernovic, dum Subftantiali Verbo, lingula atọ; univerfa, intra hexaëmeron produxit, cunctaque divinoillo Spiritu, aquistaniman. dis incubante, focundayic. Tibi, Deus gloriofe, gloria immenfa! Coli enarrant gloriam tuam, Eै opera manuilm tuarum annunciat firmamentum. Dies diei erudtat verbum, Gnox recti indicat fciehtiam.P. XIX.1. 2. Nulla non pe rennifolemniq́,, five fupra, five infra, 


\section{PRAFATIO.}

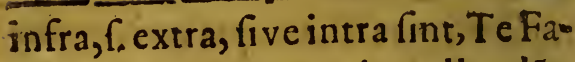
çorẽ omniü, præconio collaudāt. Interrogajumenta, docebunt te: $\mathcal{E}$ volatilia cooli,E indicabunt tibi; alloquitor terram, ES informabit te, on narrabunt tibipifcesmaris. Fob. X11.7. Clamant omnia fubinde ac ingeminant: Ipje fecit nos, Énonis pranos. Pf.C.3.

Nemo igitur, ut ad te, Lestor optime, deveniamus, facilè mirabitur, quid femper incitamenti moverit incomparabile Phyfico. rum decus, JOHANNEM SPERLINGIUM,tanti \& judicii $\&$ can doris, dum in vivis effet, Philofor phum, quantum \& fapientia \& fit des intelligiâ quôquam potelt, ut omne vitx tempus, prout officii efflagitabatratió, rimandis pari$+\cdots$

ter 


\section{PR.EFATIO.}

ter \& mirandis hifce omnipotentix divina fimulacris impenderee unicè ac confecraret. Pridem eft, quód iple alibi cum Romano Sapiente (Senecam indigitamus) quoties per occulta naturx ibar, divina fe tractare gloriabarur.

obfervationem meretur, in quit, griod prifcos Eccleja Doctores,nulla alia Pbilofopbia portio occuparerit magis. Reverentiam meretur, quod primus bomo, in beatâ illầ innocentise conditione, in bâs cumprimis exercuit ingenium. Deus enim glo iofus, adductis undiquag, animalibus, nomine ab Adamo poftulabat. Ut pericislum faceret naturalis fientieg grem digitis omnipotentic in foripferat. Etmox fubjungit Ma*apirys : non itaque pudet me infte bowp 


\section{PRAFATIO.}

dio boc decurrere fubinde, 6 confamerextatem. Meretur id.rei dignitas, qua magnificentiâ fui, mes detinet. Hæc Sperlingiana intens tio, hoc votum unicum.

Equidem janr ante ipfum, de A nimalibus qui fcripsêre, fuerunt complures, \& hi fuâ nullatenùs defraudandi laude. Omnium, inde ab Adamo abfolutisfimus Zoologorum, SALOMON erat: quippe qui docente r. Reg. lib. c.IV.v.33. 34. locutus est de lignir, â Cedro, qua funt in Libanon, E' usgad byßopwin, que egreditur è pariete. Et locutus eft de animalibus volatilibus, reptilibus Enatatilibus. Quæ omnia latiùs adhuc perfecutus eft \& exrendit Autor libri Sapientie, Cap. Vlloà v.l usque ad 21 . Hanc veQ⿻i𧘇

rô quod 
PRAFATIO.

rò quod attinet Zoologiam Saloa moneam, tantum illa nobis vel profuit, vel proderit, quantum immen $x$ Sardanapali alicujusga$\mathrm{zx}$, quas. Vulcanius exuffit furor \& nemo noltrum aut vidic , autua furpavicunquàm:

De Abderitano Democrito, fapientiffimo, quod ei encomium Hippocrates adomar, Viro, ex Diogene Laërtio; foannes Cbryfoft. Magnenus, Burgundus, ' 2 in Ticinenfi Univer fitate, Regius $M e d$. $P$.infuo, quem vocat, Democris torevivifcente, notat, quomodo 8 ipfe de Animalium foripferit docueritque caufis. Atque ita quidem contentiflime brutorum fcifcitatus naturas, temperamen ta, morbosque eft Democritus, u$\mathrm{b}_{2}$

ti in 


\section{PREFATIO}

ti in prolixâ quâdam, ad cenarum A bderitanum, epiftola fect 8. p.1z: Hippocrates teftatur, $\mathrm{fe}, \mathrm{c \grave {s }}$ in ip. ŭ primò nffendiffet, intra crebra animalium cadavera, per rotum diffect \& accumulata, deprehendis fe Democritum, exta curiofisfa mè luftrantem, mox deambulantem, pòft, intento ftudio friptio. ni incumbentem. Veruntamen quod fatum , Salomonéam deper, didit Philofophiam, idem, fed ras men ex invidiâ fequentium PhiJofophorum, Democriti annihis lavit etiam labores. Plato enim omnes Democriti libros, memo rixinvidens, comburendos des creverat. Sed hîc fortiter eı reftiterunt Philofophorum plurimi. At quod Plato defignaverat, executus. 


\section{PRAFATIO.}

cutus eft Alexandri ope Ariftoteles.

Ipfemet proinde Stagirita, undeunque fua de animalibus peries. rit, per faturas \& centones 1 arios, ut apparet, conferruminavit. Nolumus invidere gloriæ ejusdem, fed, ne pro Numine, eundem in Philofophiâ veneremur, faltem petimus. Maximuin in contexendu rerum naturalium, imprimis animalium catalogo, Iaborem cùm fultinuerit, C. Plinius Secundus: majorem \& famam \& gratiam meruiffer, fi tantunmubiq̧; fidei, quantum ftyli reliquifter. Hine cùm fabulofa (quanquàm quid mirum eft, ff ex aliorum in coms. muni fapias relatione) plurima admifceat, non tam memoriâ in

$$
\text { b } 3
$$

eval 


\section{PRAFATIO.'}

evolvendo ipfo, quàm judicio in difcernendis fabulofis opus eft.

Solinus, Pliniana Simia , ejusdemq́; ferè Epitomator, pauciora fecit, pauciora meruit. De Claudio Aliano, quid habendum fit, explicuit haud obfcurè, in prafatione, fuper eundem, Gefnerus. scaliger o Cardanus, maximi ambo Viri, qvæ de animalibus perfcripsêre pasa fim, haud proletaria funt. Sed ordo omnis abeft. Gefnerus atque Rondeletius. tam diu laudabuntur, qvamdiu homines fupererunt. Franzio, piisfimo The- logo, crimini nemo verterit, quòd in animalium hiftoriâ, ad ufum ma= gis \& Theologiam refpexerit, fi ipfius. \& rcopum attendat, \& præfationem. Omnium quicunque vel fcripsère vel fcripturi funt, operofiffimus \& consümatiffimus huc usque extitit Zoologg, ulyffes Aldrovandus, Philof. E Med.Boso. nienfis, qrem, non dicam commendare, fed admirari fatis, aut condigno,pro immenfis, Zoologix gratiâ impenfis, cùm 


\section{PRAFATIO.}

cừn funitibus, tù m laboribus, mactare praconio, nemo utiquàm poterit. Attamen cùm ne â centefimo quidem, propter fumtuofi, $\&$ in plurimos digeftimajores Tomos, operis, tanti induftria Viri, proprio redimenda are fit, opulentis potiùs, quàm quibus angufta domireș eft, fvadendus Autor.Job, Eus feb. Nier embergius, Pbyfolog as Nadrit. in Hifpania, exterorum potitus locorum , quàm in Europâ domeftic orum animalium hiftoriam contexuit. Celebris nunc eft Jobannes Jonftones quod;;, qui, ut pluribus confuleret, ea qua ab aliis prolixiùs narrantur, coarctat in com. pendia.

Quan quàm ab omnibus his, omnia confusè magis, quàm methodicè ac ordine tractata: fine famx obtrectatione utid fateamur.

Vides Lector benevole, quantam gratiam SPERLINGIO, poit fata quod; debeas. Hic enim ut prodesfet omnibus, compendiose : ut delectaret, orna. tè ac perfpicuê: ut ordine proponeret accus: 


\section{PRAFATIO;}

accurata hanc, quàm vides, Zoologiam, methodo, cum viveret, adornavit. Ec expoliviffet utiq́; magis ac dilataffet,nin\&calculo tortore impedirg, \& filix unicæ mortis interventu perturbatus, \& ipfe deniq́; inaufpicato Libirina ictu, cū ingenti Studioforum luctu Phyficagre damno, contumulatus equidem fuiffet. Quod Te, Lector benigne, non celdndum duximus, ut, fi in pifcium, aviü, infectorumque contemplatione, bree. viorem quàm alibi, ipfum deprehenfurus îs, non mirêre. Tuhis interim conis tentus vale, \& favere perge.

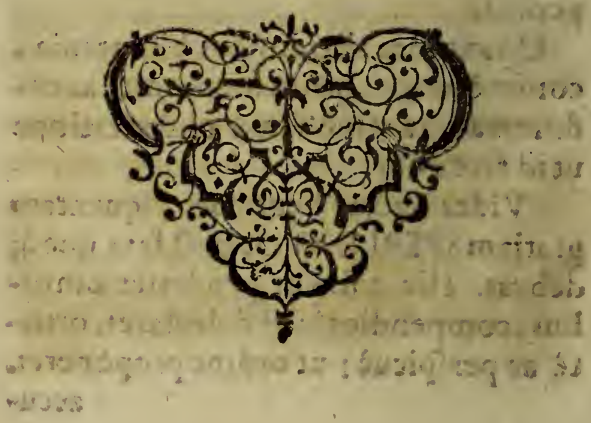




\section{I. \\ ZOOLOGIEE PHYSICE.}

Proëmium.

CAP U T I.

D. $E$

Natura Zoologix Phylicx.

Precepta.

1. Zoologia Phyfica eft fcientia bruto. rum, qvatenus corpora naturalia funt. 2. Dividitur in partem Generalem \& Specialem.

3. Generalis eft, qva brutum in genere confiderat, ejusć; naturam exhiber. 4. Special is eft, qva bruti fpecies propo. nit, earumq́ve naturas tradit.

\section{2uaftiones.}

1. Qva notanda circa Definitum? R2-D Efinitum eft Zoologia Phyfica. Zoo-

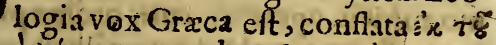
$\zeta \omega^{\prime}$ roù $\lambda$ óys: notat doctrinain de brutis. $\mathrm{Z} \tilde{\omega} \alpha$ enim non rarò exponuintur feécialiter, animantia bruta. Phyfica dicitur, ad differentiamZoologix Medicx \& Zoologia facrx. Medici bruta confiderant, non tam ut naturalia corpora funt, qvam ut materiam medendi prabent. Theologi bruta fpeetant, ut ad Del majeftatem, ad vitio depo and 
2 ZOOLOGIA

nenda, \& ad vitam corrigendamfaciunt. Olim etiam Sacerdotes fcientiam hanc ad facrificia apṕlicabant.

II. Qve notandacirca definitionem?

- R. Definitio conftat Genere Differenria.IIlud eft f́cientia, non Totalis, fed Partialis. Hacsubjectum habet, ejusq; cum Mareriale, tùm Formale. Illud, brutum eft; hoc, gratenus corpus naturale. Hic enim nolter confiderandi modus eft, fic fuum cuiq; tribuend $\tilde{i}_{2}$ \& noftrum qvod eft, non negligendum. III. Qve notanda circa Divifionem? nividenda Scientia ad rationem Subjecti eft. Brutum \& communia habet, \& propria. Ipfa igitur Zoologia partem habet communem \& partem propriam. Nor mifcenda pecialia generalibus, nec generalia fpecialibus. Divina res ordo eft:nihil in animo,nihil in operesapientis ordine praftantius. Semper nobis fit curx illud, qvo fire nec natura nec artis conftare polfunt opera.

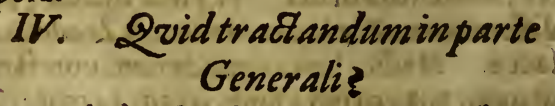

B. Primò anima brutorum: Secundò corpus. Omnia animam habent, omnia corpus habent. Hac antecedunt f pecies; cum omnibus 


\section{PHYSICA.}

bus infint. Leo animam habet, corpus habet: nec minus accipiter, aut delphinus, aut ferpens, aut vermis. Leo videt, audit, movetur: jdem aqvila præftat, idem lucius, idè cancer. V. Quid tractandu in parte Speciali? B. Brutorum f pecies. Teftatur Scriptura, Deum creaffe reptile, volatile, cetos magnos \& jumenta. Teftatur eadem salomo. nem dilputafie de jumentis, de volucribus, de reptilibus, \& de pifcibus. Hrillæ bruto. rum fpecies funt, fub quibus aliz atq́ve aliz comprehenduntur. Unde notx fcientix, da avibus, de pifcibus, de grefilibus \& de re. ptilibus. In fingulis vero tanta interim varietas eft, ut innumeras foboles in ordinem redige re neqveat hominum folertia. A deò verè dictum à Platone: Difficilia funt, gra pulchra funt.

\section{Axiónata.}

\section{Zoologiafcientia preftantißimaeft.}

Ea proponit, qva proximè accedunt ad dignitatem hominis. Ea docet, qraDeus ipfe primo homini indidit. Primus Zoologix doStor Deus fuit: : primus difcipulus, primus homo. In fanctifimo illo ftatuDeus gloriofus,adductis undiqvaq́; animalibus nomina poltulabat ab Adamo, Ut foristizhijus, A 2 
4

\section{ZOOLOGIA}

qvam iomnipotentix fux digitis infcripfe. rat, faceret periculum. Hinc facra, hinc regia facta eft hac fcicntia. Sapientiflimum Salomonem à curis publicis revocavit materiæ hujus dignitas. Et Alexander Magnus, finon fcripfit ipfe, fecit ut fcriberentalii, qve de brutis manda rent aternitati.

II.Zoologia/cientiajucundißima eft. Jucundum eft intueri ftellas, Solem, Lunam aut Jovem: fed plus amœnitatis in una apicula, in una hirundine, qiàm in cunctis fideribus. Ibi fplendor nos movet \& curfus \& ordo, \& perennitas. Hîc ingenium nos tenet \& folertia, \& futurorum notitia \& commodorum ac incommodorum difcretio. Accedit partium decor, \& numerus \& ordo \& compofitio. Infuper unumqrodq; præditum eft amictu fuo, jucundo perquam \& naturæ opportuno. Ares plumis ornantur,pifces quamis, armenta pilis, infirmior a tectis, cruftis \& conchis.Quxv is fpecies propria habet ornamenta, alterius qvælunt, horum nec a ppetens, nec egens eft. Pulcher. rima avis pavo. Sed nec anati deeft decor fuus. Eqvus fuperbit formâ, animo ac geftibus : fed non minorem fe putat gallus, nec carduelis, nec regulus. Jucundum eft fcire, qva jucunda funtipfa. 
III. Zoologia fcientia utilis sma eft Alio remittit fpeculatores Zoologia , \& meliorem, potentiorem, ac fapientiorem haturam indicat. Tres funt radil lucis invifibiles : bonitas, potentia \& fapientia.Potens eft Deus, qvi tot brutorum fecit generá. Bonus eft, gvi omnia fecit bona, \& ut ho. mini prodeffent, voluit. Sapiens eft, $q v^{2}$ ordinavit omnia fapientiffimè, difpofuit pulcherrimè. plena horum teftimonio. rum Scriptura facra eft. Qva Deus ipfe refert Jobo, de cerva', lextia, ibice, onagro, rhinocerote, ftruthione, eqvo, aquila \& accipitre, evolvântur, conftabit maximè sirpremun ubique indicar Numen. Sed \& gubernationem Reipublicx fi petit Jurisperi tôs, Zoologia eam tradit. Rex apum, clemèntiám colit, innocenti aculeo: ipfa apes ficelitatem in rêgem declarant, quem nunquam deferunt, qrem imbellem teftart, qrein erranitem qvarunt. Mediciham qui vult, adeat bruta, prebent materiam medendi praftantiffimam. Qvin Medfcina ipfa, aut ominis, aut pars, brutorung finventume eft. Pleraq́ve cognitionem \& $\mathrm{u}$ fum fimplicium habent, ac ipfa fefe reftituunt. Cancèr \& félis, cum nimvia ingluvie ope pleta fentiunt vifcera, gramina rore perA 3 fura 
6

\section{ZOOLOGIA}

fura comedunt, ut ventrem dejiciant. SinguJis hominibus qvid conferat Zoologia, ta. cere praftat, qvam leviter attingere.

IV.Zoologiafcientia difficillima eft.

Nomina brutorum faciesq́ve externas noviffe parum eft. Imperitorum habitum fuit detineri in minoribus : formas verò earumque virtutes \& operationes tenere, permagni momenti res eft. Cardanus de fubkilitate fua fcribit : Si certo fcire femper laboris -fum fuit, qvid boc argumento taboriogus? Ubi: babeam qvos fugiam, ut Plinium o Albertum, grod palam mentiantur, qvos fegvar, non habeam. Venitidem ufu nobis, qvod fcripfit iple. Infumendus in rem hanc labor eft,cum ob multitudinem, tùm ob fubtilitatem. Per tot animalium formas $2 c$ fpecies ire, laboriofifimum eft. Obfervata funt fcarabro. rum genera quadraginta, erucarum qvin. qvaginta,murcarum feptuaginta, papilionũ centũ \& plura. Probati qvidem autores non defunt, qvibus nihil debere fe qui di. xerit, ingratus fiet.Sæpè verò non tam memoriâ ad difcendum, qram judicio ad di[cernendum opus eft. Sequendi funt, cum ipfi feqvuntur verum, furgiendi, in devia cum ducunt imperitos. 


\section{A PHYSICA. CAPUT II. ATra th II DE BRUTO.

Precepta.

I. Brutum eft animal irrationale. II. Dividitur in Volatile, Natatile, Gresfile, \& Reptile?

\section{Qirestiones.}

1.Brutum 6 animal quomodo differant?

7. Ut Genus \& fpecies. Animal corpus animatum fentiens eft Dicitur de bruto, dicitur de homine.Leo corpus eft, animati eft, fen. tiens eff . Homo corpus eft, aniniatĩ eft, fentiens eft Superius igitur animal eft, inferius brutî,inferists homo. Nófunt fpecies côtra diftinct homo\& animalifed homo, brutum, \& planta.

\section{I. Irrationale quid notet?}

R. Animal bruti genus eft, ir rationale, differentia.Differentia peciem conftituit, $\& a b$ aris diftingyit. Conftituit irrationale brutum, \& ab homine qvi rational is eff, diftingvit. Errant qvibus nil nifi negatio, nil niff remotio rationis eft irrationale. Negatione non conftituuntur bruta, nec diftingvunturrectè. Frequentiffimumeft voce negativa exprimere rem pofrtivam. Ex penuriâ v́ocabulorum loqvimur ut poflumus,nonut volumus. $A_{4}$ III. 
8

III. In qvâ quantitate bruta creata

R. An in magna an parvâ edita fintquxri- endum. Benedictionem acceperunt fefe multiplicandi. Sed generatio \& multiplis catio perfectorum eft. Creabatur Adamus perfectus, perfecta Eva. Producebantur herbx \& arbores, ponis, piris \& aliis frutibus onuftx. Non eft ratio, qvin eadem perfectio concedatur brutis. Neǵs impolitbile Deo omne verbum, qui verbo fecit omnic. IV. In quo numero brute creat a fint? 78. Coneroverfia eft,an bina tantum creata fint in omni animantium genere, exemplo noftri generis. Sed terrani allocutus eft De. us cum dixit : Producat terra animam viventem ingenere fuo. Aqvam allocutus eft, cum dixit: Producant aque reptile; natatile of polatile. Non glebas aligvot terrx fumpfit aut guttu: las a ligriot a qvæ , fed totam terram, totam aqvain. Hinc pro multitudine, non pro paucitate colligendum. Placent verba Theologi præclarè meriti Polycarpi Lyferi. 2uam. primùm Cresior, verbumdicit, protinus multe iurme natatilium er volatilisw producuntur, iaģtaniâ copiá,' ut omnia foateant non aliser

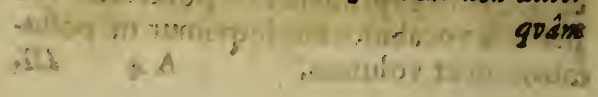


PHYSICA

quam fiputris cafesus (ut crafjo fimiliutar) ver: mibus fraceat.

$V$. An quorundam brutorum ingenia mutata fint?

R. Difputatur an iden creationis tempore feris fuerit furor $q$ vi nunc eft: An benignillimus DEus fecerit illa iracunda, rapacia; $\&$ exitialia animalia? Non exiftimandum fubftantiam brutorum mutatam efle ob hóminis transgreffionend! Indicant aitem ungves, dentes,cornua \& alia acerbam indolem. Inmoxircquidern fuiflent homini, fed non aliis brutis. Ex raptu vivunt multa qva nociva fuiffent, crudelia fuiffent; exitialia fuiffent, fi vel maximè mundus fervaffet ho. norem fuum illibatum. Poftgvàm vero homo rebellis faetus ef DEO, meruit \& iple rebelles fibi pati fubditos,

Axiomata

1. Brutorum non eft logui.

Longo ufu \& labore imitari difcunt unas \& alteras voculas fine judicio, fine articula. tione. Qvod \& campanx \& inftrumenta mufica \& alia hominum artificia praftant. Adfit in fermone vox articulata \& fit verbum ex inftituto fignificans. Nihil de his in corvis,nihilyn $p$ fittacis \& aliis fermonis nor Atri æmulis. Taceat Porphyrius qui omnia A 5

brut2 
bruta colloqvi inter fe, \& loqvelas eorurn calluifle A pollonium refert.

II. Brutorum non eft ridere.

Ridet cuculus, ridet Pfittacus : Scd. hic rifir artificiali,non naturali : ille ita more mag is \& ineptïs, quam rifu verô. Ut inter homines multi imitantur lat ratum canum, grunnitum porcorum, cantum gallorum: fic brutorum qvadam rifum, qvadam fermonem affectare videntur. Sed fpeciem \& imaginem non rem ipfam, indulgemus ipfis.

\section{Brutorum non efflere.}

Fletum non qvævis dat guttula; qvivis. humor. Non lachrymatur ftatim, cui oculi aqvis ftillant, Aut fi lachrymx dicendx:no. men habeant, recarent. Sicut plantis etamalfigna runt lachrymas, humorem guttatim prolicitum." Animi gaudent is rifus eft: \& animi mærentis fletus.

\section{Brutorum non eff velle.}

In voluntate libertas eft. In libertate indifferentia eft adutrumvis. Ut agens pofitis omnibus reqvifitis agere \& non agere, 2 gere hoc vel illud polfit. In brutis nulla libertas, nulla indifferentia eft. Non habent id in poteftate brutà, qrod accipere alliqvid ant rejicere polfint. Neceflario bo. numamplectuntur, malum doteftantur. Se- 
cus agere cum videntur, terrentur metu. Hinc qrod unus canis, id omnes agunt. Qrod unus lupus, id cuncti praftant. Qvod non libertatis, fed neceflitatis eft argumentum.

\section{$V$. Brutonum non eft intelligere.}

Nullus veritatis amor in brutis eft. Or- is dinatur autem intellectusad verum. Huic nulla poffeffio, nulla vis auri \& argenti, nullius a micitia, pluris æeftimatur gram veritas.Pro veritate pugnat $\&$ totos dies, totos annos confumit. Bruta ad cibum rapiuntur, quê eis largè \& copiosè comparavit natura. VI. Dos E'gloria Brutorum fenfus

$$
\text { est. }
$$

Singula fentiens fuâ animá gubernato

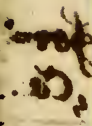
Hâc prædita, vident, audiunt, odorantur, guftant \& tangunt. Unde \& egregia accepês re membra: oculos, aures, nares, lingvam \& membranam. Minor partium apparatus in plantis eft, qux nec vident, nec audiunt, nec reliqva fenfuum munia edunt. Exizua arborum \& herbarum inftrumenta funt: vivunt fine auribus, fine oculis, fine cruris bus.

VII. Magna Sapientia Grutarum

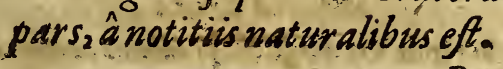

Parveres

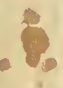




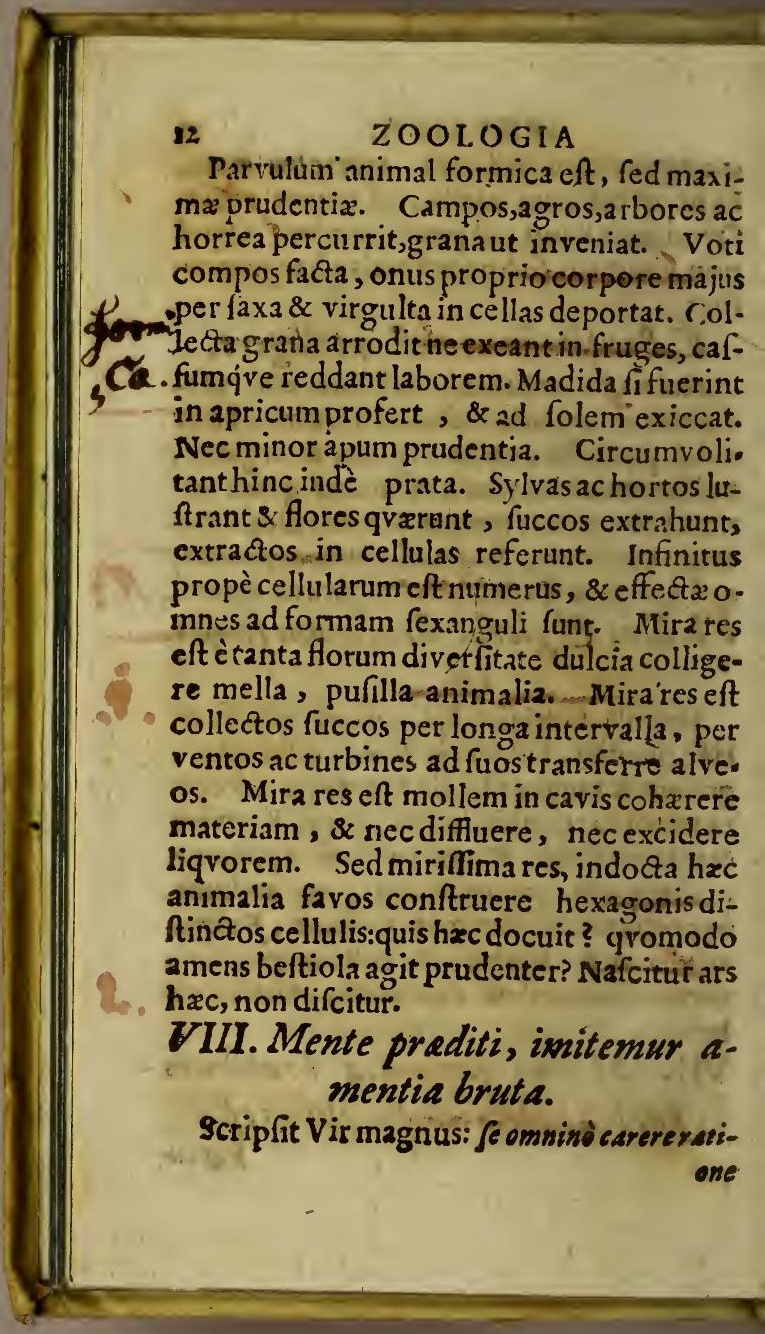




\section{PHYSICA.}

one, fulephascareat. Hacin fpeciem dicun tur, contra majeftatem noftram. Negligentes dignitatis fux funt, bruta qui extollunt ob inuftas qvasdam rationis notulas. Habent fimulacrämentisquã in nobis nó colimus, fi in ipfis revereamur. Admirationé nobisfineutitveftigium mentis in Elephante, magis admirabiles nos reddetmens ipfa. Non eft imago praftantior opere, non eft umbra berfectior lumine effigies ment is fi feras facit nobis fimiles, poffeffio ejus vera Deorros faciet proximos. Erubefcat homo, fi ultra dignitatem aflurgunt bruta, \& infia eam defcendat ipfe. Pudeat bruto. rum xmulum non effe, \& divina fectari po. tilis, qvàm humana, qvàm terrena.

FP Ferler 38. \%ino for DE:

BRUTO IN GENERE.

LIBER PRIMUS.

$D E$

ANIMA BRUTORUM.

CAPUT I.

DE NATURA A NIMA BRLTORUM.

Pracepia.

1. Anima Brutorum eff forma, qva funt; \& ad feritatem ducuntur.

II. Habe. 


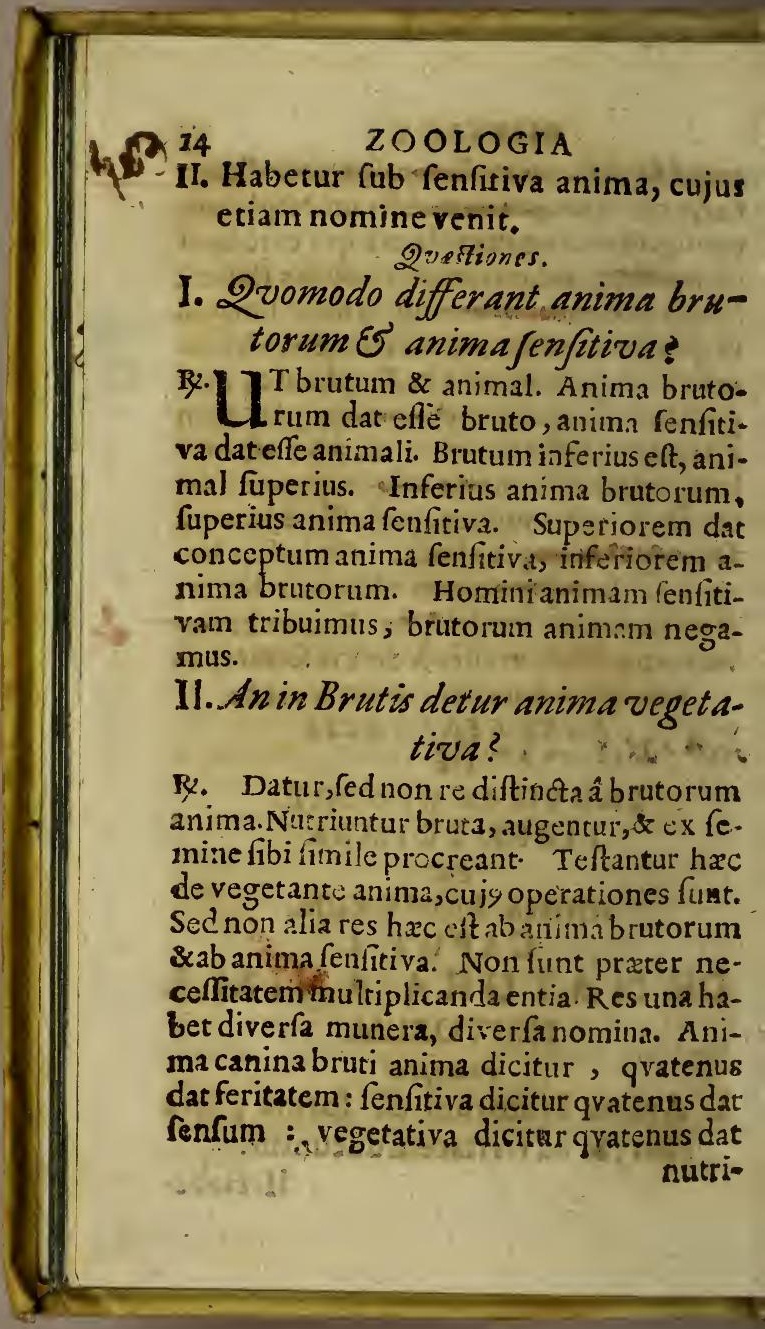




\section{PHYSICA}

nutritionem, augmentationem, procreationem.

III. Quid animaBruti,bruto praftet? I). Dat irrationale, ficut anima hominis, homini rationale. Hoc irrationale notat $e$ fontiam, connotat differentiam, connotat operationes," Brutalem naturam dat aniin bruti, brutales affectiones, brutales operationes. Manifeltahxe"funt in cane, $t i$ gride, urfo, ac Leone: Et,fi qvadamin non adeò ferociunt contra hominem, aliis tamen brutis infefta funt, \& exafperata ne homini qvidem parcunt.

IV. An omnes brutorum anime e. jusdem perfectionis fint?

\$. Specie bruta differunt, \& in fingulis iterum magna varietas eft. Alia magnitudine, alia pulchritudine, alia urroç; horum cxcel. lune. Quxdam parvitate, grædam deformitate, qvædam utroq; inferiora fant. Cele brantur alia induftriâ \& rei familiaris adminiftrandx peritiâ : alia ignava funt, inertia \& improvida. A lia elegantiarum Atodiofa funt; alia cultum omnem fpernunt. Tan't2 igitur animarum diverfatas eft, qranta morum, qvanta corporum eft. Nec pucemus candem effe perfectionem, in hirunisses

dine 
I6

\section{ZOOLOGIA}

dine aut halece, qvaeft in Leone, in Aqvila, aut Dclphino.

\& Axiomata

I. Anima brutorum non eft piritus. Intelligere \& velle potiflim $x$ fpirituum actiones funt. Hxciftorum exercitia, co gnofcere verum \&agere liberè. Nec vee rumamat, nec liberè agit brutorum natura. Duciturneceffitate qvadam nec poteft aliter. Moveturobjectis, qronam præfen. tiâ trahitur ac rapitur.

11. Anima brutorum mortalis eft.

Dependet â fua natura, qvâdêftructâ, perit ipfa. Qvicquidagit, in \&zcum materia agit : oculis videt, au ribus audit, lingvâ guftat. Simplexhrecâmateria dependentia cum immortalitate conjunita non eft. Fit enim materia tandem inepta, corrumpitur ac deftruitur. Quam deftructionem animx ipfius fequitur interitus.

Anima brutorum olim creabatur, hodie generatur.

Hxc ea diftinctio temporum, diftinctio inter mundum creatum \& propagatione confervatum. Cum bruta condidit Deus optimus,animas eorum etiain creavit. Et cumgenerationis opus concelfit brutis; anistup

mas 


\section{PHYSICA}

mas eciam gen di poteftatem tribuit. Tribuit autem ut genitorum effent caufe naturales,non morales. Per naturales enim potentias qvæ operantur, naturales caufa funt. Morales verò non agunt, fed ita fe gerunt,ut effectus eas tantum imputetur.

IV. Bruti anima communicatur

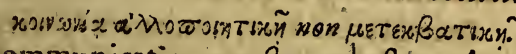

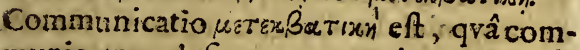
municatum deferto communicante tranfit adid, cui communicatur. Sic exfonte communicantur aquæ, ex flañấ igniculi.Com-

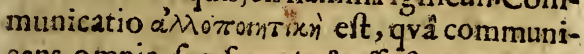
cans omnia fua fervat, \& effectum novum producit. Sic equus generans, fervatanimam fuam, fervat corpus fuum, \& novum equum, novam animam egvi efficit. $\mathrm{H}$ खc ea communicatio animarum eft, qvâ in generationis actu, anima generantis fine divifione, fine transfufione, novam animam, numero diverfam, fpecie candem, producit.

CA PUT II.

- Anima Senfriva. Praceptum.

Anima fenfitiva eft forma animali. um, qra funt, objecta rentibilia cognoman? funt, mars: $\quad$ fruat, 
18

\section{ZOOLOGIA}

feunt, falutaria appetunt \& Loco moventur.

Quafiones.

1. An anima fenfitiva fut leonis, $c \Omega$ nis, aut alterius bruti forma ßpecifica?

20. Animal conftituit, non autem fpeciem certam animalis. Generica igitur forma eft; non fpecifica. Habent omnia bruta animam fenfitivamifed differunt inter fe fpecie. Hinc fpecie diverfa anima in I.eone, in cane, \& in eqvo eft. Rectè Combachius ait : dicendum gvod anima fenfutipa non dicit formam quan. dam unam $\mathrm{P}$ byficam, fed tantitum dicit quendam conceptumgeneralera E conmunem, fubquo continentur variigradus diuerjarum formarum Apecificarum.

11. An fingularia E' mirabilia bruto. rum opera ab anima fenfitiva

$$
\text { - fiant? }
$$

8. Norunt a ranex qromodo formanda tela fit. Norunt formicx quomodo colligenda fint grans. Nec nefcix apiculx qvomodo extruendinidrfint: Lepus etiam timet canem, \& non cervum, qranquam grandior hic fit Pullus methit milviug \& non pavo- 
PHYSICA.

nem, utur major fit. Novit leoufum ungvium, equus calcium, bos cornuum. Non hre snimam fenfitixam fequuntur cum fint fingularia. Propria cujusvis fpeciei anima hxc docet, hrc praftat. Qvin \& fingularia multa, multa mirabilia, in alìs fenfitivâ animâ carentikus habentur. Norunt arbores qvomodo formanda fint poma, pira, mespi. 1a, pruna \& cerafa. Summus Tycho Brahe. fcribit: ftellas quogi foire preforepias metas guas sunquam transgredizentsur.

\section{Axionsata.}

1. Senjativä anima eo pectatu dignior, qvò cateris Juperior.

Formarum in hoc univerfo quatuor funt genera. Quædam prater effe, nihil dant: qyædam \& effe, \& vivere, quædan \& effe, \& vivere, \& fentire: quædam \& effe, \& vivere \& rentire \& intelligere.Primum genus communi formænomine notatur:cxtera animarum nomine veniunt Et diftinctis diftinet datx funt, anima vegetativa, fenfitiva, \& ra tionalis. Quamproximè acceditanima fenfitiva ad rationalem: Qvò fuperior igitur cateris, eò fpectatu dignior. Magis nio. vent, qva magis excellunt.

II. Per animam fenfition, animal constituitur.

B 3

Defi- 
20

\section{ZOOLOGIA}

Definitur animal, corpus animatum iene tiens. Genus corpus animatum eft. Hocenim animal cum plastâ convenit Differentia fentiens eft. Hoc enim aninal conltituitur \& à planta diftingvitur. Ipfam animam fenfitivam incicat fentiens. Senius enim, qui facultas eft, qui accidens eft, animal nec conftituit, nec â pianta primariò diftingvit.

III. Per animam fenfitivam animalia cognofcunt.

Cognofcunt animaliatentors fonos, $a$ dores, fapores \& qualitates tactiles. Vident canes, audiunt, odorantur, onftant \& t.ungunt. Idem eqvis convenit, leonibus, apri \&urfis.Senfitivæ anim $x$ hrec ope ra funt, $q v x$ cum communis fit, ex rqvo venit,qvod diftribuit. Vocatur hac cognitio fenfualis ac naturalis, ac inteliectui eft contradiftineta. IV.Per animam fenfitivam animalia appetunt.

Cognitionem feqvitur appetitus, cuna ggnotinulla cupido fit. Hinc objecto vifo rapiuntur ad id animalia. Odore percepto accurrunt canes \& lupi , ut indulgeant appetitui- Ipfe homo qvandoǵ; tam impotens ânims elt, ut feratur ad obję:um, antequam aude: 
audiat intellectus judicium. Quarit delitias, fugit laborem: amat fodalitia prava, \& affectat dominium : odio habet virtutem $\&$ 2nimúm fuâ forte contentum. Dicitur ap. petitus fenfitivus, ac naturali \& intellectuali contradiftinctus eft.

V.Per animam fenfitivam animas lia locomoventur.

Erat neceffe ut moverentur animalia, ad profequenda falutaria, fugiendanoxia.Hine qvædam gradiendi habent facultatem,qvædam volandi, alia natandi, alia reptandi. Direotores motuum horum fenfus funt, inpulforesappetitus. Et conjungitur qvandọ́; cognitioni fenfuali naturalis.Lepores in periculo conftituti, \& â canibus infêtati, faltus maximos poftremò edunt, $a c$ fe $a b$ fcondunt. An fieri polfit, ut canes veftigiis intercifis odorem amitrant.

$$
\text { CAPUT III. }
$$

DE

Facultatibus anime fenfitive. Precepta.

1. Facultates animæ fenfitivæ funt qqualitates, ex anima emanantes, ur animal iftarum beneficio animales edat actiones.

$\mathrm{B}_{3}$

II.Sunt 
II. Sunt tres : cognofcens, appetens \& loco movens.

\section{Qpefiones.}

1. 2vomodo facultates differant $a b$ anima fenfitiva.

5. Realiter, ut accidentià̀ fuo fubjecto, ut effeçus à caufa efficiente. Naturalia enim agentia per vaturales potentias determinantur ad naturales actiones. " Ignis per calida. tem çalefacit, aqva per frigiditaréfrigefaci t Sic animal per facultatem cognofcendi cogrofcir, per facultatem appetendi appetit , per facultatem loco movendi loco movetur. ubi datur Y. Effentia 2. potentix 3. Operatio. Huc canon fpectat: Nulla creatura inmedistum altionum fuaram principium eft.

II. Qvomodo facaltates à fe invicem differant?

R. Realiter, ut accidens ab aceidente, ut qvalitas à qualitate, ot potentia naturalis à potentia naturali.Facultates exactibus\&objeCis judicand $x$ funt. Horum diverfitas, diverfitatem facultatum parit. Aliudobjectum \& aliam actionem faeultas cognofeens habet: aliud objectum \& aliamactionem facultas ap. petens : aliud objectum \& aliam actionem faculas foco movens. Diverfere ergo funt faculs 
PHYSICA.

culrates qua diverfa diverfimodè tractąn. III. Qvonam facultatum fedes fut? B. Aliàs facultates diftingrunt in naturalem, vitalem \& animalem. Nunc animalem fumimusmiflis cateris. Hæc enim habet fub fe cognofcentem, appetentem \& loco moventem. Sedes harum omnium cerebrum $\in$ f, $\mathbf{z}$ - q̧o dependent actiones. Cerebrô malè affecto, functiones laduntur ac depravantur. Qvin \& intellectus nonnunquam furiosè ac dementer agit, à Phantafia deceptuis. Qvidam fibi caput ampurattum effe putabat. Alius cornua le geftare exiftimabat: \& piftor ex butyro fe compactum fatui:, qvi clibanum adirenefuit, metuens corpor is colliqyationem.

\section{Axiorsat a.}

\section{Facultates in $\mathcal{G}^{3}$ ab anim a funt.}

Anima faculratum eft caufa efficiens, \& fub. jectum. Fiunt abanima, fiunt in anima. Efficiens eft per emanationem, non per transmutationem: Subjectum eft informationis, non denominationis. Animal cognofcit; appetit, \& loco movarur, Sed per animam fenfitivam velut principiun primarium \& pro ximum.

II. Facultates propter actús data funt.

B 4 Acเง 
24

$$
\text { ZOOLOGIA }
$$

Actus primus datur propter fecundum: potentia naturalis propter naturales actiones. Nihil fruAra facit Natura. Non tot facultates dedit fruftra : red ut per eas animalia fuas edantoperationes. Quanqqam fieri polfit, ut facultas fit, actio non fit. Qrod prxter naturx intentionem fit, neḉ; femper neq́ve utplu. rimum.

$$
\text { CAPUT IV. }
$$

Facultate cognofcente, feu

$$
\begin{aligned}
& \text { fenfu. } \\
& \text { Pracepta. }
\end{aligned}
$$

J. Facultas cognofens eft, qva animal -bjectum fenfile perfpecies ad fe delatas organo certo recipit ac di= judieat.

II. Dicitur fenfus, qvi vel externus vel internus eft.

$$
\begin{aligned}
& \text { 20afiones. } \\
& \text { 1. An facultas cognoficens E fenfus } \\
& \text { differant? }
\end{aligned}
$$

- Non prater neceflitatem multiplicemus entia. Judicantur facultates ex actibus $\$$ objectis. Facultatis cognofcentis actio eft cognofeere.Sentire quid aliud, quàm cognofcere? 
fcere? Unde \& ip fa hac cognitio dicitur fen rualis. Objectum facultatis cognofrentis eff fenfile. Idem prorfus qvod fenfus, à quo \& nomenaccepit. Hinc ipfa facultatis cognofsentis defcriptio, definîtio fenfus eft. Hoc pacto; Senfus eft facultas, q qa animal cerio corposis organo objectum fenfile per fpecies recipit ac dijudicat.

I1. An fenfatio fit paßio, an actio? 82. A Ctio eft, coguitionempè, à porentia activa facta. Hinc fen fatio ad actiones vitales refertur, non fecus ac nutrizio \& augmentatio. Receptio quidem neceffaria eft, qva per paffionem explicatur. Sed fxpe recipitur fpecies, \& nulla fit fenfio. Habemus fpecies vifibiles in oculo, nec cernimus objecta. Anima enim rebus aliis intenta, Ipecies fenfiles non. advertit.

11I. lvenam requirantur potißit muim ad fenfationem?

B2. Illa qvatuor: Anima fenfatipa, organum, objectum of pecies. Primas tenet anima, qva principalis fenfionis caufa eft : \& quâ fublac tâ fenfio perit. Secundas habet organum, fine qua, anima effe poteft, agere non poteft. Non fie vifio absq; oculis, nec auditio fine. auribus. Tertias damus objecto, qrod fen B5 
26

file dicitur. Et hoc vel proprium vel commus ne eft. Propria funt quinq; , juxta quinqve fenfus: color, fonus, odor, Sapor $\sigma$ qpalisas tastilis. Communis qvinqve funt: motus. guies, frgura, magnitudò o numerus. Ultimas - ccupar fpecies, juxta quam fenfus de objecto judicat. Adfit id, quod fentiri debet. At longo fapè intervallo objectum diftat. Neceffe igitur eft, per fpecies fieri contactum.

$$
\begin{aligned}
& I V \text {. An duplex fit fenfus, agens } \\
& \text { E' patiens? }
\end{aligned}
$$

Re. Receptio fpecierum eft paffio, cognitio feu fenfatio actio. Non tamen duplexfentiendo fenfus eft, alter agens, alter patiens: $f_{-}$cutinec duplex fenfatio, duplex vifro, dupler auditio. Una anima, una facultate, uno organo patitur \& agit. Patitur, qvatenusrecipit fpecies : agit, quatenus per fpeciem cognoffit -bjectum.

\section{$V$. An omne corpus naturale fit fenfile?}

R2. Dupliciter aliquid in fenfü eft : Directẽ feu per fe, \& indirectè feu per aliud. Perfe, qvod qvalitaribus fenfibilibus praditum eft: five communibus five propriis. Peraliud, qvod vel per partes, vel per effectum, vel per fimile, vel per oppoficum, vel per fundamen- 


\section{PHYSICA.}

tum, velalium ejusmodi modum fenfibus obiicitur. Priori modo non omne corpus na. turale fenfile eft: nec enim maximum cxlum, nec minimas atomos fentimus. "Polteriori modo omnia cadunt tub fenfum : Si non modo uno, certe altero. Nibil eft in intellesfu, quod non fuerit in fenfu. Omnia verò ininellectu funt.Igitur \& omnia in fenfu.

\section{An numerus fentiatur?}

12. Refercur numerus ad fenfibilia epmmunia. Poffumus vifu, polfurmus tactu noviffe numerum pomorum aut pyrorum. Sed negat Ariftotes numeráre pofle bruxa, \& ne. gant communiter omnes. Si verò fentitur numerus, fi facultatis cognofcentis objectum eft, non negandum numerare poffe bruta. $\mathrm{U}$ bi enim principium commune, ibi communis effectus. Dannhauerus ait : Denegat bestiis numerationem Ariftoreles, non verò illam, que conffiftit in nuda quantitatum difcretarum peipceptione : fed eam, qroe est Aritbmevica Syllogizatio, of replicatio numerimajoris fupra mimorem. Dicimus nos, diftingvendum effe: inter cognitionem Diftinctam \& Confusfam. Videt canis fe quinquve habere catplas, fed fublato uno, numerum minorem non advertit fatis.

Axiomate 


\section{Axiomate.}

I. Senfus fapientire findament a funt.

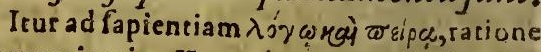
\& experientia. Utramqque juvant fenfus. Ni. hil aditmentem nifi per fenfus. Intellectui perfenfus imprimuntur imagines juxta qvas judicat. Unde receptum illud: Nibil eft in incellectu, qvodnon prius fuit in fenfu. Ex experientia omnis fenfuum judiciôn nitutur. Multa enim ejusdern rei memoriæ unius experientix vim efficiunt dicente Ariftotele. Rectè Lucietius fcripfit:

Invenies primis à fenfibus effe areatand Notitiam peri, nec fenfus poffe refelli, Qvi nifífint veri, ratio quogíg falla fit omnis. IT. Omnia animalia fenfus babent. Nulli natura iniqva extitit noverca,fed dedit cuiquve qvantum fuit neceffarium. Non autem omnibus par fenfatio eft : aqvatilia imprimis hebetioris funt fenfus. Homo quarsqvam fuperetur vifu ab agvila, audicu ab apro: benè tamen contentus efle potelt fuis in. tegris incorruptisq́ve fenfibus. Etfi quadaua interdum occurrit obfeuritas, demitur clarip tate mentis. Divinus Plato ait: Hominis no. men illud sgnificat, quod catexa quidem animabia, gpe vident, non confoderant, neg, animadvertust 


\section{PHYSICA}

veriunt, ney contemplantur; bomo autem Es videc fimul \& concemplatur, animadvertitǵ, guad videt. Hincmeritò folses ex omnibus animaintibus homo aijectoG eft nuncupaius, quafs ava tp civi comemplans, que ò $\pi \omega \pi \xi$, id est, vidut. III. Senfus fuum reqvirit organum.

Organum eft pars animalis, fpecies obje. ctorum fenfibilium ecipiens \& fenfationem edens. Dicitur aion nthiprou fenforium. Diftin. gvitur in Proprium \& commune: in Adeguacumbinadegvatum. Proprium eft, quod uni fenfui tantùm infervit. Oculus tantùm vifui, aures auditui, naresolfactui, lingva guftui, mébrana tactui.Commune eft qrod ad omné fenfum concurrit. Sic cerebrum omni fenfati. - ni infervit, dum fpiritusanimales oculis, ausibus, naribus, lingva \& membranis com. municat. Adrqvatum ef, quod objectum totum cognof cit.Sic ad omners tactum menbrana requiritur. Inadæqvatum, qrod partem objecti cognofcit. Sic curis organum eft, quo qualitates tactiles obfervamus, quana qvàm \& ibi fit tactus, ubi cutis non eft. IV. Senfus in fuum fertur objectum. Objectum eft res ipfa fenfu perceptadDicituraiba $\eta$ rò fenfibile. Diftingvitur in per fes par accidens. Illud accidens eit : hos fubitantia in 1 is

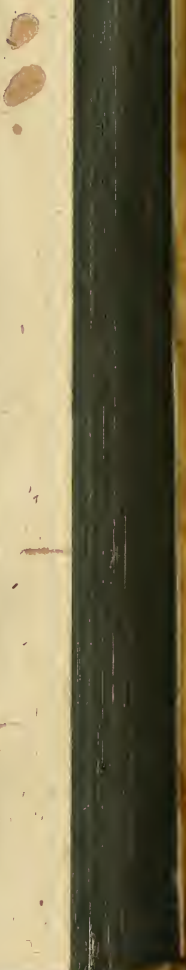


30

\section{Z.OOLOGIA}

ria. Petrus non videtur satione fubfrantis, fed ratione accidentium. Carnes olfactu percipimus, non ut fubftantia funt, fed ut ôdorem habent. Objectum autem per fe \& pro. prium commune eft. Primariò objiciuntur fenfibus objecta propria : fecundariò communia, utraq́; verò per fe. Scaliger ait: infumma: son placet, percipicommunia fenflia per accidens, fedper fe \& fecundario. Omnino enim per feetiam fenticur quies: negs folum in negatione motus: Sed in fua qpogs affirmatione; quiefit enim quod quiefcit: non qpia non movetur, neggs. magis qvies eft pripatio motus, qvam motus quietis. 2uies enim eft motus finis. Finis autem perfectio. Nulla perfectio pridatio.

$V$. Senfus objectum cognofcit

$$
\text { perspeciem. }
$$

Species eft imago ab objecto fenfili fparfa, pura \& à concretione materix libera, juxta qvam fenfus de objecto júdicat. Dicitur qualitas intentionalis, \& Spiritalis. De fpeciebas his ingeniofifimus Fracaftorius fequentes fecit verfas:

2(üper enin texies pecies, fimulacbrags rerum,

20, fluere ex ip fis dicuntur, perg, meare Omnia, dam feffor medicans, tacitusg $g_{3}$ regoiro

dvis 


\section{PHYSICA.}

doia fylvarum, of fecretaflenria folus Coginovi tamen bis ßpectris illudier ipfis: ui fenfus feriant nostros, femperǵ, laceffant

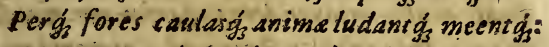
- Ac remeent, ipfaimgs nec inser fomnia lis. quant.

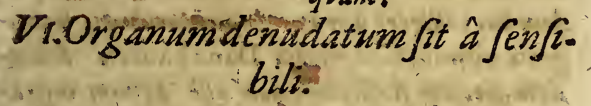

Aliàs aliter exprimunt. Recipiens denuda:um effe debet â naturarecepsi.-Intus exiftens. prohibet alienum \& externum, Rectè explicanda hxc, ne pariant errorem. Mollis digitis tangens alium $x$;́ mollem, fentit mol . litiem. Pes calidus pedi calido admotus, percipit caliditatem. Videt oculus oculum, ejusdem coloris, magnitudinis \& figurx.Non igitur exponenda de qualitatibus realibus, ac fi organa nullas habere debeant qualitates fenfiles reales. Denudatum fit organum, fecundum effe intentionale nó, fecurdum effe reale. Huc verfus fpectat:

Pluribus intentus minor eftad fingula fenfius.

VII. Species non fentitur, fed res per ßpeciem.

Objecta fenfibilia res funt, non fpecies; Res ipfatangitur, videcar, anditur. Scaliges dilcusrie 


\section{ZOOLOGIA}

difcurrit hunc in modum. Ajunt rem videriper Ppeciem. Intelligo is concludo. Species ergo jentitur. Rem ipfam baud percipit fenfus. Stolidus dicat: oculos meos videre Cafarem per ejus Statuam. Quisf vifio d statua ad Cajarem jam toe abhinc annis mortuum referatur Animus quidem boc colligere queat senfus non licet. Scaligero opponimus verba Dannhaueri, Sciendum, peciem fenfbilem non effe fignum inftrumentale, quale eft st atua Cafaris, ex qua prius co. gnitalafarem agnofco, fedformale, quo res non in precie, Jed Specie cognofi imus, five /pecies fenfilis non cft id Quod, fed id-Qvoforrmus.

VHII. Species rei imago eft.

Imago dicitur, quod procedic ac fimilitu. dinem alterius." Duohabet : primofimilizu. dinem: fecundo procefionem. Utrumg; in fpecie fenfili eft, fimiliritdo \& proceffio. Species per quam Solem cernimus, \& producitur â Sole, \& fimilis eft Soli. Infiniti homines unum intuentur Solem: tot ergo hujus imagines funt, quod oculi. Qvin plures imagines funt, cùm plura fint fpecula artis \& natura. Pelves mille die fereno pone; imaginem folis omnes habebunt. Dicit Scaliger, quomodo accidens porefte effe fimile fubstantie? Dicunt incerpretes, non entitative, fed reprafentasivè. Dicimus nos. Speciem fimilem effe, non Whishitib Subfinn: 
PHYSiCA.

Subfantic, fed accidenti: hoc enim repræfensat, non Subftaniram infam.

IX. Senfus cognofcit per medium. Medium elf incervalum iner fenfile \& fene forium exiftens, per quod Ipecies lenfibiles deferuntir. Dividiturin Internumet Exter: num. Sic aër externum medium eft, perquod fpecies vifibiles feruptur ad oculos. Color enim fupra oculos politus non videtur, juxta illud : Senfile fupra fenforium pofitum non fenti. sur. Membrana autem língva internum medium eft, per quod fapor percipirur : cuticula etiam medium incernum per quod qualitates tactiles non per incervallum, fed quam pro. ximè organa fua éficiunt.

$X$. Inter fenfle 6 fenforium jat proportio.

Minima lenfum fugiunt, maxima ladunt. Multa nec oculis hauriuntur, nec auribus. Major mundi pars in occultis eft : pauciflima exoperibus natura, humanis ferfibus cognoIcuntur. Tanta lubtilitas aêris \& cali eft; quantam non capiunt oculorum tunicæachumores. Et tantus Solis Splendor, ut mortalium luminum acies cuntueri eum nequest. Qvosdam ferunt imprudentiâ excoccatós effe, qvod in defect!bus Solis lucidifimum fidus C, intentius 
34 2 OOLOGIA

intentius adfpexeriat. Lucretius rationem dat verfu.

Splendor quicung, est acer, adurit

Sape oculos,ideò quodfemina poffidec ignes. Sanè Species perfetantam non habenteffica ciam, fed ladunt per aliud. Odor vehemens dolorem infert capiti, ob halitus conjunctos. Boinbardx fonitus laedicaures, ob aêrem uno impetu ir ruentem. Jungi igniculos cum íplendore folis certum : fed non fufficiunt ad effectum tantum: \& excœcat qvando ; animalia Iplendor nivis. Dicendum fpleudorem ni. mium, viam laxare fpiritibus. Mediocritas fenlui debetur, qvâ negatá, fenfio tollitur, damnum infuper fi infertur, caufa poffuat effe plures.

$X I$. Senfus eft fingularium.

Sola enim fingularia extra mentem exiftunt. Vifus non nifi hunc aut illum colorem cognofcit: tactus hanc vel illam qualicatem tactilem, Ariftoteles ait: Sentire neceffe eft boc aligpid, E alscubi, of nunc, qvod aucem univerfale ES omnibus est, impogibile est fentive: non enim boc, negs nunc: non enim effer uniper. fale : quod enim femper of ubigz eft, univerfale effe dicimus. Explicat Zabarella : Quod fenfis cognofcitur, neceffe est bis tribus conditionibus - ffe circumf criptwm : boc aligvid, bic , E nunc. 


\section{PHYSICA:}

Adidem Ariftoteles alibi ait: Sentitur qvidem fingulare, fenfus enim, ipfius univerfalis eft, ut bominis, at non Callix hominis. Explicatur, actum fentiendi femper effe fingularis, potentian autem feu facultarem aníverfalem. Videri quidem femper hunc aut iftum colorem: facultatem tamen nón ad eumdeterminatam effe, fedthabere fe indifferentee ad colorem quemy's. Hoc eft: Univerfi colorem \& univerfi fapores fentiri poffunt, fed ut entia fingularia want, aon univerfalia.

\section{$X I I$. Senfus non errant.}

Cognofcens facultas fenfus eft, Cognolcentis aucem eft, rectum à curvo, verum à falfo, bonum à malo difcernere. Nulla rerum certitudo, nulla ratio veritatis effet, fi cogno. rcentes facultates fallerent. Non tamen pratermitcenda neceffaria funt requifita. Juftum fi noneftorganum, aliis omniaffava, aliis omnia cruenta apparent. Medium fi non et rectè difpofitum, fol puer vubeus, \& feipfo adultomajor consficitur, ut loqvitur Scaliger. Diftantia fi non eft debita, quadrata turris, videtur rotunda, \& colores in iride nobis ap. parent ex femiffe virides ex femiffe rubri; qvos $G$ vifus Iridi proprior effet, non colores, fed Lumina tantum effe judicaret. Per accidens 
$3^{6}$

\section{ZOOLOGIA}

igitur decipitur fenfus : at pofitis omnibus ad Jenfum regrifitis, nonerrat.

$\mathrm{X}$ 11. Senfum dimittere in iis, qve fenjobus manifefta funt $E^{2}$ rationem quarere, infirmitas quadam intellectus eft.

Suum cuique tribuendum: fuum fenfui, $\mathrm{r}_{\mathrm{b}}$. um rationi. Sed nonaudienda ratio, contra fenfum. Securus arbiterny fus eft. \& cerrior longè accipitur taciocinationibus. Majus fenluum eft momentum in certo difcurfis. $\mathbb{E}$ ternas dant controverfias, fuis qui fidunt nimis rationibus. Anteferenda longè luntrationibus iftis judiciafenfuum Audiatur celeberrimus Sennertus, qvi de principiis Chymicis hunc in modum differit. Nullâ bîc demonStratione opus eft, Jed Jenfio potius: Ef fichymicus dixeric, illud quod fumi pecie, ele atur, effe fulphur, mercurium, arfenicum, cadmiam, if ud Sal aligpod volatile, non aliquod meteorum:cur jenfibus fidem denegem, $v$ Chymicis ac metallo. rum coctoribus, qvibus talia uficalıfim a june, noni credam? Imò credunt omnes Medici quita pro isdem etiam, pro quibus à metallurgis pendicansur, ufirpant. Cerie fenßabus bîc fidem dee rogare, Es demonstrationes pojcere a $\rho j$ cosia $\delta 1$ ayoías eft, E gui boc facitidem facit, ac qui

pifcatori 
PHYSICA.

pifcatori, qui lucium fe cept/fe dicat, carpionem velcancrum cepiße Syllogifmo perjpadere cone2ur.

$$
\text { C A P U T V. }
$$

Senfibus externisin genere,

$$
\text { Procepis. }
$$

1. Senfus Exrerni funt, qui fpeciem ab objecto immediatè productam in. externa corporis parte recipiunt, \& adinternos renfus transmittunt. II, Sunt qvinqve: Vifus, Auditus, Olfactus, Guftus \& Tactus.

\section{2 vaftiones.}

1. Unde numerus quinarius fenfu: um externorum constet?

B2. Ex objecta, organo \& altione. Ubi dantur quinqque diftincta objecta : qvinqqe diftincta organa : qvinque diftiscta actiones; ibi funt quinque diftincte facultates cognofcendi feu fenfus.

II. Antitillatio Venerea ad fextum fenfum referenda:

Re. Non multiplicandx facultates prater ne. ceffitatem. Non eft in titillatione ifta pecu. liare objectum, nec peculiare organum, nec $C_{3}$ pecue 
38 ZOOLOGIA

peculiaris actio. Dantur qualitates tackiles, dantur membranx , \& fit ipfa tactio. Nihil novi occurrit, omnia teftantur ad tactum re-. ferendam effeiftara citillarionem. Fruftra. eft Scaliger pro texto illo fenfu pugnans. Si Jemen ,inqvit, cangirux manu: qpo in: locoofenSus eft bomini exquifitusfimus, luculeneisfimagg. dignorio in fummo indrcis, non sisillabit: erga non à temperieféminis tisillantifima tlla volue. prasesz. Sed nec femen rectè confidesat Sca. liger, nee prater feminis difpofitionem requiri piures caufas adverrit. Laurentius zit aPrima nolupeario canfa eft, feminis trurgentis of g.pafi prurientis titillatio. Turget enim ratione

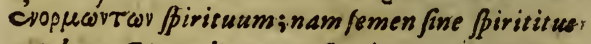
quale perGanorrbeam profundifolet, zolupeates. nullas parit, $\theta$ eá ratione, qui Vénere abutun. sur, \& frequentifimè coeant, minorem percipiunt voluptatem, qvia pauciores fpiritus: Secunda eft motionis \& excretionis celeritas: Tertia lpermaticarum partium fenfus exqvi* fitiffimus \& earandem anguftie : ita enim titillatis partibus, \& reductis qux diftendeban. tur vafis in naturalem fitum confticutionem. q́ve, voluptas ingens excitatur. Nos adjicimus caufam qvartam, imaginationem, qve non minimum in voluptatibus habet momensums: 
1. Organa fenfum externorum funt externe corporis partes,

Oculus. nempe, auris, nafus, lingva, flutis aut membrana. Refpectivè verò externx funt, non fimpliciter: Cerebrirefpectu exterior pars ett lingva, eft membrana. Alias vesò cum in fuperficie corporis non fint, potiùs internx quam exeernx corporis parres. func. II. Species (enfuum externorum ab objecto immediatè producun.

$$
\text { tur... }
$$

Species coleris à colore ipfo prod acitur,fpecies. foni â fono, , peeies odoris ab odore.Hae eft multiplicatioiftarum qvalitatum, non fecundum rem, fed fecundum fpeciem. Non deferunt qualitates fenfiles fua fubjecta, fed imagines \& fpecies producunt, qvas diffundunt. Sic cernimus per vitrum obambulastes in foro ac plateis.Campanzaut tubze fonum haurimusin muséo.

III. Species à fenfibus externis $d d$ internos transmittuntur.

Fit vifio in oculo, auditio in aur bus: fed phisultra tendunt fpecies, ut dijudicari polfine amplius, \& ut fentire nos fentiamus.

$$
C_{4} \text { Quic: }
$$




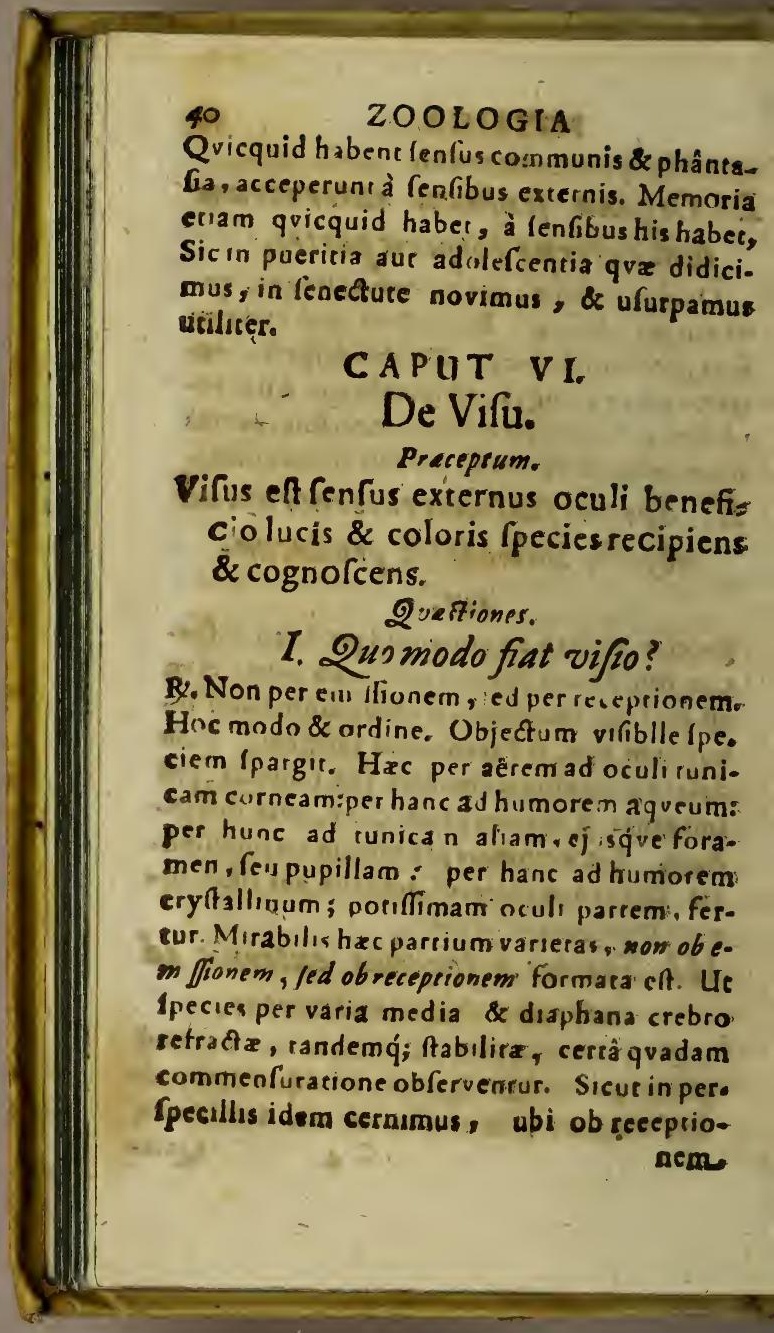


PHYSICA.

atem nune craffum, nune rarum occurrit corpus.

11. An vifionis organum fit magis igneum; an aqveum

Habent igniculos fec m tpreters viforii。 Unde expergetactis è formno, lux monounquàm verlatur ante rculos, led plusaqua concedendum oculis, quàmignis. Humores oculorum teftantur de aquarnonde igne. Et cum fauciatyroculus, aut effoditur a a va effure. Aquea etiam ceppora, ad recipiendas unagines aptiora funt, quarí ignea. Cryftallinus quidem humor lucidus: eff, \& compreffus jgneum quafi fulgorem emirtit sed non omne lucidum igneum eff: Lucent fquama pifcium, lucentcicindelæ, lucent puerida quædamlie gna : \& nec ignea funt,nec adeò congregatos igniculos habentoNix ipfa lucet, \& glacies, hoo tes ignis infenfiflimi.

III. Cur ßplendida adverja font aculis?

R. De expeditione Cyri dicitur, quosdam Ex militibus in altisfima nive irer facientibus,ex. cacasos frißse, quosdam amifiße podum digiros. Et teftantur hiftorix: recentiores vi frigoris non tantùm aures \& nares nopnullos amifffe: fed multos etiam ex continuo nivium afpectu oculie 
42

\section{LOGIA:}

oculis privatos efle. Olaus-Magnus lèribit: frigore lupi fuppolares oculis aliquando privastur. Statuendum, frigida adverfas oculis ejse, nos quà ralia fed qui.jplendide. Spleadida ats; arm, qvà nullam habent proportionem cum organo. Violentum ladit, moderatum de; lectac.

Axiomata.

I. Vifus omnium fenfuum perfedif fromus eft.

Habec enim objectum praitantifinum : lus cem $\alpha$ colorem. Haber organum praftantiffimum, oculum. Habet actionem praftantiffimam, vifionem. Habet ufum proltantifi: mum, inventionem. Hinc verfus:-

Segnius irricane animos demißà per sures;

2udm que funt oculis commiffa fidelibus. Scaliger ait. Propter anime commoditates atg $g_{3}$ perfectionem potifimum attributi fuse nobilijs? mi duso fenfus: pifas Es auditus : prim̄o quogs Nocure confilio, Itudio, fedulitate: tametfifecursdaria quod opera corporis item commodis exeubene. Ergo datus vifus eff, neg folum negs prissum: utcala, ruinas, foveas vicemus, fugiamus, coneamus ; fed eciam idgpraftantiore fune, ut as Gectu calipecie recepta: intellectu aucto : bomo otimi maximi opiffic fuifat fomilis.

Oculi 
PHYSICA.

\section{Oculi duo funt, $\sigma^{2}$ vifio una.}

Geminos dedit oculos Natura, ue tanto eelerius ex omni parte confpiei poffint objeeta. Et deficiente oculo attero, alter ir fub. fidium venira poreft. Non tamenduplexinde vifio, non res una apparet duplex. Qvafituns diu esï, cur duo duorsem oculorum imagines non dico reprefentent objeit a ?Refponfum, conjungi in itinere nervos opticos \& \& fpecies gemina in oculis perceptasuniri, atq́ue in unam coalefcere. Sed vident oculi, ancequam fpecies träsmittantur \& uniantur. Nervi etiam uniti item feparantur \& disjunguntur. Et dua gyoqve funt aures, auditio una, citra ipfums nervorum refpectum. Recurrendum ab in firce mensalis caufa ad principalem, ab oculis ad anie mam. Anima una eft, hac videt per oculum, nunc. unum, nunc geminum. Una numero eft actio, quia unum numero agens principale。

\section{In. Oculo altero clauso, alter majos}

fit:

Poffunt enim tunica, poffunt inflath humo. res. Ventriculus nofter nune major, nune minor fit, ex cibis affumptis \& copcodtis. $\mathbb{W}$ terus nunc major, nunc minor eft, \& fua cum fatufuaitincrementa. Major fit oculus u-.

มี่ 
44

\section{ZOOLOGIA}

nus claufo altero, qvia plures accipit fpiritus à quibus extenditur. Non fecus ac oculi juvenum majores funtoculis fenum ob caufam eandem. Ei ficut xgroti qvandoq́ve pupillam habent anguftam \& corneam rugofam ob fpirituum defectum Hoffinannus ait: Si alterum oculum claudamus, alcer fic major, non certe. aliunde, quàm ab influentefpititu. Er monoculi diftinctiùs quidemvident-minusa. Sed plura non vident, qvo fe alioquin folantur miferi illi. , Acidem accidit jaculatorıbus . altero oculo conniventibus.

IV. Oculi pars princeps, bumor cryftallinus eft.

Datur in qvovis organn certa pars fimilarie: actionem potiffimum edens. Hacprincipa. lis dicirur : cæreræminus principales. In 0 culo eft humor cryftallinus, nomen habens, gvia purifimm glacieiacsryftallo fimilis eft. Oportebar enim oculum claro hoc \& compa: Ctiore humore praditum effe, ut \& recipere \& retinere poffer imagines. Julius Cafferius $\mathrm{Pla}$ centinus ait: Cü in omnibus jenfories per nervüu

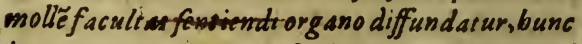
in uno grogis fenfu infprciamus, id erimqvod si immedsace opponicur , principalis iftius organi

pars. 
pars eft: per quam precipué abfolvitür fen fatio. Et ré it ieffe neceffariò debere, vel exeo colligice, good resfenfupercepere eundë nervü ad jerifü compranem bent; iut candem ad intcllectü-deforsun Hac aute in vifu ef cryf allinus bumor, hic enim nervooprito immediaiè adjacet.

$V$. Lux oculo ingenita eft.

Interna arq́ve ingenica lux oculus eft : major felibus, minorhominibus. Organume. nim objecto fimile fit atq́ve affine. Ut poffie iftud accipere, hoc dare. Unde Galenus ait, visus inftrumentum lucidum effe, auditus aêreum, olf act us vaporofum, gust us burnidum, taC7 us cerreumo- Et habetur verfus, qrem Empedo. cli tribuunt.

Conpucimus terram tellure, liquore liquore. Aërenaturam aëream, ignem cernimus igne. Humor cryftallinus corpus lucidũ ac fulgidú eft, interdiu minùs, noctu magis confpicuum. Hic ipfe humorlucidum præftar oculum, adeò utictus flamma inftar micare foleat. Crystallino, inquit Laurentius, fummus debetur bonor, eft enim qoovis pretiofior, quávis gemma illustrtor; propteré anima oculi, Pecillsm interius, centrum ocule dicifolet Solus hic à coloribus alteratur, vifibiliumq́ve fpeetra recipit; hoc pofito ponitur facul. tas videndi, reliqqzo omnes partes, aut vifio-

nem 
46

\section{ZOOLOGIA}

nem confervant, aut praftantiorem reddunt; huic deniq́ve tanquàm principi, qve in oculo funt fingulæ partes tamulantur.

VI. Non color folus videtur, nec lux sola.

Adrqvatum vifus objectum non unum, fed geminum eft. Vifibile id dicitur qrod ipe. ciem fuam perfpicuè imprimi \& ad oculum transmittit, ue moveatur facultas. Præflat hoc color, preftat idem lux. Paries coloratus fpeciem fuam aëri imprimit \& oculo communicat, ut frat vifio. Lucidiffima fidera non minus fuas Ipargunt fpecies per calum \& aërem, qværecipiuntur ab oculo, ut vide:

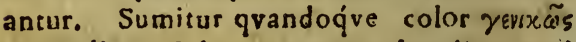
gencraliter, \&lucem comprehendit. Sed Éldircos \& fpecialiter à luce differt im: menfum. Diverfa funt indolis $1 \times x$ \& color, Q nećvenaturis neque fubiectis conveniunt.

VII. Non omne corpus videtur.

Sunt corpora nec lucida, nec colorata. Non igitur videntur, curn vifus non adfint objecta. Nemo vidit aërem, nemo cxilum. Aèr enim nec lucidus nec coloratus eft, Calum nec lúcidum nec colorarum. Corporum diftinctio aliàs fic habet. Corpus ounne aut eft lucidum at pellucidum, autopacum. Lucidum autem in divifone hac coloratum includit, non excludic.

FIIL.Magni- 
PHYSICA.

VIII. Magnitudo, numerus, figura, Ev reliqua objecta communia videntur.

Videntur, fed non fine luce, non fine colore. Objecta enim propria modis itis determinantur. Cirra concreta verfantur fenfus, non circa abftracta. Concreta habent magnitudineen, habent figuram, habent catera. Ut ergofunt, in fenfibus cognofcuntur. Hine videt Petrus qvercum proceram, humilem fambucum,rotunda poma ac pira. Quibus verò defunt color \& lux, corum neque figura, neq́; magnitudo, neque numerus advertitur. Non cernitur aêr quantumvis vaftus \& nobis contiguus fit. Praclarè fcribit celeberrimus Senrertus: Rectius illi Jentiunt qoi st at uunt cammuniafenfolia, nullas peculiaves pecres fenflibus - bjicere, fed cantium propriorum fenfibilium ßpecies determinare, peculiaremǵs modum iis addere. Quia enim fenfibiles qualitates non à Juis fubjectis abftracte, fed in fubftantios at g in concreto percipiuntur, per unam peciem fimplicem, proprium cum communi in fenfum incurrit; nonnibil modificatum tamen: aliog modo apparet color in corpore rotundo, alio in quadrato. Si vero fenfilia communia proprias fpecies amitte- 
48

\section{ZOOLOGIA}

mitterent, etian. fine propriis hoc praftare deberent. Atnonfaciunt hoc, id quod pa. tet in translucidis, cujusmodiaêr eft, cujus figuram non ab eo, qui nullus eft, colore, led continente corpore per imaginarionem potig, quamifenfu comprehendimus.

IX. Perpicuum vifus medium eft.

Non cernimus colurata oculis impolica, fed medium adfit inter objesf um \& organum, grod fpeciem recipiat. Hoc perfpicuum elt, cujus naturatranfitum dat fpeciebus vifibilibus. Qvalia funt, cælum, aèr, aqva, vitrum, glacies, \& folida quadam alia. Ut verò differunt hæc raritate, fic \& perfpicuitate, Rectitus videntnr objecta per aérem \&ca. lum,quàm per aquam \& cryltallum.

X. Lumen non obmedium, sedob objectum necefsarium.

Ut videatur color, prafencia luninis reqviritur.Non ut forma coloris, ied ut neceffaria. conditio. Nä in tenebris etaa color perfectus eft. Neq́ve ob mediü, fed ob object um.Hoc eft. Ut vifio fiat, neceffe eft objedum illuftracum effe, qramqvàm intermedius aër oblicurus fit. Nocturno tempore felium oculos in denfiffima caligine videmus. Erquó locus obfcurior eft, eò manifeltius confpiciuntur. Incendia eum funt è longingro nocte atrâ, cernuntúr ignes 
PHYSICA.

ignes. Videmus Atellas noctu, periplas tenebras, \& interdiu è profundiflimo \& obfcuris. fimo puceo. In tabella illuftrata per obicurum aêrem, cernimus colores, Fit quidem. ut ipfum quoq; medium illuminatum fit, fed uon eft neceflaria condirio.

\section{Vija non una est.}

Videncur colorés reales, videnrur apparen. tes. Ceraimus \& folia viridia \& viriditatem ab iis fparfatn.Cernimus \& rubedinem vinirubri\& rubedinem inde factam. Vidernus lucem \& lucis prolé, duos foles, duaslunas. Et quod imagines funt in aquis, in metallis, in vitris \&ahis corparibus politis. Non videtur quidem imago ut imago, at videtur us lubit rationem objecti. Hinc vifio vel directs, vel refexa, vel refract a eft. Directa, fpeciei vifibilis perunum perfpicupm receptio\& cognitio. $C \tilde{u}$ albedinem parietis per aèrem cernimus. Reflexa, fpeciei vifibilis ad corp9 politum trans. latx, \& ab eodem ad organüm reflexx, rece. prio \& cognitio. Cum imagines in fpeculo cernimug, Refracta, f peciei vifibilis per duplex perfpicuum receptio \& cognitio Cum nimirum per aêrem \& a quam, aut per äërem \& vitrum cernimus. $X I$ Sunt, que Eg videnturipsas $E$
$D$ 
50

\section{ZOOLOGIA}

ut videantur alia, efficiunt : Sunt qoa videntur, nec ut videantur alia, efficiunt: Sunt qua nec vis dentur, nec ut videantur

alia, efficiunt.

Videtur Sol, \& per eum catera. Videntur oculi felium \& cícindelæ \& ligna putrida, non tamen alia faciunt confpicua. Terra fibi relicta, nec videtur, nec ut videanturalia, præitat. Sunt enim corpora alia lucida, alia pellucida, alia opaca. Lucida aut plús, aut minus lucis habent. Si plus, \& videntur, \& ut videantur alia, efficiunt. Sin minùs, videntur; fed non, ut videantur alia, faciunt. Huc qvoq́ve referre licet perfpicua,quæanon illuminant, fed illu minantur.

\section{CAPUT VII. \\ $D E$ \\ Auditu. \\ Pracepium.}

Auditus eft fenfus externus auris benefició foni fpecies recipiens \& cogno= fcens.

$$
\begin{aligned}
& \text { 2veftiones. } \\
& \text { 1. Quomodo flat auditio? } \\
& \text { Refp. }
\end{aligned}
$$


PHYSICA

R. Per receptionem fpecierum foni. Hoc ordine. Sonus realis fpargit fpecies, qra pet aérem tendunt ad extremas aures, femper parulas \& excavacas : hoc acto fpecies in cavum atiditorium foris obvium \& patens intrant : hinc ad membranam ficcisfimam \& maximè fonoram, qre tympanum dicitur, feruntur: ab hoc ad osficula tria pergunt, $q \nabla x$ incus, malleus \& ftapes dicunrur, ab his aëri implantato communicantur, qvo nervusauditorius conjungitur, qri fpiritum animaletn è cerebre transfert. Qveomnia moram çvandam habenc, unde citiàs fua agit vifus, tardius au. ditus : fubico fügura confpiciuntur, ferits audiuntur tonitrua.

II. An realis fonifiat auditio?

Lapidere in aqvam fi injicimus, circuli fiunt, qvorum alter alterum excitar ferie continua \& jucunda. Idem fieri in aëre, paret $\mathrm{E}$. mobilitate majori : An igitur fonus etiam realis atọ́; idem numero, mocu continuo per aérem ad aures perveniat qvaritur? Species recipiuntur, non res ipf $x$. Mille homines unam concionatoris rocem audiune. Tota civitas unius campan fonum percipit. Permedium folidum brevi temporis Ipatio procul audimus fonitum. Materialibus qvalitatibus hre non conveniunt, fed immaterialibus. "Inter$\mathrm{D}_{2}$. dum 
52

\section{ZOOLOGIA}

-

dum verò fonum realem cum aëre ipfo in aures incidere, non negandum. Sed audirio non ex materiali fono, fed ex f́pecieab iplo. fufa habetur. :s

III. An medium auditus efjeposfit aqua?

- Non per folum aërem, fed per ipfam eriam ágram tendunt fpecies foni. Medium prinzarium aêr eft: fecundarium aqva. Audiunt fanè pifces in aqva, \& terrentur fonicu Audiunt in eademurinatores; non perarundinem, qvo aërem captant, cum auribus non applicetus: fedper ipfam aqva fubftantiam. Nierem. bergius fcribit. Tincinnabuli fono in multis stagnis ad cibum vocati pifces accurrunt: fugisent ingentes fonitus, ut facile proprered capianrur in lacibulis fuis. Venaturi delpbinos, eos repentè alpeis circumdabant, mox obstrepentes compellebanc univer fos fugitivos in cerram, $u b i$ o6 frepitum capice gradacos capiebant. Exi. guus namgis extra a gvam rumor iis omnibus gvi in agria audiunt, difficilis est or magnus.

\section{Axiomata.}

I. Magna auditus eft preftantia.

- Praftantia organi, praftantia abjedt \& ufus maximus id indicant. Mirabilis formatio auriä ef , mirabilis varictas fonorú, mirabilis ufus $-$ e:u: auditioniso 
auditionis. Auditus fenfus difciplinze eft:ex auditu lapienria, ex auditu fides haberur. Scaliger ait: Offeciis ac finibres uterg (vifus \& auditus) juam facilé raetur dignitatem. Difü ad vile commodi maximè necefarius: at prete. rea ad difciplinarum invenitionem ceritisfimus dux. Abeo pere Yolo maximam rerum parten ixploracsineffe, manifeftum eft. Aliditum verd. adexcipiendain ab alits artem, fcientiam, sapien. tiam, acconimodaitorem. "Pergoàm paucis enim inveritio data eft. Et quibus data, data eft mutila es insboata. "Per audituin veró judicio. sumgscommontrationem actedunt increment 2 . Jcientios atg artibus inventis: tanquan collifone. veritas excutikur : unde cujus ǵs cognitionis perfe. Etiofeqpitur. Ef \& in auditu majpo urilicas: Quippe dormientibus eciam prafidio eft : ut fono experrecti fefe tueanur.

II. Magna ex auditu voluptas eft. Audita oble et ant infantes puberes; viros; ac fenes. Nunc quidem fono,rúne fignificae to , nunc uero $q_{j} ;-$ Plorantes infantes compefcimuis cantu; ur fuaviter obdormiant Nullum peetus tàn im mité eft,quod non afficiant arć; mulceant cychara ac tubx. Multús in fioc Scaliger eft, ut oft endat \& ratiơniburs confirmet audita jucundiora teftis effe: Minus las boris; inquit, audiendo capicur : plus offert labo-

$$
D_{3} \text { ris }
$$


54

\section{zOOLOGIA}

yis lectio. Lectio muta esz, tangvorem dac persinacius continkate. Auditu magis imprimuncur porjonfum difcipline: cujus ministre aures.

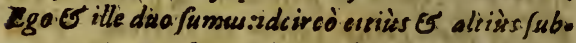
eunt animum fencentic. Ideò melius of fideliùs. berene camemoria, que auditione ascegimus,

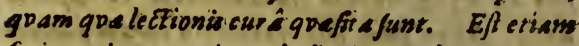
focietas in narratione: in bections jolitudo. At bomo animal ef fociale. Apud amicum logeen. tem liberter rogandi, dirguirendi: unde confequamur intelligendi cosmmodicates. Non qpic dom differt liber à recitatore. EAt recirator, lis der loqvens : liber, recit ac or matus. Obboe profectograta collognia, E jucundi dislogi, prow prered grod opulentiora guam perpecus libri. III. Auditus organum tam exsernes. quase interna funt cures.

Auris apud Hippocratem alia Externas ali incerna eff. Externa partes dua funt. Juperios \& inferior. Superioralia dicituraut pinna, \& tota fermè cartilaginea eft, ae femicircuIum refert. Inferior $\lambda$ obo's vocatur, \& car nofror ac pinguior eft ab ala pendens. Non. verò ad ornatum tantùm ha facta funt auricule, fed cumprimis ad fpecierum foni receptionem. Imperator Hadrianus ut audiree: elitus, cavas manus auribus obtendebat, ut fi

tortè: 
PHYSICA.

Fortè audiendi meatum praterfugerent Spe. cies, additamentu ifto repellerensur \& cavitatem ingrederentur. Galenus autor eft, Con. fulem e Arianum quod minus ligpido auditu utevetur, cavâ manu admotâ audiviffe rectiùs. Et quibus pracifa func aures, fonos \& voces flujtantis aqva, aut refonant is cicada in modum audiunr.: Auris interna aliqvor conftat meatibus, fepto membranofo, chordâ, tribus officulis, aëre implantaro, mufculis, \& nervo aur ditorio. Ut non minor partium aurium qram oculorum videarur apparatus.

IV.Surdi â nativitate plerumǵ Junk muti.

Aurium \& oris, lingva ac laryngis, mirabilis communio eft. Atrentè audituri non refpiramus, fed cohibemus fpiritum. Ofcip tantes fonos exquifitè non audiunt. Scalpello tympanum auris fi vellicamus, ficca excicatur cuffis. Surdaftri ommes agré loqvani rur, $\&$ vocem per nares reddunt. Lidem meliùs voces per 03, gram per aures hauriunt.Sic \& ab ortu furdi plerumq́, matifunc. Non qvia fermocinatio perdifciplinam fit, difciplia autem ex auditu, ur fublato audicu, locus ron fie difciplina, atq́ja deò nec fermocinati. oni.Polfent enim verba qoadam formare ipfi, atq́; his animi exprimere fenfa, Homipem euím quantumvis furdum ratione ad in-

$$
\text { D } 4
$$

ven- 
56

\section{ZOOLOGIA}

ventionem armavit natura. - Sed experientia eft reft is, re gemitus quidem at q́: fufpiria abs. q́i difficulrare edi ab tisdem. Carufa elf, nervus, auribus, lingvæ \& laryngi communis. Qvincum enım nervorum par in auris rympa. num fertur: \& ramulos ad lingux \& laryngis mufculos mitzit. Cum ergò naturalis biac conftiturio vitiatur, ipfx qvoq́s; actiones frmulladuntur $\&$ abolentur.

\section{Auriumpars princeps esZ äer im- plantatus.}

Si illa eft pats pronceps, cui immediatè opponitur nervus; qvi defert facultatem, non. ambigendum valdè aërem ímplantatum e $T_{e}$ principem aurium partem. Nervi enim aus. ditorii expanduntur \& cávitatí aërem continenti communicanitur. Si pars illa princeps eft, qvæ f́peciem fulcipit; \& majorem cum objecto convenientiam haber, nulla pars auriưm aéri innato ac vernaculo praferenda e. rit. Ex fi pars princeps aurium proportione selpondere debet, humori cryftallino, aér implantatus refpondet oprimè: Ut humor cryftallinus recipere poteft Species coloris; fic aerfpecies ac differentias foni omnes recipit. Ut humor cryftallinus purisfimus eft, \& â primà nativitate ínfitus, fic idem de hoc aêre sonftat. Et ficut nervi optici Spiritum animalems 
PHYSICA.

lem oculo deferune, \& fpeciem ad fenfum communem referunt, principalem aucem o. euli partem conftituunt sira nervi auditorii non minus foirituum \& Specierum latores forrí. Hinc reefè Plato, A rifforeles \& Gales nus ex Empedocle dixerunt :aërem effe instrumewrum audicûs. Repetamus verfus ftopra paulò aliter tra ditós.

Terram equidenterrî́, fed aqvans fpectamus aquâ, ignews

Confpicor rgne, fed aére cernimils aéraclartio. CAPUT VIIT.

$D_{E}$

Olfactu.

Praceprum.

Offactus eft renfius externus, nali \& proceffum mammillarium beneficio 0 doris fpecies recipiens \& cognofcens.

Qvedfiones.

\section{Qvomodo fiat olfactio?}

Quemadmodumin cateris fenfibus, fie \& in odoratu fpecies recipiuntur. Hxper aërem ad externas nares femper patentes tranfeunt: ab his ad nafum imernum feruntur, qvi offe. cibrolo \& proceflibus mammillaribus con Aat. Os cribrofunrinmedia frontis bafi fitum

D 4

at 
38

\section{ZOOLOGIA}

ad fummam nafi radicem fertur, nariuns totan ferè cavitatem opplens. Plurima habet fogamina, per qvæ aëri \& odoribus ad cerebrum patet tranfitus. Proceflús mãmillaris duo funt cubercula, in qua nervi olfackui dicati infe. suntur: fimilitudinew cum papillis mammarum habeinr, undè nomen aeceperune. Hue rendunt odores:atq́; hine ad cercobrum ipfum transferantur.

11. Utrum realis odor ad organues feratur, an intentionalis?

Refp. Effluere aliquid è rebus odoratis, \& per aérem ad irares deferri, non reganduin. Pereipimus id fapenumerò, non fine magna narium injuria. Non rarò cerebrum his ipfrs.leditur: \& infanres in utero marerno extingvantur: Democxitum morti propinquum panis. secentis odare vieam triduo protraxiffe feribunt. Pbilippus Melanebtbon audicoribus fuis recitare conlvevit, macbum quendam, quifosme necabatus, mulios dies in carcere ex nöt ore. carnis ałsate, que ipft quoridie offerebatur ut acerbior of longior efset eruciacus, fuiße jervasum. Sed bxe corpora olfactionis nacura. haud requirit. Pifces in aqva odores capiunt, perfecies, non per res ipfas. Hx enim craffusp elementum non fentiunt, fed per aërem.

potius. 
PHYSICA.

potius graffantur. Neq́ve aliàs fenfationis natura ipfa a dmircic corpora. Sufficiuns ́pecies,qua à fenfibus externis ad internos trans: feruntur.

III. An medium odoratúspoßit

\section{effe aqva?}

2. Primarium medrúm aĉr eft, frusndarium

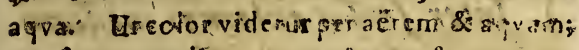
at fonus auditur per assem \& aqvam. fic odor percipiur peraërem \& aq ram. Rectiùs perillum, aliquo modo per hane. Non carent olfactu pifces, fed per ip fas aquas,elcas - dorantup eminùs. Longo in tervallo à cibo remoti natant ad eum \& capiuntur:

IV. An quibuspx aftantior odor atws, vifus fot deterior?

Refp. Plerumq;id contungere exilfimat Cara danux : fed absquve racione finta. Diverfi fune fenfus, non contrarii :-diverfa organa, diverfa objecta labent, on contraria. Poref idema homo \& videre acurè \& olfacere quàm ôptimè. Scaliger exemplo himize \& canis refutac Cardanum: andsm feliciter, ait, evenerit sibio wt prater morem tusm, tuafententic moderarpsis: moner nos fimiarem genus : qrar uin asuluo videnái poteftate nulli cedit qpadrupedum : ndo

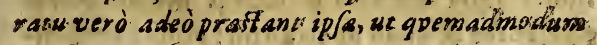

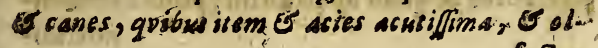
factivg 
60

ZOOLOGIA

factus preftantißimus, nibilgustare aggrediancur, quodnon prius explor averint odore. Qpe vis eis tam praftì est, ut non ad nares applicent, qood Jentire velint; fed Juprenares adnodùm celerrimè apprebendanc.

\section{Axiomata. \\ 1. Inter fenfus externos medium obtinet olfactus.}

Cedit dignitate vifui, cedir auditui. Sive enim fpectes objectum, five organum, fivea. atonem, five ufum, iftis eft inferior. Deum gaudere odoribus magis, qvam precibus \& fufpiriis, impietas eff. Superior autem olfactú eft guftu \& tactu. Hos enim facilè fuperat preftantia objecti, organi, actionis \& ufus. Ineffe nafo mon venuftarem tantùm fed \& regium quid, creditum olim eft. Quondam. imperandi dexteritatem, irteo eminere cen. fuerunt. Communiter etiam hunc obefa, ifum emuncta naris dicimus.

11. Sine repiratione non fentitur odor.

Attrahenda eft materia, odoram veficu. Ium. Qua attracta proceffus mammiflates pilatantus \& quali aperimatur: pofteà verò dimittun- 


\section{PHYSICA.}

mitcuntur \& contrahuntur. Hinc ab odore cum abhorremus, sefpirationem inhibemus. Sic enim nec fxeror percipicur facilè, necladituradeò cerebrun. Lbi verò gratus odor, fpirandocrahimus, quod delectat. Quemadmodum folet, qui globulis ex moficho \& cybe. to concinnatis, animum recreant. Rerum verò eciam fragrantiflimarum naribus admo. tarum, odorem non percipimus, nifi refpire. mus a cque aẹrem \&odoren attraha mus. III. Princeps olfactus organum procefjus mammillares fint.

Princeps parseft, cui immediatè opponitur nervus, facultarem deferens. Princeps

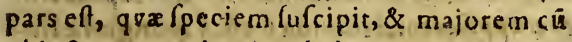
objecto convenienciam habet. Princeps pars eft, qva proportíne refpondet aliis partibus principalibus, omnia hæc de procesfibus? mammillaribus conftant. Per nares exter. nas odores quidem ingrediunrur, fed ab iis. dem non percipiuntur. Salvis enim iftis atq́ve integris, olfactus fxpè aboletur, aliis regvifitis prafentibus. Coryzâ laborantes non percipiunt odores, externis naribus illiefis. Rectè ait Julius Cafferius Placentinus. Objerpandum eft, in omniforiforio nervum mollew a cerebro defcendere, post quen immediace, favises ve. Orstige 
62

\section{ZOOLOGIA}

rum occurrit organum, at in oculo crypallinus bumor, in auditu nervus expanfus: fic etiam in olfactu fieri qpis negaverit ? Ec bac vera proprii organi alicujus fenfus inveniendi eft metbodus.

\section{CAPUT. IX. \\ D E}

Guftu.

Preceptum.

Guftus eft renfus externus, lingvæ benefició faporis fpecies recipiens \& co. gnofeens.

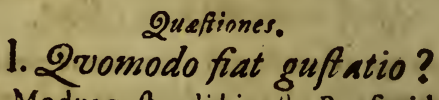

Refp. Modus guftandi hic elt. Res fapidalin. gva applicatur.Humida fi eft, à fpongiof $x$ lingux carne facilè imbibitur. Si ficca aut con. creta elt, dentibus comminuiturac folvitur, \&x cum humiditate lingva permifcetur. Sic fit faporis perceptio,prafertim verò anteriore lingra parte . Cum enim guftu aliquid explo. samus, cufpidilingra id admoremus.

11. Quodnam gustus fit medium? Refp. Medium externum quod objecti ipecic:n ad organum deferat, nullum eft. Res enim fapida applicanda lingva, q guftare non licet. Interim autem medium. pellicula porofa eft, lingra obducta. Huic primò 


\section{PHYSICA}

primò communicatur fapor, cujus fpecies ad propriam lingua carnem defertur, ibiq́veab anima fentiente cognofcitur. Julius Cafo ferus non mediun, fed quafe medium no, eninat.

111. An reatis fapor ad organum feratur?
Relp. Fertur quidem, fed juxta hunc non he
guftus. Caro lingra cum admovecur, adef guftus. Caro lingra cum admovecur, adelt iapor realis. Vinum cum potatur, dulcedo realis afficit lingvam. Sed non minus fapores hi, quàm catera fenfuum objecta, Suas f pare gunt fpecies. Recipiuntur ha à carne ling va \&x ipfis quoq́ve fenfibus internis communicanaur.

\section{Axiomata. \\ 1. Guftus nonidem cum tactu est.} Habent objecta diftincta : faporem \& qvalitates taetiles. Habent diftincta organa:lina gram \& cutim. Habent difinctas actiones: ideò \& in lingva ipfa aboleri poteft guftatio, manere tactio. Ariftoreles guftum effe catum quendam ait. Sed limitat, non ablolutè ponit. Senteatia hac eft. Guftus objectum remotum non fentit, fed admotum. Sic aliqvam cum taciu habet convenientiam, qranqquàm. duo, diftincti fenfus ruat,

11, Guftus 
$64 \quad$ ZOOLOGIA

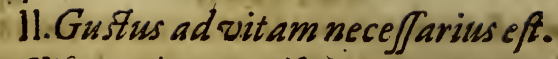

Vifus, a udicus, \& olfactus, commodiratis fenfus dicuncur: guftus \& tactus necesfitaris. Uterq́ve enim ob alimentum, qvo carere non licer,factusett potisfimum. Gufto animalia ad nutriméta capi enda invitantur. Gußtu amica \& inimica, grata \& ingrata difcernunt.Scaliger ait, Jenfum bunc anımali maximè omnium. neceldarium effe. cum aliss carere fine visejacturapofis. Nos qvidem rantam neceflitatem haud quxerimus. Vidit Columbus hominem, nomine Lazarum viventem, vigentemq́ve, guftu carentem. Voravit hic vitrum, lapides, ligna , pilces vivos \& lalịentes. Voravit lutum, pannos lineos, laneosqve, fanum, Atipulam, \& quicquid venit in buccam. Vo. ravit aromatario carbones \& faccum cui inerant. Hic postea minis ipfum a pharmacopo. lio arcere fuevit, veritus ne co iple $\mathcal{E}$ taberna, GDafa omnia cum contentis ab eo devorarentur. 1II. Guftus organum princeps propria lingue caro est. .

Caro lingva inierros habet nervos plurimosà tertio pari. Habet etiam convenien. tiam maximam cum rebus fapidis. Frincipalis igitur pars lingvæ eft, cui primariò debetur: 2ctio.Julius iterum Rlacentinus ait: 2wamvis, 
PHYSICA.

membranam inter illas partes, fine quilu commodè fieri guftus non poteft, numeremus, illans camen principalem, cujus famulatui reli que tamqvim fubfidiaria funt deftinate, ft atuirnus : propriam nempè $\sigma$ pongiofam lingva carnem. Preterqvam enim quod fubftantia ipfs salis fit, cui finsilem in nalla corporis parte in peneris; tempe. ramentum qvog ad fufcipiendos fapores, aptiflsmum babet : bumida enim \& calida eft, faporibus admodum vicina, ut ab illis alcerari facils. posfict.

\section{CAPUTX. $D E$. Tactu.} Pracepium.

Tactus eft fenfus externus, membranz beneficio qvalitatum tactilium $\int_{p e-}$ cies recipiens \& cognolcens.

Qvestionics.

1. Qvomodo fiat tactus?

3o. Modus hic eft. Res tangenda proximè \& immediatè organo admovetur." Hinc fpeciem imprimit, juxta qvam facultas cognofcit: Sic receptio fpecierum non minus in tactu, qvàm cæateris fenfibus neceffaria eft. Lapidem cum tangimus, manumáve removemus fubitò, fentimus frigiditatem.

$$
\text { E }
$$


$\$ 6$

\section{zOOLOGIA}

Sed fine communicatione frigoris realis: manus enim non frigefit. Neq; digitus realem corporum duritiem, molliticm,afperitatem, ac lavitatem recipit, fed folas fpe. cies, folas intentionales qualitates.

\section{Qvodnam tactus fit medium?}

R. Non habet medium externum, chim tantùm objecta applicata organo fentiat. Nec cogitandum, aërem inter tangens \& tactile intercipi, \& medii fuftinere vices. Ipfam ignis caliditatem fentimus, absáve aéris interventu. Et cum digitis menfam premimus, cedit aër, neutiquàm ictum fufcipit. Internum medium tunc habet, cum cutis beneficio peragiturtaqus. Cuticula enim obducta cuti intercedit \& excellentem cutis fenfum temperat.

\section{An tadtus unus fenfus fit?}

R. Verfatur circa calidü \& frigidü, humidú \& ficcú, durú \& molle, afperï\& læve, grave \& leve, friabile \& lentum, glabrum \& $\mathrm{fca}_{\mathrm{c}}$ brum. Sed omnia hrc objecta in communi conveniunt genere, qvalitates nempo tactiles. Unum igitur datur objectum generale, multafpecialia. Sic \& auditús percipit fonum acutum \& gravem, magnum \& parvum. Vifus varia colorum genera, varias 


\section{PHYSICA.}

Jucis differentias. Guftus faporem dulcem $\&$ amcenum, fapidum $\&$ infipidum.

\section{Axiomata.}

I. Tactus dignitate poftremus,neceffitate primus est.

Ignobilis fenfus eft \& quafi belluinus, ad corporis confervationem potiùs, quàm ad animx perfectionem necefiarius. Inde per omnes \& fingulas ferè corporis partes dit. fulus eft, ut fugere qveant qualitates noxias. Egregiam ê Galeno fenfuum comparationem Julius Cafferius inflituit $V, y$, inqvit, proprium insfrumentum denfifimo tegicur operculo: asdicus rariori membrana $a \mathrm{al}$ falzus minus adbuc den $f_{a}:$ guftus veri operimentum non folum magis rarum eft. Jed omnino ppongio'um : poltremo tactus tegmen omnino rarifls-

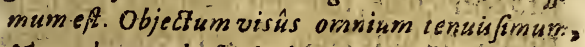
G quodammodo piritale est: crafous ve'o audisus: multo craffius olfactus : cralfius adbuc $g$ ufius: cerreftre of omnium oraffisfimum tactus. Medio indiget vifus omnium maximè : audiqus minus quam pifus: olf actus minius qp am auditus: guftus äbsǵs medio fit : omnium antem maximb fine medio foc cactus. Orgunum vifuscxtra pofitum est : auditus ver ò paulóiniror fum : olfact us magis intra: iguftus adbuc is plus later: tadtus vero infirumentum $\tau 0^{\prime}$ ivto ov of , intus quoddam $\varepsilon 2$ exiftens, 
6.8

\section{ZOOLOGIA}

existens, nominavit Ariftoceles. Hinc idem concludit, sifum E tactum externos eßse JenJus, illumgs prastantisfimum, bunc ignobilif. fomum.

II. Tadtus organum non est nerrus. Nervus fpiritum animalem defert adomnem fenfum neceffarium.Non magis igicur tactui, qvam reliquis fenfibus infervit. In vulneribus cum lacerati tanguntur ncr. $v i$, ingens qvidem excitatur dolor, fed ob membranas, quibusconftant, medulla enim absq; dolore tangitur. Etubi plures nervi funt, ibietiam fit major dolor ob copiam fpirituum, aut quia plures nervos plures circumveftiunt membranx.

\section{TaCus organums non eft caro.}

Taetusibi frpè elt , ubi caro non eft. Sencit ventriculus, fentiunt inteftina, fed deftieuta carne funt. Neq; ubi caro eft, ibi femper tactus eft. Non fentit caro pulmonum, neq; hepatis, neq́; mufculorum. Etcum fentire videtur: per aliud fentit. Per membranas nempè, qvibus veftitur.

IV. Takus organum primarium eft membrana.

Princeps organi pars , eaq́; fimilaris, membrana eft, Quicquid in çorpore ani- 
PHYSICA.

malium fentit, per membranam fentit. Hinc ventriculus, inteftina, \& alia membranofa. corporatexquifitè qualitates tactiles perci. piunt. Ipfa quoqve cutis cum fentit, per membranam fentit. Diffimilem partem qui defiderat, in homine manum habet, juxta Galenum organum tactorium \& apprehenforium. Nonenim aliud, inquit, oportebat effe apprebenforium, aliud autem tactorium organum : negs atiud gridem accipere unamgramgirem externam levando, $\sigma$ transferen. do, É omninò pertractardo : aliud' autem $p \theta-$ ficà difcernere deaccepcorum caliditate of frigidisate, of duritie., E mollitie, of aliis tic Ctilibus: differentiv: :fed mox cum apprebenderit usumgrodis; ; molius fuic fimal dignofcere, quale fit. satur $\hat{a}_{2}$ At verò neg'g decentius ; neǵ, promptius fuit, alio org ana corporis digno/cere, quant manu, \& ipfrus manus non omnibus, fedinternis parsibses, quibus eft etiam apprebenforium organum.

\section{CAPUT XI.}

$D E$

Senfibus Internis in genere.

$$
\text { Precepta. }
$$

1. Senfus interni funt, qvi fpeciem. perfenfus externos allatam in cerebro recipiunt,cenfent \& dijudicant.

E 3

II.Suntg 
70

\section{ZOOLOGIA}

II. Suntq; duo: Senfus communis, \& Phantafia.

III. Phantafix famulatur Memoria.

$$
\text { 2ufftiones. }
$$

I. An differant Senfus communis

$$
\text { E P pantafia? }
$$

8. Sensus communis eit, omnia Senfuum externorum objecta recipere, cenfere \& $j u$ dicare. Idem præftat Phantafia, qvæob. jecta illa reatius examinat, \& magis exactè dijadicat. Sic conveniunt, \& fi differunt gradibus differunt. Sed phantafia infuper efpecierum conjunctione ac confufione nova format phantasmata, qrod negatum fenfui communi. Phantafia etiam abfentia cognolcit, fenfus communis prafentium eft. Phantafia in fomno laborat, fenfu communi qviefcente.

$$
\begin{aligned}
& \text { II. An Sedibus differant Senfus } \\
& \text { interni? }
\end{aligned}
$$

h. Senfum communem in anteriore, phan. tafiam in mediâ, memoriam in pofteriore cerebri parte collocant. Memoriam enim duriorem cerebri partem, fenfum communem molliorem, phantafiam mediam regvirere ftatuunt. Sed cerebrum fecundum 
unam eandemq; Subftantiam pradictis fenlibus infervire aptum eft. Omne cerebrum molle eft, igitur fpecie rum receptioni pars gravis idonea. Si viget magis in parte una phantafia, in altera memoria, magis \& minus fpeciem non mutant.

1II. An actiones fenfuum internorum organica fint?

R. Actiones organicx funt, gqvas totum organum edit. Ubi non ad temperamentum tantùm, fed ad ipfam qroq; conformationem partiumq; difpofitionem ref́piciendum. Qvales actiones funt vifio, auditio, elfactio, guftatio, tactio. Interni fenfus cerebrum regvirunt \& ratione temperat menti, \& ratione conformationis recté difpofitum. Actiones igitur iftorum organicæ fuit.

IV. An potentia aftimativa annumeranda fenfibus internis fat?

Potentiam xftimativam circalpeciem infenfatam verfari putant sut ea percipiat, qva externi Senfus percipere non potuerunt. Cum ovis novit inimicitiam lupi,gva fub externos fenfus non cadit. Cum pullus fugitaccipitrem, non anferem, non egram, non canem. Cum hirundo nidum extruit, 
72 ZOOLOGIA

extruit, aranea telam, apis favos. In univerfum, cum animal ex fpeciebus fenfatis colligit objecta non fenfata. Sed non eit renfurs , qvî non verfatur circa fpecies fenfiles: \& accipit internus fenfus fpecies ab externis. Vis difcurrendi â noto ad ignotum, rationalis animx eft, non fenfitiva.Exempla qræafferunt, notitiam naturalem inferunt, non notitiam fenfualem. Naturâ norunt commoda fua \& incommoda, non bruta modò, fed ipfr qvoq; herbx \& arbores. Specificas formas ifta inleqvitur notitia,non animam fentientem aut vegetantem.

\section{Axiomata. \\ 1. Senfus interni â fenfibus exter- nis dependent.}

Ab externis accipiunt Ipecies, fine qvibus judicare non licet. Non judicat crecus â nativitate de coloribus. Vifus enim fpecies colorum phintalix non offert Neq; de $f_{2-}$ poribus judicabat Lazarus ille â Columbo deforiptus. Carebat enim lingva cjus nervis guftatoriis. Qvartum par nervorum inqvit Columbus, qrod guftatui dicatum eft, non ad lingvam \& palatum, fed ad occipitium reptabat.

II. Obje: 
11. Objectum fenfuum internorum, funt omnes externorum fen-

\section{juum pecies.}

Circa unum verfantur objectum, fenfus externi. Circa colorem vifus : circa fonum auditus: circa odorem olfacus: circa fapo. rem gufus : circa qvalitates tactiles, tactus. Interni verò fenfus circa omnia fenfuum externorum objesta occupati funt. Qvic. qvid vifum, qricquid anditum, qvicquid $\epsilon x-$ terisfenfibus notatum fuit, denuo fefe fifit ad examen.

111. Organum fenfuum internorum non eft cor, fed cerebrum.

Vitales actiones â corde, animales â cerebro pendent. Nihil confert Cor, quod proximè faciat ad fenfationem. Cerebrum verò fpecies fenfiles recipit \& fpiritusanimales communicat, potifimafenfationum inftrumenta. Celeberrimus Sennertus ait: Si de principio \& organio non remoto, fed proximo quar atur ommino concedendum est, actiones bas in cerebro É âcerebro exercevi; gyoditivm alia docent, tüm boc, good lofo cerebro, be act.ones leduntur, \& qood in curatione non cords, fed cerebroremedia applicańtur."

IV. Pars 


\section{4}

\section{ZOOLOGIA}

IV. Pars princeps organi propria cerebri fubfantia eft.

Habet cerebrum ventriculos fuos, habet finus, membranas, \& plura alia. Sed primaria pars proprium actionum organum \& facultatum fedes, propria \& peculia ris ejus caro oft. Qva de re ita Spigelius: Substantia ipfa fui generis eft, ac peculiario, grod cum pracipuum generationis ßirituum organum ipsa serebri fit fubftantia, É verò bec abomnibus alis diverfa, banc nulli communem efe docweric. Craßa sutem eft we flueret: netamen vicifin ni. mis dura, non reciperet /pecierum imprefionem, glutinofes ac vilcida.

$$
\text { CA P U T XII. }
$$

\section{Senfu Communi}

Preceptum.

Sonfus Communis eft fenfus internus, fpecies fenfuum externorum recipiens, \& renfibilia propria $\hat{a}$ fe invicem \& commu. nibus difcernens.

\section{Questiones. \\ 1. Vnde id nominis acceperit bic fensus?}

32. Non à communibus fenfibilibus, fod quis 
qvia communiter \& indifferenter fe habet ad omnia fenluum externorum objecta. E. t.am externi fenfus verfantur circa communia objecta: at non ut communis fenfus omnia objecta judicat.

11. An deturaliqris communis jenfus?

R. Ex operationibus fenfus hujus patet neceffitas. Difcernit animal inter diveriorum fenfuum objecta. Non hoc agit lenfi. tiva anima immediatè, quia non eft immediatum actionum fuarum principium: \& ipfi alias externi fenfus removendieffent. Nec id preftat fenfururn externorum ope, qria difcernens 60 gnofcere debet objecta: at non cognofcit vifus fonum, nec auditus colorem. Reftat igitrr conmunis fenfus, qri objecta externorum fonfuum difcernit. 111. Unde animal fentiat fe fentire? Norunt non homines folim, fed ipfa quoq; brutafe fentire \& fenon fentire. Arrigunt aures, aperiunt oculos, traliunt naribus, qrægrata funt, ingrika refpuunt. Nonea ratio agit, cum in brutis obferventur. Non fenfus externi, quibus fatis eft cognitio nuda. Sed communis fenfus objecto adhure prafente, cum fentiunt animalia, judicat qròd fentiant.

Axi- 
$7^{6}$

\section{ZO,OLOGIA}

\section{Axiomata}

1. Senfus communis officium regium eft.

Regisinftar aut judicis cft, qvi in throno fro fedet, $\&$ ab externis fenfibus, ceu miniftris fidelibus, vifa, audita, od'orata, guftata \& tacta, accipit, æftimat \& dijudicat. Hic est alle, ait Julius Cafferius, ex grocognof cimus nos audire, videre, reliqporitmíg finfuum murni fubire. Hic eft ille, qut in jommo ligatus, fenfacionis nos infcios relinquit: eff ille, qpi nifsadffit, omnesfenfus inutiles erunt: bic est ille, quiper. ceptorum fjeciem phaneafix, stǵs bas intellectui offert: bie in fumma eft ille, fine qDo nec Jenfibus externis, neğ internis, neǵsprincipibus anime faculiatibus jua integritas of abfolusio conftare. potest.

\section{Sensus communis officia va- ria funt.}

Primò omnes fenfuum externorum fpecies recipit: fpecies vifibiles, audibiles, \&alias. Sic multitudinem in unitatem prudens revocat natura, fenfibus externis in unum communem confluentibus. Secundò fenfibilia propria à fe invicem difcérnit: differre monfrat colorem â fono, fonum ab odore, - odurem â fapore, faporem â qualitatibus tacilibus 
tarilibus. Non enim id agunt externi fen. fus, cum quilibet proprio contentus objeto, alieni nullam habent curam. Tertiò, fentibilia propria à communibus diftinguit, colorem ; fonum, odorem, fa porem \& qvalitates tactiles, â motu, quiete, numero, figura ac magnitudine. Deniq; pratat ut fentiant animalia fe fentire, fe nempe percipe. re odorem, videre colorem. ubi paulò poft actum fentiendi fentire fe animal cognofcit.

111. Senfus communis fenfibilia coms munia fentit per propria.

ut fenfus externi primò propria fentiunt objecta, \& per ea communia; fic communis etiam communia objecta per propriacognofcit. Propriis fublatis communia percipineqveunt. Habet fe fenfile proprium ad commune, ut res ad modum. Modus non imprimit organo peculiarem fpeciem, fed propriam tantùm modificat. Quædam enim fpecies fenfiles fpargunt per fe \& primo,ut fenfibilia propria, qvedam per fe \& non primò, ut fenfibilia communia; qvædam nec per fe, nec primò, fed per accidens, ut fub. Aantia.

CAPi 
78

$$
\begin{aligned}
& \text { ZOOLOGIA } \\
& \text { CAPUT XIII. } \\
& \text { De Phantafia } \\
& \text { Preceptum. }
\end{aligned}
$$

Phantafia eft fenfus internus, fpecies $\hat{a}$ fenfu communi ad fe delatas diutius reti. nens, altiùs examinans, novasq́ve inde eliciens.

Qvxptiones.

1. Quanam primarie phantafie actiones fint?

Bi. Conftant è defcriptione. Phantafia primò fpeciesâfenfu communi allatas dijudicat, \& in naturam phantasmatis convertit: Deinde, fpecies novas efformat, conjungendo aut feparando fpecies acceptas. Undè nihil tam ineptum, qvod accu inter fommia non reprafentet. Dicuntur alias actiones immanentes.

II. Qvenam fecundarie pbantafie actiones fint?

R. Plurimx ató; mirandxe ex funt. Oves Jacobi Patriarchx ex appectu virgarum agnos ferebant fimiles coloribus vingarum Mu:lieres deformes èpicturarum pulchrarum infpeetione formofam edere prolem, Galenus mautor eft. Idem refert: Phantaficum fuijfe, goi obfer atio jaswis vitrea dafa ad fenefor ramprotulerit 


\section{PHXSICA}

eslerit, ac pretereuntes interrogaverit, juberent nè ea prójicere, É cum annusiß’nt illi, fingula qDé fuis nomenibus appellivit,cum fpect ancium rifu of acclamatione projecerit: poste à interrogaverit, juberentnè puerum qvoğs dejici, of cum jusffffent, ilico ipfum quog. dejecerit. Hzationes dicuntur Tranfeuntes, qvia â Phantafia ad aliud subjeitum tranfeunt.

III. Quid de inftinctu naturali referant?

8. Singulares brutorum actiones inftinAui naturali tribuunt. Cum formica conftruit horrea, \& comparat in xftate grana. Cum aranea facit telam\& capit mufcas. Cum lepus fugit canem, pullus milvum. Nierenbergius fic habet: Nec arimalium inftinctum alisd reor, guamoperationem pbantafie, adiudicium commodi vel incommodi determinatam, determinantemǵ, appetitum ad impetum pel fü gam. Judicium non propriè intelligo, Jed biftrionem quendam ejus. Differt autem inftinctus, licet brutorum phantafia in eanden fpeciem coëat, pro formarum \& temperamentorum diverfitate, qvæ bafes indolis funt: inde tanta operum varietas, ut bombyx lanam, apis favos, formica horrea, araneus telam, hirundo nidum architestentur:

IV. QDis 
so

IV. Qvid de boc inftinctu notandü?

k. Phantafia dependet â fenfu communi: fenfus communis â fenfibus externis. Sed aranea qvæ nunqvam vidit telam, qvæ exovulo fuo jan egrefla eft, telam format. Nec typos intuentur apes, aut juxta exemplar præfcriptum laborant animalia cætera. Non igitur hx actiones phantafix tribuen. dre funt : non cognitio ea fenfualis eft : non animam fenfitivam, qvæ forma generica eft, infeqvitur. Reciè Nicrenbergius ad diverfitatem formarum recurrit : malè verò maxima ifta artificia ad iemperamentum refert: malè pro phantafix effectu eadem venditat. Verè Seneca: Nascitur bac ars,non difcitur.

\section{Axiomata. \\ I. Phantafustupende funt vires in corpus proprium.}

Mirari eas potius, qràm rimari licet. Co-itando lata, latamur; triftia, triftamur. Fretida movent naufeam, jucunda appeticum. Aufteros fructus comedentes cum obfervamus, ipfi perfundimur hor rore. $\mathrm{O}$ fcitante uno, ofcitat alter. Cogitantes intenfiùs de urinx excretione, torqventur admodum fi praftare nolint. Efurient magis edentes øुvi cernunt alios, Peftis tem.

pore, 
pore, pefte corripiuntur quandog; , peften qui fibi imaginantur. Dolor dentium acerrimus fit, cum laborantes indulgent cogitatronibus ifts, Ex imaginatione inepta multa, multaltulta cogitant, logvuntur \& agunt amantes. Adeo qvosdam tenetamor, ut ex obefis macros ê lanis ægrotos è vivis morruos praftet:

U. P.banta fia stupenda funt: vixes in: corpus alienum internum. - A

Stzperant frec admirationem omnem. Accidit, tefte Münftero, cum mulieres dux in platea confabularentur, \& âtergo accederet tertia s, ac frontes utriusq collidèret, altera earum qræ prægnansfuit, duas pe. periffé filias, froncibus ad siafamioberentes, quedecemannosita conjunßte vixếre. Quxdamobnegatum a lanionefrultum carnis, catrum incaliuitirâ, , ut fangvine ftillarent nares, qrem cum abftergeret, enixa eft tandem farum labio fupremo carentem. Tor modis teneris fxtus inutat ac diftorqvet membra phantafias, ut fxpè $2 n$ bruti, an hom in is f pectes partes, neferas.

1II. Pbantafas oires in corpus alicnum externumnullaj funt. Avicenna \& Albertus Magmis fcribunt, - 5 
$S^{2}$

\section{ZOOLOGIA}

pullam gallinaceum aliquando cervice prodiif soc spitrina, éo guod gallina, dum incubaret c wis, territa fueric ab aecipiere fupervolante.Pu tant alii pavones produci albos, fi fremin incubans ovis, albis tegatur linteis. Scribi Micbael Medina, non pullum fed ferpenten producturam effic, fi dum in cubat ovis, can ceilis inclufus terpens, ejus femper obverfa tur oculis. Cenlent qridam, gallinas edi muras diverficoloris pullos, fiova variis pin gantur coloribus. Sed âneceßario ad nimiwn. Junt progreß3i. Non hî́c tanta datur, focietas gqvantam requiruat impreffiones.

\section{Nonperfe, fed per accidens. pbantafia mutat corpora, ${ }_{\text {eut }}$ propria, feu aliena.}

Facultas enim cognofcens eft. Proprius hujus cognofcere, non mutare, non defor mare, non pervertere corpora. Etfi per fi praftaret ea, illi qui cornua fe geftare,qu è vitro fibi conflatas putavere nâtes: qvi butyro fe credidere compactos., evafifen rales: Per accidens vero mutat corpora qratenus facultatem cognolcentem, requi tur appetens, appetentem loco movens, lo. co moventem mutationes ift $x$ mirandx.Pul. chra hic datur \& caufarum \& actionum co. 
rona. Phantafia excitat appetitum: appetitus locomotivam : locomotiva fpiritus \& humores : fpiritus \& humores pro fuo acceffu \& receflu mutant corpora. Sic timidis \& meticulofis crebra funt fpectra. Sic quisquis amat ranam, ranam putat effe Dianam. Sic ad fupplicium ducti qvidam, virgx aut linteimadidi iqu expirarunt, sicholtium injurias, qvi volvunt mente, horrent, tremunt, rubent, ipfamá; fermè cum fangrine animam evomunt. Sic fatus nafcitur muris gcrens fignum, qrod mater mure territa fuerit : fic Simix afpectu fxtus producitur Siniam referens.

$V$. No omnis imaginatio fignat fatu. Infinitx fibi imaginantur gravidx, ut nemo hominis referret vultum, imaginatio qvavis fignandi fi haberet potentram. Fru: fra funt omnes imaginationes, qva fiunt absá; affenfu. Ubi enim nullus affenfus, ibi nullus affectus, ibinulla motio, nulla mutatio. Defiderium verò, terror, amor, Ira, ac triftitix; maximis fignandi pollent viribus. Hippocrates ait: Si mulier grapid's rerram aut carbones comedere defider aperit, eddemg conedat, in capite pueri note â talibus apparebunt. Et non fugit peritos, gravidas, cum re defiderata potiri neqveunt, magis

$$
\text { nit } F_{2}
$$
fignare. 
84

\section{ZOOLOGIA}

fignare. Majus enim tunc fit defiderium \& quo iftud majus,eò efficacius eft. Terro qrớ;, a mor, \& ira vehementifimi affectu funt, ac fpiritus humoresq́; turbant maxi mè, fatumǵg; utero inclufum vehemente afficiunt.

\section{CA PUT XIV. \\ De Memoria.}

Praceptum.

Memoria eft facultas miniftra, fpecies á phantafia dijudicatas, retinens \& confervans.

\section{Qvaftiones \\ I. Andetur Memoria?}

Fy. Animi gratia Scaliger de re fplendore Sdlis clariore dubitat. Difputat de quaftonc an fit, ê qvaftion ibus qvid fit, qualis fit, u6ific. His impellinos purtat, ad credendum,

- nullam dari memoria m. Sed tam evidens experientia memoriam probat, ut nulla machinationes evertant eam. Redeunt aves ad nidos, apes ad apiaria, lupi, lepores, ac leonesad latibula. Invica hrc memo. rix in brutis a rgumenta funt. Nos ipfi memoria fi deftitueremur, fruftra docerea mur: præterfluerent enim audita. Omnis difciplina memoria conftat, qva the fanrus artium \& fcientiarum eft.

$$
\text { - II. Quid }
$$




\section{PHYSICA.}

\section{Qvid fit memoria?}

8. Eft potent ia fpecies dijudicatas reci, piens a confervans. Scaliger ad quaftios nem fic refpondet: $V$ is anima communis eft, ad retinendum tam rerum imagines, id eft phaniasmata, quasm notiones imiveifales; cas gु vel fimplices, vel complexas. Sed poftcriora verba memoriam fenfitivan non explicant. Senfus enim fingularium funt; non univerfalium. In brutis animalibus tantùm phantasmata dantutinon conceptus aur noxiones Iimplices ac complexæ.

\section{II. Qvalis fit memoria?}

R. Yel bona vel mala eft. Cujus ratio quxrenda in cerebro. Unde qvibus cerebrum durius, is difficilior apprehenfio, re. tentio pertinacior : qvibus mollius, ii facile recipiunt, retentione utuntur minus fidels ac diuturnâ. Scoliger reponir fegrentia: His igitur species efle videtur in materia. Cate. rìm que materia suns aut alteralpecie indura fucrit, addectertiam aty etiam millefamam: sa plena erit, ac fortaßße confufa. Sed nec verè, nec ex animo dicithrc. Omninò fpecies in materia eft. Non funt oppofita, fed fubordinata : fpeciem effe in lomine, in anima, in cerebro, in f piritibus. Homo ftbjectum prio marium eft, anima fecundarium, cerebrum

F 3

8 


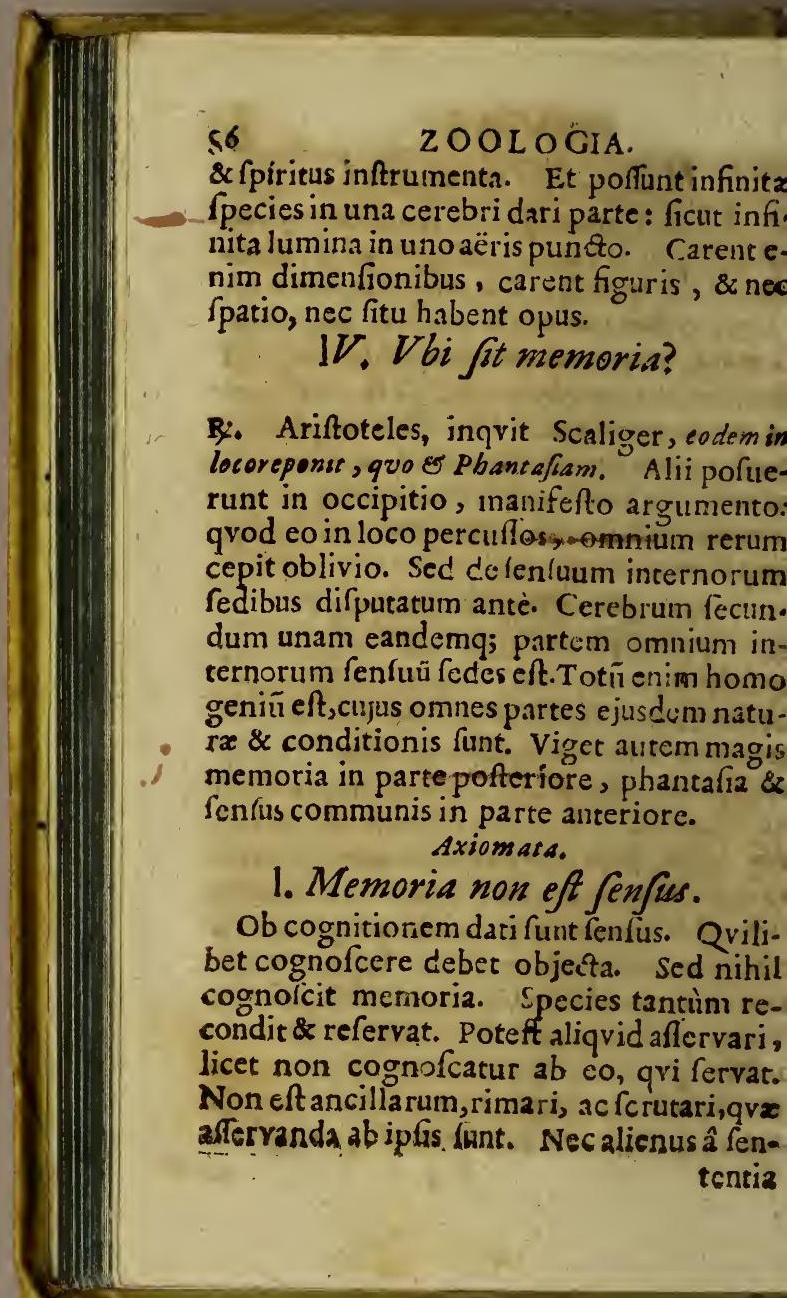


PHYSIC,A:'

entia videtur Ariftoteles. Memoria eft, inquit, neq; fenfus, neq; exiftimatio, fed horumalicujus aut habitus, aut pasfio.

1. Virtus"mémorice eft, facile recipere, diù retinere.

Data enitn memoria,ob receptionem $\&$ aflervationem. Sed non facilè ex aqro, in una moranturfede. Alterum enim humidam cerebri pofcit temperiem, alteram ficcam. Hinc multi addifcunt facile, cuftodiunt zgrè. Alii diù retinent, difficulter recipiunt. Landandi.temperati, qvorum cerebrum nec humidumnimis, nec ficcum valdé. Facilè enim recipiunt, \& fervant fideliter.

111. Arte parare menoriam, plena periculi reseft.

Alii medicamentis rem agunt, alii per memoriam, qvam rocant localem. Naturalem cerebri temperiem medicaments mutare, periculo non vacat., In delirium qrosdam incidiffe ex applicatione medic.tmentorum, teftem habemus experientiams.' Multi etiamacquifiverunt memoriam \& amiferunt jodicium - Sed magno emit me moriam, qvi difcurfus difpendiô emit. Loca vero \& imagines, tantum forfan laboris, tantum temporis reqvirunt, grantum res ipis 
SS 20OLOQIA

ipfx edifcendx. Et lufus ifte non parmm obeft judicio at ́́j difcurfuir-Adhlbenda potiùs maturè exencitia : obfervanda in rerun tractatione recta methodus \& âmimio verborum delectuabftinendum.

- IV. Memorice opporitsur oblivio. Mater fapientix memoria eft, mater ignorantixoblivio. Fit hac nunc ob fenium, nunc ob percuffionem capitis nunc ob atia osatq; alios morbos. Quidam, tefte Plinio, ictulapidis percuffus, matrisjaffinium है propinqvorum oblitusfuit. A Tius ex praalto tecto lapfus, literarum omninò oblitus eff. Georgius Trapezantius in fenio omnium litera. rum Gracarum \& Latinarum oblitus seft. V. Meminisfe Eveminifcinonidem

Memoria homini cumbrutis commonis Junt. eft. Soli homini convenit reminifcentia. Memoria continua confervatiolpeciei eft: reminifcentia oblivionem pramittit. Exci. ditenim res ante, nec fuccurrit promptè. Igitur ex aliarum rerum memoriâ fervata. rum ad eam, qvæ periit, fit recurfus.

$$
\text { CAP UT XV. }
$$

Somp̧o \& Vigilia. 


\section{precepta.}

J. Somwus eft privatia actionum fenfus communis \& lenfuum externorom, ex negatione fpirituum, ob a nimalium falutem facta.

II. Vi gitia eft operatio fenfus commu=nis.\& Senfuum externor:am, â fpiritibus prafentibus excitata, ob anima: lium utilitatem.

\section{2veftiones.}

1. Quxnam Somni carfa efficiens

$$
\text { fit? }
$$

R. Privationes non tam Efficientem, gram Deficient em habent caufam. Somnus fit pro * ximè, qvia fipiritus animales in cerebro detinentur \& organis fenfum non commuaicantur. Placent verbaSennerticaufas fo. mni defcribentis. Sicaufas fomm omnes cond fideresnus, animad vertemus, alias fomnum inducere, Jpiritus animales abfumendo, quales funt vigilie, labores Es defatigatio, cura, balnea, aftus: vel obcsindendo E minus mabiles, Ef quafs ignavos ac turbidos.spiritus animales red dendo; feu ut alis placet, viam iis occludendo, ut füt DAporofiodores, Es" vapores â cibo Es potu. afcendenses, E. fiqua bujus generis funt alia; vel Jpiritus animales goajîplacide fifrédo, ơ â motu ad goien. 
90

\section{ZOOLOOIA}

sem invitando, ac ne diffluant probibendo, qvales funt cantus foavis, murmur a avarum, friEiso Glanda, cogitationsem fuspenfio, lectio parum stenta, filextsum, tenebre. Si verò ad communem efficiendi rationem reducendx funt omnes illx, ea cómuni ratione fomnum inducere percipiemus, qròd fpiritus ani. males in cerebro quietas detinent, \& faciunt, ut ad organa fenfus \& motus non influ. ant.

II. Qrodnam Somni Subjectum fit? R2. Animal fomni fubjectum eft; ficut \& vigilix. Subjectum hoc adrqvatum dici. tur. Tale,cui fomnus compctit reciprocè: òta ut æqvè latè pateat cum ipfo. Omne e. niri animal vlurimas operationes edere na. tum eft. His vero exhauriuntur fpiritus, membraǵ; reficcantur. Igitur qviete opus eft, ad f pirituum reftaurationem, partiumq́ve humectátionem. Qvod caret alterna requie, durabile non eft.

\section{Qvenam fomnifedes fit?}

Animal quidem $\&$ vigilare \& dormire dieitur. Inter corporis vero partes quadam eft diverfitas: hinc de fede fomni difputatum eft. Qvanam nempeilla fit pars in animali, qvæ primariò afficitur fomno? Aria Eforeles, qui cor effe voluit primum fenforiti.

illud 
illud etiam in fomno affici primario ftatuit. Galenus qui primum fenforium cercbrum clfe leripfit, fomnum etiam non cordis, fed cerebriaffectionem alferuit. Et fanè à cerebro Ipiritus animales per nervos communicantur partibus. Cerebrum itaq́; fomni ac vigilia propria fedes eft.

IV. Cur animala fomno expergifca-

\section{tur?}

Fi. Caufa duplex eft ; altexa interna, alcera exierna. Incerna calor \& ipirlius. Conclufi erant fpiritus, calor etian incrò abdiderac fefe, his proruentibus a cliberius graflantia bus, ceffat fomnus. Reduci huc poteft Phantafia, qva cum fortis eft, etiam appecitum \& 10comocivam ftimulat. Hine ipfa quogif fomnia nos excitant. Externa funi omnia ob. jecta fencibilia excellentia. Lux fplendidior, fonus gravior, odor fragrantior, aëris vapor a ut humor, ac validis concaceus. Marimámautem excisandi vim habent fonus \& ractus. Unde his potisfimum modis excita: re folemus dormientes.

\section{Axionaca.}

1. Tempus fomno aptis fmum efi, quod prafcripsit natura.

Naturam feqventibus omnia faciliasomnia expeditafunt. Cọtra naturam nitentibus cuncis 
92 ZOOLOGIA

cundta grävia funt, cuncta noxia. Turpe eft th officia Jucis noctisq́; pervertere. Turpe in ea. dem urbe antipodes dari, quibus noxef, cū dies nobis: dies cum nox nobis. Aves nocturnatimitantur, qvibus, cum lucer, tempus fomni eft, cum tencbra ingruunt, tempus la. borum \& exe rcitiorum. Evertunt naturam, qvi retrò vivunt; \& ne gratis faciant, evertunturab ipfa. Nihil enim æqvè fanitati adverfü, qvam dies noctibus,noctesğ; diebus ầ quare.

11. Ordimur vitarn âvigilits.

Natus homo fentic, \& vitam aufpicaturâ lacrymis. Hoc edimur principio, riec alio Principes ac Reges, In utero verò modò con. ceptus foetus, nec dormit propriè nec vigilat. Naturales potiùs exercet actiones, qvam ani. males. Vigilia autem \& fomnus animalibus debencur actionibus. Vivimus primò vitam plantæ, at nec vigilat planta nec dormit.

III. Egrè capiunt fomnum cibo nimio repleti.

Pauperes ac divites, miferos ac felices $x$ quare fomnus dicitur. Ut dimidio vita nihil differant fortunati ac infortunati. Imò re altiùs xftimatâ, fuaviùs dormiunt pauperes divitibus. Hi enim plerumq; cibo \& potu iatemperanter fe obrunnt. "Eduliorum illa

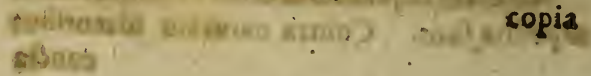


PHYSICA.

copia ventriculum opprimit. Oppreffus venter cibum nec digerit, nec tenues yapores excitat.

\section{A P U T XVI. De Somnio, \\ Prezepta.}

I. Somnium eft phantarma animalis dormientis, cerebro obverfans, phantafix operatione factum.

II. Er eft vel animale vell naturalie

III- Animale, qrod ex imaginibus interdiur conceptis ac relictis formatur.

IV. Naturale, quod ex humoribus, temperamento ac fimilibus caufizin. corpore latentibus oritur.

Quiftiones.

1. 2vodnam Sommii Subjectum fit? 18. Primarium eft animal. Non enim ho" mo tantùm fomniat, fed ipfe qroq: beftix Teftatur hoc experientia de canibus, feli- buss, eqvis, capris \& aliis, qve fomniorum terrieulamentis frà a agitantur repenteq́; expergiffuntur. Secundaxium eft cerebrum : Sicut enim cerebrum fomno afficitur;iza qvoब: formio. Cerebrum verò crudoram, hali(7) dammodo. 
94

\section{ZOOLOGIA}

danmmodo. In aqva turbida aut nulla fit effigies; aut tortuofa \& confufa. In cerebro ab halitibus agitato ac turbaro aut nulla formanzur fomnia aut indiftinça \& parùm cohrerentia.

\section{Zvid de incubis not andum?}

R. Somniant homines nonnungvam fein. vadi \& premi ab aliqvo fermeq́; fuffocari. in -

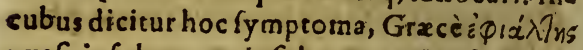
quafi infuleor, aut infultator. Caufa eft vapor,qui partim diaphragma, partim cerebri partem pofteriorem obftruit. Hinc refpira. zionis lafio \& gravitatis fenfus. Ubi phantafia fomnia format, \& comminifcitur, quafi prematur ab aliqvo dormiens. Sicut ubido. for in parte quadam oritur, fe vulnerari, $a b$ animalibus morderi, aut alio modo lædi fomnint. Quanqvam non negandum, conjungese fefe nonnunqvara Satanam, qvi nullam nocendi pratertisitrit occa fionem.

\section{Quid de noctambulis nos tandum?}

- Reperiuntur qvi dormientes ĉlecto fuzgunt, nudi incedunt, fcalas afcendunt, \& loCa vigilantibus non adeunda fuperant. Di-

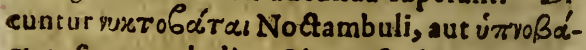
Tal Somnambuli, Phantafia hic occupata maximè 
PHYSICA

maximè circa phantafmata eft, ut dormientes ca, qvæ obferuntur, veriffima effe credant. Hac phantafia appetitum \& loconotivam. ftimulat, ot exequantur mandata nocu aqve ac interdiu. Et tantd feliciores in opere funt, qvantò fecuriores \& audaciores. IV. Quomodo intellectus fe babeat

\section{circafomnia?}

Refp. Non ceffat in fomno intellectüs, fed ipfis fe immifcet fomniis. Difcurrimus fapè in fomno \& rectrits forfan quam vigilantes. Liber enim tunc animus eft, \& folutus â cot* porispenfo, Zanardus defe ipfo feqrential. feribit: Hoc mirabite sas sae cognovi, quod cum nen fim in composendis carminibus multum peritus (verumfateor) negí in Graca Habraags lin. gva, in fomno, currente difcurfu, carinina gulcberrima Lasina vulgariaǵ, formavenims. Ee serminos ante dict arum lingvarum cognoverim, ut manè expertus fum: Consionesgg ordinatas; ornatas of pulsbriores in fomno confec erim, qvä in vigitia, Es qua in pigiliacum mulso labore non penetravi, in fomno in prompeu bal wi, \& $p^{\prime}$ 'ura bec mibi acciderunt, qua fine operwincello ds $\mathrm{fos}$ eri non polfunt.

Axiomats.

\section{Dantur Somnia divina}

Freqventia admodum olimerant, hodic ferme 
96

\section{ZOOLOGIA}

fermè ceflarunt. Diviaz erant. fomnia Pha. raonis Regis. Egyptii de feptem tauris pingvioribus, \& totidem macilentis devoratis; deǵ; feptem turgidis \& prægrandibus fpicisâ tơtidemaridis \& fuccis abfumptis. Divinumerat. fomnium Nabuchodonofaris Regis. Ally: riarum, qui videre vifus eft ftatuam giand em \& fublimem capite aureo, pectore \& brachiis. argenteis; ventre \& femoribus $x$ neis, ferreis, imis pedibo partimferreis partin fictilibus, \& tandem avulfum à̀ monte pragrandem lapidem, fuopte nutu \& impetu pracipitari in ftatuam:

- DI. Dantur Somnia:Demoniaca.

Eruditè perqvàm de his fcripfit. Peucerus, in Commentario de pracipuis divinationum generibus. Diabolici, inquit, generis funt omnis illa; qpe Diabolus olim offudit Et bnicis,ubi ad delubre Idolorum, captandarum calium, preftigiarün caufa, involutivicitimarum peliebius cubabant: queg nunc Andbaptiffis, of onsitem. pore, Entbufiaftis, of fimilibus fanaticis iv aldito adnoras patefactiones velut biantibus, aut $M a$ agis ÉV eneficio, épromifcuè omnibus non converfis ad Delum, Jed fue fubjectis tyrannidi: exbi. bet, eafine, utcedes, flagitia ac fceler s: frrat of azabiliat; Idololatriam.

III.DAKe 
PHYSICA.

Recurrunt no.ctu, quæ gesfimus interdiu. 97 Concionantur in fomno Paftores, rixantur Caufidici, difputant Philofophi, unde Lucretius ait:

In fomnis eadem plerig, videmur obire, Caufidicicaufas agere E componere leges, Induperatores pugnare es pralia obire, Naute contristium cum ventis degere bellum. Ec Claudianus:

Omnia qua fenfu volvuntur vota diurno, Tempore nocturno reddit amica goies. Vexat or defiffa zhoro cum membra reponit. Mens tamen ad lylvas ef fua tustra redis. fudicibus lites, aurige fornnia currus Vanags nocturnis meta cavecur eqvis.

\section{Dantur Somnia Naturalia.}

Miranda vires remperamenti, \& aliaruma caufarum latentiumfunt. Hinc novum fomniorum genus animalibus fomnis contradiftinéum. De incubo Poëta dicit:

- In mediis conatibus agri ,

Succidimus, nec ling a valet, nec corpora noCEu

Sufficiunt vires, nee dox aut verba fequuntur.

Spectant huc. fomnia fangvinea, cholerica, Phlegmatica, Melancholica. Sangvinea de rebus latis funt, de conviviis, de mufica, de G

flori- 
98

\section{ZOOLOGIA}

floribus \& aliis. Cboierica de litibus \& rixis funt, de pugnis \& bellis, de incendiis. Phleg. matica de aquis funt, de pluviis, de balneis, \& natationibus, navigationibus, de oneribus gravantibus \& fugam retardantibus. Melancholica de rebus triftibus funt, de tenebris, de fpectris, de morte \& inferno.

\section{$V$. Varii fortune cafus varia pre- fant fomnia.}

Cui fortuna favet, jucunda funt fomnia. Quem premit adverfa, fuos patitur manes. Prater corporis difpofitiones, inquit Fraca. ftorius:Sunt E alia quedam, qua jolent nonnulla fomnia frequenter inducere, ut is qui in paupertate funt, quod femper vident fibi deeffe aliquid, fapiffimè etiam fomniant de Je ipfis, ut carentibus qpibusdam : 6 in prafentia aliornm. eße aut fine vestibus, aut fine calceis, aut iisdem mutilatis ह5 finilibus. Contya verò qvibus multa fuperabundant, fomniant alies dare, geminatas babere vestes $\sigma$ ejusmodi. $20 i$ verò valdè ansipites E perplexi funt, vel confili. orum, vel inqvifitionum circa fcientias, illi fop̀̀ fomniare folent, circuitu longo de domo in do mum, de via in viam progredi, ac demum in avguftiis quibusdam fefe invenire. Formidulofis certa funt fomnia of maxime fibi familiaria:cer-

ca ADG- 
PHY SICA.

avaris, certs amantibus: \& nemo ferè bonsinun eft, qpi peculiaria quedam non faciat fomnis propier peculiarem corporis difpafitionem.

VI. Vanitas eff fomnia orninia ob. fervare, temeritas omnia

\section{negligere.}

Divinz negligenda minimè funt. Infor: mant nos de rebus neceffariis: five manifefta fuerint, five obfcura. Deus veritas ipfa eft: à veritate nil nifi verum. Dæmoniaca fugienda maximie funr. Satan enim patermendacii olt, \& mentes hominum fallacibus concitat vifis, nunc apertis \& claris, nunc tortuolis \& obfcuris. Animalia vana funt, \& vani, qui obfervant. Phantafia enim actiones prateritas vel repetit tantùm, vel multis modis con fundit. Nihil tam ineptum, tàm abfurdum \& monftrofum, quod fominia hæc non obferant. Rectè de illis dicimus : Somania dor mientium deliria, deliria vigilantium jomnias. Naturalia notatu dignifima funt. Deducunt enim nos ad humorum, ad temperamen toram, ad affectuum, aliarumq́ve lacentium rerum cognitionem. Sic is iple qui ftare fib nuper videbatur in cifternâ langviné plena, fangvinis evacuatione egebat ob plenitudia. nem.

G.

GAP. 
100

$$
\begin{aligned}
& \text { ZOOLOGIA } \\
& \text { CAPUT XVII. } \\
& \text { DE }
\end{aligned}
$$

FacultateA ppetente.

$$
\text { Pracepta. }
$$

I. Facultas appetens elt, qvâ animal ad bonum profeqvendum \& malum fugiendum fertur.

II. Dividitur in concupifcibilem \& irafcibilem.

Quafiones.
I. An detur Appetitus fenfitivus à voluntate diftinctus?

F. Facultas appetens alio nomine appetizus fenfitivus dicitur. Se givitur enimjudici. um fenfuum - Ignoti nulla cupido. Differt à voluntate, qvid hac intellectum prareqvirit, ille phantafiam. Hac libera eft, ille neceffarius. Mufca repulla manibus aut flabello, reditusq́ve \& usq́ve ad objectum gratum.Nec poteft abftinere pofitis omnibns ad reditum. reqvifitis. Voluntas deniq́ve fpiritualia et.iam bona petit:Appetisus fenfitivg gaturalia rantùm.

11. Unde pugna inter rationem E Appetitum?

Rerp. Ratio ad opcimaquvquehortatur homines : 
PHY S ICA.

ror

mines : Appetitus in contrariam ferturpartem. Ratio inMedea dicebat:

Excute virgineo conceptas pectore flammas,

Si potes.

Appetitus refpondebat:

- - Infelix fi pofferm; sanior efferns Sed trabit invicam nova vis, aliadǵs cupidos Mens aliud fuadet: video meliora proboqve, Deteriora Jequor. Fit ex accidente, nonex natura debito, fed ex rature vitio. Non funt in homine facultates oppofite, ratio \& appetitus, fed fubordinatx. Per accidess pugnant: perfe confentiunt:

\section{Axiognata.}

1. Cognitionem feqvitur Appetitus. Nec cognitio omnis, nec appetitus omnis loci hujus eft. Non naturalis cognitio: nec naturalis appetitus. Senfuum cognitionoAtre data fuit fpeculationi; hanc feqvitur appetitus fenfitivus. Sic qvæ vifui, qqa auditui, qva tactúi videbantut grata, a ppetuntur,imô phantafia judicium prapollet, ad cujus repre. fentata fequitur cupido.

11. Appetitus ad bonum fertur.

Bonum prodeft, malum obeft : bonum confervat, malum deftruit. Abhorret omnis

$$
\text { G } 3 \ldots
$$

natura 
102

natura à deftructione fui. Ad bonum igitu fertur impetu pleno. Canis panem videns bonum fuum judicat, indeq́ve appetit :cev. nens baculum, malum xeftimat, indeq́; horret Ipfrinfantęs altis clamoribus petunt poma ac pyra, cerafa ac prana, velut praftancifirma bona.

$$
\text { CAPUT XVIF. }
$$

$D E$

Facultate concupilcibili $\&$ irafcibili.

Precepta.

I. Facultas concupifcibilis eft, quâ animal ad bonum profeqvendum, $\& \mathrm{cma}$ lum fugiendum fimpliciter fertur.

II. Facultas irafcibilis eft, qvâ animalad profequendum bonum, \& malum fu. giendum cum difficultate fertur.

'Quomodo differant

cupifcibilis E' irafcibilis

Refp. Differunt objectis, organis, \& actioni. bus. Concupifcibilis objectum eft bonum * malum abfolutè tale. Qvicquid nempe eft delectabile, fvave $\&$ jucundum, concupi. fcit animal: qvicquidmoleftum, tædiofum \& noxium: 
noxium, averfatur. Irafcibilis objectum eft bonum arduum:ubi adverfus holtes pugnandum, qvi eripere conantur bonum. Concupifcibilis organum hepar eft : Irafcibilis cor. Heparamare cogit, cor iram concitat. Áctiones concupifcibilis funt, profeqvi bonum, fugeremalum. Irácibilis, irafci, atque de. fendere fe adverfus vim oppofitam. Minuis autem concupifcentia intenfa iram: ira major remitrit corrcupifcentianz; ut fimul habjtare nequeant codem modo in eodem fubjecto:

\section{Axiomata.}

Fruftra eft appetitus concupifcibilis fine irafcibili.

Impediret vis adveria concupifcibilis acti. onem, fi non fuccurreret iraf́cibilis. Notase dum, ait Titelmannus, good appetitus datus ef aximali propter concupifcibilem \& eft velut propignator concupifcibilis. Sine appetitunamgis irafcibili concupifcibilis e ßét velut inermis $\sigma$ absque defenfiore. Negi Jufficiebat apoetitus concupifcibilis ad bence effe arimalis, nifa fuifject adjectusetiam irafcibilis. Frequenter enim contingit circsid, quad animali ef conpeniens, occurreve arduitatem of difficultatess, per quam affect us concupifibilis ftatim retraberetur, nija ajfec adjunctus appecisus ir ascibilis, qpi confirma$G 4$ 
104

ZO OLOGIA

rec concupifibilem or velut animaret infuo a. more es profecutione.

\section{CA PUT XIX. \\ $D E$ \\ Affectibus in Genere.}

Pracepta.
1. Affectus eft paffio anima fenfitiva à cognitione objecti excitata, quâi il= lud aut profeqvitur aut fugit.

II. Seqvitur aut facultatem concupifci- bilem aut Irafcibilem. III.Concupifcibilem, amor \& odium, latitia \& triftitia, defiderium \& fuga. IV.Irafcibilem, ira, Ipes \& defperatio, timor \& audacia.

$$
\begin{aligned}
& \text { Qvestiones. } \\
& \text { 1. Qveram affecturm efficiens } \\
& \text { caufa fit? }
\end{aligned}
$$

Refp. Anima fenfitiva cùm potentiarum, tùm diffectunm caufa efficieris eft. Et cùm fuperior anima habeat omne id quod inferior, rationalis etiam anima , \& facultatum \& affeCluum efficiens eft. Unde Ariftoteles ait, trise efe in anima, affectus, faculeates of babitus. Per faculicates idonei reddimur ad affectus capi. endos:perbabtus ad babendos eos benè aue malt.

II. Utrums 
11. Utrum affectus boni, an mali

\section{fint.}

Refp. Natura fua boni funt omnes : refpectu objectorunt \& fubjectorum mali nonnulli. Naturâ nobis infiti funt : naturalia autem ominia bona. Ob objecta in malos $\&$ bonos dividi poffunt. Lxtitia \& ipes ob objecta bona, affectus bonilunt. Triftiria, metus \& ira, ob objecta mala, mali funt. Ob fubjecta etiam bonis bonifunt, malis mali. Illi enim modum fervant : hi peccanc, nune in exceffu, nunc in defectu.

\section{An bomines magis affectibus obnoxii fint, quàm bruta?}

Refp. Plura homo cognofcit, qvàm bruta. Supera, infera ${ }_{5}$ media $\&$ omnem mundi finum pererrat: Necprafentium tantùm, fed longè prateritorum cognitioni intentus eft.Qvin \& futurorum cara anxiè perfapè eum tener. Cro plura itaque cogroorcit, eo pluribus etianz obnoxius eft affectibus. Multos inopia metus premit, alios contempeus, qrosdam roluptates fenfuum afficiunt, quibus homo omnium maximè indulget.

\section{Axiemata.}

\section{Affectus Paßio eft.}

Non ca palfio, qua demonttrationem inG 5 gredi- 
106 ZOOLOGIA

greditur \& affectio dicitur. Necilla, qva receptio forma eft, five fubftantialis, five accidentalis. Nec ifta, qua actioni opponituse \& peculiarem conftituit claffem. Sed qua tertie fpeciei qualitas ct. Ibi enim pantio datur \& patibilis qualitas. Pafto in cam dividitur, qva anime \& qve corporis eff. Animx paffionunc notatur, qual is lexitia, trifti. tia: non corporis, qualis rubor \& pallor.

II. Affectus opinio non est.

Opinio eft incerta notitia, cui languidè affencimur. Sicut imaginantur fibi nonnulle, effe pygmros, bella cum gruibus qvi gerant, effe materiam primam, privationem, alterationem \& Elementorum transmutationem. At non eft incertum aliqvid, lætitia aut trï ftitia, amor, ira. Norunt iratife irafci, norunt triftes, triftitia fefe affici. Nemo nefcit, aliter ira, aliter defiderio nos difponi.opinia nonesí res, re autem conftat affectus.

III. Affectus moderatiferroant naturam, immoderati defruunt:

Moderati affectus rofeo colore corpus pin. gunt, ipfamque animam fvaviter afficiunt. Nimii nunc palloré, nuncruborem inferunt, munc ipfos tremere faciunt artus. Unde verfus.

San. 
Corpus, $\mathcal{E}$ attonicos fubitus trenor occupat

Intellectus qroq́ve judicium impediunt, diftrahunt, tollunt. - Voluntatem feducunt, \& in præcipitem deferunt. Mulci qvi acerrimos hoftes vicêre, vincere non potuêre fe ipfos. $A$ jacem, inquit Seneca, in mortem egit furor, in furorem ira. Cìm arma Acbillis interfecti ì Paride, non fibi, fed lliyffis, à Gracorum exercitu eßent tradits.

IV. Hominum alius alio concitatior.

Nationū varii funt affectus, mores, ingenia. Diverfitas regionum diverfos hominibus ingenerat affectus. Nunc naturalis levitas populos agit, nuncferocia, nune loperbia. Etiam ztas, fexus \& ftatus, certos pariunt affectus.Minus inquietantur viri fxminis, provectiores xtate ad olefcentibus, fani agrotis." Varituns Es mutabile emper fiemina. Qveruli ac diffi. ciles agroti, fenes duri ac morofi. Temperamentum qvos inferat affectus, clam neminem eft. Sangvinei laci funt, cholerici iracundi, phlegmatici veternofi, melangholici trittes. Magni refert, inquit Lemnius, in af. fectuum differenciis, quale cujusqvam temperamentum existat, qpibss busmoribus corpus fit ofpletum, qve piritusm, qui ex bumoribugese,

rantur, 
In 8

ZOOLOGIA

rantur, fit qualicas: fiquidem qvi calido funt of facco corporis habitu, celerius incandefcunt, prafertion qvi in parvo pufillog $g_{3}$ corpore exiftunt, qvibus oblar eciam futili quavis caufa nulliusg momervioccafione, cicisfimè bilis accendicur, quia propec loci anguftiam, minimumg organorum intervallum mentem confestim corripit, $\mathrm{Atg}_{3}$ ut bumiles cafas ac euguriolainflammac accenditg.

CAPUT XX.

$D E$

Amore \& Odio

Precepta.

1. A mor eft affectus facultat is concupifcibilis, qvo animal ad bonum propendet, cum eoq́ve vult uniri.

11. Odium eft affectus facultatis concupircibilis, quo animal â malo abhorret, ab coq́ve amoveri cupit.

Quaftiones.

I. An amor fine latitia efJe queat? B3. Amare eft pati, amari agere. Dolorem infert paffio hres, non gaudium. Si voluptas eft, multum certè alieni admixtum habet. Fracaftorius putat, amorem ex gaudio proficifii. Sed Refpondet Scaliger, nec ex omni gaudio amorem, nes cx. Omni amo. regals- 
PHYSICA.

re gaudium eße. Gaudent multi, dum injurias injuriis ulcifcuntur. Amant plures dolens tes, quàm gaudentes. Nongaudemus, perg it Scaliger, ex quocungis amore: /ed modestè ferimus convenientis rei conjunctionem: gve pera atgis inculpata boluptos sft. Qvippe conjugio negs gaudeo, negstristor: fed fat is babeo.

\section{Qvotuplex fit amor?}

Scholaftici dividunt amorem in concupifcentix, defiderii \& complacentix. Concupifcenti\&, qvo resamatur: non propere fe, fed proprer amantem, cui prodent. Sichomo amat benefactorem : rufticus vaccas \& eqvos. Defiderii, quo res ablens amarur, cuibona opramus.Sic amicus ámicum ablentem diligit, Complacentie, quo res prafens amatur, cuibe. nè cupit amans. Sic amicus amicum prafentem diligit. Sed confundieur defiderium cum amore \& omnis amor concupifcit. Alia dari poffet divifio 2 moris ratione principii, ins naturalem, fenfualem E rationslem. Magnes amat ferrum, ignis ignem, aqva 2qvam amore naturali. Parentum etiam so mor erga liberos natoralis eft : dicitur $50 \xi \gamma \dot{\text {. }}$. Pulchra amamus, fæda horrenus ob fenfus. Amor virtutis \& odium vitii, rationem feqvi. sur $_{3}$ non fenfum, non naturam. Deus amatur, 
rur, non ex concupifcentia naturali, fed ex fidecui ratio ancillatur.

III. An odium affectus compofitus fit? R2. Siriplex cif atfectus, non egens alterius. Noneft in odio fipes. Qvid fperat,quiodir ingratos, mendares, avaros? Non elt in odio triftitia. Excitat animum odium, non cohibet, non deprimit. Non eft in odiometus. Oderunt principes, qvos non metuunt. Non eft in odio ira. Sine ira in odio funt multis mendaces, ingrảti, intemperantes. Non eft in odio offenfio. In odio iniquus judex eft, iis quoq́; qvos non offendit. Non eft in odio defiderium; quo malè vovemus alicui. Odi mendacium, irquit Scaliger. Qpid mendacio poffin imprecari ? Qvia odi impios, lirigiofos: goibus tantum abest, ut male velim : utuliró cos effe difupiamjuftos. Atg boc quidem cx inge. nioineo.

\section{Amor affectus unionis, odium averfonis eft.}

Amant coujungi amantes, disjungi petunt hoftes; Sicut ignis ignem petit, aqvam.fugit. Qvod enim cum amata re conjundtum eft, validius eft, \& qvò validius, eò fecurius, eò â corruptione longius. Qvod cum re infenfa conjun* 
:onjundum eft, interitui quam proximum eft. Pulchrè Scaliger ait : amansscum amata e unum effe, quoadlicec, appetit. Qvo circa is berent E corporaconferisne: E Piricus duo ofculuram conjunctione unus ut fit, faciunt. Id avod amoris fundamentum cism putarent eße pe. eres fapientes, Gafium grat î voce nominarunt.

11. Amor amicitiaminor eft.

Mutua fit benevolentia in amicitia. Eodem modo, inquit Tullius, erga smicum affecti fimus, quo erga nosmer iplos \& nolira in amicos benevolentia illorum in nos benevolentiæ pariter æeqvaliterq́; refpondeat. - In amore fatis eft inclinatio\& cum bono conjunctio: Amor inter homines \& bruta eft, inter homines \& horros, led non amicitia. Deeft enim benevolentia reciproca.

\section{CAPUT XXI. \\ DeLxtiria \& Triftitia.}

\section{pracepta.}

1. Lxtitia elt affectus facultatis concupifcibilis, qvo animal extollitur ob bonum, aut prafens, aut futurum.

11. Triftitia eft affectus facultatis concupiscibilis, qro animal deprimitur ob malum, aut præfens,aut futurum. 


\section{Questiones. \\ I. Anmoripoßint bomines ex latitia aut triffitia?}

R. De mortibus repentinis Plinius habet : Gandio obichre, prater Chilonem, de quo diximus, Sopbocies E Diony fuus, Sicilia Tyrannus, utergi accepto Tragice vichorie nuncio: Mater púgna illa Cannenfi, filio incolumivifo, contra falfum nuncium. Pudore Diodorus Sapientic Dialectice Profeffor. Pelle triftitiam, inquit Ecclefiafticus, longè âte, Multosenim occidit triftitia, \& non eft utilitas in illa.

II. An latus latum generet, tristis trifem?

R. Abeunt mores parrum cum femine \& rangvine in natos. Ton fortes modò creantur fortibus, of imbelles imbellivus: (ed of trifies triftibus, latilatis. Placent verbaLcmnii : Qvi Stnectus ecmpore producuntur, plerumǵg graciles ex. if unt, tenelli, imbecilles, inpalidi, improceri, \& qui minus virium, minusǵg roboris obtinent, qDod natura ( in fenio generantium) vires collap/e fint, ac naturales vitalesg. piritus imminuti, gro etiam evenit, ut animus demißus existat of dejectus, mens minus agilis, viva, alacris, erecta, quoniam omnia parcius contractiusgóconfequuti fint, niff forfan genitores blandi at $g_{3}$ bilares ac moderate calefacti vino generatini operam inpendans. Axio. 
1. Letitide objectum $\varepsilon$ prafens

$$
\text { E abjens epe potest. }
$$

Gaudemus ob præfentia bona : gaudemus æ; ob fucura. Lætantur, qvi Iperant pecuniam, qua egent. Nonrefert, inquit Titelman. nus, ad pasjionem gaudii in appetitu faciendam, utrum jam actu fit prefens objectum, vel propine quum \& cercum, quod janjam babebicur. Qpod enim propè est (juxta Ariftotelis vulgatam fen. tentiam) nibil distare videtur. Undc gaudium etiam de eis, quapropinqua funt, É jamjam ventura,quafi pro prefentibus exiftimatur.

11. In latitia cor dilatatur, in tri-

\section{sitia constringitur.}

In gaudio cordis fit dilatatio \& fpiricus ad exteriores partes feruntur. Hinc rubicunda. facies, pleni oculi, ac vividus animus. In. triftiria cordis fit conftrictio \& ad internas partes rapiunturSpiritus. Unde pallor in facie, tabidi oculi ac flaccidum corpus. AdCardanum inquit Scaliger: non reddis caufam, qpare Spiritus in laticia fersntur extre, in tristitia retrabantur. Llbi ergo putaris te ftatuere fubti: licatem, nefcio." Caufa est: quia fimilia maximè appetunt unionem. Qpod enim non eft unum; non est quidem. Lta qood est a fuo fomili feparo" 
Ixq

ZOOLOGIA

tum, videtur $\&$ illud defraudare, $v$ ip fum ab illo defraudari eßentia quafi complemento.

CAPUT XXII.

$D E$

Defiderio \& Fuga.

Precepta.

7. Defiderium eft affectus facultatis concupifcibilis, qro animal inclinat ad habendum bonum, qvo caret.

71. Fuga elt affectus facultatis concupifcibilis, qvo animal declinatâ malo, qvodimminet.

\section{Unde defiderii vis fit?}

Refp. Vehementer afficiunt defiderata, \& quo diutiùs abfunt, eò majores acquirunt vires. - Morbis qvi premitur, ardet amore fanitatis. Gravidx ex ceraforum defiderio effigiem eorum imprefsêre nonnunqquam foetúi. Caufa eft phantafix robur,qvo alix facultates obruuntur.

H. An fuga foliusmali fit?

Refp. Ut bonum aliud verum, aliud apparens: Sic \& malu m aut verè tale eft, aut fpecie tantum. Fuga mali êt five veri, five appären. tis. Non mortem modò fugimus : fed labo- 
res etiam, doctrinam \& optima qpæq̣;,Commune malum eft univerfo affectum gèneri competens, Defiderant multiVenerem illicitam, licitam fugiunt. Lxtantur alii in malis; triftantur in bonis. Titelmannus ait : Non enim objectum appetibile fecundum fo ipfum, vel fecundum grod in fe est, mopet appetitum: sed fecundum quod in $P$ bantafia proponisur; fipe its fit in re, five aliter res babeat.

\section{esiomata. \\ 1. Defideria dilatione crefcunt."}

Bonum futurum concupifcimus, defidera. mus, asfiduè in illud fufpiramus. Augetur concupifcentia, crefcunt defideria, cumulantur fufpiria diutius, cum abfunt defiderata. Sicut bona valetudo, inquit Cicero, jucundior eft iis, qui ê gravi morbo liberati fuat, qvam qvi nunqvam gro corpore fuerunt: Sicomnia defiderata magis, q́vam asfiduc percépta delectant.

\section{II.Fuga mali bona, boni mala est.}

Recellio ab objecto malo imminente bona eft: Naturale enim cunctis confervarefefe, \& fugere ea, qva perniciem inferunt. Recedere verò à bono difficililicet 3 arduo, ac fúga fibi çonfulere , turpe eft. Turpe militi fugam adoraare, aut latibula, aut uterum $\mathrm{H}_{3}$ è qquo 
116 Z OO LO G IA

è quo emerfit, quærere. Cornificius,tefte $E$ rafmo, videns milices in bello, qvod inter Augu. fum E Antonium gerebatur, fugere, appelladi coslepores galeatos.

CAPUT XXIII.

De Ira.

Preceptum.

Ira eft affectus facultatis iarfcibilis, qvo animal malum præfens propulfat, \& in auctorem rejicit.

Qpeftiones.

I. An ira affectum contrarium babeat?

Refp. Malo præfenti opponitur bonum præfens. At circa bonum præfens occupatur lætitia, cui opponitur triftitia. Inirafcentia feu carentia iræ, iræ opponi poffet. Ar hæc privatio eft: fed de affectu iræ oppofito nunc reseft. Rectè Armandus de Bello vifu ait: In irafcibili faculcate funt duc conjugationes, fcilicet pes Es deperatio, qporum utrumgís eft reBpectu boni fucuri: timor $\mathcal{E}$ audacia, qporum ue irumgis refpectu malifuturi eft. Unica autem esf pasfio repectu mali prafentis of dicitur ira., 11. An ira bominem interficerepoßit? 3." Moderata ira neminemnecat : immode- 
fata in furorem agit, cujus comites morbiac. mortes lunt. Aliinimia fervore, ait Seneca, rupére venas, \& fanguinem jupra vires elatus, slamor egesfit, of luminum Suffudit aciem is aoulos. pebementius bumor egestus of in morbos agri recidére. Nulla celerior ad infaniam vis 8. Mult it iraǵs continusverunt ira furorem, nec qpam expulerunt mentem, unguasa recepes? sure.

Axiomats.

1. Iracor contrariis agitat ma-

tibus.

Duplex cordis morus in ira eff, conftrictio \& dilasatio. Conftrictio ob malum, quod animal a verfacur. Dilarario ob malum, qvod in au ftorem rejicere conarur. Vehemens admodura mocus hic elt, qvô incalefcitcon \& \& fangvinem ac foiritus fervidos in univerfum corpus diffundit, Spiritus exeunt, inquit Scaliger, quafi fuppetias infitrumentis.laturi. Praducunt enim fefe murf culiadictum inferendam ins fortibus, at in Ac bille : in imbellibas, of Cicerons fimilibus, ad lingoe arma. Ibi illorum laurea effo

11. Ir a immodicares feda eft.

Pulcherrimum aliàs corpus deforme facit: Ansinum praftantiffimum foodisímum reddit. Utrumq; egregiis deslaravit verbis Seneca. Non eff ullins affectits facies turbatior. $\mathrm{H}_{3}$ Pulshera 
n8

\section{ZOOLOGIA}

Pulcberrims or a foedavit, torvos vulcus ex er ars. gpillisfimis reddidit. Liquit decor omnis ir atós of five smisfus illius compofitus fit ad legem, at. trabet vestem, annemgs curam fui effunder. Si capillorum, naturâ vel arte jacentium, non informis est babitus, cum animo inborrefcunt, tu. mefcunt vene, concutitur crebro piritu pectus. Rabida vocis eruptio colla distendit. Tunc artus erepidi: ingviete masius, totius corporis fluctus tio. 2valem intra putas effe animam, cujus extra imago tam faeda eft? Qvando illi intra pedtus terribilior vultus, acrior piritus eft, intenfor impceus, rupturus fo nifi eruperit?

III. Ira dominatur affectibus
omnibus.

Senecam expofitorem habemus. Amorems inqvit, ardentisfimum vincit. Transfoderunt itags amat a corpora, E in corum, quos occide. runt, jacuere complexibus. Avaritiam duris $\sqrt{2}$. mum malum, minimum ǵ flexibile, ir s calcavit, adacta opes fuas/pargere, \& domuig, rebusg in summ collat is injicere ignem. Qvid? non ambiciofus triagno affimatus ira projecis infignia , bozoremgs delatum repulit? Nullus affectus eft its goem non ira dominetur.

IV. Ira quasdoǵs licita est. Irafcendum nonnungram fine culpa, fine labe. 


\section{PHYSICA:}

labe. Tunc ubi caufx dantur graves, adver: rus improbos. Utrumq́ve non vacat vitio: levi caufa irafci, \& gravi non irafci. Irafcendum eft in honorem Dei, Ecclefix, patrix, Reipublicæ \& parentum. Irafcendum conjugum, liberorum, amicorum \& famx causâ. Sed \& tunc mediun denegatur inter nimium \& parum. Cavend um femperne magnas ge: ramus iras pro parvå offensâ.

$$
\text { CAPUT XXIV: }
$$

$D E$

Spe \& Defperatione.

$$
\text { Pracepta. }
$$

I. Spes eft affectus facultatis irafcibilis, qvo animal inclinat ad bonum abfens, qvod acquiri poffe confidit. 11. Desperatio eft affectus facultatis irafcibilis, qvo animal declinat à bono abfente, qvod acquiri poffe diffidit.

\section{Qpesiziones.}

1. An pes Es Triftitia fimul efsepof sint in codem Subjecto? Refp. Diverfi affectus funt, oppofiti non funt: Non igitur pellentis funt naturx, fed polfunt effe fimul, Poffunt a mantes affici triftitia, qros tamen erigit $\int_{p e s}$, fore ut amore potiantuso $\mathrm{H}_{4}$ Rerpos: 
Refpondet fpes in irafcibili, amori in coneu. pifcibili, ficut \& defperatio odio. Spesc ?t velut amor boni ardui : defperatio velut odium ardui, qvaténus arduum. In fpe fot mocus cordis dilatantis \& praparantis fe adbo. num futurum amplectendum. In defperatione fit motus cordis contrahentis te \& fugientis arduum ac difficultate \& periculis plenum. bonum.

11. An deperatio toleranda?

B. Defperatio duplex eft, alia virtuti, alia affectui oppofita. Sicut fpes ipla, nunc affeetus eft, nunc virtus eft. Defperatio ut affeetus coleranda \& laudanda eft. Malum enirn ubi tantum, ut fuperari neqveat, prxftat deIperare, q́vàm amare periculum $\&$ in eo perise. Gallorum pugnam cum cernimus, pri. mum uterqve ingenti lactatur fpe :poftalter defperat, \& voce querulâ fugam capit. Pra. tat hîc arripere fugam, quam amittere visan.. Defperatio verò habitui ac virtuti oppofita roleranda non eft. Nemohic defperet,remo diffidat. Judam interfecit non tàm Icelus, gram defperatio.

\section{Axiomsia.}

1. Animali dulce perare.

Optima promittit fibi, futurorum fpe prodacitur. Objectum fpei gratuor conditiones habet. 
habet. Eft bonum: elt futurum:eft arduum: eft polfibile adipifci. Hinc ea promilfio ic expectatio. Thales, quid maximè commune effet omnibus, interrogatus ?Spes, Refpondit. Hanc etiam illi babent, qvi aliud nibil.

11. Spes non eft fiducia.

Fiducia boni prefentis eft, fpes abfentis. Qvi confidit rohori in gerendoonere, aut ingenio in habendo difcurfu, fiduciam habet, non fperant. Non fpei elt, fibi ipfifidere, \& certam in femeripro habere fiduciam.

Fallitur augurio pes bon fopéfuo.

1II. Deperandum in impoßibilibus.

Defiftıt apperitus, dato impoffibili. Si fumma difficultas êt, gram fuperare non licet, averticur àbono animal. Cumcanis, inquit Titelmannus, cibum appetit vebementer, jed pidet flagellum tam terribile $\mathcal{E}$ tam terribiti: tervibrantem flagellum, qui adfiat cibo, ut nows difimet, fe poffe arduit atem fuperaxe, Ev verbers talia evadere vel perferre, bic certe dejpera: quia ab ejusmodi appetisu definit objecticonvenientis propier arduitatem $\mathcal{G}_{4}$ difficuliaceris, groam astimat infuperabilem.

CA P U T XXV.

DE

Timore \& Andaeia.

$$
\text { H } \mathrm{s}
$$


122

I. Timor eft affectus facultatis irafci bilis,qvô animal malum imminen: fuperare diffidit.

II. Audacia eft affectus facultatis irafci. bilis, qvo animal malum imminens fuperare confidit.

2pestiones.

1. 2vomodo feprodat timor?

Refp. Cor fe contrahit, \& calorem ad partes interiores revocat. Hinc pallor in facie, ex setracto fanguine : Ovidius ait :

Me timor invafit, ftabam fine fangoine mafius.

Prodit etiam fe timor trepidatione. Poltqvàm fangvis fpirituofus ad penitiores partes retractus eft. Horror quoq́ve feqvitur, ob fpirituum in partibus exterioribus de. fectum.

II. An audacia fit, ubinulla pes eft? Refp. Cardanus dicit : audacia ef ßpes maxima. Scaliger refpondet: quid is, qui in maxima ac certisfima ßpe futura libertatis, propterea ne est audacisfimus? Sed converfionem inftituit Scaliger, ubi nulla eft. Omnis audax fperat; at non omnis, qui fperat, audax eft. Audacia ex fpe oritur;. at fpes non ex audacia oritur.

Scaliger 
Scaliger pergit: quin ex deperatione quoties audacia maxima? quam pem putes in illo verfu?

Una falus vilt is nullam fperare fatutem. An tibi videtur in bâc audacia fes? Verü ex defperatione timor oritur, non audacia. Qui defperat, definit appetere ac profequi obje ctum propter arduitatem. Audentiores autem cum fiunt defperantes, fpe nova ducuntur, \& ob conjuncism iram ac furorem denuo rem aggrediuntur.

\section{Axiomata.}

1. Fortis affectus timor eft.

Vehementer homines torqvet, qvi non prafentibus tantum fed \& futuris anguntur. Sæpè imaginatio terret \& futuri mali fufpicio.Plusrafune, inquit Seneca, que nos terrent, acpreo must. Sepiùs opinione ampliùs laboramus, quam ré. Citò accedimus opinioni, Ef foc vertimus terga, quemadmodum aliqvos pulvis, motus, fugapecorum exugt castris, aut qros aliga a fa. bula fine autore conterruit. Nefcio gromodo vera perturbant. Vera enim modum fuum babent: Verifimile eft, aliqvid futurum mali? non fi atim verum est; qvam multa expectata venerunt; qoim multa expectata nunqpìm comparserunt

11. Timidus non eft, qvi metuenda metuit. 
124

\section{ZOOLOGIA}

Alia majora funt humanis viribus, alia fu: ftineri poffunt. Non eft rimidus, qvi metuis fulmina, terræ motum, exundationes. Supra hominem hxcfunt, \& velanus, qri eacontemnit. Pfylli contra Aultum, ut vestun illis nimirs infefrum, armatâ manu profecti funt, ut forsitudinem oftenderent, fed arenà obruti flultitix mercedem reportarunt.

III. Audentes Deus ipfe juvat.

Audacia ex fpe oritur \& fit cum bono arduo propofita, non avertitur appetitus propter arduitatem, fed fuperare conatur. Hoo ut agamus Deus jpfe autoc aft. Vult ut bonure profequamar, quanquamarduum \& difficile Git. Claudianus ait:

Fors jubat audentes, prifcifententias $V$ atis. Alexander audiens Darium multas militum. parare myriades, refpondit, unus lupus non mullas timet oves.

\section{CAPUT XXVI。 $D E$}

Facultate Locomovente

Rraceptum.

Facultas locomovenseft, qra animal fertur de loco in locum ad objedtum vel profegvendum vel fugiendum.

20atis 


\section{Queftiones.}

I. Qromodo fiat locomotio?

Refp. Primo objectum cognofcitur, deindè appecitur: hinc locomotiva acquiritur.Primas renet facultas cognofcens:lecundas appetens: tertias loco movens. Data hæc eft, ut bonum ấfenfibus cognitum,a appetetitu defideratum, animal affequatur; aut ut malum â fenfibus oftenfum, $\&$ ab appetitu repudiatum, fugiat vei perfequatur.

\section{An repiratio buc pectet?}

Refp. Dividunt losomotivam in cotalcm \& partialem. Totalem dicunt, fecundum quam animal fe totum de loco in locum movec. Patsialem, fecundum quam membia \& partes certa fe movent. Refpirationem ad partialem referunt, \& defcribunt eam, qvod lit mo. sus thosacis ac pulmonum, quô aër infpiratur \& exfpiratur ad cordis refrigerationem. Sed huc non referenda eft refpiratic. Mocus enim de quo fermo nofter eff, cognitionem fenfuum \& appetitum fenfitivum fegvitur. Sed neus trum in refpiratione fit. Non ob fenfuum judicium refpiramus, nec ob qvendam affect $\bar{x}$ : fed tantum ex naturali neeeffitate.

IIl. An pulfus buc pectet? Rerp. Pulfum etiam ad partialem anotum se: feruat 
126 ZOOLOGIA

ferunt. Definitur quod fat motus cordis or arseriarum, dilatatione É confrictione const ans i faculcace pitali ad caloris natipi confervationem infticutus. Idem verò de hoc ferendum judicium quod de refpiratione. Non feqvitur fenfuum cognitionem, nec appetitum fenfitivum, neqve fit ad nutum \& imperium animalis.

Axiomata.

1. Facultas appetens eft imperans, locomovens, exequens.

Cum appeticus inclinat ad bonum, locomo. vens mandatum exeqvieur \& objectum profequitur. Cum appetitus declinat â malo, locomovensfugit, malumq; avertit Qvantum illa appetens facultas valet affectu, tantum hic locomovens effectu. Lubi foras egreditur \& in opere ipfo confpicitur, quod harebat in anima.

11. Locomotive adtus varius eft.

Alius gencralis, ali us fecialis eft. Generalis locomotio, progreffio aut promotio dicitur. Specialis qvadruplex eft : ambulatio feu gradatio, volatio, natatio, reptatio. Qvadam enim animalia progrediuntur ut qvadrupedia : quxdam volant ut aves: quædamnatant ut pifces : quædam repuntut ferpentes Crea- 
PHYSICA.

jit crim Deus beftias terye Ejumente fecúndum periem tam," omne volatile, omrenatatile, 6 oxnne repile anima viventis.

11. Locomotive acius fpontaneus est.

Spontancus motus naturali opponitur. Nacuralis eft, qui fimplliciter â natura fit, neque alicer fieri poteft. Sic moventur fidera in coe. 10, elementa cum afcendunt aut defcendunt. Spontaneus ef, qui ad nutum \& imperium animalis fit, \& fieriac non fieri, fieri hoc, aut illo modo purteit. Sic animalia moventur,quando volunt, quamdiu volunt, quomodo vo. func. Ubi in brutis quoddam cernimus lie bertatisveftigium. Qvodradix iis eft a ctronum contingentium : ne agant omnia ex necefliate. Qvanquam liberaliores non oporteat fieri in beiloarum liberrate.

"LIBER SECUNDUS,

DE

Corpore Brutorum. C A R T I.

$D E$

NATURA CORPORIS BRUTORVM. Precepta.

I. Corpus brutorum eft Subjectum anima lenfitiva, eleganter \& artificio. sè ad 
$12 \delta$

ZOOLOGIA

sè ad varias operationes edendas confitutum.

II. Dividitur in partes continentes, contentas \& impetum facientes.

I. Qualtiones.
Iubjectum innuatur?

Refp. Anima fenfitiva eft forma. Forma requirit fubjectum, qvod dicitur informationis. Qvod ingreditur, qvod perficit, \& cum qvo compofrtum confticuit.' Ábefre nunc volu. mus Subjecta gva vocant in hxfionis, cognitionis, operationis \& pradicationis. 11. Quid praftent in corporetot partes?

Refp. Ad varias operationes edendas formatæ sunt. Pedes ambulationi, oculi vifioni, auresauditioni, alix aliis actionibus inferviunt. Peretat effentia canis effefine oculis, poterat ellentialconis darifine pedibus. Sed actiones requirebant \& oculos \& pedes. Canis cculis orbatus è brutorum genere non eximizur, neq́ve leo carens pedibas. Aliudeffenlia, alisid integritas. Mutila dicuntur talia animalia : animalia tamen $\&$ funt $\&$ dicuntur.

III. Qvidpars imprefentiarum notet?

venits 
Refy. Pars nunceft, qrod ad totius conftitutionem facit. Qvod demere non liceta toto corpore fine ejus detrimento, id jam partis venit nomine. Hinc antig viffima illa divifio, qva uóess dividuntur in "quтa,

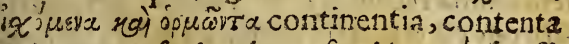

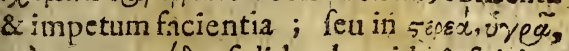
भg) бevuar won, folida, humida \& fpiritu. of a Aliàs ftrictius pars defcribitur,corpus toti cohærens, communemq; cum co vitam participans, ad illius actionem aut ufum conftructum. ubi excluduntur è yartium cenfu, \& contenta. \& impetum facientia. Axiomata.

I. Corpus brutorumparsef, totum est.

Refuecu'eflentix, pars effentialis ef, cum forma effentiam totam conttituens. Refpectu integritatis, totum integrale eft, expartibus integrantibus conflatum. Ibi eft unio, per modum actus \& potentix:Hic per modum continuiratis. Ibi puncium eft, cui nihil addendum, nihil demendum: hic dantur incrementa, dantur decrementa.' II. Corpus brutorum bumanos mo vet oculos, movet animos. Magna dilatatur feculationi noftrxplas I. nities. 
130

\section{ZOOLOGIA}

nities. Dulciffima fpectacula objiciuntur - culis \& animis. Cuilibet bruto corpus, aptum animæ moribus, datum eft. Talem corporis ftructuram habent animalia, qvas lem anim $x$ facultates \& mores reqvirunt. Corpus eft tale, qrit a nima eft talis. Cornua bos habet, qvia anima ipfrus pugnax eft. Canis nos ferit dente, qvia anima cius mor: dax. Ridiculum corpus Simia habet, qvią animam habet ridiculam.

$$
\text { C AP UT II. }
$$

\section{D) $E$}

\section{Partibus Continentibus. Preceptum.}

Partes continentes funt, qvæ ob Subftan: tiæ foliditatem manent, aliasq; partes ruentes \& fluentes concludunt Ut offa, ven $x$, arterix, cor, hepar \&c.

$$
\text { Qvastiones. }
$$

I. Anpili, vellera, penne, $\sqrt{q u a m}$, cornua EO ungues partes continentes fint?

R. Non minus, qvàm offa, quàm cartilagines \& carnes, ad continentes partes fpeQ Qant. Habent in fe fuccum \& langvinem: habent fpiritum ac vitam.Nutriunturyerè,

zugentur verè, Cohxrent Gmm toto ab eog; 
ogrè divelluntur. Ne putemus excreṃenta fie, qva ornamento funt corpori $\&$ emolumento maximo.

11. An colorem babeant fquame. cornua, ungues Es ungula?

R. Corpora pellucidá funt, colorata non unt. Ex accidente quandoq; ob fubjectas partes colorem non tam habent, quàm habere videntur. A riftotelesait: colores cors num, ungrium, ungularum procutis pilorum go colore fegpuntur. Elenim cutis nigra, cornu Ef ungule nigre oriuntur, $\mathcal{E}$ candide pari moda in colore repondent, of cornua, E ungues, $\sigma$ ungule: mediis ettam medium eadem colorem preferant. At dentes naturain osfaim amulantur : go am abrem bominum nigrorum, ut Eibiopum atgsfimilium, dentes of oßacandent: ungDes nigri modo fue cutis apparen:.

Axiomata.

I. Partium continentium quadam propter effe, quadam propter i benè effe, facte funt.

Effe non poterat animal fine capite, fine thorace, fine abdomine. Sunt enim in his vifcera primaria, cor, cerebrum, hepar. Neq; effe poterat fine- is qva inferviunt iftis: fine venis, arteriis, nervis. Poterat

I 2 ; autem 
132

\section{ZOOLOGIA}

autem effe fine cornibus, fine fquamis, fine pennis, fine pilis, fine ungvibus. Facta hax funt non propter êt(va) fed propter

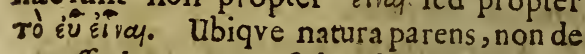
neceffario tantum, fed \& de utili follicita fuit.

1I. Partium continentium quadam perfecte, quadam imperfecta, fed perficiende: quadam necperfe$\not{Z} \dot{a}, n e c$ perficiendenafuntur.

Aqvila perfectis nafcitur oculis: canes \& felesimperfectis, fed tamen perficiendis: Talpa nec perfectis nec perficiendis. Perfecta funt tria osficula auditus : malleus, incus \& ftapes. Non crefcunt qvantum corporis moles crefcit, fed quantitatem de. bitam in ipfohabent primordio. Offa fin. cipitis adeo imperfecta funt in infantibus, ut hiatum quendam efforment: unde ibicerebri motum videmus in recens natis. Primum igitur membranea videntur; poft cartilaginea, deniq; offea. Coftr fpurix, nec perfect $x$, nec perficiend $x$ funt. Nocumento enim effent, fi perfectx effent.

IIL. Pars omnium prestantifima cor eft.

Yiden: 
I34

\section{ZOOLOOIA}

\section{2vas caufas Janguis babeat?}

2. Efficiens principalis anima eft, qvæutizur organis, hepate, liene, venis. Hepar pracipuum organum eft. Ad hoc enim vena laeीeætendunt: hîcfarcinam deponunt. Hîc etian radices, venæcavæ \& portæ funt,ut in univerfum corpus freri posfit fangvinis diftributio: Fitiseft, ultimum animalium fangvineorum alimentum effe, Alit enim cibus, alit fanguis, hicimmediatè ac proximè, ille mediatè, \& remotè, Materia genevationis chylus eft, proxima nempè. zemotacibus \& potus eft. Materia conftitutionis, lerum, liqqvor ruber, fibræ fargvinex \& alia. Alimenta enim ex diverfis conftant partibus, undè diverfitas in chylo, diverfitas in fangvine. Forma, rubicundus ille humor. Humor à partibus continentibus \& impetum facientibus differt. Ruhedo autem cumprimit decer langurnem. Sanum enim franimal, mec flavum, nec nigrum, fed rubicundum ha: betiangrinem.

\section{1..An Sangris totum bomogeneum ... . jew? Refp:}

$\therefore \quad \therefore$ है 
I HYSICA.

R2. Senfuum judicio quavis pars fangvinis, fangvis eft. Rationi ferum non eft fangvis, neq́; fibra fanguirex. Sicut lac homogeneum çorpus videtur, led tribus diverfis fubftantiis conftat : Butyrofa, cafeofa, ferola. Butyrofa calida eft $\&$ oleofa : Serofa agvofa \& falfa: cafeofa, terrea, frigida \& ficca. Sicut urina, fero $\&$ contentis,tum naturalibus cum praternaturalibus conftat. Sicut vinum prater fubftantiam propriam, materiam tartaream \& calculofam continet. $\mathrm{Ha}$ bet verò fang vis iftam pattium diverfitatem à cibo \& potu. Hippocrates ait: in omnibus cibis 5 potibus, \& brliofi quideft \& aqpofi of fanginei 5 pituisofi, ins alia plus, in alio minus.

[1. An Sangris menftruus vitiofus

$$
\text { fit? }
$$

Refp. exiam in revili magni quid ine?t. Non poftroma fapientix pars eft noffe corporis lui primordia.Hac femen, \& fangvis funt. Menfruas dicitur fangvis; qvia fingulis menfibus ejicicur : finon invenit, cui profit. Subftantiâ â reliquofangvine non differt, fed ejusden cumeobonitatiseft. Exeodem enim chylo formatur, in eodem hepate generatur, \& per easdem vias difribuituro Et I 4 vitia 


\section{ZOOLOGIA}

vitiofus fanguis focui concep:o, qvi cedat in alimentum \& augmentum? Hic enim ejus finis eft. Cum ejicitur ató; perit, prater natura intentionem fit. Lactis etiam generatio bonitatem fangrinis hujus confirmat. Ex eo enim lac formatur: bonum è bopo, laudabile è laudabili,Si nocet,per accidens nocet: è morbofis qui fluit,non eft fanus. Fit etiam qvandoq́ve fuppresfio,ubi mora contrah't labem. Sic optima abeunt in peffima : ficut triticuin degenerat in lolium, ficut fenen corruptum fic noxium: frcuchominis cadaver olet pelfimè. Axiomata.

1. Sanguis non unus $\sigma^{2}$ idem eft.

Qvauruplex Cangvis datur. Sangvis in fpecie dictus, qui humidus \& calidus elt, dulcis, rubicundus ex partibus chyli temperatioribg formatus, \& alendis partibus temperatis aptus. Sangvis biliofus, qvi calidus \& ficcus eft, è partibus chyli calidioribus \& te: nuioribus formatus, atq̣ve alendis partibus tenuioribus aptus. Sangvis pituitofus, qvi frigidus \& hurnidus eft, è frigidiore chyli parte genitus, alendis partibus frigidioribus, \& humidioribús aptus. Sangvis melancholicus, qui frigidus \& ficcus elt, è frigidiore \& fxcul entiarc chyli parte factus, alendis partibus frigidioribus \& fecioribus dicatus. Atq́ve 

ǵvehinc ortadiverfieas-\& temperamentorum \& fomniorum eft, ut habeamus temperamenta \& fomniafanguinea, cholerica,phlegmatica \& melancholica. Qvæexpradominante fangvine hoc vel illo oriuntur.

11. Magna fanguinis vis eft, magna moles, $\sigma$ corpora mutandi

$$
\text { poteftas. }
$$

Carnificès \& Iatrones humanobibitofangvine, ferociores fitnt. ranes mitiores, calido beftiarum cruore-aftumpto, mordaciffinievadunt. Qvidam fuillo paftus fangvine, porcorum mores induit: Puella farguine ebibito felium, naturam-animalis imitata eft, voce, geftu, faltu: qvia mures qvefivit in anguftiflimis-foraminibus.Caufa refertur ad fpiritusimfangvine contentos, qvi maxima agendi \& mutandi pollent virtute- Unde cumprimis calidus \& fpiritibus refertus fangvis tantas infertmutationes. Ut nunc gridem communes, nune proprii beftia rum mores cum fangrine in . ftillentur homini. Hinc gloriolus Deus in facris literis feverifimum dedit edictum, de noncomedendo fangrine. Qui, inqvit, $R$ vefcetur ullo fangvine, ei opponam ir atum meum - ultum, or exfindám evin è mediolpopwli mei. Atten- 
138

7.OOLOGIA

Attendere id debebant mortales, ac non temerè \& corporis \& añima fefe exponere periculis.

III. Sangris animätus eft.

Non ille qvidem, qvi à corpore decifus ac feparatus eft, fed contentus in vafis \& cons ceptaculis fuis. Hic anima inftrumentam, hic caloris fomentum ac fundamentum eft. Anima non ablens, fed intimè præfens in. ftrumenta fua regit \& ordinat. Neq; etiam cum format fangvinem abipfo abelt. Scd infinuat fe primum in materiam, â qva corficiendusifte. Sic \& in perficiendo $\&$ in confecto fanguine datur. Facta atitem fe tione, qvi effluit, animatus non eft.Sublata enim unio cum toto eft, qva ad vitæ \& animæ communicationem reqviritur.

$$
\text { CAPUT IV. }
$$

Partibus impetum facierribus.

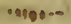

Praceptum.

Partes impetum facientes funt, $q v æ \mathrm{ob}$ fubftantix tenuitatem huc \& illuc ruunt, vafisque propris maximè ınJjgent, ut Spiritus.

\section{Qneftiones. \\ I. Qvidfint Spiritus?}

Refp. 
Refp.Sunt corpora fubtilistima,maximè mobilia, potisfima animæ ad actiones obeundas inftrumenta. Corpora funt. Habent enim materiam \& formam, qvantitatem, qvalitates, locum \& alia. Spiritus dicuntur ob tenuitatem \& invifibilitatem. Corpora fubtilisfima funt: ubiq́ve enim preftò funt anima operanti, omniaq́ve corporis membra, etiam qva nullis confpicuis cavitatibus pervia funt, permeant facilè. Corpora mobilia funt, Núnc enim huc, nunc iftuc ruune, nunc furfum, nunc deorfum. Surfum autem natura fua : deorfum virtute moventis animx. Potisfima animæ inftrumenta funt. Omnes enim actiones mediantibus Spiritibus funt. Ubi defunt, neq́ve vifio fit, neq́ve auditio, neq̣ve ambulatio.

\section{Qvotuplices fint Spiritus?}

Refp. Primo Spiritus alius eft infitus, alius in. fluens. Infitus eft, qui cum ipfo femine communicatur, indeq́ve partibus continentibus implantatur, primum animæ \& corporis vin. culum. Influens eft, gri in corpore perfedto generatur, \& per vafa fua in membra omnia diftribuitur ad fpiritus infiti inftaurationem \& animalis operationes. Dividitur in naturatem, vicalem of animatem. Naturalis eff, qui in hepate ex puriore fangvine generatur, indeg; 
140

\section{ZOOLOGIA}

indegve per venas in totum corpus diftribuitur ad naturales actiones; edendas.Vitalis eft, qui in corde ex naturali fprritu generatur, indeqve per arterias in totum corpus diffribuitur ad vitales actiones edendas. A. nimalis eft, qvi in cerebro ex vitali fpiritu generatur, indeqve per nervos in totum corpus diftribuitur ad animales actiones edendas.

\section{AnSpiritus infitus mobilis, an fixus fit.}

2. Ut animalia variant, fic varins Spiritus infrus of Ariftoteles ait: ut nobilitate, ignobilitateve anim $x$ inter fe differunt: ita $\&$ natura ejus corporis ( $($ piritus infiti) differt. Perfectorum animalium fpiritus in feminibus contenti magis mobiles funt, im perfectorum minus. Promptius exeunt ex humano ferrine, qvàm è ranarum ac pifcium genituris. Elaborato ve rò corpore, infitus ille Spiritus in continentibus partibus firmiorem habet fedem. Tunc qvietus ac fixus omnibus ineft membris, potifimum anim $x$ \& corpo ris vinculum.

Axiomata.

1. Spiritus infitus idem cum calido innato, influens idem cum ca. - lido infuente eft. 


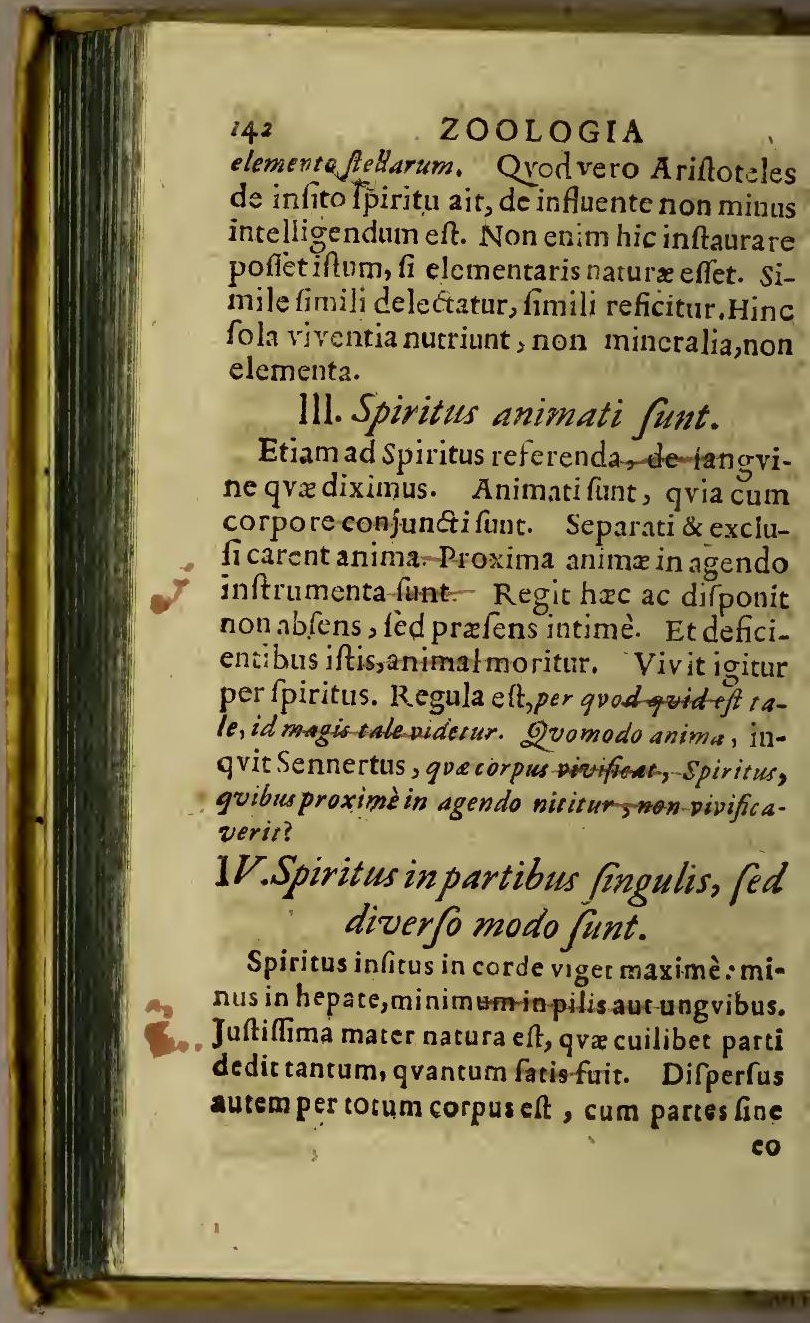


eo nec vivere, nec agere queant. Spiritus naturalis fedem habet in hepate vitalis in corde : animalisincerebro: inde in partes 0 mnes diffunduntur perfua vala, venas, artexias, nervos. Et fimul funt in una parte fine fenetratione. Etiam minima membrana pars vivit, nutritur, fentit. Qvæ actiones diverfis perficiuntur fpiritibus. Hi præfentes funt fine confufione, fine penetratione. Hæc enim miftionis accuratæ ratio eft; ut minima jungantur minimis.

PARS SPECIALIS。

$D \varepsilon$

BRUTORLM SPECIEBUS.

LIBER TERTIUS.

De

Qvadrupedibus. CAPUT I.

$D E$

Qvadrupedibus in genere. Precepta.

I. Qvadrupes eft brutum gresfile,caput? collum, dorfum, ventrem, pedesq; qvatuor habens.

II. Eftq; leo, fimia, elephas, camelus, tigris, eqvus, afinus, bos, alces, cer: vusg 


\section{$14, \quad$ zOOLOGIA}

vus, caper, fus, lupus, urfus, canis, vulpes, felis, lepus, cuniculus, melis, glis, iciurus, mus \& c. ...

$$
\text { Quationes. }
$$

1. Qvenam qriadrupedum fint caufa?

B.. Caufa efficiens prima Deus eft. Dixit Deus; produsat terra animam viventem fecun.

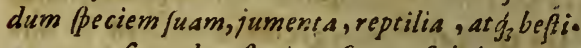
as terra, fecundum Beciem fuam, fuitgy it a. Anima vivens hoc animalium genus indigitatur, quia aninex vis perfectior in eo quam creteris elt. Caufa efficiens lectinda natura eft : partim ftellx, partim fpecies fe fe multiplicantes, juxta illud : crefcice of multiplicamini. Finis primus of ultimus Dei gloria eft. Hujus enim enarrant potentiam, fapientiam,providentiam. Finis intermedius homo eft, cui dant alimenta, veftimenta, obleetamenta. Et proprium fuum finem fpecies qvavishabet, qrem novifle non datum mortalibus eft. Materia creationis terra fu: it: generationis femen : conftitutionis, partes corporis. Forma in genere anima fenfitiva eft: in pecie pro parietate fpeçierum varia, Alia loonis,alia fimia, alia elephantis.

4. 2 ;

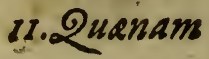


II. Qvenam quadrupedum conve nientice ac differentis fint. Refp. Animam fenfiuvam \& corpus organicum, capite, collo, ventre ac cateris partibus conitans, omnes habent. Moribus etian ad. madum conveniunt, cum ad paftumabjecta Int, ventrem curent, \&:terram fpectent.

prona $y_{3}$ cum Jpectent animaliacieter.aterrains Os bominifublime dedit, celuengstueri Jusfic, E erect os ad fidera tollene vultus."

Differunt autemindole \& aliis affectibus. dum qvedam manivetx ac domefticx, qvadam ferx ac fylveftres funt. Differunt nodo ajcendi, dum qvadam ruminantes, qqvedam non ruminantes funt : qqæædam etiam carnivóra, qvadam herbivoræ, quadam omnivore Uunt. Differunt divifione pedum, dum quxđam ungvifida funt, qquadam folipeda. Differunt mwnditie, dum qqæædammundæ, qvædam immundx dicuntur. Non tratione effentix, fed ratione ufus \&efus.

III. Qvenam potißimum de qua. Arupedibus arotanda fint

Facultates communes \& propriz. Communes aut regetantem aut, fentientem feo. quanturanimam. Illius funt facultas nutrix, faculcas auetrix; \& facultas procreatrix. Hu$\mathrm{K}$ กิن 
I46 ZOOLOGIA

jus fenfus cum externus, tum internus, appe. ritus \& locomovens. Proprix propriam ac Ipecificam comitantur formam. Hac ut aliis alia, fic proprias ac diftinetas infert fa. sultates.

Axiomata.
1. Quadrupedes incoleterrarü funt.
Parturiit cerra primum herbas \& arbores: Uleanimantium annona effent,anteqvam ipfa effent. At nondum laborum finis, nondum operis terminus fuit. Etiam greffilibus \& reptilibus repleta eft eadem, ad ituporem que wsqi, ut hominis mox creandi fenfus mentemqve afficerent qvàm fvaviffimè. Sic terra genitrix prima, fic gremium primum quadrupedum facta eft. Et quas femel accepit pofferfiones, fervabit perpetuod. Unde hodieqve in campis \& fylvis, in hortis \& agris, fpectaviffime vagantur qvadrupedes. His occupa. tur incolis, his fuperbit civibus valtus terre globus.

II. Qvadrupedes dignitate uperant
bruta cotera.

Perfectiorem hahent animam \& perfectius corpus. Unde fplendent magis operationes fenfunm in, iftis qvam in reliqvis. Ad hominem, qui animalium rex, regula ac menfura. 
PHYSICA.

eft, qvàm proximè accedunt. Vnde anatomia pro ca davere humano fubiti tuút fxpè canum, vitulorum, porcorum ac fimiarum corpora. Plerunú; enim idem partium fitus eft cadem figura, eadem magnitudo, eadem con. nexio. Etcum hominum viventium fectio crudelis atú; inhumana fit, fecurè ad bruta recurritur, qva \& mortua \& vi $v a$ fecare licet. Ut ex alienis opibus de propriis informemur, te. aumq; de frmilibus facia mus judicium. Danaus ait:terrena animalia reliqgis animalibus perfectior a funt. Nam babent E membra plu-

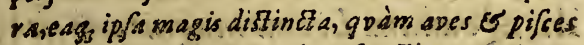
Ep plures pegetioresás anims functiones, Es que etiam ifta generant, funt omnino perfectiona. Deniq; cum homo omnium animantium fit perfectiffimum, ad humani corforis naturam proximè accedunt.

\section{CAPUT II. \\ De Leone. \\ preceptum.}

Leo eft brutum qvadrupes rugiens, generofum, fuperbum \& ferox.

Qveftiones

1. Qvodnam Leonis nutrimentum fit?

Vefcitur animalibus, pradag̨; vivit, Infe-

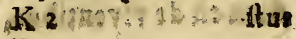


148

\section{ZOOLOGIA}

Itus eft cervis, apris,bubus,urfis $\$$ aliis qva. drupedibus. Herbasnonifi agrotus guift at ad concitandum vomicum. Cadavera non tangit, nifi fame coactus. Preffưs hâc, vrllas paftorumq; cafas accedic, ac homines étiam invvaditac dilacerar. Pradá proftratâ, fangvinem fugit primum, mox curpusipfum crudelem in modum dilacerat ac devorap. Cibo replequs nimium, infertis in os ungvibus extrahir,quod deglurivit, ne copiagrave. tur. Abltinet interdum à cibo, per dies duos, cum perfectam non effe coctionem feritit.

11. Qvenam Leonis magnitudo fit? Egregia ea elt, fed non maxima. Major "quantitas cameli, major elephantis eft." Eo vero modo comparatum corpus eft, ut fingula partes,fumma fortitudinis fint argumenta. Capat firmum eft, pectus validurn, juba du. rior, præclatè armos \& colla veftiens, Jatera robulta, nervi folidi, ungves magni, oculi rerribiles, cauda pugnæ prænuncia, rugitus horrifonus, Offa leonum folidiffima effe feribunt, ut vix habeant cavitatem ullam. Collifa ignem gignere, ficut chalybs 'flice percuffus, fentiunt, Aft ex mufca elephantem faciünto Eft foliditas in leonum offibus, fed bb vitz ac nutritionis reqvifitum, fucco non carent. Neq; ex mortuis ac aridis osfibus judicam dum eft de vireatibuse

illo. 
PHYSICA.

IIt 2 wanam Leonis generatio fit? Refp. Magna leonuis libido eft, \& major in famina, quam mare. Unde Pardúm etiam ada mitcit, quod fentiens, leo tota vi confurgit in. ultrices pxnas. Polt coitum tenacisfimè cobarent, ficut canis \& lapi. Osficulus enim in penis medio pofitus eft, circa qqvem maxima dacur fpiriruum \& humorum copia. Et cum membrum fic ofeum, leomingens pedenelevat 2. ne urina confpergat pedem. Catuli autem cum membrum molle habeant, ut ver-. fus terram flecti polfit , pedem non eleyant. Exiftimarum olim ent leanas femel parere pervitan, eoque partu noo nifi unum eniti. Nam fxtum ungviculis fuis matricem difcerpere, \& hinceam laceratam cum fatu ip ro ejici. Sed fabulam refutat Arifoteles his verbis: 2vod de Leena fertur, vulpam cum partuemitsere, delira fabula est a, facta ex eacaufa, quod rarum genus boe animalis est. Solinus. fcribit , primo paxtu leanam qoing $g_{3}$ catulos proferre, ac per annos fingulos una minus abua no Aeritefcere.

IV. Quid de Jenflus leonisnotandum?

Sedit ea quibusdam opinio, clatiùs cateris animantibus videre leonem, qvia apertis. $\mathrm{K} 3$ nafci- 


\section{200IOOrA}

nafcitur oculis \& dormiens oculos non clatidit. Sed praftantior acies à qvilis \& pluribus aliis eft. Qvod aurem apertis quafi oculis mafci ac dormire videatur, ob palpebras,pro amplitudine oculorum breviores, fit. Brevibus palpebris magnos oculos tegere curm neqveat, videcur videse femper etiam, cum dormit aut aliud agit. Clauderet, fi poffer, - culos, cum inter dormiendom maximè vezetur à culicibus. Odoratu multum valet, indeǵve mafculus fremella adulterium agno. feit, qra tamen aqua fefe abluit, ut marem de. cipiat. Egregiam deleone \& urfa-refert $h_{j-}$ ftoriam Elianus. In Pagnoo, Thraciamonte, ait,urfa leonis ingreffa antrum catules inceremos: mox parentes ex uenatu reverfs, ubi catulorum frorum necem cäplpexerant, acerrimo dolore pref: $\beta_{3}$, autorem odorati es infecuti funt. Ulrfa mse. auess arborem confoendit. Illi autem cum fe alcifci non poffe animadverterent, leana ad am. boris radicem excubadic. Leo in fylpa oberrans sandem lignatorem offendit, oumg, amplexacus est. Primum ducit in lastrumo offendit lajos catulos, mox fignis qvibusdam moner lignata. rem, ut arborem prafcindat, go am ubi profira. vit, urfam in terram prolapjam fere difcerpfeunt, of bominem ille fum leo itcrum ad eum reduxir locam yubiprizus offendißer.

V.2vid 


\section{PHYSICA}

V. Qvid de appetitu Es affectibus Leonis fiendum?

B. Immoderatiorem habentappetitum, immoderatiores affectus. Sxvisfimus ac ferociffimus ef leo in feva ac ferocia animalia. non partem quandam vulnerat, fed totum animaldilaniat. Iratus terram caudâ peteut tit, \& mox dentibus ac unguibus crudeliter prąam. Timeré gallum ejusğ́; cantum dicitur, per qualitates occultas. Ignem etiam formidare, \& ftrepitus rotarum, \& fonitus tympanorum creditur. Subtilitatem inde ducit Scaliger, quanqvàm fubdubitet de re. 2vedan fubtilitas, inquit, eft ob caufarum ignor rantiam :ut quare galliobtutum exborrefcat leo, fuis Itridorem Elepbas, ut ajunt. Verùm loce pavore, fine horrore, galli cant \& alpectu movetur leo. Nec flammis \& fonitu ac ftrepitu terrezus qvicgvam. Irritatus potius. \& iracundior ft, rubicunda galligallinacei cri. $\mathrm{fta}_{2}$ lonora voce, tutilantibus flammis. Sicut Elephas ferocior reddiear fucco mororum. Habet ruber color vim movendi fpiritus in rubro fangyine contentos. Snnus etiam acutus pertranfit fubito\& commovet animalia. Qrod ex gallopavone dilcimus,quem irritanc

$K_{4}$

rubsz 
is:"

\section{ZOOLOGIA}

rubra veftes \& voces fonora. Täntum abeft cimidum fieri inde leonem, $u_{t}$ aúdacior factus invadat fxpè gallum, arḉve difcerpat.

$V 1.2$ romotu progrediatur leo?

Qvanquàm curfu valeat velocisfimo, frepius tamen pedatim incedit ut homo. Cum lce Ingreditur, ait Elianus, nee rect diter facic, nee fimplexponic veftigium, fedvarium imprimit es mulciplex: Modo enim progreditur, modo regredieur, tiem rurfus procedit, idemǵ, vicisfim retro commeat : nune quafe furfum verfus, nunc per. mistum facit veftigium; deindè partim precidit viam, partim obliterat, ut nec venatores ejus vefigiis infiffentes luftrum,ubi cum catulis habitat, reperive polfint: quod divina munere proprium. mature leonum'dicatum eft.

VII. Quenam propria leonis af fectio fit?

耳ugitus. Potentia rugiendi leonis proprium eft : ficut canis potentia latrandi. Ter. ribilem vocem habet, $q$ va confternantur animalia quaque. Confiftunt boves \& vacca, Iupi \& canes, audito ifto horribili rugitu. Al. drovandus fcribit : Etiamft interdum preda feu animalias ab ipfis loonibus longiffimè abfant, ita ut epadere poffent, tamen terribili rugitu ifto 
PHYSICA.

153

itaconsternat as reddunt feras, utconfisftant rangoim dictima Es fiant preda leonum.

\section{Axiomata.}

1. Leo quadrupedum Rex eft.

Rex generofus fic ac potens. Generofus leo eft, 8 excelfus in eo animus, qui non frangirur periculis. Neque ulli qvadrupedum major, ulli vires preftantiores. A venatoria bus cum petitur, neqve fugit, neqve occultac fefe. Gradatim incedit , \& cauda pedum veftigia tegit, ne amare videatur periculum. Sivulneratur, recta in venatorem itruí, eumque profternit, focios dimisfis. Si infeftatur folùm, telumque arertitur, non proAternit jaculatorem, fed leviter caudâ percutit ac terret. Rex clemens \& marfverus, fit. Novit robur fuum leo, \& ferrum frangit, cum objicitur, catulum non lædit, fed tractata. micè. Sxvit in feroces, quos aperto aggrediturMarte: fed veniam dat mi eris \& fupplicibus. Unde verfus:

Parcere fubjectis foit nabilis ir a leonum. 11. Leo bomini infeftus noneft.

Terror brutorum eft, non haminum. Non fadit hominem, nifilafus ab ipla. Et feræ fi non praftò fint, extrema cogente neceffirate invadithominem. Difcernere eum putant inter homines nobiles \&ignobiles. Leonem $\mathrm{K} 3$

e nim 
154

\section{ZOOLOGIA}

enim folarem effe, \& parcere magis hominibus folaribus. Rectius expresfit rem Bodinus his verbis: Cur bomines leo metuat, nullaratio probabilis effe poceft, nifigrod Dei munere of conceßutributum est bomini, wt ad ejus non madò aspectum, fed etiam at vocem omnia animantia terreantur , ac timidiffrmi etiam bombnes Elephantes paffifsmos calcaribus ac fustibus urgeant, good divina vox ad bomines poft dilk. vium testatum religoit, omnibus animantibus merum bominis incuffffe: eff enimi iliud arcanum, cujus ratiop probabilis non alia reddi pocef, qpam, quod aternâ lege comparatum est, ut meliora Es ad imper andum magis idonea deterioribus imperent : fit enim nature opifex angelio, bi bominibus, bi bestiis, anima corpori, vatio im. perat cupiditati.

III. Leo benefactorem amat.

Lubet hoc exponere verbis Nierembergii, qvi gratum leonis animum fic depingit.Nobilis quidam Hi panus illuftri fatis loco ratus, gpoddam defertum tranfiens, videt leonem oum dra. cone acri certamine nifugdz confligentem. 2uo conßpecto bumana nobilisas o favere, \& opem. ferre fere capit, que inter ceteres dominatum fert, leoni inquam, adeò ut nobilios ille baftâs, go am gesta a at, draconem aliquoties impetens, eumgh mort ali farcians plag $\hat{a}_{2}$ leonem ab co, in 
gro verfabatur, periculo eripuerit. Leo porrò furm liberatorem refpiciens, nullo alio edocente vel impellente, its ad amandum eum moverica. pit, ut quocung $g_{3}$ is fe conferret, penè ceu canes fidé $\checkmark$ domestici equum, feqveretur, id'g, amore aded fincero of vebementi, ut nulla ratione abigi poffec : Adeo verò is affectus increvit, ut cum eques navem confcendere pararet, in Hisf aniam tra. jecturus (jam enim usgis ad litsus eum leo fecutus erat ) visierecgs leo fe eodem excludi, rugitu alio of editis fognis, quendam mort is praferre dolo rern coperit: q qibus failicet ostendebat, quancoperè bec eum à Damino ac benefactore fuso dimif fo corqueret.Denigh cum navem magis magisg àlitcore dimoveri elongarig, cerneret, as dalorem distius ferre non valeret, in agvam fefe conjecit, sut gpem adeò diligebal, abeuntem faltens nasalu jegperesar, of misrabili hac gratitudinis Es amoris demonftratione vigente ram diu cü mais fuctibus luctarus est; donec os defatigation: nancit, Es interiori afflid ione viltus fun ... dum peiiit, aquis mergendus.
CA P U T III.
De Simia:

Precepirm.

Simia cf brumm: quadrupes hom ine na externaformareferens, in plerisque asnionibus initans,

2uำ 


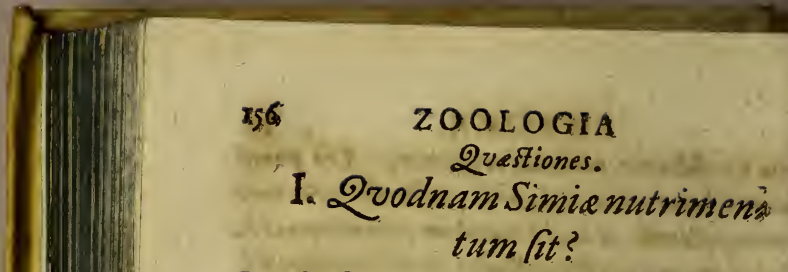

R. Vefcitur nucibus, pomis, piris, omnibusq́ve cibis promifcuè. Avidisfima mellis eft, quo expleri ac fatiari vix poteft.Etiam pediculos ori injicitac devorat. Vino delectatur valdè çaq́; inebriatur. Sed non facit impune, cum ebria facilè capiatur.

II. Qusnam Simis magnitudo fit? Sunt magnx, parva,mediocres : ficut ipra varietate fe jactat Natura. Hominis magnitudinem qvibusdam attribuit Cardanus: Scaliger tantas fe neque vidiffe, neq́ve legif. fe, neqúve audiviffe fcribit. Simias plures vidimus, ait, quantum puer,eft annorum octo. Alias formam bumanam baber, fed non amicam. admodum. Facies enim foeda eft, naresfuppreffa, rugx turpes, ubera foeda in pectore, corpus totumpilis.denfis Atipatum. Oculos profund os habet \& cavos, eosqre exiguos:un. gues craftos \& corpus validum. Sola inter qvadrupedes cauda caret.

III. Qva fimiageneratio fit?

Libidinolx funt Simix, \& humano more complexibus mutuis coêunt. Nec tantum fui ge$+4$. 


\section{PHYSICA.}

ai generis fed \& hominum foemellas amat fi. hius. Amatpueros Es mulieres, ait Cardanus b on fecus ar bomines fuxe regionis, conaturg $g_{3}$ cum incula rffugerit, palam concumbere, quod nos idimus. Antonius Detarrecremata feribit: famio quodam yoeminam diportatam ad quan. am infulam ex iis, quas voc ant Lacertam, fuftu. iße aliquot liberos. Sed placetNierembergii orrectio : Si qui veripartus beftiarum fuerunts unde forus bossiniformes prodiêre, inanes potius nevite fuevint, E fempercumpignore aliquo ir. ationalis nature.

IV. Qvantum frnia fenfuvaleant? Vident, audiunt, olfaciunt \& reliqua fenfuum opera edunt. Przclari nihil hábent, nifi quod aituta valdè fint. Simie, qvod miraberis, inquit Nierembergius, usg. adpericulum fidei Arithmiticamnoperunt. Osulatis testibus $\sigma$ certis nuncito compiertumefin, in Peruana regione fimias tantam cum incolis fasmili.iritatem contraxiffe, ut cum iis pro argento colludant. ulbi eos vicerunt, unà tabernam petunt bibendicaufa, E pretium numerant ex lucropar. to. Sed fidem fuperat narratio.

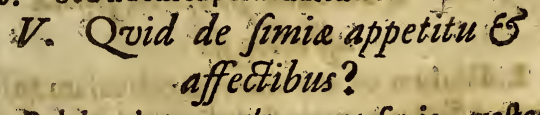

Pulcherrima qqvaq́ve amat fimia, veftes, Ipe 
758 ZOOLOGIA

Ipecula, faminas. Et nullum animal impen fius amat foetus fuos. Geftat cos fubinde complectitur, contuetur, ac fi pulcherrimi ef fent. Omnibus in tota æde eos monftrat, 8 gaudet, cum contrectantur. Tantus frepè a mor eft, ut in ipfo complexu charam prolen enecet. Et ardencior in mare videtur amor. quàm in fromina. Marem sidi, ait Scaliger, E famisam cum prole. Filiolus, fi quid vide. retur defider are, manu pugnogs faminam à ma. riso male tractationis ream, stiam addita vulsus acerbit ate, castigari.Nempe fupercilio, rictu, murmure, iratipacris, atgs reprebenforis mariti, animusm prafe ferre.

VI. Qvid de motu finis?

Quadrupes eft, fed humano more ftat bi. pes,incedit bipes, faltat bipes. Petulanti infuper membrorum agitatione mira ac ridicu. la patrat. Nunc fiftula canit, nunc aurigam agit, nunc militem. Ludit libenter cum infantibus, qvos matribus ab/entibus lavas fervidiffrmâs fuffufáa aqpấ, qva aduruntur nonnungram É necantur.

VII. Qvenam propria fimie. affectiofit?

Ridiculum corpus habet \&ridiculam animam, Affectio propria ftoliditas videri poffer, 
PHYSICA

vam femper producit in theatrum. Sed cum iec aftutia carea:, magis naturalis ei videtur. ana æmulatio. Omnes enim hominum getus \& actus imitatur, fed fine jüdicio, fine repeetu. Lavantfefe venatores, agit idem finia, \& capitur, Induunt homines calceos, $x$ exuunt ac difcunt, mox fimia relictos calce. ss applicat pedibus \& irretitur laquveis. Viderat qvadam lavari infantem ànutrice, pofttà abfente nutrice, infantem nudavit, calie difimam aqqam fuperfudit, infantemq́ve inorfecit.

\section{Axiomata.}

1. Simia anizual malignè aftutum eft.

VerfutaSimia eft, \& blanditur homini,prarertim faeminis. Sed ladendi occafionem naata, nihil pratermittit, quo obeffe poflit. Injuriarum qvoq́ve diutifime memor eft, \& fimultates nunc obfcuras, nunc apertas gerit. Cùm excandefcit, verberibus \& cateris vix coêrceri poteft.

\section{Simia eft fmia.}

Imitatur hominé, diu bipesincedit, hom:num veftes induit, gladio accingitur, \& hominis loco ab incautis quandoǵve falutatur. Sed ferv at naturam fuam, licet purpura veftis atur. 
780 ZOOLOGIA

atur. Redit cito ad ingenium, \& naturz fue reqvitur impetum. Omnibus ornata phalexis, fi poma aut atnygdala projiciantur, accurrit, \& ineptiis fuis rifum movet fpectantibus. III. Simia faciem bominis refert.

Mulka fimiarum genera conftituunt. Vehuntur in Germaniam cercopitheci, cynose, phali, remivulpes, \& alia ejusmodi. Convenientiam habent cum fimiis, fimix verx non funt. Moribus enim maximè differunt, \& quadam cum fimia capitale gerunt odium: Simiæ dicend $x$ fimplici ter, qva hominis referunt faciem \& cauda carent. De cercopithecis Scaliger fcribit : Hos vidimus fibi ippis caudnritm exedere extremas partes. Hoc ajebant ab is folis committi, gyvi gufftaffent aliquando carnes. Nosidem Wirteberga ob. rervavimus, ubi cruentam fuam caudam cercopithecus efitabat.

$$
\begin{aligned}
& \text { CAPUT IV. } \\
& \text { De Elephante. } \\
& \text { Preceptum. }
\end{aligned}
$$

Elephas eft brutũ qvadrupes, barriens, robuftū, maximü, horridum ac docile. Qvaftiones

J. Qvodnam elepbantis nutrimes: tomjet?

Ex r8:- 
Ex rapto non vivit, neque carnibus ve. citur, fed contentus eft herbis, fœnumq́; ovis inftar comedit. Hinc nullam infert im animalibus minoribus, fed ea tractat anicè. Fønum ac herbx cum deficiunt, $q v x$ it radices \& evertit arbores. Etiam obla. um panem ac placentas non refpuit, fedavidè captat.Plurimum bibit, \& nec à vino, abhorret, qvo fumpro animofior fit ad pugnam. II. Quenam Elephantis magni-

\section{tudo fit?}

a. Stupenda ejus magnitudo eft, ad eò ut in. rer terreftria maximum animal judicetur. Proceritas æftimatur fedecim pedum. Capue habet prægrande, minoribus pro tantæ mo. lis portione præditum auribus \& oculis. A nafo pars qvadam immanis porrigitur \& nunc extenditur, nunc contrahitur. Probocis dicitur, ac apprehenfioni \& refpirationi intervit. Non panem modò oblatum pro. bofcide capit, fed minima qquoģve numisma. ta. Et profundiora trajiciens flumina, ut to. tum demergatur corpus, per fublatam in altum probofcidem refpirat. Crúra priora pofterioribus longiora funt, ex aqyo fere fupra \& infra cralla, inftar columnarum. Dicunt vulgo,ea folida \& inarticulata elfe, ue gectinequeant, nec furgere polle animal pro $\rightarrow$ men. 
782

\section{ZOOLOGIA}

grande, fi concidat. Lst dulcis bec pbanusfia eft, gram vifus refellit, cum Elepbas nunc fle. ctat, nunc erigat cruma of genuibus Jubmiffis fiat fupplex.

III. Zuomodo generat Elepbas?

Genitale maris pro corporis magnitudine parvum eft, genitali eqvi quantitate refpondens. Famina ad genua procumbit, cum mas fupervenit. A pertè ac in oculis hominum non coëunt, fed fecedunt. Lltero gerunt men. fesododecim, \& pariunt nunc fingulos nune plares, magnitudine vituli trimeftris. Catulus we natus eft; ; Dider oramibulat, Ecumab bomi. nibustangitur, non indignantur parences. IV. 2uid de Jenfibus Elepbantis notandum?

Refp. Exqvifiti olfa ctus eft; dum melones \& cucumeres è longingro -odoratur. Hoftem exiam olfactuanimadvereere dicitur. Memoria groq̣ve non parum valet, illatarum injuriarum memor admodum. Miles quidam in urbe Cochim perlarciviam Elephantem pue enminenucis in fronte percusifit. Studiosè putamen Elephas fuftulit, illudqve in ore recondit. Poft dies plures in qqầdam via publica militem obambulantem confpexit. whenguses on ore elacum puramen probofcide 
fas acricerin illum conjecit. Tum exaltabuss dus abiit, quaja calione illa ixjuriam probè estrus.

V. Quid de appetitu $\mathcal{F}^{2}$ affectibus Elephant is fciendum?

Refp. Nihil habet immoderati, Appetitnecefiaria, vitat fuperflua. Cibo nimionom fe obruit facilè, \& î quando plus juitè fumpfit, sinediâ fe currat. In pocu videtur nimius, dumplurimum aqve uno bibic bautu. Scriptura dicit, ipfum ebibere flumina. Et Ariftocel es refert, uno paitu Elephantem fumere novem modios Macedonicos, plenumg aurem sbibere fex vel fepiem. Sed copiam hancicorporis requinit vafizas, non jpadet voluptas. Neqiex lafcivia coir, Ied prolis caufa, id qque in occulto facie, non f pectantibus hominiburs, necreliquis Elephantis. Prolem amat, fed non more fimiarum. Nutrit eam acifortiter tuetur contrahoftes. Amat etiam hominem \& proborcide lambit ejus manus ac faciem, \& quantum poteit teftatur iaffectum.

VI. Qvid de motu Elephantis?

In mocu alacricatem oftendit, licet vaftisfimua fit animal. Et gregatim incedunt, ordiniq; excelfisfimus præelt. Reliquos in amedio collocant, ut agmen claudant paulo

$$
12 \text { majores. }
$$




\section{ZOOLOGIA}

majores. Aqvas tranfituri probofcide geftant parvulos, ne fibirelicti fuffocentur. Natare enimnequeunt, qvanquam delectentur' impenfe \& aquis \& navibus.Membrorum mon tus varius eft, unde in theatris partes fuas optimè agit, ac honoratisfimum obtinet 10 sum.

\section{Quanampropria Elepbantis affectio fit?}

Refp. Barritus. Nomen an Romanum fit, an nonfit, difquirant alii. Vocem autem elephantis non malè exprimit.' Dat fonum iftum, quem prima refert fyllaba. Alias barrire qrog; dicuntur milites, cum ineune prali. um.Soleni enim clamore accendere animos, ut pugnam ineant, Qrangram vafa vacua maximè tinniunt, neq; audax fortis. Qui nimis eft audax, fapè infeliciser auder. Axiomata.

1. Elepbas animal borridum ac deforme eft.

Horrida magnitudo eft, horridum corpus univerfum : pelle cegitur turpi, afperâ ac validâ, quam gladius penetrare nequit. Omni Setarum tegumento caret, undè à múfcis ani. mal vaßtumangitur valdè. Sed prafidio illi 
PHYSICA.

165 cutis cancellata eft, quam extendere \& conrahere poteft. A múcis igitur, cum infefta tur, arctat is in rugas, repente cancellis, quotquot adfunt, erecat. Cauda cauda Bubali limilis eft, longitudine trium fortè dodransum, paucis in extremitate pilis.

11. Elepbas virtutibus eminens eft.

Laudant Elephantis probitatem, prudentiam, xquiratem, cąfitarem, religionem \& glorix cupiditatem : addunt Sermonis patrii insellecturo \& imperiorum obedientiam. Adumbravit virtutes has Plinius: expolivit Lipfius : Omnia extollunt, ut ex Elephante hominem facianto Sed tam verè quam eleganter Lipfius adjicit:.ut:-eria roulia: E. vers ineffe nibil amb́igo: ita qpadam majora pero: nec usg gr quagos in bis talibus peteres illas fidei litaffe, facile tecum credam - 2 is enimime magni oneris fit, ut quicquid illi imponunt, pebat? Nec tamen mali quidpiam in istic, etiam faljps : qpia innoxia mendaciola jant.

III. Elepbas docilis eft.

Difcit ea, qva ægrè -capit ipfe homo: fivs corpus Ipectemus, five animam, fatis id pa+ tet. Conformat corpus ad omnes ex arte motus ac geftus. Choreas ducit, \& per funom in theatro extentum decurrit. Gladiatorios etiam ac militares adie motus, ad certamina

$L_{3}$ 
566:

\section{ZOOLOGIA}

\&spralia paratur. Explodit bombardas minores \& moxterga vercit. Literas etiam pingere difcit \& rectè; \& cogitatè. El Elianus ait: vidi gooipfe quendam intabolla liceras Romanas promufcide fcribentem recte so non con. corte. 2vin E cum firiberet, oculi ejus cum vigore dejectí in rabellam er ant: ut plaved inters- os diceres es foriptitantes.

\section{Elepbas robuftisfimus est.}

Fidemfuperat, fupra unumonimal adifi. cari currim fortisfimam; fed fupra clephansem xdiffcata eft, juxta expreffa Scriptura verba. Necea vacua, (ed machinis referta: fuit, \& duabius $\mathcal{E}$ eriginta militibus armatis. Iacredibile ergobeftix robureft. De Behe. moth in Codice facro gra habientur, elephantis funt pleraq;o. Ita enim Jobus cap. 40. v. ro. Ercenunc Bebemorb, qDem fecitecum, berbantanquam bos comedit: En nuanc potentia ejus in lumbis ejus est, of fortitudo ejus. in umbilico veneris ejus: Ofja ejus baculi arei, ofjicjus ficue virg a ferrea. Profectì germen monies ferunt ei, onnes beflie agriludunt sbi. En rapiet fluvium, it a utnon feftiner, confsdit fe educturum effe fordinem in os furum. dn ir oculis ejus capiet emen qpisquam, tendiculis perforabit nafum?

$$
\text { V. Ele- }
$$


7. Elepbantem irritat ruber color. Rex Antiochus cencum millia peditum \& viginti millia eqvitum cum triginta duobur elepbantis ad pralia inttitutis contra Judzeos. produxit in aciem. Elephantis autem fangvineus uvarum \& mororum liqyor oftend?batur, quo irritarentur ad pratium. Caufa rei eft, fy mpathia inter fanguinem \& colorem rubrum. Simile erim movet frmile. Rubrarum rerum intuitu, ruber agitatur (angvis, quo agitato, commoventur Spiritus \& exch. tatur ipa.

$V I, A b$ elepbante ebur eft.

Ebur quafi â barro dicitur. Nón enim santùnt barrire dicuncur eleghantes, fed barri \&eigh vocantur. Horatiusait:

Qvid ribi vis mulier nigris dignis form barrist? Germani dicunt Jjelffenbetro quafi oeg Jelphanten ober bas Elephanter Beitr. Nihil a fiud ebur eft, quam dens, elephantis. Sunt illi intus utring; dentes.qvatuor ad mandendom, \& prater hos dilo grandiones exerti prominent. Nen autem Curfum, utin apris, fed deorfum retorquencur. Ex: his ebur ol maximi pretii : vafa varia inde formantur. Olim fimulachra Deorum vel exeboretan. tùm, vel ex ebore \& auro facta funt. Inter L 4 Salo. 
168

\section{ZOOLOGIA}

Salomonis opes throng fuic de ebore,grandis veftitus auro fulvo, qui habebat lex gradus.

\section{CAPUT V. \\ De Camelo.}

Camelus eft brutum qvadrupes, friPrecepeum.

dens, callofum, robuftum, manfvetum ad portanda onera factum.

1. Quodnam Cameli nut

fit?

Vefcitur gramine, fóno \& frugibus. Cibo. Senon onerat, fed pauco admodum contea. tus ef. Bibit parum, licet calidum fit animal \& ficcum. Scaliger ait : pasticisima cibo, nulla. potusontenti funt. Adeò fitis patiens oft camelus, ut quindecim to tos dies coactus ferat. Ex more quinto quoque die cum minimum, tum plurimum nono bibunt. Cumq; minus infeftentur fiti, laboris patientiores funt. Captant autem aqvas turbulentas, puras fugiune. Et nifi turbulenta fuerit. aqva, coneulcatione asliduâ ipfi limum excịant , ut turbetur.

1I. Quenam Cameli magnitudo fit? Rerp. Vaftisfimum animal elt, \& ob longiona 
crura altisfimum. Unde \& Seriptura de hy. pocritis dicit: colantes culicem \& glutientes Camelum. Et de divitibus ait: facilius eSt Camelum transire per foramen acûs, qDams divirem introire in regnum roelorum. Tuber in dorfoeft, unde callofum ac gibbofum dicitur animal. E pilis ejus formanturveftes qvedicuncur Camelota. Qualem habuiffe Jobasnem B aptistam non obfcurè seftantur fa. cre litera. Dentibus in maxilla fuperiore caret, red loco eorum plures habet ventresingefumq́; cibum tota nocte ruminat. Maris membrum ita nervofum eft, ut nervus exco. confici posfit, gro arcus intendatur. Pedes. divifos habet, unde ad animalia bifulca refertur. In facra fcriptura tamen legimus $\mathrm{Ca}$ melum immundum effe, qria ruminat qui. dem, fed ungulam friffam non habet.

\section{Quid de generatione Cameli?}

R. Lafcivum animal eft, \& coitus tempore favit, nec intervenire datur fine pernicie. Quamvis antem in furorem rapiatur amore, tamen nec matri, nec forori mifcetur. Singulos.gigrit: ficut omnia animalia, qxò majore funt corpore, hoc minus fxcunda fitnt. Annuam foturam Camelo adfcribit Ariftoteles. Scaliger fichabet: manfvete admodum beffin eff, nifi cum accenditur in veL.5

nerems. 
ì

\section{ZOOEOGIA}

nerew. Id grod initio peris fit. Tum goaf. memar omnium perberum atǵ, injuriarum, qvas accepit drebtare, in eum fevit. Mardicus ar. reptum in iěrem fublimem ventilat : projectum pedibus conculcat. Qundragine dies furore zenetumboc: quibus exactis, pristine lenicati reffisutirur.

\section{Quid de fenfu Cameli?}

B. Nihil occurrit notatu dignum. Videt, audit, guftat, fed non habet qvo excellere posfit. Neq; memoria adeò valet, undeindocilis valdè eft. Proverbium datur: Camelus falteat, de eo qui finlte o inepie opus aliguod aggredicur. Modum tamen qrofaltare do. centur, defcribit Scaliger. Calido, inquit, in loco, folousem calido, juvenculum Camelum fiatuunt: Extra fores; qoamdiu ille intus est, tympanum aut Atrabalas pulfant. Beffice ob caloristadium pedes fufollit alternatim. Ita permenfes aliquor afjuefaciunt, donec tandem etiamin aere libero, ac folo non calefacia, audito fono videcur exercere pedum motu faliationem.

V. Quid de appetitu E affectibus? Refp. Non appetit multa, nec magna.Con. entus paucis eft, qvanqvam ob vaftitatem corporis pluribus videatur indigere. Felle

carere: 
carere dicitur, qvod de affectibus rectius. explicatur, qvam de humore. Tempore coitus tamen feroces cameli funt, $\&$ in ipirm recturem fxviunt: Sefe vere invi. cemamant, \& xgrotantibus prafertim fe. runt opem.

\section{$V$ I. Quid de motu?}

Ry. Velocisfimum motum Camelo tribuunt Lino die viginti guinǵgmilliarsa Genmanic perficere dicitur. "Id autemnon pernicicatipedum. quàm longirudini adfcribenclum. Propter paffum! cnim amplitudinem curfus videtur celerrims Feflinullisadmonitionjbus, nullis minis ac verberibus, fed fraviore cantu ad continuandum. iter ducuntur.

VII. Quenam propxiä caméli affedio?

R. Stridor. Stricter refertur ad funeso fignificatione prim at propria. Unde ftrdor de funibus dicitur, cumagitatiftrepitumedunt: Virgilius feribit:

Exoritur clamorgigs pirûm firidorğ, rudentumo. Per ampliationem autem vocis, ftridere dicuntur camelii sic ftridor transłatus eft ad. camelum tanquasmvox propria.

Axiomate 
172 ZOOLOGIA

\section{Axiomata.}

1. Camelus deformis est.

Pulchrum ex partibus pulchris, \& putchra omnium proportione conftat. Tam neceffaria hac pulchro eft,ut proprius ejus fit cenfus, forma ac perfectio. Camelits grande animal eft, longo ac gracili collo, capite exili amplo pectore, binis in dorfo gibbis \& altisfimis cruribus. Parum amani hîc,ubinecpartes, nec proportio delectant 11. Camelus cornua defiderans eti am aures perdidit.

Apologus eft, Gamelos per oracorem cox. nuapoßtulaße a fove. Ir atum fovem Es stultâ poftulatione offenfam, aures qoog refecuißse. Externx enim aures breves ac rotundx funt. Dicitur de eo qui aliena fectatur, \& ne fua quidem tuetur.

III. Camelus adportanda onera faEtus eft.

Natura ipfa damnavitad labores came. lum. Corpus enim habet tuberibus' eminentibus conftans; ut onera ingentia reponi ibi poffe indicet parens rerum natura. A. riftoteles dicit:proprium inter beftias gradru. pedes boc babet, Camelus in dorfo quod dicitur tuber. Et proverbium habet: etiam feabiofus

Cane- 


\section{PHYSICA.}

Camelas plurimorim a finorum geftat onera. Nam morbis groq; aftectus \& morti vicinus amelus onera non fugit.

\section{CAP UT VI. \\ De Monocerote. \\ praceptum.}

Monoceros eft brutum qvadrupes, a= trox \& terribile,diram eden's vocem ac durifimum in fronte gerens cornu.

\section{Quaftiones.}

1. QuodnamMonocerotis nutrimentum fit?

Refp Vefcitur gramine \& frugibus. Evegetantibus enim pleraq;; bruta fuum petunt cibum. Exiftimat Nierembergius lupis atq; leonibus etiam a limenta primum fuppeditafie vegetantia. Monoceros autem montes altishinos inhabitans, herbis contentus eft.

I1. Quenam monocerotis magnitu?

$$
\text { do } \int i t \text { ? }
$$

Magnitudine ad confirmatx xtatis equum accedit.Capite cervo, pedibus Elephanto, cauda apro, reliquo cerpore eqro fimilis eft : unicum cörnu ê media fronte protendit 
$x 74$

\section{ZOOLOGIA}

dit fpirisicontortum, ad longitudineın pedum qvatuor, tam validum, ut quicqvid impetat, perforet. Hinc inexpugnabilis eft, nec'facile in hominum venit potefta. rem.

III. Qusenam monocerotis generatio?

Refp. Coitus tempore manfuefcit, feritatemq; vi amoris deprimit. Elapfo hoc temporc faminas juxta acmares fui generis in. feitat, vitamq; folicariam agit. IV. Quid de jenfibus monocerotis: notandum?

Nihil occurrit, grod mereatur notari. Et peregrina hac'beftia eft', ac toto orbch ânobis divifa, necunqvam in Europam adducta. Plerig; rerum harum fcriptores.auriti potius, qvamoculati teftes funt. undo diverfisfimx Autorum de animali hoc narrationes ac fententix funt.

V. Quid de appetitu ac affectibus notandoun?

A. Ferocisfimum animal ett, \&nullisvin. culis, nullis artibus, nullis beneficiis cicurari potelt. Scribunt qvidem, vifis puotlis manfvefcere, \& aligvando juxta eas deJabl 
PHYSICA.

abi in fomnum, earumg; amore \& odore ilici. Poft venatores accedere, beitiam igare, ac cornu refecare. Sedaliaalits ententia.

\section{Quid demotu monocerotis?} 3. Celeritate pedam valet. Ad ea referur animalia, qvibusvclocifimus curfus eft. Qvalia funt cervi, tauri tylweftres, ibices, saprex,canes, eqvi,pantherx \& lepores.

VII. Quanam affectio propriamonocerotis?

Vox propria nomen certum nen habet. Nierembergius ait: Dox obscena $\sigma$ diras.atis E monaceroti. De.catis mon obfcurum, qrod varia is vox for , pro vario affectu. Libidine accenfi borrendas edumt voces ac ingentibus ades replenticlamoribus.

Axiomata.

\section{Datur unicornis.}

Divinisac humanis literis celebratum animal eft. Multa funtanimalia unicornia, ut onager Indicus, vaccx qvadam in Zeila, Camphur animal amphibium. Omnibus dignitate antecellit, qrod propriè Gracis dicitur Monoceros, Latinis unicornis. Hujus defcriptionem Scaliger his dedit verbis: unicornibus equi magnitudo: crurai, saput, per" 
178 ZOOLOGIA

des,cervijpilicolor pallidus; equi juba rarior, brevior. Coxe villofe: Cornu anum integrum Nicea vidimus, alia alibi.

II. Unicornu raram, pretiofum, $E^{2}$ viribus egregiis praditum eft.

Placent verbaRhenodxi: Cum monoceros animalfot E rarum of ferum, nungoam cicurabile, nififorfan cum adbuc pullus capitur, nec ei ut cervis cornua quotannis decidant, non min rem, fi illius cornu rarum fit Ef pretiofum. Lnsum ramen longisfimum $E$ bominis procericatem agpans, tanquam tbefaurus ditisfimus fervatur in templo B. Dionyfii juxta Parifios, Es multa Jegmina fingulipbarmacopole Parifienfes in of ficinis ferpant, ut qoaties ufus poffulet, boc infsgni prafidio juventur. Laudatur autem plurimum adverfus venena $\&$ ad partes nobiles exhilarandas \& roborandas. Proinde folet dari pefti, morbis contagiolis \& omni. bus renenatis.

111. Unicornem in diluvio periißse figmentum eft.

In Bobernie, Tburingie ac Mifnia locis qvibusdam cornua effodiuntur è terris, ufum habent infignem in Epilepfia, febribus malignis,pefte \& aliis morbis vehementisfimis. Venditantur, quandog; pro cornu minnos 
PHYSICA.

gonocerotis. Et funt qui exiftimantin diuvio periiffe monocerotem, \& nuncextare antum cornua. Sed tanta creatoris induftria uit, ut nulla fpecies periret. Neç; tot cornua idhxc usq; tempora ex uno alterove animali elicta effe, vero confonum. Mineralia funt cornua illa, qva terra fuppeditat, non animalis avadrupedis partes. Neq; tantam duritiem. c foliditatem habent, qvantam unicors au genuinum.

\section{CAPUT VII. \\ De Tigride. Preceptum.}

Tigris eft brutum qvadrupes, rabidum, robuftum, indomitum \& maculofum.

1. Quodriam tigridis nutrimentum fit?

Refp. Vivit ex rapto, Cervos, boves oves, equos, \& canes invadit, interimit ac devorat. Elephantem etiam aggreditur, unde robuftior Elephanto , ac ferocior leone dicitur. Neq; hominibus parcit, fed perfequitur eos, \& quos fuperat, dilcerpit. Eo temporepre.

M cipuè,

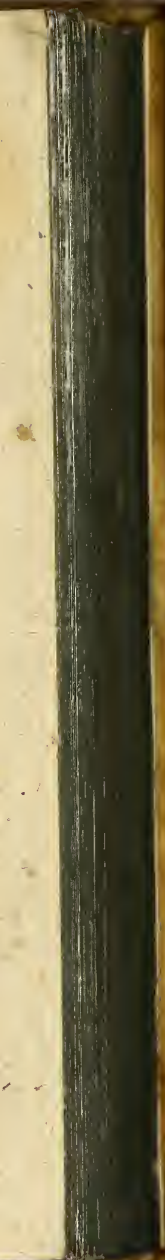


178

cipuè, qro carulos alit, adoritur homines, fi prius occurrant, qvam animal brurum.

II. Quenam tigridis magnitudo? Refp. Maximum equum refert. Ungves ha. bet aduncos, dentes acutos, pedem multifidum, oculos igneo fplendoremicantes, cutim variis maculis diftinctam. Tantum pulchritudine intergresfilia praftat, qrantum. inter volatili a pavo.

III. Quenam tigridis generatio ?

Fallo creditur omne genus tigridum foemineum effe, nec coire cum ullo mare, fed ex vento concipere. Capitur enim nonnunquam mas, etfi rariùs. Rarò autem capitur, qvia vifis venatoribus, catulis relictis, in fugam re conjicit : famina vero caculis adftat, \& a nimo mxfto â laxis venatoribus irretita capitur.

IV. Quid de fenfibus tigridis?

Dlfactu valere dicitur, ut vix primas in fenfu hoc concedat alteri. Hiftoria refertur de venatore \& tigride. Venator obfervat cue bile tigridis, czum predas fectatur, catulos eripic of fugir. Beftio rediens odore investigat, qua fingerit vernator cumcatulic of Ifupenda celerisace ipfum infegritur. Venator adpertens non

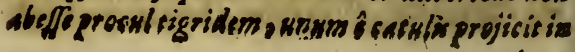
niam. 
PHYSICA:

179

Diam. Huncills reportat, Es in cubile refert. Ocyus redit, retiquos etism repecens. Venator etfi eqvo infidens qoam maxime fugiat, vix tamen unum retinet.

V. Quid de appetitu E affectibus? Relp. Armenta \& greges infeftat, uec homi nes ab ea tuti. Qvarit nidos in domibus \& calis, \& in barbarosillos continuo facit impetum. Nec arbores afyla funt, quas hi cóncendunt. Fugientes enim jnlequitur, dejicit ac lacerat. Catulos amat vehementer \& ad imaginem eorum lxtatur. Hinc venator, qvem infequitur ob ereptos catulos, interdum pbaras vitreas infeqventi objücit. Hxc, imagine quam fpeculum reddit, delectatur, catulosque ineffe putat. Sed cum fpharam pedibus confringit, ut plenius fruasur catulo, delufamfecernit, venatoremgre denuo petit. Hic alias fubinde fphæras objicir, beItiamque deludit, donec vel navim vel cirie tatem ingredi liceat.

VI. Quid de locomotione :

Tante pelocitatis esz, ut fimilis dicatur $Z_{t}$ pbyro genitori fuo. Curfu facilè fuperat hominem velocifímo eqvo infidentem. Ee navim usque ad milliaria triginta infeqvitur per littora, quâ aufugit læfor, Obviis autem $\mathrm{Mz}^{2}$ quibus- 
quibuscunque hominibus \& feris atroxef. Maximè verò famelicx horribili illa pollent velocitate \& ferocitate. Paft $x$ dicuntur tanta elfe ignavia, ut àgregariis etiam canibus in fu. gam agantur.

VH. Quenam propriatigridis affectio fit?

Refp.Rancatus.Hiftoriam defcribit Gefnerus, in qua hæc inter alia. Necesfutate rogente tandemars inventa eft, quâtanti fangvinis penas luevet. Exploratis anguftiis femitarum, gribus è cavernarum latebris ad predam soctuprodire folebat, iter/cißsumest. Excadatam firobem cratibus ơ egefá terrâ, parte fupervacua di: persâ, ftraverunt. Veniens incautus, mas qvidem erat, tigris decidit in foveam, of judibus acutis infcrobis fundo fixus inbefit. Rancaicu futo univerfam obtundebat viciniam, fo montes illo fridore reboabant. Saxis ingentibus if foßse fupercilics in eum fudibus infixum dejectis peremprus eft.

\section{Axiomats. \\ 1. Tigris ferocior leone est.}

Oppida invadit, \& eqvos, porcos, \& ca: acsadoriturac devorat. Navim in orâ fí profpexerit, profequitur eam, ut, fi quis in cerram fe conferat, devores.InGlit qqandoq; in na. 
in naves, \& homines abripit. Aliqvando tygris cohortem militum aggreffa eft, \& in medio omnium dilaceravit unum. Hifuanum, tres Indos, tutagve $\&$ immunis: evafic. Carnis humanæa avidiffima fertur.

11. Tigridi difcretio bominum eft.

Parcit albis, necat nigros. Ethiops quidam fervus cum fomniaffet à tigride le abreprum, fequenti nocte fub navis, qva vehebatur, prora le abfcondit. Rogatus à Domino caufam, fomnium nodturnum enarrat; cujus veriıatamilla ipsâ nocte eventus probavit: ornibus cnim dormientibus, tigris in navim infiliens, caterisgs quiplus quam triginta in navt jacebant, intactis, jub prora mijeri tibiopis ap. prebendit latus 5 alripuit. Nierembergius ftatuit, tigridem parcere Hipanis, invadere Intos, binter mulcos Europeos internofcere barbarum.

\section{CAPUT VIII,$$
\text { De Eqvo }
$$$$
\text { preceptum. }
$$

Eqvus eft brutum qvadrupes hinniens, generofum, docile, fidele, humanis ufibus maxime aptum.

$$
\text { Queftones. }
$$
1. Qvodnameqvinutrimentum fit? $\mathrm{M}_{3}$ 
$18 z$

\section{ZOOLOGIA}

Nutritur gramine, fœeno, paleis, avenâ, hordeo \& aliis. Gramen autem ac fxnum. firmum nutrimentum non dant, fed avena $\&$ hordeum. Hordeum tamen magis prabendum iis, qui exercentur, quàm otiofis. Et cum magna hordei fit ariditas, pariter \& averia, madefacienda hre pabulafunt,ne exficcentur equi. Fruftum panis nonnunquamiis offerri falubriter, vidimus, parcim ut reficirntur, partimut in labore perdurent. Aquam turbidam \& crafiam fuaviù bibunt, quàm c larā \& puram. Qvanquam reperiantur, qviturbidam aquam faftidicint, fortasfis ex confuctudine.

II.Qvenam eqvimagnitudo fat? Maguifudocorporis nota ef. Ccmmen. dantur autem altiores, firobur refpondeat, corpusq́; mufculorum denfrtate nod ofum fit. Fibieudo etiam corporis mediocris optima. eft, que inter obefam\& macilentam media eft. Caput laudatur erectum : \& exiguum præfertur magno. Oculi funtmagni \& prominentes. Aures breves, arrectæ, acutæ \& explicaræ. collum mediocre, nec longum nimis, nec breve. Dences numero fune qradraginta, \& in malares \& caninos \& incifores dividuntur: à feprimo anno ad octavum demumomnes adfuns, Et collojuba prominet, quấ valdè fu. perbi- 


\section{PHY SICA}

perbiunt \& gloriantur. In pectore laudatur latitudo, \& ad formam, \& ad robur, \& ad firmiores greffus. Dorfum qvidem probatur craffum \& latum, fi tamen fpina paulo fit ela. tior, commodius preftat equiti fedile. Venter frit moderatus, non nimis amplus. Latera laudantur demiffiora, oblonga, \& fupra ventrem turgidiufcula. Femora fint nervofa, clunes maxima, rotundx, folidx.Cauda prolixa fit, denfa, fetofa \& erifpa, longitudine totum ferè corpus aqvans. Pedum pracipua habenda vatio, \& militi \& agrícolæ, \& peregrinatori. Nec color negligendus, ubi niger prafertur albo, animumq́ve fortem ac gee nerofum indicat.

\section{Qvid de generatione equi?}

2. Sala eiffiram animal egvus eft. Mas tanto libidinis furore agitur, nt vel odore eqvarum percepto nulla vi cohiberi polfit. Etoquarum famofior eft falacitas, quam eqver rum. Generant autem per rotam fermè vitam, ad annum usq́ve qvadragefimun. Pariunt ftantes \& quidem fingulos. Optima ad congreffum $x$ tas elt $a b$ anno fexto ad vicefimum usq́ve. Partum eáust imenfe duodecimo. Ex ventonon concipiunt, ut fabula vulgi eft. Mas \& fomina congrediuntur in confpects eriam hominum, arque in rabiem ferè vercunctur. M 4

Virgin 
184

Virgilius ait:

\section{ZOOLOGIA}

Nonne pides, ut tota tremor pertentet equo rems

Corpora. fitantum nocas odor attulic auras? Atneǵ, eos vel frena dirûn, nec perbera $\int_{e v a,}$ Non fcopuli rupesǵg cav\&, atgí object a retardant,

Flumins, correptos undä torquentis montes; IV. Qvid de enfibus eqri?

ik. Videre nactu dicuntur eqvi, leones, Iupi,capra,feles, \& quicunque nodtu pafcuntur. Sed falfa eft opinio, in experientia fallaci fundata. Objecta nifi fuerint illuftrata,à nullo animali cernuntur. Odoratu potius valent maximè, unde mares fominas olfactu perci. piunt. Odor porcorum ingratusvalde equis eft, ficut fuilla omnia. Et fectore extincte lu. cerne abortiripofunt, non fecus ac ipfiquog $g_{3}$ bo: mines.

V. Qvid de appetitu E affectibus? Refp. Amicus ac fidelis homini eft. Augecur amor, fi hominem habec benefactorcm. Li, beraliter enim à Domino tractatus, tanta cum perfequitur benevolentia, ut pro falute ejus vigilet. De Mithridate dicunt, quód fomnia capiens, non latellicibus modo, fed exiam Tauro, Eqvo, E Cervo, cuflodiañ fu: commiferit. Ad.

$v$ gils. 
PHYSICA.'

vigilarunt bruta hec, \& grodam adpentante, reiem taurus mugitu; eqvuus binnitu, cervus fua joce, éfomno excitarunt. Nec defunt exempla,ubi mortuis Dominis, mortem fibi ipfis intulere eqvi pertinaci inediâ.

$$
\text { VI. Quid de motu equi? }
$$

Motus celerrimus eft præfertim in planitie. Hinc peregrinantibus, negotiantibus ac praliantibus maximè infervit. Patria autem attendenda tellus eft, cum alia terra alios alat equos. Abundant eqvis regiones omnes. Ungaria, Bobemia, Polonia, Germania, Dania, Norvvegia, Turcia. Sed ob pernicitatem pedam celeberrimi funt Turcici Hinc verfus:

Turius acercampis, parvis contentus, obefus Tergore, perlacos ceteri pede fertur agellos. Sedplerumgón fuis [usfercur) testibus orbus.

VII. Quanam propria equi affectio fit?

Refp. Hinnitus. In pugnam cum ducitur, hinnitû magnoq; injpetu in hoftes irruit. Solas cum relinquitur in fabulo, hinnit, fociosque requirit. Libidinis ftimulis cum agitur, hinnit, affectusqre veliementi. am indicat. Ex binnitu eqoi Darius factus Rex M. 5 $e / R_{3}$ 
186 ZOOLOGIA

eft, juxta Herodotum. Mortuo euim Cambyfe fatutumeft, ut magnates eqvis fuis Deberentur in fuburbium, Erex crearetur, conjus eqvis primum binniret. Nocte precedente Darii fervus eqpam adduxit prestantisfimam, \& loco cerro alligavit. Mox Darii equumad duxit o cum eqpa illa commifit. Hinc adpenientibus Magnatibus of de fururo rege cogicantibus, bin. niit primo omnium equus Darii. Congreffam enimpetebat, $\sigma$ libidine fua Domino imperium
impetrabat.

Axiomata.

1. Equus generofus ac fortis est. Acriser pugnat mordendo, calcitrando, faliendo, ac to to corpore. Erigit jubam, $\mathrm{fpu}$ man ore emittic, natesinflac, maxillas huc \& illuc torguet, terram ungulis fodit, fremit $\&$ hinnit. Hoftern \& equorum adverfe partis voces agnefcit, \& nécfonantibus tubis, nee fulgentibus gladiis ac clypeis terretur.Hanc animi generofiratemScriptura defcribit apud Jobum verbis magnificis. Numqvid dedifis eqvo fortitudinem? Num qvid induisti collum ejus tonitri?? Numqpid terrebis illum, ficut lo. cuffam? Robur naris ejus cerror. Fodiunt vallem, Es geftit forticudine, egreditur in occurfum armorum. Deridet pavorem, nes formidat nea repertitur à fasie gladii. Super eum fonat pbaetra, 
b barelwa, femur lances of baste. Cum impetu ES. î́ fodit cerram, negis credit, grod fac fonitus bucciac. Inter buccinas dicit, Euge, $\sigma$ eminus odoratur bellum, commotionem principum Es cla. morem.

\section{Eqvus fuperbus est.}

Phaleris ornatus feipfum circumfpicit, miratur dona, \& inceffu fuperbo fe oftentat: Pugnâa a tâ cum victor evafrie, geftit audaciùs, \& in folentiùs effertur, inque ipfo inceffu vehementer fuperbit. Viatus autem fi fuerit, dolet, \& fe ipfon cum rectore fuo contemnit. Buccpbalus Alexandri Magni neminem alium, goàm Alexandrum, regiis ormatus pbaleris recepit in fedem. Idem verò nudius eqvifonem etiam ferye recufavit. Et obfervant accurate equi Dominos, peritis ac praftantioribus fidem praftant \& obfequium, imperitis \& abjeEtis viribus omnibus repugnant,

\section{Equas docilis est.}

Agnofcunt equi hamanas voces, fiftunt, currunt, vadunt quò jufferis. Militandiar. rem \& falrationes, eos didiciffe conftat. Egregiè Scaliger dectum equum, deformem alias depingit. Egrum pufillums, deformem circumducebat Ag yrta gvidam: cujus juffu atóns cticm fuo interdum nucu ille omsia faceret. Ambulare 
158

\section{ZOOLOGIA}

bulare, fuccus fim properare, currere, faltare del quadrupes velbipes. Vinum biberevidimus, in clunibus fedeniem : anteriores pedes adpateram ferre. Pelvim feu malludium cruribus fustinere, quafi àtonfore lavarecur, qualem pidTum vi. vimus afinum cucullatum. Humi lefefternere; projectum àtág etiam porrestum jacere: ciliorum compresfione annuere. Caput adberinutum atcollere: in terga vertere: fupinus oftendere, gro corporis fitu mulieres ineunte admittant virum. IV. Ex eqvi putrefcentis medullavepas Es crabrones nafci fa. bulofum eft.

Eriam cadavera \& ftercora equorum prod. effe fribunt. Emortuo equo vefpas \& cra. brones fieri dicunt: : \& è fimo fcarabæos. Sed advolare Scarabæos ad fimum vidionus: $g e=$ nerari inde, nec novimus, nec admittimus. Cadavera equorum viderunt umnes : abiffe in vefpas \& crabrones, nemo è noftris oblerva. vit. Rectiùs D. Franzius ait:vepe of cra. brones perbibentur nafi ex exanimato corpore eqvi, ut excadavere boves apes, quod aliter ta. men accipien dum vix erit, quam grod illud genus animalculorum gaudeat bumorem fuum genitulem,vel ovula fua deponere in ejusmodi cas
daveribus.

$$
\text { CAPUT IX. }
$$


PHYSICA.

\section{De Bove}

Preceptum.

3os eft brutũ qvadrupedes, mugiens, animofü, robuftü,libidinofum, homini multū inferviens. Qvestiones.

1. Qvodnam bovis nutrimentü fat? Refp. Nutritur gramine, foenô, paleâ, hordeô $\&$ alii's. Panem avidè captatac devorat. Amat nemora, \& frondibus delectatur \& arbsAt is, quibus pinguercit, \& reliquiis ciborum adeò pingुvefcere dicitur, ut ne incedere qvidem amplius qveat. Nierembergius fcribit: in provincia Aden, boves, equos, camelos of o. ves pifcibus vefii. Idem autor est nonnullos luporam inftar, effe carniporos. Et fieri poffe tantam palati mutationem, ut ì paftu ad raptum, à gramine ad greges fe vertant bruta. Sicut alienum non fit, carnivora quogis berbis, fruċibus ac terrâali. Aqvam bibunt \& libenti. us claram, qvàm turbidam.

II. Qvenam bovis magnitudo? Eqrohaud cedit magnitudine. Frontem habet validam, pugnæq́ve idoneam. Cornua ge rit bina, majoraq́ve caftratus, minora tauIus. Collum eft robuitiffimum, corporis co. lor varius, \& ungula bifida. Boves Indici u. nicornes $\&$ folipedes dicuntur. Laudatur nobis bos, fivulsus fit minax, $f i$ pédes anteriores I 
290

\section{ZOOLOGIA}

zeriores fortiter figat, $\sqrt{2}$ terrä fodiat, $\sqrt{i}$ cornua a feriẽdü in pröptu babeat, sis cauds erecta, E modis sè incurvat a fit, ac longitudine corpus totü aqvec

III. Qvenam bovis generatio?

Libidinofum animal eft, led non xquè o. mni anni tempore libidine flagrat. Optimum congreflus tempus eft, medium veris. Et li. cet primò ztatis annô generare incipiat, ta. men ante tertium annum admittendi non funr. Sicut nec, qvi duodecimum annum. excefierunt, foccundi admodum funt. Dllo caurivaccisseptuaginta lufficiunt, qvia gravide eos non tolerant. Non autem tolerant, gria percuffionem uteri feqvitur dolor, dolo. rem fuga congreffus.

IV. Qvid de fenflbus bovis?

Tempeftatum prafcium effe ferunt. Odoratu nempe prafentire mutationes aëris. Alias fimplex animal \& ftolidum bos eft: parum fenfibus externis, parũ internis valens. Ufus boum in agris potius, qvàm in urbibus eft. Unde proverbium; bos incivitate; de co, qvi prater meritum evehitur ad honores.

V. Qvid de appetitu E affectibus boris?

Intemperans ac valdè libidinofus eft. Hine ingens taurorum pro vaccis pralium. Armentadi: 
a diverfa cum funt, tauri à grege fecedunt, \& lii in alios mugiunt. Propiores fadi, infe. to vultu fe intuentur, ignem naribus fpirant, cerram pedibus fpargunt, \& effreni impetu pugnam ineunt. Ambiguâ clade tamdiu concurrunt, donec victoriam retulit alter. uter. Victor cervicem jactat, \& magis jam robori fuo confidit, ad gregem revertitur, ac magna ferocitate exultat. Grex arrectis capitibus adftat, \& hunctaurorum \& vaccarum regem vehementer perhorret.

\section{Qvid de motu fciendum?}

Refp. Tardus inceffus \& piger bobus eft. Hine aratro. aptiores quàm bigis aut quadrigis funt: juxta proverbium: Equus in quadrigis, in aratro bos. De eo qvi adhibetur ad negotium, ad qvod natus \& educatus eff. Germanicè : Einem Mund ift nirgend befer/D:ñ im Nilo= feer. Eincm Diebe nirgend beffer / o chn am Galgen. Caret tamen lege neceffitas. Hodie enim trahune quandoq́; currum bos \& e* qvus, ut cauf́ focia: Sed non absq́ve utria usq́ve damno, dum eqvam retardat bos, bo: vem impellit eqvus.

VII. 2oenam propria bovis affectio?

Refp. Mugitus. Vaccas adfe re recat bo's mugitu 
192

\section{ZOOLOGIA}

gitu. Ad pugnam rivales provocat mugitu. Victoriam promittit fibi, cum validiorem fuum, quàm hoftis, lentit mugitum. Et redur proft rato hoftele victorem efle indicat mugitu. Sylux tefonant fapè. Et vox afcenlu nemorum ingeminata remugit.

Axiomats.

1. Bosindigena melior peregrino eft. Alendi frfunc boves, ob ufú arảdi praftảtior eft domi natus,qvä èPolonia autHelvetica adductg. Helvetici boves cômendantur à teneritudine carnis: Ungarici à pingvediné, Polonici à firmitate nutrimenti.Praferimg hos noftris ob pala un,fi mactandi funt.Sin alendi ad domefti. cos ufus,dometticos praferimus iftis. 2 Fon enim aqua, non pabuli, non cxli mutatione rentantur. Neǵve conditionibus loci infe. ftantur, ficut cum è planis in montana \& ̀̀ montanis in plana \& campeftria träsferuntur. II. Bos bomini infervit carne, lacte, corio, cornibus Eoperâ.

Bovis vox \& pro viculo, \& pro caftraco, \& pro tauro, \& pro vacca fumitur. Vaccam. norat,cum Livius dicit: Bope eximia capta de grege. Hinc illa utilitates, qvanqvam non 0. mnesejus dem fexus, Caro vituli tenera eft, boni fucci, fvavis faporis, \& tacilis coctionis,

Crasfior 
craflior autem taúcrum \& vaccarum ac difficilis coctionis, imprimis feniorum. Lac oubulum boni eft odoris, dulcis faporis, $8 z$ oene nutrit, fangrinem auget, ac corpoa pingyia reddit E corio calcei funt oped di litoris. E cornibus, fiftula, pectines, uenfilia. Olim achibebantur boves in triturando, qvia circumducti in a rea, granula è culmis excutiebant. Hodie agricultura in ferviunt ad aratra aptifimi.

111. E cadavere tauri apes nafis, fabulofum est.

Sententia communis eft, è cadavere tauri pafci apes, ficut è cadavere equi crabroness' ecadavere hominis ferpentes. Non obfervantur hxc in noftris cadaveribus, fed creduntur in gratiam autorum. Multa taurorum cadavera habuimus, paucos ante annos, cum miferanda gre gem infeltaret lues. Apes indè natas nemo vidit, \& nemo do hac generatione cogitavit. Maneat alta mente repofitum illud D. Franzii: Sispe du tio mens Dei in prima creatione fuit, $\sigma$ adbue. bodicest, ut generationes fimilium peciarum mon nifi ex fimilibus Beticbus certißima of con: fantisfim perpetuagee regularitate confervas rentur.

N

CAP. 
294

$$
\begin{aligned}
& \text { ZOOLOGA } \\
& \text { CA P U TIX. } \\
& \text { De A fino. } \\
& \text { Praceptum. }
\end{aligned}
$$

Afinus eft brutum qvadrupes rudens, tardum, ftupidum, libidinofum, $\mathrm{fa}_{\mathrm{a}}$ mis, laboris, \& verberum patiens.

1. Quodnam afini natrimentum fit: k. Exiguo \& qvalicunq; contentus eft pabulo. In viis enim, carcuis, tribulis, fpinis, \& aliis vilisfimis plantis vefcitur. Unde carduos afino acetarii loco effe dicimus: Diffeln find bes Efrls Salat. Lautiffimè eos alituri , furfures hordeaceos auttriticeos exhibent. Potus eft aqva turbida : ungrentis offenditur. Hinc proverbium : Afinus in ungvenso. De eo, cui offertur, qvod nec amat nec novit. Ut fi qui dono det militi librum, paftori gladium.

11. Quenam afini magnitudo fit: B\%. Dantur minores eqvo, dantur æqvales eqvo. Afpectu a finus turpis eft: aures habet longas ac latas, nec refpondentes proportioni corporis. - Labra funt craffa, caput magnum, cutis dura, denfa ac folida, ut fuftim vix fentiat.Duri etiam in cute funt pili, \&lanificio inepti.Cor habetmagnum:unde timi. 

timiditatem colligunt. Color murinus ei vulgaris eft: cauda eandem penè longitu. dinem habet, qvam corpus.

\section{II. ouid de generatione afini.}

Refp. Salacisfimus eft afinus, membrumá; genitale enorme habet.Parit menfe duode. cimo, \& lac habet craffisfimum. Fxcundus admodum eft, qvia mature incipit coire, \& coit tota vita, ufque ad atatis annum tricefimum. Coiturus horrido clamore fominam advocat. Rudere enim afinorum rox ef, etiam cum blandiuntur.

IV. Quid defenfibus notandum: Refp. Auditum habet acerrimum. Rationem hujus dant prolixitatem aurium. Sic cnim fonum à longo etiam editum facile percipit. Sonos tamen non difcernit, unde non tim ad voluptatem qràm ad neces. fitatem fenfu hoc excellit. Alias ftupidum animal eft, nullius difciplinx capax. Qvi* dam â tyranno, indictâ pcenâ, cogebatur; ut informaret Afinum. Provinciam recufare non potuit, fed decem annos expetiit ad boc negotium. Admonebaturânonnullis, ne hoc qvidem tempus fufficere, fed prorfus indocilem effe afinum. Refpondebat: nopi eqvidem, fed incereà vel afinus, vel ego, vel tyrannus vel nor onnes fimul moriemur.

$$
N=\text { Quid }
$$


$\$ 6$ ZOOLOGIA

V. Quid de appetitu Es affectibus?

F. Intemuerans \& libidinofus eft Pullos ardentet amat, sin neceflitatibus defendit. In pericula fi incidunt, per a qvam\& ignem ruir opem laturus. Timidus infupereft raldé \& patiens laborum. Non calcitrat, nec repugnt adinodum, licet plus oneris iniponatur; qvam ferre queant humerî.

\section{Quid de motu?}

a. Motıs tàrdus elt-Undo animal ignavum, pigrum, iners \& fegne dicitur. Neqve cedit a finus hoininibus, fed pergit viam, hom:resq; ejectat. Naturale autem afino eft, duriculas fubinde movere. Hinc cum refer. tut a liquid afino aditante, annuere videtut ob mottuna auricularum. Proverbiam datur: Affinus suriculas movens. De eo, qui, cumnihil intél ligat, nutibus ita alludit, ar. ridetg; ac fi probè teneret omnia.

Vll. euenam propria afiniaffectio sit $\mathrm{k}$.

k. Rudere propria afinotum vox eft. Oridius ait:

Utrudit à fiabrá turpis ajella mesá. Rudit nempè pơft laborem, cùm lextatur de re benè geftâ. Rudit cùm foeminam cer. nit, \& voce horridá blanditur. Et rudere son definit, etfí auro \& argento exornetur. 


\section{- PHYSICA.}

Axiomata.

1. A finus afino pulcberrimus.

Etiatn deformes bucca fuos habent bafaatores, Afinus amat afinum \& fus fuem. Comicus fic effert:

Resmiranon eft, ista fic fic prologvars Ipliǵn nobis fiplacemus invieem.

Pulcbreg nazifis pidemur. Nam, E canis oh Pulcberimus cani videtur, bas, bovi: Af lnus a lello pulcher eft o of fus fui.

11. A.inus patienter fext onora.

Dorfo imporita onera vehit in urbem ac reportat. Magnitudini cum yideturimpar, 'non abnuit valdè, fedaurestantun demittit.

11l. Onages pullis propris vim infert:

Onager fylvefaris afinus eft, \& Arufur? corporis cum afino domeftico convenit. Moribus differt qvodammodò, cumprimis amore erga fortum Oppianus ait: Onsger ex emulatione E rivslitate tantoperè labo. rat, ut fui pulli de matre. fint ei fußectio Itoghs femine parienti proximus aßidens, partum expectat, et $\sqrt{3}$ fermin soditur, umat partum, of lambens ip fum lingo a conformat: fore autem ediuza marem videt, tum fand animo incit atup \& $N_{3}$ 
198

ZOOLOGIA

ex agritudine laborare incipit, qued alter mases

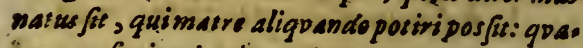
propter furienti animo of prompto pullorum testiculos aggreditur abfindere: maser exfs pariendi dolaribus debilitata, fuo tamen infeliciflio contra patrem auxilis molitur. $O$ me miferam, änquit, qpe partum edidi infolicems ob foelus pasernum ! O fitivin boc miferiorem, qvod non ungribus Leonum, fed plus qvim bofilibus patric dentibus ob rivalem invidiam castr atur.

1V. Ex adulterio afini $\mathcal{F}^{\circ}$ eque fit mulus?

Mulum rocamus eum, qvi afinum habet patrem,eqvam matrem: qui partin patri, partim matrifimilis eft: magis autem patri, qvàm matri, cujus etiarn refert vocem. $\mathrm{Ha}$ bet magnitudinem eqvi, aures afini, \& corpus macilentum. An generet 2 pariat, litigant autores. Ariftoteles ftatuit, concipere guidem poffe aliquando mulam, fedenuerire \& in finem perducere non pose. Marem verò putat gencr are poße, cum calidioris for nacura, quàm femena, qua nibil corporis per congreßum ad gemerationemconferat. Scribit autem Columella Africe regionibus mularsm ferus adeà non - pradigiofos babari, ut ràm familiares fint inca lis qràm equarum. Sic difting venda funt loca, at conftet veritas. Multi multa negant, rel

qria 
PHYSICA.

quía non obfervarunt, vel quia ad principia referre nequeunt.

\section{CAPUT XI. \\ De Alce. \\ Pracepeum.}

Alces eft brutum qvadrupes,velox, fimplex, ftolidum, ficbilem habens vocem.

\section{Quaftiones.}

1. Qvoduam nutrimentum alc is fit: 82. Nutritur gramine \& fono. Cibusfimplex fimplici animali datus. Oermanicè dicitur Elinot/velà morbo, vel à voce. Vo. cem enim e dit miferabilem, undè non inepte id nominis ei impofitum. Et Gesnerus ait, verè miferum eft animal, jicradendum, quòd fepè audivimus, qvotidianum eimorbum comitialem ingrueri, à quó non prius levetùr, qvèm dextri ( fi benè memini) pofterioris ped is ungulam auriculiz finiferx immiferit: qood ego, fi fit, fortuito fieri fufpicor, convulfas of disie vortis morbi magnieudine membris.

II. Quidde magnitudine:

R. Major eft cervo \& hirfutior, cornua habens porrecta in tergum, in primo egref. fu exilia \& rotunda, in receffu lata, è quibus fell $x$, cochlearia, aliaque formantur. UnN4 gulam 
200

gulam habet ut oos bifulcam. Ungula hxc in magno ef pretio, qria medetur epilepilix.

III. Quid de generatione?

Refp. Salax eft, \& gregatim degit. In fylvis Borushiz \& Illy rici habitat, locaque frigidi. ora amat. Singulos pariunt, nec focunditate adeò celebres funt

1V. Quid de fenfibus?

Refp. Sagaciffinum animal dicitur. Hominem enim olfactu percipit per longum intervallum. Hincex metu in foveas \& pro. fundos fpecus fefe conjicit.

V. Qvid de appetitu $\sigma^{2}$ affectibus? Rel. Venerem valdè appetit \& pullos amat. Proprix gentis etiam amans eft, un dè gregatim incedit.

\section{V1. Quid de motu?}

Rel. Motus velox eft, inftar cervorum Hinc monente Gesnero, alcem cum fera illâ, qvam Sieutthice vocant, confundunt, eamq; tantaceleritate effe contendunt, ut plus die uno conficiat, qràm equus tribus, imprimis fuper glaciem aut nivem an bem Sdlitten. VII. Quicnam propria ejus affectio? Refp. Miferabilis rox. D. Franzius ait : vocemedic, us ipfe ex animali audivi, admodium neis? flebilom 
PHYSICA. 201 Gebilem Et miferabilem, adeo ut fi non confiesceecur, exiftimarecur efle infans. Et hincinveait nomen, Eै dicitur apud Germanos, Elend id it, miferum.

\section{Axiomata.}

Alcis motus rapidisfinus, figmenes. tum eft.

Scaliger ait : pebiculo junctum inoffen 0 . tesore fuper glacie quatwor of viginti horarum patio trecenta germanic milliaria transmitatere curfu foribunt. Tante vires, tanta pernisitas, tanti fpiritus, tanti pertinatia. Hoe nos neutigram afformamus.Virum enim nobilem csrere decer, Es crimine mendacii of criminis fußpicione.

11. Ungula alcis medeturepilepfia. Auro \& argento includitur, ac de collo puerorum fulpenditur \& magns cum fiducia geftatur. Sed cum morbus vehementisfimus fit, plura medicamenta, eaque interna adhibenda funt Scio, inqvit Qesnerus, id non raro prof uiffe, fapius tamen fruftre teintasum.

CAPUT XII.

De Cervo.

praceptum.

Cervus elt brutum qvadrupes, velox Ns

timidùm. 
202 ZOOLOGIA

timidum, rancorem edens, \& cornua habens qvotannis decidua.

\section{2vaftiones.}

1. Quodnam cervinutrimentum fit:

18. Vefcitur frugibus, oleribus, graminibus, aliisq; agrorum \& hortorum fructibus. Incredibile damnum infert agricolis, olitoribus, vinitoribus. Undè Laurembergius exultantem cervam fic defcribit: Ych rociß von feiner Saubforge/meiue Spetfesammer finse id alleutfhalben / wenn bie $203 d$ lber mit

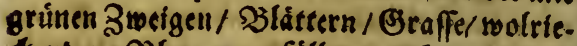
denden 3 laumen exfullet und bebcaft fengn. SMit furksen: Tha habe Speifevie fülle oḩue Gilo/ uno meinen ziff allezsit gebefet.

11. evid de magnitudine:

Refp. Magnitudine \& pulchritudine corpo. ris excellit. Multum fuperbit cornibus fuis, folidis, in ramos fparfis, \& qvotannis deciduis. Cornua autem habent mares, non foemellx. Faciesilli carnof 2 , nafus fimus, collumoblongum \& grasile. Aures funtveluti fcifre ac divifx, cor magnum, in qvo os peculiaris virtutis reperiri cenfent. Cauda brevisfima eft, de qva memorabile id dis cunt, qvòd venenum contineat, qrod potun fyncopen \& mortem inferat. Sed fellis fubftantia 
ubftantia eft, quodvel flavus ille color ndicat. Neque in omnibus deprehenditur ervis, fed paucillimis.

\section{Quid de generatione:}

- Salax animal cervus eft.Libi.linis tempo. re mares efferuntur, homines atrociter insdunt, feiplos etiam mutuis vulneribus ad mortem usqve conficiunt. Fit hoc in fine menfis Augufti,qvo tempore A rcturi fidus cum fole exotitur. Fœmin re libidine tentat maribus obediunt, extra libidinem fugiunt -os.Sapè magna celeritate mares infeqvan: cur foeminas, easque inexorabiles a d cond fiftencum prioribus pedibus amplectuntur. \& in ipfa coëunt fuga. Poft illud tempus mares à foeminis feparantur, \& qvisqve feorfim palcua qvarit. Absqve difficultate pax rit formina, - pullosqve ad prærupta ducit, faltum is monftrat, fugamqve capeffore docet.

\section{2uid de fenfibus:}

Ref. Odoratu plurimum valere dicunt cer. vos. Hine cavernas, in quibus ferpentes latent, adire, vehementerfufpirare, \& fpiratuhoc narium ferpentes extrahere, extractos pedibus conterere, in frufta lacerare, \& omnia devorare. Sed rem, non nif in libris vifam, menquant. Non vefcitur carne: ecrvis

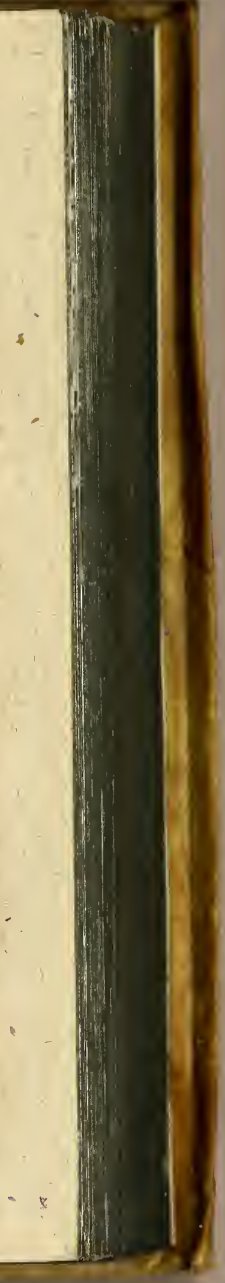




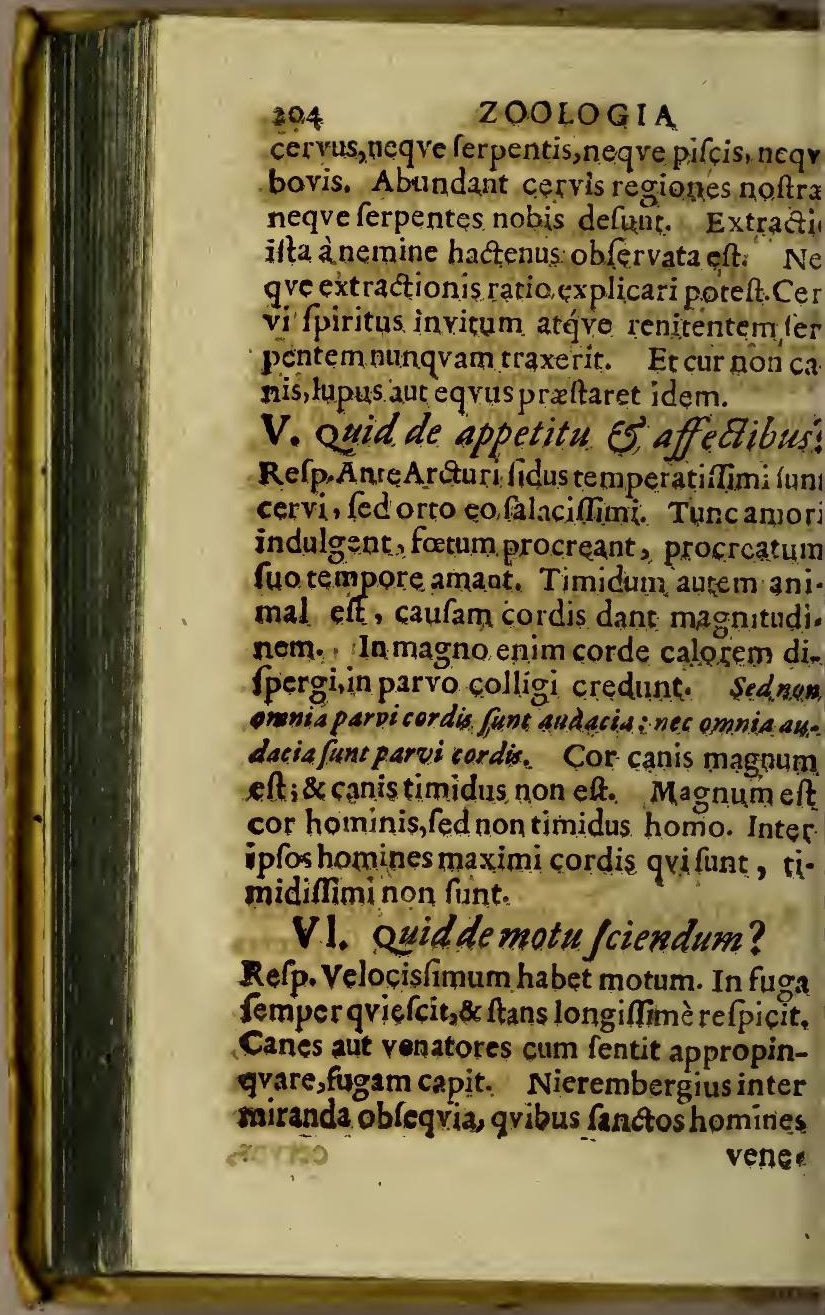


cherentur bruta, refert fequentia. Timifimum animal cerva, duim venatorum tela uti. fugerer, ad Biaffintim Epifropum Laudenin je recipit: qui perjegpebantur, miraculo obupefactifierere. Quidam veróliceniùs acceens,eam de manu Epifcopi cripere voluit: fed re prercptise à Diabo!o vexari cupit. Epifoopus atem, qui bestiam blande amiscgexteperat, clementer fuerat tut at us, nec in bominis vientiam irafipotult, ab immundo fpiritu op, reffum iniferatus, inc unctanter priftes \& reftitufanit atio Idem igit sr o tutele fidem of patiatice benignitatem lerobuit, amicis inimicisg exta favens.Nos iftud scaligeri repetimus: irum nobilem cavere deces of crimine mendat iis criminis fufpicione.

11. Quenam propria cervi affectio fit?

elp.Vox cervorum ancor eft. Tunc cum: rimis cum libidinis a guntur fimulis. Nunc lato capite, nunc ad terram demiffo, ranore illo mares convocant fominas. Alias locitare dicuritur , cum fitibundi frigilam petunt. Huc fcripturam refpicere olunt, cum in ifta erumpit verba rex Daid. Quemadmodumtervus glocirat ad córentes aqparum, ita anima mea clamat ad ie Deus. Silivit anima mea ad Dexis, at! Detiôn

- pivum, 
206 ZOOLOGIA

wiukm, dicens: quando peniam, Es apparebo toram Deo?

\section{sxiomata.}

\section{Cornua quotannis abjiciunt} cervi.

Ornamenta \& a rmamenta cervorum funt cornua. Anniculis nondum nafcuntur, qroddam tamen initium pretuberans, qrod breve hirtumgre eft, habent. Bimis cornua produnt fimplicia \& recta, trimis bifida:qvadrimis trifida:\& fic deinceps usq; ad annum fextum. Poft fimilia femper exeunt, ut ramorum numero xtas dignofci neqreat. Numerofiora tunc cornua non hunt, fed craffiora. Ejiciunt vero qrotannis fun cornua, necneri fint. Interdum ra. mis a rborum implicantur \& vi avelluutur. Sed anteqvim cadant, nova prius fubnafcuntur cornicula. Poltquam cecidêre, oc. cultant fefe cervi, quia \& ornamenta \& armamenta fua amiferunt.

11. Cervus multiplicem bominiprefict $\pi$ fum.

Placent inulea è cervis : caro, pellis, pint gvedo, cornua \& alia, Melamcholicis \& $\mathrm{fe}$ nibus qvidem non admodum proficua caro aft. Difticuler etion sogtitur, frccum me¿ 
PHYSICA.

ancholicum confert, \& hepar atque lienem bitruit. Sanguineis zutem \& juvenibus irmum prabetnutrimentum. E pelle vetes conficiuntur, pingredine lentigines cu. aurur, cornibus venena expellüntur.

CAPUT XII!

De Capro.

preceptum.

Caper eft brutum qvadrupes, vocem debilem ac fonoram habens, libidinofum, timidum \& multıplicis ufus.

\section{Qpestiones. :}

I.Quodnam capri nutrimentum fit. Refp.Vefcitur graminibus, fono \& foliis ac ructibus arborum: corticibus arborum $\&$, Eruticum fummitatibus delectatur maximè. Dignum notatu eft, qvod exHippocrate do capra memorat Sennertus: Alatur capra berbis quibusdam purgantibus: lac capre illius oid bat nutrix, fiet ut infans qui lac fugit, indè purgetur. ubi primo in ventriculo capra herba ill mutantur in chylum;ex chylo fit fangris in hepace, ex fangrine in mammis lac. Lac hocubi nutrix bibit, rurfum fit ex lacte in ventriculo nutricischylus, ex chylo fan. gris, ex fang vine lac: lac hoc fugit infans \& purgatur. Atque ita vis purgatrix cum fiva 
$20 \delta$

ZOOLOGIA

fuo fubjecto proprio \& f piritu in tot muta. tionibus integra \& incorrupta manet.

\section{Quid de magnitudine?}

Refp. Corporis ftatura egregineft. Commendatur qui elt jugnacior, animolior, robuftior magni corporis, mollioris pili, $\mathrm{CO}$ loris albi, capitis parvi, brevis cervicis \& colli, cui crura funt crafli, coft firm $x$ \& coxa amplx. Imprimis barba \& cornuá oblervent:ır, qva quò majora fuerint, cò majorem hirco dantautoritatem. Tam valido ictu ferit interdum hircus, ut aflerem aut futum obtentum perforet, hominem verò iplum profternat. Ac quoties contravenientem pugnamgve indicantem cernit. pararus eft, \& prevenire conatur. Capra ciberiseft maximi \& lacte abundat. Si quis - apram barba apprebenfam é gregetrabat, cates rafímpent, o quidreisgatur adimirabunda $B_{e}$. ctrint.

IIx. Quid de generatione?

Refp... Animal libidinofum eft hircus, ac profoemina pugnam init acerrimam. Se $\alpha$ ptimumazens menfem coit, \& ad generandum habilis eft. Dum alitur uberibus matris, matrem ftupró fupervenit. Qvinqvennis parum idoneus habetur implendis forminis. Senefcit enim maturè, nimia libidine exhau - 
PHYSIC $\bar{A}$.

exhaufus. Capra etiam coire incipit menfeCeptimo, dum lacte materno a dhuc alitur. $\mathrm{O}$ stimum admiffura tempus eft men fis Noveme ser, ut Martio turgefcentibus virgultis pariint. Pariunt maxima ex parte binos, nonaunquam eriam ternos. Ei ubi major coli Elementia \& pabulicopia, anno bis pariunt.

\section{I $V$. Quid de fenfibus:}

Refp. Capra natura fua frigoris impatiens eft. ostem impendentem, terra motum, cali falu. iritacem, of frogum fertilutatem prafentire. Eliano dicitur. Sed admodum dubicamus, de hâcfenfuum excellentia. Sicut necillud dmitcendum, acutiflimi auditus effe capras, \& non tantum auribus, led \& qradam guttuis parte audire. E noftris nemo id obfervavithadenus, \& fortaflis nemo obfervabic unquam.

V. Quid de appetitu E affectibus: Refp. Magna in capris libido eft, adeò ut \& in tenerrimam cadat ætatem. Hinc celerier ante fextum annum confenefcunt. Et vita hircis ca prisque brevis eft, nec decimumfa. cilè fuperant annum. Hœdi matres amant \& circa eas lafciviunt.

\section{$V I$. Quid de motu?}

8. Caper natara mobilis ac velox eft. Capre O _. - Caltan- 
faltar.tes, adeò perfpectx cunctis funt, ut \& meteoro cuidam dederint nomen. Qvidam caprix lacte nutritus, cum adoleviffet, lem: perfaltarefuevit. Sicutille, qui à cerva :ducatus fuit, fugientes cervos lumma pedum pernicitate infecutus eft.

\section{Vll. Quenam propria affectio:} Refp. Vox debilis elt ac fonora. Nomen quando recordamur, proprium non datur. Confiftendum igitur in voce debili, molli ac remiffa. A grege fi ducitur capta, uno tenod re clamitat; ac defideriutn indicat.

\section{Axicmata.}

1. Caprea capro preftantior.

Capri nomen nunc totum notargenus ca. prinum, nunc unam fpeciem. Speciem cum exprimit, caprea capro praftantior eft. Tunc enim differunt caper, badus, bircus, capra caprea, capella, ibex. Caper eft mas caftratus: Ein gefđanttener $\mathfrak{B}$ ec. Hoxdus eft mas juven is ein ungeldinitten 20 doflein. Hircus elt mas non caftratus ein ungefđinittener 20 of. Capra elt farmina, quæ peperit, cine Sitege. Capella eft formina qva nondum peperit, junge 3 iege. Ca prea eft Capra fylveftris ein शReb. Ibex eft caper fylveftris cin Steinbocf. Sic caprea praitat capro. Valdè eaim ejus caro commendatur, 
datur, quia fuavis eft faporis, bonifucci, facilis coctionis, \& paucorum excrementorum. Motu enim frequentiorifuperflux humiditates abfumuntur, caroǵve tenerior ac fubtilior redditur.

11. Sangrine bircimolliri adamantem non aßerendum fimpliciter.

Non alı rumpi vi adamantem, quàm hirci Cangvine recenti \& calido, plerique credunt. Alii ad qualitares occulras, alii ad manifeAtas rem deferunt. Si fir, non fangvinis virtuce, fed eorum qux continentur in fangvine, perficitur. Alendus enim prius hircusilfe herbis folutivis, fileré montano \& petrolelino.

\section{CAPUT XIV. \\ De Ove. Preceptum.}

Ovis eft brutum quadrupes, balans, fimplex, timidum, $\beta$ atiens \& manfvetum.

\section{Qvefiones.}

1. Quodnam ovis nutrimentum fit? Refp. Vefcitur gramine \& fœno. Panem eriam devorat cum voluptate, nec avenam reTpuit. Salis admodum appecens eft, \& pa.

$\Theta 2$ rietes 
$2 \pi 2$

\section{OLOOIA}

rietes urina humana confperfos lambit. Aqqa frigidâ ac limpida delectatur, cifternas \& im. puras aqvas odit.

1I. Quenammagnitudo ovis. Refp. Minor capro elt, mollia vellera habet, nunc alba, nunc nigra, nunc varia. Capue parvum eft \& infirmum, pedes bifulci, cauda craffa \& longa. Oculos habec paculos, mam. mas inter femina, casque binas. In India ad maximorum afinorum magnitudinem as. cedere dicuntur.

111. Quid de generatione:

Refp. Minus falax ovis eft. Maturè quidem coire ineipit, fed fterile femen emittit. No. Atris in locis anniculi rarò implentur. Pariunt annis feptenis, maximâ ex parte fingulos, raròbinos aut ternos.

\section{IV: Qzid de fenfibus:}

Refp. Sagacicas magna \& fingularis induftria inovenondatur. Memorabile effe dicune, agnos fration ab ipfa natipitate agnofcere matres fuas, Ev docem earum inter mulse millia dijcernere, aliena ubera prexerire of folius matris fugere. Sed contingit fapè, ut reperiantur fub alienis matribus agni : fapè clamore magno matrem qvaritant, qram habent propè aftan- 


\section{PHYSICA:}

Hac enim animalis fimplicitas ac fermè ftoliditas eft.

\section{V. ouid de appetitu E affectibus:}

Refp. Moderata videntur omnia. Patiens \& contenta eft ovis paucis. Neqve pugnax eft, eum natura inerme fit animal. Non valet ungvibus, non dentibus, non calcibus, non cornibus.Manfuetum animal eft, mite ac placidum. Non clamat admodum, five tondeatur, five magtetpr. Nulla hîc vehementia,nulla iracundia, fed fingularis patientia, \& miranda fimplicitas.

\section{$V I$. euid de motu?}

Reíp. Moderatior etiam greffus eft.Non ac fi negatus prorfus fit motus celerior. Necesfitas fi datur, velocisfimè currit: fed cum non irsia tatur,nihil facit raptim. Agni faltant lubenter \& fuis lafeivis faltationibus nobis faciunt: delicias.

$V 11$. Quenam propria affectio it: Refp. Balatus, Balare propria ovium vox eft, Lavare oves, Poëtafic exprimit :

Balantumgog gregem flupio merfare falubrio Alibi ait:

Qvefitus matri mult is balatibus agnus. Pro balare veteres etiam dixerunt belare, $\$$ bee, qvam rocem clamore exprimere fuo videntur.

$\mathrm{O}_{3}$ Axi 


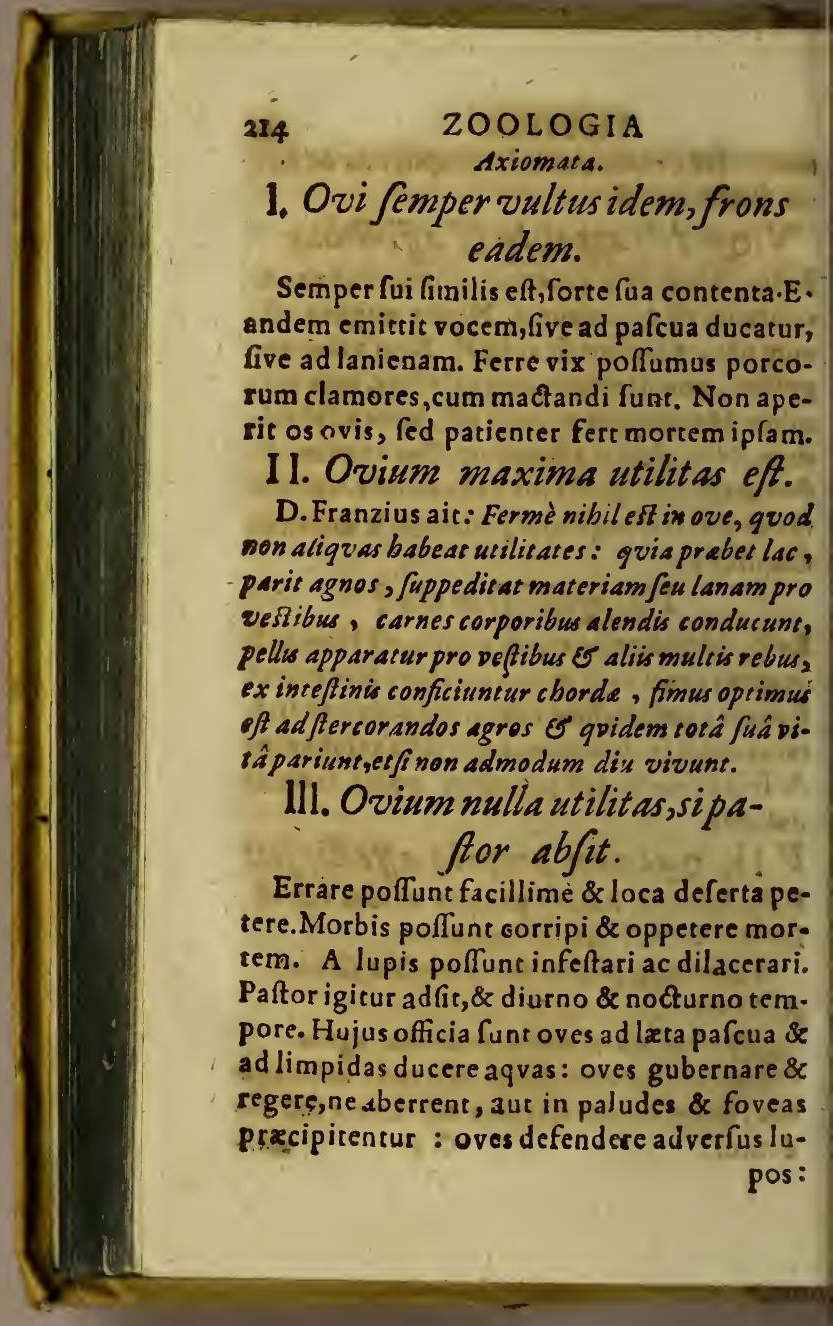




\section{PHYSICA.}

pos : \& infirmiores in finu quafigeftare: oves deniq; præfervare â morbis, fanas ab ægrotis feparare,\& ægrotantibus ferre auxilium.

\section{CAPUT XV. \\ De Sue.}

\section{preceptum.}

Sus eft brutum quadrupes grunniens lafcivum, immundum \& vorax.

Qvestiones.

1. Quodnam fuis nutrimentum fit:

Refp.Animal voracisfimum eft, pra cateris ad paltum natum. Appetit herbas \& fruges, fed magis radices, qrạs longo oris rictu è terrâ extrahit. Delectatur glandibus, pomis, piris, \& aliis fructibus. Etiam carnem devorat, \& ipfis cadaveribus vef citur. Nec ftercoribus, aliisque fpurcisfimis rebus parcit. Hinc loca impura inqvirit, \& quicquid reperit, movet. Adeò ad rem attentus eft, ut firmo intuitu terram confpiciat, \& nequicquam ad coelum vertat oculos. Potus eftagqaa, feu pura, feu impura, ferum \& alia.

II. Quenam Juis magnitudo: Refp.Quantitas egregia eft.Exterior corporis conftitutio vilis \& contempta. Fronsilliangufta, óculi cavi ac profundi, roftrum longü \& Latum. Collum habet craffum, corio durio-

$\mathrm{O}_{4} \quad \mathrm{ri}$ 
216

\section{ZOOLOGIA}

ri cinctum. Venter amplior eft, \& in foemina mammis duplici ordine præditus. Crura brevia funt, ungulæ bifidx. Cauda minus hirfuta eft, quam frequenter intorquet. Totum corpq pilis crasfioribus ac rigidioribus tegitur. $P$ ingvefcit valdè, ut nonnunquam furgere neqveat. In clunibus mures qvandogु formane antra; nidum juxta ae cibum nacti.

111. vid de generatione:

RefpL ibidinofum animal eft \& multiparum. Cùm mares,tùm fomina coire incipiunt, 0 ctavo atatis fux menfe. Prxgnans fcrofa eft menfes quatuor, pacitq; octo, decem, ac duo. deeim uno partu. Reperiuntur aded impro. hatut proprios devorent porcellos. Pecus enim hoc impatiers famis eft, \& fi non adfit quo vefcatur, fobolem ip fam invadit. Præftantior eft proles menfe Martionata, minus praftans hyeme, peffima xitate.

Refp. Prafentit lus pluviam, unde ore AramiIV. Quid de-jerylibus: na portat \& ad ftabula properat. Odoratur panem, poma ac pira è longinqvo. Memoria qroq; valere multum dicuntur, qvod Elianus confirmat fequentibus: Porculat oris vocem Juillum pecus fic agrofoit, ut etiamfi ab eo procul Seductum fuerit, appelldxtem intelligat, cui qui. dem reicefimonio oft id, grod proximejequitur.

Cùms 
ecim maris predones adTyrrbenam terram pirawsicam navem appuliffent, ex bara permult os fues furto abact os impofuerunt in navim, quant folventes ad navigandum incubuerunt. Subulci prejentibus piratis flentium tenebant, fuesg gassenus abduci quiefcebant, quoad ex portu latrones fe eripuiffent, $\delta$ à terre folvißsent. Tum voce fuibus audiri folita fuarii quàm maximè poterant exclamantes, cos retrò verfus adfe revocabane. Porciprimum st fublatum clamorens pafforum exasdierunt, statim fe in alterum navis latus compellentes eam everterunt: malefici pirate noufragio gram mox funditus perierunt, fucs ad fuos enat arunt.

V. Quid de appetitu E affectibus? Refp. Intemperans eft, \& vix expleri poteft. Omaia appetit, \& jucundisfina putar, qva fottent maximè. Luto delectatur, \& fi quid luto foedius eft. Nequit ferre rolas, \& poma aurantia ac citrea, fed amat ftercora. Porcus ctiam gaudet porco $v$ clamante uno; omnes accurrunt opem laturi. Fœtum qvoq; proprium amat, \& vehementer grunnit, fi clamorem audit charæ fobolis. Qvanquàm fame preflus oblivifcaturamorisac devoret prolem fuavisfimam.

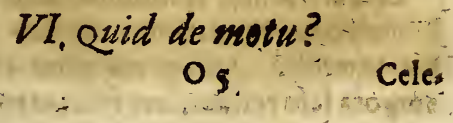


Celerem habet motum, ut hominem maxis. mo currentem nifu prævenire posfit. Pigerri. mi fiunt interdum ex nimia pingvedine, \& volutatio in luto fuillo generi gratisfima eft. Rationem Ariftoteles dat, quia olf actum bebetiorem babet. Sed nulla in olfactu hebetudo datur.Ac cum rofas \& majoracum \& amaracum ob fragrantiam ferre neqveat, cur non à luto abhorret ob fotorem? Potiùs fuum cuigs pulcbrum, \& animal impurum impuritate gaudet. Creavit Deus naturæ autor animalia munditiem amantia, creavit etiam, qva mun. ditiem deteftantur:

VII. Quenampropria Suis affectio jut?

Refp. Grunnitus. Propria porcorum vox eff grunnire.Grunniunt currentes, ,tantes, fedentes. Grunniunt cum cibum capiunt a c patum. Grunniunt cum blandiuntur ac lxtantur: Grunniunt cum comprehenduntur \& ma: ctantur.

1. Simia E fus maximè corpus bu-

Secant libenter Anatomici Simias \& fues. Simiz hominera partibus externis referunt, fues internis. Anteqvam igitur ad humana corpora fefe vertant, fues velut exemplar pramittunt. 
PHYSICA.

mittunt. Majori autem cum fructu fectio in macris inftituitur, qvàm in obefis.lV afa enim rectivis confpiciuntur, nec pinguedo nimia. impedimento elt.

11. Sus vivens nemini prodeft,mortuus multis.

Cramdiu vivit, omnes offendit torvo' a. spectu, fœtore \& grunnitu. Cum mactatur, fu. um habent ufum carnes, farcimina, pellis \& ferx. Caro fuilla non anteferenda qvidem. omnibus carnibus eft.Scaliger medicos dementes ac vecordes vocat, quicarnem fuillam preferunt perdicibus. Ventriculum tamen qvi habent temperatum ac robuftum,ea non inutiliter vefcuntur. Rufticis cumprimis, fofforibus, mefforibus, fabris, \& aliis firmum alimentum petentibus, optimum prabet nutrimentum. Farcimina etiam negligenda non funt, maximè carne \& ventriculo repleta, è Sangvine verò E cerebro facta, deterior a funt. Pellis fuilla libris praftat operimenta, magis durabilia, qvàm ovilla ac vitulina. Setis utuntur pictores \& alii.

III. Suibus peculiare eft grandine affici.

Grandines funt grana albos rotunda, me gnicudine lentis, binc inde grandinis glacialib instap 
inftar difper a $_{1}$ qua dolorem afferwnt, ficangano tur. Fiuntex inflammatione fangvinis. Hine irâ concitati fues facillimè marbo hoc velut leprâ corripiuntur. Caro horum infalubris ac pesfimi fuccielt. Cagnafcuntur igrefiu, cim pofterioribus pedibus stare neqveunt. Setam etiam dorfo qui evellit, cruorem in radice pili es vulficernit. Et os cum aperitur, inferiorelingve parte grandines babentur. -

$$
\begin{aligned}
& \text { CAPUT XVI. } \\
& \text { De Lupo. } \\
& \text { Preceptum. }
\end{aligned}
$$

Lipus eft brutum qvadrupes, ululans. rapacisfimum, varacisfimum, \& ovibus infeftisfimum.

1. 2vodnam lupi nutrimentum fat? Refp. Voracisfimum \& infatiabile fermè animal lupus eft.Carnes, pilos, offa, aliaq; folida $\boldsymbol{2}$ integra, devorat potius, qvam comedit. HincGermanorum proverbia:Er frift wie cin 23olff:Er hat eíuen2Bolffsmagen. Savit mi. rum in modum, \& nec homini, nec ulli animali parcit. Oves \& capras auticulâ apprehendit, \& fecum abducit. Cum verò renitun:tur,clunes cauda ferit, cogitq; ut mifera animalia celerius currant feductore ipfo. Ad.alia 
s lupos cum pervenit, prædam dilaniant, \& quisque pârtem fuam fibi feorfim fumit.

\section{Qvonam lupi magnitudo fit.} Refp. Forma lupi fímilis magnis paftorum canibus eft. Dentes habet acutisfimos, ad morfum validisfimum. Oculi funt fplendentes, noctu luceme aculantes. Hinc noctu videre dicitur,quanquam contra rationem. Cerebrú crefentem ac decrefcentein lunam fequitur. Armos habet validos, quibus ovem gerere, \& fugere paltorem poteft. Crura funt longa, \& genitalia offea.Inteftina minus fpiris involu= ta, undè citiùs exeunt, quæ devoravit. Cauda eft villola et propè corporis longitudini $x$. qualis.

\section{Qvid degeneratione.}

Minus libidinofus efí lupus, ac̀ toto anno non nifi dies duodecim coit. Membrum habet offeum, \& a verfo modo canis inftar cohxret. Parituno partu feptem, aut novem. Nonum, canem \& non lupum efle ajunt. Sed fabulam fapir,cum fimile fimile gignat. Lupam primo partu, unum eniti dicunt catulú, fecundo geminos \& fic deinceps, usg̨; ad catulum nonum, indeq; fterilefcere.

$$
I V \text {. Quid de fenfibus }
$$

Tempeftatis acerbitaten prafentit lupus, Hinc 
Hinc maturè frigidiora loca cum calidioribus commutat. Graffatur noctu, \& cumprimis circa tempus ancelucanum, ue minus confpiciatur. Vifu non parum valet, quanquam â neceflario ad nimium progresfa fint homines. Putant enim in crasfioribus qvoquetenebris â lupo confpici armenta. Qvod cum vifion is repugnet natura, â vero eft alienurm.

\section{$V$. Qvid de appetitu EF affectibus?}

Immoderatus appetitus cibi elt, moderatior veneris. Amans eciam prolis eft, atque tùm maximè frevit, cum catulos alit. Si ca. peus fuerit, mitefcit, nec infert damna fociis. Ceciderunt aliquando in foffam mulier, vulpes\&lupus. Singuli occuparunt certa 10. ca , \& quieri fuerunt totâ nocte. Lupus ne. qve vulpem, neqve mulierem attigit, fed' in ftatione fua perftitit timidus. Venator $\mathrm{ma}$. nè prædam triplicem confpexit, \& ad conSpectum færmina, vicinæ fux cohorruit. In. filiit foflam fubitò, \&z primolupum interfecit, deinde vulpem: denique extraxit mulierem femimortuam, \&zuna nocte canam. factam.

\section{Quid de motu:}

Non parum valet motu. Curfu celerrimo infeqvitur anferes, qros cum fatigavis, ap. 
224 ZOOLOCIA

audaciores funt, villas accedunt, \& in prafentisfimum periculum fe precipitane. Hinc illud proverbium:Lupus pilum mutat, non mentem, pro eo; Senectus improbo adfert qvidem canutiem, fed non aufers malitian r bas Xlter

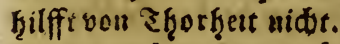

II. Vifo lupo non obmutefcit bomo.

Multorum infedit animis, hominem vifo lupo obmutefcere aut raucedine corripi. Hine Germanorum proverbium: - Er trat einen IBolff gefehen. De eo cui repente vox adempta eft. Sunt etiam, qvi tunchominem obmutefcere putant, cum lupus iptum prius conlpexit. Servius ait : boc Pbyfici confir. mant, qpod vox detrabieur ei, qvem primùmlupus viderit. Undè etiam proverbium boc narum eft: Lupus in fabula, qwoties fupervenit ille, de qzo logvimur, onobisfua prafentia amputat facultatem logvendi. Phyfici igitur zantereicaufas inguirant anxie. Sed dant caufam rei, qvæ nunqvam $f a c t a$, nunqquam. futura eft. Non defunt nobis lupi, qvi \& vident nos, \& videntur à nobis, fine periculo vocis, Rectè Scaliger ait : Cur vifiss lupis bamia nes obmutefcunt? gria in illins oculio pis. QDid 5 ejus oculos non vidit? Nom ejus ocudi dorfum penetrant $\&$ occiput ad lingpa:m? Ultinam tot feru. lis cafligarentur mendasionum affercores iffi:

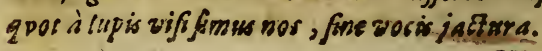

III. In 
III. Is lupsim non convertitur bomo.

Maxima hominum pars delectatur fábulis." Fabula eft homines in lupos mutari, per cam. pos divagari, in armenta graffari, \& obvia qvervis dilaniare. Animahumana non mutatus in animam bruti, neqve humanú corpus incor. pus beluinum. Homo fi moritur, feparatur anima \& in Separato ftatu perfat, ad finem usque mundi. Corpus verò exanime cor. rumpitur, \& in pulverem redigisur. As it? lud impoffibile nature univerfx, poft cerțum temporis intervallum deponi lupinam fpeci$\mathrm{em}$, \& affumi denuo humanam. Lufus Sata. ne eft, qui hominum pervertit fenfus, ac plsa bem incautam decipit.

\section{CAPUT XVII. \\ De Urfo.}

Praceptum.

Urfus eft brutum qvadrupes, murmis. rans, frviens, deforme, robuftum ac perniciofum.

\section{2ueftiones.}

1. 2vodnam ur $/ 2$ nutrimentum Jit? Refp. Devorat promifcuè poma, pira, nucess caftaneas, cancros, \& ipfa quoque dulsia mel- 
226

\section{ZOOLOGIA}

1a. Confcendit arbores altisfimas, non tan. tum, ut omnis generis fuctus quxrat, fed \& ut trimas unguibus aperiat, \& mel inde ra piat. Cum pungitur aculeis apum, parum capit detrimenti. Prodelt enim punctio gravedini capitis. Defcendit ex arbore avertus, primum pedibus pofterióribus, ut anterioriby fuftentet corporis molem. Vefcitur etiam formicis qrodadmedicinam eum facere fua fpicatur Scaliger. Neque d̀ cadavetibus abfti net fedluporummore ea fecum portat ac devo 32t. Hine Ovidius ait:

Corpora magnanimo jasis eft profirâffe leoni, pugna fusm finetm, cum jacez boffic , baber. Aolupus $\mathcal{E}$ curpes inftant morientibus urfi:

Ec qrecungs minor nobilitate fera est.

11. Qvid de magnitudine?

2. Corpus habet grande ac deforme. Pellis fpiffa \& villofa eft. Caput invalidum, ob ofra infirma, prafertion in fyncipite. Hinc vel colapho exiguo ladi poteft maximè animal sobuftum. Pedes habet humanis manibus Gmiles, ac pofteriotibus interdum infifit, anterioribus ineptias agit. Vis magna illi in brachiis \& lumbis eft, qvibus obvia qvavic difcerpit, ovilia oliveta frangit, animalia apprehendit \& necat. Color eorum pleturio q̨ve niger eft,é frigidisfimis tamen locis bodo nivingrama albi ad nos defercuntur.

tII. 2vid 


\section{PHY SICA.}

H1. Qvid de generatione?

Refp. Flagrant libidine urfi, ccềuntọ́ve non canum auc eqrorum, fed hominm in ore,mutuis complexibus. Nec fur tantum gentis, fed \& hominum amare folent forminas. Fuic quidam, qui puellam in fpeluncam rapuit, eandemque ol culatus quotidiè eft, \& ex pomis \& piris agreftibus macuriora ac pulchriora fe. legit, eidenque edenda a maroric̀ obrulit. Johannes Saxo \& Olaus Magnus Icribunt: Reges Dassorum urfum progenicorem babere, qpi dor. ginem rapuic pulc berrimam, que ex fera fliwn peperit, forma elegantem,/ed pillofum, Docasums i patre Urfutm, Hac noncredi liberaliter o. portere, ftatuitNierembergius : nec eciam ul. tra natura vires effe, fi muliebre femen efficax fir. Nobis alfurdum eft ex bominis \& brusi. congreffu persm edi polfe bominem.

$$
\text { IV. Qvid de fenfu? }
$$

13. Senfus tactus in nalo tenerrimus eff: Hinc perculfus $i b i$, irritatur vehementer: Undè psoverbium: Ne tentes nafum niofo. Pro eo ne tentes cos, qvi nocere queunt. Auditum delectar Mufica, sujus amantiflimus eft. 0 . laus Magnus refert, in jepcentrionalibus locis. pafiores ab ur is sircumsencos ludere cötinuopa

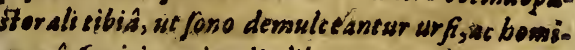
aes a foritia animalis liberentar. Maree dis. ' $a$ cans. 
225

\section{ZOOLOGIA}

cunt hybernis menfibus fomno fepeliti gra. draginta diebus, foeni nas qpaeuor integris mun. fibus, \& tunc maximè pingrefcere. Excitatos pedes priores cum murmure fugere, ac mirificè illo pedum fucco refici \& nutriri. Nos illud damus, latebras hyeme quærere urfos, \& fomno indulgere maximè : fed abltinere prorfus à cibo, \& fucco pedū nutriri,nega mus. V.Qvid de appetitu E affectibus? g. Prolem aunatvehementer, eamqre pecto: ri admovet, fovet, actegit. Caculi fi matri fuetint abrepti, agerrimè fert, ac mirum in. modum frvit. Et aliàs iracundum animal eft, ac vindictz cupidiffimum. Si ladi. tur à qroquam, indefinenter perfequitur \& pedibus ancerioribus, $q$ vi inftar manuum funi, reum lacerat.

\section{Qvid de motu?}

Refp. Motus tardus eft, nec tàm fugâ, qvàm manibus fe defendit. Corpus enim valdè craffum \& vix mobile habet. Paratus aliàs ad omnem nequitiam eft, incedit pedibus du. obus, confiftit erectus, faltat, ludit, fasa projicit, \& ad magittri fui nutum fe componit. Qranquam autem interdum nimia confidentiầdeceperit rectores, qui lacerati ac peffimè tractati ab aftutc máligno animali funt, 
$-\operatorname{sid} 3$ zOOLOETA

easto, majorem mure, pareve foleat, wadum itew $\checkmark$ cecum, 6 cruribus propensodum membring. slis plurimis indifcrecum of rudem. Hinc opinio illa, arfam gignere fortus informes, nue dx inftar carnis, fine oculis, pilis,aliisque par. ribus, qvam carnem informeps lambendo port modo componat \& efformer. Ad hee Scali. ait : Bonum Pbidian : f grantsum demendium, gionesum relingvendum fit, fciat. Quid bujus Sse fabule antoribus fidei babendere for , ex bae bisioria cognofies. In nofiris alpibes venatores

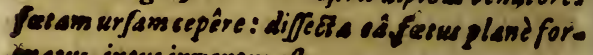
-orw, ineus inventus eff.

C A P U T XVIII.

De Pardo

Preceprum.

Pardus cft brutum qvadrupes, robuftum, ferocisfimum, aftutum, jucundis ma- culis in cute praditum.

$$
\begin{aligned}
& \text { Quefsones. } \\
& \text { 1. Qvodnam Pardi nutri- }
\end{aligned}
$$
mentum fut?

- Venatur animalia \& vivit ex rapto. Ag. greditur apros, cervos, lepores \& ipfos qvo. Gre homines. Simulat interdum fe fomno aut morte oppreffum effe, \& repentè irruit in beftios circamoftantes, easque diloaiat ac de-

vorato 
PHYSICA.

232

vorat. Mifit aliquando Romam Rex Portugallix pantheram equo Perfico infidentem. In fylvas dediuct a à venatore, qui rector erat beftix, miranda celeritate in apros \& cervos infiliit, eosdemqve jugulavit.

II. Qvenam Pardi magnitudo?

Canem venaticum magnitudine refert. $\mathrm{Ca}$ pite felem repraententat, ficut omnia fermèa nimalia freva, feli Gmilia funt. Parvum autem eft capur, parvi oculi, frons longa ós ma sgnum, auro rotundx. Collum longum eft e tenue, longum dorfum, clunes carnofx, cauda prolixa, ungves magni \& acuti, corpus cotum maculofum.

III. Qvid de generatione?

Libidinolum animal eft, \& congreditus cum diverlis fpeciebuse E congreffu Leanes \& pardi genezatur leo, red ignobilis, nec. jubatus. Sentit enim congreffum olfactu in adultera leo, totâqre vi confurgit in poenam. Congreditur etiam leo cum panthera, \& fit Leopardus. Cum lupis quoqqe ac canibus panthere mifeentur, \& fiunt fotus utramqve fpeciem referențes, fi non femper corpore, tamen animo. Credunt catulos Panthera prevenire juftum partus tempus. Lacerare enim ungribus fuis uterum, indegre effundi dolore cogente. Atg; hine parere amplius 
232 ZOOLOGIA

non poffe pantheram, sùm non hareat femen in illa corrupta \& lacerata matrice. Sed falfa hac funt, è falfs nata principiis. Nullus in utero ufus ungvium eft: Recondunt ungres fuos leones, pardi \& feles, \& non nifi requi. rente ufu promunt. Nihil igitur hine metu. endum mali â condito, in corporis vaginas , ungvium mucrone. IV. Qvid de $e n\}$ ?
Refp. Olfactu non parum valei. Hinc cum vi.
ni avidifimus fit, venatores vinum fuave \& ni avidiflim apponunt \& affundunt, ut odore odoratum apporunt \& affundunt, ut odore
vini alliciatur. Qvo facto, Pardus vinum bibit immoderatius, eoqve accenditur, acfine difficultate capitur. Aromatibusetiam gau. det, \& permulta locorumintetvalla fragran-. tiam feqvitur, prefertim cum arbores ligvore turgent, \& venti odorem vehunr.

$V$. Qvid de affectibus?

Refp. Trahituramore odorum. Qvin ipfa. quogve Panchera admirabilem odoris fvavi. tatem haberedicicur. Solinus ait : Tradune odore pantberarum \& contemplatione armenta affici mirè, $a t g_{3} u b i$ cas prefentifcant, properatò convenire, necterreri, nifi folius oris corvitate, gram ob caufan Pantber abfonditis capicibus, que corporis religua fumt, pectanda prabent, $u_{E}$

pecuarios 
oecuarios greges stupidos in obtuto populentur coura vasiatione.

\section{Qvid de motu?}

Refp. Velaciffimum animal elt, \& fubitò in. vadit armenta. Non autem tàm curfu,quàm faltu rem agit.Pollux ait: Susem of aprum dices oup'p'ŕy $\delta a \tilde{v}$, id eft laltare. Citò autem fatigari \& ex. hauriri dicicur.Imprimis enim impeius, omnes vires, omnemq́; corporis contentionem in. Cumit.

\section{Qvenam propria affe- ctio fit?}

Refp. Vox propria nomen non habet. Al. bertùs dicit: Pantbera tempore libidinis admodum vocalis eft, o ad vocem ejus alis ejusdem. Aut vicinigeneris animalis conveniunt. Qves namautem ifta vox fir, non exprimit. axiomata.

1. Pantberabene olet, fednon nifi beftiis.

Olfactum homines habent minorem, bruta excellentiorem. Nullam in panthera 0. doris fuavitatem invenit homo. Bruta tantam percipiunt, ut alliciancur \& capiantur. Hinc Erafmus fcribit: ui pantbera benèolet, fednon nifibefitis, quas ad fe trabit: ita Srotus P 5 bonis 
234

ZOOLOGIA

bosis ingeniis gravis est, slupidis ifis of bardis guovis aromate gratior.

II. Pardus non mutat maculas fuas. Manent naturalia, mutantur qva veniune ufu \&zarre. Sanc̀ pulchra pardi pellis eft, maculis ornata nigris aut fubalbis. Tenentur hac corporis pulchricu dine cùm bruta, tùm; homines. Et ipfe quoque pardus novit hæe naturalia fua ornamenta. Unde caput torvum abfcondit fxpè, corpus reliquum fpecandum prabet. Contentioaliqvando erat pardo cum vulpe. Pardus contemnebat vul. pem, qvod ipfepellem haberet colorum ma. culis variegarem, vulpes autem fubrufam \& fodam. Vulpes refpondebat, fibi id effe in xnimo, qrod illi in cute. Prefiare ingenium varium, verficalore cure.

\section{CAPUT XIX. \\ De Cane. \\ praceptum.}

Canis eft brutum qvadrupes latrans, fagax, vigilans, ac herofuo miré blandiens.

20effiones.

1. Quodnam canis nutriméntum fit? Voracisfimum animal ê, a \&ecipit qq romu 
PHYSICA.

vomuit. Nutritur osfibus, carnibus, pane \& aliis. Humana eriam cada vera devorat, quin hominem vivum allatrare, lacerare ac devo. rare geftir. Nec inperegrinos tantum $\&$ ho. fpites, hanc fuam exerit ferociam, fed in iplos domefticos; \& è quorum manu fape fumpfite cibum. Memorie prodisum eft, ait Scaliger: of famulos, of beviles liberes, aigh etiam beros ipfos id domefticis canibus laceraros. Neg canis cani amicus esf, fed alter alterum lancinat. Carnem autem caninam non tangunt, quibus. cunque etiacm odoribus ac faporibus trans:formetur.

II. Qvid de magnitudine canis notandurn?

Varieras magna eft. Sunt majores, fune medii, funt minimi. Sicue dantur venarici, villatici,pecuarii. Bodinus ait : Nonpoßsunt ejudem specieiplures fpecies baberi, figuracanrum pluives effe polfust, quales /unt canum in ipfis diverfffirme. Alios enim ad pevationem, alios ad pecudis cufrodiam, alios ad bominum prafrotica fapiens opifox procreavit. Quin ctiam incer venaticos quibusdam tibie brevifime, ac lengiffimascorporatribits funt, ut for arum incime latibula/ubirent, curforibus però longisfimas of ficcisfonias tibiar, alvism friatam, latisfimum. pectur 


\section{ZOOLOGIA}

pedus ad refpirationem faciliorem, of roftrum acutisfinoum ad aiéris fectionew, caudam cateis longiorem, adconverfiones in curfur recipre. co regendas.

\section{III.Qvid de generatione?}

Refp. Libidinofum anumal eft canis, palam in omniuar confpectu colunt. Etiam cum ma. tre, cum fororibus ac liberis congreditur. Nee fua fpecie contentus eft, fed cum lupis, vulpibus $\&$ hominibus mifcetur.Mares de fominis maximè pugnant, ad fangvinem usque. Poß coitum tenaciffsmè cobarent ob officulum in penis mediopofitum, circa quod piritus E bumores aggregantur. In uterogeftant dies fexaginta \& unum, aut duos, aut ad fummum tres. Et nafcuntur oculis \& auribus occlufis, ab imperfecto ad perfectum procedente natura. $\mathrm{Pa}$ riunt uno partu quinqve \& plures.

$$
\text { IV. Quid de fenfu? }
$$

Refp. Sagacisfimus elt canis, \& non iantum veftigia heri â peregrini, fed \&cluporum, aprorum, aliorumqve brutorum â fe invicem dif. cernit. Qvidam etiam coturnices ac perdices fentiunt eminùs, nee difcedunt priùs, quàm aut ielô petita, ant retibus capta fuerit preds Caufa tăte fagacitatis eft netrus odoratûs, major in cane, quàm in bove, eqvo aut alio anìmalt. 
PHYS ICA.

Imali. Vigilantisfimus etiam eft, \& noctur. 30 diurnoqve tempore agit excubias. Cum urem aut beftiam adeffe fentit, indefinenter rociferacur. Cum dormir, formia babet.s Capeg $_{3}$ nemine prefente latrat $\mathcal{E}$ ululat, Salfos deceptus imagine. Valet etiam menoria. Nam per egregia temporum \& 10 :orum fpatia domum repetit, domefticos â cateris difcernit, benefactores amat, hoftes metuit.

V. Quid de appetitu E affectibus? Refp. Iracundum eft animal. Vix cohabitare poffunt duo in vaftisfimis adibus. Neque dominorum amicitia canum parit focietasem. Nibil profeltò, inquitScaliger, eft inbospicalius cane : boc enim penè folus babee, aue cum paucis commune, st nullam cum fuis popun laribus ineat fociecatem. Hinc proverbium: llas domus ron alic duos canes, De invido, qua parem ferre nequit.

\section{Quid de motu?}

Relp. Motus celerrimus eft, leporesque, lus pos, \& reliqqas feras curfu fuperat. In gratiam Domini autem, dato figno oppidò fubliftit Tam reverenter herum fuum habet, ut dimittat pradam ad ipfius nutum. Sunt etiam rebus ludicris dediti, ligna, lapides, a pileos abis. 
235

\section{ZOOLOGIA}

- bjectos reportantes. Ercum incaluiffe fe dicunt Domini, pileum ê capite tollunt. Qvidam macellum petune, carnes emune, $\&$ do. muas reportant. Alii cum alfatur caro, vercunt veru, \&ancillis potiùs, đ̧vàm ventri ac gulx obediunt. Adhibentur qroq; in $\mathrm{Co}$ modiis, \& faltationibus, variisque gefticu. Iarionibus delectant fpectatores.

VII. Quenam canis propria

Refp. Latratus. Lacrare \& allatrare canum et. Propriè idagunt, \& exdebito. Judicio autem pollent, ut hunc filentio pratereant,alium impudenter allatrent. Gellius de Scipione fribit: folum id cemporis in Capicolium ingredientem cancs, femper in alios feviences, neg latrarunt eum, nec incurrerunt.

Axiomaca.

1. Cor canis nibil adver fus lat ratum. Corcanis ajunt, fi qris lecum habuerit . aut etiam comederit, á cane non mordebitnr, asc:allatrabitur. Refellitid Bodinus verbis iftis: Ego, quispois bec sredic, non caninum duntaxat babere cor, fed cotum effe canem credo. 11. Lupinon tranfeunt in canes. Erat hoc Cardani ablurdum, quod Scaliger diluito Ais ê sisuribus lupis, goi june deinceps

gene- 
yenerati, eos poft muleas generationes in canes transire. Neg confiac boc, negis tibi compersum est, negis sapientibus fit verifsmile, nifi illk sanibus commifti fint. Quod fi femper êfws Bocie pregenersent, non futurum. Mitiores gaidem fore : Inpinam formam baud ungoam depofituros.

$$
\begin{aligned}
& \text { CAPUT XX. } \\
& \text { De Vulpe. } \\
& \text { Praceptum. }
\end{aligned}
$$

Vulpes elt brutum qvadrupes, ganniens, callidum, crudele, malitiofum \& gulofum.

\section{2vastiones.}

1. 2vodnam vulpis nutrimentum $\int$ at?

Refp. Animal ferc̀ omnivotum eft. Vefcitus gallinits anatibus, anferibus, muribus, pifci. Bus, uvis , vefpis \& aliis. Raftum egteditue potisfimumnoctu, nec in hominum confpes Atu cibum capit. Gallinas cum invenit, 0mnes jugulat, anteqvam gufture incipiae. Esimum verò amicitiam fimulat, ac fingula sem pietatem. Hinceffigies de valpe in velio. giofo veftitu, gallinis of anferibur consios? misetr.

$$
\text { II gupar }
$$


240 ZOOLOGIA

1I. Quenam magnitudo?

Refp. Quantitas \& figura cani abfimilis non eff. Pilos autem denfos habet, plerumque coloris rufi., Cauda crasfior ac prolisior eft, qva pífcibus, vefpis \& canibus infidiatur. Pi. fcibus cum ftruitinfidias, juxta ripas obertat, caudamqre in aqvas immergit. Pifces famelici caudam arripiunt, pilisque fe involvunt, $\&$ â vulpe trahuntur ac decipiuntur. A vefpis cum vexatur, terre cavernas aut arbores cavas petit, caudâ foris relictâ \& extentâ. Hü Ic vefpa fefeimplicant, ut liberum non facilè habeant egreffum. Vulpes ex antro reverfa, ad parietem, murum aut arborem le convertit, vefpas comprimit ac devorat. Canibus cum urgetur, urinam caudx immittit, hac canum oculos \& ora diverberat. Moleftiz impatientes canes, pedem figunt ac vulpern defe. sunt.

\section{Qvid de generatione?}

Refp. Genitalia habent offea. Pariunt uno partu qvatuor, eosque coecos. Rarò gravida vulpes capitur, cum fe abfcondat mirifice. Foetus etiam in lucem editos occultat, \& 0 . mnibus modis exhominum confpequ tollit. Congreditur etiam cum diverfis fpeciebus. cane, lupo \& aliis. Hinc fpecierum mutationes, \& mira confufio.

IV.Qpid 
PHYSICA.

IV, Quid de fenfor?

R. Vegetum habet fentum, femper parata ad quodvis patrandum. Cumprimisanditum acer rimum habet, ut a qva morum fub glacie percipere qreat. Unde forites de vulpe aures admovente flumini :

Quod frepit movetur. Qvod movetur non eft fixwm. Qvod non eft fixum cedit. Ergo fub. mergar, $\beta$ abacire pergazo.

Quamquam non vulpisfed hominis hxc fit ratiocinatio.

V. ouid de appetitu $\mathcal{E}^{\circ}$ affectibus? 37. Animal neqram \& malitiosè aftutun eft. Omnis ejus caliditas in aliorum perniciem tendit. Catulos fuos amat, aliàs nulli amica eft. Canes deciuit, gallinas trucidat, anates \& anferes perfequitur, nec lepo. resabea tuti. Quanquam canum potiùs præda lepus fit. Hinc canem terreftreun fugiens lepus a rupe repentè in mare pracipitatus, ac â cañe marino morfibus petitus, querula voce dixit:

-.. In me omnis cerrie pelagig̉ rapina est;

Forfican \& cali, fi canis aftratenes.

Vl. Quid de motu vulpis?

Refp. Semper claudicat, qvia cru ra dextr2 breviora funt finifris. Motum tamen ce: Q $\quad$ lerem, 
243 ZOOLOGIA

lerem habet, \& noctulepores continua per. fecutione fatigat. Cum enim curfu prz. venêre lepores vulpem, inftat hac totiesq; illos fedibus exturbat, donec optatam reportet pradam. Et à canibus, cum urgetur, tortuolis utitur ambagibus, miraqve calliditate canes abigit.

VIl, Quenam propria vulpis affectio?

R. Gannitus. Voces aliorum animalium vulpes imitanfur \& latrant cum canibus, llhulant cum lupis, murmurant cum urfis. Propria autem earum vox gannitus eft. Et ut alia nomina â brutis translata in hominem funt, fic gannire qroqve homini tribu. tum eft. De indignante \& occlamante illud dicimus: 2uid gannit ille? Lucretius canes quogre gannire dixit, cum lambunt aut lactant catulos.

Ait casulos blandè cum lingus lambere ten. rane.

Aut ubi cos lactant, pedibus morfug $p$ o. tentes,

Supenfis teneros imitancur dentibus bauffus Longe alio pacto gannitu vocis adulant. Axiomata.

1. Caro vulpina non eft comedenda. -

Ift 
244

\section{ZOOLOGIA \\ CAPUT XXI. \\ De Fele. \\ Praceptum.}

Felis eft brutum qvadrupes, blandum, velox,aftutum, omne genus murium profeqvens.

1. Quodnam felis nutrimentum fit?

R. Nutritur iisdem ferè, qvibus canis. Id habet peculiare qvod avibus \& muribus ftruat infidias. Magna cum voluptatedevorat mures, quos \& nocturno \& diurno venatur tempore. Felem cultu fponfalitio exurnatam in nuptiali die velue fponfam collocat fabula. Ea percurrentem cum fpectat murem, fponfa qvidem erat fed \& felis. Irruens enim in murem, nuptialem neglexit cœnam. Hinc proverbium: $C_{a}$ sus mures saptare non defanis. Pro co, difficile eft murare naturam. Convenit curn iftis: Calism, non animum mutat, quitrans mavecurric. Naturam expellas furca, iamen wós recurret.

II. Qvonam magnitudo?

Refp. Quantitate minor vulpe eft. Capur ha. bet rotundum, oculos iplendentes, pedes ungvibus acusis inftructos, Corpustotum 
dlusûs varios difpofitum maximè eft. ium pendere aligvid, aut trahi, aut àlio 10veri modo cernit, affultat, ore \& ungvi: us captat, nunc refilit, nunc profilit, de. uò rapit, projicit, mirègve gofticulatur. tt cùm quâvis occafione data ludere gefti$t$, propriam fapè caudam capit, dimittit, efumit, itaqve fe gerit, ut pueri \& otiof comines rifus habeant nateriam.

\section{Quid de generatione?}

Libidinofum animal eft, magnoqve clamore coit. Marem magis libidinofúm ticunt, quàm foeminam. Hanc enim fugere iftius confuetudinem ; \& apprehenfam ac compreffam horrendum edere clamo. rem. sed provocat foemina fapè marem, par igitur in utroqve fexu libido. Neqve clamor folius fomellx, fed illi cum mare communiseft. In congreffu verò, fi tacente aut murmu rante mare, epulatum edit foes mina, ex genitalium dolore fit. Pariunt partu uno qvaternos \& plures. Foesus memfe Martio editus probatur, Augufto rejicieur. Sxvit autem in foetum marculus, euma que interimit. Hinc mater follicita toties loca mutat,ut contramaris rabiem charam defondat fobolem.

1V. erid de fenfu?

$$
\text { Q3 Rerg. }
$$


246

\section{ZOOLOGIA}

Refp. Odoratu valet plurimum, muresqve anteqvàm vidit, invadit. In tenebris vide. re dicitur â plerisq; , \& rectiưs, qvàm clara luce. Sed non fufficit ad vifionem oculus fplendidus. Objectum illuftratum fi non fuerit, nulla dabitur vifio. Splendor autem oculorum felium tantus non eft, ut \& medium \& objęta illumina re queat. Ne proprium qvidem corpus fel is illuftrat,nedum aliena atque remota objecta.

V. 2vid de appetitu E' affectibus? R:. Mures appetit atqve odit. Non appetit, ut amer atqve confervet. Etiam cum fatur eft,captat eos ac necat. Etiam qros non devorat, apprehendit \& occidit. Interdum ludit cum nuribus catus, dimittenseos ac denuò captans, fed finito lufu occidit ac devorat.

\section{VI. euid de matu?}

8. Motum habet velocem, \& Icandendo, progrediendo, reptando, faliendogve fe exercet mafculè. Murem cum cernit,toto irruit impetu, gratainque captat pradam. Omnes angulos ædium percurrit, operta apertaqve perluftrans. Ex altifimaturri cum de jicirur, parum admodum capit detrimenti. Volare enim videtur ob pedum, eaudx, ac totius corporis extenfionem.

VII. 2Ua. 


\section{PHYSICA.} VII. Quenampropria felis affectio? Varia felis rox ent, pro vario atfe $A$ u. Ob. cona vox eft, cum libidine turget. Terrioilis ac dira, cum rati de fominis certant. Miferabilis, cum foemina marem adrocat. Mollis \& remiffa, cum liberior ab affectious eft. Germani dicunt : Dic Siakin masnen.

\section{Axiomata.}

I. Feles non ex arbitrio oculos contrabunt ac diftendunt.

Pupillam oculorum ad folis ortum aut occafum feles contrahere \& extendere, exiftimarunt antiqvi. Cardanus arbitrio felium id adfcripfit \& libertati proprix. Scaliger, arbitrium felis nullum efle, pule chris declarat verbis: Ambitiose fcripfifti: felempro arbitrio pupillam contrabere ac dis. cendere. Esfot enim motus voluntarius. Ergo à mufculis. At ibi nullus: quemadmodum in illorum opticorsm difiretione compertum nobis ef. Sed variatio temerè fir, ac fine lege, aut voo luntate , ab affluentia piritum, conne atione, retractione, refolutione, que neutigvam funt in animantis potesiate: Quod O cojudicio manifeftum fiet: grando alcero claufo ocule, alcerius pupilla dilat atur.

$$
24 \quad I I .06=
$$




\section{ZOOLOGIA}

11.Ob felium prefentiam in deligris un animi qvidan incidunt.

Naturale eft diffidium inter grosdam homines \& feles. Prafentibus his, in delis qvium animilli cadunt, \& faltem non exanimantur-Nec vim retrahere poteft cifta cui feles includuntur. Major enimen, qram nt impediri qveat aut doma ri ligno. Ad occultam fugiunt qva Titatem Sanjores cum manifeffarum tanta poteftas non fit. Nos etiam fubjectum iftarum qvalitatum advertendum cenfemus. E corpore enim felis effuvia egrediuntur, qrx qrosdam af ficiunt homines. Fieri potelt, ut gravida fele territa, imprimat foboli naturale cum fele diffidium. Hins ferre neqvit ittius ef Pluvia,gra vim inferunt, qqva uaturam ipfam deftruunt.

\section{Feles amant munditiem.}

Tegunt excrementa frua, \& abf condunt. gvantum poffunt. Non ob odorem, ne prodantur muribus. In libero campo id agunt, ubi nec venantur mures, nec diu perftat odor. Nec ob invidiam, ne homines utantur iis ac fruantur. Livor exiguus eft, qvi monalio nos privat bono, qvam foetido excremento. Caufa eftamormunditiei. Ne 
PHYSICA:

248 fatida ifta materia, xdes, hartos terrasq confpurcet. Sicut ob munditiem, pedes, ventrem , caudam, \& careras partes perpetưò feles lambunt.

\section{CAPUT XXI. \\ De Lepore.}

\section{Praceptum.}

Lepus eft brutum qvadrupes, timidisa fimum, velocisfimum \& focendis imum.

2uaftiones.
1. Qvodnan leporis nutrimentum fit?

8y. Vefcitur brafficâ, malvâ,, atriplice, Iaetucâ,uvis \& aliss. Noctu potiùs gram interdiu cibum capit. Carnesnon petit, nee edit, fed contentus herbis eft. Nierembergitis ait: Carnevora fune digicata, wivipare. onnia,preter leporum gencra.

11. Qvenam magnitudo?

Feli zqualis ferè eft. Caput habet bre: re $\&$ in acuturm definens. Aures longas, 0 culos exporrectos, \& palpebras pracifas. Hinc oculos femper habet apertos, \& $\mathrm{ma}$ gis cum dormit, minus cum vigilat. Cor maximum habet, unde timiditatern naturalem colligunt: Redes funt inxqvales. es poite. 
pofteriorss anterioribus longiores, hinc montem facilius afcendit, quam defcendit. Facilius etiam montem dẹ cendens, qvàm afcendens capitur. In genu pofteriori of ficulum eft, qro ceu bafi inter faliendum lepus nititur. Dicitur talus: Germanicè Derfa afnfprung. Cauda ei brevis eft, cur. fumque auribus potiùs, qqàm caudâ mode. ratur.

III. Qvid de generatione notandum: Refp. Animallibidinofum eft. Coit ac parit tempore quovis, maximè vernô. Et dum fertuterum, luperfoetat. Cum enim peperit catulos, alios in utero habet. Hinc qvo plures capiuntur, eò plures inveniuntur. Partununo parit foetus qvatuor aut quinque.

$$
\text { IV. 2uid de fenfrbus: }
$$

Auditu pollet acutiffimô, \& ad qremlibet frondium frepitum expavefcit. Prx. Ientiensigitur pericula futura, fugit maturè, no pereat. Videre dicitur noctu $\&$ dormire apertis oculis. Hinc proverbium: Lepus dormiens. De co, qvi qrod non facit, id facere fe fimulat : aut qrod facit, id face. re fe diffimulat.

V. Quid de appetitu es affectibus?

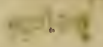


R. Mediænaturæ inter fera \& manfueta animalia eft. Naturâ fuâ timiditatem fumman habet, \& omnium præda fit. Proverbium eft: Mortuoleoni so lepores infultant. Deeo; qvivivens terror omnium erat, mortuus ludibrium omnium. Aut de iis, qvi cum larvis luctantır, cum umbris decertant ac mortuos benè meritos mordent.

\section{Vl. Qviddemotu?}

Refp. Saltat magis, qvàm currit, velociflimè tamen properat. Omnes ejus partes ad celeritatem coinpofitx videntur. Prover: bium eft : cancer leporesn capu. De re abfurda \& impolfibili. Tardus enim cancer, lepus velocilfimus eft. Flexuofo autem curfu utitur, \& unâ eademqve via exit \& redit. VIl. Quanam propria ejus affectio Refp. Vocem acutan \& fonoram habet. Catulicum premuntur manibus, acutifilmum edunt clamorem. Nomine hic non exprimitur, ficut alix res plurimæ ob penuriam rocum.

Axiemata.

I. Efus leporis pulcbritudinem non dat.

Caro frigida \& ficca elt, firccumg; melancholicum gignit. Fruftraigitur funt, qui 
252 ZOOLOGIA

qvi efum animalis hujus, pulchros dare homines, fibi habent perfuafum. Frultra ctiam in fummis habetur deliciis, juxta ilInd Martialis :

Inter aves turdus fi quis mejudice certet:

Inter quadrupedes gloria prima lepus.

11. Lepores nonutrius ǵs unt fexus. Totam fpeciem Hermaphroditis conAtare imperiti qvidam venatores ftatuunt. Sed recentiores Experientia docuit, mares î foeminis fexu effe difcretos. Bodinus ait: Hermaphroditifune quidam,nec tamen omnes, idg â venac ore peris isfino didicimus, cwm es de re dubitaremus. Is entm firmabat, Hermas. phroditos lepores effe plurimos, nec tamenea fecinditate, qua faminas; marem autem nunquam utersm gestare, multo minus fuperfecsare.

III. Malum omen non eft, speregrio "santibus per transwerfum occurrat lepus.

- Fortunam noftram non moderatur lopus, nec curfus leporis, fed Deus, qvi greffus noftros dirigit, fine cujus nutu ne pilus qvidem de capite decidit. Occafionem fuperftitioni dedit, qvod lepus folitudinem amat; loca autem deferta periculofa funt.

CAP. 


\section{PHYSICA. \\ C A P UT XXIII. \\ Dé Cuniculø.}

Praceptum.

Cuniculus eft brutum quadrupes libidinofum, focundum, femiferum, cuniculos fub terra agens.

20estiones.

1. Quodnam cuniculi nutrimen:

tum fit?

R. Nutritur iisdem quibus lepus; braficás malvâ, oleribus, pomis, piris \& a liis fructibus. Pane qvogre delectatur maximè, \&e pugnat acriter de oblato cibo. Noctu potius, qqvàm interdiu, cibum capit. Bibit aqvam, fed fresè dies aliqrot abftinet $\hat{a}$ potu.

\section{Quanam magnitudo?}

Lepore minor eft, partibus autem fermè convenit. Hinc â nonnullis lepufculus vocatur,\& generis leporini efle putatur. Color plerumqve candidus eft,alias etiam fufcus. Ungulas habet divifas \& ruminat. Ue non refpondeat natura ifti Latinorum rero froni : Camelum \& leporem \& cuniculum non comedetis, qvia ruminant, \& ungulain nọn dividunt. Lutherus: Das fols the abes nids 
254 ZOOLOGIA nid̆t effen oas roteberfduet / uno bie Silautn nid)t fpaltet/Das (Sameel/ Der Saafe uno (Saninidicn / bie ba twieberfauen uno bod oif Rlauen ntas fpalten/follen eudis uncein fenn. III Quid de generatione notandum? R. Animal libidinofum eft \& focundum. Parit toto annô, partu uno ternos aut qvaternos. Superfoetat etiam, undèfingulis menfibus catulos alit. Et hac foecunditas adeò fxpè numerum auget, ut $x$ dibus inferant damna. Sub terra enim habitant in cavitatibus atque antris. Fuerunt qui legatos Romam miferunt, aliasque terras ac regiones petierunt, cum ê fuis â cuniculis ejectarentur. Martialis ait:

Gaudet in effo/is babitare cuniculus antris, Monstravie faciles boftibus ille vias. IV. Qvid de fenfibus?

$R \circ f$. Vifu non admoduin valet, fed pius autditt. Et cùm timidum fit animal,ad qvem vis Atrepitum exhorrefcit. Magno igitur coantu fugam capit,ne pereat in periculis. $V$. Quid de appetitu so affectibus? Refp. Semife rum animal eft, cum nec manfvetumnec ferum; fed medix qvodammo. do natura fit. Et natura fua timidus cunieulus eft, fed irritatus pugnat acriter. Tan, 
tầ inter eos fxpè pugnatur vehementiâ, ur dentibus pellem dilacerent, \& ad tempus bene longum pugnare continuent. Mares etiam in liberos crudeles funt, ac fatum vix. calicum enccant:

\section{V1. Quid de motu? ds}

Motum velocemhabce: fed velociorem lepus. Recta verò ire viâ non amat, fed fle. xuofo utitur curfi. Pedibus pofterioribus terram pulfat,atq; fonum ingratum excitat. Vil. Qusnampropria affectio. it Vocem acutam habet ac tenuem. Murnurat etiam quandoqve, cum panem oblatum retrahimus, aut cum marculus fae: mellam infeqvens illuditur.

\section{eAxiomata.}

1. Cuniculus animal femiferum eft.

Nec manfvetum, nec ferum, fed medix qvodammodò naturz eft. Manê \& vefperi egreditur ex antro, reliqro tempore $\mathrm{fe}$. rè latet. Et licet inhabitet ades, non tamen mantvefcit adeò, ut tangi \& portari temerê posfit absque offenfa.

1. Cuniculus animal fecundum eft.

Parit anteqvam ablolvat primnm atatis. annum. Et parit ternos ac quaternos. Stsporfatat etiam non fecus aclepus. Hinc fingulis 
258

ZOOLOCIA

fingulis fxpè menfibus catulos alit. Qux frecunditas adeò replet ædes, ut maxim 3 iis inferant damna.

III. Lepus EO cuniculus pecie dif-
ferunt.

Habent enim diverfas actiones, diverfasqve operationes. Non corpore tantùm minor lepore eft cuniculus, fed \& robuftior atqve audacior eft. Cuniculos etiam 2gere,nunqvam vifus eft lepus . qrod tanta promptitudine preftat cuniculus, ut inde nomen tulerit. Curfu qvoqve cuniculus lepore tardior eft, non tantum pedibus, qrantum animô valens.

CAPUT XXIV.

$D E$

Mele feu Taxo.

pracopium.

Melis eit brutum qvadrupes, fomnicus - Jofum, obefum, cavernas amans \& lucem fugiens.

2vaftiones.

1. Qrodnam melis nutrimen-

tum fit?

Ref́p. Vefcitur melle, radicibirs, frugibus, divis.oomis, piris, caterisgre fiuctibus. $A$ dr.t. mat 
258

\section{ZOOLOEIA}

Id verò cumprimis notatu dighum elt, qvod parentes xtatefeffos nutriat. Placent verba Nierembergii: De eruditione $\checkmark$ exemplo bruso. rum ad omners nos inftit wentium frugem, cegimus noefermel, patse a adjicere liceat. Parentes, fuos atate grande's natrisunt Elephaniti, glives, leones, rupicapre Es alie capre fyldestres, raxi,ciconice. VI. Quid de motu?

Refp.Pigrum animal eft, frequentius dormiensacquiefcens; qvàm femovens. Neque etiam longè s cubili ac caverna difeedit, fed in vicinia fe continet. Imprimis nodu ê caverna egreditur, ubi omnia turò cernit.

V11. Quanam propria affectio it? vocem acutam habet. Fortia animalia plerumqve gravemedine vocem, ut leo, bot. Timidis rox acuta elt, ut lepori, cuniculo, meli.

\section{Axiomata.}

1. Luna crefcente augetur taxi adeps, decrefcente minuitur.

Hacea luna humorum Domina poteftas eft. Auget \& minuit humores, cum augecur a minuituripfa. Latius crefcunt pili noftri, crefcente lunâ refecti tardiùs decrefcente. Cerebrum animalium ad luna augmenta \&

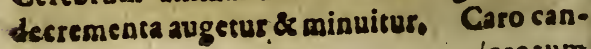

(crosuma 
A PHYSICA.

259

crocum \&oftrearum fucci plena eft plenâ luâ.. Verres, hados, \&́ eqvos decref cente lun: aftrariconvenit, non crefcente.

1. Meli disfidiun naturale cum vul. pe eft.

Bella gerit aflidua cumvulpe. Vulpes vecum robore taxum fuperare nequeat, ad raudes \& dolos fe vertit. Urina \& Atercore uveam melis polluit, Fotoris hujus impaiens melis ef. Migrat igitur, aliasqre fedes jvaritat. Ingreditur tunc vulpes, actriume hans Specum occupat.

\section{CAPUT XXV.}

\section{De Glire.}

Praceptsm.

Glis eff brutum quadrupes, fomno. lenturn, validum, mordax, yorax, gallinis infeftum.

\section{Questiones.}

- Qvodnam isutrimentum gliris fit? efp. Vefcicur fructibus arborum, fed maximè ppetic oya atque gallinas. Has undique convirit, inventasqqve trucidát. Occisâ unâ, non evorat ftation pradam qvam naclus eft, fed nqvirit altiùs. Qvotqvocreperit, jugulatac scondir. Nulla demum fuportite, devora-

R 2

88 


\section{ZOOLOOIA}

re incipit ac replere ventrem. Dominis pro. priis non facile ova ac gallinas furripit, fed tum, ubi neceffitas urget. Cátulos cum álit maxima inferre folet damna.

\section{Quenam magnitudo:}

Refp. Magnitudinem felis habet, membra va. iida, colorem varium. Dentes funt exerti 4 acuti, quibus ora capit. Foramina duo in. renimus in ovis acutis dentibus facta. Capui etiam gallinatum dentibus iftis perforat, \& fubitò easdem necat.

III. Qvanamgeneratio?

Refp.Fæcundum animal elt , \& partu uno plu. res edit. Parvo tempore adeò fe multiplicat, ut pagos totos \& tota oppida repleat. Capi. tur autem non difficulter admodum, fi colum. ba aut pullus gallinaceus inferatur decipula IV. Qvid de fenfibus notandum: Refp. Odoratu pracellit, qvo gallinas lacen. ses inveftigat. Dormire dicitur tota hyeme, necullum tunc eapere cibum. Hinc verfur eft:

Tota mibi dormitur byems, of pingeior illo Tempore fum, gDo me nil nifi fornnus alis. Sed \& hîc â necellario ad nimium progiese fifunt ausores, Confpiciuntur eaim hyber 
30 qroqve tempore in horreis, ova \& gallinas jvarentes.

V. 2uid de appetitu E affectibus? Refp. Semiferum animal eft, habitans partim in fylvis, partim in adibus, \& crudele eft, inexplebili aviditate fitiens fangvinem gallivarum. Foveas facit profundas, qvas réplet poliis , we terrâ, foliis \& lignis operit.

\section{Quid de neotu?}

Refp. Motum habetmediocrem \& felis inftar arbores \& parietes fcandit. Sxpè fciurorum.

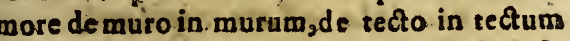
Caltat. Nee periculum gravioris lapfus eft, cùm expanfo corpore rem agat, felium moribus affumptis.

V1l. Quenam propria affectio? Vocem hobet acutam. Clamante uno; concurrubt reliø̨vi,\& clamore amicum teftan tur confenfum. Hinc proverbium: consurrune feut glires. De iis, qgi conjuntis viribaraligrideractant.

\section{Axiomata.}

1. Glires non moriantur Eirevivifunt.

Glires hyberno tempore inventos nulli iatibus, nullisque vulneribus moveri dicunt, R 3 Revi- 
262

Revivifcere autem redeunte vere ac fole, noo fecus ac homines nonnulli qrondam obdor: miverint, alii annos fexaginca, alii trecentos, acpofteà revixerint. Et fidem \& veritatem hac fuperant. A privatione cotali, quais mors eft, ad babirum of ditam, nan datur regreffiu naturaliter. Alias verò â negatione actusfe. cundi ad negationem actus primi argumenta. si nonlicet. Non neganda vita ipla, ubi non patent virales actiones.

II. Glires nec tota byeme dormiunt, nec tota aftate vigilant. Labor affiduus frangit vires: \& quies nimia polluit perditqve vigorem. Non eft durabia le quod alterna caret requie:

Occidet,ad circifi quis cert amina femper

Non intermis fis curfibus ibit equus.

Firma fit illa licet, folvetur in equore navis,

- Que sunquam liquidis ficce carebit aquis. Me quog̀d debilitat feries immen a laborum, Ante meum tempus cogit \& cffe Jenem.' Otia corpus alunt, animus quoǵ́ pafcitur illis Immodicus contra carpic utrumg labor, CAPUT XXVI. De Erinaceo. Preceptum.

Erinaceus eft brutum qvadrupes, pelle acule. 
PHYSICA:

aculeata veftitum, malignza aftu: tum.

\section{Qvafiones. \\ I. Qvodriam nutrimentum}

\section{Erinaceifit?}

Relp. Porna, pira, uva , \& fructus alii. Hinc arbores áfcendit,poma ac pira decurit, in iftis fefe volutat, ut fpinishereant. Poft ad iter fefe accingit \& ad cavas arbores, in quibus habitat, properat. Romum unum fi decidit, mox omnia abjicit, \& ad arborem redit, novum que cibum requirit.

11.2uenam magnitsdo?

Refp. Parvumanimal eft inftar porcelli, Ger manicè Sau Jgel. Roftrum habet porcino roftro fimile. I fúm corpus aculeis vallatum eft, ut apprehendi neqveas. Hinc infidias fibi feri cum rentit, in formam pila convolvitur, ut tractari nequeat. Undelocutio proverbialis: Totus echinus a per. De homine intra-

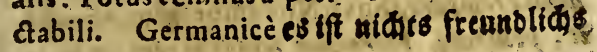
an ifm.

\section{Quenam generatio?}

2. Ernacei hominum modo fe complexi coëunt. Et cum partus inftat tempus; fomi nam contrahere alvum dicunt, néfpinis lasdatur. Deriorem aurem poftmodum \& $\mathrm{R}_{4}$ alpe. 
264

ZOOLOGIA:

afperiorem fotum, majores inferre cpuciatus: Hinc proverbium: Ecbinus partum differt. De iis qvi in perniciem fuam nectunt moras. Sed profectò res camoram non patitur. Et fecundinâ tegitur echinus, ut uterum lad'ere neqveat. Etiam inclufus utero molliores habet $\int_{p i}$ nas, unde nihil metuendum mali.

IV. Qvid de fenfu notandum?

Refp. Prælcire tempeltates dicitur, adeò ut pluvia imminente petat cubile. Nierember. give ait: Qpam Sagacitatem demir abimur brucorum, fi prefagie damus. Erinacei mutationem Aqvilonis in Auftrum contendentes in cus bile prefagiunt.

V. civid de appetitu 6 affectibus? Refp. Malignè altutus eft, \& una fallacia in omnibus periculis triumphat. Timidum alias animal, fed fpinofum eft. Spinis igitur contra quemvis holtem fe defendit, Spinis etIam alimenta acquirit \& reporta t, Ecbinus vir.. demic tempore, inquitNierembergius, vites/ub. it, pedibusgly botroram acinos in terram deak. tit, quos ibidem volutatus undiǵs Pinis confsxos excipit.

$$
\text { VI. Quid de motu? }
$$

Refp. Motum habet mediocrem. Arbores afsendit, \& pira ac poma decutit. Homi. 


\section{PHYSICA.}

sem accedentem cum cernit, fugit, De fuga cum defperat, inglobum fe volvit, ne appre: hendatur. Interdum urinam emittit ex me.tu.. Sicut timor plerumg animalia ad excrementorum eniffionem fimulat.

\section{Qvanam propria affectio?}

Refp. Vocem acutam tribuunt Erinaceo \& propriam eam faciunt animalium simida: rum. Qvanquă canis timidus mon fit, lices acutam vocem habeat. Plerumqve igitur contingit, non perpetuò.

\section{Axiomata.}

I. Erinaceus intradabilis eft.

Propter aculeos enim tractari \& apprehendi neqvir.D. Frantzius ait : notiffrmum boc eft ani: mal pinis acutisfimis obficum, inde impina non potef apprebendi, or redtè eft imagointrata bilis ruftici, vel fopbift e finofi, cum qpo nemo potest'converfari fine lite.

11. Facilius eft Erinaceum capere,

\section{quam tessere.}

Simplex eft Erinaceus, unde facilis captu; Aculeis antem cum praditus fit, undigre impunè teneri negvit. Hinc Ellianus fcri-

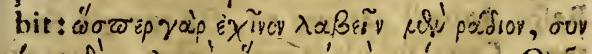

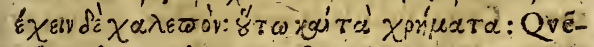
admodum echinum, fic etiam numos capos Rs

res 
266 ZOOLOGIA

re, facile eft,tenere verò difficile. Germanicèz wiecin Igel nohl zubefommen / aber nidht woh̨lzukgalten ift/alfo aud\% oas Belo.

\section{CAPUT XXVII. \\ De Sciuro.}

Preceptum.

Sciurus eft brutum quadrupes, prudens, folers, velox \& fomniculo. fum.

\section{0eftiones. \\ 1. Qvodnam fciurinutrimen. \\ tum fit?}

Refp. Nutritur glandibus, nucibus, pomis , piris \&aliis fructibusac frugibus. Imprimis delectatur fuavioribus cibis, Saccharo \& amygdalis dulcibus. Accum cicurari facile queat, hominem fpontè accedit, à pedibus ad caput afcendit, in faceulo nuces, amyg. dalas, panem \& alia qvartt. In fylvis degens, cibum aftate congerit,quo per hyemem victitet.

\section{Quanam magnitudo?}

Refp. Animal parvum eft, fed egregix forma. Caput fubtile $\&$ breve habet, dentes a* eutos, quibus acerrimè mandet. Auricu: Ix funt 
Ix funt rotunda, cauda villofa \& longa ad reliqui corporis magnitudinem. Hxc non ornamento tantum illi eft, fed \& varios habec ufus. Cum movetur, eă fe gubernat. Cùm pulicibus ac mufcis vexatur, ea le defentic. Cùm calore aftivo uritur, eâ fuper dorfum re: pofitâ,calorem frangit. Cùm tranfit aquam, câ provelo uticur. pili plerumqve funt ruffi, interdum nigri, rarò albi. Pedibus anterioribus cibum capit, orique admovet : pofterio. ribue verò infidet.

III. Quenam generatio?

Refp. Genitale maris ofteum eft. Edunt partu uno plures \& coêunt tempore verno. Nie. rembergius ait : coêunt of pariunt quovis tem. pore lepores 6 cuniculi. Quadrupedum pre. gnantes Venerem arcent prater equam of fuem. Ariftoteles de muliere of equa folis animalium id affirmat. Vere coền lacerti, clephanti, equi, glires, fciurus, canis. Menfe feprembri Cameli: Hyem is initio unfs, apri. Lupitoto anno non coëunt dies amplius duodecim:/ues agreftes femel quocannis coëunt, domeftici Sepè.

IV. Quid de fenfibus not andum? Refp. Prafentit rempeftates, ac nidum qvà Spiraturus eft ventus obturat, aliaqve in parte foramen format. Somno maximè indulget, 8 
268

\section{ZOOLOGIA}

\& non hyberno tantum, fed altivo qroqve cempore totos dormit dies. Memoriam egrea giam habet, foveasque; qribus nuces injecit, poft menfes aliquot fine errore repetit.

$V$. Quid de appetitu EO affectibus? Refp. Appetitum moderatum habet. Non affamir plus cibi,qvàm reqvirit natura. Satur, licet verberibus adigatur, nihil comedic amplius. Sedqva offeruntur accipit acre. condit. Optimum agit patremfamilias, qvemmediocris victus \& accurata reliquia: rum cuftodia decet maximè. Timidum alias animal ef, \& horret canes, magnoque clamo. refugit infectantes.

\section{Quid de motw:}

Refp. Plurimum motu valet. Et de ramo in ramum, de arbore in arborem falsitat. Flisvium trajiciens affere vel cortice pro navi utitur, \& cauda pro velo. Ridiculis etiam geftibus homines delectatmirificè. Sxè lafciva \& hiftrionica faltatione, rifum fpectantibus of: fert. "Non rarò fupinus alludit : heri menue prehendit, eas leniter dentibus detinet, mox dimittit, iterum arripit, projicit,recipit.Cumqve denegatur manus murmure fubmiffo eam infeqvitur, ludnmqre continuare geftit.

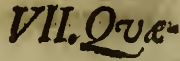


PHYSICA.

VII. Quenam propria affectio fit? Refp. Vox acuta eft. Canem sum cernit, fuga fibi confulit, \& voce acuta, pedumq́ve ftrepitu,teftatur affectum. Murmurat qvandog; , cum oblatz nuces retrahuntur, aus negantus autrimenta.

\section{Axiomata.}

1. Sciarus amat munditient.

Animal jucundum eft, formamqve amat \& puritatem. Lambirfe perpetuò, comit fe, \& quàm maximè poteft exornat. Singulis anais depilatur, fermeque calvefcit, Sed mox pulchrioribus pilis de novo veftitur, acpriftinum corporis decus recuperar. Hinclatatue admodum, nihilque agit magis, qvam ut pilorum æqvabilitati corporisq; puritati fudeat. 11. Sciurus non dormit tota byeme:

Deglire qrod ajunt,etiam Sciuro tribuunt. Qvanqqam fciurum non femper dormire, fed hyeme quoque cibum capere ftatuat Bodinus. Nobis nec glires, nee feiuri tota dormiunt hy me. Nec enim ratio id fuadet, nec confirmat experientia. Bodinúsait. Pleragis animan= tia cota byeme delitefcunt, ut murium ac muste. laram genera, erinscei, calpa, wr fi, taxi, ferpen. tes, birundines, glives, gea fine cibo ac potsu bye-

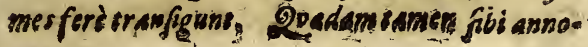

sam 
270

\section{ZOOLOGIA}

namparant, cujus ope byense in latibulis vefcamour , fcilicet cuculi, apes, formica, velpe, foiurio.

Glires tamen ex omnibus cibo vacui ac fopore je. pulti byeme reperiuntur.

\section{CAPUT XXVIII. \\ De Muftela.}

Preceptum.

Muftela eft brutum quadrupes, folers, tinidum, callidum, malignè afturü. Qpafiones.

I. Qoodnam muftele nutrimentum fit?

Refo. Venatur nuures, cosdemque devorat. Plures capere dicitur, qvàm felis, eosdem. qve majores ac minores. Nec talpis parcit, led aggreditureas \& occidit. Aviculis infuperinfidiatur, quas captat ac comedit. Ova quogreforbet, \&pullos gallinaceos aufert.

I1. Quenam magnitudo?

Refp. Animal parvum eft, ted formolum. Caput breve habet \& dentes acutos. Aures funt rotunda,cauda pilofa \& longa. In dorfo \& lateribus plernmó, fnntrutil $x$, in vétre candidx. Pelles in veftimentorum ufum veniunt;

111.2vanam generatio?

Genitale maris offeum eft. Edunt partu uno. plares 
plures \& coẻunt tempore verno. Aure concipere, \& ore parere dicuntur. Nierembergius fcribic: Muffelam ore parere fabalantur. Fabulantur certe. Neg enim ventriculus gestations; apsus, nec aur is conceptioni.

\section{Quenam Jenfatio?}

Refp. Domem ruituram fentit \& paulo ante migrar. Dormit plurimum, hyberno maximè tempore. Imò rotẩ hyeme dormire dicí: tut, more glirium.

\section{V.2vinam affectus?}

Refp. Amat fotum, qvem maturè quidê emittit, fed rurfum in periculis intrafe recipit.Ado verfatur fuibus, cornicibus \& ferpentibus. ExiStimani Â naturâ datum effe animalculwm boc,ut posgnet cum B afilifro. Aliàs timidum animal eft, \& ad quemvis arborum ftrepirum exhor: refcit.

\section{VI.Qualis motus?}

Refp. Velox eft muftela, \&xpradam,gram fecit, citisfimè aufert. Corpus admodum fle: xile habet, \& ad furta clandeltina aptisfimum. Mutat loca fubinde, ut cubile reperire difficile fit. Vifa dicicur muftels continuatis faltibus furium sranfiißse, fine fubmerfonis periculo. 
272 ZOOLOGIA

\section{Quenam affectio?}

Refp. Vox acuta elt. A fono nomen feciffe

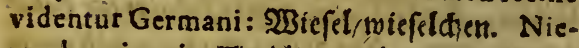
rembergius ait: Timidis pox plerumg's acuta, ut lepori, murium generi, mustelis, canibus.

Axiomata.

1. Muftela novit rutam.

Difcernunt bruta inter bona \& mala, intep noxia \& falutariz. Canes inter amicos \& inimicos. Leointer magranimos \& humiles. Mußta inter rutam \& allium. Prius. quàm ineat muftela pugnam cum ferpente, rutam edit, cujus odor ferpenti inimicus eft. Ad hominum fermè accedit judicium, quipefis tempore rutâutuntur. Prodeft enim cum butyro, cum jufulis, cum aliv cibis fumpta. Etiam vinum per rutam deco. latum ac potum, contra venena porrigitur u. tiliter.

11. Muftela malignè aftuta est.

Nierembergius feribıt: malignè aftuta funn, gre funt angustis oculis vel pupilits, at inufiele; iebreumor, cati, fimie, vulpes, stellio, lutra, cro. cocilus, mures, lupi, lynces, castor, ur/s, erinacei, bycna, cbamaleon. Hac omnia funt etiam mordacia : Simplicia \& ftolida bos, alce, cer puropic, afinus, fus:

\section{GAPVT}


PHYSICA.

CAPUT XXIX.

DeViverra.

praceptum.

Viverra eft brutum quadrupes, vorax, mordax, terra cavernas amans.

Qpestiones.

I. Quodnam viverre nutrimentum fit?

Rế. Vef́citur hordeô, triticô, avenâ, \& cæxteris frumentis. D. Frantzius ait : Alio nomine dicicur fur jenfursunculus, guita plursma forratur E comportat in fuos specus fine fine, vel. innumera grana pro byeme, E. illa quidem emnia pura fine paleis: ita ut Sepé dimidius modius in uno antro unius viverre reperiatur, adro ut red è fit diEf a viverra, qDafi pi omwia ad fe perrens, cin STamfter.

11. Qvenam magnitudo?

parvumanimal eft. Caput habet exiguum, ventrem folidum, pedes breves \& craffos. Cutis color fubrufus eft, cui pili pertinaciter hrent, ut cutis laceretur priùs, qvàm extrahatur pilus.

111. Quanam generatio?

Refp. Geftant in utero quadra ginta dies \& pariunt partu uno plufes. Nierembergius S

ait: 
274

\section{ZOOLOGIA}

ait: multifida of parda ejusdem generis mults pariunt:ut canes, feles, oves, lepores, lupi, Diverre, rygres, leones, liutra. Supra cuncta murium fas tus: ex uno genitos cencam viginti, tradiderant Arif̧oteles \& Plinius.

IV. Quxnam fenfatio ?

Refp. Senfum habetdebilerin. Nec vifu, ilec auditu, nec alio fenfu celebris eft. Avaritia claram fecit viverram, quâ primas senet inter pèffima animalia.

$V$. Qvinam affectus?

Refp. Amat fotum, cui grana colligit \&s probe profpicit. Caterum timidum animaleft, \& fugit lucem; vitamgrc in craffo \& obfcuro loco degit. Odit cuniculos, qros venatur \& ex cavernis propulfat.

\section{V1. Qualis motus?}

kv. Tardiorem habet motum. Neque faltu valet admodum; qyanqvam lacesfita impetum facere in hoftem conatur.

VII. Quenam affectio?

Vox ei acuta. Cum interficitur, voce clara finit vitam.

Axiomata.

1. Viverra nimia eft in acquirendo ac retinendo...

Vorago 
PHYSICA.

Vorago avidifima eft, nunqram expletur, nunqvam fatiatur. Et quæ acquifivit, libi fervat, ipfam qroque fominam ab efu arcens. Avaros imitatur, quife ipfos rerum fuarum Dominos ac haredes arbitrantur.

11. Viverra famina mare dolofior.

Mas fœminx negat cibum.Hxc clam aliud fingit foramen,aditumqve fibiad cibum parat. Qvanto tenacior ille, tanto hæc voracior ac liberalior eft.

111. Viverra domi audax, foris timida.

Decuplo major cuniculus viverrâ eft. SEvit in iftum hxc, aggreditur in antro, lacerat \& necat. Extra cavernam aggredi non audet.Sicut gallus in fterqvilinio poteft plu. rimum.

\section{CAPUT XXX. De Lacerta.}

Praceptum.

Lacerta eft animal quadrupes, folers, velox, venenofum, homini amicum. Qvaftiones.

1. Qvodnam nutrinentum? Refp. Ad omnivora animalia refertur. PaPta herbarum vivit, nec carnes refpuis. Vermiculis, muribus \& talpis vefcitur.

ops. 
276

\section{ZOOLOGIA \\ II. Quenam magnitudo?}

b. Corpus parvum eft, flavi \& viridiscolo. ris, variis infignitum puntis. Caput exiguùm, cauda ejusdem longitudinis cum corpore reliqvo. Lingvâ bifidâ, \& ore aper. to infpirat aerrem. Pedes proportione minio mi,cruraque brevifima funt.

111. Quanam generatio?

Refp. Lacertxhumano more re comple: ctuntur \& coëunt. Coëunt autem vere, \& pariunt ova. InAnglia nuilas generarilacerrasfcribunt.

IV. Qvenam fenfatio?

Refp. Tota penè hyeme dormire dicitur. Vere verò profilit \& æftate le exercet:luditque in confpectu hominum.

\section{Quinam affectus?}

Refp. Serpentes hoftes habent, \& rubetas, \& cochleàs. Hominem amant valdè, \& vifo eoprofiliunt, ludunt, blandiuntur. Venen 6 autem cùm conftent, non merentur aroorem mutuum.

\section{Qvalis motus}

Refp. Velox animal eft, \& cum infertatur, fugá fibi confulitmaturè. Corpushabet flea xile, \& varijs gefticulationibus fuum erga homines teftatur affectum. Caudam agitae crebro, \& motu illo homini blanditur.

VII.QDe- 
VII. evienam affectio?

Refp. Sibilum edit, nec major ei clamor a Qvamvis diffecetur in partes, non dat ejulatum. Diffe tra autem partes, vivunt $\&$ denuò coètunt.

\section{Axiomata.}

I. Lacerte fimilis eft Salamandra. Animal venenatum eft, nigri \& flavicoloris. Caudam habet prolixam \& flexurofan, cutim afperam, pedes acutos. Stellulas in dorfo habet, feu lucida qvadam puncta. I. gneæ dicitur naturx, adeò ut vivere atqve fupereffe queat in flamma. Sed penetrat natura ignis, viventium corpora diffipatac deftruit. Placet fententia Galeni ac Diofco. ridis : Salamandra non diu vivic in igne, fed $d$ majoriftamno uritur ac confumiaur.

II. Lacerta familis est cbamaleon. Habitatin Africa \& India, \& figuram la. certx habet, fubitque cavernas. Non alio qvàm aëris elenento vivif juxtaplinium. A. lii chamaleontein rore\& mufcis ali fcribunt. Proprium ejus eft, ex metu varios aflumere coloresiserinper eum reddere dicitur,quem proxime attingit, preter rubrum $\&$ candidum. Hinc varum hominem chamæleonte mutabitioren dicimus. Sed ģvemadmodum $\mathrm{S}_{3}$

aliàs 
278

\section{ZOOLOGIA}

aliàs affectus mutant colores; fic idem cha. mæleonti contingit maximè ob corpori fubtiiitatem.

\section{Lacerte fimilis est Stellio.}

In Italia \& Thracia nafcitur ftellio. Habe in tergo guttas lucentes inftar ftellarum Vefcitur araneis \& rore, fed libentius melle Odio habet fcorpionem, cujus ferre neqvir confpectum. Cutim exuit, qrx reftituitur, perindè ac in ferpentibus.

\section{Lacert a fimilis eft crocodilus.}

Nafcitur in . Egypto \& India,ac eft ovipa rus. Habet pedes quatuor, dentes validos 2 exfectos, lingram immobilem, totamque adhxrentem. Duriflimam cutem in dorfo habet, in ventre molliflimam. Die in terra, noctu in aqva degit: hyeme totâ dormire dicitur. Indicus immanior \& crudelior eft. Integrum hominem cum veftibus devorare eum feribunt, \& hoc acto profundere la chrymas. Nullum animal ê tam parvo initio in tantam vaftitatem excrefcit. Parit enim ova, paulò majora an!erinis, \& excrefcit in longitudinem feptendecim aut etian viginti ulna rum. Proverbium eft: Crocodili lacbryme. Do is qvi fimulant graviter fe affici incommodisalterius, grrepfi attule. sunt.

CAP. 


\section{- De Rana. \\ Preceptum.}

Ranz elt brutum quadrupes, coaxans, in jucundum, \& invalidum.

\section{Qveftiones.}

I. Quodnam rance nutrimentum? ReIp. Herbas \& flores.comedit. Etiam carnes 8 mortuas tal pas devorat. Necab avena, hordeo,pomis, piris \&cxteris abttinet.

II. Quenammágnitudo?

Reíp. Parvum animal eft, led foemina major mare. Oculi funt pellucidi, pectus latum.Pedes quatuor habet \& pofteriores prioribus longiores funt. Caret vefica, nullamque redditurinam. Irritatæ ejaculantur humorem: noxium, quodcum agunt, mejere dicuntue vulgò. Sed ê clunibus non ê vefica iftum hus morem expelluat.

111. Quenam generatio?

Refp. Congrediuntur rana \& femina mifcent. Semen hoc Germanis dicitur Frofdigeffecte / frofd̆ragen. Mutatur autem in ova, ê quibus ranula parva fiunt, rotund $x$, nigra, oculis tantum \& capite infignes. D. Frantzius ait: Quandog $g_{3}$ femen pel ova ranarum ab incautis of imprudentibus una cumporu imbibuntur, wade $S_{4}$ 


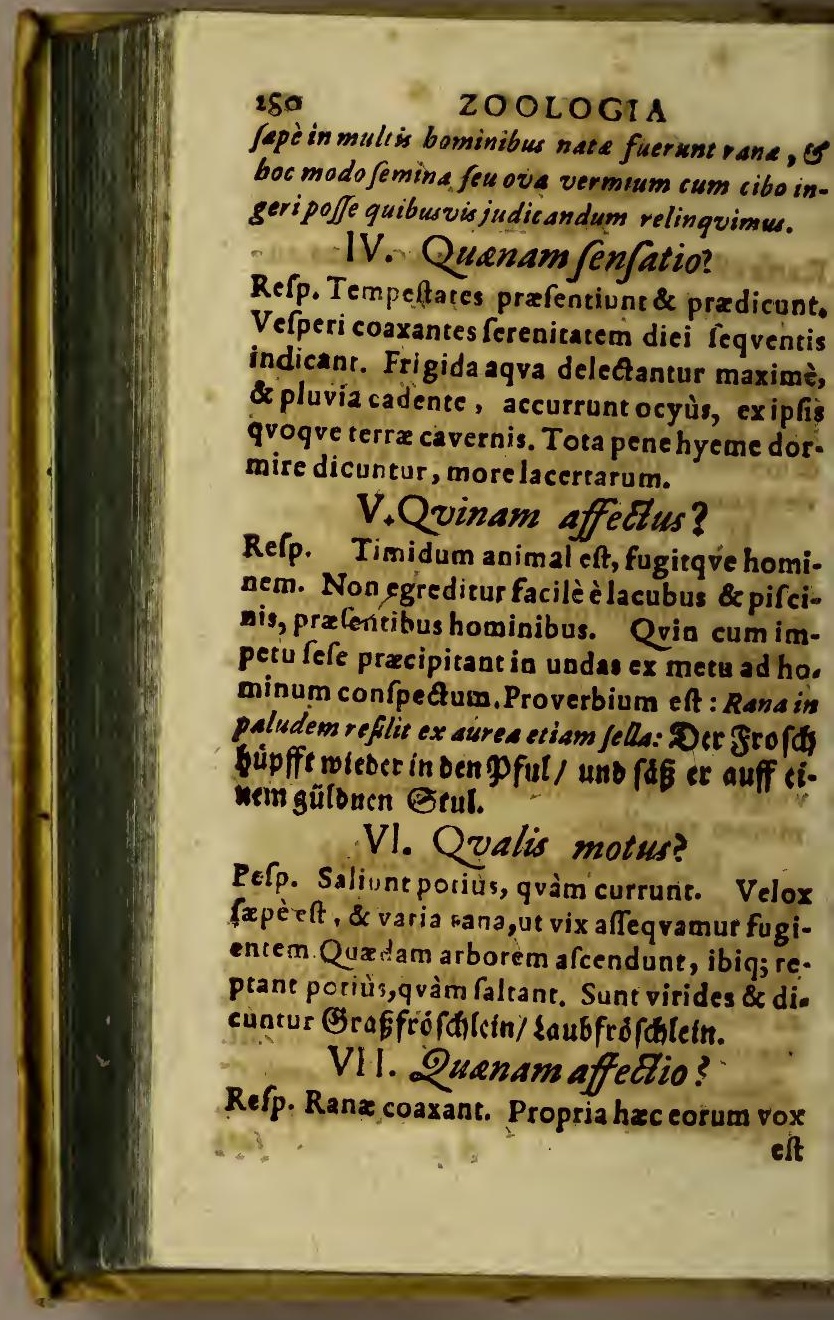


eft, quã omnibus moleftæ funt. Ululare etiam dicuntur mares, cum ad generationem foc: minas vocant. Ranas in Cyrenaicâ planè mutas effe fcribit Ariftoteles. Plinius contra ex accidente id fieri ftatuit. Qvodmuta fint es, inguit, in cauf a oft aqvarum natura of nimiam bumiditatem. Undefi quis transferat boc animal, loqvax 8 atim fecerit, \& ad propriam nath: ram reduxerit, quafaliberatum Girces vinculis. Axiomata.

1. Rana nec ex limo, nec ex luto, nec ex aqva, nec exputredine fit.

Non ex quolibet fit quodlibet, fed ex certó certum. Animatum ab animato vegetans â regetante, fentiens â fenciente, rationale â rationali eft. Simile fimile gignit, diffimile o. situr â diflimili.

\section{Rane fmilis eft rubeta.}

In hortis \& agris inter frutices reperitur pu. beta. Germanicè eine R̂dote. Foctum animal eft, dorfum habet gibbolum, eminentibus uerinquead latera officulis. Mogna ex parte circa noctem progreditur. Congreffum etiam nodturno agit tcmpore. Generaturex ovis. Germanicè Sirótengelfede. Mifcentur etiam cum ranis, \& cum venenat fint, foetus noxius acvenenatus otitur. Non vefciturterra, fed $S_{5}$ herbir, 


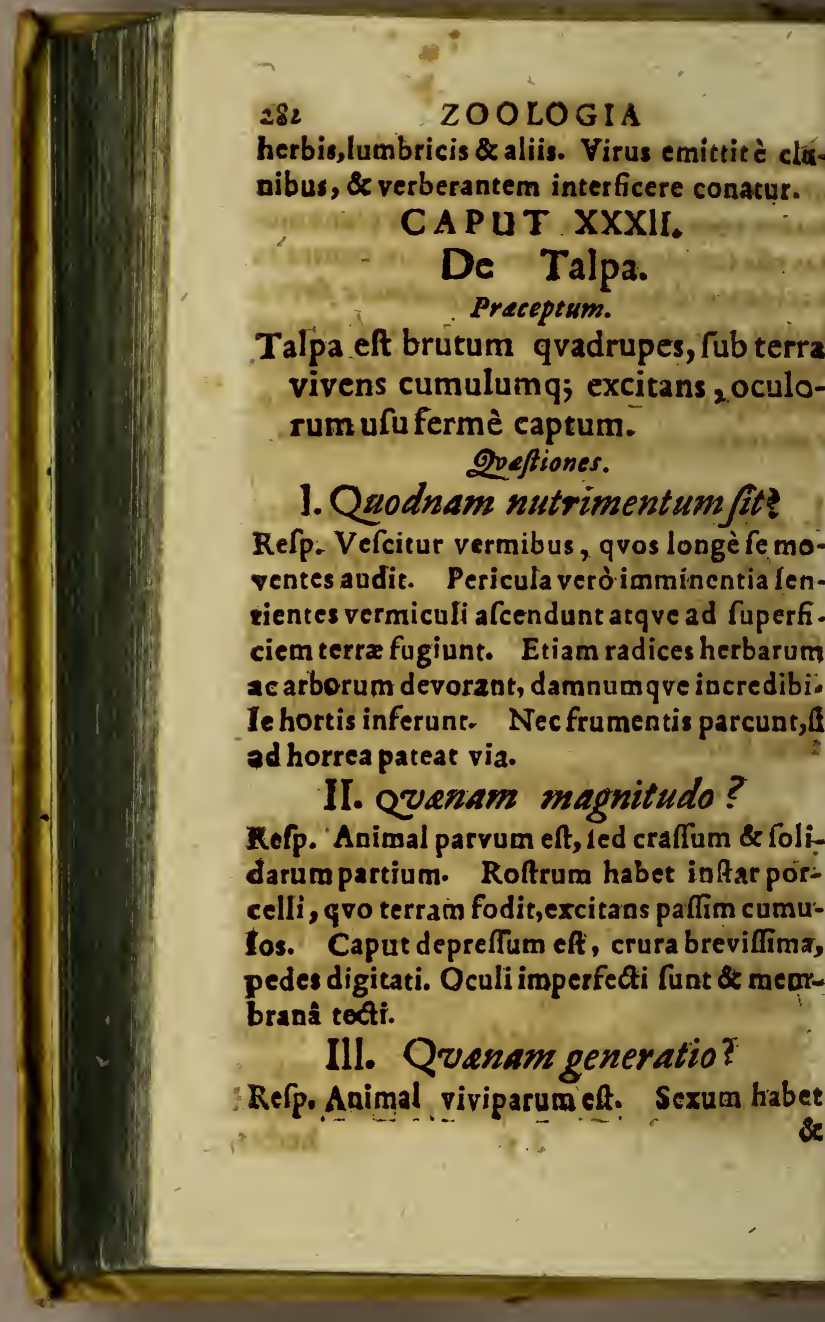




\section{$\triangle$ PHYSICA.}

\& congreditur fub terra. Falfum eft qqood dicunt : talpam è terrâ pluviis madidà \& putre. factâgenerari. Nec animam dat terra, nec corpus.

\section{IV:Quenam fenfatio?}

Refp. Auribus carere dicunt tal pam; \& auditum habere praftántifimum. Explicanda hac funt, ne unum evertat alterum. Non eft tanta auditús praftantia in talpa, ob aures quafi refectas, Audit liqvidiùs fub terra, non ratione organi, fed medii. Habitat in terrâ excavatâ, ubi colligitur fonus, collectusq; ad internas transmittitur aures.

\section{Quid de affectibus?}

Refp. Timidumanimal elt. Fugit lucem,amat tenebras. Semper in obfcurodegit loco, \& cum egreditur, qvod potifimum meafe jus niojfit, facile capitur.

\section{2uid de motu?}

Refp. In terra cum habitat, parum movetur. Quieti magis; qvàm mocui indulget. Egreffa ex antro, tardior eft, nifi ex metu fugâ fibi confulat.

\section{Qvenam affectio?}

Refp. Vocem edit acutam, prafertim cum verberatur.Proverbium eft: Talpa logvax. De co qui impendiò garrul tus, fed nullius judicii eft. Axiomato: 
284 ZOOLOGIA * Axiomara.

I. Talpa ceca non eft.

Cecior talpa, proverbialis eft locutio. Sed videt talpa, licet obfcuriùs, \& magis in tenebris quàm luce clarâ. Habet oculos, fed tectos. Cute enim detracta orbiculus quidam in loco oculorum apparet. Qvem fruftrà feciffe naturam, abfurdum eft.

11. Talpa murifimilis non eft.

Sealigerum audiamus caftigantem Cardanum: Talpam formâ of magnitudine muri familem cùm firibas, diligentiam tuam defideravi. Longè magis diverfz pedes quàm cauda funt. Ulyfinis enim fimiliores. Totum corpus latius, depresfius, crurabrovifioma. Caput deprefums: ut bufonio proprius fit, quam murino. Os qpos qsab ore muris valdè aliesum.

CAPUT XXXIII.

De Mure

Preceptum.

Mus eft animal qradrupes, timidum, velox \& callidum.

\section{Qvestiones.}

I. Qvodnam intrimentum? Refp. Animal fermè omnivorum eff. Cafeos multos cum invenit, optimum eligit, cateris Spretis. 
pretis. Poma ac pira etiam devorat, habito fubinde delectu. Qvandoquelegetes populatur. Agris, hortis, horrejsque incredibile inferunt damnum mures. Aqvam eos bibere negat Ariftoteles. Sed vidimus fapè \& cibum \& potum mures cum avibus cepiffe. Qvin Tpuia hominnm lingunt inopia aqvis:

$$
\text { I1. Qvenam magnitudo? }
$$

Refp. Corporis quantitas exigua, varia tamen ef. Multa enim murium genera funt, quorum aliqqi majores, qvos Rattas vocamus: alii minores funt. Caput habent longiufculum, caudam proceram, colorem cinereum? nigrum, fufcum, ruffum. Prioribus pedibus pro manu utuntur, cum grana tritici ac hordei aut uvas devorant. Alii domeftici vo. cantur, alii agreftes. Addunt agvaticos, fed natant tantum per agyam \& in terra habitant,

III. Qvenam generatio? Refp. Pariunt vivurn animal, \& duodecimae plures uno edunt partu. E putredine aut qvisquiliis non fiunto Cum animatum ab inanimato, vivum â non vivente produci ne॰ qreat. Salis guftu pragnantes feri putan: tur. Qrod fenfu ifto admitrendum, qvo fe men fit calidius.

IV. 2थs: 
286 ZOOLOGIA

\section{Qvenam fenfatio:}

Refp. Pracellit odoratu. Hinc odoribusal. licitur facilè, \& mufcipulis capitur.

\section{2vinam affectus?}

Rerp. Timidi funt mures: Ted \& ipfi â multis timendi. Elepbanti borrent mures, \& non pauci inter homines ipfos. Museciam muri favet. Lapfos in aqvas extrahunt, tenentes mordicus caudas.

\section{I1. Qvalis motus?}

Refp. Motum habent velocem Noctu difcurrunt, interdiu ferè dormiunt.

VII. Qvenam affectio?

2Vox exilis elt. Sibilun edunt potius, gram clamorem.

\section{Axioms.}

- Murifmilis eft Ichnermon.

Ichnevmon fpeciem muris majoris habee. Dicituraliàs mus Indicus. Nafcitur in A:gypto, caput habet oblongun, aures rctundas, caudam longam. Vefcitur ferpentibus, zvibus, \& aliis. Infeftus crocodiloef, cui infidias ftruit, mortemque infert. Sic par. va maxima, fic imbecilliora fortia fuperant. A parvis etiam caveri oportet, cùm magnas frpè gerant iras, \& jucundam nabeant yindiçtarn.

LIBER 
PHYSICA.

LIBER QVARTUS

DE AVIBUS.

CAPUT I.

De Avibus in genere

Precepta.

1. Avis eft brutum volans, fangvineum, roftratum \& pennatum.

II.Eft aqvila, accipiter, vultur, ftruthiocamelus, grus, ciconia, cygnus, pas vo, anfer, phafianus, anas, gallus, no\& tua, corvus, pfittacus, columba \&c.

\section{2 uafiones.}

1. 2vanam avium caufe fint?

Refp: Caula efficiens prima, Deus eft. Dixit Deus, producant aqva reptile anima viven: tis , \& volatile volet fuper terram, in fuperficie expanfienis coeli. Casufa effociens fecunda, natura eft : partim ftellx, partim fpccies fe multiplicantes. Ha proximæ caufa; illa remota funt. Finis primus \& ultimus, Dei glo ria eft. Finis intermedus, homo. Homini enim dant alimenta, tegumenta, oblectamenta. Proprium verò infuper habet finem avis qualibet, fed ignorant iftum mortales. Materia creationic, aqva fuis : generationis femen eft, confititutionis partes corporis. Forma in genere anima fenfetive eft: in f́pecie alia ate qvealia, Alia aquilim, alia nscipitris, alia an: ferifs 4 2pe: 
II. Quenam avium convenientie Ev qua differentia fint?

Refp. Animâ fenfitivâ \& corpóre organicô omnes conftant. Moribus etiam conveniunt valdè. Sed differuut formis specificis, in. dole \& aliis affectionibus. Qvadam rapaces funt, ut a qvila, accipitres, vultures; qvædam mites: ut columbx, gallina, anates. Qve. dam focietatem amant, ut anferes, gallinz, anates. Quadam folivage funt, ut a quilx, vultures, accipitres. Qvadam sarnevore funt, ut aqvile, vultures, falcones; qvadam granivore, ut gallinæ, columb 2 , pafferes : qvadam, vermipore, ut philomela, hirundo, upupa, qvadam omnivore, ut pica, cornices, corvi. Qvadam perpetue funt, ut columbx, pafferes, picz: qvadam affipe, ut ciconix, hirundines, alaudx; qvædam byberne,ut bombycilla. 11I. Quanam potifimum de avibus notanda fint?

Rolp. Qvadam vegetativam, qvadam fenfitivam, qvadam propriam infeqvuntur animam.Hinc (peetanda nutritio, augmentatio', generatio, fen 9 , appetitus, motus \& peculiaris affectio. Prolixiores effe fi deceret; temperamentum etiam notanduin foret. Neqve pratermittenda xtas, quaricum homine , \& aliis habent communenr. Sed brevitati Itudendúm, nec recedenduta â propofito. Axio. - $x$ bot? 
PHYSICA.

Axiomata.

1. Aves quinto creationis die facte funt.

Difquifitum olim, utrum gallina, an ovum priusextiterit? Novimus ex vefbo Dei, animalia ipfa integra perfectaque ẩ eo condica effe. Septimo creationis die non potenciâ, fed acta corporanaturalia fuerunt. Sic confummati funt coeli, confummatus munduseft. De avibusita facer codex habet: Crsadit Deus cetos magnos, S omnem animam viventem reptantem, qpamproduxerunc aqvajuxta ßpeciem füa, atğomne vol atile alatum fecundum peciem fusam oc. Et fuit vepera fuitgó dies quintes:

11. Aves ex aquis create Junt?

Dixit Deus,ait Mofes, producant aqua reptile anima viventis, \& volatile volet fuper serram in fuperficie expanfionis coli. Aqvam igicur allocutus eft crearor. Hac ad verbum. Domini dedir prima pifces, deindè aves. Nie. rembergius ait: Fraterculant aves cumpiscibus. Communis pulve bumor est. Ideo Eo pifces per aqoam volant, Ef aves per aërem natant.Illi aves pelagi, ista pifces fublimes. Siniilitudo ince Jus of. elementi conjunxit nativitatem.

111. Aves aëris incole funt. Albertus ait : disendum quò 1 motus nvium T' - est 
290

eft in aëre \& qvies, in terra: \& illud elensentum. dicitur ormari illo gencre animalis, grodeft locus motus ejus E non qpietis. Nierembergius feri bit: Ad illud elementum Bectant animalis, ubi frequentia funt, qpo Batiantur, qvo vivune, in guo delectancur. Atque hinc colligit laudatus Autor incolas aëris aves effe, cum ibi freqvenres fint, ibi $\int_{\text {patientur }}$, ibi vivant cogre deleo हीentur.

1V. Aves partibus quàm maximè conveniunt.

Expofuit rem in Phyfica Chriftiana Lam. bertus $D$ anæus. Primswomnia, inqvit, vo. latilia funt Jangvinea. Itags \& cor E bepar \& pulmonem, E arterias, E venas, religpag fan guinis opificio \&s officina fubferdientia membra babent : imò \& sefficulos: veficâ autem carent. Farme lle vulvam juxta feptum adjunct arm babĕrs. Bipedia autem funs omnis, gre propriè avium \& volatilium numero comprebendunsur. Genus babent; jed in adverfum atgognos inflexa. Geniculatio enim eorum retrorfum fic, non antrorjum. A Alat a funt omnia, roftrats, caudacapplumis Deffica: qDadam etiam admajorem decorem crijfer geftast.

$V$. Aves ex ovis fiunt. Ova alia fubventanea, alia prolifica dicuntur. 


\section{THYSICA.}

sur. Crediderunt qrondam, vento qvadam ova concipi. Hinc fubrentanea, aut ova vena ti appellata funt. Rectiùs dicimus, ova fub. ventanea in ventum, prolifica in fœtum mue rari. Et illa femine fominæ tantum; hac femine \& maris \& foeminx conftant. Modus formatiois ab Ulyfle Aldrovarido fic defcri. bitur. Que coivit gallina, aut alia quevis von lacris, opum concipit fuperius ad feptum trans: verfum : ubi primo minutum of candidum cernitur, mox rubrum, cruentumgs, deinde increfcens lateum E fladum efficitur tocum ; jam amplius auctum difcernitur, ita ut intus pars lutea fit foris candida ambiat: ubiperfettum est, abfolvizur atgsexit putamine dum paritur, molli, fed protinks durefcente, qvibuscung srumpit portio sibus, nifz pitio pulve defecerit.

\section{CAPUT II. \\ De Aquuila. \\ Praceptum.}

Aqvila elt avis, clangens,generofa, belli: cofa, vifum,acutisimum, volatumqi altisfimum habens.

\section{2uaftiones.}

T. Qvodnam aquile nutrimentum.

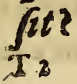

Reŕp: 
292

\section{ZOOLOGIA}

Refp.' Vivit extapto. Infelts admodum eft brutis, cervis, tauris, canibus, columbis, anfers: bus. Magno impetuadoriturea, \& aduncis unguibus; roftróque acuto dilacerat. In u. noaquilænido inventæ funt aliquandotrecente anates, centum anjeres, guadraginta lepo. res, oplurirsipifies. De potu lis eft, an aqvila aqvam bibat, an nòn? Sed cùm animalia dilaniet, fangvine illo contenta eft, nec aqvam petit. Hincapud Jobumextat: pulli ejus lambunt Jangvinem.

11. Quanam aquilemagnitudo, $\sigma^{3}$ formatio fit?

Ref. Ultra magnitudinem anferis aut cygni non excrefcito Maxima tamen apparetobalarum longitudinem. Habet roftrum durum \& aduncum, ungvès recurvos, carnem duram, offa folida ac firma. Dentibus caret, cum ferratum intus roftrum dentium fit loco. Oculi funt rubri, concavi ac profundi. Crura haud ita longa, \& pes dexter finiftro major. Penne rigidx funt ac duræ, collum longum, cauda brevis. Halitus pesfimè olet, adeò ut inficiat prædam. Unde religuias befternas, nec ipja aquila, nec alia animalia repetunt.

III.Quanam generatio Jit? Refp. Aqvilix nomine cum mas, tum formina, venit. 
PHYSICA.

anit. Verè fexus dilcrimen habene, \& mari enis, foeminx uterus datus. Majores, pulchrie res, \& ferociores fomina funt: mares miroes \& mitiores. Salaciflima a vis eft, \& foumina er decies comprefla, poftquàm furrexerit, fi nas revocet, denuò accurrit. De ovis ex Mue xi verfu recitat Ariftoteles:

Excludit binos edit terna ova , fed educat unum.

Aft ternos excludi, ternos ali \& educari, inq; aidis inventos effe, reftes fubc Ornitbologi。 Insubant diebustricenis pullum que maturè ad volandum exeitant, alis fuis impanunt, \& nee dum potentem ratis, ejiciunt. Tota regione, guàm parences incolunt, liberos exterminant ut fingula aqquilarum paria tractum tencank ingentęm.

\section{Quenamfenfatio?}

Refp. Vifum acutiflimum habet, \& folem ia: pfrum absque noxa intuetur. Nec acririffimè tantum, fed \& longiffimè cernit ob ecta. De locisenim altisfimis clariffimè confpicit 0 mnia, aviculas in cerra, pifciculos in mari. In exploranda prole de vifu fumit argumentum. Qu immotam tenet aciem contra plenum Solis jubar, eam progenuina agnofcit, reliquam quvafi degenerem abjectate Nıctare dicitur âScaligero adverfusLnna fplendorem.

$$
\text { I } 3 \text { Sed }
$$




\section{ZOOLOGIA}

Sed caltigaturScaliger â doctiffimoAldrovando. Nec audiendus eft, inquit, ille magnus adids fubtilitatum indagator, alferens aquilam. adverfus Lune fulgorem, cium plens ef, nidtare: nam omnibus clarum eft, aqvilam inter aves diurnas cenferi, ac reverà eßs. Q Q e verò diurne funt, noctu quie/cant neceffe est: Es quidem ma. ximi rapaces, que dictum labore ac corporis nroeu fibi querunt fub fole; ut ê conerario nod urne, nangvam vel rarisfimè interdiu videntur. Non eft ergò exiffimandum, ut mea fert opinio, in cale difcrimes a natura voc.sri agoilam, ut vijum probet contra luse fulgorem, cum illum in $"$ ber. Seos radios lucidisfomos E acutifimos fggat intrepide.

V. Quid de appetitu E affectibus aquile?

Refp. Appetitum cibı habet infatiabilem. Pulchrè fcribit Aldrovandas : Avide admodam Es penè inexplebiles funt agvile, deog $_{s} / 2$ quancio fa. mem (cujus alioqui patientes funt) tolerarint, iùm diuturnum jejunium, mules cibi ingeftione compenfant. Undefigridex copiofo venatu fis pereft jars ex/atiatis, religuis avibus, goe ip [as bujus rei caufa affect are folens, relingpunt; at fi eis adplenam faturitatem gvidpiam deficiat, ad consivas revertuntur, qpibus fuam ingluviem, violaro 
PHYSICA.

violato boßpisiijure, explent. Nam justa 0 vidium:

Vivitur ex rapeo, nec boßpes ab bosfite tutus: Imd fi forfan major fames eas premat, neg. âfis generis volucri abftinent. : Caterum naturale odiam inter aquilam \& alias aves effe fcriptirant. Pennis a quilinis etiam cum aliaruma avium pennis dilfidium elfe putant, adeò , ut fi pennis à has corrumpant \& confumant. Sed univerfale \& commune odium non afferendum. Alic enim plures ex quadä fermè liberalitate. Ferre cas optimè poteft: fed fame preffa favit in ip [as. Particulare verò o diúrn cum cygno $\mathbb{E}$ grue non negandum. Pennæ aquilinæ duriores; dentiores, \& corruptioni minus obnoxix fune. Hinc fuperitites manét cateris corruptis. Sicut cannabis cum lana contexta confumere videtur lanam Sed cum durior fit, fopereft ea corrupta.

\section{Qvid de motu?}

Refp. Volatum habet velocisfimum \& altiff. mum. Aqpila, inquit Aldropandus, pennas saA2 funt valde denfas, of corpus, fif id illis com: pares, adnsodum exigusm. Qvare tam fublimes feruntur, ut ceteras aves omnes, atgicas potisfimum, gre corporis mole, Es pennarum raritate in alcusn fe efferre non poßunt, jub fe dejpiciant. I 4 . Sca- 
296 ZOOLOGIA

Scaliger ait : Tam fublimis volat aqnila, tam indefeßâ pertinaciâ, ut fub fe omnes alias defpiciat volucres, tim robore; pondere: impetu nulla ei par effe poreft. Scriptura quoque per aquila pennas aut volatum, fummam pernicitatem. indicat.

VII. evenam aquile propria affectio fit?

Refp. Clangor propria aquila vox eff. Non canit, fed clangit, ftrepitumqve omnibus avibus horribilemi edPt. Etiam Dracones, a quila volantis clangorem audientes, fugiunt $\&$ in Ipeluncas fuas fe recipiunt. Differt autem clangor aquila ab aliarum avium clangore. Longè enim gravior, longè terribilior eft. Pullos aquilarum mutos dicunt, \& nec clangere nec murmurare poffe teftantur Caufa eft copiofus humor, qui lingvam nimis humeat, \& ad fonum efficiendum ipfumque moturn ineptum reddit.

Axiomata.

I. Rex avium aquila eft.

Imperium debetur generofiori ac potentiori : at generofisfims ac potentifina avis aquiIs eft. Sit audaciffimus gallus, fit formofiffmus pavo: fit maximus fruthiocamelus. Aquila generofitate \& potentia principatum tenet. Magni- 
PHYSICA.

Magnitudine animi omnes aves fuperst. La: ceffrca verò â cornice aliisqve minoribus, innatâ quada m animi nobilitate diffimulat, easque praclarè contemnit. Si tamen infectari eamnon defiftant, coacta tandem unguibus. acutis dilacerat viliffmum hoftem. Proverbium elt : Áquilam connix provocat. Si homuncio qui nec prodeffe, nec obefle potelt, fuperiorem aggreditur. Etiam iftud in ufu: Scarabaus aqvile obfetricatur, aut, Scarabaus equilam querit. Cum impotentior mala molitur majori. Ferunt enim Scarabzum perdere velle ova aquila. Tanta verò avis hujus dignitas eft, ut in inffgnia Romanorum Imperato. rsm relata fit. Caput autem divifum eft, cùme nulta ab co ablata fuerint partes. Tanta praftantia aquilæ eR, ut Evangelittæ Johanni ad: fignata fit. A divinitate enim Salvatoris aufpicatur, \&fi fublimius altiusque locutus effet, nemo hominum intellexiffer.

11. Aquile ejusdem generis non funt. AqvilaGracè dicitur a'erós aut ajstós. Sex potifimùm fpecies defcribunt Ariftoteles \& Plinius. Prima eft Melanctus Stod abler / colorem habet nigricantem, cora pus non adeò magnum, roftrum vero aquilinum \& admodum a duncum. Verfatur in sue pibus. Sceundaeft, Pygargus weifgerdntoenka

$$
\text { I } S_{s,}
$$


398

ZOOLOGIA

set2dolet. Caudam habet albicanteui, magnirudinem mediocrem, roftrum luteum \&aduncum, manfitat in oppidis \& campis. Nonnunqvam tamen cxterorum more, montes, fylvasque petit. Tertia eft Morphnos Enotenabler/ magnitudine \& viribus Pygargum pro* simè feqvitur, \& faltus, convalles ac lacus incolit. Quarca eft Percnopterus Benerablee vulturina aquila, fubaquila magna quidem, Sed ob alas parvas, \& ob ignaviam ac deformicatem,omnium viliffima \& maximè degener. Imbellis eff, in quit Plinius, ac degener, ut quanm -erberet corbus. Eadem jejunajemper apidititas tis, of querule murmurationis. Sola agvilas ram exanima fert corpora: caser a csm occidere, confidunt. Quinta eft Halierus \$eerabler clariffma oculorum acie, qvæ vifo in mari pifce, praceps in eum ruit, \& difcusfis pectore aquis rapit. Sexta eft Cbryfaetos, fea aurea aquila, qua fola genuina, fola vera, omnium maxima, fortisfima \& generofisfima eft. Hæcintelligenda, cum nomen aqvilx fimpliciter $\&$ : fane addito dacur.Latifimè eam laboric fisfizous Aldrovandus, ê qvo velue tefte oculato pauca notamus. Summâ ferociâ, in quit, qvidvis obvium lacegigbat, E feles, canes, sad caveanz paulo imaprudentiùs accefsiffent, atǵ, adeò bomi. nem ipfum, aut unguibus, ast rogitro impetebat.

Inters. 
Interdum vocem quandam guerulam, lamen. tantis in morem of clangofam edebat (clangere enim feu plangere propric ac peculiariter agvila. rum eft, ) minimo obfireperam aut ftridulam, fed acuté fonor am ac claram. Tandem laqueo cerbici injecto strangulata, atg ad stateram examinata libras áuodecimpendere comperta eft. III. Aquila cadaveranon tangit.

Ex generofitate fpernit aquila cadavera. Proprium avis hujus obvios quosqve, \& qvi nullo labore parantur, cibos refpuere. Vulwres intelligendi funt, aut aqvile vulturinx, cum vel in facris, vel in profanis fcriptis,aqvila cadavera fectari dicuntur. Laudatus fepè Aldrovandus fic habet : Cadavera $\& c$ exanima corpora non tangunt aqvila, prater folum Perciopterum, avem degenerem.Qvare qrod in Evangelio Matthxi fcriptum eft: ubicung $_{3}$ fuerit corpus, illic o congregabuntur agpibe, ut de mýftico fenfu, de qvo agere non eft hujus loci, nihil dicam, D. Johannes Chryfoftomus de vulturibus intelligi vult, cum inquit, De vulturibus enim dicit foriptura in fobo:2 qvoniam ubicung fuerit corpus, illic invenientur vulturum pulli. Hoc enim naturale bis eff, ut dicit D. Hierovymus, ut etiam transmearixa CAdavera fentiant. Ne verò facrum textum aut corrumpere, a ut in eo temerè quidpiam inve. niri. 
$\pm 00$

\section{ZOOLOGIA}

viri, veletiamantiquorum Patrum ac Eccle. fix Docforum fententix refragari velle videa amur, accommodum utrique reconcilianda loco, \& veritati hiftorize naturalis maximè confonumerit, exiftimare cum Ariftorele aquilas, qva cadavera fectantur, vulturioas. effe, \& vulturis fpeciem referre, dubil nempè inter hunc $\&$ illum generis.

\section{Aquilapoft fenectutem non juvenefcit.}

Non redeunt prifa quercus in molles furculos, necfalices vetuft in teneras arbufculas, Annofa vaccx non juyenefcunt, licer. recentiffmis vefcentur graminibus, Retrogradum nihil eft, fed â principio ad finem ren. dunt omnia. Fidem fuperant, qux de aqui. la narrant fonecta \& juventa. Ex feniore aquila non fit juvenis : ficut nec es feniore gallo junior. Pcnnas mutant nonnull aves fiń. gulis annis, atque fic quafi rejuvenefcunt.Sicutferpentes pellem veterem qvotannis exu. unt \& renovantur. Sicut arbores folia \& frondes deponunt novasque recipiunt. Mibi, inqvit Aldrovandus, wulla ratio tam probabilis brjus mutationis effe videtwr, gpam qve de mas tatione pennarum intelligitur. Videntur enim aves, grapennas mutarunt; renovari ac velut fenecto 
PHYSICA:

$30 \%$

rect depofot a rejuperiefcere. D. Frantzius ait: Et bac eft fententin expeditifina. Sicuc enm. ferpentes quotannis fenebtam exunnt, ita inser. volatilia aquile 0 ejus cognascerapaces alizaves.

$$
\begin{aligned}
& \text { CAPUT IIr. } \\
& \text { DeAccipitre } \\
& \text { Praceptam. }
\end{aligned}
$$

Accipiter eft avis pipans, animofa, robufta, volatum citisfimum \& altisfimum habens,

\section{Qoxfiones. \\ I. 2uodnam accipitris nutri- mentum fit?}

Re. Rapax avis eft, \& gallinas, colimbas, corvos ac lepores devorat, Viliores etiam muribus, ranis ac talpis victitant. 2Nobiliores nes pilces fpernunt; \& cancrorum carne delectantur maximè. Cor animalium, \& imprimis avium non comedere dicunturab Ariftotele \& Plinio. Sed periculum fecerunt Albertus \& Aldrovandus, \& abfumpta ab iis corda confpexerunt. Animalibus viventibus qvamdiu vefcuntur, aqvam non bibunt. Satisillis eft fanguis, quem fugunt. Bibunt verò aquam, cum cicures facti cibariis ficcis utuntur.

II. 2va: 
302

\section{ZOOLOGIA'}

1I. Qusnam magnitudo E

\section{formatio}

Rerp. Qvantitate corporis parum cedit aqvi. lx. Fomina majorac ferocior, mas'minor eft, ut in omnium rapacium generc. Majores etiam in frigidis regionibus dantur, qvàm in calidis. Color ex albo, fulvo \& nigro diItinctus, maculisque confperfus eft. Pectus habet acutum \& firmum, pennasin alis \& cauda magnas, ac craffas. Crura lucea funt, ungves mucronibus herrent. Cor magnum eft, lien exiguus, cerebrum copiofum.

1II. Qvanam generatio?

Refp. Salaces admodum funt, fed parum foe. cundi. Ut plurimum tria aut qvatuor ova pariunt, \& vicenis diebus incubant. Pullos grvamprimùm volandi facultatem nacit funt nido expellunt. Albertus ait: Accipitres pullos fuos volantes cibant ferè menfis $\beta$ atio, Evoofts. ea recedunt ab eis. Et docent coscapere aves, guas vivas adferunt \& coram eis dimitcunt, incitanog, pullos ad capiendum. Ubi autem perfeltè jam volare, E ad capiendum idonei fuerint, cjiciunt aut relinquant eos at gós deferunt.

IV. Quxnam fenfatio? Refp. Vifu \& memoriâ valent. Solem, ut 2quila, o culis intentis confpiciunt. Elocis o tim 


\section{PHYSICA:}

tiam altisfimis fpeculantur pradam, qram to. to impetu profternunt. " Informantur â majitris, quorum voces audiunt, juffaq; capefunt. Gaudent hominũ confortio, eorumq; affectant qquodammodo confvetudinem. Do. ciles funt admodum, a nutui hominum ob. temperant quàm promptilfimè. Ad omne venationis obfeqvium parati funt, Dominis fuis ubique præetantes obedientiàm ac reve: rentiam.

V. void de appetitu $\sigma^{\circ}$ affectibus? Refp. Animal vorax, audax, \& iracundumeft. Calidam \& ficcam habet temperiem, quam. audacia leqvitur \& iracundia. Odium na. torale eft inter aceipitrem \& gallinas. Galline acutam accipitris vocem cum percipiunt, fugiunt, \& quàm ocyşimè quveunt, fefe. occultant Pulli qroque gallinacei vix ovo exclufi confpeftum è longinquo accipitrem. horrent \& fugâ fibi confulunt. Putat Plinius, ova vitiari,figallina vocem accipitris audierint, dum incubant. Sed ex more fuo, â neceflatio progreditur ad nimium, cum nulli ê gallina in ovum fint ductus.

\section{VI.Qvid de motu?}

Refp. Volatus velociffimus, \& altisfimis eft. Sicut rapacia omnia rapidisfimi pernicilf. 
304

\section{ZOOLOGIA}

ciffimique funt volatûs. Tam altum habent volatum, ut vifum humanum effugiant. Et exaltitudine illâ præda $\dot{m}$ in terris confpiciunt, eamque rapidisfimæ fagitta in tar petunt. Nonnunqiam in aêre fe fufpendunt refupini. Nam alas caudamque deorfum expandunt, in aëre hærent \& ungvibus roftro. que contra fortiorem ac fuperiore dimicant. VII. Qvanam propria affectio jit? Refp. Vocem habet variam pro affectuum ra. tione. Aliam cum irafcitur, aliam cùm blanditur, aliam cùm cibum quariti, aliamcum prædam invenit. Lucretiusait:

Accipitres aty ofifrage, mergig.marinis Fluctibus in falfis victum vicamgis pecences, Longè alias alio faciunt in tempore voces. Clamofam tamen \& acuram admodum vocem habet. Dicíturfpecialiter pipare juxta Au. toris philomelæ verfum:

Accipiser pipat, milvus biansgi lipat. Axiomata.

I. Accipiter acceptus ef $M$ agnatibus. Sylveftris \& rapax avis familiaris atque do. meftica fit homini.E manu heri fui egreditur, avesad nubes usque perfequitur, \& feffa ad manum Domini regreditur. Vociferantibus aucupibus, \& dimicantem ad pugnam fortius

urgen- 
Irgendam hortantibus, ferocisfimam le ræbet, \& magno impetu hoftem perfequiur, pradamqve reportat. Incredibilem res 2 adfert exercenti voluptatem , nec param, fi ob qrafum fiat, utilitatem. Hinc rincipes \& magnates avem habent in deli¿iis, \& ad fummum dignitatis evexêrc faftiritum.

II. Accipitres ejusdem gener is non funt. Accipiter ab accipiendo dicitur Lacinis, \& avidam,cupidam, ac ra pacem ayem notat. Jermanis rocatur \$abidot / quam in rem egregia Aldrovandi extant verba. Germanoum, inquit, lingo a locuplet isfoma, ac propriis imnium rerum rocabulis, figpa alia, ditisfima, quams roslla bactenus alieni indiomatis fex peregriniconfufio corrupit, adeog's fincera basc po. cem Hapicb, vel Habich pro accipitre in genere.t.t. Curpat, qDam fi examinifubjicere, ctymologiam os jus curiose indagare libet, smultio exastius ren fia gnificase, uc pleragis bujus lingere pocabula alia. nasurams exprimu ve comperiemus, qpàm vel acs cipiter Latinis, rel aliarum gentium bujus aris gvevis vernacula nomine Ec. Cxterum ampliffima eft accipitrum familia, \& Afturen fen fellarem, palumbarium, fen Falconem columbarium, Nifum oen Epatber/Circun, Fafalonem, Tinnunculum, Bliteo-

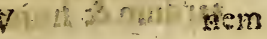


306

ZOOLOGIA

nem feu triorchidem, fubbuteonem \& alia genera complectitur. Omnes hæ aves con. veniunt qvấdam cùm interna, tù̀m externa ratione, quanqvam in nontrillis differant maxime.

III. Panis accipitri.lethalis non eft.

Frưges refpuunt accipixres \& aliæ rapaces aves. Carne gallinarum, columbarum, anatum \&anferum delectantur. Hinc ab Auguftino foriptum eft : panis bominem alic,accipitremnecat. Verum nihil contemnit jejunusfomachus, \&fames dulcia redditomnia prerer feipfam. Fame coactivultures non panem folum ac fruges, fed ipfa qroqve ftercora deglutiunt. Artis etiam magna vis eft, \& nihil majus affretudine. Arte factum, ut fuppetente carnerejecerint eam \& panem devorarint accipitres. Sicut taurus primò aratrum detrectat, affrefactus fert benè, quod mutare neqvit.

Ac relutiprimò taursus detrect at ar atra, Poßf penit afjpeco mollis ad arva jugo.

CAPUT IV.

De Vulture.

Praceptum.

Vultur eft avis pulpans, vorax, audax, 0 . factu \& memoria valens, volatum rardum \& humilem habens. 


\section{PHYSICA.}

\section{Quaftiones.}

1. 2uodnam vultures nutrimentum?

Refp, Nutritur cadaveribus, imprimis humanis. Homines qui propter fcelera honore fepulchri indigni judicabantur olim in a. gris in humati, canibus, corvis \& vulturibus relingvebantur. Incredibilis vulsuris eft voracitas, ob gram famofus femper fuit. Hinc proverbiun: Vulcure edacior. An parcat vit yentibus, difceptatum eft. Sed experientia confirmatum vivas.cùm Folucres, tùm qra drupedes eum dcrorafle.

\section{2uanam magnitudo?}

F;: Magna moles corporis eft, \& aguilam nonnunquam fesquialtera proportione ex. cedit. Roftrum habetaduncum, oculos fodos ac torvos, pennas.in capite \& collo parvas. Quttur longum eft \& capacilfimum; crura hirfuta $\&$ cutis crafia. Alarum pars interior vellere tecta eft, fecus as aliss fp: ciebus, quibus nuda contigit.

\section{Quenam geseratio?}

ReIp. Magna vulturis libido eit, qvå tentata fominx, fi mares abfint, inter fefe faliunt. Exiftimant multi fubrentanea ova in caterisirrita efle, at in vulturibus focunditate infignia. Allianus fcribit: vulture to ron nafis marem ajunt, fed faeminas omnes generarb, V 2 
305

gram rem non igsor antes be bestia, pullorumgis folitudinem ac inopidm timences ad gignendos pullos talia macbinantur. Adverfe Auftro volame, vel fi Aufter non Biret, ad Eurum ventum oris biatu fe pandunt. Spiritus venti influens, ipfas implet. Sed recitaffe hæc, eft refutaffe.

$$
\text { IV. 2uanam fenfatio? }
$$

$R \in f p$. Acutum habet vifum, ut ex alto confpiciat, qva multâ montium obfcuritate celantur. Olfactu verò maximè celebris eft, juxta verfum:

Nos aper auditu precellit, aranea taCZu:

Vultur odoratu, lyna vifu, fimia guftu. Modum verò non tìm per fpiritales qualita: tes , qvàm per effluvia explicandum cenfe. mus. Cadaver innumeras fpargit atomos, qvæaèrem replent. Integer exercitus omnes tractus replet, fioccifus refolutus fuerit. Hinc ultra maria, quin \& ultra quingenta mile lia paffuum putorem cadaverum percipere vultures dicuntur.

V. 2uid de affectibust

Refp. Amat foctida, fugit fuaveolentia. Mi. rum in modum capitur odore cadaverum, ungventa tantopere abhorret, ut eorum odore perire dicatur. Similis $S c a r a b æ o$ eft, qui fortidiffima excrementa amat, nnguenta ac rofas fugit.

1r. 2eid 
B. Tardum ac pigrum habet motum, \& vix tertio aut qvarto nifu in altum tollitur. Fit hoc ob magnitudinem \& gravitatem corpo: ris. Aldrovandus ait : Reverà difficulter adt modum fe fe bumo collit, qvemadmodum of fruthioc asenclus, nimio corporis pondere pregravatus non volare, fed alarum remigio curfum promoverevidecur. Sic cum in aërem fublatus esi; tardum etiam volatum exercet: guem foitiffimi Ariftophaneseade caufa natationem quandam vocare videcur, gvod lento graduper aëra cvectus, velutinatare in nubibus pideatur. Unde $e \vec{z}$

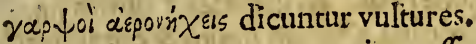

VII. Luanam propris affectio? Refp. Quoad rocem, proprionomine, pulpare dicitur, communi, clangere. Ita Aldro. vandus: Vulcures cum vocem edunt, proprio vo¿abulo pulpare dicuntur, wt Ovidius, fen quisquic est, Pbilomele autor, test atur illo verfu:

Dum clangunt aqvila, pultur pulpare proba.

$$
\text { tur. }
$$

Et Thomas Rhodinus in eo libello, quem A byffum ftellarum infcriplit, inqvit : vultur pulpans, accipiser pipans. Homerus tamen cos dicitclangere.

Axiomata.

I. Vultur Jagax eft. -

Per 
310

ZOOLOGIA

Per longa locorum intervalla fentit ca. davera. Hinc proverbium: Vulture fagacior. De eo,qven dapum odor facilé allicit, qvi nidorem qvemvis prafentit.Quidam eo pro. greflifunt, ut cadavera futura prafentire viulures credant. Unde verfus:

Hanc volucrem narrant luces tres noße cadaDer

Venturum, olf actu tam viget bac volucris. Sed olfactus rerum præfentium, non futura. rum eft. Ubi nullum cadaver, ibi nullus cadaveris odor, nullaquc odoris perceptio. II. Vultures ejusdem generis non funt. Duo generadat Ariftoteles : unum parvum \& albicans, alterum majus \& cinereum. Numerum augent recentiores, \& qvatuor, genera defcribitAldrovandus. Primo dat vulcurem cinereum 2 f đạnfarb́en geyer / fecundō Baticum Braunen gejer. Tertiò leporinum Dafen gewer. Quartò aureum BSologener.

CAPUT V.

De Struthiocamelo.

Preceptum.

Struthiocamelus eft avis lugens, maxima,ftolida, greffum habens, \& ova fua in arena condens.

Questiones:

1. Quaram nutritio?:

Refp。 
Refp. Nutritar feminibus \& fine delectu f $x$ pè quicqvid offertur,devorat. Fer ro nutrirf creditur communiter, fed nec ratio permittit, nec experientia probat. A vivente qrod non eft, viventi in nutrimentum non cedit. Albertus ait : Strutbiocamelum ferunt ferrum edere Éconcoqucre, guod ggo sŏ füm expercus. Nä ferrom ame pluribus bujus generis avibus objectum est, quodilli deaorarenoluerunt. OJja tamen - magnain breves partestruncata 6 lapides avide comederunt. Aldrovandus ait: Egoferrifru-

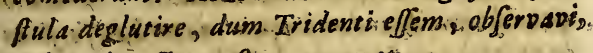
fed qua incodta rur fis excennereh.

\section{Quenam magnitudo.?}

Refp. Omniummaxima avis eft; \& Plinio é quitis infidentis equo altitudinem excedero dicitur: Qund eo accipiunt modo autores, quaten a collum quantum poteft, erigit. Rofrum habet exiguimm fed acutum \& validum. Caputanferinum eft, \& parvum ac ce-rebrum in eo fermè nullum. Collum \& caput plumis carent, exiguis pilis tantum flavent. Co!lum autem longiffimumeft, quo Camelum imitari poteft. Longa etiam crura funt \& carnofa, camelorum cruribus fimilia. Pedes in ungulas cuas divifi funt ficut equorum, boum \& vaccarum. Pennæin dorfo nie gerrimx funt maribus; foeminis fur c $\&$ mol दोग

$$
\checkmark 4
$$
les. 
les. In cauda fuballbid $x$ maribus, fubfufca foeminis. Varietaten colorum cum habent, artis nor nature inventum eft.

\section{2uenam geveratio?}

Refp. Libidinofum animal eft , \& multa edit ova duriffina \& maxima. His autem non in cubat, fed in arena condit ea ac difcedit. Ex fabulo nidum humilem conftruit in terram \& aggere munit, ne cadente pluviâ, obruatur aqua.Solis calore ex ovis tandem excluduntur pulli. In fcriptura hac extant : Strutbio quando opa fua develinquit in cerrâ,tuf forfotan in pulvere calefacies ea? Oblivifcitur, quodpes conculcet ea, aut bestia agri conterat. Strutbio dura eft in pullosfuos, quafi non fine fui, frufire laboravit nullo timore cogente. Privevit enim e. am Deus fapientia, non dedir illiintelligentiam. IV. Quid de fenfu?
Refp. Nihil qvod excellens fit, occurrit.C2-
putenim habet exigutum, \& cerebrum fermè nullum. Hinc ftolida avis eft, nec judicio, nec mernoria valens. Manus hominum effugere cum vult, caput inter arbufta \& umbroia loca condit, \& fic toto corpore latere fe exiftimat. Scalicet quosipf a non videt, ab iis nee viderifoipfam putac. Secura de capite, tota cum capite capitur.

V. 2uid de appetitu of affectibus?

Rerp. 


\section{PHYSIC A:.}

Refp. Vorax avis eft, \& omnia ingerit. Necit difcrimen boni $8 \mathrm{mali}$, falubris \& infalubris. Ovorum fuorum non habet curam, fed eorum oblivifcitur, \& alienis, qvæ fortè invenerit, incubat, undè exclufi pulli miferè lamentantur parentibus orbati. Cum eqvo naturale diffidium habere dicitur, \& ab codem infeftari vicifim,

\section{2uidde motu?}

Refp. Greffum habet potius, qràm volatum. Magna enim corporis moles, ne in fublime feratur, impedit. Pennas habet, non ut volantem dirigant, ied ut currentem adjurent. similes magis qvadrupedum pilis, quam avium plumis funt. Currit autem celerrimè à venatoribus cum urgetur , \& alas ad modum veli erigit. Non autem fpes omnis in fuga eft, fed currens pedibus lavides arripit, retroqve in venatores ejaculatur.

VII. Quenam propria affectiofit? Refp. Raròvox ejus auditur, \& cum auditur luctum ac ululatum refert. Pulli maximè â parentibnș deferti lugere ac ululare dicuntur. Hinc in facro codice Dominus ait:Taciam plandtum Draconis, E luctum ficut filie Strutbionis. Et alibi: Frater fui Draconum, Es focius fliorem Strutbionis.

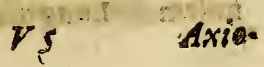


$3 \sqrt{4}$

\section{ZOOLOCIA}

Axiomata.

T. Dox Struthiocamelifinilitudinens notat.

Parvæ avis nomen gerere videtur avis. maxima.Plerique omnes per Antiphrafin ac Ironiam qvand.um factum. putant. sicut bellum quafi minimè bellum. 5p89o's enim dicunt paffer eft: $5 p \&$ fíov pafferculus. Cardanusait: Srutbio pafferculus dicitur Grecè, quafe per Ironiam nomine compofato, velut fo qvis gigantem pjgeneum diceret fimul, vel bomunculum gigsntem. Rejicithoc Scaliger, nec fine caufa. Nominis rationem, inquit, fubtitius enucleare licet $\hat{e}$ veterum monumentis. $5 p 8$ fóv prifci non pafferem vocabant, fed gallinam. Id quod etiam de Nicascdro, qui defitarum affectavit ufum vo. cum, doprebendes. Et forraßse aves omnes quas Bxpias dicit Aristoteles. Scaligerum feqvitur Becmannus, cujus hxc funt verba: $5 p 87$ o's paffer eft: 5 pq fiov pafferculus. Qui autem magna ills avis ags, vocatur Strutbio, Strutbioca-

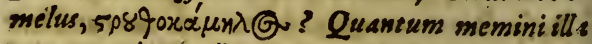
nungram ita nude vocatur Strutbio : verum

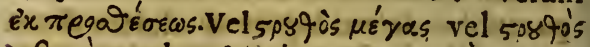

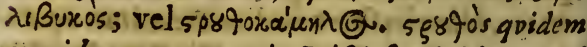
cum id nomen gener atim Prifcis fueric idem, quod ales, aut eti am gallina. Colligere est è citatis his, Struthio camelum notare avem Camelofi. milem. Longiflima crura habet, ficut ca. melus. 
PHYSICA.

melg. Carnofa cru ra \& crebris corticibo inecta habet, freutCamelus. Pedes in ungulas inas divifos habet, ficut Camelus. I.ongisfinum collum habet, ficut Camelus. Solidifinam carnem habet, ficut Camelus.

II. 'Strutbiocamelus avis $e f$.

Ad greffilium potiùs, quàm volatilium ordinem, moles corporis eum transfert. Pedesetiam non in digiros, ut alia rumavium, ed in ungulas, ut equorum \& boum divifi tunt. Habet infuper palpebras avibus ne gatas : non habet volatum avibus propriè ributum. Sed in avium cerfu eft, cum tota corporis forma avem referat. Bipes eft, haoctalas \& pennas, roftrum, caudatm, ova \& alia, $A$ friptura quoqve interaves, easque immundas recenfetur: Si non convenit fatis cum cxterisyhabearfy mbolum: dipers $\hat{a} a b$ aliis nat ur â valernus.

III. Seruthiocamelas pulcherrima avis non est.

Multi funt in pennarmm Struthionis oZentatione milites \& niercatores. Candidas. nigras,rubras virides \& caruleas exhibent. Qva diverfitate pulcherrima fit avis, fed ignorantibus. Scaliger ad Cardanum fcribit: majorers rifum movent colores, quos ab infecterum officinis in apothecas nature transtuliffis. . 3.

2vir$$
\text { (1) }
$$ 
316 ZOOLOGIA

Quis enim te non rideat illa venditantem? Hofee eolores, quos in galeis infigume nativos effe strua rbiocameli? Omnes enim ê fufcoEs albo pidtifunt: wt mibi dixerust multi mercatores Africani. Quod ut melius intelligerem, Giconia coloricom: pararsut.

\section{CAPUT VI. \\ De Grue.}

Precepeum.

Grus eft avis gruens, prudens, focietatis amans,ordinem inter volandum ob: Cervans.

Questiones.

1. 2uodnam gruis nutriment um fot?

R. Frugibus nutriuntur anferum ferinorum more. Ingentia inferunt damna agris, dum eos noviter tritico fatos depafcuntur. Gratiam aliqram rependere dicuntur colo. nis,cum \& ferpentibus vefcantur. Qvemadmodum ciconix â ferpentibus liberant Theffalix incolas, fic idem factitant grues. Lapides etiam devorare, \& au rum revome. re dicuntur. Sed ineptix ineptiis tegendx, mendacia mendaciis.

II. Queram magnitudo?

17. Valdè augetur, adeo ut viri mediocris magnitudinem referat. Collum duos do₹i.

dran. 


\section{PHYSI C A."}

drantes longum eft : altitudo ab imo pedis ad tergum fummum quatuor ferè dodrantes babet. Helluo qridam optavit fibi collum gruis, ut majori cum voluptate efcam inge a reret. Pennxin alis longiores funt, qvas milites ornatuis gratia pileis addunt. Nigri cant autem natura fua, fed arte nunc Hayx, nunc auree formantur.

\section{Quenars generatio?} 84. Fœminx non confidentes, fed ftantes
coëunt.Pariunt ova bina, \& inter ea lapicem ponunt juxta Albertum. Non certi generis, fed qvemcunqve fortè invenerint. De aquila ferunt, qrod lapidem Alitem inferat nido. Ethujus lapidis cam effe vim-fcribunt, ut qualitate occultâ ferviat parturientibus. Admotum enim femori parturientis, partum juvare: brachio verò gravidx junctum, Fee. tum in utero fervare, ne excidat. Delectum hunc non habent grues. Fermè ficut gallinx pariunt lubentius, fi ovum aut lapidem ov fimilem in nido reperiant.

IV. 2uenam fenfatio?

4. Vifu non parum valent, feminagve in 20 gris fparfa accuratè feligunt. Hinc granile? gxdicuntur, qvia grana legere folent. T2. fum etiam exqrifitum habent. Frigus e. nim prefentiunt, \&\& maturè ê frigidiotibus lox cisin calidora peregrinantur? 
V. Quales motus?

R. Volatum habent altisfimum \& ordinatiffmum. Sive enim volent, five palcantur, fe noin feparant, fed conjungunt. Hinc verbum congruere a gruibus dictum putant. Et fub duce grodam cum aqvila, \& aliis rapacibus avibus pralia gerune.Dux atate \& experiertia reliqvos fuperat, bellaqve $\&$ itinera $f_{x}$ pius agit. In medio conttituunt juniores ac imperitiores. $\Lambda$ gmen claudunt $x$ tate \& calliditate infignes.

\section{2ualis affectus?}

R. Amant fefe mutuò \& in profpera $\&$ in adverfa fortuna. In pullos tantus amor eft, ut - as \& formina certent de educandis iftis. Fortem habent animum \&ad pralia fub eunda paratifimum. Nulla tamen in iftis avaritia , nulla injuftitia, nulla invadendi ac prædandi cupiditas.

\section{2uanam affectio propria?}

Refp.Grus â gruendo nomen accepifle dicitur. Ut enim fues dicuntur grunnire;ita grues grùere. In gencre etiam clangor \& clamor gruibustribuitur. Magno enim conatu vociferantur.

-....- Atgs etbera tranant

Cumfonity, fuginnigs 2Notos clamore for. cunde.

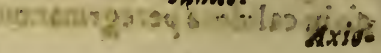




\section{Grues aves astiva funt.}

Hyeme ingruente avolant \& peregrinanar, Thracia patria elt, quam mutant ob inlementiam hyemis. Tendunt in . Igyptum c Fethiopiam, ab extremis ad extrema. Sa= rafcriptura dicit: Eriam Cisonia in coloconovit tempus funm, ef turcur, of gris, of birun. o objervant tempus adventus fui: populus autsems neus non novic judscizim fe hora.

11. Grues cumpy gm ais non pagnant. Aristorelis, Plinit, Alberti \&aliorum afferio eft, grues pugnare cum pygmais. Res ea nultis habita eft pro figinento, pro mendaio. Aldrovandus ait : Cùm pygmeos dari regemus, grues etiam cum is bellum gerere, ut abulantur, negabimiss, $E$ tam pertinaciter ne, abimus, ut ne jur antibus credamus. Sciticet bo. minum narrat a afertionis fundoment a funct. At poorum bominum ? Primism Pö̈raram : po peregrinantium, fed

....... PiEzoribus atg poëtis

2uodlibet audendi fermper fuit eqpa patesfas.' Peregrinantes verò fiden perdiderunt jam dusa dum. Ec.affirmare non veretur Strabo, unipesCos Indice foriptores fabutamenta friptis com -

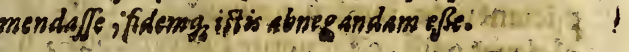


320

ZOOLOGIA

CAPUT VII.

De Ciconia.

Praceptum.

Ciconia eft avis glottorans, prudens, calta \& jufta.

Qveficones.

1. 2vodnam nutriment um ciconie fit? Refp. Nutritur ranis, lacertis, bufonibus, fe:pentibus. Hinc ftagna amat, \& hortos, \& \& prata, aliaqve irrigua loca. Quondam in Theffalia magna afficiebantur pazâ ciconiarum occifores. Serpentibus enim mirum in modum fcatebant fta gna.

II. Quaram magnitudo?

Refp. Angetur valdè \& crura habet longa, longum collum, longum roftum. Pennxalbxfunt, nigris diftinctx. Roltrum craflum eft \& fufcicoloris. Non multum habetcar. nis, pennarum autem copia magna eft, caus. da brevis, ad volatum minus apta.

III. Quanam generatio?

8. Ciconia cafta eft, \& ycneri non indulget, iifi in nido. Ovis non fomina tantum, fed \& mas incubat. Spatio menfis abfolvitur ineubatio. Interdum ovum aut pullum qroqve pjiciunt nido, famem metuentes. Cum ad- lelcunt pulli, educuntur à prontibus, ut ipíinet qुvarant vjêm.

IV. Qus: 
Refp. Frigus prefentiunt, unde â nobis avoant, loca calida petunt. Alias etiam tempetates fentiunt, anteqvam veniunt. Cùm enim mminent, in nidum inedium ambobus pedibus le confeftim liftunt trifti habitu penzas diffundunt, roltrum in pectus condunt, lumas ceu barbam promittunt, vultumqve demiflum eò obvertunt, undè tempeftas ingruit.

\section{Qualis affectus?}

Refp Odium habent cum ferpentibus, bue fonibus,vefpertilionibus. Virgilius ait:

Candida penir adis: longis invifa colubrise Elianus fcribit: Ciconia nö modo magno veßpero. rilionis tenceur odio: fed bas etiam illius.

VI. Qualis motus?

Refp. Volatum habent nunc altiorem, nunc humiliorem, nunc velociorem, nunc tardiorem. Dum volat, pedibus moderatur iter, velut gubernaculô nauta. Et uni innititur pea di plerumqve cùmvigilat, uni etiam cum dormit, caputg்; humero alteri imponit.

Vl. Quenam affecitio?

Refp. Ciconin a vis glottorans eft. Linguxe cmim \& roftrimotione glottorat. Et roft rum modo in hoc, modo in illud latus, modo in pectus, modo in tergum jacit, cum crepitat, Verfus eft:

- Glotcoratimmenfa de turre ciconiairoftro.

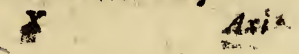




\section{Z.OOLOGIA}

\section{isxiomata.}

I. Ciconia avis aftiva eft.

Ut grues fic \& ciconix fugiunt inclemen. tiam frigoris. Abiturx in certis locis congregantur, \& more gruum, gregatim difcedunt. Noctu id faciunt, non interdiu. Ma. nè circumvolitant \& non tàm redire, qvàm rediiffe ânimadvertuntur.

- Il. Cic onis carent vitios, preft ant virtutibus.

- Profunt omnibusCiconix, nocent paucis. Columbasnon dilaniant ut accipitres. Gallinas non rapiunt ut milvi. Non vefcuntur $c_{a}$ daveribusut vultures. Non in confpectu ho. minum congrediuntur, ut anates Non furto res auferunt ut corvi: fed juftitiam, caftita. tem, prudentiam \& omnem virtutem exercent.

\section{A P UT VIII. De Ardea.} praceptum.

Ardea eft avis clangens, vorax, fagax, nimofa, arduum habens volatum. Qpastiones.

Refp. Devorat pifces, non minores tantum, fedintegras anguillas, aliosqve majores. Qfreis etism infidiantur, qvorum carne de. lecantur maximè. Ingrediuntur aqvas, de 
acili negotio venantur pifces Majores aqva ifuerint, ftantes in littore pifces q quos de. orent, expectant. Accurrunt enim illir, ni dore pedumallecti, \& præda fitut animali oraci. Hisc pifcium inefcacores, Antese sedipem

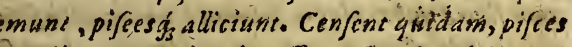
manibus comprebendipoffe, fiardesoleo inun: gantar.

II. Quenam magnitudo ; Córpus parvum rion eft, fed adaccipitris qrantitatem proxımè accedit. Roftrum longumeft, cavum \& capiendis pifcibus aptum. Collum longum habet 8 infolutum. Crura etiam longa funt, \& digiti pedum terni. Corpus totum nacilentum eft; renue \& leve.

\section{Quevam generatio?}

Refp. Dicunt ardeastanto coire dolore, ut lachrymas emittant fangrineas: formellas etiam fummo ctim dolore parere: sed zidit Alberius coire arsicas ova parere lechicymas illas non vidit, neǵ, dolorem tentum oúfsrvadis. Lacbrymatiam ad bruta non refercinda fant: \& fidifficilis partus primus, faciliores cieteri es une.

IV. Quinam fenfatio?"

Refp. Prafentiunt tempeftatem; quâ inminente multo cum clangore avolint. Atdrovandus, fapra nubes efferri rcribit, dum inquit : Profesí longe magis in eo animali ad. $X_{2}$

miran. . 
$\hat{j}^{2} 4$

\section{ZOOLOGIA}

morandum efl, quiod imminente pluviá fupra ns: ues evolet, ac fi planè calleat, â nubibus pluvias o. riri:qua in re cateris avibus multo prudentior $f f$, que quidem futuras jamj am pluvias optimè prafagiunc, fed eas vicare ne gueūc, guod facit Ardes dumi fupra nubes pluvia fomenta quam altisfsmo volatufefe effert,ut incer alios plerosg gravisfas mos ausores testatum religvit Virgilius:.

.... .... .... Notasque paludes

- Deferit, atqque altam fupra volat ardea nubem.

V. 2ualis affectus?

Refp. A rdeam amant cornices, odio habent aqvila, accipitres, falcones. alaudx. Inimicam etiam vulpem habet, â qva capitur \& devoratur. In pugna ardex \& accipitris multa funt admiratione digna. In maximis anguftiis ardea anum opponit accipitri, \& excrementis pennas iffius confpurcat.Quase cunqve attigerit, corrumpuntur \& comburunitur.

\section{Qualis motus?}

Refp. Ârduum habet volatuIn!, unde \& diciam ardeam putant. Volat autem collo contracto, non exporrecto, ut anferes. Oregatim non volat, licet gregatim nidificet. Pullis enim ejus infidiantur accipitres \& alia aves rapaces. His igitur refiftere ut posfint, femper ardex complures fimul circa nidos verfantar. 
VII. Quenam affectio?

efp. Clangens avis dicitur. Differt veró langor hic abaqyila clangore. Gravior im aquilx clangor eft, levior ardex. Axiomata.

I. Ardea a vis diverforam generum eft. Ardea Grxec̀ cesoorós dicitur, \& â Oræxo er fyncopen facta $m$ Latinam vocem quiam conjiciunt.Germanis rocatur ein Diencr. Dantur autem ardea varia: : cinerea 26 dienfarben Rerger/ alba weiffer Pienger \& tirc vel major vel minor: caftanei coloris $\mathcal{E}_{a}$ tunten farben Dienger : ardea aftra feu fiellaris Jobrouninimel.

II. Lirdea prefaga futuroxum est. Quatuor modis hoc praftat. Cuin caput ectori imponit, cum altum volat: cum plus olito obftrepera eft; cum mediis in arvis ut arenis triftis refidet. Infirmum enim corpus habet, \& ob raritatem cutis ab efflu. riis it aëre hærentibus facilè afficitur. Hinc dolorem variis geftibus prodit, $\&$ futuram cempeftatem vitare conatur.

$$
\begin{aligned}
& \text { CAPUT 1X. } \\
& \text { De Pelecano. }
\end{aligned}
$$

$$
\text { Praseptum. }
$$

Pelecanus elt avis boans, vorax, folitudi nem amans, humilem habens volatum, 


\section{Qpaftiones.}

I. Quodnam Felecani nutrimentum fit?

Relp. Nurritur pifcibus, ferpentibus,vermibus, \& arundinum ramentis. Capturus pifces non toto corpore meigitur, fed in caput pra cipitanter volvitur, collum fubindè demittit, dorlo interion fupra aqvas eminente, pilcemq; obvium ampliffina fauce exceptum devorat. II. Qmenam magnisudo? Refp. Corporis magnitudine aqvalis cygno aueanferieft. Penna funt longa \& forisal. bicant, in fundo rubrum colorem oftendunt. Collam longum eft, longum roftrum, crura brevia. Ala longiffime funt, in extremitate fummánigra. A polteriore roftri parte datur ingluvies, velut facculus propendens. Mira hujus ef capaciras, adeò ut in hocutero parvuluspuer Ethiops aliqquando inveatus fit.

\section{III. Quenam generatio?}

Refp. Avisperegrina \& incognita eft. Deovis \& incubatione pauca dant autores. In terra nidificare \& fcrobem facere dicitur. Incubant ibi ovis anferinis xqualibus. In pullis enutriendis fingularis occurrit benevoléntia. Alıundè fi non fuppetit cibus, efcul enta qva prius fumferunt, revonunt.

$$
I V . \text { Qvenam Jenfatio? }
$$

Refp. Defenfibus nhil dignum notatu occurrit. 
it. Inhabitat enim loca ab hominum sonfortio remora, paludes, fluvios \& maria. Undè literæe facre Davidem Pelecano fimilem tradunt, cum errabundus per folitaria loc a fugit. ..V. Qvinam affectus?

Refp. Pulles amat mirificè, \& ignem circa nidum â venatoribus excitatum, non absque vita periculo extinguit, Aldrovandus fcribit: Animofi atǵs imperterriti ante omnia animantia leones: illi tamen tàm feroces, tam in-? victi, tanto corporis animig' vigore prediti, consternantur ftat im ad unius pretent e faculacon=Bectum, praǵs timore propemodum exanimafount. Videt Pelecanus ignem, iujus non igno rat vehementiam, audacter accedit, ardorem. in nembra fingula intolerabili cruciatu penetrantem fentit, neg loco dimovecur exuritur pee nècoca, negitantillü qpidéconfternatur, patien-s tisfimago cöfantia pigens intenta potius, qpãfue mortis genere omnium atrocifimo conficitur, tane. ta in ea cbaritas, tantus amor, tanca vis pietatis? elucefsit: E quispiam audebit eam ftuporis infa-? mulare, of maleferiatam avem dicere?

\section{Qvalis motus?}

Refp. Altum volatum non habet, fed petit ima, innatat aqvæ, roftroque in fundum demiffo pifces excrahit. Volant nunc foli, nuiac X 4

grega- 
gregatim. Cum volant, fonum alis edunt,ficut cygni.

\section{2vanam affectio?}

Refp. Pelecanus boare dicitur. Vocem enim habet torvam boatui norr abfimilem. Undè \& Onocrotalus dicitur, quia voce rudentem 2finum refert.

\section{Pelecani defcriptiones varia funt.}

Nomen ett à Graco $\pi \varepsilon \lambda \varepsilon x \alpha^{\prime} \omega$, rodo. RoAtro enim rodit arbores. Aliis dicitur, quod pellem habeat canam, feu plumas albas. Nunc deferibitur per ingluvi-: em illam maximam \& vocem abfurdam. Undè alio nomine Onocrotalus dicitur â voce afini. Germanicè §ropffuogel Nunc fub ar. dex fellaris fpecie notatur, qua ingluvie caret, nec aqvis inmatat. Nune $\mathrm{Platea}$ dicitur \& Palmipes â Plinio \& Gaza. Germanicè ber Soffler/oie !dffelganßs. Nunc fub Ipecie avis pectus vulnerantis depingitur. Undè Aldro. vando dicitur ber \$naḩler-ober gemeine po. belspelican. Vulgaris \& vana defcriptio ul. tima : minus accurata fecunda.

II. Pelecanus pictiorum E anigigorum nonnulo lorum figmontum eff.

Pictores Pelecanum adunco pingunt roftro, pectus fauciaitem, \& pullis mortuis fangvi. nem e丹luentem communicantem, qvi ore hi-

ante 


\section{PHYSICA:}

onte recepto fangvine vivificentur \& refticuantur. Hieronymus feribit: Pelecanum, cum uos liberos a ferpente occifos invenit, ligere, $\sigma^{\circ}$ e E latera fua percutere, \& excuffo fangvine sorpora mortuorum in vitam revocare. Dicit Aldrovandus : Egoprofecis $\dot{s}$, nejuranti eacredam. Dicimus ros: A morte ad vitam non. datur regreflus per naturam.

\section{CAPUT $X$. \\ De Cygno}

Preceptum.

Cygnus eft aris drenfans, candida ,robufta, animofa, natatum magis qvàm volatum amans.

\section{Qpaftiones.}

I. 2 penam nutritio?

Refp. Vivit herbis \& granis. Carnibus non vefcirur nifi in pugna, ubi ex iracundia alterum devorat. Ariftoteles ait : Oloribus y ut alter alterum devaret, in more off, maximb ${ }_{2}$ in polucrum genere.

II. QDanam magnitudo?

Refp. Formâ anferi fimilis êt, fed multo major, totus candidus, pedibus nigris. Pennas. habet molliffimas, quæa â mollibus inlectis expetuntur maximè. Roftrum latum \& in extremitate obtufum eft, ferratum falcis qi in moe dum. Collum longisfimum elt, multâ carne: $\mathrm{X}_{5}$ pradi. 
330

\section{ZOOLOGIA}

preditum. - Unde aqvila magnum cernens cygnum, aves minores dimittit. Unum enim cygni corpus ventrem famelicum exfaturat melius, quàm decem ac plura aliarum volucrum.

III. Qvenam generatio?

Refp. Semel anno parit idque initio veris. Libidinis tempore colla mares applicant fominx naribus, amplexandi gratia. Poft mutucs illos a mplexus mas foeminam confcendit. Facto congreffu tàm mas quà on foemina aquis fe immergunt. - Plures producunteos. quefpeciofos fatus. Ovafuas oblonga ;teftâ dura obducta.

\section{Qvalis fenfativ?}

Refp. In fenfu nec exceffum, nec defectum habent. Aqvis delectantur maximè, commoranturqve inlacubus, paludibus, \& $\mathrm{fta}$ gnis. Prxferunt Atagna fluminibus, præfer. im cum impetu labentibus. Qvietiora enim funt Atagna, natatumquenon impediuat.

\section{Qvalis affectus?}

Refp. Fortis eft cygnus, \& corpore \& animo. Pugnat cum aquila, \& vincit qvandoque. Plures cygni unum aqvilam fi adoriuntur, fuperant. Aqvila unum cygnum â cærteris feparatum fi offendit, vincit atque ungvibus diferpit. Pugnam cygnus non incipit, fed rovoca tus atque la cesfitus fortiter fe defendit. 


\section{$\therefore$ PHYSCA.}

dit. Exiractundia eo progredịtur, ut cygnus: cygnum devoret, \& nec pullis nec ovis parcat..

\section{Qoalis mocus?}

Refp. Benè nitant, malè ambulant, mediocriter volant. Malunt narare in aqqvis, quàm volitare in aëre. Nata ntespedem alterum. verfus caudam extendunt, ut illo tanquam. yelo utantur. Longius iter fi abfolvendum, gregatim volant, gregatimque natant. Ev pofteriores caput imponunt dorfo anteriora.

$$
\text { VII. Qualis affectio? }
$$

Refp. Cygaus drenlare dicitur juxta verfum: Grus gruit ings glomis iygni prope flumina. drenfant.

Sibilare quoq́ve dicuncur, fed cum anferibus atǵ̣; aliis vocem hanc habent communem.

\section{Axiomala.}

\section{Cantio cygnea fgmentum est. w hitit}

Cygnum yitx lua finem nofle, 'lxtogreanimo expectare, ac lvavisfina cantione fune bre carmen fibimet canere credunt. Innumerabiles id ft atuunt Autares. Homerus, $F$ laso, Ariftoteles, Ciceronseneca, Virgilius, Lucretius \& alii. Laboriofisfinus eciana Aldrovandis, ob unanimem omnium omnis xvi Scripto : rum confenfum, \& ob atteriam afperam ad tuba cantionum efformasam, dulce melos, ? 
के 2

\section{ZOOLOGIA}

prafertim morti vicinos cygnos cantare affe: rit. Sed nihil frequentius, qvam multitudine, qvàm autoritate decipi. Et quam omnium literis demandata hac cantio eft, tam in audita, nullique unquam audita fuit. Trifti etiam ac placida, ac taciturna ante obitum fiunt animalia. Si aptisfimum inftrumentum, fi tubam elegantisfimam nacti fune cygni, cur vigentes, florentesque concesfis non utuntur bonis? Placent verba Scaligeri, De cygni ve -ò, inquit, cantu fuadisfimo, quem cuns mendaciorum parente Grecia jact are aufus es, ad Lusianitribunal, apud quem aligvid novi dicas , Statuo ie. OMultitudo ingens ad Garatonum flupium. Qvid dicam tibi? Anferesfunt. Sic Scaliger cygnum canentem cum crepitante \& fibilante anfere comparat. Eucianus, quem judicem conftituit, nautas qvafivit, an cygni cantibus ac modulis indulgeant? Retponde. runt hi, fe audiviffe cygnos, qvi incomptatn \& inamxnam vocem ediderint. Adeò quidem ut corvos \& graculos illis collatos Syrenas effe confirmare posfint.

II. Candidus cygnus candoris exemplumest.

Candor tygni proprium dicitur. Provere bium eft: cygno rarior atro. Et verfus: Rara avis in cerris nigrog fimillima cygno. Candori corporis candor animi refpondet. Pacem 


\section{PHYSICA.}

Pacem babet cum omnibus avibus, \& non nif lacesfirus pugnat. Pugnat autem fortirer, \& ne bellicofisfome quidem aquilx cedit. Domi \& forisica fe gerit, ut laudetur ab omnibus, culpetur â nullis. Summa làudum hac eft: Cygnus benè nafcitur, benè vivit, bend ferrefcit, bencmoritur.

$$
\begin{aligned}
& \text { CAPUT XI. } \\
& \text { DeAnfere. }
\end{aligned}
$$

Precieptum.

Anfereft avis gingriens, robufta, timida, natationi magis, quâm volationi dedita.

\section{Doestignes.}

\section{Q2enamonutritio?}

Rerp. Nutritur herbis, frumenris, oleribus. Quidqquid fermè offendit, devorat, \& in terris $\&$ in aquis. Hinc \& rufticis imprimis gratus eft, non tàm, qvia magni fructus, qqvàm quia parvi oneris eft.

\section{Quxnam asgmentatio?}

Refp. Corpus magnum eft, collum longum, roftrum latum, craffum, \& lerra inftar dentacum. Pes infimus latus eft \& planus, inrercedentibus inter digitos membranis. Hine palmipes, planipes, \& latipes dicitur, Multa conftat carne, qva grata gultui, fed difficilis coctionis oft, onultisque fratet excrementis.

Color 
Color non niger eft, nec viridis; fed vel albus vel cinereus, vel ex utrogre miftus.

\section{HI. Quenam generatio?}

Refp. Avis verecunda eft, \& coit non fre. qventer, ut gallinx \& anates: non qrovis annitempore ut boves : non in omuium prafen. tia, ut fues \& canes: led plerumque feorfim in fluminibus \& Aagnis. Singulis maribus qvinque debentur foeminx; qua pariunt duodecim ac plura ova. Incubat cantum fomina, \& excludit circa vigefimum octavium aut trigefimum diem. Praftacautem propria ova füis fubjicere matribus dum aliena admite tere nolunt.

$$
\text { IV. Quenam jenfatio? }
$$

Refp. Multum auditu valęt, ut \& cum apro certare posfrt. - Tempeftates pralentit, qvas continuo clangore pranunciar. Multi ex offe pectoris ante folltitiū hyemale colliguni, qvàm fava fit futura hyems: \& qvamdiu duratura, Si pectoris os clarum eft, efis carni. bus hiems erit rigida. . Si fpiffum \& opacum, nix plúrima hyemsque tepida fequetur. Fides efto penes autores.

\section{$\nu$. Qualis affictus?}

Refp. Animal timidum eft, \& ad quemvis ftro. pitum exhorrefcit. Sed cum commodo aliqro conjuncta timiditas elt, quia pracavet pcricula 
pericula imminentia. Pro pullis autem dimicat animofitate maxima. Tunc pectori. bus fe percutiunt, alis diverberant, roftris hæerent, clangaribús increpitant.

\section{Qpalis motus?}

Refp. Anceps animal eft, terras \& aquas a. mans:

- Anfer aquis gaudet, lylvis uper, aëre falco. Minas valet alis, gravemque haber volarum. Volat autem exporrecto collo, ficut contracto ardea. Bene natat nec absque aquis facile degere poteft. Mira in iplo pedum eft velocitas. Qvondam pedeftri itinere inlonginquas venếre regiones.

$$
\text { VII. Qualis affectio? }
$$

Refp. Clamare, canere, Atrepere, garrire, G. bilare \& gingrire dicuntur anferes. Maxime propria vox eft gingritus bas fdinattern. Iterum iterumqque frepitum huncedunt, cum. vorant, cum ambulant, cum volant. Hine conventiculum mulierum, anferum more blatsrantium o pulgò forkm anferinum cin Sోånfs: mardit appellant. Axiomata.

I. Anfer ferus Es domefticus ejusdem funt Beciei. Eadem in is effentia, eadem propria, ea dem corporis itructura, Moresfunt ali $i$, feriqqe nunqvam manfvercunt; domeltici ferie interdum fefe milcent. Caro ferorum do. 
$33^{6}$

\section{ZOOLOGIA}

mefticis prafertur, cùm minus fcateat excre. mentis. Feri acfylveftres hyeme imminente difcedunt, \& ut grues tum volandi duces, tum fomni cuftodes habenc.

II. Anferes intelligurt voces fwas.

Habent voces diftiuctas anferes, \& alio dif. cedentes, alio peregrinos, alio familiares $\mathrm{ex}$ cipiunt. Diverfi illi clamores aliud nihil qràm figna latentium affectuum funt. Qvol nobis vox articulata praftat.

III. Anfer fingularis prudentic non est, simplex eft \& ftulta avis,parū habens ingenii. Femina hominem minus fapientem, pruden. tem anferem vocaut etuefluge Şan f. Et verIus eft:

Colum, non animum mutant, quitransmare currurt.

Redditur: Es flogeine Banß úber sen Diţein/ unb fam Bigad weted bsim. Proverbium eft: Bibente anfere uno, bibic $\mathbb{O}$ alcer. Hoc eft, quod unus futeserm facit, omnes faciunt.

\section{CARUT XII. \\ De ..Pavone. \\ praceptum.}

Pavo eft avis pupillans, pulcherrima, fü perba, libidinola, 


\section{Qvaftiones. \\ 1. Quas nutritis?}

efp Nutrituromnis generis frumentis , aximè hordco. Ubi freqventiores funt, er agros vagantur, fpontè fe pafcunt \& vevere altior s arbores petunt. Sin pingrives lis, inqvit Aldrovandus, tunc bordeum like. aluer offeras; nam borcieo,gvamues alioquin oini frumento refcantur, inter catera grana maimè oblectantur.

\section{Qvanam magnitudo pavonis?}

efp. Egregra eft, fed pennarum potius, vam corporis aut carnis ratione. Caput xigium elt, collum longiusculum, doram maculis qvamplurimis confperfum, in apite fpeciofa extat crifta, qva coronæ nftar illud exornat, \& non tàm è pennis/. vàm ê fcapis tenerrimis viridescentibus onflata eft. Unde Plinius ait: Pavonis apiem crinice arbufcule conftituunt. Cauda tantâ olorum varietate, taniogís oculorum nitore orata of , ut naturam nibil pulc brius fingere pouiffe exiffimatum fit. Ita difpofita eft, ut in luas quafi dividatur, majorem \& minorem. te oculi pennarum inftargemmarum nitio liffimarum omnium oculos in fe converunt. Magna tamen differentia inter maa es \& fœminas eft. Pulchriores enim illis? ax mians formof $x$ funt.

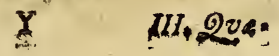


338

\section{ZOOLOGIA}

III. Quenam generatio?

Rerp. Pavo malculus falaciffimuseft, ut uni qvatuor aut qvinqve fromellx concedend $x$ fint. Adeò libidine flagrat, ut incubantem etiam fominam invadat atqve ova frangat. Fominxova pariunt duodecim non couti. nuatis, fed binis aut ternis diebus interpofitis. Enituntur autem ea plerumqve noctu perticis infiftentes. Foenum igitur aut frramina inferenda ftabulo, ne frangantur. In. cubant dies viginti \& leptem aur viginci o. co. Ut enim ter feptem dies dati generi gallinaceo : ita ternoveni pavonino gencri, IV. Qvenamsenfacio?

Refp. Prafentire venena \& loca ubi recondita funt, fugere dicuntur. Deqva prxrogativa Aldrovandus fcribit: Apud mefide carent, aliigvibus lubet, fidem adbibeant. Cum plus folito clamitant, pluviam prefagire credun. sur. Paracelfus autem infolitum illum clamorem, mortem alicujus in domo, in qva "habitat portendere autumat. Sicuti enim, inqvit, vulturi â natura infitum eft,ca. daveris trans mare odorem percipere, \& $2 d$ id fe convertere : ita \& pavones odorantur cadaver futurum. Sed nugamenta funt, cum fenfus verfetur circa entia; non circa non entia.

V. Qvalic affectur?

Refp. 
Refp, Malevolum \& invidum dicunt pavo. nem, qvia tegit excrementa fua, ne cedant in hominum ufum. Sed leve admodum argumentum hoc eft, \& vitium qvarit, ubi pofinit laudem natura prudens. Pavo munditici ftudiofus ac fordium hoftis eft. Hinc excrementa tegit, ne aperta exponantur luci. Idem feles, idem canes agere cernimus, absque invidix fufpicione.

\section{Qualis motus?}

Refp: Parum volat, fed greflu majeftatem qvandam prx fe fert. Non enim vulgarem habet inceffum, fed tardum ac regium.Hinc comparatur cum Junone, de qua Paræmia ha. bet: funonem ingredi. Dicitur de is, gvi fpectari gaudent, \& fuperbillimo inceffu movent oculos \& animos.

\section{Qualis affectio?}

Refp. Pupillare dicitur, undè verfus; Pupillat pado, trinfat birundo vaga. Nocku expergefactus vociferatur, fed qvo fine non conftat. Perfvadent fibi multi cla. morem illum triftitix fignum effe. In tenebris enim conftitutum pavonem pulchritudi * nem fuam cernere non polfe, eamqve perdidiffe exiftimáre. Dicendum potiùs, tempefatis mutationem clamore fuo indicare ali-: sem pradentem.

$$
\therefore \text { I } \mathrm{Y} \text { Axiop }
$$




\section{ZOOLOOIR}

\section{Axiomata.}

1. Pavo avis pulcherrima eft.

Pavoni formæ palmam ê volucribus dedic natura. Nullam, inquit Cardanus, avem pul. cbriorem papone nofiro fingere natur am poffe credam. Solon â rege Croefo purpurâ auroque ornato \& in throno fuo regali conftituto, interrogatus, nunqvid ungram fpeciofius qvicqvam Ipectaffet? Refpondit: pavones \& phafianos venuftiores fibivideri. Fabula eft, aves plerasque in electione Regis pavoni ob pulchritudinem, najeftatem, faltumque planè regium, imperium committere voluiffe. Sed corvos ac cornices a quilam, non tam ob formofitatem, regiumque fplendorem, quàm ob rapacitatem ac tyrannidem, pavoni pratu, liffe.

II. Pavo avis fuperbißima $c$ It.

Formam fuam ipfe m ratur, cum aclaudatur : magis magisq; componit greffus, \& gemmantem oftentat caudam. Præclarè tenet, ubi : forma fita fit dignitas, hinc caudam elevat, undiqve expandir, feipfum circumagit.; \& qvandam qrafi pompam pulchritudinis agit $\&$ exercet. Necignorat folis fulgorem corporis pulchritudinem angere poffe, undè ifti fe exponit, coloresque variis modis immutat, \& ģvovis fermè greffu novam formofitatis: prabet fpeciem. Hinc Ovidius ait:

Laudas 
Laudac as ostendit avis junonia pennes, Si tacitus /pectes ip a recondit opes.

III. Pedes pavonis deformes non funt.

Pedes cinerei funt, maculis nigris confperf氏 \& calcaribus armati, Omnium fermè fenteñ. tia eft, pedusn deformitatem zerrere avem, ut. qroties compiciat cos; contristetur E pre dolore vociferetur. Cardanus ait: Sentit pado pulcbritudinem fuam, exclamatğ dum pedes intuctur, deformitatem eorum appernatus. Sed refpondet Cardano Scaliger fubtilis : de pavo. nenoftro plebeja narras. Conspectis cruribus, quodec iurpisfint, vociferari. QDis boc tibi Cardane palam fecit? Qpoties ipfe fibi crura obtuetur, quare non femper, fed aliqpando luget in-: vifum 2 naturadecius? Qvoties evenit ei ut pafcatur wec crura consficiat fua. Ulbifigat peftigium, nefcit: niffoculis captet locum, in qpo posate pedem. Ac eoßpectaculo cum fot â primis aßpetus annis, quid nopi paticur in veteri memoriâ : Anicularum fabella funt be, Cardane, â quibus, modo aliqvid dicas, nusquam te abstinere video. Qvid verò babeant ejus pectes obscanitatis, baud equidem fcio.

\section{CAPUT XIII. \\ Dè Gallo Pavone. \\ Preceptum.}

Gallo pavo eft avis crocitans, pulchra, fie$\mathbf{Y}_{3}$ perbad 
342 ZOOLOGIA:

perba, libidinofa, maximè cum pavone conveniens.

\section{Qvestiones. \\ I. Qvenam nutritio fit?}

Refp. Nutritur hordeô \& avenâ, inftar galli. narum \& anferum. In frigidis regionibus agerrimè vivit, \& non nifi maximo labore educatur. Ante centum, ef quod excurrit, anwos delata avis bac ex nova India in Europam. ef. Et cum carnem lautisfimam ac laudatis. fimam habeat, nonnifi ingentibus fumptibus alitur.

II. Qvanam magnitudo fot?

Refp. Magna a vis eft, \& collo, \& cruribus , \& carne, \& pennis. Collum non fecus ac ca. put â plumis nudumeft, \& tantum pelle pur. purafcente obducitur. Capue duriffimum êt, conftans appendiculâ quâdam carneâ. Contrahit hanc, cum cibum capit, aliàs tantoperè eminet, ut digiti longitudine roftrum fuperet. Crura proceriffima funt, \& cauda longiffma. Cum irafcitur, totus inhorrefcic plumis caudamque in rotam verfat, \& gradu - Cuperbo accedentes exterret. Mas foeminá major eft, cæteris ad è conveniunt, ut decipiantur fxpè incauti, fominam pro mare ba. bentes.

III. Qpenam genoratio?

Refp. Salax avis eft, \& mas ex, defectu fominarum 


\section{PHYSICA.}

narum gallinas $\&$ anates invadit : foemina in maris abfentia gallos invitare, urgere \& coge. re conatur. Uva pariune quindecim , viginti \& plura. Incubatio diebus tricenis abfolvitur, \& fi mari pateat acceffus, invadit incubantem frangitque ova. Pav́ones etiam cum gallo pavonibus mifcentur \& plurimos proa creant pullos.

\section{Qvenam Jenfatio?}

Refp. Sentit facile frigus, qvo vehementer af ficitur. Pluvii fi fuerint dies, labore multo, multisqve curis vix fervantur pulli. Radiis folaribus etiam adeò afficiuntur, ut concidant \& fubita morte pereant.

\section{Qvalis affectus?}

Refp. Iracundum animal eft, prafertim cùm: libidine flagrat. Pugnant inter fe totis viribus, \& glabrum caput roftro validisfimo adeò percundunt, ut nifi fortisfimum effet cranium, frangeretur, Nonnunquam vero tanta iis timiditas eft, ut ne cum gallinaceo qvidem gallo ineant pugnam, totiesq́; lacesfiti turpiter fuga Gibi confulunt.

\section{Qvalis morus?}

Refp. Parum volat, cum grave admodum fabeat corpus. Inceffus máris fúperbus eft \& pavoninus. Uc enim pavo inceffum lentum, faftuofum, \&ut vocant, Junonium habet : ita 
344

\section{ZOOLOGIA}

\& gallo paronis greflus nil mifi faftum referr. Gallina amore cum capitur, fefe circumfpicit, lento inceflu accedic, ac corporis animiggve dotes oftentat.

VII. Qvalis affectio?

Refp. Sicut corpore \& animo partim pavo. nem, partim gallī refert: ita voce no mul. tum iis disfimilis eft. Aldrovandus ait : Gale lopavo vocem quardam edit, crocuationi galli-acee pavoniaǵs non disfimilem, cum fragore nempe per collum longè laceǵs pagantem, quafi inftar liquoris in dolium infuji obstrepentem.' Axiomata.

1. Gallopapo eft quafi species.

Mentitur fpeciem, fpecies non eft. Sicut mulus non eft fpecies, fed monftrum fpecie mutans : ita gallopavo mronftrū eft, ex gal. lo \& pavone natum. Prima n.origo fuit mófrofus illecongreflus, ex quo natum hoc monftum eft. Placet tamen fpeciebus annumer re gallopavonem, finon ob rem io pam, faltem ob fimilitudinem.

II. Gallopavo cedic pulcbritudine pavoni.

Speciofus quidem eft, \& formâ multo rú in fe vertit oculos. Caudam etiam jactabundus admodum pavonis nore in orbem explanat. Sed caret fpeciosâ criftâ, quâ fuperbit pavo. Caret etiam oculis in cauda; ob quos fáfigium tenet payo.

III. 48 
PHY I CA.

III. Appendicula exponit gallopavonis affectus?

Pellicula illa carnofa criftam galli referens, nunc colore caruleo, nunc pallido, nunc rubro tingitur. Fervente irâ, adeò rubore fuffunditur, ut vel lychnum ab ea accendere polfis, Non fecus ac hominesirati vindictra cupiditate flagrantes, adeò exa rdefcunt, ur omnem fanguinem proje. ciffe in faciem videantur. Hinc proverbitz de iratis: ir firhiet aub/mie ein Calcutifber Sabquin Samn. Caufa rubedinis humores ac fpiritus funt in faciem irruentes.

IV. Gallo pado of enditur colore rubro.

objecta mavent fenfus \& externos \& in. ternos Hinc in gallopavone ipfe quoque fanguis movetur rei rubra intuitu. Sangui-, ne agitato, agitantur fpiritus, qui fervidio-' res facti iram magis concitant. Hoc non ignoraffe videntur Perfa, qui cum Judxis pugnaturi, fuccô uvæ \& mori in elephantes fulo, eos irritare \& in pugnam provocare fueverunt.

\section{CAPUT XIV. \\ De Gallo.}

\section{preceptians.}

Gallus eft avis cucuriens,animo 2, fuper $^{2}$ ba, libidinofa, tardi volatus.

Qveftiones.

I. Quanam nutritio?

I.

$\operatorname{Ref}$ ? 
Refp. Nutritur etiam omnis generis granis. Etiam vermes devorat, ac ftercora, venenataq; anir.dlia. Pane oblectatur \& carne, nec â lapidibus abfinet. Avis igitur omnivora eft, nullog; difcrimine vefcitur quibusvis. I1. Quanam augmentatio of formatio?

\$2. Quantitas egregia elt, \& gallus gallina major. Multum etiam; differunt corporis ftructurâ mas \& fơmina. Mas criftam in ca. pite habet erectam, qua nec ca ro nec cartilago, fed peculiaris fubftantia eft, fanguinis copiâ rubens. Fœmina crîtâ quidem nó caret, fed ea tantum minor ac depreffa eft. IMas fub mentoutrinque à malis palcam habet egregiam, barbx in modum dependen. tem. Fominis ut crifta minor, fic \& palea minor eft. Mas in collo jubas feu longiores plumas collumac cervicem undióue ambientes habet, quas iratus explicat, fuamque generofitatem oftendit. Mas caudam habet egregiam, in eaq́; duas longiores pennas. Fœminis \& cauda vilior, \& plumæ colli minoresfunt. HII. Quanam generatio? 7x. Sala x animal eft gallus, gallina autê non xque libidinofa. Unus gallus plures habet gallinas \& fingulis diebus : vel quinquagef es init. Pugnat etiam acriter pro gallinis, tantum eo fine, ut folus iis potiatur. Oallina poft coitum inhorrefcunt, \& fefe excutiunt,

non 
non fecus achomines languidiores pandiculationem liabent. In primo partu ova in putamine, cruore fuffunduntur, ob loci an. guftiam. Pariunt ova viginti, triginta \& plura, \& dies viginti incubant.

\section{Quenam fenfatio?}

R2. Vifu plurimú valet, oculisq; intentis So. lem intuetur. Aves etiam rapaces maximè diftantes cognofcit $\& a b$ aliis diftinguit. Guftrm habet exquifitifimum, quia aridiffima quaque, etiam dentibus nondum fraeta dijudicat. Nec exquifitiori caret tactu. Aëris enim mutationes præfentit, ac cantu prænunciat.

\section{Qualis sffectus?}

R. Animofa avis eft, \& iracunda. In certamine pertinax eft, \& pugnam fortiter init, acriter urget ; ac feliciter finit. Magna animi conftantia eft, hofte præfente. Excelfo enim animo adverfariumadoritur, terram ferit, plumas circa collum exigit, pennas cauda deorfum furfumq; vibrat, hinc infilit, \&e nunc acuts roftro, nunc calcaribus ite rum iterumq; ferit. Superba av is eft, \& femper fibi majorê tribuitquantitatem, quam habet ipra. Per fores cum incedit, inclinat fefe, ne fortè ladatur.

VI.Qualis motus?

Refp. Volatu minus valet, greffum autein habet 
348

\section{ZOOLOGIA}

habet fuperbum. Erecto capite incefiuque lento in fimo fuo valdè glorjabundus incedit. Hinc Proverbium : Gallus in fuo ferquili. nio plurimum potest. Qermanicè. Ein Şafin auff frinem פiptite fft oer fércfefte: Non abfinile multum illud eft: duobus gallis in eodem ferquilinio, duobus fatuis in una dosso nö cö-

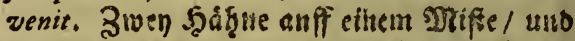

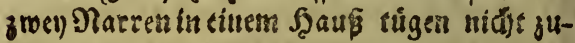
fammer.

\section{Quanam affectio propria?}

Refp. Cucurrire dicuntur galli, fominx glocitare. Notifimus hic galli cantus eft; cujus naturam \& prifci \& recentiores inquifiverunt. Gallinx glocitantis amorem cum ardentifimo Dei amore confert facra pa gina. Varios etiam alias habent clamores, $\propto$ cum invenerunt cibum, galli gallinas, gallinæ pullos, infolito clamore convocant. $O$ va etiä fua non fine ingentibus clamoribus pariunt gallinæ. Axiomata.

I. Certum cantus tempus non obfervat gallus.

Et variis temporibus, \& variis de caufis cantatgallus. Cantat cum provocat ad duellumn holtem, quia avis a nimofa eft. Cantat poft congreffum cum gallina, quia avis libidinofa eft. Cantat, cum cantare auditalium, quia avis æmula eft. Cantat cum evafit victor in pugna, quia animal gloriofum eft. 
PHYSICA.

Cantat cum gallinas de fomno excitare laborat, quia paterfamilias eft. Cantat cum aêr is imminent mutationes, quia tempertatum prinuncius eft. Cantat ante exortum Colis, quia latatur. Sed cantu horas ac miail a obfervare, bonique inftar horologii efle, frabula vulgi eft.

1I. Gallus non edic oos.

Ova in gallinis ad feptum transverfum, hoc eft, in fuperiore ventris infimi parte concipiuntur. Hinc in mediam \& infimam inferioris ventris partem deferuntur, $1 \mathrm{bi}-$. que perfectè elaborantur, elaborataq; exuero per anum ejiciuntur. De gallis vero Levinus Lemnius feribit, in pasria fuaduos onnojos gallos ovis fuis tanto ftudio incubaffe, ur. itiam fustibus abigi agrè potuerint, cives autem oba,ne 6.3filifci exindè emergerent, confregiffe, $\mathfrak{E}$ gallos firangulaffe. Sed nec edunt ova galli, nec ex femine galli bahilicus fit. Dicendum vetuftiorum gallinarum fuiffe ifta ova, 8 eniores gallos cùm maris officium præltare nequiverint, ftultè affectaffe forminarum munus.

III. Multa bomini commoda è gallis of gallinis.

Caro boni fuccieft, grati faporis, facilis coctionis , \& paucorum excrementorum. Cónvenientiflima iis eft, qui minus exercentur laboribus, cxteris non fatis firmum 
350

\section{ZOOLOGIA}

prabet alimentum. Eft tamen aliqua ejus differentia. Primas tenet caro capi, fecun das caro pullorum,tertias caro gallinarum: ultimas caro gallorum.Præter carnem ova etiā gallinarum fuum preftant ufum. Optima funt tromula $\delta$ forbstia, in aqua fervente cocta.In cine ribg qux coqvuntur, cedñt bonitate forbilibus. Qvx ad duritjē majoré coqvuntur, deteriora funt. Omniū infaluberrima quafrica funt in fartagine. Deterio. ra etia féper antiquiora, meliora recétiora. IV. Capus inter gallum O gallinam meatus est.

Sicut Eunuchi \& fpadones nec mares nec foemin $x$ funt : ita capus nec mas eft, nec foemina eft.Fit enim capus, cum inflicto vul. nere evelluntur tefticuli \& refecatur crifta, ac caduntur calcaria. Tunc omnis perit virilitas, adeò ut nec cantet, nec coëat, nec curam familix gerat. Caftigatus pullos du, cere, \& quafi novum animal, novos recipere mores infit. Calcaria autem recifa \& crift $x$ exfectx loco infita, coalcfcunt, nu. triuntur \& augentur.

$$
\begin{aligned}
& \text { CAPuT XV. } \\
& \text { De Anate. }
\end{aligned}
$$

Praceptum.

Unas eft avis garriens, libidinora, fordida, tardi volatus, lacus ac flumina amans. ..." 2vafiones.

1.2uodnam nutrimentum?

Refp. 
PHYSICA:

Refp. Nutritur feninibus, verinibus,ranis ananeis, lacertis \& quibusvis reptilibus.Sor dibus delectatur maximè, \& roftrum ccenc mmittit, ac quicquid reperit, ingurgitat. In qua, quam in terra verfatur lubentius. Gaudet aquis fluviorum, \& difficulter absq; is । vivit, prefertim cum cibis ficcis nutritur.

11. Quenam augmencatio \& formatio? Refp. Anfere \& gallo minor eft. Mafculis omnia mcmbra preftantiora \& coloratiora funt, quam fomellis, Roftrum iis latum eft, lati pedes, latum dorfum. Color in capite $\$$ collo plerumg; viridis : pedes ruffi funt : ala albo viridi nigroq́; colo re diftinctxesút. III. Qusnam generatio ?

Refp. Libidinoium animal eft, \& congresfum capitis agitatione indicat. Mares dua vel tres unam fominam inire certatim non verentur. Mirum quod amoris focios ferre poffint, cum nec gallis, nec anferibus, nee columbis id eveniat. Interdum mares tantæ libidinis fervent $x$ ftu, ut gallinas etiam invadant, licet non deftituantur proprix fpe. ciei fomellis. Ova pariunt plura, \& incuba* tum ablolvunt diebus viginti \& feptem.

$$
\text { IV. Quenam fenfatio ? }
$$

Rofp. Nihil præclari in fenfibus eft. Pennas roftro purgantes ventum præágire dicun: tur, ficut \& pluviam imminentem figniflcas 
352

\section{ZOOLOGIA}

re putantur, cum alias concutiunt, \& fub tecto latere a mant. Cum frequentes congregantur,aut fe fæpius lavant merguntójifuturos creduntur denunciare imibres.

\section{$V . Q$ ales affectus?}

Refp. Anates naturâ timidx funt, \& ad̀ quê. vis ftrepitum expavelcunt. Sunt etram aftutx, \& aquilan aliosq; holtes fxpius fal. lunt. Alianusicribit: cum agutla in anates rapiendas involat, le intra aquam lubrnerfione abdunt, atgó infra aquam natanáo ex alio loco extra aquam eminent. Quod fi aquals illuc quo. que incumbat $v$ instet, verum demerguntur atque tam diufurfum deor/um commcant, cums. quila fucri-fubmerfione fuffoc at a aut d jeefferit in aliam predam licentiorem. Tum enim he de. pofito boftisfui metu adfummam a guam relate rurfus natant.

VI. Qualis motus?

Refp. Greffus tardus eft, adeò ut quandam gravitatem monftret, unde Poëta:

Non velox peninis, of pede jegnis snas.

Caufa tarditatis funt crura breviora, ita formata ut ad natandum magis, quam ad gradiendum fint apta.

VII. Qualis affectio?

Refp. Anas garrire dicitur. Valde clamofar avis eft, \& Pythagoras eam non nifi locis ab bounum frequẹtia femotis alı voluit. ivias.

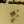

rosers 


\section{PHYSICA.}

vocem habet raucam \& tenuiorem, fœmina crafsiorem. Pontanus de clamofo ait :

Hic clamore grues pecerit atğs anates.

\section{Axiomata.}

I. Anatum naturalis domus aqua eft.

Natura duce undas petunt. Vix egreffx ex ovis, aquain amant, \& natare incipiunt.Plinius aic: Super omnia est, anatum ovis fubditis galline at ǵ exclufis admiratio. Primo non pland cognofrent is fretum, mox incertos incubitus follicitè convocantis : poftrenio lament a circa.pifcin slagna, mergentibus fe pullis naturâ duce.

II. Anaces domefuca es fylveftres, jus dem fúnt speciei.

Eadem forma, eadem potentia natan di, eadem vox, eadem corporis ftructura eft, Plus tamen volatu valent fylveftres, minus domeftica. Caro etiam fylveftriurn magis laudabilis quam domefticarum eft. Non le. cus ac caro anfertim fylvefrium præitantior carne domefticorum. Motu enim huma. res abundantes cü excrementis difípipantur.

CAPVT XVI.

De Corvo.

Preceptum.

Corvus eft avis crociens, nigra, viivax, vocax, \& fagax.

$$
\begin{aligned}
& \text { Qvafiones. } \\
& \text { 1. 2uanam nutritio? } \\
& \frac{2}{2}
\end{aligned}
$$




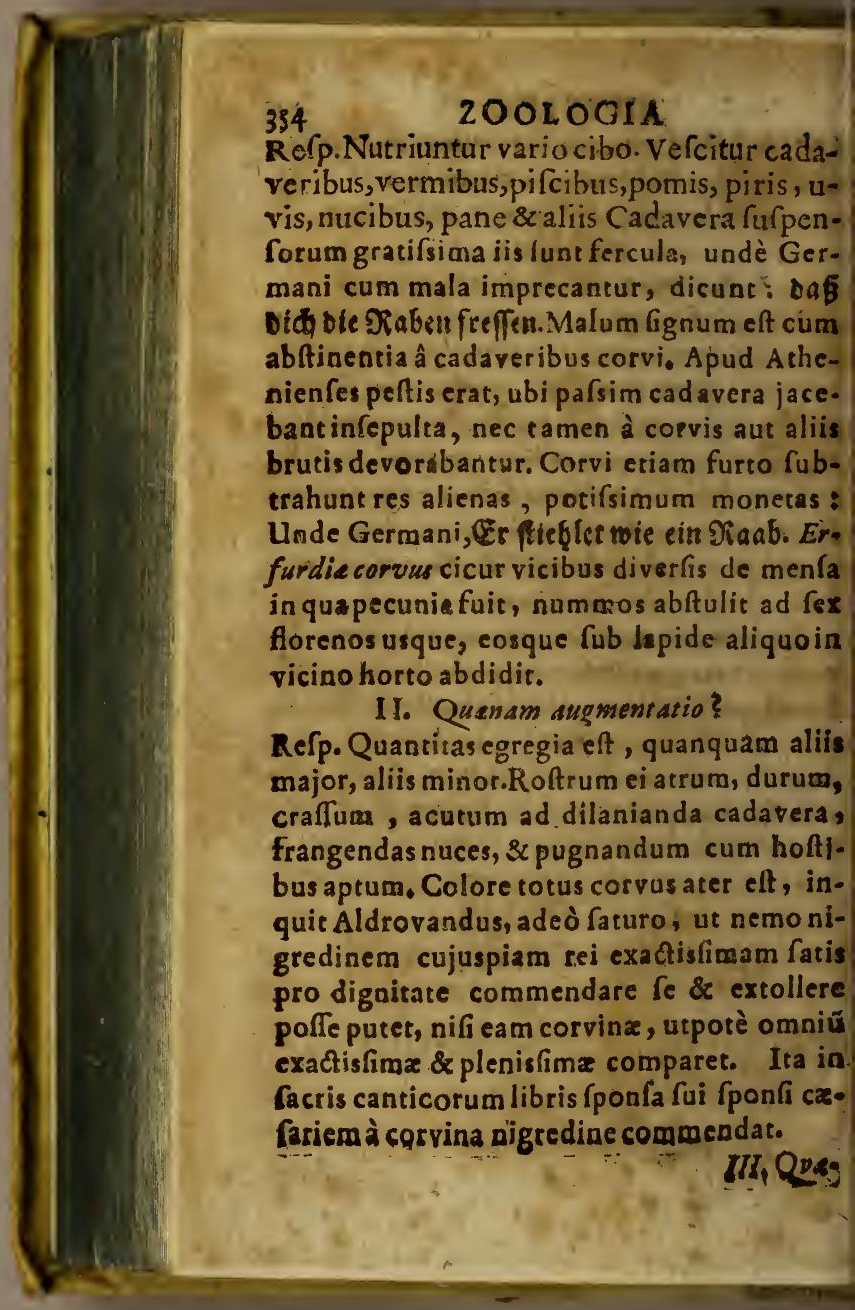




\section{P HYS I CA.}

\section{Quenamgeneratio?}

. Salas non elt, fed rarò coit, femperq; bini nviolara conjugii jura lervant. Ova pariunt ton duo tantum, fed quaruor etiam, aut quinue. His incubant dies viginti. Faciunt hoc nature, menle frilicet Martio, pullosq; aliIrum avjum more nutriunt.

\section{$I V \cdot$ Quewamfenfatio?}

Relp. Odoratum haber fagacisfinum, \& vulurum more cadaverum odores facilè fentit, Hinc ftrage editâ, mox advolant, non fecùs ac fi futuram pravidilient.

$$
\text { V. Quales affectues? }
$$

Refp.Magna corvi audacia eft. Non mortua tantum, fed viva etiam animalia rapit ac devorat. Elianus fcribit: Córvus aquile nibil de animo concedit, quo minus quam bac audax fic. Non exim contra pufilla ientium animalia penire audet, fed E contra afinos $\&$ boves pugnat, quorum is cervicibus confidens cor percucit of mulcoruin effodit oculos.

\section{Qualis motus?}

Refp. Diu non quiefcunt, fed circumvolia tant frequenter. Volatus tamen gravior ac tardio reft cb gravitatem corporis. Clamore hominum nonnunquam factum fuiffe ferunt, ut fupervolantes corvi attoniti \& velut fagit. fauciati deciderint. Majori enim voce äe.'

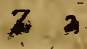

ceas
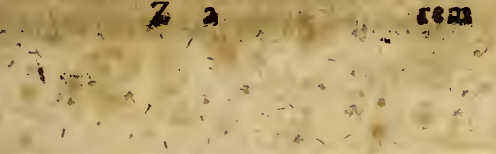
350

\section{ZOOLOCIA}

rem disjunct am fuisfe, nullamque volantib, firmitatem prabuiffe. Sed aut fabula eft, awt alia caufa fubeft. Fortaffis timor deturbavit aves volatuminus valentes.

\section{Quanam affectio?}

Refp. Varias edit voces, adeò ut Fulgentius fexaginta quatuor numeret. Maximè verò propria \& naturalis vox crocitus eft. Nulloenim affectu, nullaq; tempeftace impulfus crocire feu crocitare folet.

\section{Sixiomata.}

1. Nigredo cordi non eft injeparabile accidens. Albi corvi fuêre vifi fxpius in Norvvegia \& aliis frigidioribus regionibus. Niviumafpectum animalia efficere candida exiftimãt. Sed folus afpectus, folus vifus id neutiquam præetat. Deferenda cau/a est ad Janguinem frigidiorem, unde \& homines in locis frigidis albi, in calidis nigri funt.

II. Corvi pullos alere non recufant.

Albos effe corvorum pullos, adeog; deferi â parentibus \& efurire ftrenuè dicunt. Sed nec albi funt pulli, nec à parentibus deferuntur, nec efuriunt. Non minori cura corvi aluae pullos quàm columbx aut pafseres. Laurembergius ait : Dian mađit viel Elagens úber oes Siaben Ulnbarmh̨erz̧igfeit ; nimbt aud bitet.

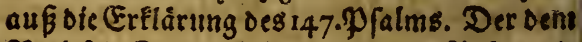
DBieb fein Jutter giebrtoen jungen Diaben ofe 
Jḩn anruffen. Sit alles ersiditet/ falfth/ uno ber Natur uno tågliđan Erfał̧rung ju wieber. Qzanoer ifts das man folden fabiln glauben giebt/Da dodidie Niaben bey uns und fonften hin uno wieber haduffig genung : 2alfo basein ieber biefes rooḩl fonte in Augen/đein. nelimen.

III. Corvorum pipacitas celeberrima eft.

Novem fecula corvum vivere volüt. Hine Theophraftus moriens naturam accufavit, quod corvis \& cervis vitam dederit longio rem, hominibus breviffimam, qui tamé longiflima digni fuiffent. Sed experientia docuit recentiores, ultra centum \& octo annos corvum non facilè protendere vitam.

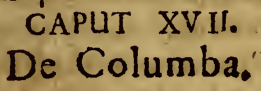

Preseptum.

Columba eft avis gemens, fimplex, munda, mitis \&innocens.

\section{Qvestiones. \\ I. QHenam nutritio?}

Refp. Nutritur tritico, hordeo, a venâ, lolio, milio,pifis \& aliis granis.Maximam partemipfa ex agris quarit victum,ac non nifi hyeme paucis menfibus, cum diuturna nives agros operiunt, impendio Domini alitur. Hinc major columbarum quaftus elt, qquàm anferum, gallinarum \& anatum.

$$
\text { Z3. II. 2us. }
$$




\section{Quenam angmentatio?}

R. Quantiras corpnris media eft. Capue pla. num, quibusdam crifatum. Pedes etiam afiis nudi, aliis pennis ornati. Color varius eft, quibusdam ruffin, aliis cinereus, nonnullis albus. Albe da mnantur ab Ariltotele, quia ab accipitre confpiciuntur ê longinquo. Sed in domefticis non improbabitur albedo, cùm accipitrum injuriis adeò expofitæ non fint.

III. Quenars generatio?

Refp.Salaces quidem \& lafcivæ funt, fed fervant jura conjugii. Plerumq́; mares of culantur forinas, priùs quàm afcendant. Ova pariunt bina, eaq; candida, è quorum uno femper marem, aliero foeminam generari,fabulo. fumet. Focundiffrmx funt, quippe qux fingulis quadragenis aut tricenis etiam diebus concipiunt, pariunt, incubant \& pullosenutriunt. Cum verò nec aptum locum nec cồmodum cibum habent, hyeme quiefcunt. Incubatio cùm fominx, tùm maris opera perficitur\&excludunt pullos die vigefimo aut et. jan decimo odtavo. Et tunc fobolem cùm mas tùm fomina forent, fœminx tamen in opere illo ferventiores maribus funt. Pulli à partu coeci funt, ficut \& pulli corvorum.

\section{Quenam fenfatio?}

Refp. Plurimum valent fenfu, præfertim vifu, au. 


\section{PHYSICA:}

fu, auditu \& guftu. Accipitren tanquam hoftem communé ê longinquo vident, \& quod. libet illius genus accuratè agnofcunt, Quin \&xclamorem eccipitris cum audiunt, ocyùs aufugiunt. Omnia granorum genera edunt, alia tamen aliis libentius. Triticum ftatim agnofcunt $\&$ amant, hordeum autem non nif ex melioris defectu affumunt.

V. Qualis affectus?

Refp. Mitis \& placida columba eft.Etiam fimplex, imbellis, \& innocens, prudentia quoq; cum fimplicicate conjun cta eft, cum fimplicitas fine prudentia stultitia fit, ficut prudentia fine fimplicitate perfutia : Verfus aliàs habentur : Felle =olumba caret, roftro non lèdit, \& ungues Posfidet innocuos, puraǵs grana legit. Gaudet aquis, quarit ǵ greges, celerigós polats Tutapesit, fotus educat alterius.

- Ma/culus ipfe fovet foetus, at ǵs incubat ovic, Conjugii Jerpant féder a cafta fimul. VI. Qualis motus?

Refp. Perniciflimum habent volatum, ut cum quavis ave pernicitate certare queant. Unde Rex David in anxietate fuâ exoptat fibi non aquilx, non vulturis, non ciconiæ, fed co. lumbre pennas. Quis dabit mibi pennas ficut calumbe, of volabo, of requiefcam? Quamvis autem avolent, tẹctorum tamen fuorum memo-

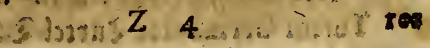




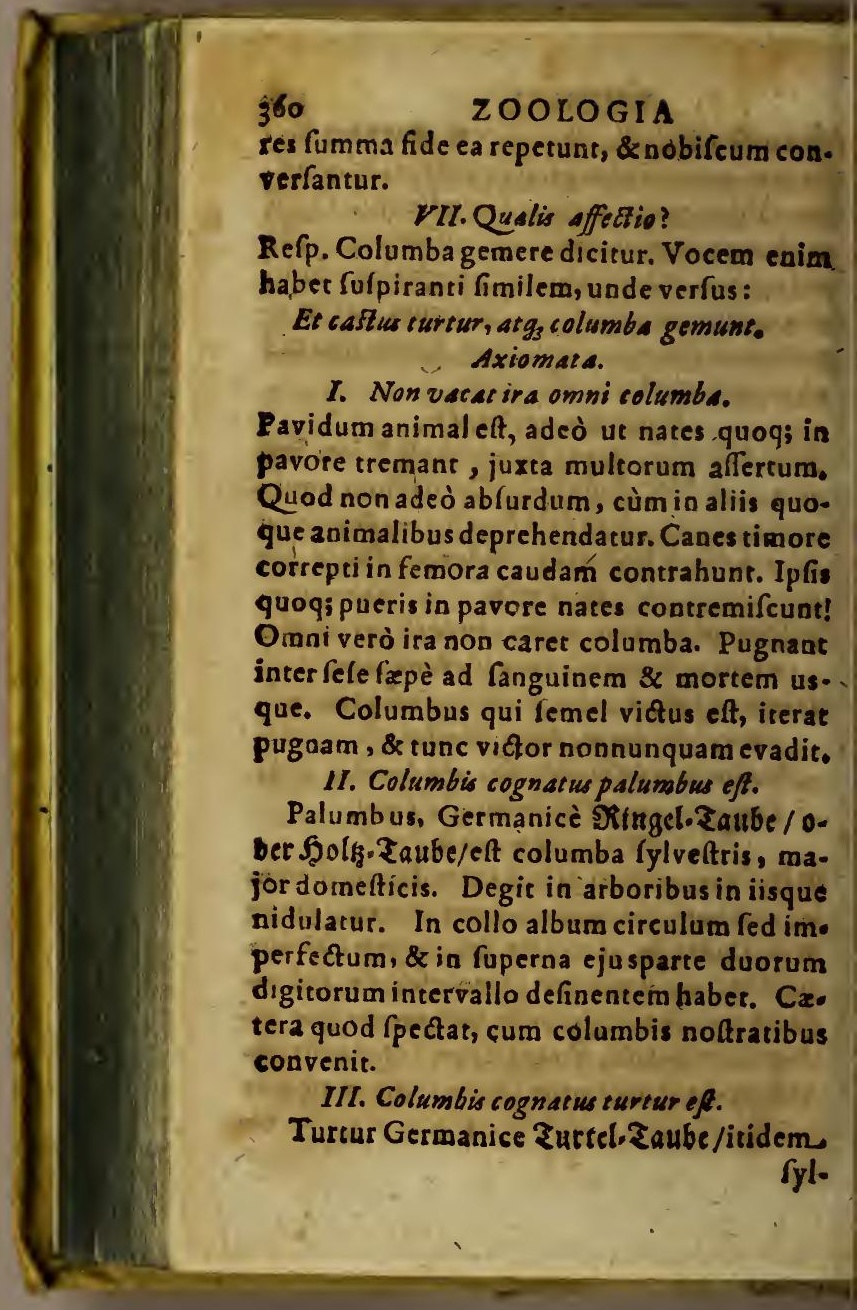


ylveftris columba eft, minor domefticis. Ni. dulatur iis dem ferè in locis, quibus palumb9, nempe in arborum verticibus \& montium jugis.Vocem habet gementem, unde \& curtue vocatur. Frequens ejus fit mentio in facris \& honorifica. Vox turturis audica est in terra nofrâ. Ne tradas congregationi inimicorum animam turturis.

LIBER QUINTUS

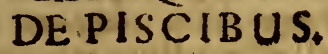

CAPUT I.

\section{De Pifcibus in Genere.}

\section{Pracepta.}

1. Pifcis eft brutum natans, branchiis, pinnis, fquamis, fpinis \& vefica in ventre conftans. II. Eftque Cetus, Silurus, Sturio, Canis, Sala mo, Lampetra, anguilla, loligo, cyprinus, lucius, halec \&c.

\section{Qoaftiones.}

1. Quenam pifcium caufe font?

Refp.Caufa efficiens prima Deus eft. Ita Sacra Scriptura : Creavit Deùs cetos magnos, \& omnemanimam viventem reptantem, quam produxerunt aqua juxta fpeciem fuam.Securda natura eft, partim ftella, partim fpecies fefe multiplicantes. Pergit Sacra Scriptura :Be* nedixic sllis Deus dicens : Crefcate of muitiplicamini, \& replete aquas maris. Finis proprius of Z;

slitio 
362

\section{ZOOLOGIA}

ultimus Dei gloria eft. Finis intermedius, hó. mo. Omnia enim propter hominem, homo propter Deum. Finis proprius, mortalium vo. cibus exprimi nequit. Materia creationis aqua fuit, generationis femen : conftitutionis corpus organicum. Forma in genere anima fonfitiva eft; in fpecie alia atque alia. Alia delphini, alia balenx, alia anguilla.

\section{$I I$. An pifces refpirent?}

Refp. Refpiratio fit ut temperetur calor cordis. Habent pirces calidum cor, calidum fan. gvinem, calidos fpiritus. Opus igitur, habent ventilatione \& refpiratione. Nec exiftimandú aèrem refpirationis materiam effe. Quod quis non habet, alteri dare non poteft Aèr non eit frigidus : nequit igitur frigefacere. Aqua affumenda eft, ut refrigeratio cordis fiat. Pifcibus aqua cruda \& craffa, ob crafiores fpiritg: avibus, quadrupedibus, \& hominibus aqua refoluta \& fubtilis ob fubtiliores Spiritus neceffaria eft.

III. Quomodopifcesgenerentur?

Refp.Congrediuntur \& femina mifcent, atq; fic multiplicantur. Placent verba D. Frantzii: quod attinet ad rationem pifcium propagationis, aliqui arbitratifunt, omnes eße freminas, of concipere fine maribus, fiquidem aliqui ftatim babrnt ova cum nafcuntur. Sed experientia osten. 
dit ipfos coire, admot is invicem partibus fupinis; E plerumǵs'citisfimè abfolvire coitum, exceptis piculis marinis, quitanquam canes diu coberent: Paulò poft: Oda pi/cium à pi/cibus itca foveriv defende, ficut ab avibus, utig, nemo, ut puto, campercum procerro babet, nemo etiam dicet. Quis igitur incubat ovis, quis infantulos pifces defendit, quis ut in infinitum augeantur boc genrus animalium fuo nutricatu efficiet, nije folus Deus? Dimu Da fómpt feines Mienfhet Sand Daju.

Axiomata.

I. Pifces aquarum incols fune.

In aqua generantur, in aqua formantur, in aqua nutriuntur, in aqua augentur. Voce vel muta alloquuntur nos mottales Hûc animos advertite rerum novarum cupidi. Pragnantem aquarum uterum introlpicite. Fat us magnit udi: ne mirabiles, multitudine inestimabiles perpen. dite ! Non minui uterum bunc,quam is innumeri exeant nati, notate. Dominus enim eft, qui uterum implet, \& foetus in eo confervat. Ult fapientiam incomprehenfibilem, potentiam inxftimabilem, \& providentiam imperfcrutabilem homines depradicent.

II. Elegans pifcium structura eft. Fabrica pilcium omaium ad fe oculos animosq́; trahic. Habent caput, oculos, aures, nares. >

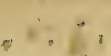




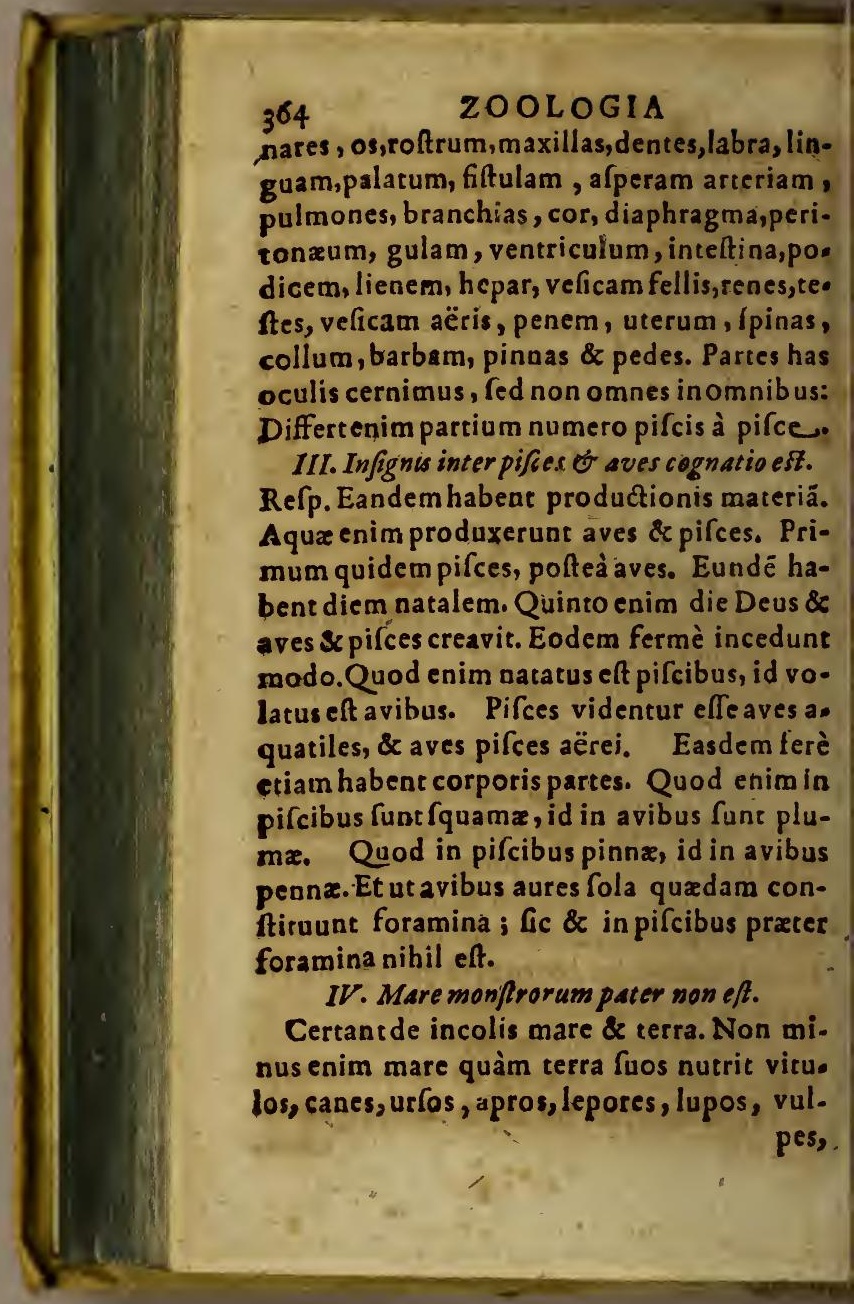




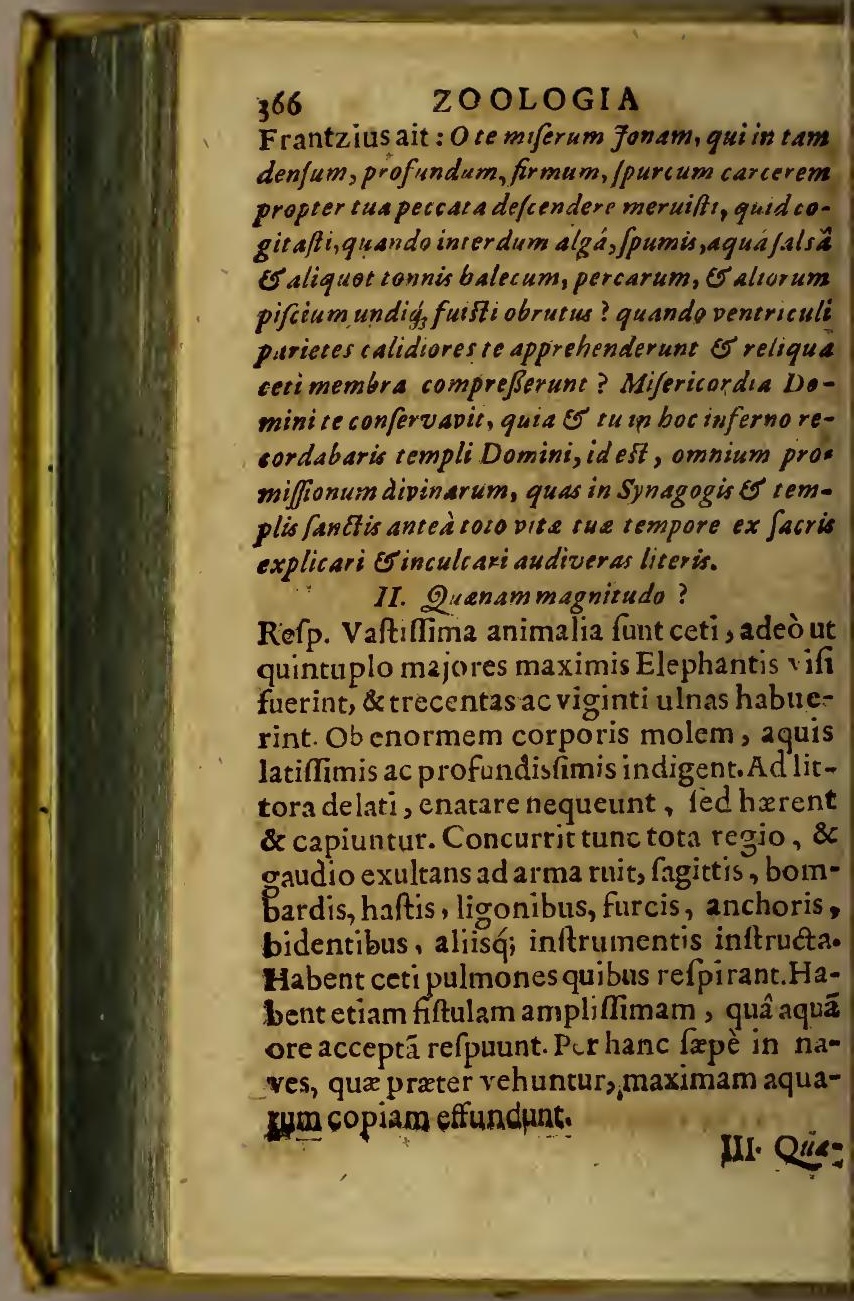




\section{PHYSICA:}

III. Quenam generatio?

28. Oenerant non fecus ac animalia terrefria. Ova enim non pariunt. Sed intrafe perfectum anima! generant. Er membra generationis non fecus ac terreftria animalia habert. Vidi equidem, inquit Rondeletius, $b a$ lene mentulam tantam, quectiam â procero bomine bumeris gest ara, uirinque terram contingeret, unde guants fit, cum bolens libidine cons citate ferustur, conjicere oportet. Mammas etiam habent \& lac, quibus catulos, interium binos, nutriunt. Catuli hi teneri adhuc, matrem fequantur, non autemut plurimi pifium coterorum in mari fine difcrimine vagantur.

\section{Axiomata.}

I. Cetus animal verax est. :

Voracitas fumma in ceto, adeò ut imple. ri vix polfit. Inhiat inter omnes pifces po tiffimum halecibus ob dulcedinem carnis: Et hanc alimentorum copiam, ut $\&$ infidia rum ablentiam caufam magnitudinis fum$\mathbf{m x}$ dicir Cardanus.Sed Scaliger grandefcereait, quia non capitur. Nos naturæa autoré cuivis pifcium fpeciei certos pofuifle terminos, \& ampliores quidem cetis dicimus, quia fic placuit.Volantas creatoris eft ratio Sati.

15. Cotus maximb pingvefoit.

Pingut 


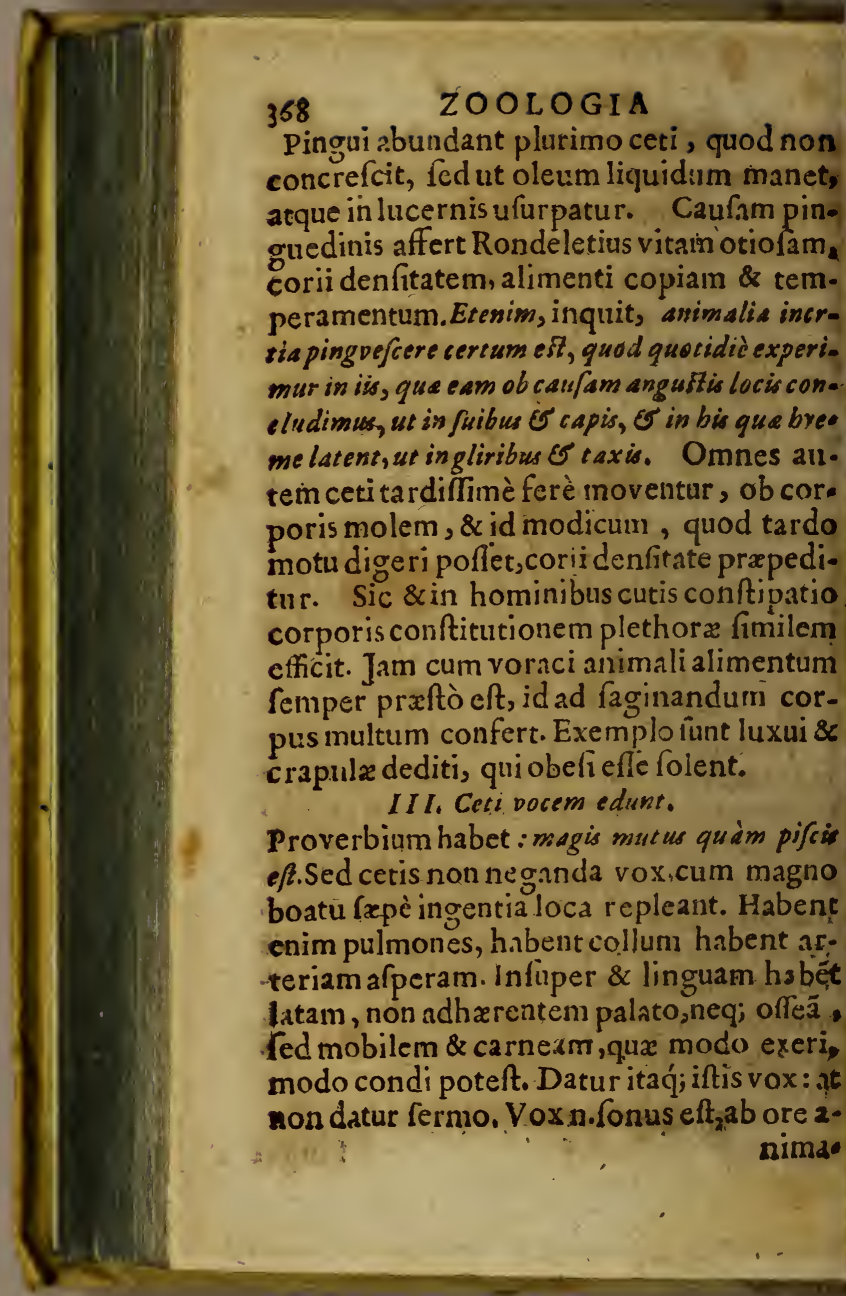




\section{PHYSICA.}

nimalis prolatus ad affectus exprimendos. Sermo autem eft, vocum articulatarum difpofitio, sd communicàndos conceptûs, neceflaria.

\section{CAPUT III. De Salmone.}

Salmo eft pifcis medius, \& in mari $\&$ in flus viis degens, maculis rotundis infignis, fvavilimi faporis, \&non mali fucci.

\section{Qraftiones.}

\section{Quenam nutritio?}

R. Salmo, Germanicè Salmen ober sadis an ciboullo, \& quonam tandem utatur, nó conveniunt Autores. Multi eum non aliô cibô, quả folâ aquâ vićtita re credunt. Hinc in ventriculo exenterati nihil reperiri aunt, preter fiflum quendam humorem, aut mucum fubfiavum. Alii Horibus ruris, pediculis aquaticis \& pifcibus, eum frui as: ferunt. At ${ }^{\prime} ;$ in diffecti inteftin s talia $f_{c}$ inveniffe teftantur. Nos rationem alimento. rum attendentes.pofteriorem fententiá magis approbamus, \& fi aquẩ nutriri quandoque videntur, non tam aquâ, quàm contenis in ea aluntur. Hiricaquâ, qux nivium liquatione, herbis variis, \& agrorum pingueinecraflior fit, magis delectantur.

W. Qhandis angmenticio ? As 
370

\section{ZOOL O GIA}

K. Magnitudinem egregiam habet, ob quâ eum pifcem cetaceum dici posfe exiftimāt. Maximam partem bicubitalis eft, \& Deffavia à libris viginti quatuor usq́; ad triginta fex capitur. Squamis tegitur exiguis, maculis rotundis ita notatis, ut fub ruffis illis \& luteis notis infignis fit. Dorfum cæruleo eft colore, ad nigredinem vergente: venter argentei coloris æmulus. Os h abet a mplum \& valdè denticulatum. Non n. tantum dentes in utraq; maxilla habet, fed palatum etiam quadrup lici eorum ordine munitur, \& lingua ipfa iisdé hxret. Oculos habet magnos, $\&$ branchias quaternas. Pinnas habet binas juxta branchias, binas in dorfo \& tres in vé. tre. Cauda etiam in unam latam \& rotundi ufculam pinnam definit.

III. Quenam generatio?

R. Mares geniturî̀ pleni, cum forminis coëunt, qux ova pifortum magnitudine pariunt, \& in locum fabulofum reponunt. Certĩ a. nidum conftruunt, cujus latera lapidibus muniunt, intus excavant, ut detecta fint ova, ne pluviæ impetu difpellantur. Fit tamé quandoq́; bi pars à pifcibus devoratur, pars fervatur atq; augetur, atq́; in pifcem perfectum formatur. Ova nonnunquam imminutis fuvirs in ficco relingruntur, nec tamen pereunt, 
PHYSICA.

fed aquis reftitutis perficiuntur, ac fi nunquamdeltituta fuifent undis.

\section{Axiomala.}

I. Salmo certum nativitatis of educationis lo. cumnon baber.

Et in mari \& in Auminibus gignitur, alitur, augetur. Suaviter a. dulci fundinum aqua afficitur. Unde in illis Ocenni locis, u. bi copiofiores infunt 2 qux dulces, 8 plures \& nieliores capiuntur. Magno nonnunquam agmine ê mari in flunina tranfeunt, \& circa æltivum folltitium in $\mathrm{Albi}$, Mulda, Săla alirsq; fluviis capiuntur. In oceano per hyemem,aut faltem bonam ejus partế tranfigunt, circa veris a. initium flumina petunt.

II. Salmb carisem babet non ingrat am.

Caro avequam coquitur,albicat, cocta velfalita rubefcit:Tenera eft \& firavifima, nec malum præbet fuccum. Noderatus tamen ejus fit ufus. Larogan. manu devoratus Salmo, ob nimiam pinguedinem, noleftam affert fatietatem. Habenda etia ricio xtatis, loci \& temporis anni. Commendantur magis juniores, monfe Aprili, Majs\& Junio, \& qui in dulci fluviorumaqua fuére. Agris a. \& quibo minus validus eft ventriculiss, non conveniunt. Viscofin. funt $\&$ conco 7 tu difficiles. Non modo recentes fed \& fale conditi fumog; indurati comeduntur $\mathrm{sed} \mathrm{hi}$ concoetu difficiliores.

A.2 2

CAPLI 


\section{ZOOLOGIA \\ CAPUT IV. \\ DeCyprino; \\ Praceptum}

Cyprinus eft pircis medius, fiuviatilis \& lacuftris, craflus, fqvamis validisfimis praditus, numerofa prole brevi tempore pif́cinas replens.

\section{Qviaftiones. \\ I. 20enam nutritio?}

82. Cyprinus Germanice Rarpffe/vécitur herbis, muco,tritico, \& aliis frumentis. Domi cùm alitur, panem immittimus in pileinam ne tabefcar. Alias luto delectatur admodum as ierrâ argillosá.

11. Qvenam augnentatio?

R. Craffers magis, qvàm longus effe videtur. Plerumq́; librarum quatuor aut quinque habetur, interdum etiam vigintj.Squamas habet latisfimas \& validisfimas, ut facilè ietus lapidú fuftineat atque repellat. Caput habetbre. ve, dentes inxquales, \&barbã gemina..Pinnz ei variæ funt, duæadBranchias, dux in medio vétre, una propè caudä, \& una infignis in dorfo. Cauda illi lata ex nigro rubefcés. Senioris co. Jor flavus eft, junioris ad fufcú magis inclinat. III. Qpenam generatio?

8. Pifcis focundisf mus eft, qvinqvies aus fexies uno anno paxiens. Noa tantum maris is foeming 
\& foeminx commiftione nafci; fed fpontè etjam fine ullo maris ac foeminx femine genera. ri, communiter dicitur, Vidi, ingrit Rondeletius, in aquis, in cava loca Es montibus fepiareceptis \& collect is , poniè generari cyprinos, in qpe loc a nec rivus, nec st agnum, nec palus, nec lacus, nec fluvius ullus, pulla denique agva praier co. lefter influxiffet. Sed non recurrendum ad pontaneam illam viventium generationem. Latere folent femina, \& fucceffu temporis prorüpere in actü. Axiomata.

I. Cyprino terra argellofagratisfina.

Habitat in foviis \& lacubus, ted non $x q^{\prime}$ benè in quibusliber. Albertus ait. Hic pifcis in oliquibus aqvis generat, of in aliquibus graßs. tur É crefcit: Jed optime valet in fundo argillolo, eritice primum feminato, of poftẹà argillà defuper Parfâ, Ébinc a qoa fuperfúâ.

II. Cyprinus carnem babet minus falubrem. Caro mollis \& humida eft, fuccumque prebecnon parum excrementitium Imprimis illi, qui in fluviis, civitatibus vicinis ac fordes excipientibus degunt, pravi fucci funt. Affumendi, ut pifces ferè omnes calidi,ne ventriculum nimis refrigerent $\&$ hurmedtent. Poft efum eorum non aqua, aut tenuis cerevifia, fed generofum yinum bibendum.

$$
\begin{aligned}
& \text { CAPT V. } \\
& \text { De Siluro. }
\end{aligned}
$$


374

\section{ZOÓLOGIA \\ Preceptum.}

Silurus eft pifcis magnus, vorax, deformis, pingvis \& boni faporis.

Quaftiones.

1. Qvenam nutritio?

Refp. Silurus Germanicè $W_{3 a l s} / \mathscr{W}$ all obée Wellce/valdè norax eft, ac lacubus, ftagnis \& fluviis pernicicfus. Venatur enim minorés pifcès, \& in cos mirâ voracitate tanqvàm heloo graffatur. Fanra eft, in Pannonia captum aliguando fusfe Silurum, in cujus vifceribus, bumana manies annulis ornata, inventa fic.

1I. Quanam augmentatio?

Refp. Crefcit in magnitudinem egregiam. Nonnunquam rres $u$ in as longus, \& pondere ad centenas us gaslibras capitur. Corpus habet fufum \&nigris maculis plenum. Tulla eifune fqvamx, fed coriurn fatis craffum \& lubricum. Gaput habet grancie, latum \& limum. Rictus oris amplus e $t^{2}, \&$ ad capitis longitudinem patulus. Labia fupra infraque af pera funt, qvibus prædam retinet \& frangit, cùm dentibus careat. Venrer niagnus eft, cauda tenuis \& lata. Duas habet pinnas ad branchias, \& unam ab ano, quæ ad caudam extenditur.

III. Qvenam generatio?

Refp.Congreditur \& ova parit,eaq; diligenter cuftodit, \& cum ipfó foetu in dulcibus aqvis

liben. 
libenter verfatur. D. Frantzius ait : Siturus fos ova diligentifimè cuftodit, ità ut Japè in ip la euse Stodia capiátur, préertim quando caudâ fuâ verberat agvam ut terreat pifces, undè etiam nomen accepit â $\sigma \varepsilon_{i}^{\prime} \dot{\omega}$, qrod est moveo, â pebemente motu É fanicu caude.

\section{Axiomata.}

1. Silurus pingeis admodum eft.

In dulcibus aqvis pinguefcit qvàm maxime. Inter $\mathrm{Pafcha} \&$ Pentecoftem é mari migrat in Albim. Hinc capitur obefus admodum \& craffus. In magnis nonnunquam pingvedo per dorfum duos eriam digitos crafla eft, non fecus ac in porco terreftri.

\section{Silurus gratifaporis eft.}

Suavitas in carne eft, \& fuccum prabet fatis bonum. Tùm recens, tum falfusin cibo laudatur.Sed facilioris coctionis recens, difficilioris falfus.

CAPUT VI.

De Sturione.

\section{Preceptum.}

Sturio eft pifcis magnus, pingvis \& fuavis,paucocibo cótentus, êmari in fluvios tendens. Quaftiones.

\section{Qpenam nutritio?}

Refp. Sturio, Germanicè Gtór ober Stiek/ nihil cibiâ nonnullis capere dicitur. Carda: nus Sturionem non vefci fcriptitát. CaltjAa 4 gatus 


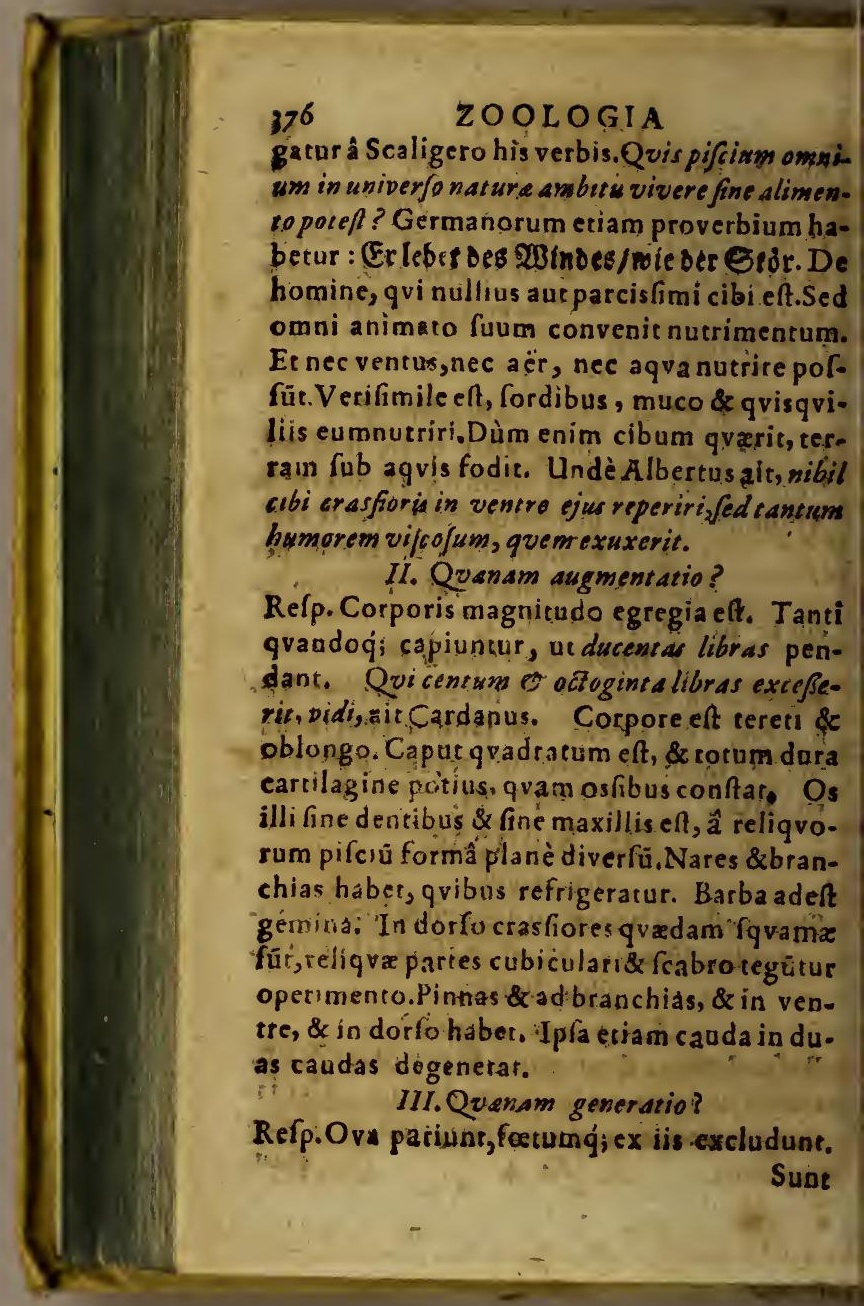


Sunt qvi ova colligunt, \& nunç nutrimentua gratinfimum, nunc medicamentum efficacisfimum inde parant.

\section{Axionate.}

I. Sturio gratisfonus antiguis exat.

Romani cum ceperunt eum, cum tibiis \& coronis in conam procefferunt, caronatis et iam iis qui geftarunt. Undè faierè Comicus ex perfona parafiti ait: Quis est meortalis taxtâ forcunâ aff ichus ungvam, qpia rg? nusi fum ? curjus bec ventriportatur pompa, vel nunc qui mibi in mari accipesfer lacuit antchac, cujus ego latus. in latebras reddame meis dencibses of manilüs.

II. Scurio gule potius igramananit.ariconfert. Delectus habetur ratione lexûs, temporis, loci, magnitudinis \& praparationis: Praferuntur enim mares foeminis \& inter has ovis plepx cateris, qux enixæfunt. Probantur imprimis circa folftitia, 82 qui longius recefferunt i maris litoribus.Praferuntur minores majori bus. Comed untur \& recentes \& fill conditis: illi tamen thic gratiores funt. Recentes vino, faccharo, zinzibere, pipere, caryophilis, unis pasfis majoribus \& minoribus parantur. Omni apparatu faeto, habent adhuc catnem duriusculam, prepinguem aé glutinosá. Hinc neq; $x$ gris, heq; debiliorem ventsiculum habentitusapponenddi funt Sánis vesò \& ventriculo validiore preditis ferculum gratisfimun funt. Aa 5

CAPUT 


\section{ZOOLOGIA \\ CAPUT VII. \\ De Lampetra. \\ Preceptum.}

Lampetra cft pifcis medius, corpore oblongo: celebris faporis elegantiâ, in mari \& fluvii: degens.

\section{Quastiones}

\section{Qvanam nutritio?}

Refp.Lampetra, Germanicè \&amprete vefci di. citur aqva \& mufco. Sed non tam de aqva : qvam de contentis in ea hec admittendum. Cum capitur, efca qradam compofita in fon. tibus \& aqvis dulcibus nutritur ac fervatur.

II. Qpenam augmentatio?

Refp. Corporis crasfitudo exigua eft, longitudo eximia. Cute tegitur lævi, nunc albicante, nunc nigricante, ma culisóf; confperfa. Os neq̨i in longum neq; in latum fcifum eft, fed excavatum, in qvo cavi fparfi funt dentes plurimi, acuti, flavi, hamati. Pinnulam membraneam fupra caudæextremũ habet,aliam qú; hâc paulò fuperioren. In lateribus pinnis caret, cum iis ad natandum opus non habeat, fed flexuofo corporis impulfu promoveatur.

\section{Qvanam generatio?}

Refp. Nihil notatu dignum de generatione 2pud Autores. Ova parit,ê qvibus nova proles. Axiomata. 
1. Lampetra olim in inagno bonore fuit : ApudRomanos, fex, leptemi, viginti quoq; aueis olim una emebatur. Aldrovandus fetribit: sodé modo bodić Rome pifaiü ferè noubilus fima cenccur, adeo ut nobulis quidamcoquis (referente ? $\theta$ pio) aule Romaneproseram, coturnicibus eam sompararit. Scribit Platina, Romana aule foraffis offenfus, benè anaturs actum effe, quod Roma ex Tibericapiuntur ef delicatisfime, gooniam vallate ibi guls inter fe duct is pretiis cercant." IT. Lampetre fucicus tanre bonitatis non eft. Habęt faporem gratum \& delicatum, fi recte prxparentur, vinoq́; enecentur, \& aromàtibus condiantur. Ubi condimentum magis ad pa: tatum eft, qram pifces ipf. Hinc condingento illufum fuiffe paraficun:, memorat Aldrovandus. Huic enim funem instar Lampetre coctum, multog jurulesto immerfum grandi in patina guis appofuit, ut not am omnibus ejus edacitatem gilamǵ eluderet. 'Hic jum magna pultarii parte abfumpiá pfeudolampetram aggreffus, diu mul: tumg's cum illa maxillis of dentibus inberente col. luci atus, cacbinnum cundt is tollentibus, facerè respondit : utinam mibi fapius foc illudatis! Nam in boc condimento non modo funes fed E ip fas catenas, (qv bus infani vobis fimiles vincuncur) o cum viluptate qvidem abfumerem:

CAPUT VIII. 


\section{Pracepium.}

Loligo eft pifcis medius, corpus hábens rotun. dum \& in acutum definens, in metu atra. mentum effundens, ut abfcondatur.

Qpaftiones

I. Q⿺ewam nutritio?

Refp. Loligo Germanicè \$B!adfif fa dicitur ab humore atramento fimili, qven effundit. Nutritur variis in aqva contentis ac diligenter, qricquid in ventriculum demittit, roftro atterit. Unde cuncta qua in Stomacho reperiuntur, pulmenti formam habent.

\section{Qperam augmentatio?}

Refp. Magnitudinem trium cubitorum interdum habet. Cutis at mollis, non fquamofa, non afpera, non tefacea. Pedum numero \& promufcide infignis eft. Pedes inferiores minores, fuperiore: majores funt. Totum corpus tenerum, longiulculum \& rotundum eft, definens in acutum.

\section{Qpenamgeneratio?}

Rerp. Mas flagrat amore foemina, \& frpè caufa ejas perit. Foeminam etiam captam mas liberare laborat, fed à pifcatoribus pecitur ipfe \& capitur.Mas fi captus fuerit, foemina fugit. Parit formina ova, maximam partem gemina binosg; gignit foetus.

dxio- 


\section{PHYSICA. \\ Axiomata.}

1.Löligo Es fepiapifies cognatifnint Conveniưni ftructurá, atra mentito, carne $\& 20$ iiss. D rctimen Gèrtianice fie interpretatust Gefnerus: Loligo eis lang Bladfifh/[epia cih_sunder Blarffirti.

\section{Lóligo cruddefucci eft.}

Non a dmodum cómmendatur lóligo, cum carnem habeat durath ac difficilis coctionis. A perito vérò có qvo cúm apparatur, non ingrathis eft. Co quitur cum atramento fuo a djecto butyro ac pipere.

\section{CAPUT IX. \\ De Afello.}

Preceptum.

Afellus eft pifcis medius, tumidum habens ventrem, \& grande caput, ac carnem minus laudatam.

\section{Qpeftiones.}

I. Qvenam nutritio?

Refp. Afellus Germanice Stodfif nutritur côtentis in aqva. Maximus apud Britannos \& Hollandos eit afellorum qraeftus. Tanta enim corum ibi copia, ut poft patríz telluris faturitatem in Germaniam aliasq́; longe disfrtas regiones, non fine longo fanore transportenwe.

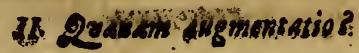

Refp. 


\section{ZOQLOGIA}

Refp.Duos \& tres cubitos fxpe excedit. Caput ei grande, os amplum, \& venter tumidus eft. Hinc nunc ventricofus, nune capitofus afinus dicitur. Aद exteras regiones cum mittitur,caput praciditur.

III. Qpenam generatio?
Refp. Ova parit, indeq; prolem gignit.

$$
\text { esxiomata. }
$$

I. Afellus ignobilis pifcis eft.

Odiofum nomen habet \& Græcis \& Latinis \& Germanis. Recens, carnem albam, mollem \& friabilem,palatoq́; non ingrata $m$ habet Ex: iccatus verò offeam ferè induit duritiem, undè robufto baculo diverberatur, ut affusá aquâ rectius diffolvatur \&elixetur.

II. Afellusfalitg E butyro immerfus glutinofior fit. Caufa eft humoris tenuis ablumptio. Sicurt farina aqvâ multâ affufa, \& aliquandiu conjuncta, tam fpiffa redditur ac glutinofa, ut eâ ad ferruminanda multa utamur. Tenuiores enim partes ab igrie abfumptafunt. ' Et ficut faccharum aqvâ difli lutum coctione fit fpiffig $\&$ glutinofius. Ita etiam atramentum, cum. partes tenuiores exhauft $x$ funt, craffus fit, \& adeò digitis adhærefcit, ut non fine labore avellatur.

CAPUT $X$.

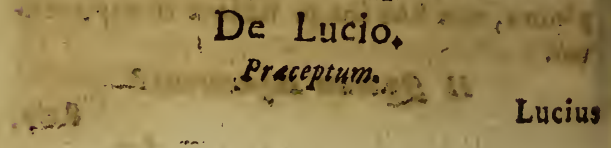


ucius eft pifcis medius, oblongus, parpis ac enuibus fquamis praditus, voracisfimus, Iudacilfimus \& vivacisfimus.

\section{Qvestiones}

\section{Qvenam nutritio?}

Refp. Lucius Germanicè ein Scedtr /nutritur ilcibus, ranis, \& aliis in a quam immiffis. Vo. racisfimus \& crudelifinus eft, in propriam faviens gentem. Lusios enim qui diffecant, frequentisfimè in ventreinveniunt non alburnostantum \& tincas, fed minores quoq; lucios. Pifcem fapè feiplo paulò minorem adoritur, qven cum apprehendit, caput $\&$ religras psrtes fuperiores ingerit, inferioribus ex. rra os aliquandiu dependentibus, donec pricribus mutatis ac digentis, has quoq́; trahat ac digerat. Certum eft feles etiam parvas \& ca. nes in vivaria conjectos ab iis devorari. Cracovienfis quidam Polonus Rondeletio retulit, anferis pullos duos in ventre lucii âfe vifos eßse: aligpando etiam lucium, psdem ancille in pifcira. apprebendiffe.

\section{Qvenam augmentatio?}

R. Pifcis egregix magnitudinis eft. Argen. tinæ aliqvando captus fuit, quilibras viginti fex appendic. Corporis figura oblongior eft; dorfum latum \& ferè quadra tum, perpetuo $x$ quale donec ad poftremas pinnas ventũ fucrit.

- Capur 


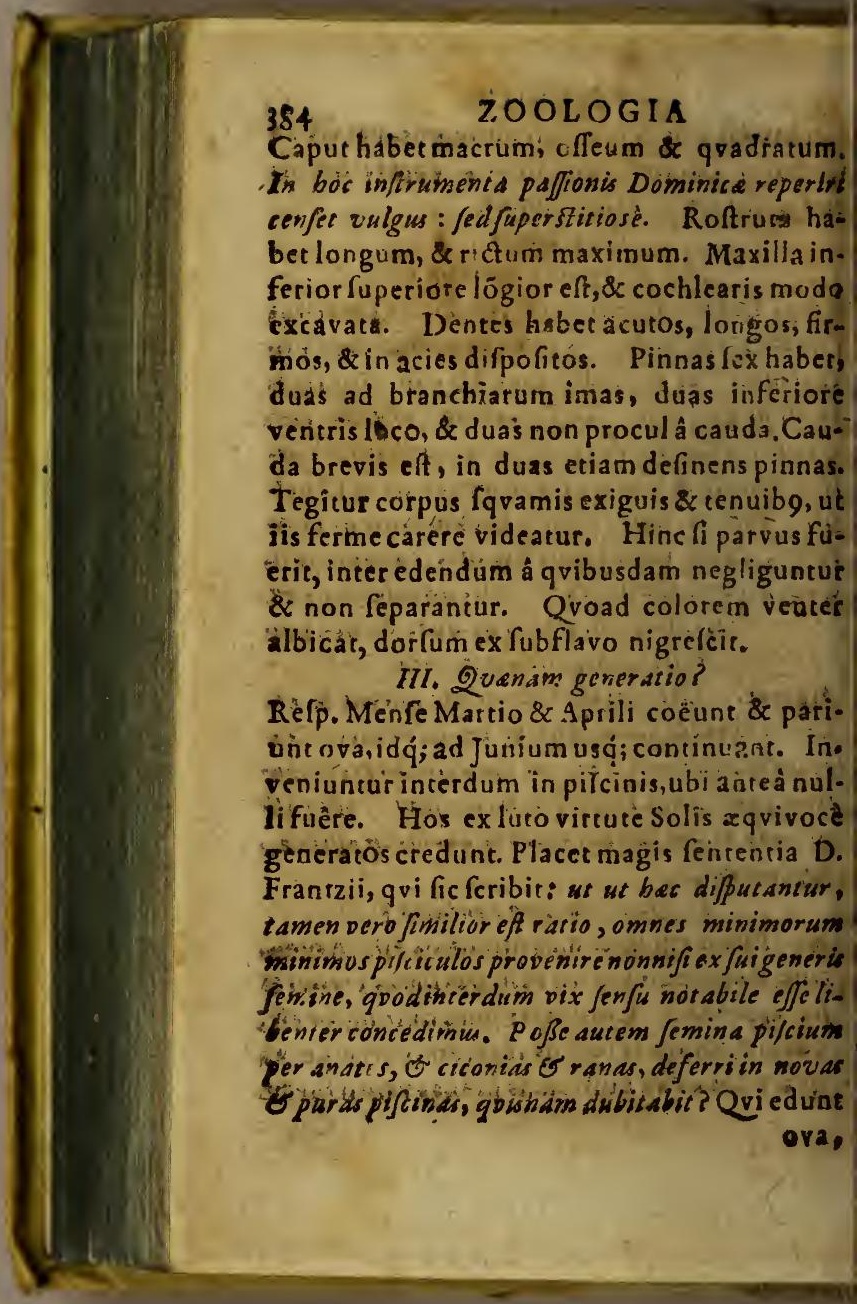


PHYSICA.:

Fa, folent ipfa egerere imperfecta, ica ut e. ita augeantur, $\widehat{r}_{\text {non }}$ aliter ac farina tumore ubada augetur, tum fcilicet pars folida auetur tumore, \& polf eà fpiricus ipfi provocai tumorem effciunt.

\section{Axiomats.}

\section{Lucius divacisfimus eff.}

Ilera ducentos annos vivere dicitur, nifi perat inorte violenta. Exemplo hoc confirmaur iftius, qui â Friderico II. Ixiperatore catus, \& cum cercâ infcriptione aquis iterum mmerfus, atq; polt trecentos ferè annos deuò inventus eft. Inferiptio talis fuit : Ego umille pifcis buicftagno omnium primus impo. ius, per mundi Redtoris Friderici II. manus, die - Octobris. Captus a. fuit Anno falutis $1497 . \&$ mmiffus anre annos fermè trecentos.

\section{Lucii caro laudabilis eft.}

Carnë häbet friabilé, coctu non adeò difficilê, ec multis excrementis fcatentē. Hinc agris ōcedi folet, imprimis salidâ \& ficcâ téperie aborátibo. His nó tm.nihil nali, fed \& plurinum emolumenti adfert. Esú ejus puerperis tiam concedunt, quibus tamen reliquoum ufus pifcium interdictus eft.

\section{CAPUT XI. \\ De Anguilla. \\ Praceptum.}

$\mathrm{Bb}$

Angvil- 
Anguilla ef pifcis medius, corpore oblongo, lavis, jucundi faporis, fed inta lubris. Quxftiones.

I. Quanamnutritio?

R. Anguilla, Germanicè Zál/ nutritur vermibus, ranis, pifcibus, radicibus, herbis $\& \mathrm{fi}$ milibus. Totus in co eft Rondeletius , ut anguillas folâ aquâ nutriri probet. Solà aquâ, eàgs pausisfima ac dulcisfirr! $\hat{a}$, inquit, anguills pafcuntur of augefcunt. Quamobren ii, quibus angvillarum vivaria curafunt, dilagenter dant operam, ut quim maxirnè pura fiaceragjsfit aqua affluens, of effluens femper per ripas, ubivivaria extruunt :nam nifi a qua limpide fit breve strigulata interwunt. Sed quod nec animatum eft, nec ab animato venit, nutrire nequit. Et nó tàm ad aquam, quàm contenta in ea refpiciendum elle, vel ipfa monet dulcedo, quá requirit.

\section{Quensm augmentatio?}

Refp. Anguilla in tantam nonnunquá ex. crefcit magnitudinem,utbrachii craffitiem xquet. Lævis \& valdè lubricus pifcis eft, ut manuteneri nequeat. Caput habet longum \& acutum, os a pertum, dentibus parvis \&x acutis præditum, ordine multiplici. Color pro varietate aquarum variat. Qui puram ac defluentem aquam incolunt, ventré habent candidum, \& dorfum fubcxruleum : 


\section{PHYSICA.}

ui verò impuram \& fagnantem inhabitat, entre fubalbo \& dorfo fubvirici aut fub. igro conitant.

111. Quenam generacio?

efp. Ariftoteles ait: anguill: neg, mas negis cemina esti, $n g_{3}$ prolem ex fe aliquans gunerare ocest. Item: Hoc unum inter janguisea, totum enus, fine coilti, fine ovo procreatur. Qhod ica Beconstat argumento, quod infoculentis itanis aquá ornai exhaujtá o limo decractó enguil. e denu' generantur, ubi aqua accellit pluvia. ed Rondeletius fcribit: fe vidiffe anguillas orporam complexuscoëuntes, $s$ in inforiore vê. ris parte, छvuivam on faminis of firmen in maibus reperiri.

\section{Axiomata.}

I. Anguilla fisanes est, led infalubris.

picis delicatiflinus eft, ob fuavitatem arnis. Idem infalubris tamen \& nec xgris ec fanis proficuus eft. Glutinola n. pingneline, \& pituitofo fucco ac lento abundat. Inde nec facilè coquitur, nec prabet laulabile nutrimentum.

\section{Anguilia puram aquam amat:}

n Germania non cater anguillis, vel Albis el flumen facilè aliud: Panubius non alere licitur anguillas, ob aqux frigiditaté. E flujis autem mare ipfum ingreditur, fecus ac $\mathrm{Bb}_{2} \rightarrow \mathrm{lam}$ - 
lampetra aut Silurus : hi enim pifces è mari ad flumina tc ndunt.

\section{CAPUT XII. \\ De Trutta, \\ Praccpt:}

Trutta eft pilcisimedius, oblongus, maculis varius, ob faporis elegantiam fuccique praftantiam celeberrimus.

\section{Quxitiones. \\ I. Quanamnutritio?}

Refp.Trutta, Germanicè fof̧re/forel / vefcitur vermibus, locuftis, limacibus, variisq́ve in aquam immiflis. A pifcibus etiam nó abftinet, fed percas, barbos, fundulos, alios. que invadit. Tanta aviditas in ea, ut ab imis ad fumma tendens fupra aquam efferatur \& in fcapham nonnunquàm incidat.

\section{Quenam augmentatio?}

Magnitudinem habet cubitalem, fqua. mas exiguas, maculas multas, pinnas cuas ad radices branchiarum; duas fub ventre, unam verfus caudam, \& duas in dorfo. Cau $\mathrm{da}$ eft brevis \& non divifa, roftrum minus acutum, oculi rubentes, dentes acutisfimi. Totus ferè pifcis ex albo flavefcit, aureisq; maculis pingitur. Quamvis pro varietate fluminum variet color, \& pifcis \& macularum. Cutis fa cilè rugatur, \& à ca rne absq́ule difficultate divellitur. 


\section{PHYSICA:}

III. Quenam generatio?

efp.Coëunt \& pariunt menfe Octobri,cīue partus inftat, modicas fcrobes faciunt. jiaum itıq; formant, in quo edautur \& nuriantur pulli.

\section{Axiomata.}

\section{Trutte caro laudabilis eft.} 3rati eft faporis, faciliscoctionis, paucoriz xcrementorum, boni, multi ac tenuis fuci. Minores preferuntur majoribus, macra inguibus, ac maculas rubras habentes $c x-$ eris. Menfe Oatobri minùs falubres funt, uia tunc pariunt.

1. Trutta mult a cü Salmonibus cömunia babent. $n$ utrisq; eadem fermè forma, eadem cororis partes externx , caro rubicunda, maulx multx, afcenfus ad fummas aquas, faltãii vis \& agilitas, fvavitas in cibo. Ma. nnitudine etiā a liqua truttarum fpecies Salnonibus ferè xqualis eft, undè \& trutta almonata \{ađsfokgre dicitur.

\section{CAPUTT XIII. \\ DeBarbo. \\ Praceptum.}

3 arbus eft pifcis medius, oblongus, \& in latera modicè compreffus, fquamis exiguis præditus, \& barba gemina celebris.

12 vafiones.

I. Quenam nutritio?

$\mathrm{Bb}_{3}$

Rerp: 


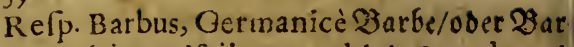
me/vécitur pifcibus, cochleis \& cadaveribus. Adeò vorax $\in f$, at ne fuo quidem par cat generi.

\section{Quenam augmentatio?}

Refp. Plerumg; unius librx pondus eft; ali quando duarum, trium pluriumve. Figure corporis oblonga eft, in latera modicè có preffa. Roftrum etiam longius \& auctiu: habet, cartilagineum \& pingue. Eo fuperi. oris roftri extremo dua appendices, \& es lateribus dux alix propendenti, quas bar bam vocant. Eft a. fubitantia cutanea quidé. fed mollis, lubrica \& fubrubra, oculi par. vi fint, pupilla nigra, quam atureus circuls ambit Dentibus caret, pinnas duas ad brá. chias habet, duas in ventre, unam à podice: unã in dorfo. s pra quoq́; cauda ê pinna gemina conflatur. Squamas habet exiguas, \& colorem varium. Venter colore eft lacteo latera argenteo, dorfum ex albo flavefcit \& parvis nigrisq́; maculis confpergitur.

III. Quanam generatio?

Refp.Congrediuntur \& ova pariunt. Ova hæc ne $a b$ aliis devorentur, diligenter $\mathrm{cu}$ ftodiunt.

\section{Axiomaca.}

I. Barói caro damnanda non est.

Cardanus ftatuit, barbum neq́; frigidū, neque calidum; néǵ; elixum, neq́; affatum,bo- 
wh effe. Placet magis fententia Sennerti, ajus hæc funt verba: obfervatum effe non menimi.aliquem ex carnis ejus efu aliquid damni eperiße. Eft enim candidifim i, facil s,coctionis $\checkmark$ diftributionis, alimentigy E fucci non mali.

II. Barbi ova venerata non funt. rægnans barbus innumer is refertus eft 0 is. Hxc affumpta nonnullis tormina ventris xcitarunt, vomitum crearunt, alvum turarunt, choleram generarunt, fyncope induxe runt, aliaq; graviflima mala intulerint. Hinc venenata \& malefica vi predita efle ova illa dicuntur. Sed à noftris quandoque comeduntur fine noxâ. Cenfendum potius ova illa à debili ventriculo corrumpi, in fe verò noxæ expertia effe. Sicut lac in vitiofum ventriculum immiffum, adè corrumpitur, ut veneni infer at fymptomata.

CAPUT XIV.

\section{De Tinca.}

\section{Proceptum.}

Tinca eft pifcis medius, brevis ac craffus, fquamis exiguis præditus \& muco plenu's. QDastiones.

I. Qvenam nutritio?

Refp.Tinca,Germanicè Sđlten/à muco qué Sdileim appellamus, fordibus rerum pu. trefcentium vefcitur, à carne verò abfinet B6 4

II.2Ua 


\section{Quanam augmentatio?}

Refp.Quatuor \& quinq; librarum pondere alibi capitur, fed in Albi libras duas non facilè excedit. Brevis \& craffa cft, capite cras. fo \& retorto. Roftrum habet breve ac rotundum, \& prodentibus ferrata offa. Oculi funt nigri c aurei, pinnæ ad branchias binxx, binx in ventre, à pódice una, una etiä in dorfo. Squamis minutis ac valdè conne. xistegitur. Color in quibusdam fubalbus, in aliis fubflavus, in nonnull is fubniger eft. III. Quenamgeneratio?

Refp. Et ex femine \& absq; femine generare cenfetur. Sed toties caftigatum polterius,ut videatur fuperfluum, quicquid etiam obji-, ciatur. Lucios quoớ; ê tinca rum femine generari putät, quod fabulosî effe ftatuimus. Axiomata.

\section{Tinca piffis vilis est.}

Nec grati faporis eft, nec boni fucci, nee facilè coquitur, nec rectè diftribuitur. Ple bejus pircis eft, indignus qui apponatur mé. fis niagnatum. Hinc cùm nobilis quidam Flo. rentinus tincam condivis fuis laudabit, omnibus excufict lac brymas ob riffan:.

II. Tine. a a at lacur Es paludes.

Rarò in fuminibus habetur, frequenter in lacubus \& ftagnis. Non gaudet aquis curretibus, fed ftagnantibus. Sic putredine de. lectatur, 
PHYSICA:

lectatur, ut ipfa inter fordes nafcatur \& educetur.

\section{CAPUT XV. \\ De Haringo. \\ praceptum.}

Haringuseft pifcis parvus, dulcis, brevis extra aquam vitx, in oceano degens.

Queffiones.

I. Quenam natritio?

Refp.Recentiores Zoologi ex penuria Græe ci \& Latini nominis, Germanicum vocabu. lum latinitate donarunt. Communiter halec $\&$ haringus utLatinum \& Germanicum differre putantur. Sed pifcis in Latinorí (cri. ptis halec appellatus, fluviatilis ac dulcium aquarum pilcis eft, haringus verò marinus. Halec etiam vilis pifciculus \& fex pifcium illis dicitur: haringus verò celebris \& non ingratus pifcis eft. Nutriri creditur aquâ: fed contenta in aqua nutriunt, nō aqua ipfa. II. Quenam anganencario?

Refp.Longitudinis eft pedalis, unicum habensinteftinum, quod jejunum effe afferit Albertus. Dorfo eft caruleo, ventre albo, fquamis acutis cutiç; pertina citer cohærentibus. Noctulucent ventribus verfus sĩmú æquor obverfis. Squama tm. emittunt fplendorem, ut mare fulminare videatur.

III. Quenam generatio?

Bb 5 Refp; 
394

ZOOLOGIA

Refp.Pariunt femelanno, fed tantâ foecunditate, ut multa millia hominum iis fuftententur. D Frantzius a.t : $V i x$ alius eft inter omnes pifces, qui fit foccundior, unde baleces fermè tocum mundum pafcunt. Prxterea caro horum pifcium, nativo, eoǵ; bono conftat, unde pleriq; pifces in mari, præfertim grä. diores, his ipfis pifcibus ftruunt infidias. Itaque ceti his ipirs pircibus infidiantur, quod dum fit, haleces ad littora difperfis agminibus approperant, quafi poffint effugere in. fidias. At tum in hominum poteltatem veniunt, non tantum haleces, verum etiá perfecutores, ceti. Et ita lingulari Dei providentia duobus fummis bonis ditefcunt, \& fruuntur regiones ma ritimx.

Axiomata,

I. Haringiomnium regionum incolis grati. In omnes regiones transportantur ê locis maritimis. Comeduntur non tantum recentes, fed \& fale muriá́; conditi, imò \& fumo indurati. Recentes carnem habent albam \& friabilem, bonifaporis, boni fucci \& facilis coetionis.Sale conditi difficilioris funt, nunquam boni faporis \& fucci. Bibacibus a. gratiffimi funt, cum fitim iis provocant, ut alacrius fvaviusq́; potent. Infumati, quos Zilufling rocamus, difficillima funt coctio. nis \& mali fucci. 
PHYSICA.

II: Haringus pifcis marinus eft.

Habitat in oceano \& frequentifimuseft in Anglia, Scotia, Hybernia, Norvvegia, Dania, Belgio. Capitur poft aquinoctium autumnale, reliquo tempore maris fecreta petit.
CAPUT XVI.
De Alburno.

\section{Preceptum.}

Alburnus eft pifcis parvis, albedine infigais, molli carne, in fuviis \& lacubus degens.

Quasiones.

I. Qtanam nutritio?

Refp. Alburnus $a b$ albedine nomen habet: Germanis Weiffict. Pif is vorax eft, unde \& hamo facilè capitur. Devorat a. vermes, ra nas, aliaq̣; in quam immifia.

\section{Qasnam augmentatio?}

Refp. Longus eft tres at quatuor digitos, oculis magnis rubefcentibus, capite parvo, corpore latiusculo fed depreffo. squamis tegitur tenuibus, \& candido praditus colore eft. Pinnas habet duas â branchiis, duas in ventre, unam propè caudam.

\section{Quanaim generatio?}

Relp. Congreditur \& ova parit,bis autter anno.

\section{Axiomata.}

1. Alburnus facilè percipit odores. In cavernis cumlatet, \& efca hamo aquis. im. 
396

ZOOLOGIA

immittitur, odore evocatur \& capitur.Dubium eft, an refpirando, an absú; refpirationeodoretur? Refpirationem qui negant pifcibus, alburnum fine ea odorari cenfent. Sed \& refpirant pifces \& refpirandoodorantur. Branchiarum enim beneficio aquam attrahunt, \& cum ea odorem.

II. Alburnus $\mathcal{E}$ in fluvio in lacubus vivit. Communiffimuspifcis eft, cunctisq; notis. fimus. Et lacuftris \& fluviatilis eft, fucci ex. igui \& faporis minus grati. Homines plebeji cum cœpis coqvunt, indeq; 3roiebelfifare appellantur.

\section{CAPUT XVII. \\ DeFundulo.}

Praceptum.

Fundulus eft pifcis parvus, carnem mollem \& falubrem habens, in fundo fluviorum aclacuum degens.

$$
\begin{aligned}
& \text { Q2afiones. } \\
& \text { I. Quanam nutritio? }
\end{aligned}
$$

Refp Fundulus à fundo nomen habet. In aquarũ fundo enim degit. Germanis Şrúnoling feu Bruinocl appellatur. Nutritur mufco, hirundinibus, aliisq́; in aqua contentis. Cadavera etiam fubmerfa devorat calvariisq̧; bubalis delectatur.

II. Quanam exgmentatio?

Rerp. 
Refp. Pifcis digitalis eft. Maculas à capite verfius caudam habet nigricantes \& rotundas. Squamis tegitur parvis. Caudam habet exiguain \& bifurcatam. Duas pinnas in lateribus habet, duas in ventre, unam in tere go, \& fub cauda ad anum unam. Quanquam fint duo genera hujus pifciculi : alterum có. mune \& majus, alterum fpeciale \& minus.

III. QHewam generatio?

Refp. Paritanno bis aut ter. Ova fingulari folliculo inclufa funt.

\section{Axiomata.}

I. Infignis fundwli bonitas eft.

parvus hic pilcis in maximo verfatur honore. Coquitur vino, \& fub finem modicíx affunditur acetum. Boni eft fucci, ficilis cofionis \& ad voluptatem fanitatemó; non parum confert. Hinc ægris etiā non incommodè apponi poffe cenfetur. D. Sennertus inquit:incer minores pifces boni faporis, falubrisgs planè alimesti, coctu facilis, os qui diu in Itomacho non morancur, atg ad voluptacem Es fanitatem plane commodi, ơ qui agris etiam thtò cancedi poffunt, funt quos vulgo fundulos Solnerlen vel Srinoling â fundo nominamg. II. Fundulus in fando maximè degit. In fluviis \& lacubus maxime habitat, ut \& 2 in fontibus campetribus, In rivis etiam "phi rime 
398

rimi capiuntur, praciuuè Februario, Mar. tio, \& Aprili. Foft palcha parere incipiunt, \& turic gratiam perdunt. In cœio qui vivuni, conofilint \& ipfi: prattantiores funt areiza \& faxis adherentes. Asant profundiora 10 ca, fundumq́; petunt lubentilímè.

\section{Appendix.

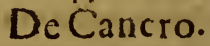

Cancer eft animal exangue, parum natans, lubenter progrediens, terra cavernas inhabitans.

\section{Questiones. \\ I. Quid de nutrusore?}

Refp. Cancer, Germanicè Siribs / vefcitur conchiliis, ranis, alijsq; carnibus. Eturgenie fame à propria eciain gence non abltinet. Lacte fine aquà, \& potare poreft \& nutriri multis dietrus.

\section{2uid de augmentatione?}

Refp.Quanticas efir media. Capice \& collo ca. rere dicıturâ Galeno. At ubı oculi, ibi capur, quamvis tamen à reliquis partibus diftinçum fatis non fit. Dentes ectam habet duos, juxia os, \& duos in ventriculo. Ventriculus vero ab ore parum diltat, quem inteltinum lequitur fimplex usq́; ad extremam partem tendens \& excrementa ejiciens. Oculos habet duras, non in rectum fed obliqu um atq́; ad latera difpo. fitos 
fitos.Pedes haber denos cura duobus forcipibus ac chelis, maximan part $-m$ denticulata funt, \& q rum pars fuperior mobilis, inferior immobilis eft. Coloris ef fubviridis, qui ad rigrum tendit, fof coctionem a.rubefcüt. Deponit tempore veris eruftam fuam de toto corpore, capite, yentre, pedibus, \& fingulis partibus. Caudarn an habeat difputant, led non videmus, curillud ultimum, licet operimenturn corporis lit, cauda nomine non veniat? HI. Qurd degeneratione?

Refp. Sexum habent, maresq; velde libidinofi funt, ut unus in una caverna vel tres habeat foemelias. Pugnat pro his vehementer, \& alteri alter ob id forcipes frangic. Mares duas inter ventrem $\&$ caudam habent f́pinas, quibus for minz carent. His verò hirfutior \& amplior rauda data eft. Poit congreffum in fominis intrinfecus nalcuntur ova, qua fucceffu tem poris in latam illam \& hirfutam caudæ parté deponuncur.

Axiomata.

\section{Crefcente lunacrefcit caro in cancris.}

Carnem habent duram, frigidam \& humidam, undè difficilis coctionis funt, \& non nifi validis ventriculis conveniunt. Condimentis tamen atteuuantibus $\&$ calefa cientibus e. mendarur. Crefcente lunä crefcit, decrefcen. ze decrelcit caro ejus. Donû̉nân.humorum vigentẹ, 
vigente, vigent humores, faccumbente fuc. cumbunt.

II. Forcipes fracti renafcuntur.

Non n. ex femine formati funt, fed ex humorefangvini refpondente. Sicut renalcuntur in arboribus folia, in avibus penna, in pifci. bus fquamx, ita \& in cancris forcipes.

IfI. Cancer non est retrogradus.

Ducesitineris oculi funt. Cam horum poficu fi concordat progreffus, in anteriora fit, non in pofteriora. Cancrorum oculi non in rectü, fed in obliquam difpofiti func, Hon fequitur cancer, \& ratione fui corporis recta progre. ditur. Nec cum Scaligero dicendum, oculos propter progresfionem in latus flecti. Con. trarío fic modo : progresfio propter oculos fie in latus. Horum difpofitio non eft arbitraria, fed naturalis ac neceffaria.

LIBER SEXTUS

De Serpentibus.

C A P UT I.

De Serpentibus in Genere.

$$
\text { Precepta. }
$$

1. Serpens eft brutum reptile, callidum, venenofum, homini infeftum.

1. Eftó; draco, afpis, vipera, natrix \&c. Quefiones.

1.Qve: 


\section{PHYSICA.}

1. 2uomodo ferpentes bomini infundant venewz̈? 401 Reip. Purat vulgus ferpentem lingoa val nera. re, \& cauda vulneri venenum immittere. Sed homines lingram pro telo habent, non item ferpentes. Vulnera qua lingua fiune, non ram corpus quam famam liedunt. Alii prudentiores, ferpentem dentibus vulnus infligere, cauda caudà non tangane partem vulneratam, vee neno tamen eam inficiunt. Dicimus nos ferpentes ferratos habcre dentes, fiftula tenui perforatos \& pellicula parva ex parre oper. ros. In parva itta pellicula harer venenum, indeq́; vulneri, ubi dentibus lasêre, infüditur. II. An venenum pars jerpentis, an excrementum illius fit ?

Refp. Excrementi potiùs quàm partis habet rationem. Eu modo quo excremenra per totum corpus ejicienda, retinentur, \& ad pelliGulam dentibus adnatam propelluntur. Baffo, ait : linge que in bornine funt noxia, queg, per rotü corpus differfal lant, ac per cucem, reluquosque ineacus exeuns, in unsum locum cosre, ibigig dio utius paulatim, concogrii. Quid futurum peras, sbi maligni illi peritus in unum cong.egasti, lienogs, calore adjuti, majora impedimens sper con: coltionem exegerint? Si bumores excrementitit, dum egerineguewnt, putrefoentes deforunt in piC. 


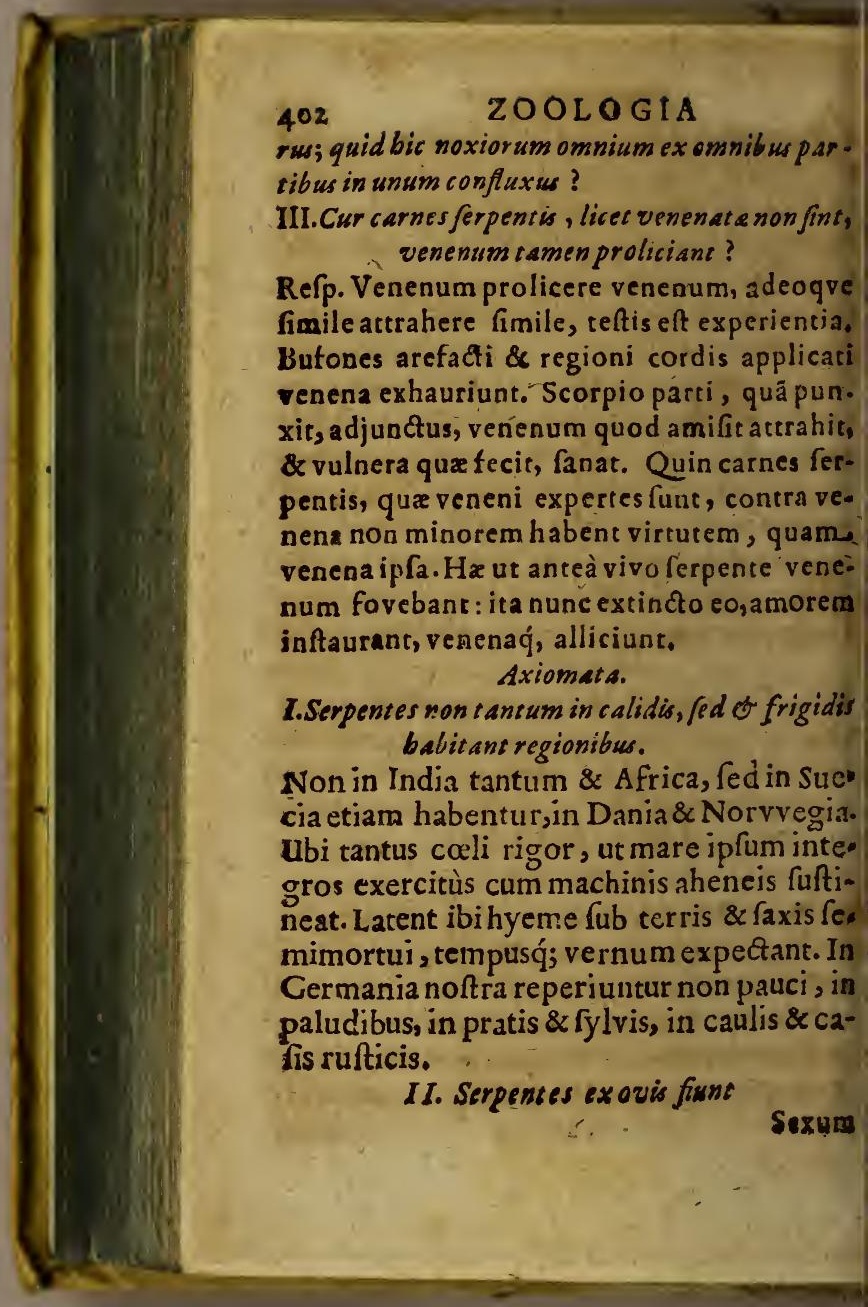




\section{PHYSICA.}

Sexum habent, \& tam arctè cohærènt, ut longinquo unum corpus effe putetur, cum duobus capitibus. Unde frgmencum illud, dari lerpentes bicipires, ac bilingues. Pariunt ava,ê quibus foetum excludunt, fola excepta vipera, quæ vivum parít animal. Indeó; id accepit nominis, quafi vivipara.

III. Serpentes ê Binali bominis medulla nafci, fabulofum eft.

Verum formarum originem qui teriet, falfitatem plebejx hujus opinionis agnofcit facilè. Experientia etiam nos informat, cùm paffim cadavera humana fint, ferpen. tes a non fint. Si alicubi in cadaveribus in. ventifunt, cibum quafiverunt. Delectan. tur n, dulcibus, fed dulcis humana caro eft. Igitur odorum luavitate ad loca illa alliciuntur, non verò ibidem generantur.

\section{CAPUT II. \\ De Dracone. \\ Preceptum.}

Draco eft serpens maximus, validifimus, ter ribilis, caudx robore plurimú valens. Queftiones.

T. 2uenam ustritio?

Refp. Vefcitur carnibus \& cadaveribus. Tanta in eo roracitas;ut una vice totum

$\mathrm{CC}_{2}: "$ cetrum 
404

\section{ZOOLOGIA}

cervum confumat. Fame compulfus homi. nes etiam aggreditur, necat ac devorat. II. Quenam generatio?

Refp. Magnitudinis ftupendx eft, \& alius viginti cubitos, alius triginta, alius quadraginta longus eft. Nicephorus tam mirandx magnitudinis draconcm defcribit, ut illum interfectum octo paria boum vix loco mo. vere potuerint. Quem \&, ne aërem infice. ret, interfequn combufferunt. Caput habet oblongum os triplici ordine dentium refertum, oculos magnos \& acutos, duas mem. branas in dorfo, fqua mas afperrimas in to. to corpore, caudam longam ac validisfimā. Color aliis ruffus ef, aliis cinereus, aliis niger.

\section{Quenamgeneratio?}

Relp. Ova parit,indeq́; pullos excludit. Hi cum fitiunt, nec aquam, qua reftingvunt $\mathrm{fi}^{-}$ tim, inveniunt, miferabiles habent lamen. tationes.

\section{Axiomata.}

I. Draco mammas non bubet.

Dicunt draconem, licet animal crudele fit? mammastamen fuis prabere pullis. Hinc mulieres inammas negantes infantibus re. prehendunt. Imprimis in meretrices in vehuntur, qux jugulant nonnunquam infantes, quod nec dracones, nęc aliz beftiz 
agunt. Sed mammx draconum in natura non dantur. Nec figmentis opus eft, ad vitia hominuin corrigenda. In Scriptura cum mentio fit mammarum draconis D.Frantzius inquit, nan effe intelligendum de ferpentibus odraconibus /pecialiter fic dictis, fed de magnis quadrupedibus, quia foriptura voce Hebras quasvis immanes belluas intelligat.

$$
\text { II. Draco alas baber. }
$$

Etiam hæc vulgi opinio Sapientum non in trat animas. In multis draconibus neveftigium qvidem ala rum deprehenfum eft. In cæteris pinnæ potius feu membranæ inftar pinnarum quam pennæ aut veræalæ fpectatæ fuêre. Non autem negamus Satanam fub fpecie alati draconis apparuiffe veneficis. Mille enim artifex eft, omnia tentans, quibusdecipiat, ipfumque Deum gloriofum blafphemet.

\section{CAPUT III. \\ De Afpide. \\ Praceptum.}

Afpis eft ferpens venenofisfimus, aftutisfimus \& maximè noxiưs.

\section{Queftiones.}

iI. Quenam nutritio?

Refp. Afpis eine Dtter / nutritur herbis, in quibus lubenter degit ac fefe occultat, ut foCe 3 . loca: 
706

\section{ZOOLOGIA}

lo capite emineat. Muribus etiam velcitur ; quin \& avibus, quas necat cum advolitant, capite cx he rbis exporrecto deceptx.

II. Quanam augmentatio?

Refp. Longitudinem habet quinq́; cubitorum. Cervicem latam \& tumidam, oculos cavos ac hebetes. Cum mordet, nulla morfus apparent veftigia, \& tamen veneno inficit ac interticit. Hxc enim qualitatum occulta rum natura, ut in minimo etiam maximas habeant vires.

\section{Quenam' generatio?}

Refp. Sexum habent. \& pariunt ova fimilia monilibus aureis. Inter marem \& foeminam maximus amor eft, adeò ut læxsâ. parte unâ, altera fuperfes, cædis autorem perfequatur. Axiomata.

I. Aßpis per fe vocem incant atoris non percipit. Brutum animal eft, quod incantationes non intelligit. Satan verò fefe conjungere folet, qui voces \& verba percipit. Hic in perniciem hominum fuos habet lufus, ut veneficos a. gnofcere, verba intelligere ipfasque adeò aures obturare dicatur ferpens ipfe.

$$
\text { II. Si Bafalifcus eft, aspis eft. }
$$

Vifu \& halitu Bafilifcum animalia omnia necare feribunt. Et tam exactè defcribunt cum, ac fi vidiffent \& manibus palpaffent. Si quid verỉ 
veri fubeft, non Baflifcum, fed afpidem coneernit. Hujus n.venenun perniciofisfimũ eft, prefertimpin calidis regionibus. Homines verò augent, omnia, \& fimplici vera duplex aut triplex falfum milcent. Placet illud Bodini : Cui vifus est unquam ? fa afpectufolo necàt.

\section{CAPUT IV. \\ De Vipera. \\ Praceptum.}

Vipera eft ferpens, morfus acerrimi, vivum, pariens animal.

\section{Qveftiones.}

I. Quenam nutritio?

Relp. Vipera Germanice Brano/đilange/nutritur herbis, ranis, muribus $\&$ aliis.

II. Quenam augmentatio? Refp.Longitudiném habet cubitalem.Quamvis prolocorum varietate variet. Cervicem habet tenuem ac corpus tumidum \& amplú. Cum irritatur, oculis corufcat, linguam exerit, \& acerrimè mordet.

\section{Quenamgeneratio?}

Refp. Mares fœminis conjunguntur, prolemque vivum edunt. Tradit Plinius, faminane in congreffu mariti collum comprebendere, eumque necare. $110 \mathrm{c}$ a. eam impunè non facere, cume catuli in wtere poftmodum ventrem matris dif-

Co 4 .

ceve: 
408

cerpant, eamg interficiant. Hinc of viviperam dict am eße, quia vi perit, aut quia viparit. Ree ctiùs verò Bodinus air: utriusğg fexus vipere lagenis vitreis inclufe partus eniti vifa funt, utrog $g_{3}$ parente fuperftite. Quam verius eft,viperam dici, quod fola ex omni ferpentum genere vivospariat.

Axioms.

Vipera acerrimì mordet etiam diffecta. Rufticus fuit, qui cum pratum demeteret falce, viperam fortè diffecuit, mediamq́; di. vifit. Et cum eam mortuam effe putavit, partem alteram in qua caput erat comprehendit. Sed vipera caput erexit, ac rufticum acerrimè momordit. Hic ori Atatim admovit vulnus, ut fanguinem exfugeret, vulnusq́; purgaree. Sed correptus veneriô, fubitâ morte periit.

CAPUT V.

De Natrice.

Praceptum.

Natrix eft ferpens maculis infignis, ftagna ac paludes amans.

Quxftiones.

I. Quanam nurritio?

Refp. Natrix Germanicè Natter aut hydrus

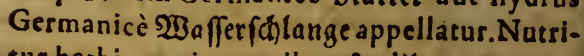
tur herbis, ranis, muribus \& aliis.

II. Quenam augmentatio?

Refp. 


\section{PHYSICA.}

Refp. Longitudinem habet cubitalem :Color cutis cinereus eft, maculis tamen undiq̣; có. decoratur. Amat ftagna ac paludes, cum autê exficcantur, in terram redit.

III. Quenam generatio ?

Refp. Mares fominis conjunguntur, ovaqúus pariunt, \& indé fotum excludunt.

\section{Axiomat.}

Singularia, que natricitribuunt, figment a funt. Natricis inquiunt flatus adeò noxius eft, ut firgam recenter cafam ori ejus admoveris, in cortice, velica fellex excitentur, Gladium fulgentem ori natricis $f i$ admovoris,eum linguâ veneno inficiet, quod usq́; ad fummum gladii delatum, tetro cæruleoq́; colore ipsú tingit. Hominem in calce fi momorderit, ve. nenum per totum corpus in momento fpargitur. Unde morfus pedibus fufpenditur, ne ad cor afcendat venenum. Sic nature admirandas effingant vires,mirabilia ingenia,

\section{Additamentum \\ $\mathrm{DE}$ \\ Infectis in Genere.}

\section{Preceptum.}

1. Infecta funt animalia minora \& infirmio: ra, commiffuris infignita.

Cc 5 II. Et 
410

\section{ZOOLOGIA}

II. Et funt apis, formica, aranea, mufca, pa: pilio, locufta,pediculus, vermis \&c.

Qpestiones.

J. An infecta refpirent?

Refp. Tranfpirant potius, quam refpirant. Refpiratio eft frigidi corporis per os aut nares, aut aiiud membrum in corpus attractio, \& ejusdem cumfuligine expulfio. Transfpiratio eft frigidi corporis per totum corpus ingreflus \& egreffus. Hxc infecris competit, ut fiat refrigeratio \& reftauratio. Cũ etiam ex iis fonum, murmur \& cantī quxdam edant, attrahant aërem neceffum eft. Quin \& odoratu prædita funt, adeò ut apes dulcia, \& culicesacida, procul fentiant,attractione aëris igitur opus habent.

II. Cur infect a iss partes divifa vipere queant?

Refp. Vermis cum fecatur,pars ad caput Ipectans, caput veríus tendit: pars ad caudam fpectans caudam verfus fe movet. Et vefpx cum dividuntur, vivit cum pectore caput, vivit etiam alvus. Neque tantum de bimembri infectorum divifione, fed etiam de ea, qux in plures fit partes; hoc intelligendum. Caufa eft, quia humidum cum calido æquabiliter fermè per totum corpus diffufum eft. Hinc comparari folent plan. tis, 
cis, qux ipla quoq; djflectæ vivunt, fed dium iùs longè quam inlecta.

\section{Axiomata:}

I. Infect a prest ant incifure.

Infecta, Græcè हैyт funt. Commiffuris énim infignita funt, nunc in fupina, nunc in prona, nunc in t:traq; parte.Nonnunquam etiam animalia rugola,aut annulofa cicuntur. Et hâcimprimis ratione â grefilibus, volatilibus,natatilibus \& reptilibusdif́cernuntur. Non admittenda ea diftinctio, qua cómmuniter da. tur, ratione perfecti \& imperfecti. Nullum infectorum imperfectum eft, habent omnia, qux habere debent. Rectè Aldro. vandus ait: cenfuerimus animalia effe imperfeEta, bestiolas quibus natura plus virium $E$ in. genit contulit, quam muliò grandioribus? 2uis non miretur potius minutisfimorum sinimalculorúm industriam, arten \& fagacitatem. Si quis in permiculo quid defideret, preter congruens vermis anime corpus, ut pennas advolatum, aut pedes ad ingrelfum, roftrum adefum, non erit boc animal vermis, fed monftrum quoddam verc imperfectum, quod ad nullam certam animalis $\int p e$ ciem referriqueat, non fecus ac Horatianum ilo Ind:

Huma: 


\section{ZOOLOGIA}

Humano capiti cervicem piOtor equinam

Jungere fi velit $\&$ varias inducere plumas.

II. Natara in minimis animalibus ma. ximaest.

Plinius ait : In magnis corporibus, aut certè ma. joribus facilis officina fequaci materia fuit. In his tampardis, atg tam nullis, que ratio, quanta vis, quam inextricabilis perfectio ? ubi tot fenfus collocavit in culice? Et funt alia diEfu minora. Sed ubi vifum, in ee pratendit? ubi guftatum applicadit? ubi odoratum inferuit ? ubi verò truculencam illam E proportione maximam vocem ingeneravit?

$$
\begin{gathered}
\text { CA P T II. } \\
\text { DeApi. }
\end{gathered}
$$

Apis eft infectum nobiliffimum, laborio fiffimum, ingeniofisfimum, \& utiliffimü. 20aftiones.

1. Quanam nutritio?

Refp.Vefcitur melle, aliisq́; rebus duleibb, bibitáue êfontibus limpidiffimis. Sibi format dulcia mella, fed maximus induftrix ipfius fructus in nos redundat. Sicuti ubique inferviunt homini bruta, \& plantx, \&ç,creaurre omnes. Unde Poëta canit: 
PHYSICA.

ic vos non vobis mellificatis apes: ic vos non vobis nidificatis aves : ic vos non vobis fertis aratraboves:

ic vos non vobis vellera fertis oves.

II. Quenam augmentatio?

erp. Quantitatis exigux eft, ut miremute a ajectisfimo \& minimo illo corpore, haitare tam laboriofum ac fapientem animü. Caput in proportione ad partes alias, manum habet,antennas breves, alas breves $\&$. andidas, intus currentibus flavis lineolis: Color corporis ad cinereum vergit, totaque apis fermè hirfuta eft.

\section{Qpenam generatio?}

Refp. Sine coitu generat, omni deftituta fecu, non fecus ac plantæ. Cardanus eas ê melenafci siatuit-Sed rectè Scaliger refpondet: zon è melle quat enus mel eft, fieri potest generas. io ; effet enim Jemen apis. At boc falfum eft. Neque ć melle putrefacto, quippe quod non putren cit, fed probibet putrefactionem. Genitale guiddam apes in cellis ponere planum off,ex quo opiculeprogignuntur.

Axiomata. 


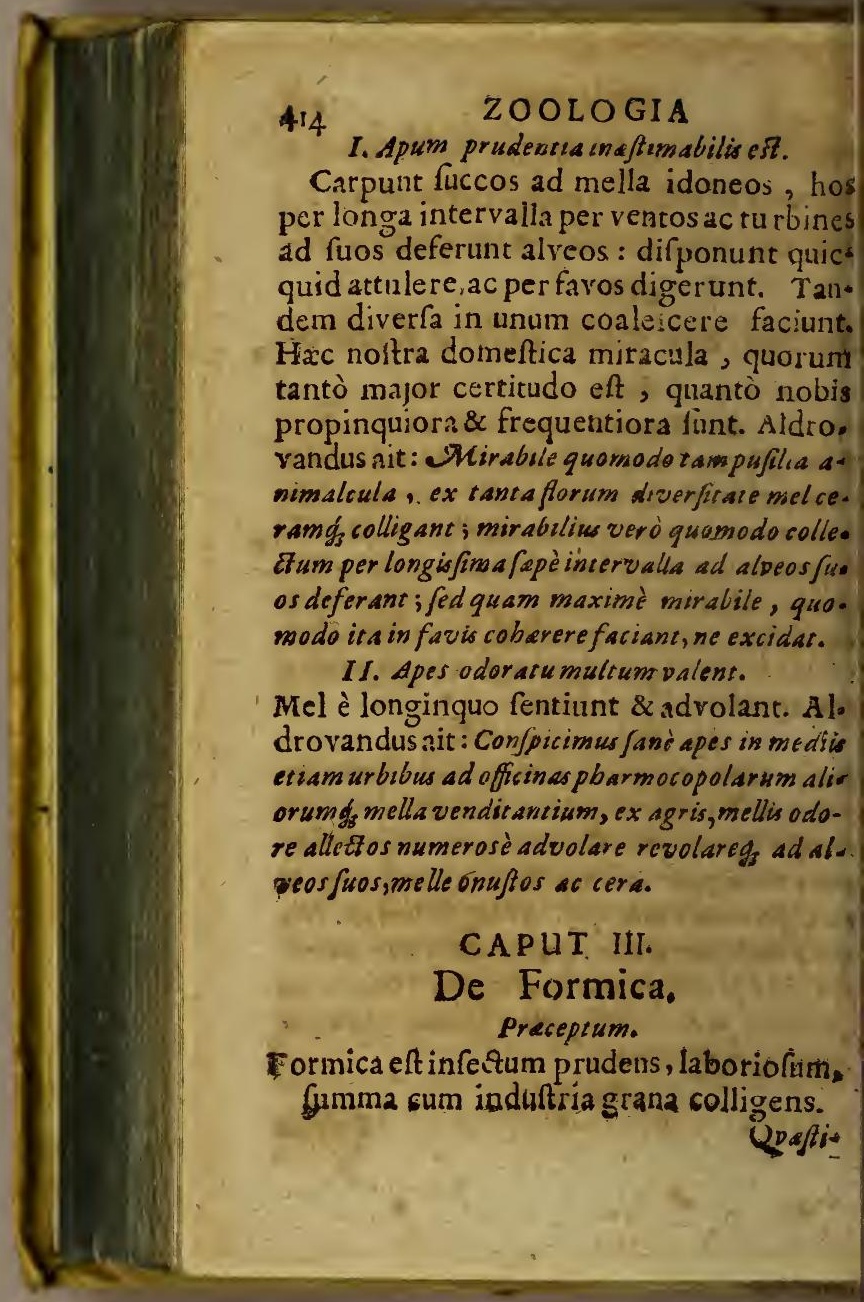




\section{PHYSICA. \\ Qvastiones.}

I. 2 Henam nutritio?

Refp. Vefcitur frugibus \& fructibus, inde. ue frugilega ac granifera dicitur. Ovidius ait:

Híc nos frugilegas alpeximus ordine longs, Grande onus exiguo formicas ore legentes.

II. ¿Uenam augnentatio?

Refp. Quantitas corporis parva admodùm eft, fed omnia membra t: m fapienter formata funt, ut minimum corpus maxima nobis Sapientiz divinz præbeat argumenta. Oculis carere dicutur Cardano, fed improbat fententiam Aldrovandus. Formica fenes, sit, alas emittunt, of polant non paruss: quas bidere in jenectute discemus, cium in juventule non viderint."

\section{III.Quenam gencratio?}

Refp. Ova pariunt, qux in vermiculum hujus ipfius fpeciei abeunt. Albertus ait: Ova formice funt oblongs, exirag, corpus paulatim recipiunt in locis calidis incrementa, quousque perfectè compleansur: 0 fi fortè ab aliquo de loco fubmot a ac difperfa fuerint, à formicis recolliguntur, E adfuos nidos referwntur.

Axiomata.

I. Formica prudentisfima eft. Grana colligitæeftate, ne hyeme, ubi arene umnia ac defunt, fame pereat. Collecta

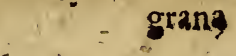




\section{6}

\section{ZOOLOGIA}

grana in principio, feu acumine ubi culmg furgit, exedit. Madida grana in apricum profert \& ad folem exficcat. Tanta hicfapientia, ut in Scriptura Sacra dicatur Sapienrior rapientibus ipfis.

II. Formica laboriofifima efl.

Campos, agros, areas \& arbores percurrit, fruges \& grana quxrens, \& cum invenit, quod quxfivit anxic̀, fapè onus corpore propriô majus in nidum deportat. Neque in. terdiutantum, fed \& noctu, fi plena tit Lu. na, opus cxptum continuat. Vade ad formi. camó piger, ait Salomon, E cofindera vias ejus, E difce sapientiam, que cum non babent Ducem, nec praceptorem, nec Principem, parat in aftate cibum fibi; $\sigma$ congregat in meffe quod coms. dat.

\section{CAPUT IV. \\ De Aranea. \\ Pracepcum.}

Aranea eft iniectum venenof $x$ naturx, ob telam quam format, induftria fin. gulari deçantatum.

Qvaftiones.

I. Quanam nutritio?

Refp. Vivit ex raptu mufcarum \& alio rum animalium minorum. Hinc laxos pasfim fufpendit cafles, mufcasgáuc inharentes

magno 
P.HYSICA.

magno aggreditur imperu, \& mox fuperaras necat, polt fuccurn fanguinemíúe exfugit.

\section{Qvenam augment atio?}

Rép. Parvum an inal elt, octo habens pedes diverfælongitudinis, ob diverfas, guas illis edit, opertiones. Aldrovandus ait : Quibusdan fila que nederunt, atterizadit. $G$ in longum protrahuret, alis eadem in telarn dedus cunt ac invicem conjungunt, aliisg, pereadem prorepune, er cum volunt, ex is ceu immobiles fefe fuspenciurit.

III. Q Qenamgeneratio?

Refp. Qeneratur ê congreflu, more eorum animalium, qua ex animalibus fui generis procreantur. Aldrovandus feribir: ODa aranearem cum aliquarado abjervarcm, incrui effe onulta, modica, livida, exiguis maculis nefperfa, divifa, invitemg feparata, mollia ev vifida, quafic caju aliguo fuerine perdita, arares diligenter inquirit, E/ /ui add̆l amentis interiorbus, or roftroctiám reportat

\section{Axiomata. \\ 1. Aranea prudestufina est.}

Hrc ea prudentia, qux naturam feguitur, non fenfum, hon intellectum. Seneca ait : Non vedes quam nulli morialium zmitabilie fic

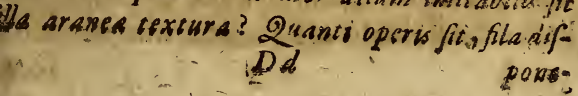


ponere? Alia in rectum immißa firmamenti loco, alia in orbern currentia, $\in x$ denjo rara, qui. busminora animalia, in quorum perniciem illa tenduntur, veluti retibus implicita teneantur. Nafcutur bec ars, non difcitur. Itag nullum eft animal alcero doctius.

II. Arance verenum ron onsibus noxium.

Ab homine fumptum araneæ venenum, feu crim potu, feu cum cibo, miferè afficit $\&$ affligit corpus. Nunc caloremnuncrigo: rem, nunc,pruriginem, nunc tumorem, nunc tremorem creat ægroto. A gallinis verò, aliisque avibus fine periculo aranca comeduntur. Sic non omribus venenum eft, quod alicui venenum eft.

\section{CAPUT V. \\ De Mufca. \\ Preceptum.}

Mufca oft infequm trediofum, protervum, audax, importunum $\&$ inquietum.

\section{Qpeftiones. \\ I. QDenam nutritio?}

Refp.Mufcæ omnia fermè deguftant, omnia liguriunt, maximè verò fangvini inhianto Murca hominis \& conviva, \& contubernalis \& commenfalis eft. Plenam ubique men a 


\section{PHYSICA.}

fam habet, five in pauperum degat tabernis, five in Regum Principumque turribus ac palatiis. Huic coqui oblonia condiunt, qux deguftat antequàm Domini ipfi. Imò invadit dominos, isque pungendo molefta adnodum eft, \& cum repellitur, redit 0 cyus, ac iterum iterumque repulfa magis magisq́; regredi laborat.

\section{Quenam algmentatio?}

Refp. Magnitudine \& ftructurâ va riat.Quxdam enim magnitudinem minimam, qux. dam mediam, quxdam major en habeut. Quxdam capite funt magno, quxdam par. yo; quxdam ventre crafío, quxdam exiles antennas feu cornicula in fronte gerunt, quædam is carent. Habent proborcidé, quâ ominia libant ac vorant. Habent alas non ut aves, fed ex pelliculis conflatis. In fole quas cum expandunt, varios exhibent colores, non fecus ac formola cauda pavonis.

\section{Qvenam generatio?}

Refp. Coëunt $\&$ conjunctim fxpè fimul vo. lant. Materia generationis femen eft, ê quo primum producitur vermiculus, mox mufca. Scaliger ait: Acutior cum exittimaveric ovum eße plus quam femen. Et quidem fine ullo fequestro procedere starim â femine in ani. mal: in nonnullis aliter fieri. E femine enim $D d 2$ 
420

\section{ZOOLOGIA}

non illici snimal feri, fe a quoddam mediums. Hoc medium est duorum modorurs : unium ef perfectius, uc vermiculi mu/carum foboles, $\hat{e}$ qui. bus fiunt mufce: alterum imperfectius, ut ova Cujus proportionis funt planta. Non gitur fructum femen eße, sut ovum puto, quale femen est animalis: fedfartum integrum ex feninis internis occultio, noń camen deartuculaeum. Per. fectum inquam coteris omnibus nifi dearticulatione. Hec extra ulgi opinionem, rudiora ingenia non admißura frio.

\section{Axiomata.}

I. Mufce oleô aut squa extincte rebivifeunt.

Salem fi afpergimus aut cinerem extinctis iftis, mulcarevivifcumt. Extincta itaq́; fue runt quoadvite actum fecundum, nos primum. Adfuit anima, adfuit vita in exinctis illis mufcis quoad actum primum : abfuit anima, abfuit vita quoad actum fecundum. Hinc \& non tain mortux, quàm quafimortue, aut fe. mimortua mufca dicuntur. A torali enim. privatione ad habitum naturaliter non datue règreflus.

II. E mufcarum majorum excrementis funt vermes.

Immundum animal mufca eft, ftercore fue 


\section{PHYSICA,}

fuo tabulata, picturas; veftes. libros, aliaque confpurcans. Et non rarò ê ftercore illo, prafertim majorum, vermes nafcuntur carnibus imprimis infefti. Scaliger in manu mufcam materiam illam, ê qua vermis natus fuit, deponere vidit. Ratio rei hujus animis candidio obfcura effe nequit. Mufca enim omnia liguriunt, vermiumq́uemateriam unæ cum cioo affumunt, affumptumq́ue per als vum redduni.

\section{CAPUT VI. De Papilione. Praseptum.}

Papilio eft infectum fragiliffimü, tempus vernum indicans, \&flor res amans,

\section{Qveftiones.}

\section{Qvenam nutritio?}

Refp. Papilio Germanicè Sommerßßogd aut MoldfenDleb/ cibum capit minimum \& potiffimum ê floribus. Flores enim amat, \&c fugit inde, quicquid ad palatum eft.

II. Quenam augmentatio?

Refp. Quancitate \& ftructurâ variat, cum centum \& pluribus conftet generibus. Ple-

Dd 3 riqg: 


\section{2}

\section{ZOOLOGIA}

rique antennas habent $\&$ alas farinäceas ac fragiles, quarum quadam maculolæ funt, quadam maculis carent. Et ipfi papiliones nunc uno, nunc duobus, nunc pluribus præ. diti lunt coloribus.

III Qvenam generatio?

Refp. Cuëunt \& ova pariunt. Nafci etiam dicuntur ex arboribus, vermibus $\&$ aliis. Sed inielligendum idcum rarione, quâ dictum. fxpiùs. Quod in arboribus, in foliis, in rebus putridis fit, non ftatim ex iis fir.

\section{Axioma. \\ Lucernas advolane quidam papilio.} nes.

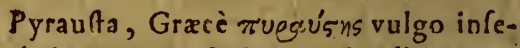
ctum in igne natum dicirur, led nulli anima. to talis compecit nativitas. Quoddam papilionis genus flammæcapitur fplendore, is gnique involitat accomburitur. Tales ergò habemus pyrauftas naturales. Hinc prover. bium eft, pyrauste interitus. De eo qui fibi ipfr exitium aiceffit. Et pyraufta gaudium. gastet. De momentanea voluptate, quam iequitur perperua calamitas.

\section{CAPVT VII. De Locufta.}




\section{PHYSICA.}

Locufta eft infectum vorax, in quietum, medium tenens inter volatile \& reptile.

\section{Queffiones.}

\section{Qoenam nutritio?}

Refp. Locufta Germanicè Şetwftsrede/ hero bis ac frugibus infeftisfima eit. Fruges enim abfumit, ac iplis quoǵ; atboribus 'ftragem infert. Hinc DEUS iratus mulra Ixpè locuftarum agmina immịifit, is q́; impios afflixit. Non ieonibus femper ac urfis, fed lacuftis eriam, aliisque abjectiflimis animalıbus. hominum punit improbitatem.

\section{Qpenam augmentatio?}

Refp. Mulra locuftarum funt genera, diverfa - quantitate \& ftructura pradita. Habetautem locufta pennas fragiles. \& pedes inaqua:Jes, cumque fedet,alata effe non puratur. In falcu continuo elt, non fimpliciter ingredi* ens, neque volans, fed inftar pulicis faliens.

\section{Qvenam generatio?}

Refp. Generatur ê coitu mutuo, minor- que mas, major fæmina. Ova parit, qua Dd 4 hye- 
4,24

\section{ZOOLOGIA}

hveme fub terrâ lacent, \& vere fequenti in locultas mutancur. Hincvernis aguis pereunr ova paucioresque nafcuntur locufta: veb re autein ficco mulica locufarum daritur. agmina.

\section{Locuftas manducavit Jobannes Baptifta.}

A'xébas reu locultas nuanducaffe Jo. hannem Bapriftam referunt Evangeliltz Matchæus, Marcus \& Lucas. Ubi per locuitas quidem herbas, alii arborum fummitates, alif cancros, alii aliud intelligunt. Sed nodum in firpo quxrunt. Cum enim o xédschoc ipfum notent infectum, populi etiam Orienrales procibo infectum hoc habuerint, ipfe quoq́; Mofes in feligendis cibis diligentiflimus, locuftas Jodxis permifit, cibum Johannis fuiffe hoc infeceum facilè int. telligitur. Durus quippe ac ingratus cibus dura ex afperæ Johanis vitæ conveniebat.

\section{CAPUT VIII. \\ De Verme.}

Preceptum.

Vermis eft infectum ignobile \&

$$
+\quad \text { abje. }
$$


abjectum, pedibus carens, motum plexibus variis perficiens.

\section{2ueftiones.}

I. Q:enam nutritio?

Refp. Nurricur fucco corporum animato run. In herbis $\$$ arboribusqui vivunt, fuccum inde petunt, In animalibus qui degune, indefuccum ac fanguirem trabune. In terra qui funt, radicibus herbarum \& arborum, infelti funt.

\section{Qvenam augmentatio?}

Refp. Magnitudine \& ftructurâ variane, cum dentur maximi, mesii \& minimi. Ha. bentur in homine, brutis, plantis, terris $\mathbf{S}$ aquis. Nierembergius lcribir, in bominibas quicirca Nigritarum regiones nazigant, nafci permes intenfffinum delorem excitantes: $f$ ap. pareve cos in deverfis covporis partebus, in furis 5 pedibus, in genibus \& poplite, in ing wine E fcroto, in femore, in bracbiis, of plerwm in partia bus carnofis. De caula mali nihil certi definire andet, litem fub judice relinquens. Credibile tamen omnium maximè, ex aqua potabili eos progenerari, qua ex lacunis \& ftagnis hauriatur.

$$
\text { Dds IIIQRes }
$$




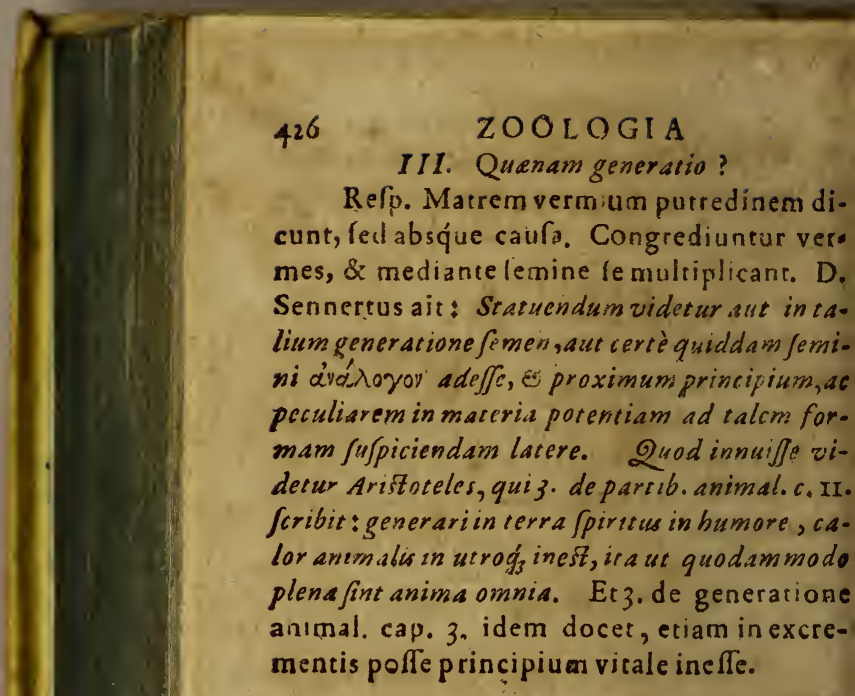

\section{Axioma.}

Etiam Dermes perbenedictionem divinam/e multiplicant.

Non acquiefcendum in colo \& illis : funt enim caufæ univerfales. Non acquiefcendum incalore: eft enimaccidens, \& commune natura inftrumentum. Ad propriam recurrendusn furmam, quá fe muluplicant, ficut cæetera animelia. Rectè D Franzius ait: Ex materid putridágenerarı dicuntur permes; rectius autem 
PHYS I CA.

itiam ita prodire fatuendum, ficut in boc traezau Caprus monuimus, ut Jalva maneat benedictio divina omnibg creatur is mulsiplic ands initio orbis pronunciata, nimerum ex annis, creati oropemodum in lenfib libus, que cum cibo ab bominibus fine dubio, lepe attrabuntur, O. êcalore intestinorum â putridamaterna vigetantur.

\section{CAPUT IX. \\ De Cimice.}

prideprum.

Cimex eft infectum, foctore fáo horrendo, \& morfibus omnibus odiofum.

Questiones.

\section{Qperiam nutritio?}

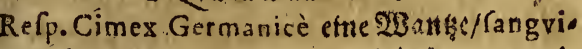
nem humanum qvarit, qvo delectacur maximè. Quia etiam fyiveltres dantur, alia quoqu; proftaf materia olera nempe \& Airpes. Vo. lut Chry animal, utilitatem quandam præftare homin $i$, dùm excitat eum êtomno, ut curam adhibeat in locandis rebus Refpexithuc Scaliger, cum fcripfit: Qvis miferius aut in felicius natura incerprecabirur ópera, qvàm qui ad ea cimicem allegatom dicat: ut noctu ex importuno fomno excitet nos ad preces Calitibus fundendas?

II. Qraes: 
II. Qvenam augmentatio?

Refp. Cimex corpus lacum potiùs quàm lon gum babet. Adeò verèfanguineus eft, ut le vi manu comprimatur. Compreffus tà peffime olet, ut nihil videatur abominabil us. Animaladrnodum invifum eft tam div tibus, quàm pauperibus.

\section{Quenamgeneratio?}

Refp. Generatur in lectis \& prelertim in eo rurn rimulis. Fiunt etiam in pariecibus, lecti quàm proximis. Pauperum verò habitatio nes magis infeftantur cimicibus, quàm divi tum. Hi enim ftramina \& lintea \& reliqvi mutart fubinde, pauperibusidem agere no licet. Ex excrementis hominü nafci putantur fed in excrementis potius dicendú, qvàm et excrementis. Quin imò minùs infeftansm le â cimicibus, quädiu ab hominibus occupan tur. Rectè Ariftoteles, cimicem per coitum ge nerari is lendes producere Jcribit, incerim ex fordibus nibil fieri putat.

\section{Axioms.}

Ecimicibus contritis oriri nopos non credendum.

Non enim ibi principium feminale, $\hat{e}$ quo novi cimices. Scaliger ait: vulgo ja ctatum eft, $\hat{e}$ cimicibus contritis cimices item exoruri. Quodmibi quidem non fit perifmile.

Sea 


\section{ZOOLOGIA}

429

ied quibus primordis illis in locis, concreabantur lin it, qivi fuerunt ibi contriti, /ubsafcialios. tignaenim quedam; ut absegna, Es paleas baiercillus ac Becies fecuna rudomenta natiaralias. naxifeß um es?. QHa natura fapperfitic atg $g_{3}$ inolusi anente, noa sàra redincegretur in conritoram tabo, quaxs nova cx vetcribus principiis abfituatior geiseratio.

\section{CAPUT $\mathrm{X}$. \\ De Pediculo. \\ - praceprssiss.}

Pediculus eft infectum ignobilisa fimum ac vilisfimum, tædium $\&$ odium $\&$ odium pof. feffori pariens.

I. Quanam watritio?

Refp. Nutritur fucco hominum brutorum ac plantarum. Habent enim fuos pedia culos planté, fuos bruta, fuos homines. Et ubi humorum copia, ibi plures ac frequentires pediculi. Hinc pedicastis magis infeftantur, formina, quam diri, pueri magis quam juvenes.

\section{Qunnam augmentatio?}

Refp, Quantitas corporis minima eft; diverf:

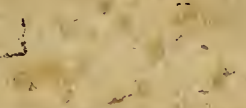




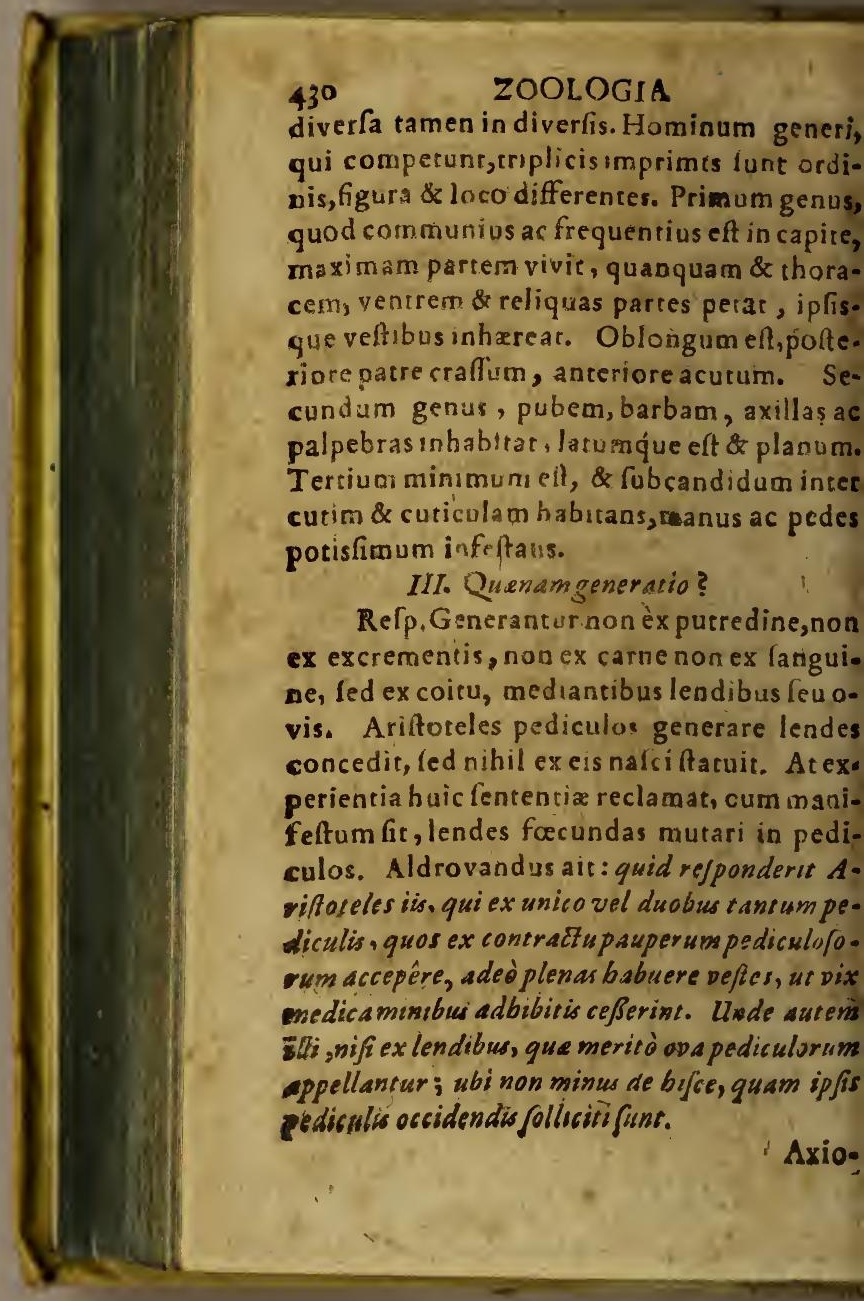




\section{PHYSICA.}

Axioma.

Pediculi deferunt morituros. Scaliger ait: pir civesmaximè fciur tboc, grod 'cribant, ubi $\hat{e}$ majeris ift is moritur aligois, confefimex veteri bofpirio, fcil cadavere, emigrane oedicali. Qpestio autem de caufa rei certe indubitate est. Putamis caulam effe hanc; gria pediculiamant teporem \& fuccum fangvie neum ac dulcem. His negatis in jam jam mo-. rituris, loca petunt commodiora.

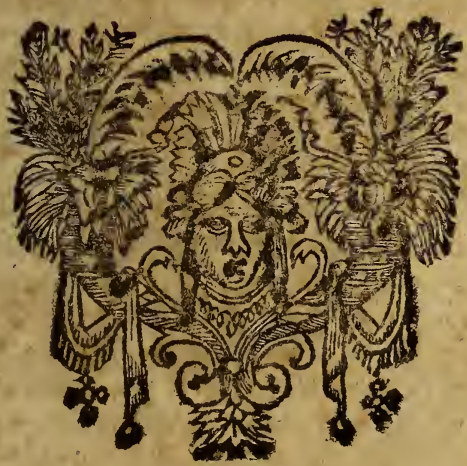




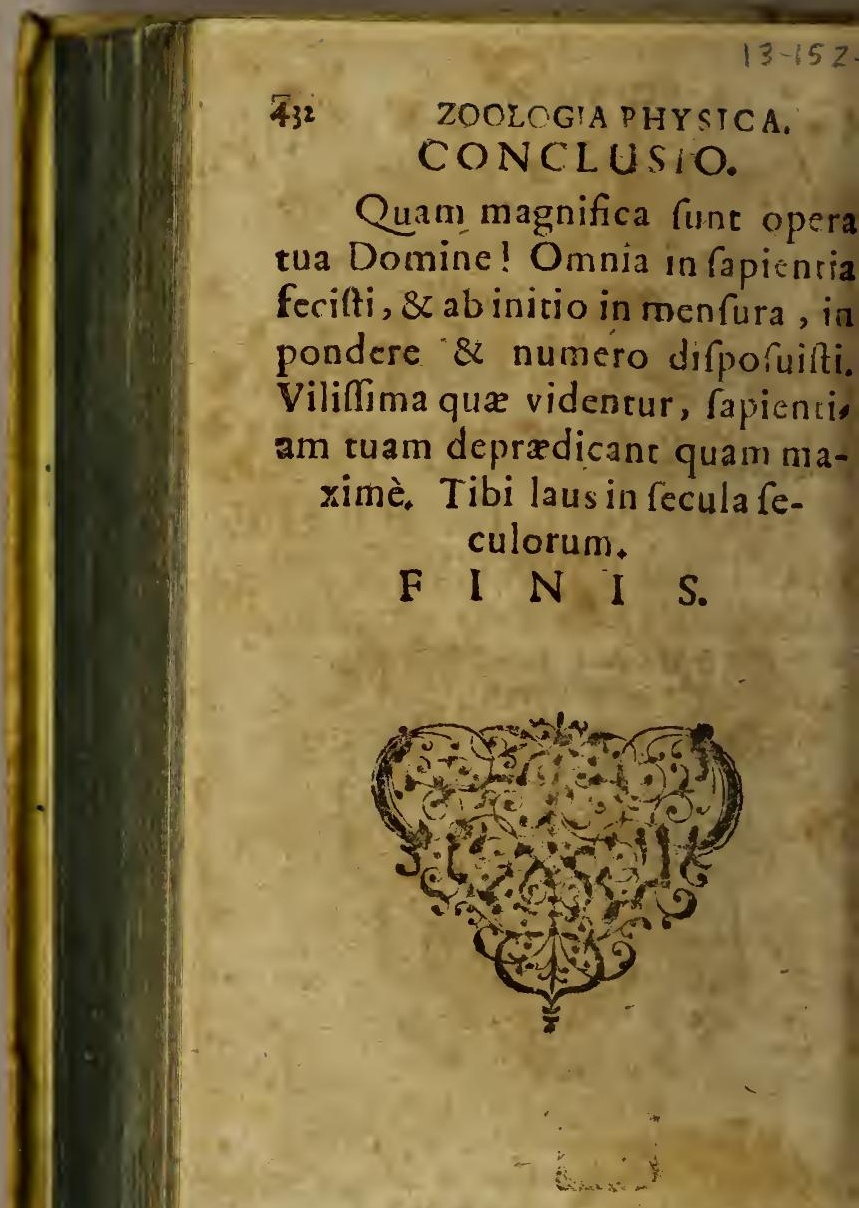




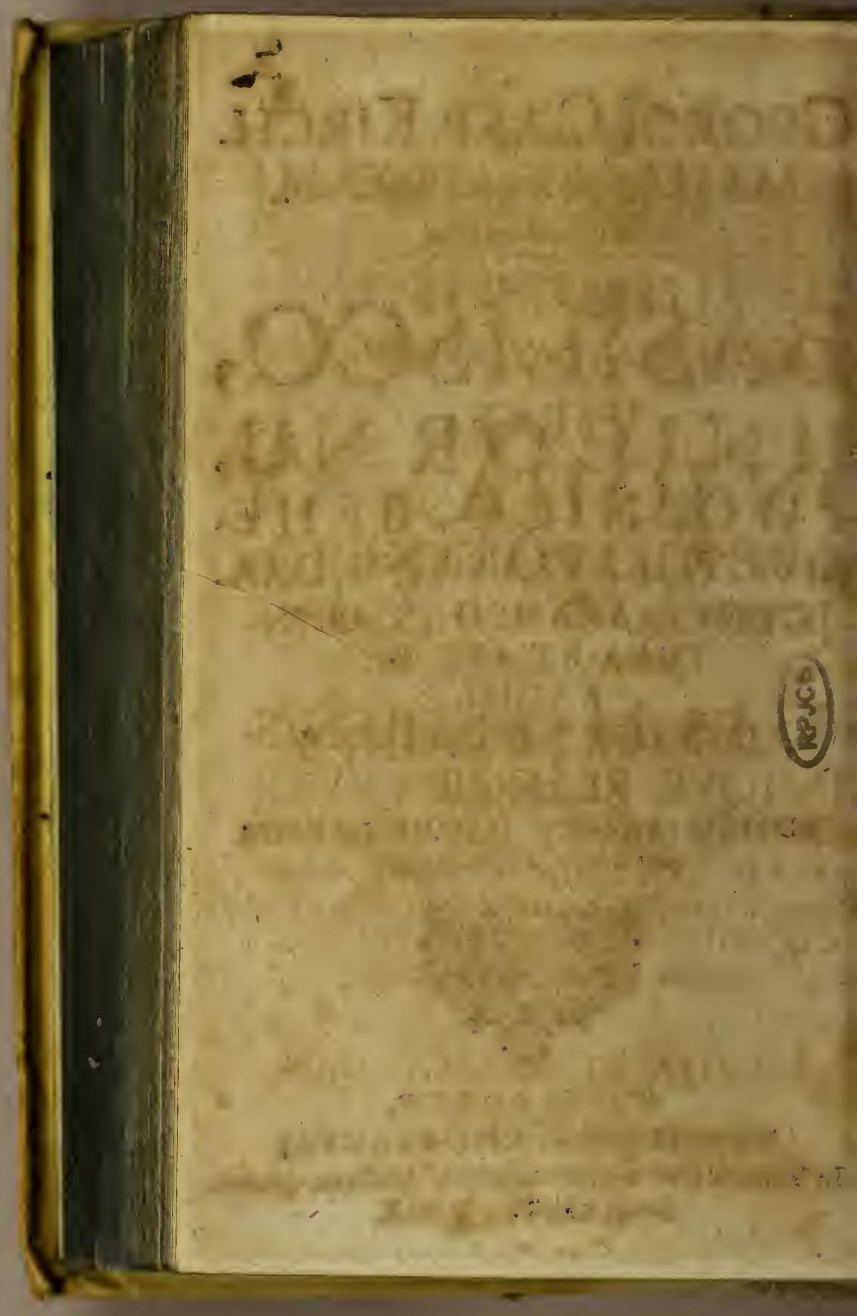




\section{T EPISTOLA.}

irtutis tur ac eru. ditionis, JOANNES AL BERTE PORTNERE, tanta magnitudo eft, ut, cùm tute ignarari illam, quâ es modeffiâ, , praxaptes, fumma tamen Principum \& Literatorum nomina ambitiosè eam colant. Sanè quanti fecerit Egregius FORSTNERLIS, in publicâ verfatur luce. Et magnâ paffimlaude veheris in Auguilta Sacratisfimi Imperatoris aula ; ut de aliis non dicam in præfenti, qui nitil $x$ què exfecror, ac adulandi fervitutem.. Dabis interim hanc copiam fatendi, totum mein admirationem pariter ac venerationem Tui raptum. Et quidni ? jubet com- 
DEDICATORIA.

nune beneficium, qvo alligatus fraer fratri eft; ut \& illuftri Reipubl. ib.Ratisponenfi, \& inprimis Tibi, atrone, infrgnes agam habeamq; ratias, quòd poft ingentia liberali. atis documenta, SEBAST IANUM amantisfimum Germanum neum, tam honefto apud VOS nunere dignari nuper voluiftis. Cujus falutem, fi, ut fpero \& obeftor, porrò eftis curaturi, erit proétò, cur inter clientes referri vetros publicè contendam. Tu verò, Nobilisfime PORTNERE, fimlicitati mex indulgebis, qvòd, yas olim celeberrimis nominibus, ENTZIO nimirum \& URSINO, Jeftris, toís paxapítass, deftinabam, uctiores aliqvantum Tibi nunc $\mathrm{JaC}, 3$ inferi- 
EPISTOLA DEDICATORIA. infcribere Differtatiunculas nullus erubuerim. Ita folent humiles animæ, qvandoplura non affeqvi, qvæ volunt, poffunt. Tu vale, Domine,\& fave

Dab.prid.Non. Januar.

Anno 1669.

\section{Virtutum tuarum \\ Admiratori}

\section{G.C. Kirchmajero.} idy lo masect. 


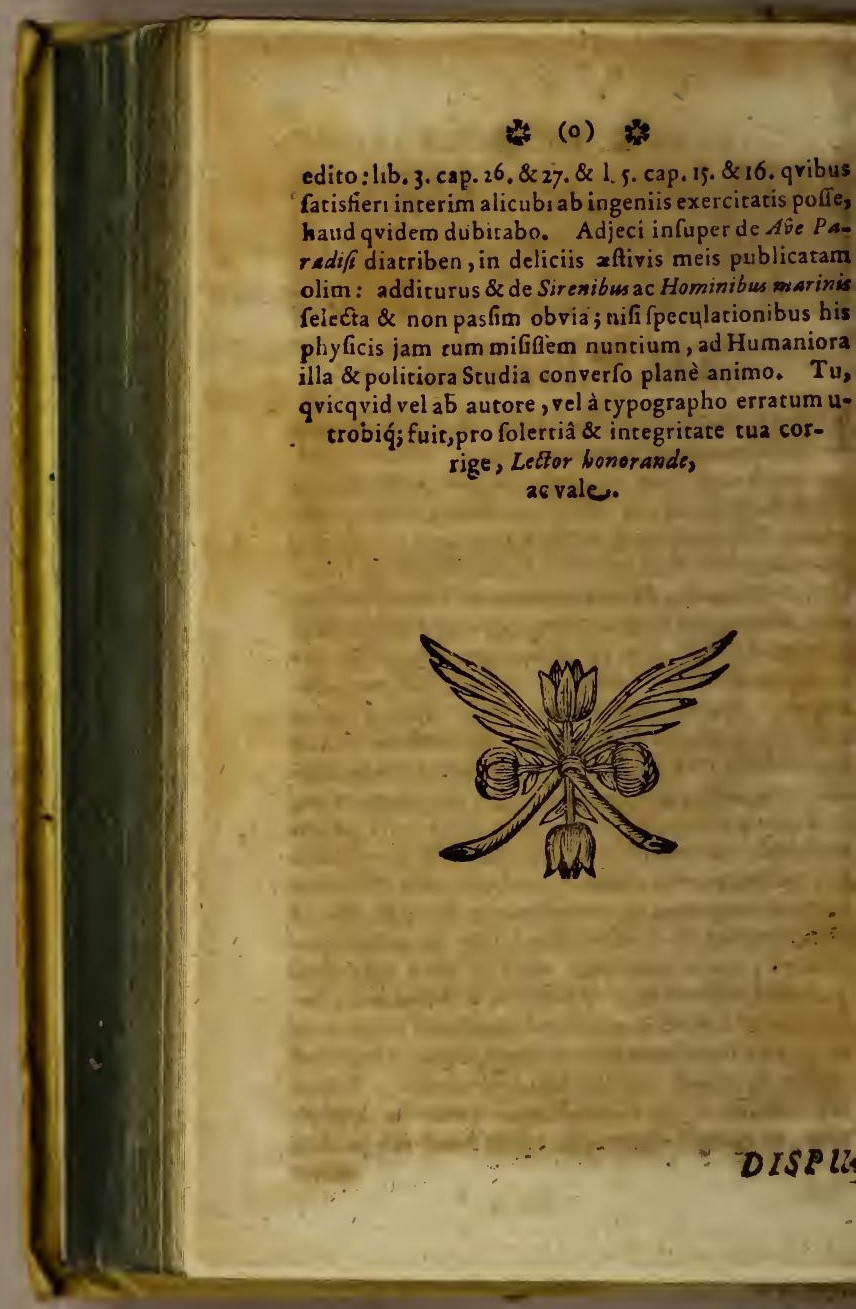




\section{2}

(dummodòjic nominandus jure venit) commu nis hactenus, quod nos fciamus, plerorumǵ, ob fedit animos opinio: effe eum Gallo feniore, o vumpariente \& Bufone incubo, oriundsm ani mal, ,pecieiutriusgs abortum, Denenofum ade E malignum,ut velfolo adpiectu, à fe primù difos in momento enecet. Grandiores profeca bolibi,qvàm qvi uno abliguriri Spiritu polfin QDamobrem è anniternur, ut ex Zoologis qvorum nobis facultas fieripotuit, praflantil. mis, deprefente causấ rognofcamus.

univerfa tamen ad nature dircs \& fan rationis trutinam revocaturi. Tu fons Verisa tis, DEus, fac veritatem propugnemus \& fa fitatemoppugnemus!

\section{$C A P U T$ I. ARGUMENTUM.}

1. Bafilifci, frequens in SS. mentio. Itemg, profanis.

2. Etymologia Bafilifci. Reges inter bruta, qui 3. Homonymia edolvitur.

4. Additur Synoriymia.

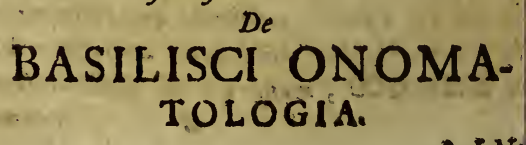

$S_{1} I_{0} N_{6}$ 


\section{*4 4}

tiâ. A potentià quidem, quia potentiflimu inter omnes minorum ferpentum fpecies, $B$ filifus, \& infuperabilis, propter præfentis fimum verrenum fuum, dicitur. Qvô nomi ne etiam à multis aliis \& vitari \& timeri befti is putatur. Inter grandiorum verò gener feipentum, Draconi ferimus I'rincipạtum. It avium $R e x$, generofifima aqvila. Qvadr: pedum, robuftifimus Leo. Pifcium. Delphinus, aut Balrena potits. A cor venientiâ yerò cum coronâ quadam, dum tes nis fubálbidis, in capite maculatus eft emi nentiis, adeò ur prr fe ferre criftas videatu. Zob. Eufebius Nierembergius ex Soc. Fef. in Aca. Reg. Maćritenfi Pbyfiolog. Prof. Lib. VI. Liij Nas.6.20. fol.102. inquic : longitudine trius palmorrm eft, corporeflavo, capice acuto, $i$ goo tres haber eminentias, maculis fubalbidis in fognitas ad diadernatis formam, ob quam etian caufam Rex ferpentum fuit dictus.

5. III. Homonymia Sequitur. Vox B: filifcimultis obnoxia ambiguitatibus eft. A deò nec nomini, nec rei fub nomine notata tuta fides. Primò enim attribuitur avicule cu dam, qvam alio modo Trochilum falutamu

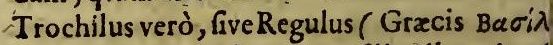
ox (3) Der Zauntónig / pufilla illa avis ef qva inter frutecta \& juniperos nidula 


\section{4) 5}

flolet, puniceis in capite furrectis plumulis ecora, dimidio minor paflerculo, frigidiois auræ, in Majo potiffimùm prænuncia, caluli medicatrix. (2) Coronatis ac criftat is, cerfpeciei, pi/cibus. Alaudæ criftatæ, fiveGaeritæ, ab Ornithologis adiàs vocantur. Ceeberrimus, atque omnium Princeps Zooloorum lllyfes Aldropandus Pbilof. E Medicus iononienfis lib. 1. de Pifcib.c. 25. fol. 42. fic haet: Si gquis modo criftatos, ac quodammodò oronatospifces, vel aliguem ex iis, ad Bafsilifcos Ppiani, quos circa petras littorales degere fcriit, referre velit, is, meo judicio, mibi nibil ibfurdi flatuerit. Ll namǵs di criflà fuum pifcem, Pondeletius Galeritam aliig ${ }_{3}$ ferpentem, candiIÁ in capite maculâ infignem Bafilifoum nossiarwnt : Vexifimile itidem apparet, ob fimileme erè in capire notam, Bafilifcos pifces appellasfe. 3) Plant.e alicui, ut Nierembergius alteribi otavit. Qvâ de rẹ̣adeundi Botanici atq; conulendi. (4) Sub propriâ nomenclatura cometit Bafilifci appellatio nobiliffime alicui in iiß ania familia, qva ob virtutem gentilium uorum, tanqvam qui folo confpectu hoftes rofternerent, Bafliffcorum Blafcorumve fanilia dicebatur.Ut prolaudatus Nierembergiis Lib. VI. Hifo. Nature c.XX. fol.103. teitaur.

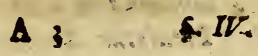


S. IV. Synonymia fubjungenda brev

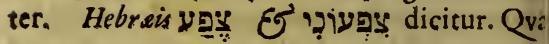
voces per Regulum, Bafliffcum of Hemorrbo. $d a$, venenofiffimi ferpentis genus interpret:

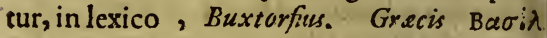
Frov, domefticâ lingvâ dìci, fuprà common fecimus. Latinis Regulus audit, Gallo-Bt fo item, Criftata afpis, Peremptorius Adfpr etor, Virulentiffimus ferpens, \&c.

\section{CAPUT II. ELENCHUS。}

1. Datur in rerum naturâ Bafolifcus.

2. Locus Sealigeri E Cardani faflitur.

3. Vifus eft in Marchiâ Bafilifcus. Bafiedea Zviccavice \& Hale Saxonum, viforum ac buc extant monumenta. Calidis regionib. familiarifimus Bafilifcus.

4. Warfovia in Poloniâ, à plosquam duabus ba minum millibus, vifus Bafilifcus.

5. Adducitur ex D. Mo Sano E Fob. Pincierc bifforia.

6. Th. Bartholini obferpatio of teftimonium.

7. Inquiritur in fentientiamSperlingianam. 8. Continuatur idem. Notatur Matthiolus. Laudatur sebizius. 


\section{2 \\ De \\ BASILISCI EXI- \\ STENTIA.}

5. I. Exiflentiam Bafliffi procaciter ne-

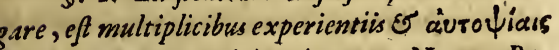
ablatrare. Datur igitur in rerumNatura Baflifcus, truculentißima, omniumg's animalium nocentiffema befia ac peftis. Scilicet nec xqvivocam illam \& plufquàm monftrofam Bafilifcigenerationem, nec mortiferum illius adfpectú, ner: alia, anilibus verifimilia fabellis approbamy. Sed pro exiftentiâ venenofillimæx huis afpidis pugnamus. Multi , ni fallor, contradicent. Sed profectò ipfis obloqvuntur fenfibus. At contrariari fenfibus \& rationes petere, quid uifi äpóssia 2lovoías? Producemus verò teftes non auritos folummodò, fed \& uculatos, qvi fuis ipforum oculis ufurpavére Bafilifcum.

§. II. Jul. Cær. Scalig, ut fufpicionem fabulx de Bafilifco tolleret, Ex.246. fect. 4. fic inquit: quoniam de Bafilifco que narrantur, fabulofa nonnullifuspicatifunt, qpe apud Recentiores legi, fcribam. Leone Pontifice Maximo ad KEdem Lucie, fub fornice ftabulatum Bafilifcum : cujus afflatu, magnâ lue affecta A 4

Roma 


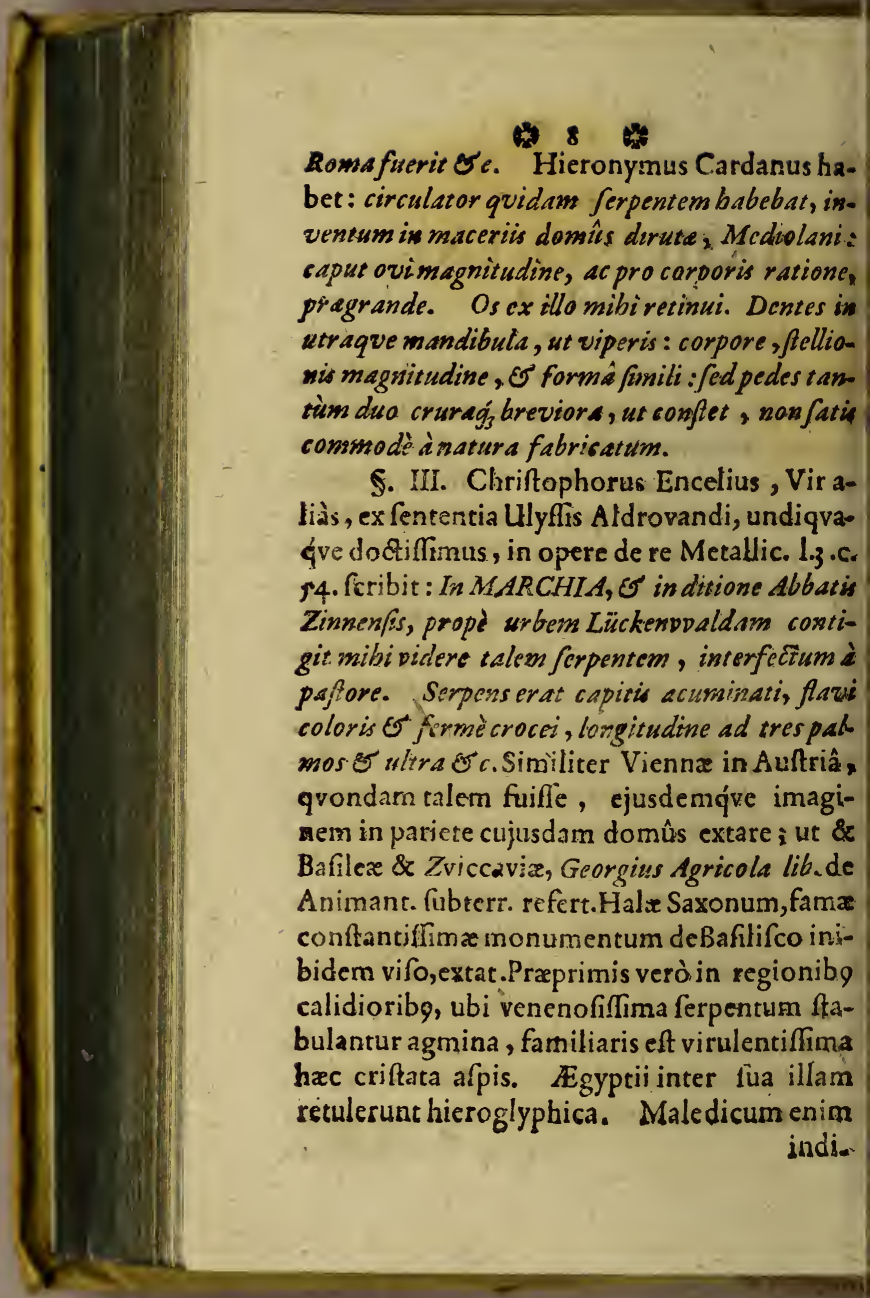


adigitacuri, Bafilifcum efformârunt. Unde wcanus:

Sibilag, cffunders cunctasg tenentia peffes, Ante penesa rocess, late fibi fubmoovct or mne .

Vulgus, $\delta$ in vacuâ regnat Baflifousarená. vin nec Ethiopibus ac Mauris planè inco. nitus Bafliffus. Ita enim iterum Lucanus :

2oid prodeft miferi, Bafilifous enfyide Masui

Tranfactus ? velox currit per telx penes

- Invaditǵ: manum.

S. IV. Sed fide digniora, eaq́ve indubia lanè, adferenda funt. Warfovix in Poloia, fpectantibus plusquam duobus bominars nillibus, vifus aliquis ex collapfarum æodium uderibus extractus ferreo rutabulo Bafili. cus. Memorabilem hiftoriam illam, quoad omnes circumftantias defcripfit $D$. Mofanus, Arcbiater Casfellanus, itemq́ve fobannes Pincier Enigm. lib. 3. ænig. 23. Uterq́; tamen prolixifimè defcripfit : quapropter ne aberiora adducendo, farigemus lectores, \&c fupervacaneam verborum cumulaffe fegetem videamur ; . fumma duntaxat delibajimus capita, restamen fingulas, negatio prefenti militantes, bonâ fide adducturi.

$$
\text { A } 5 . \because 7 \text {. }
$$




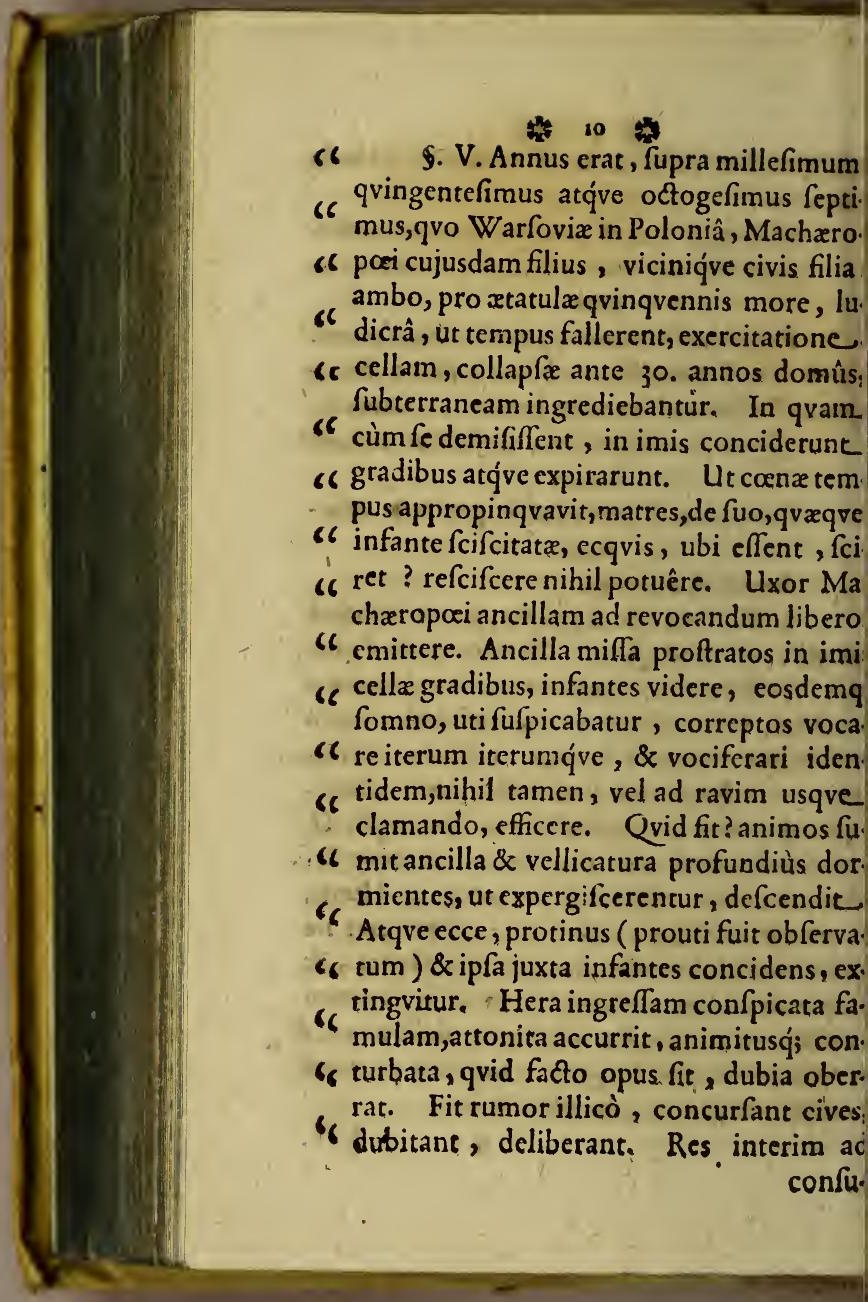




\section{* 11 \%}

Confulem \& Senatum defertur. Hi in ce mandatis dant, ut uncis incendiariis cadavera extrahantur. Extracta, tympani in- 6 far turgebant, lingva intumuerat, color ic erat fufcus, oculi extra fuas cavernas, ad dimidii ovi gallinacei magnitudinem pro- 66 minebant. Acceffit ad hoc Tragicum. ic fpectaculum, Confulis rogatu, Palatinus \& fenex quidam Archiater'Regius, Benedicts cc nomine. Hujus conjectura fuit, ferpentern veneni præefentiffimi in defertâ illa i 6 cellâ ftabulari , cujus perniciofo halitu aer ce in eâ conclufus, inquinetur; cum autem. infirmam hominis naturam perferre non "c poffe, ut fua ibi latibula habeat Baflifcus. ic Interrogatus, qvâ ratione rei veritas explorari queat? refpondit; effec aliquem in cel- 66 lam mittendum, eumqque circumqvaq́ve 66 fpeculis averfis muniendum. Baflifcum enim, fi fuam ipfius imaginem videat, 66 protinùs emori. Fuêre illî́c, fub id tem- 66 pus, duo rei, capitis fupplicio, intra triduum afficiendi, qvorum alter Polonus, Sile- CC fius alter. Atq́ve huic nomen fobanni fau- $\measuredangle 6$ rera fuit. His conditio oblata, uter eosum defcenderet in cellam, ferpentemque ${ }^{c}$ illum venenatum venaretur, ei capitis 66 fupplicium remitteretur. Conditioni SiJefuus fe illicò accinxit. Itaq́ve corio, to- $\$ 6$

to cir- 


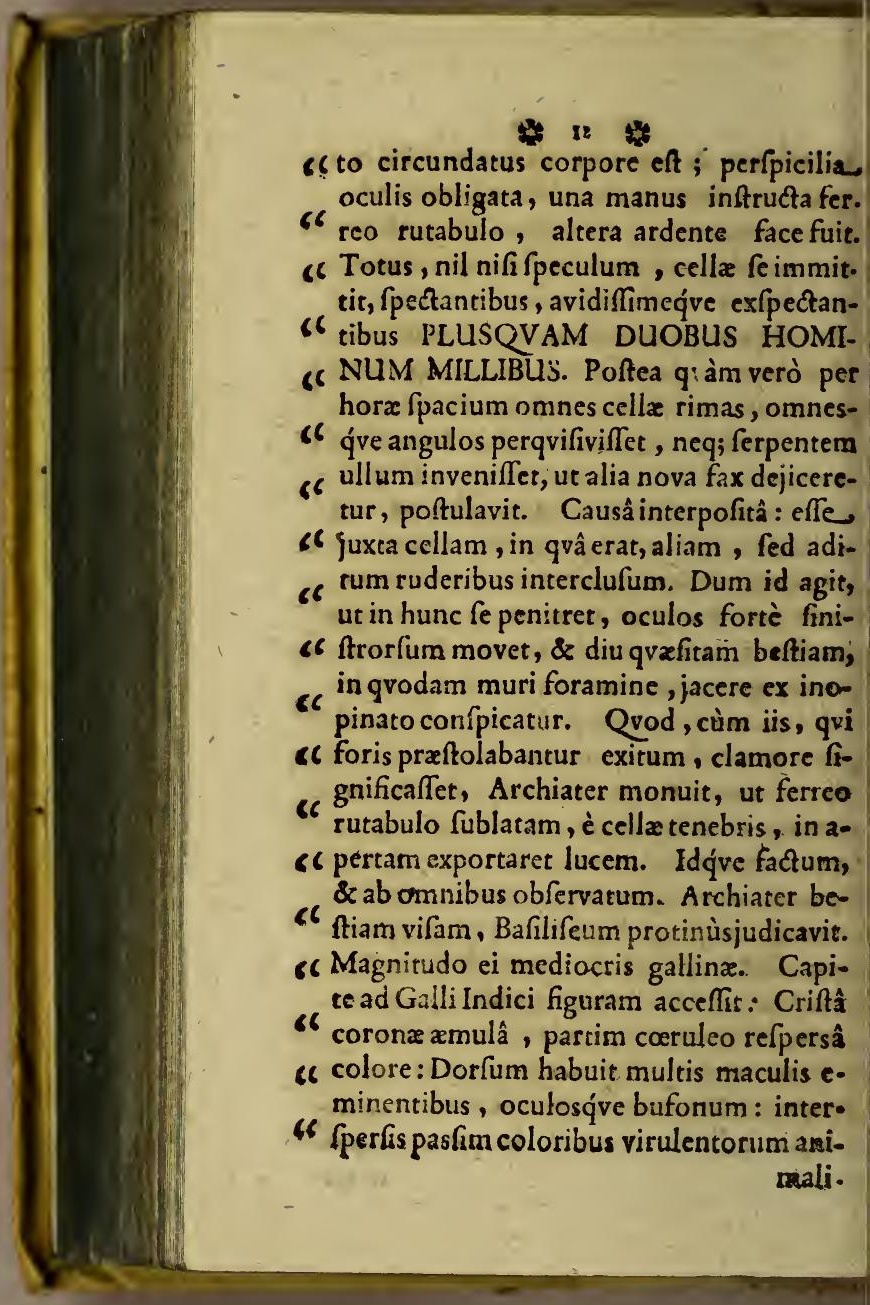




\section{$13 \%$}

6 malium, ut plurimumverò flavo. Cauda illi fuit incurvata , ac furfum reflexa, in6 feriùs flava, in extremo bufoni concolor. ic \&c. Hac prolixiusculè ; forfan, tuis, benevole Anagnofta, non ingratiis.

5. VI. Faciunt huc etiam, qvæ in libro de Unicor. c. 7. fummus Vir 7 bomas Bartholinus refert: Si vera de Bafilifco fama, ex opo gallifenioris exclufo, poterat indurata longiori etate materia adfubfiantiam corneam transferri, Fo in caput Bafilifis exfurgere, qvodgalli calcaneo beferat. Ea metamorpbofis qpangpam minus ufitata fit, Batilifcum tamen, unico in fronte cornu confpicuum, Roma gentium Naturxáve mater, non ita pridem ế (pecie tulit, qvam raibi pilior exbibuit.

\$. VII. Apparet inde, quídjudicandum de virulentislimâ beltiâ Bafilifco fiet. Inde incomparabilis Natura Interpres SPERLINGIUS, pro ea, qvâ erat Sagacitate, non aufus uppidó inficias ireBafflifci exiflentiam.Sed, cùm afpidem, venenofisfimam, per hoc animal intelligi oportere, animadverteret, illas faltem anilium fabularum appendices, qvas \& nos confutabimus in Decifionibus fubfecuturis, refutavit. . Sic enim in Pralectionibus ZOOLOGI死 publicis, part. fpec.lib.VI. Cap.LIX.de ASPID. axiom. 2. ftatu-

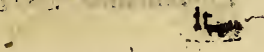




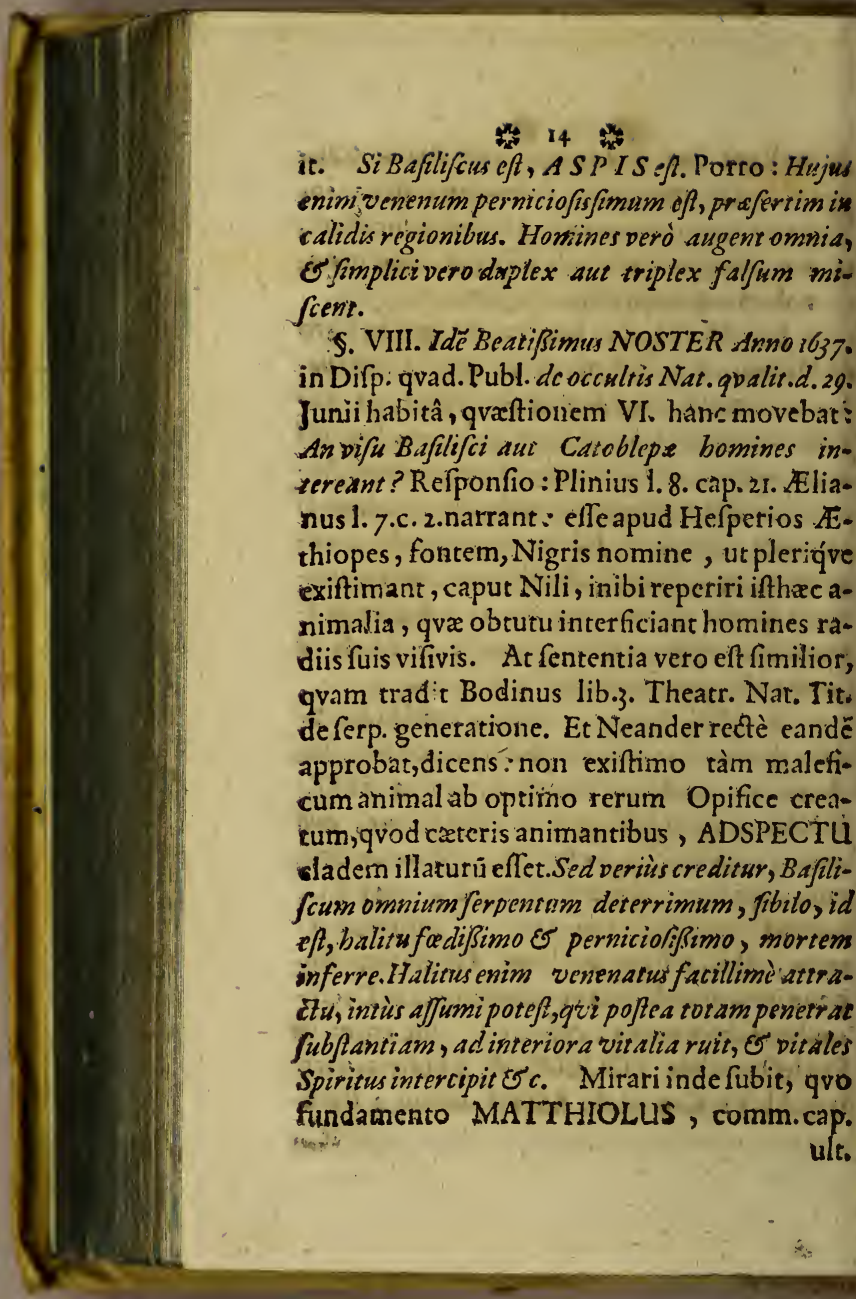


It.lib.6.Diofcor. fabulofa cuncta reputet, qve e Bafilifco prodita memoria fuerunt. Et ametfi tres adduxerit pro fe,MATTHIOLUS, atiunculas, fatis fecit tamen pereruditè illis, fir Experientisfimus D. MELCHIOR SEBIIIUS, in append. Difcurs. Med. Phil. de cafu dolefcent. Argent. Ubi inter alia qvoq́; reert, quâ ratione HIERON YM. MERCURIAIS I. r. de morb. Venenos. \& Venenis c. 26 eltetur, fe, dum apud Imperatorem Maximiianum eflet, cadaver Bafilifci vidiffe, qvod in hefauris illius fuerit affervatum. Evicto igiur qvod in rerum Natura detur Bafilifcus, Ividnam ille fit, indagandum reftat. Ubi, it ad difcutienda alia tranfire liceat, breviter cem proloqvemur. Fiat igitur

\section{CAPUT III.}

\section{SYLLABUS.}

- Defcribitur Bafilifcus.

2. Falfum E fabulofum eft, ex ovo Galliferio. ris oriri Bafilifcum.

3. Dantur rationes.

4. Lfvinus Lemnius inaniter bî́c contradicit.

5. 2vemadmodum or Encelius, Ferrantes itese Impe- 


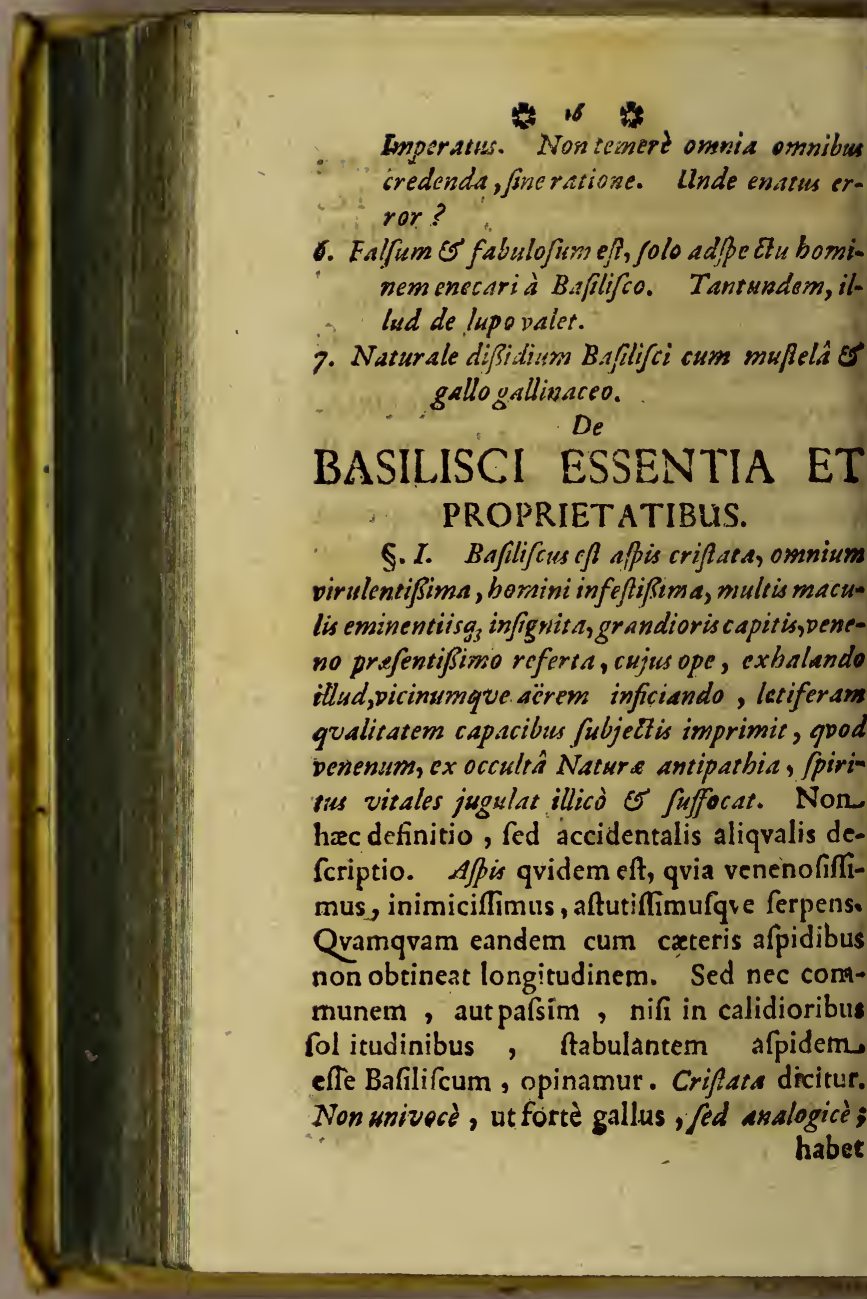




\section{is 17}

bet enim, ut ex relatione Autorum liquvet, $\hat{a}=$ vid coronæ crifære analogum. Hinc Relus dictus, Baflififus. Virulentiffima nunpabatur afpis : ex effectú fcilicet. Plurimùm im atrocisfímo veneno fuo nocet. Honi infeftus cxteroqvin omnis ferpens. At inimicitiâ phalangem ducit. Hæc noa hominum pona eft, ut in ultionem fcele, adverfus Conditorem optimum comfsi , ipfi proprimis armarentur ferpentes. vibus, fi in concreatâ perftitiffent integritate otoplafti, cum univerfis animantibus catedominandum fine noxâ fine periculo furet. Tanti conflitit, contra Creatorem fün peccáfe. Tanto nocúmento nunc ferntes naturales, lfub qvorum fchematè rfonatus ille ac præternaturalis, Draco an. yiffimus, DEI homínumque calumniator̆, bis impofuerat primitus. Nolumus reliqvom explicationem dare verborum. Êt e$\mathrm{m}$ obvius fenfus, $\&$ confirmatior fiet ex concuturis. Ult autem inter \& $x$, \& lupinum; ter verum falfum quve difcernere rectiùs qvenus, removenda illa five fomnia five comenta de Bafilifco erunt.

§. II. Falfuis \& fábulofus eft orius ille $B \vec{a}$ ifci,quo eum ex ovo Gall gallinacei fenioris \& ovennis orivi, É incubo Bufone excludi, vitlo atwunt. Adducemus; quar vulgo narrant
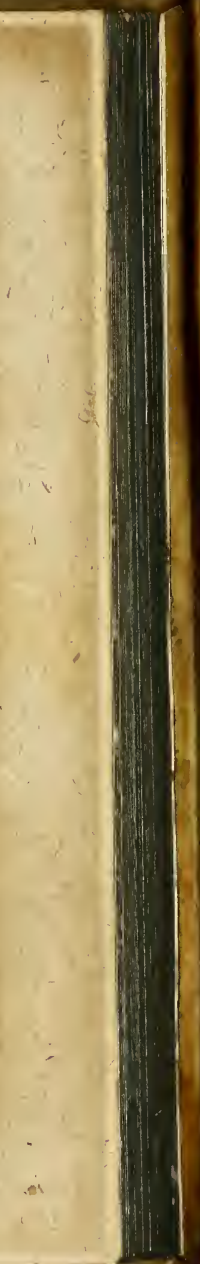


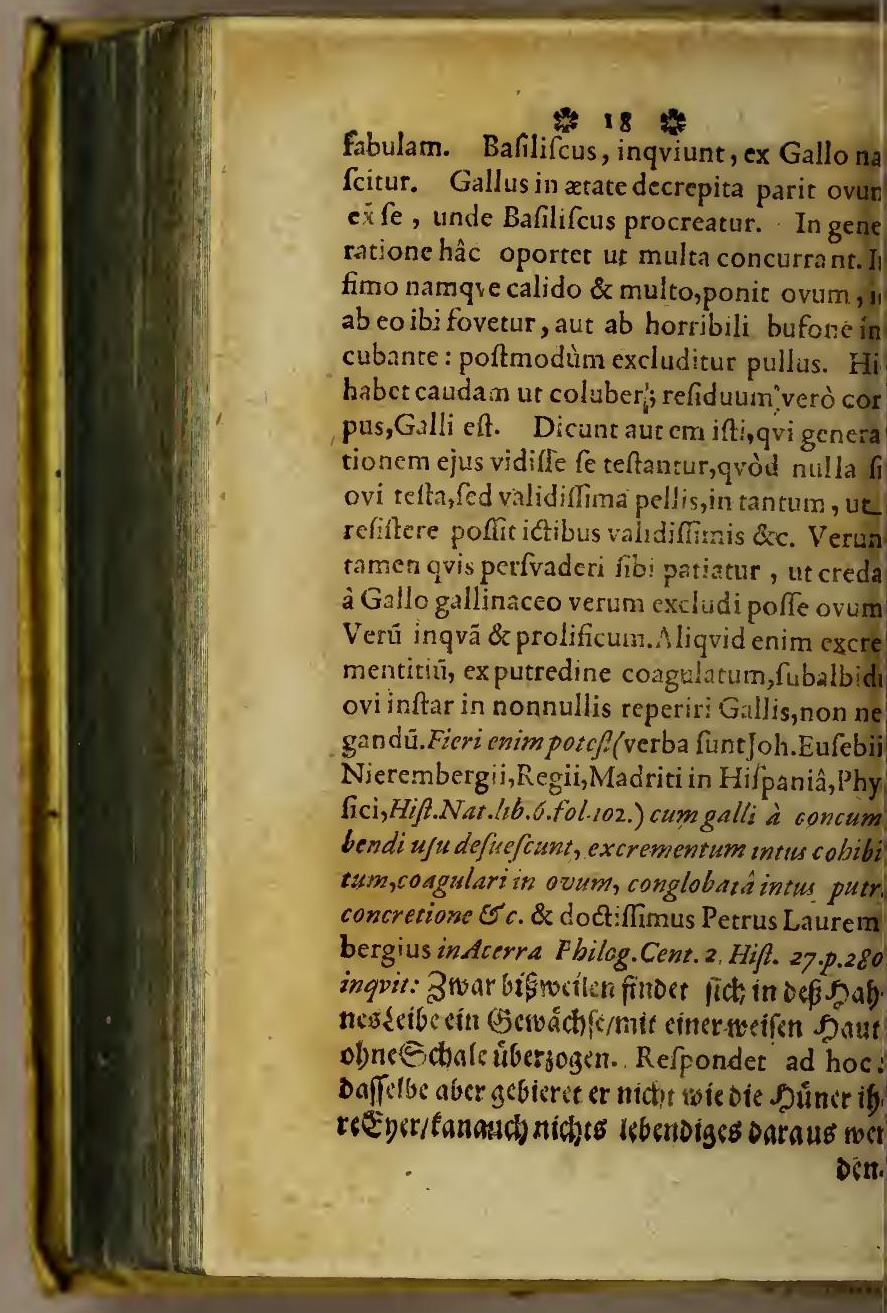




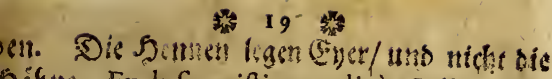
tifne. Exclufum iftiusmodi à Gallo ovum lie VI. Maij Anno I661. Noribergx obfervaum eft. Ac ne quid hîc difimulemus, vidinus ibidemiftud ante annos aliqvot, oftenum \& exhibitum interalia ab celeberrimo Cheologo Philologoq́; DN. DILHERRO; ùmillâc nobis tranfeuntibus, egregiæ vifenIx Norimbergenfium, Bibliorhecæ data coia fuiffet. Repetendum id tamen: fimile on effe idem.

\$. III. Qvis enim facilè ac credat,gallum, nimal faluberrimum, deterrimả teterrimamve iftiusmodi producere ex fe beftiam poffe? vis hanc equivo cam monftrofiffmamque oncefferit generationem: A ferpente ferpens it, à gallina gallus. A gallo Bafilifcus nulus. Qvis credat gallum fenefentem atq́ve viratum, ubi nulla ferè amplius vis fuperat, rolificum concipere ovum atqve parturire offe? Qvæ illa horribilis fuperveniens Rubea,fubolfacere illicò atque ftato naturæ ordie, certò adventare poterit,ad excludendum vum? Age quifquis tim ampliter nugari baud rubefcis, dic per candorem animi tui : viderifne alia ? obfervaveris? didiceris ? Profectò in linum fimumgáve recidet hoc fubventaneum, Salli ovum.

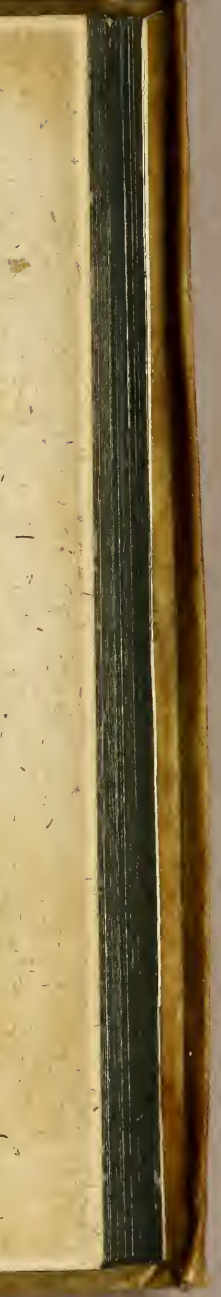




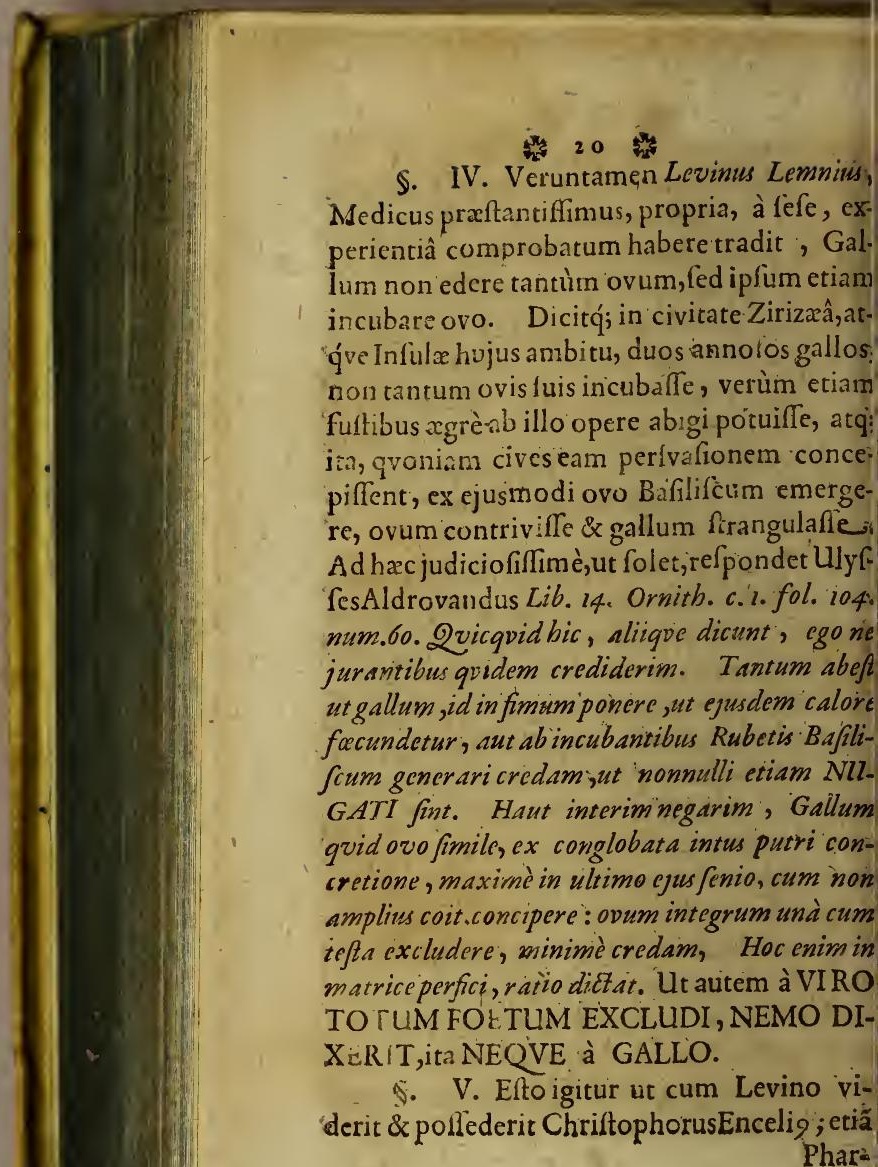




\section{3) 21}

harmacopxus ille Neapolitanus, quem Ferantem Imperatum dixêre, talia à Gallis galinaceis ova edita. Nempe, non cuivis mira de nonftrofo animalium qvorundnm foetu jactianti credendum. Aliàs, qui facilè credit, deipitur facilè. Cum Natura in confilium ab. undum. Explorandæ ejus vires funt, qva, jvid valeant, quid ferre recufent, curiosè fci. citanti manifeftabunt. Fundamentum cómmentitio huic ortui dediffe fufpicamur illam. Hermetis fabulam. Dixerat Hermes, ex Gali ovo, generari Regulum, in utero five fimo. Quam tamen non intelligi voluit de vero $\mathrm{Ba}$ ilifco, fed de Elixir Chymico, qvo imetalla. convertuntur. Conf. Nierembergius Hif..Nat. ib.IV.cap.20.f. 102 .

s: VI. Falfum tamen \& fabulofum ef, Baflifcum folo adpectu five bominem five ullum aliud animal, goodprior ipse conpexit, inerficere poffe. Galenus lib.de Theriacâ fejuentia refert a Bafilifcus bellua lubflava of trilici frontis apicemunita, tantummodò conQectu, E quando,fibilat, auditu, VIDEN $E S$ e. \& AUDIENTES necat, atque $\sqrt{2}$ good aliud inimal illum ctiam mortuü attigit, flatim moritur. Ejusdem farinæ funt, qvæ Plinius, ftudii majoris qvàm fidei Scriptor, lib 8. cap. 2r. Hiftor. Nat. atq́ve Exlianus memorant, com$B_{3}$. menta. 


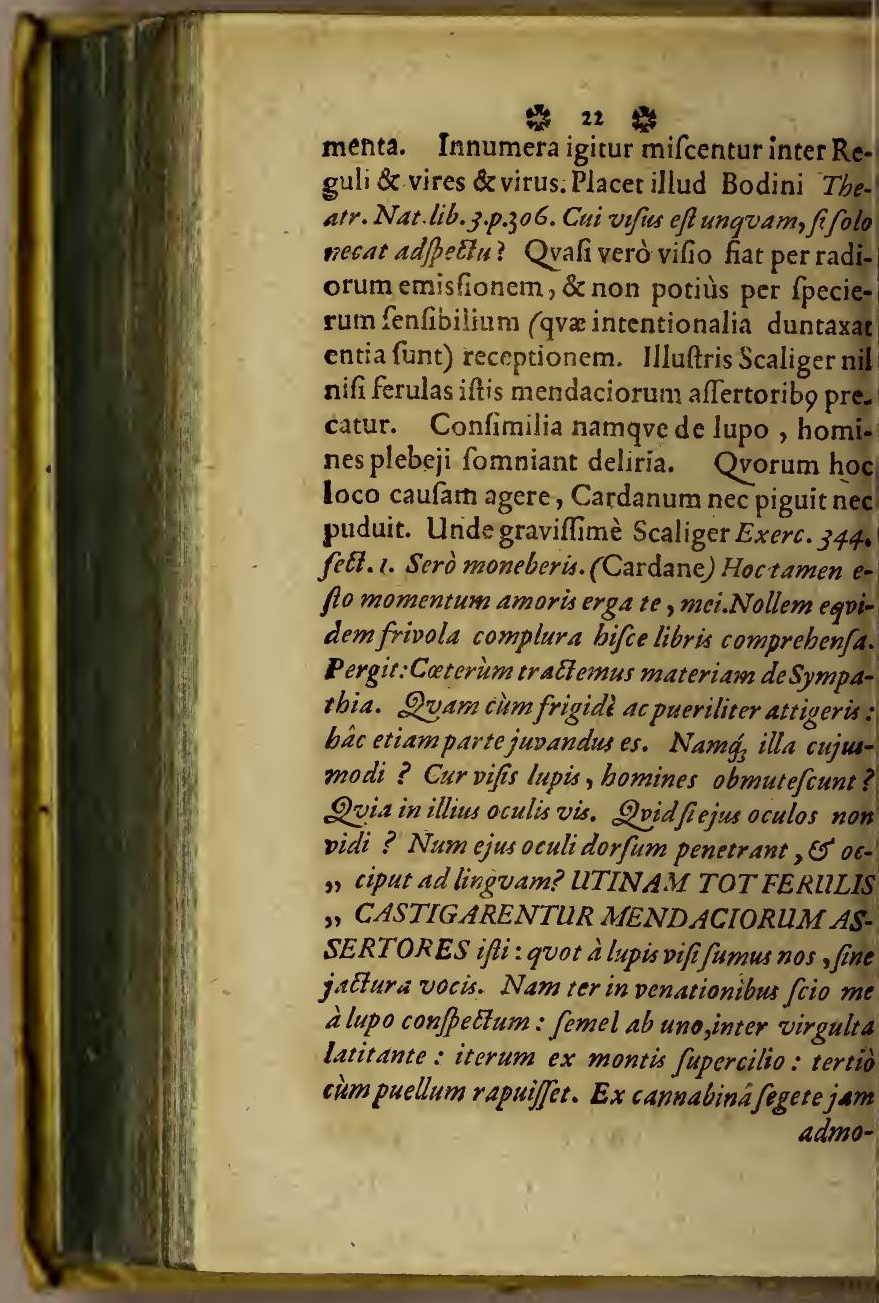




\section{3}

invodìm adultâ, caput idéntidem promoverat lfpeculam. Tum quidam ex eqvalibus pueldixit: O ingentem canem! Ego ab illo, cum fociis, vififumus, ille à nofrûm nemine. Tantume abeft ut obmutuerimus, ut magnis clamoribus primo perterritum compulerimus àd fugam: iox infecuti, predam, licet fine vita, abftuleriaus. Fiat in negotio compari, ad Bafilifcum, dfpectorem illum peremprorem fcilicet, ap. liatio. Facilè, quidfentiendum fit, conftait, Videntes enim nihil ex oculis vibramus nateriati,fed fimulacra rerum, in cryftallinoeprefentata humore, recipimus. Vid. inprinis hîc Athanaf. Kircher.in Arte Magnet.lib.3. art.9.cap. 1. p. 777 .

$\$$. VII. Siverum eft,mirabile eft, Muftele out galli gallinacei prefentiain fugere $E$ exhorefcere Bafilifcum: Homines invenias, qui fi hypocauftum, in qvo felis eft, etiam intra ciAtam conclufa, intrent, contremifcunt, fudo: rem largiffimum emittunt $\&$ animi deliquium non rarò patiuntur. Ita boves ad locum, in quo biduo triduove antè, alius mactatus bos fuerat, devenientes, vocifcrantur atque conturbantur. Ufqueadeò arcana Natura mater eft. Usq́; adeò maximæ, in minimis licet, occultre qvalitates.De internecino, Gallum inter atque Bafilifcum odio, ex Solino Ulyffes B 4 , Aldo-

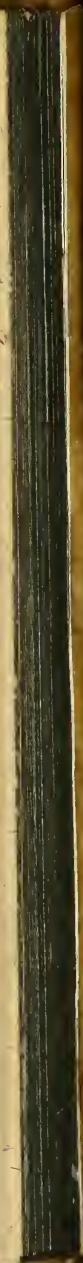




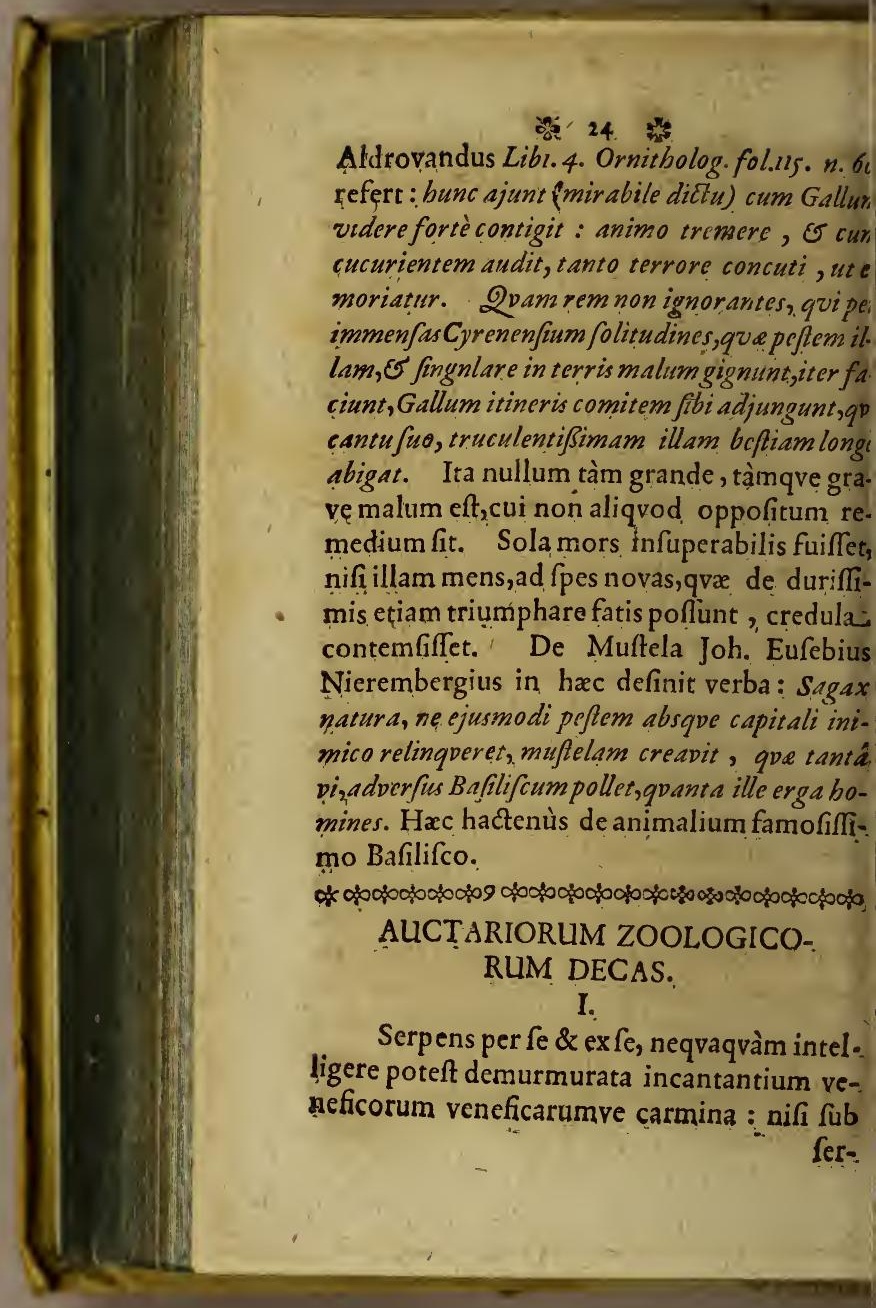




\section{5 .}

erpentino fchemate, ferpens ille perfonatus: raco antiquus, Mundi feductor, hominum. alumniator,Cacodxmon latitet, illudens imeritioribus mirificè , atq; imponens.

II.

Si propriè acceptentur, fabulofa prorùs funt: fị impropriè, xnigmatica, qvæ de. Ave-unica PHOENICE, paffim profcruntur.It non abs re admiratio fubeat, qvi perfvaderi ibi paffus fuerit, Exerc. 233. Jul. Cæfar Scalier, ut affenfum fabula largiretur.

III.

Dari Gryphos in rerum naturâ : h. e.-reerente B. Franzio Hift.Animal.C.38. tantæ va * titatis \& fortitudinis, alites qr adrupedes, ut cto Leones \& centum A quilas fuperare, arnatumǵve virum, in medium evehere aera. raleant,fimpliciter inficiamur. Placent veraGabrielis Rollenhagii: cum milites Saxonici is Scythici in Greciam appuliffent, inbiantes redis extra urbes, multos spoliare falebant, fuientes, equitando celerrime infequebantur E? lamabant: greiff/greiff oen Sierl! Hinc Grybinon à forma; jed à crena poeticâ; non ex. cmine, fed ex carmine.

\section{IV.}

Ridemus eos, qvi totam Unicornuum peciem, in Cataclyfmo illo catholico interiif: epopinantur.

B 5

$\mathrm{V}$. 


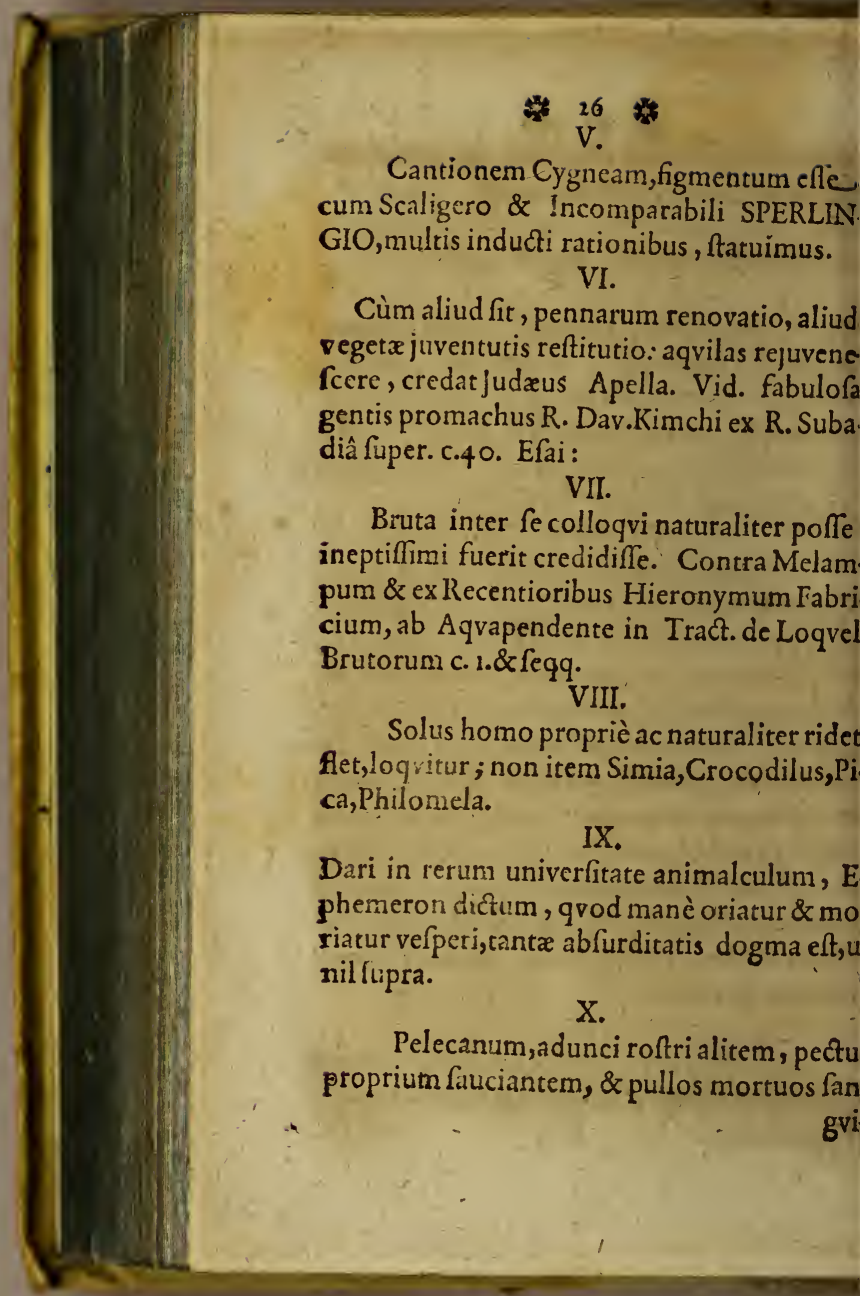




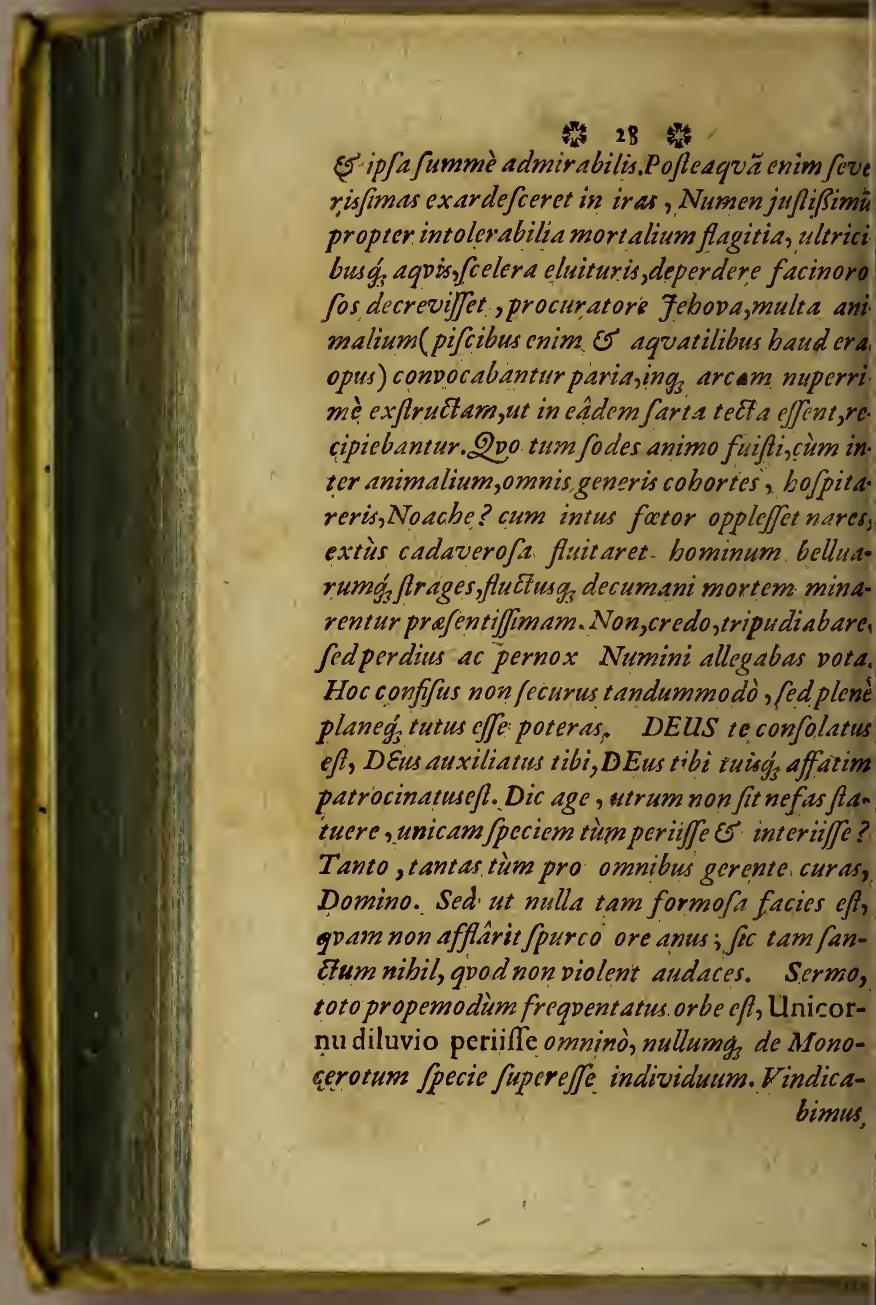




\section{9}

mus injuriam, E dignum olle procurabimis crculum, adjutore DEO.

of

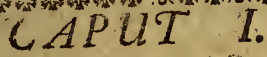

\section{ELENCHUS,}

Monocerotis notatio $E$ formatio.

Unicornu dicitur pairs Crucis Chrífit.

Sumitur pro minerait.

Continuatur troxvonnilas evolutio.

Dantur unicornes pifces.

Lufitani viderunt aves unicornes.

Monocerotes Vipere, quibus Cleopatria ufa ejf.

Caftigatur Cardanius.

- Scarabeos unicorries" inter Salernum E Neapolin vidit Bartbolinus.

- Afinus unicornis Indicus.

o. Eqpus llnicornis Saxonice Elect. Divo $70 H$. GEORG.I. don'atus. Similes. vifífapè funt ab aliis.

1. Inveniuntur Bopes Vaccego unicorres. Hui referuntur Borusfie Bifontes.

2. Mirabile animal Oryx explicatur.

3. Rbinoceros exitialis Elephanti boftis exponitur

4. Non confundendus Rhinoceros, cum Mo. nocerote.Cardanus accufatur. Defenditur. Laus Scaligeri.

51. Ulni: 


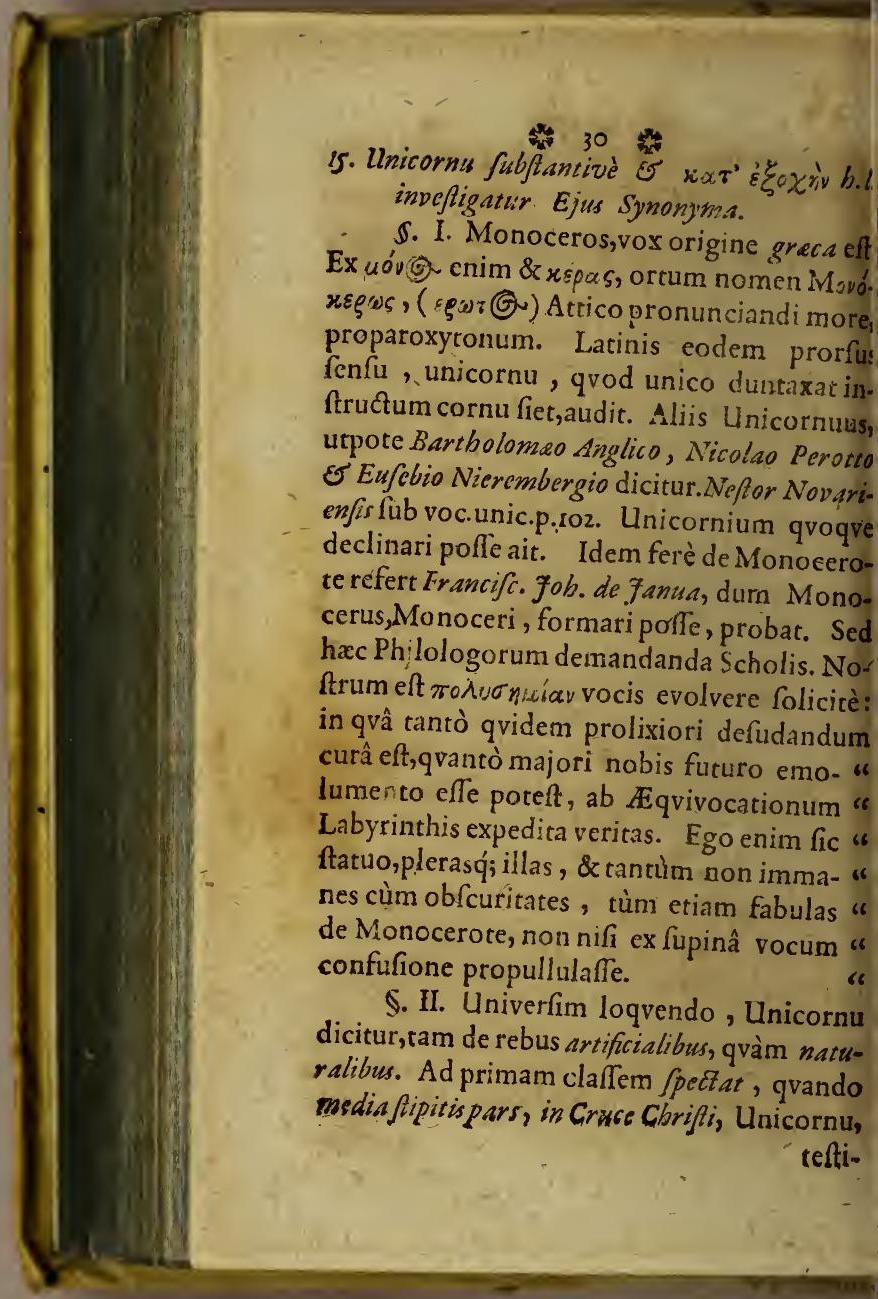




\section{$3 \mathrm{x}$}

Atibus Ireneo, fufino \& Tertulliano apellata ait. Occafionem Tertulliano prabuit locus eut. XXXII,17. Verba ejus funt ex cap. XI. ib. contra Jud. Chriflus inquit, in illo jignificaatir, taurus, ob utramós difpofitionem, aliis feus, ut judex, aliis manfvetus, ut Salvator, cujus Cornita effent crucis extima \&C. Ilnicornit auem mediaflipitispalus. Qvæ tamen Tertulliai verba,non exiguam Criticis peperêre curioitatem. Expreffit verò luculenter fenfurn præer D.Georg. Calixt. in not.ad Lipf. de Cruce, Dn.Ditherrus in Animadverf. ad Crucifixiosem. Unicornur enim ideò Crux illa dicebatur, artim qqòd in curvum emineat $\&$ acūtum: artim qvod fine pari, in medio ftipitis, velut n mediâ animalis fronte exftet. Vid. Nobiliff. Bartholin. cap. 23.q. 14.9 \& feqq.de Unicornu.

$\$$. III. In ordine verò naturalizm accijitur vel pro minerali, vel animali. Scilicet in. Bobemiâ, Thuringî̀, Moraviầ \& quibusdam Mifnia locis, lapides è mineris aliquibus effodiuntur infignem contra Epilepfiam,luemq́ve epidemiam, febres malignas, aliosq́ve deterioris notæ morbos, virtutem obtinentes. Audiendus Germaniæ Efculapius SENNER. TUS scient: Nat.lib.4.c. 4.p. 423. eft : inter.lapides porofos primo loco merito explicandus ille, gui pulgò pro.Monocerotus Cornu babetur; alii, Cor: 


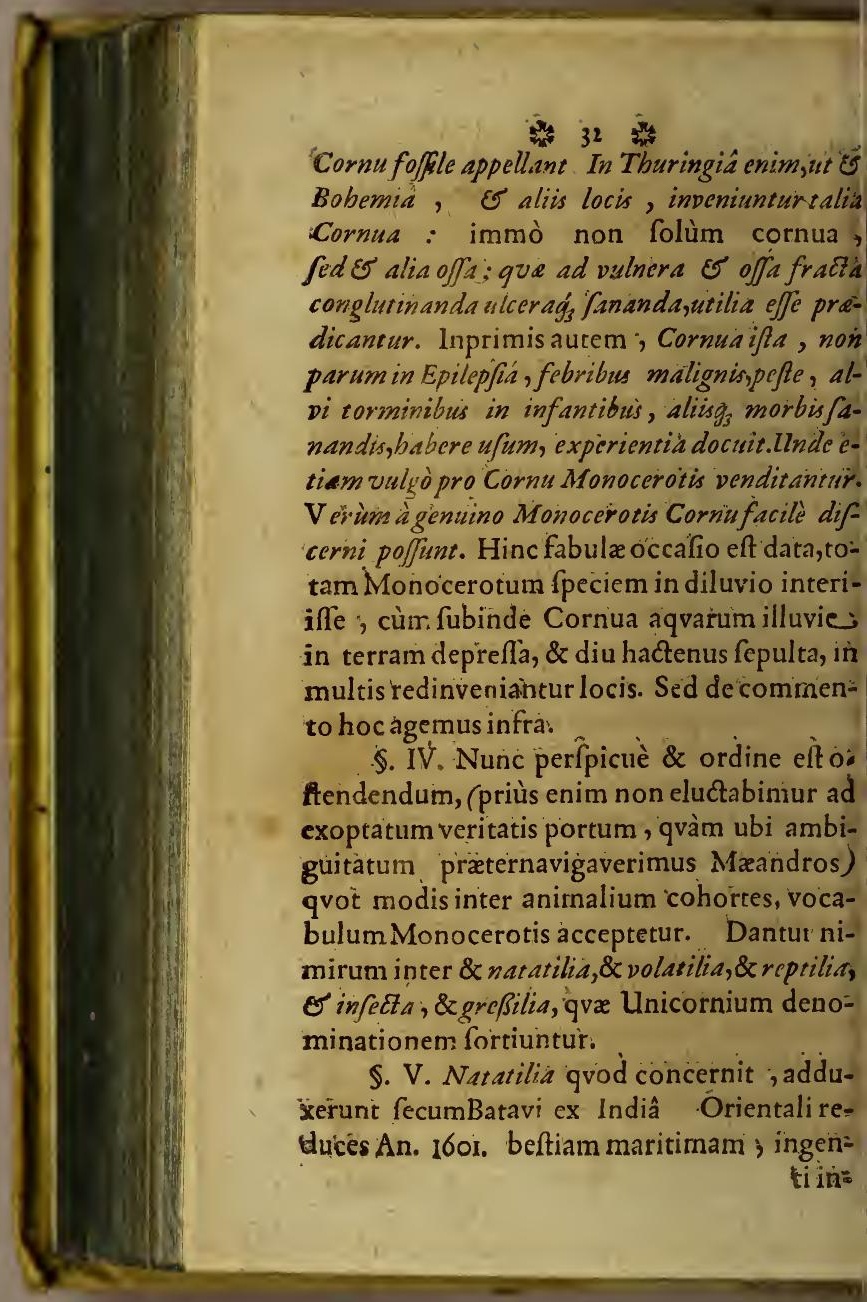




\section{3.}

infignitam Cormu, ejus iconem nobis do. tisfimus Vir Clafius lib.2.exot.c.27.reliquit. Hippodami genus quoddam fuifle, adfirmant lii, alii aliter fentiunt. Quicquid fit, res erta eft. Anno 1976. Martinus ForbifJerus $n$ Oceano Septentrionali, inter ingentes laciei montes, Unicornem pifcem, cornu, Jua hus ferè ulnis, è nafo protuberante, ofendit, Cap. ab Ens lib.2. hift. Ind. Occid. 26. Olauis M.I. 21. c. 10. inquit: Monoceros fo monftrum (mallem abftinuilfet injuriosâ ac, in naturam voce, Olaus) marinum, batens in fronte Cornu maximum, quo naves ob. vias penetrare polfit, ac deftrwere $E$ bominum multitudinem perdere; ; Jed in boc, pietas diving Numinis, sdvigantibus providit, cùm ferox fit bac bellua, tarditas fis, quam babet maxi. nam, provifa cimencibus ejus acceflum, fugam concedit. Hujus etiam pifcis meminit in Momoceróte Albertus M. atq; Rondeletius Conf. etiam Clarisf. OLEAR. 1.3. Itiner. Pers. 4. fol. 175 .

§. VI. Ex Volatilium ordine, adduxit Unicornu Ailianus lib. 17. hift. AEanimal.c. jo. Similiter in Etbiop. Unicornes reperiri aves, Dinon (Scriptor Hiftorix Perficx, ut ex Cornel. Nepotis Conone, \& potisfimum Athemaxo difeimus,) memorat. Lufitani vifa eft, 


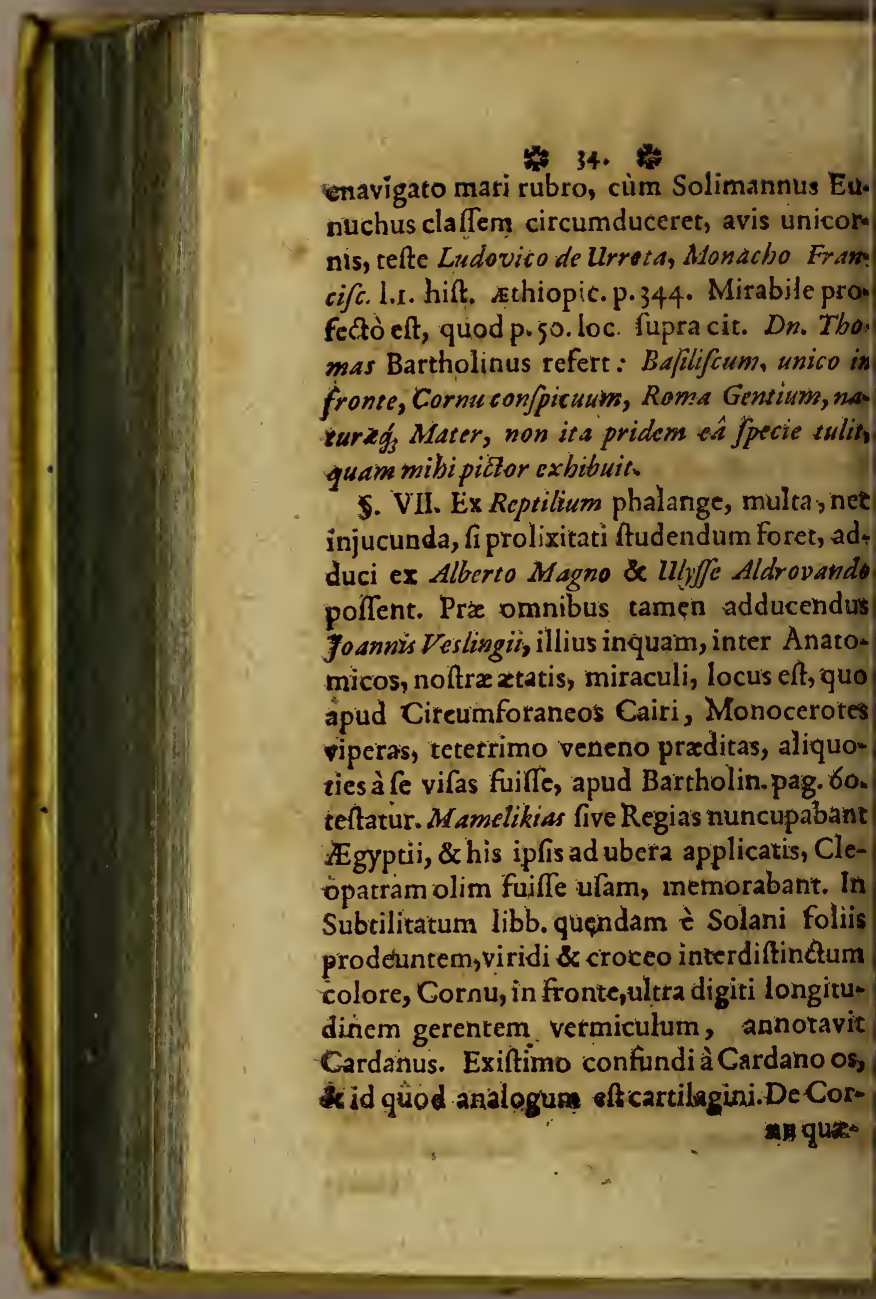




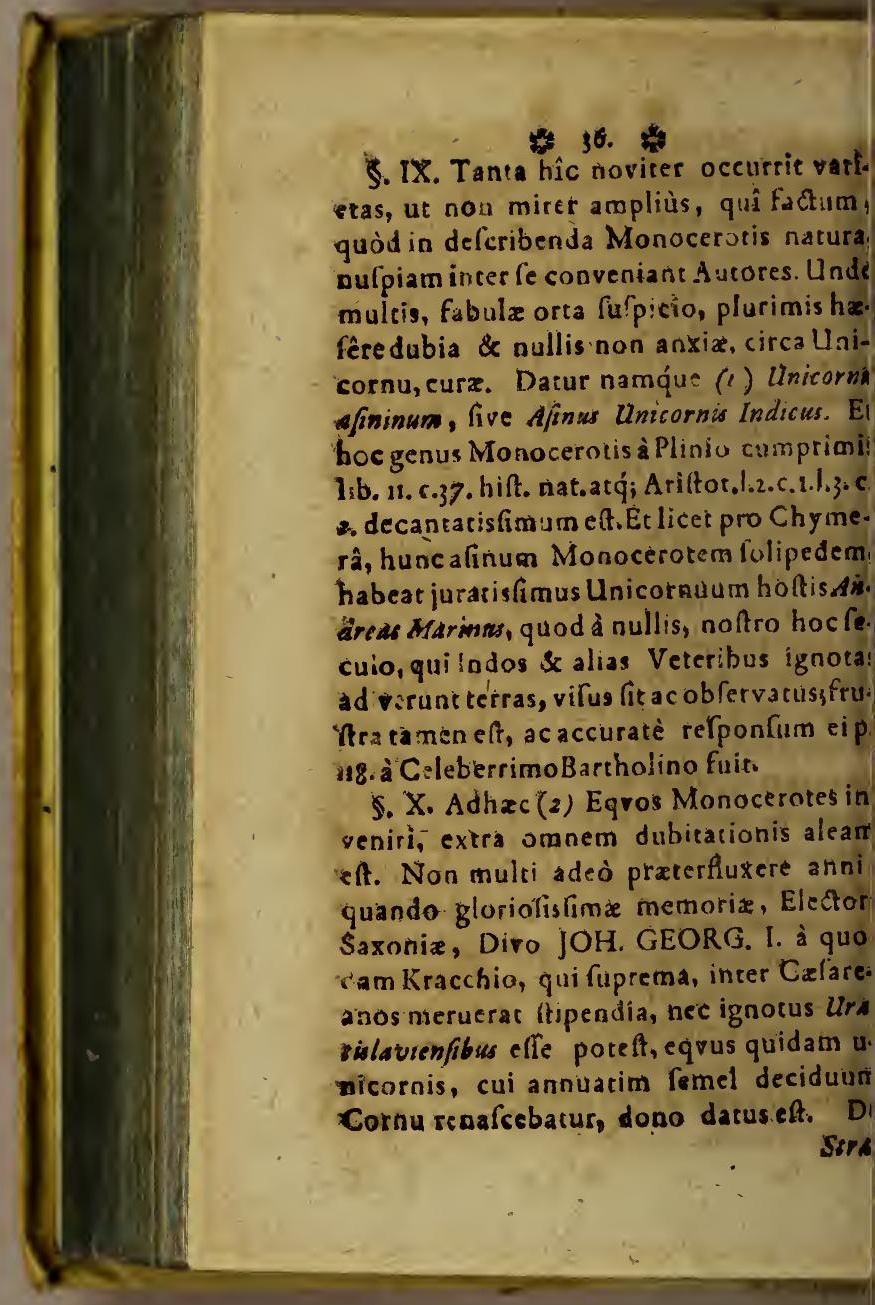




\section{*37.}

Urabonis, Plinii \& Solini teltimoniis cum ufpecta nonnullis habeancur, (quanquàm ccufare non fit refutare) nihil hic mone. imus. Ciarisfimus Vir, Madritenfis in $\mathrm{Hi}$. b.aniâ Pbyfiolog. Profeffor, Jabannes Eujebium Vienembergius lib. 7 - hult.nat. Adm. c. 2.te in ulâ Philippicá, equum quendam cornu. um ex Indiâ allatum vidifle, ait. In ftabulo. Principis Stiliasi, eqvum fimilem vidit, (tetance Thomâ Bartholino) fuperioribus anis, Leo'Allatius, magnitudine exilem, fed erociâ fummuns.

5. XI. Nec (3) boves non funt in natura anicornes. Plinium, qui volet, adeas 1.8.c. r. Mihi ejus certè inconftantia, dum aunc olos Afinos Indicos, nunc boves etiam corautos concedit, arridere nequit. Natali ais tamen locus Ethiopia eft, \& India. CeGar etiam de beli. Gall. in Hercyniâfluâ boves. n mediâ fronte, celfum, \& directum quodda in cornu geftantes, reperiri ftatuiz Sed $\&$ Vaccas unicarnes alibi nutriri, certum eft A ufcultandum Scaligero Exexa.206. Selt.7 bî́c putamus : in eodem, quem fenpra memo. ravinaus, agro, Zeila oppidi, quad eft in Et tí. opin, vacce lunt coloze atro, cum cervinis cora nibus. Quas idsircè Cervicas appellavimus. Alis nimsirum î fronte mediê prodit Cornw, C. 3 .

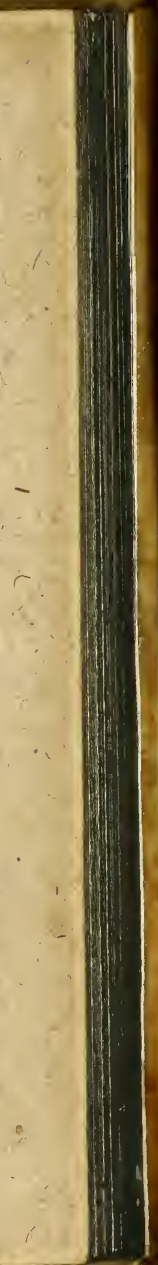




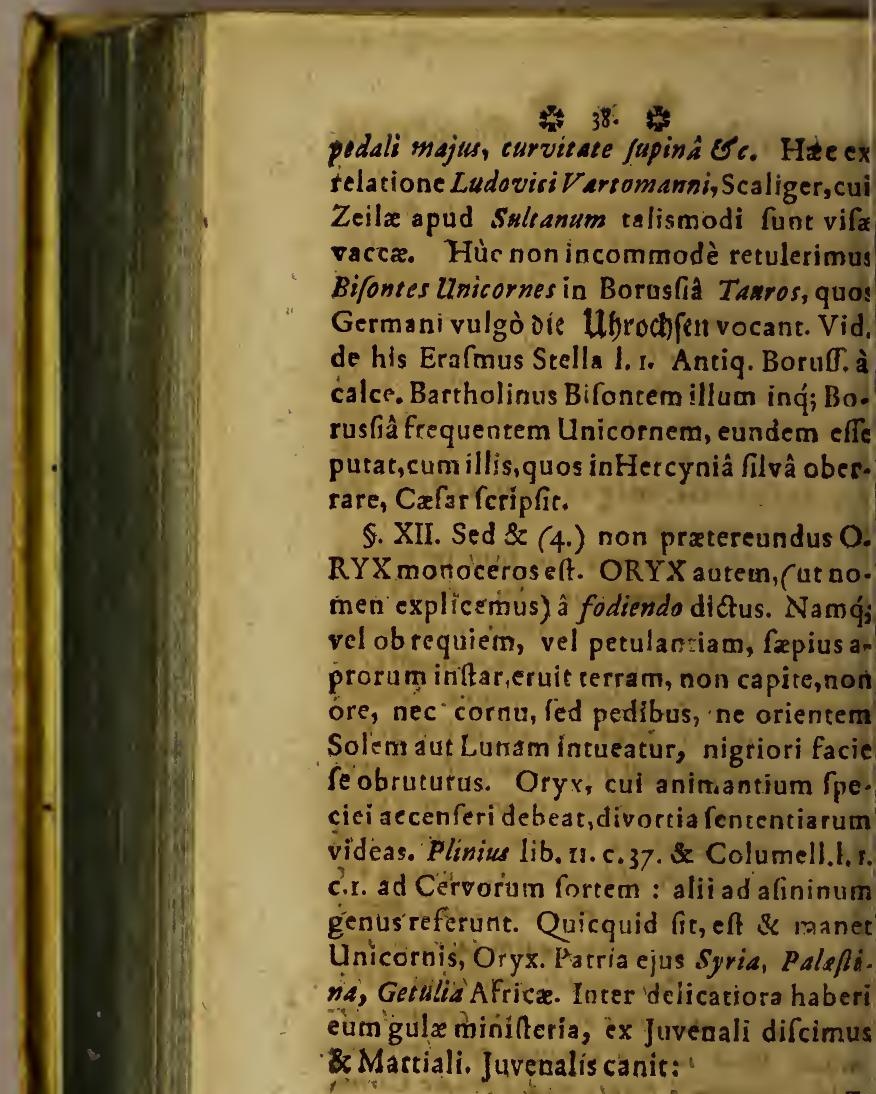


Ea Scyebice volucres of Plemico pterus ingens,

Et Getulus. Oryx.....

Lnrtialis verò lib. 13. epigram. 99.

Matutinarum non ulsima prada ferarum

Szus Oryx, conftat, quod mihi more

te canum.

itis pastentisfimus Oryx, magnitudo ei aediocris, colar caprino fimilis. Egyptii lim Reges orientis. Solis tempus accurati xploraturi, Oryges confcendere folebant:iro uf horologio. Scio tamen negari d octisfimo Salenafie, quòd ob corporis exili. atem vehere, revehereq́; fefforem potuenit:

ry*. Sed heec hùc non fpectant.

5. XIII. Solus, nîfallor, nobis ( 5 .) reftat binoceros, Vox primò, pònt, res ipfa, deniue confufio ejus cum Monocerote, explianda. Rhinoceras verò $\sigma^{2} g^{\prime}$ Triv piva five talo, \& réegs, Corou, quod minacisfinumató; Elephanto etiam ferale, ènaribus. rominulum gerit, dicicur. Undehamines afuri, qu liberalisfimi, juxra Phyfiogno. ron, aljorum reprehenfores funt \& aduaco maia fulpêdere nafo folent, Rhinocerotis afum habere dicunturMartial, l.1. Epigr.4. Majores inugnam rancbi, jupenesglenesés Et pueri najum Rbinocerotis babent.

D 4 Es pu. 


\section{0.}

Rhinoceros humilior aliquaneumElephan to, fialtitudinem; filongitudinem fpectes pareft, Ungulas bifulcas haber, buxei co loris tergum, eoq́; a b impenetrabili duritie duplicato, tanquàm perpetuo thocace, uto verbis Camerariz c. 25. I.1. hor. fubcifiv. qu E iple ex Paulo fovio iftoce petist, ex Came rariê verò B. Franzius in hiftor. animal. c.u p. ilo.) protegicur, armaturq́; pedali ofleo cornu fupra nares eminente, quo ferire ató transfodere fub ventre Elephantum!, ä. - rovda hoftem fuum folet. Incredibilem namq́; natura parens, ex occulta qualitatur vi, antipathiam, inter Elephantum \& Rhi. nocerotem fecit. Annofalutis 1513. delatus unus ad Lufitanix Regem, Calendis Maii, quem Rex biennio pòt, Spętaculi causâ, Ulyssepone cum Elep'ianto commifit, vicitó; Rhinoceros. A $q_{q} ;$ hoc tàm certum, ut non dubitandum amplitis. Vid, poft Pastum Fo $^{-}$ vium; Cardanus l, x. Subt. de anim, perfect. fol m. 328. Sculig. Exercit. 20s. fect i. Franz. loc, cit. Adde Cl. Tbom. Bartbólin. de Unicornu, inter addenda adpag. 147. De OCFA vio. Augufto idem difcimus ex Sveronio cap. 43. Ut proinde fruftrà fint, qui temerè hoe negant, Viditidem Ann. I515, Ulysfip, iten

sum 


\section{1 \%}

rum fub Emmanuele Rege, Damianus a Goës Eques Lulitanus.

S. XIV 4 Cavendum autem fedulò, ne cum Monocerote, Rhinoceros confundatur, quod pasfim commiffum ab antiquis fuiffe, legas. Ejusdem errati reum agic Scaliger Cardaoum exerc.ros, fect. l.inquiens: quona malo fat $0, a ̀ \mathrm{Grammat} i c o r u m$ ferulâ toties fubductus, in Pbilefophorum plagas incidifit? Ne queo tibi, Cardane opitulari, qui Monocerotem fub Rbinocerotis nomine pinxifti: qvüm due fons bellua longè diffinct isfime. Hxc Scaliger: quem tanti nos alioquin veneramur, quanea fuum ille Orbis Démitor Homerum. Hît interim non defendemg ipfum. Profecà injuriam Cardano intulit. Contrarium enim Cardanus lib. X. fol, m.326. Edit Bafil per Henric. Petri editâ, defendit. Poftéa. quàm enim Rhinocerota definiviffet, \& a d Monacerotem acceffum parare deftiuaffet, hac interferit: Conftat, bunc ficilio cet Rhinocerotem, de quo hadepus loque batur) longe alium effe à Monocerote, crum gue SOLUM NOMINIS SIMILITUDINE collu. dat. Nifi fortè ad alium Cardani locum attendat Scaliger, qualem tamen nullibi ireo deprehendere nobis licuit.

\$. XV. Multas hucusq́; Moneceroturm fpecies habuimus, Quanquàm non tàm C. fube

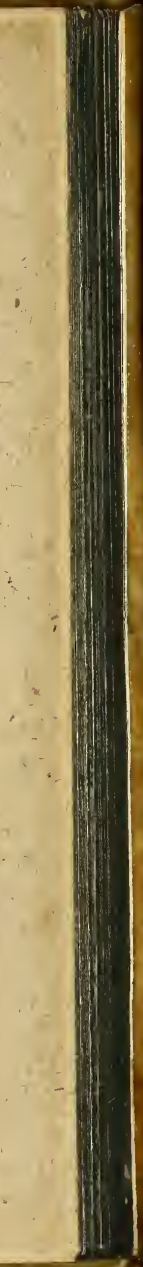


fubltantivè, quàca adjectivè ita nominatas. Nunc poft generalirer fic dicta Unicornua animalia, ić nobis indagandum reftar, quod

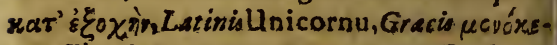
pos, Ebrais Gallis Ly corau, Itealis Alicorno \&Lioncorno, aliis atter confvevit appellari. Hoc quid. fit, ubi fit, \& quibus præditum affectionibus, nunc porré indagendura reftat. Fiat proinde

\section{GAP. $I F_{\text {. }}$ \\ ELENCHLS}

1. Definitur Unicornss.

a. Indomitam Monocerot is ferociam Deus ip/e adfrsit. Eft asnimal Solivagum. Examinatur Idaitb. Aga, Oratoris Turcici tefii. moniam.

3. Unicessu à Deo ipfa commendiatur ob for. titudiness है celeritatcon.

4. Eft Arabie, Syrie, Tartarie, Eibiopice argo Indic incala. Dus Mecclos vidus Ulnicarnua, Nobilisfimus $V$ arromannus. Per/axum Rex multea alit.

7. Magnitudo, figura,babitus canporia 2 voxq Mowocerotis adducustur.

6. Negliguntur nonnullorum witistigationes. Datur ratio. Excusatuse of canciliatur 


\section{Vartomannus.}

\section{0}

- Confirmatur argument is exiffentia Mones cerotis.

- Magnates non deftituntur Unicornibus, que vifuntur pafim. Duo vidit Aldrovandus. - Standum eft experientiu, fenfibu of biforicà fide.

o. Refusatur fabula, quòd diluvio interierif Unicornu.

1. Ulrum Unicornu fit Alexipbarmacon usiverfale?

Quomodo dignofci Unicornu verum ab a 2. duiterina posfit?

\$.I. Unicornu(quo de in prafentil loquia. mur) eft brutum quadrupes, unico eogs pres longo cornu praditum in fronte, indomitum, ferocisfimum, folitarium, Arabia, Syria, Ethiopia atque India cesqua incolens, Eqri magnieuisinem, of jubam: capuit, pedes, cruracervina, caudam caprinam aut frillam habens? dirisfinamǵs vecomedens. "Formam anima. lis, ut omnium rerum, homine excepto, â priori ignoramus. Definitionemea proptex accidentalem,à proprietatibus \& notis quibusdam diftinativis fumtam, eamq́i prolixiorem damus, Utpoffumus, ton, ut debebamus, (aliter enim nec licet) procedimas. 


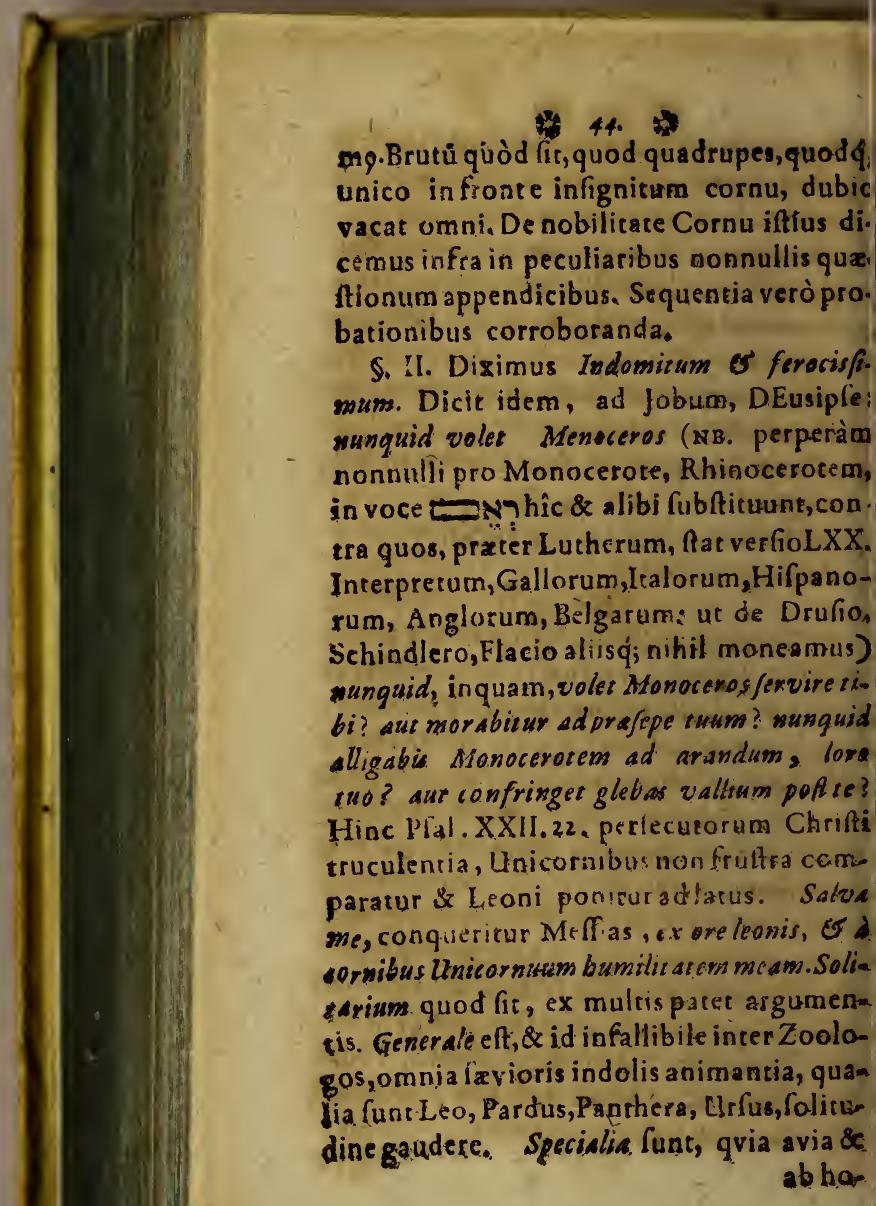




\section{45}

$b$ hominum adipectu remotisfima inhalpi: atur tesqva. Rarisfimè in bomintam, nifi avod cornua decidua inveniantür, veit pocéftatem. Hinc quia rarum eft, cha um eit \& earum quoá, Indeq́; coll'go, Uniornua nar' "č $\chi^{n}$ iv \& fubitantive fic dicta ion fuilfe, qvæ Idaitb agd (Orator Soly: nanai apud Maximilianum, Imperatorem, Marcus Scherer, ante abjuratam Cinriftia. a im Religionem, dictus, \& Llyflis Aldro. vandi popularis) Vienne in frequenti, primariorum Virorum coronâ a uíuseft proloqui: fe in Arabis defertâ vidiffe grege. irn; ut armenta, obverfantes Monoccrotes.

5. III. Forricudinum ejus, DE US iple I. dict. rap.30.v. 14. depredicat, ad Jobum, : sunquid fiducians babelis in magnà fortitudiresjus, Et cap. Num. XXIII. 22. Deus eduxit populion illum ex Egypro, cujus fortucudo fimidis eft Monoceroris. Eadem ex afle habentut c. XXIV. 8. Celeritaiem Monocerotis non minorem, quàm vel Caprex́, vel Pantherá, vel lepori, vel Eqvo, vel Cani veadicamus. Noranter enim Plalm. XXIX. 6. Cedros Li bani, Jehova falcare facere dicitur, non fecus" acque filios Unicornuum. Et quidni ägillis num effe poffic, cum corporismole null. pragraverur. Alacrés certè \& beftio \& hominesfunt, fortes qqi funt.

S.IV 


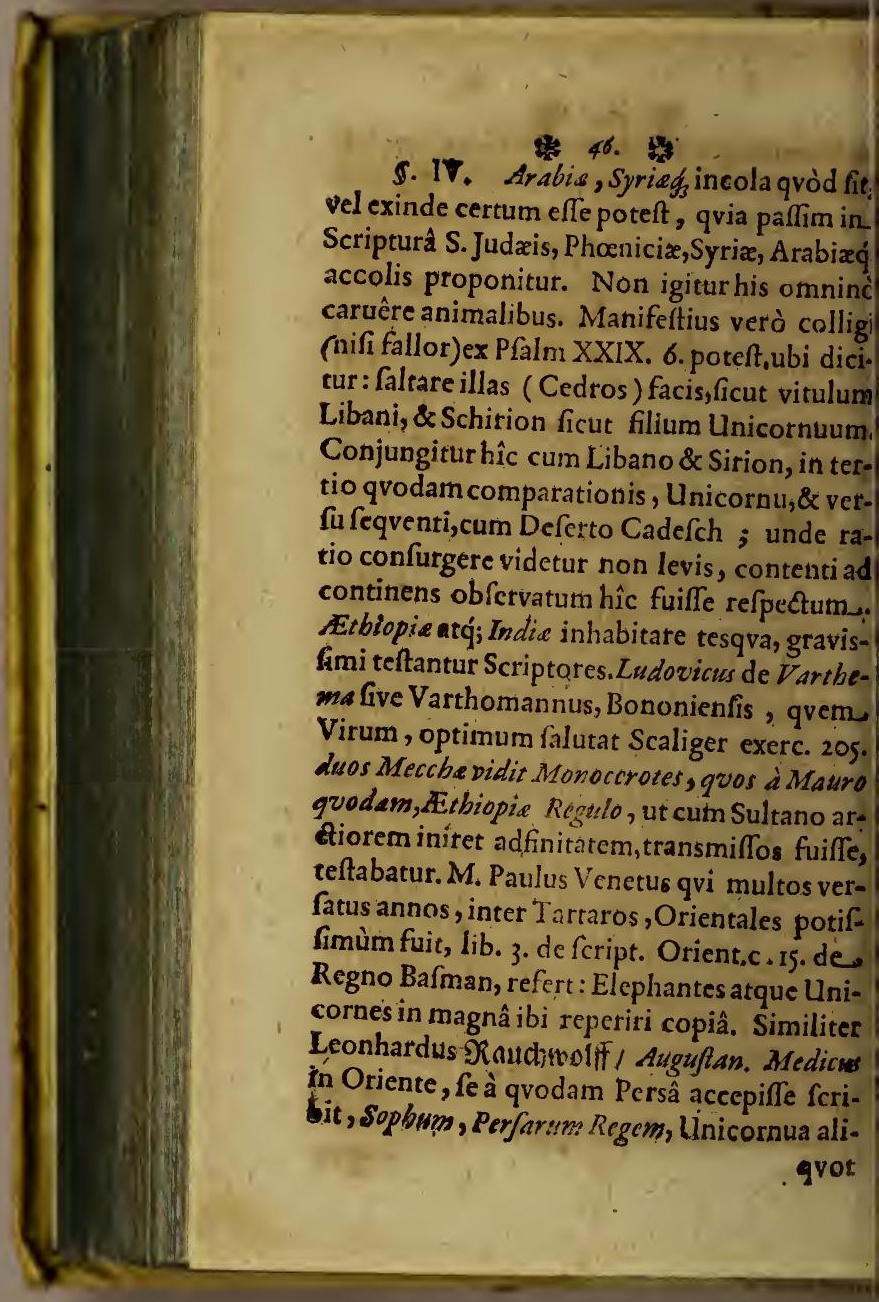


votSamarcandi alere.. Thomas Bartholius loc. fuperiùs citato p. 163. \& feqq. Tefanur, inquit, idex regno Chine, reliquisgós Indie cis, in Eurbpans nofir am fubinde reverfinawte arcatoresgive, quosichm furtivo pede itineruss afitatem emetirentur, per deferta Arabia, of ccultas alias folitudines, ob fuge metum in fibis bivitsǵf ferä banc Mo ocerotem, ust vulgd deingitur, non fineterrorisfenfu vidiffe; fed tan$\hat{a}$ effe pedum pelocitare, ut ex oculis derepente ibduite, accur atiorem Bpect antibus fui contemIatiostem prestipuerit.

§. V. Reliqva, qva magnitudinem, figum, habitum corporis, \& vocem Monocero$s$ attinent, ut breuitati ftudeamus, conjungeuss, non fine teftimoniis tamen. Polt Cardaü, cujus fupra notabamus locum, adducendus caliger Exerc. zo5. Unicornibus equi mognituo: crura, pedes, caphit cervi,pili, color balig. Eque iba, rarion, brevior. Coxa villo fe. Cornu wizum, tegrum Nices vidimins: alis alibi. Subfuloun num, unumfublarewim, accedews maximè ad uxcum: Umum fubpunicenem. Etiam babetas fruftum candidum. Vocem Alianus wà-

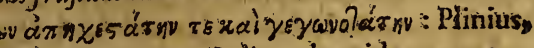
utugitum gravem: Solinus, horridum vocat aciunt hûc, qra in pralect. Zoolog.de Moacerote cap.6,qvaft.7. SPERLINGIUS is $\mu$ di

$x \times$ 


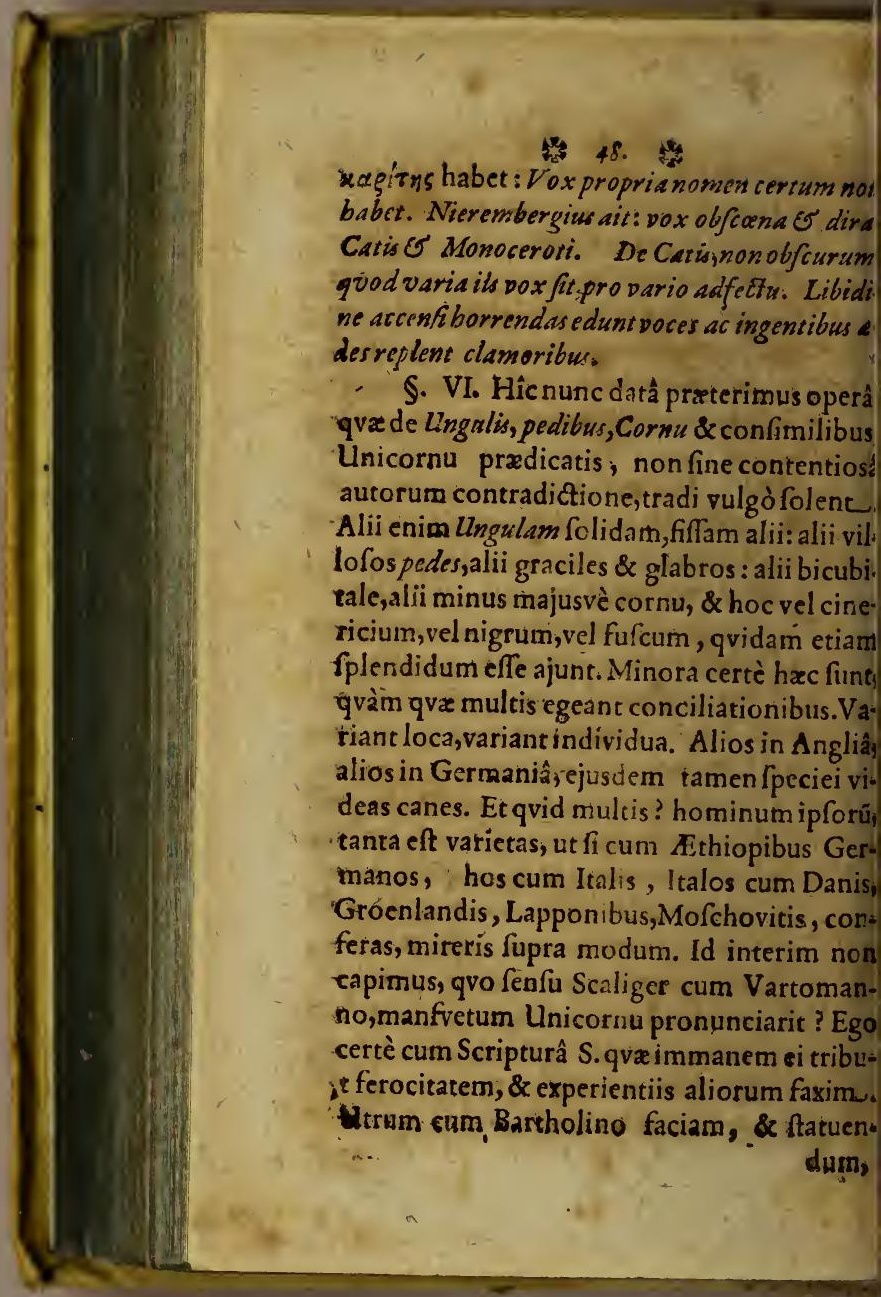


dum irrepfiffe in Ithrufoum Vartomann contextumaligvid vitioli? Si tamen aliâ excífatiot ce juvandus uterg; ; effet, dicendum foret, longâychos iflos à Vartomanno vifos Monocerctes, \& cuftodiâ \& adfrefaction'e mitiga cos; \& expugnatam qvadantemùs indomitam. itlam aliàs ferociam fuiffe. De Leonibuts, Ur: fis, Pardis, animalium ferociflumis., idem cert? cóniftit.

5. VII. His ita fe habentibus, ecquis tanta vel audaciz vel pertinaciz amplius éffe velit, 'qui contra to't divina husmanaqve de exifterntia Monocerotis, teffimoniza opponere fe, inon dubitet? non vereatur 'Loqvitur :Scripturầ S. \& infignès, Monocerotipaffim adornat laudes. Nos

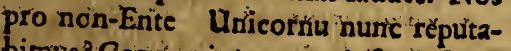
bimus? Conqueritur natura ipfa, \& fuam loqvax in àpologiam eft, dùm, noon fruftra usqúve adeo pro animalibus vigilem fuiffe, os rerum Confervatorem; inftantis diluvii tempore, ingerit idéntidem. Non fruftrà generàtionis opus etiam conceflum.Pere- is ant individua, f pecies peréninant c cer̀tè. SubtilisScaliger Exerc.250. Sett. St. Sin deeffet aliquids diretur inforis Qvod longè majus in natura effet flagitium, pasm pasensm in govatititate fine corpors. 


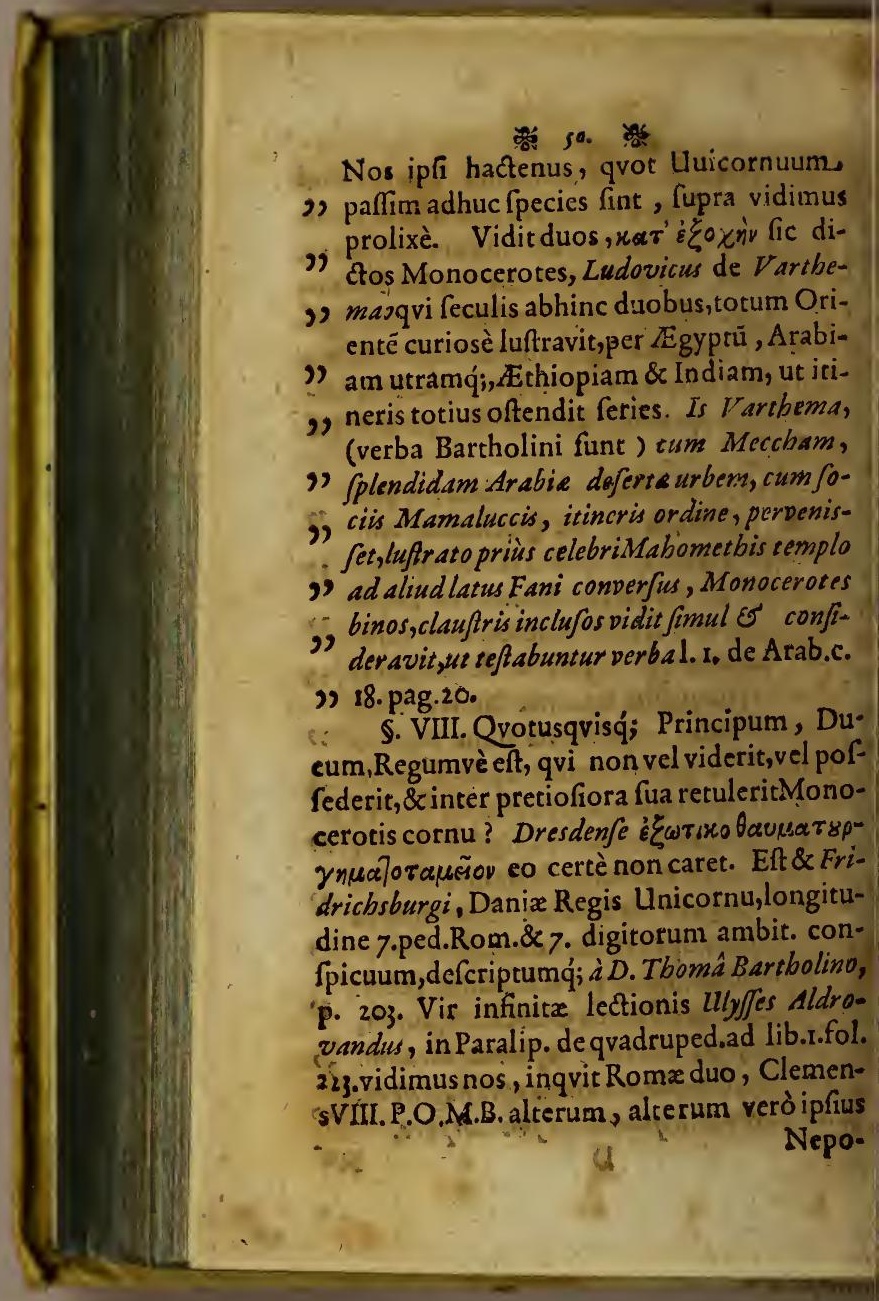




\section{\$.}

Nepotis illuftriffmi.Principis,Petri Cardinalis Aldrpbrandini \&c. Vidimus nos etiam. non unum in pharmacopolio Wittebergenf ante annos aliqvot.

§. IX. Hiftoricis hiftorica vel danda fides, vel demonftrandum verius qvid eft. Qvid nos tandem erimus, fi non hiftoria fuo Atabit talo ? Eant nunc \& crepent quidam atóf; nunc autorum nonnullorum in defcribendo animali noftro, diffenfum, nunc aliud qvid futile obtendant. Breviter tefpondeo: NoN AuDio. Gravifimè graviffimus Aldrovandus hift. nat. qvadrup. .1. c. 6. fol. 190. apud qvos modò responfiones noftra cariture funt fide, eosego dixero carere intellectu pertinacesg, appellabero, qvi ipfum non erubefcunt nigare fenfum scium tot paßim apud Principes unicornua oftendantur. Credo tamen, qrod pleraq́; non tàm. venatione captis, quàm ex defertis locis ( decidua enim cornua funt, $\&$ nubc effectu, nunc colore, magnitudine, figurâ, facilè $a b 2=$ liis difcerni poffunt cornibus) habeantur.

\$. X. Sed hîc jugulandus error eft, qvi plerorúq́; animis infedit.Ajunt enim diluvio univerfali animalia hæe periiffe, nunc terrâ erui offa.Veruntamen, qvod felix fauftumq́; his nugivendulis fit, eft hoc genusMineralis cujusdã, grod nec duritie, ne c gravitate, necfoliD 2 


\section{s. s.}

ditate, nee odore quicquam cum Unicorau noftro commune, prater effectus nonnullos nobiliores habet. Effoditur in Tburingiá, Bo. bemiâ, filva Hercyniâ, propè Elbingerod. Hildesbeim É Heidelberg. in Sitefsâ, Mor aví, \& \& non. mull is Mifnielocis. Qvam in rem plura ex $A$ gricols \& Boctio Kircherus lib. 8. Mund. fublerr. fea. 2. cap. 5.Idem in Italiâ inveniri menorat Clufius. Refert Ferrantes Imperatus lib. 25. \& Francifcus filius ejus Posfidet Olans Wormim fruftula plura, qrorum unum, (Battholino teete p. 277.) cclore candido, friabile, mollé odo. ré gratisfimo \&z.

5. XI. Ut tamen aurum à fcoriâ, vètum. q́ve à falfo liberemus, duas pro appendice formaturi Qvaftiunculas fumus, quix \& abufúm impugnabunt, \& propugnabunt ufum. Qvar. Utrum Unicornu fit Alexpbirmacon univerfale, vel ad minimum tandem, cas obtineat virtutes, gvas vulgo ei tribuunt? R. Mundus vult decipi. Volenti non fit injuria. A jufto ad nimium. itur. Fama Echo eft : triplicat, qvadruplicat univerfa. In gratiam Magnatum multa dicuntur. Venena tàm funt vartia, ut imposfibile fit,unum dari omnibus refiftens àntidotum. Homines pro opínione fuâ, ombia augent. Agyrtarum \& circumforancorum. fraus ineffabilis. Non obticuiffent divinisfimas illas dotes, Medicorum Antefignani, Arabes, 


\section{53.}

bes, Ethiopes, Graci, Latini. Nihil amplls laudatur, nifi quod ex Indiis \& Moluccis Infulis adfertur. Cotidiana, etfi optima, \& $\approx$ • quivalente vi pradita, nimio fui ufu es vilefcunt. Experientisfimus Vir D. Thom: Bartholin p.266. pro fe citat Cratené âCraffebeim, Baccium, Horativin Angeniwm, Horfinem ac alios, \& Monoceroti ne minimum cedore cornu Cervinum atḉ; Unicornu fosfile, aito Idem apud Aldrovasd loc. cit. fol. 183. Am. dreas Maxinus ES Apoll. Pbilofopbus, Atatuunt. Unicornua quoq́; pifcium in feptentrione. pro quadrupedis unicornui pasfim vendi-. xi, incredibiliaǵ, diAtu â quibusdam temezare affingi illis, nulli dubitamus.

\$. XII. Quar. 2uomodo dignojfi Uniconne genuinum â juppofititio foleat? R. Si aquze cao lida injectum bullas excitet, djunt: fi prezfente veneno, emittat fudorem: fi canibus veneno potatis medeatur: fi beneficio cornu iftius definiarur circulus, quo, ciclo immiefus, vel fcorpius vel araneus, egredi nonaufit. Ubi tamen fuperftitio cum fallitate certat de primatu. Falfum eft, fudare folũ Unicornu:falfü, femper in ferventibusaquis,at. que folum Unicornu excitare bullas. SuperQitiofun verò atğ; Magicum, quod de Ju(1) 


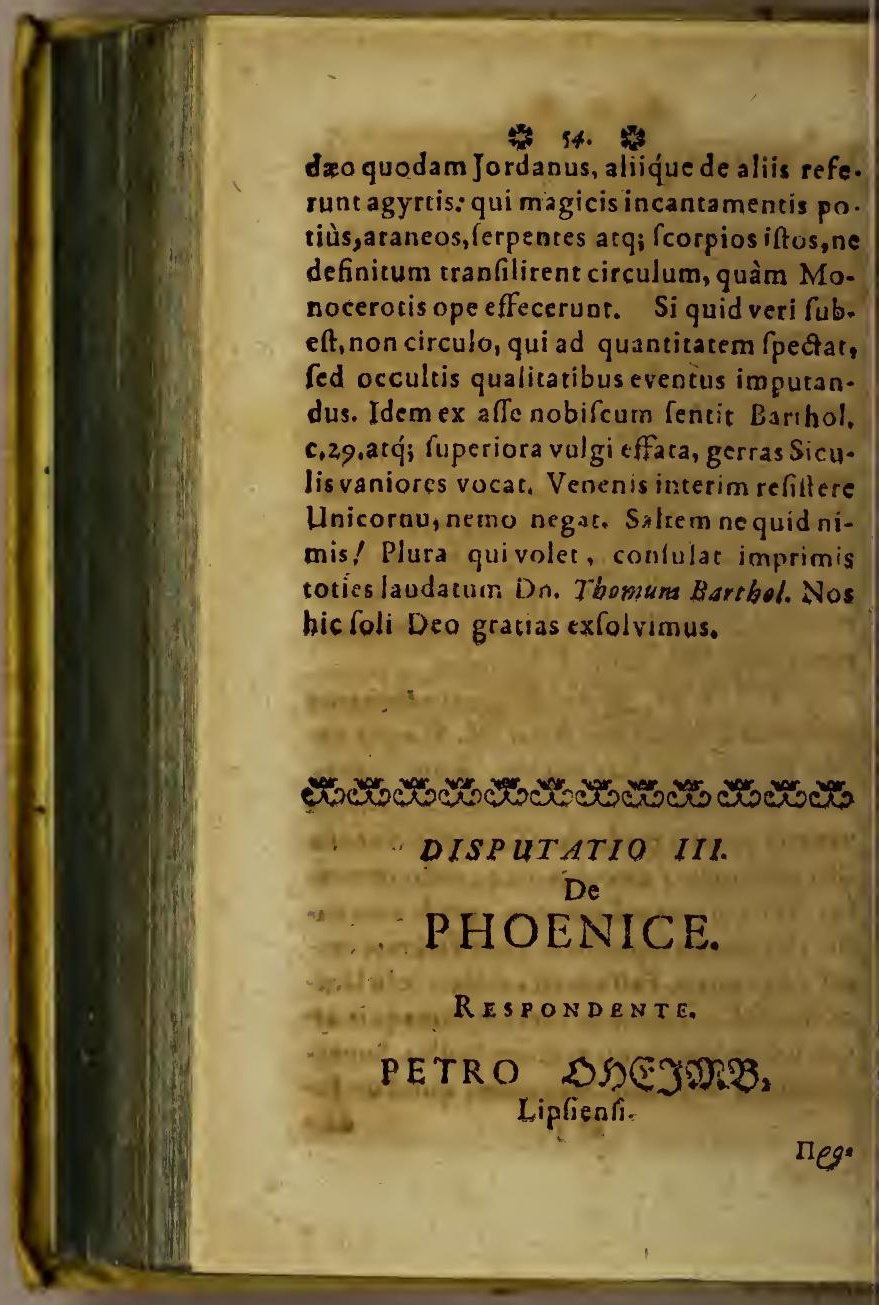




\section{5.}

\section{तegaúdiou}

R Ara cbara fant. Profunt exim es dele. REant non Poetce tantium,fed ES Pbilofopbi. Nos inter eruáitos infimi \& poftremi nibil borum nobis vendicatum imsus. 2aid enim im. modeftius feret? Effectum nullum, conatum tamen non omninò illa udabilem paramus. Hine anno abbinc fuperiore, de BASILISCO diffe. rueramus. Nuper UNICORNil inveftige. vimus. DE BEHEMOTH \& LEVIATHAN, alio, $\sqrt{3}$ Numiniplacuerit, agemus tempore, Nunc de PHOENICE. Jufcipienda indago eft. Tote. nim de bấc Ave unicâ, quam vocant, fmilia, dicteria, enigmata, quot nuspiam alibi. Viden. dum, auxiliante $D E O$, quid in receffu Pbenix babeat.

\section{CAPUT. I.}

\section{FXEGETICUM. ARGUMENTUM.}

1. Pbenicis notatio. Palma quid.

2. De accentuatione, pauca.

3. Evolvicur Homonynia Phonicis.

4. Pbonices populi adducuntur.

Non fuerunt primi Naura. Sednec primi invenêre literas.

5. E 6. Continuatur multiplex vocis acceptio. D 4 7. Pbe.

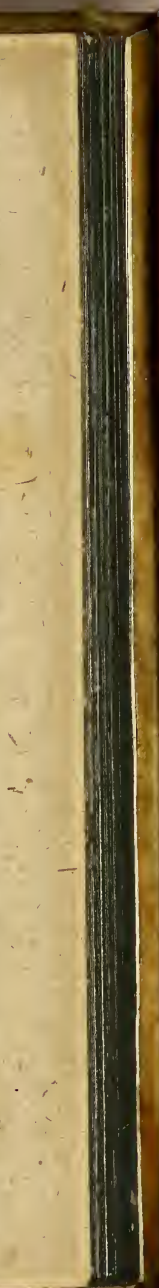




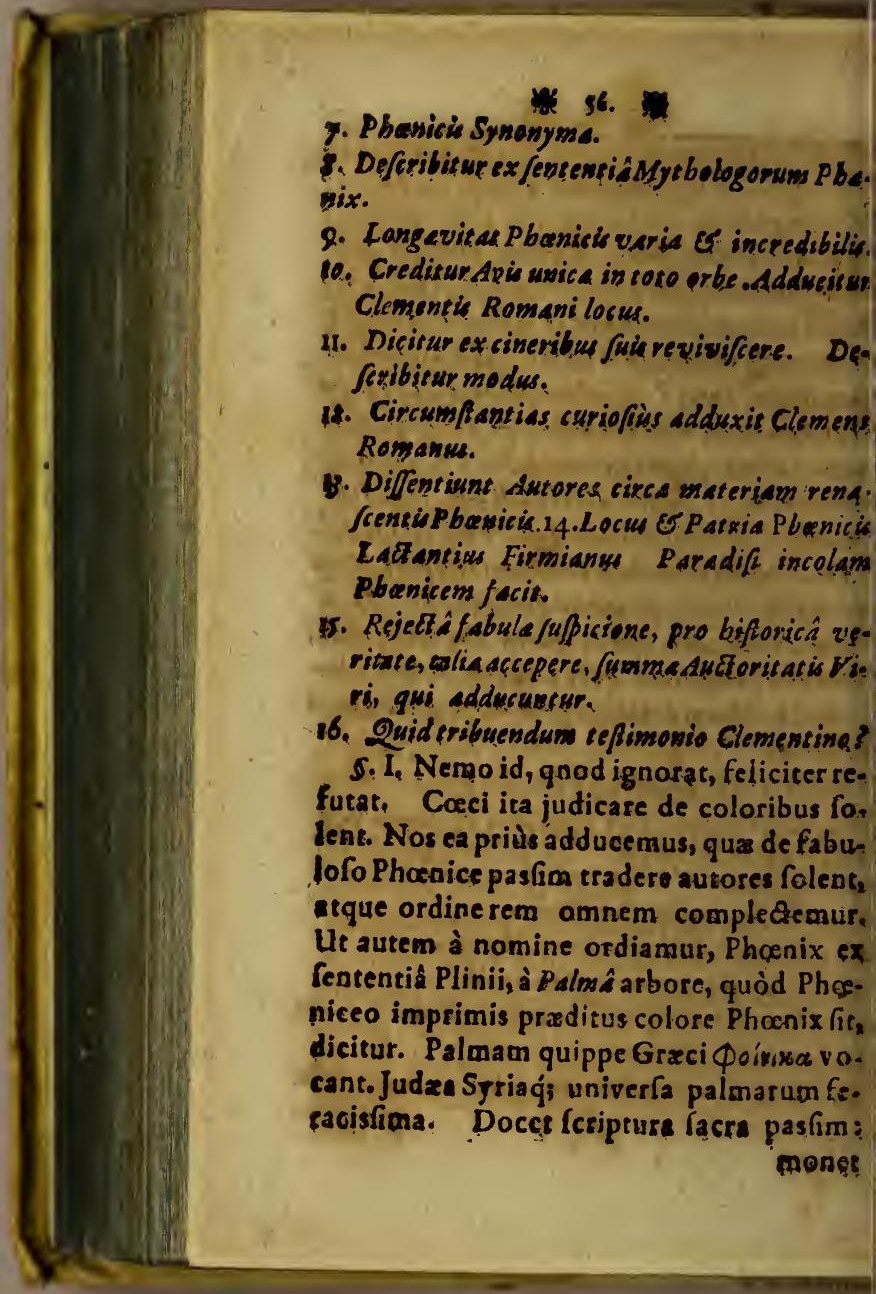




\section{\% st.}

nonet Plinius 1,13, c.5. de Syriz arboribua bi agit. Elegautisfima Plinii, in defcríendis palmis, verba funt, ex 1. b3. Tectorit ricem hic Parietibus plerisq́i in locis preze tane, $\in$ contra âfpergines. Incertá tamen tia sidine etiam mitioribus fe mifcent, Relique eretes atç; proserz: denfis gradatisq́; core icum pollibus, ut orbibus, faciles le ad candendum, Orjentalibus populis prabeint. Coma omnis in cacumine: \& pomum At inter folia, us in cateris, fed fuis, inter ramos, palmitibus racemofum. Folia cultrae. o mucrone, lateribus in fefe bifidatis, bella primùm demonftravềre gemmas: nunc ad innes, vitilium qu nexus \& capitum tevia ura. racula finduntur. Hac de Palmâ Plinius.

S. II. Aliam denominationis fationem Ifi: dorus t. 12. orig. cap. 7. habet: Nam, inquit, Ar abesrem fingularem, Pbanica vocant. Pboes six autem in toto, orbe fingularis \& unica avis Noftrà parum refért. De accentuatione aliavid addendum. फoins in réto, jota vo,cae em brevem habet pofitione qvidemlongam, n obliqvis veró naturâ jùxta Euftachium. B.

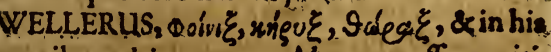
omnibus, ultimam naturâ longam effe, genitiro id nos docente, ait, p. 69. Grammat. Gr.c.2. de accenc.reg.3.Pafor in A ccentuum libelt, reg 


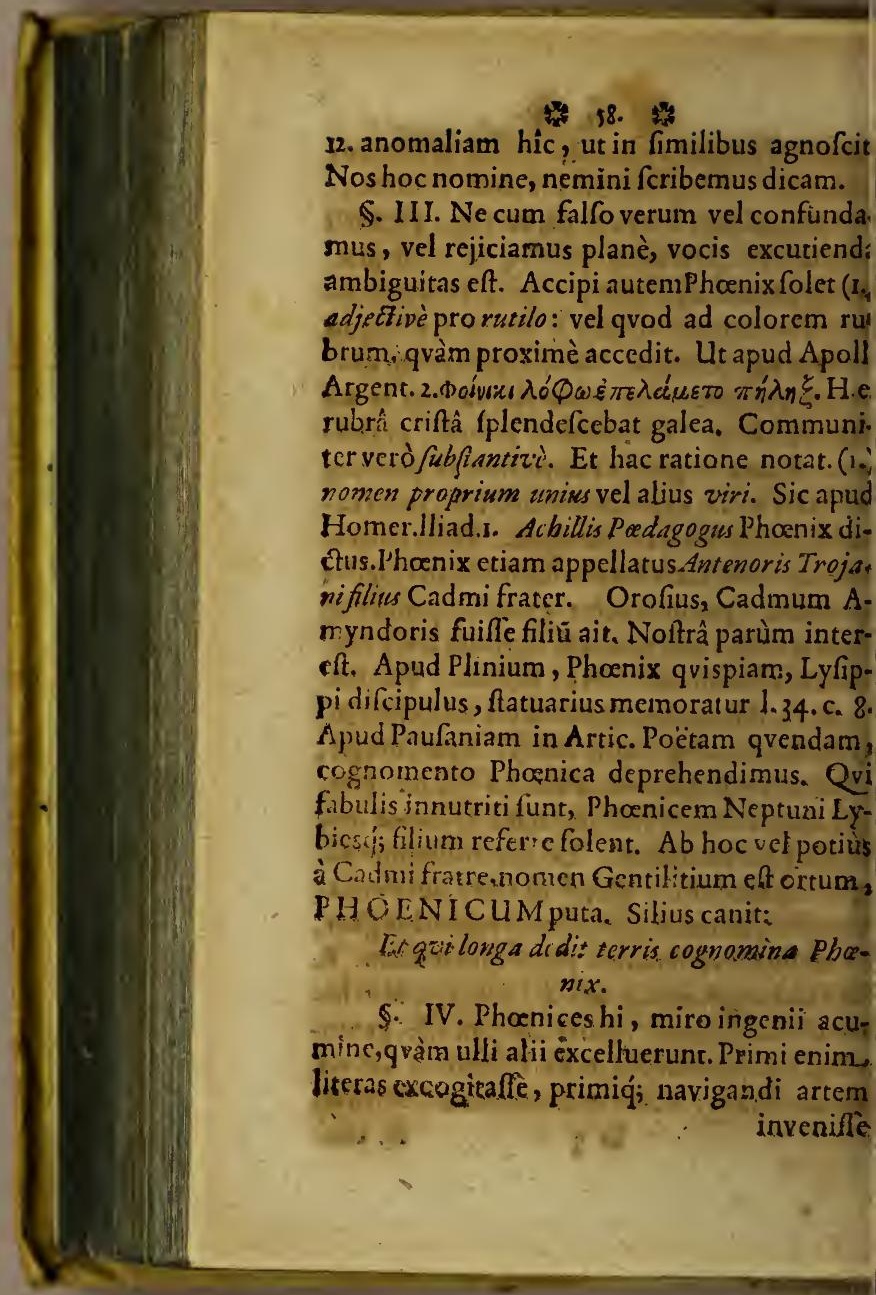




\section{9}

reniffe, vulgò putantur. Dionyfius ausindus :

Phornicum Regioeft : bi rubro gurgite quondam

Mutasere domum, primiǵs per eqvora vecti,

Luftrapêre faluḿ, primi docuére carini Ferre capis, orbis commercia -Lucanus 1.3 .

- Phoenices primi (fame ficreditur)aufi Manfuram rudibus wocem fignare figuriso os etfi accuratisfimos \& nautas\& difciplinam, imprimis Mathematicarum cultores pra is fuiffe, Phœnices non negemus : negamus men,quòd primi omnium \& navigandi arm \& literarum invenerint figuras. Ubi c . $\mathrm{m}$ Noachus, qvem, \& confequenter pofteros usdem, navigandi peritiam DEUS ipfe documanet? Pro qvâ fententiâ nobifcum puant Simon majol. in Dieb. canicul,coll.23. p. 6. Andreas Senftleben, \& nuper Loccenius 1 . I. c. I. de jure Marit \&.nav.thef.2.p.10.Litera. Ebrxis potiùs, fancto Dei populo, qvàm. Phœnicibus in accepto funt ferenda. Oftendit fonus, monftrat ordo, fvadec ratio fana vult codex facer. Athæc obiter.

\$. V. Jam \& (2) eqvus quispiam, Clea benis Epidamnii phonidictus eft : Paufanias 


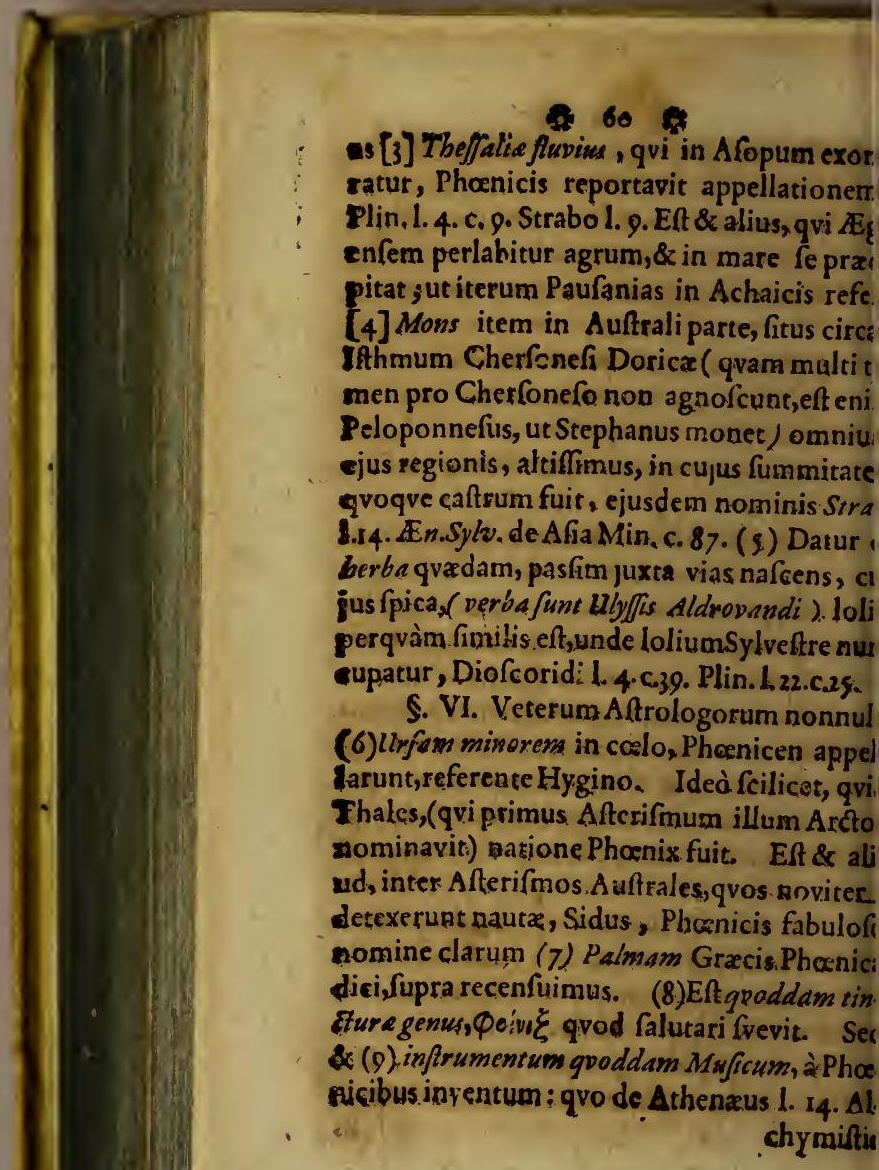




\section{a 61}

ymiftis (10) Elixir denotare Phonix dicitur, Aldrovando 1. 12. Ornithol.c. 27. vid.\& Kirm er. Mund. Subterr. lib. It. fect 4.c.2. Quín (in) emplaftrum at collyrium grooddsm, ur in xic.Grac.lar. Stephanus monet, fignificat.. aprimis verò (12) avem illam fabulofam, de agendum in prefenti nobisliumfimus.

§. VII.Hujus Synonym funt varia.Claw-

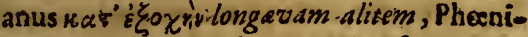
vocat lib.2, exim de raptu Proferpin, ca$t:$

QDidgoid ab extremis ales longersacolo: nis.

Colligit,optate referens exordia vitit. Hid. 2. Amori:El. 6.Simperiunicam sppellato

Ee vipax Pbonix unica-femper avis. pud Textorem, avis reparsibilis Pboria, lon. eva, vivax, Gangetica, Afsyria, Avis Solis, feu Timia, Thuricrema, É incendiaria: à Gall.Phoelix , ab Ital. Fenice, Hifp. Fenix, à Germ. Der Jogel fonix nominarifolet. Sed nunc ad $\mathrm{em}$..

\$. VHI. PHOENIX fecundumpictore tque Poetas, efl avis maxima, pulchernima, Diacißima, usicu in toto orbe,neutrius. fexus, $\dot{e}$ cieribus fuis fubinde reviziffens: , Confiderabíaus per partes Phocnicerti, ejusdemq́ve varis, qyịas vulgo, \& nefcio qgâ credulita tis fur-

pers

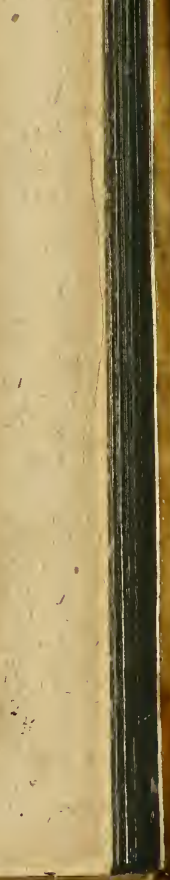




\section{2}

perftitione ducti, affignare folent affectione evolvemus. Magnitudo expendenda prim tùs. Aqvilæxqualis effe dicitur. Herod, tus in Euterpe, non parem tantummodò cus aqvilâ magnitudinem illi vendicat, $\mathrm{fed} \&$ tot corporis habitu, aqvila fimilem effe refert Qvanquàm ex relatione aliorum. Philoftra tus, referente Tzeze 1.V.Hift.Chiliad 6. Pavon majorem effe fcribens, parum ab Herodot diffentit. (2) Pulcbritudo feqvitur. Lactanti us Firmianus [qvo nemo magis in hâc caufsấ x ৎ̧ußav7iã ut hoc hîc verbo utar ] confcript integro Poemate, qrod Phœnicem infignivit ait: .

Hoc bumeri,pectusgos decens, velamine fulgent :

Hoc caput, boc cervix, fummaǵs terga nitent,

Caudaǵsporrigitur fulvo diftinct a met allo. In cujus maculis purpura mifia rubet.

Clarum inter pennas infigne eft, defuper iriss? Pingere ceu nubem defuper alta folet. Equatur toti capiti radiata corona:

Pbebei referens perticis alta, decus, Effigies inter Pavonis miffa figuram

Cernitur, \& miftam P bafidis inter avem. S. IX. Nunc (3) Vipacitas. Variant hîc, fi ufquàm 


\section{3}

q àm alibi, Scriptores. Adeò fibi diffor is falfitareft. Cornelius Tacius fcribit : de mero annorum varia radun cur; maximè ligatum quingentorum fpatium: Plinius xcentos \& fexaginta ; Herodotus, \& Mela 10. Pbilofiraîu 600. Seneca 500. Albertus 350. mos vivere Phonicem affeverarunt. Hæ: tas mentibus ad fuperftitionem propendenbus, non magna nimis videri potuiflet, nifi b.eremun Egyptius, aliiq́; Poetz ( qvorum rivilegium eft,fingere) fex, fupra VII. mill.anos, Phonicis revo tribuifient. Tolerabiliùs vidius, fecundum communem computum ronunriavit lib. XV. Mețam.fab. 37.

- Hec ubi qving fue complevit fecula vite, Ilicis \& in ramis, tremulog cacumine pal:

\section{ma,}

Ungvibus \& duro nidum fibi conftruit ores Ec.

roverbium eft: Phaenice vivacior. Longrvitis hujus rationem Oppianus hanc adducit: voniam neqve fagittis neq́ve lapidibus, neç; liis hominum infidiis peti potelt. Sed de his ugis infra.

S. X. Unicam in toto orbe avem, ac prode neutrius volunt effe fexûs ; Phœnicem. ta enim in nuper reperto monuméto, hoc eft piftol. Clementis Romani ad Corintb. (Cui ta-

men

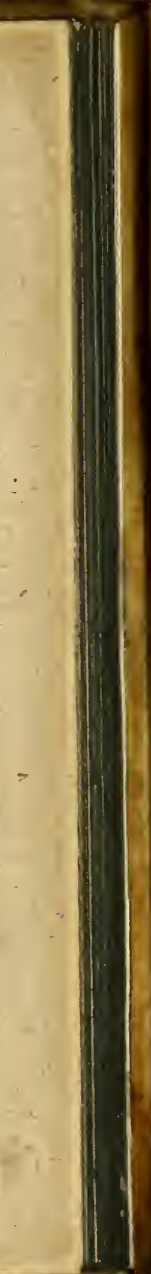




\section{4}

men quid tribuendum fit, paulò pòft dicemus legimus : confideremus fýgnum admir abile, qpoc in Orientalibus locisfrue in Arabia accidit. ADi eft, que appell atur P boenix : ea fui generis unic eft, E folitaria, vibitg quingentos annos. La. Cantius inquit:

Farmina vel mas bat, velneusrum for ma Felix, ge felix il

Felix, gpe Veneris freder a nulla colit. Mors illi Venus eft, fola eft is morte volw. uipolfit naficibac, Et Mantuanus :

Sols inter poluctes, nec imas net fernine, $\sqrt{e x i}$ Sola caver, tenteris fola adper atur bonores: Hine contentio inter Grammaticos orta, cu jus nam generis hæc nullius fexûs avis fiet? Sei de afini difputatum umbrâ fuit.

5. XI. Ex cineribus fuis revivifeere Pho nicem,nemo, quihoc idolum Poevarum co. lit, negat. Plinins, qui \& ipfe pro fabulâ Pho nicem habet, ex Manilio inqvit 1. X. Hift. Nat c. 2. Primus ató́; diligentisfimus Togatorum. de eo prodidit Manilius Senator ille, maximis nobilisdoctrinis doctore nullo:neminetn exti. tiffequi viderit sefcenté : facrú in Arabiam So: li effe, vivere annis 660 ; fenefceritem; cafie thurisquve furculis conftruere nidum, replert - doribus \& fuper ernotio Exolibus deinde medul. 


\section{5. $6 ;$}

redullis cjus nafci primò ceu vermiculum: de fieripullum : principioq́; jufta funeri rori reddere \& tocum deferre nidum propè anchajam in Solis urbem, \& in arâ ibi depo: ere.Lactantius hâc audiendus extr. de PhoenIp $\int_{a}$ fibiprelesifaus eft pater \& fuus bires,

Nutrix ipfa fuisemper alumna fibi.

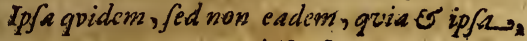
nec ipja eft,

Eternam visam wortis adepta bono. vid.1. cir.

Una ef que reparet, feg ipfar efeminet ates: Asfyriilbxnicasecant

5. XIY. Clariùs adhuc \& qroad omnes cirimftantias, ex Clementis Romani illâ ad orinth. Epiftola , quam ob Viri Apoftolici ctoritatem, maximi fecit Patricius Junius, imus ejus editor, negotium conftare poteft. erba futit, ex recenfione Clarisfimi BOELERI in Programmat. Acad. XII. p. 6r. um autem animadvertut fuum finem inftare, $i$ a fibi loculum facit ex thure \&o myrrbâ, aliiscaromatibus: revolutoqve tempore ingrediin eum Es nsoritur. Solutâ deinceps in prfactionem carne, vermis inde generatur, qvi bumore defuncti animalis nutritur, plumei, robuftio rqve factus, tollit illums loculum i offa parentis funt, of portans ies in Egy- $^{-}$ E

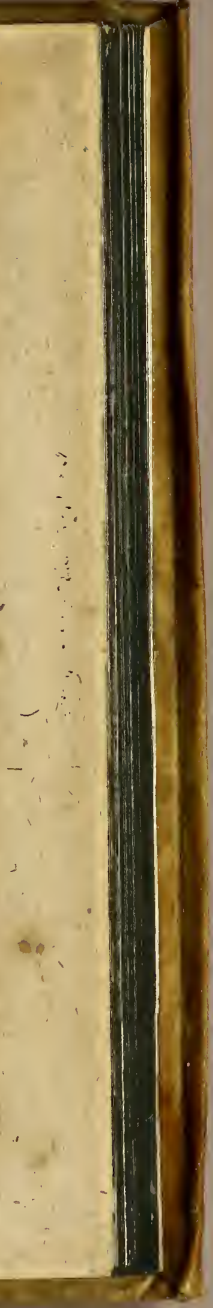

ptum, 


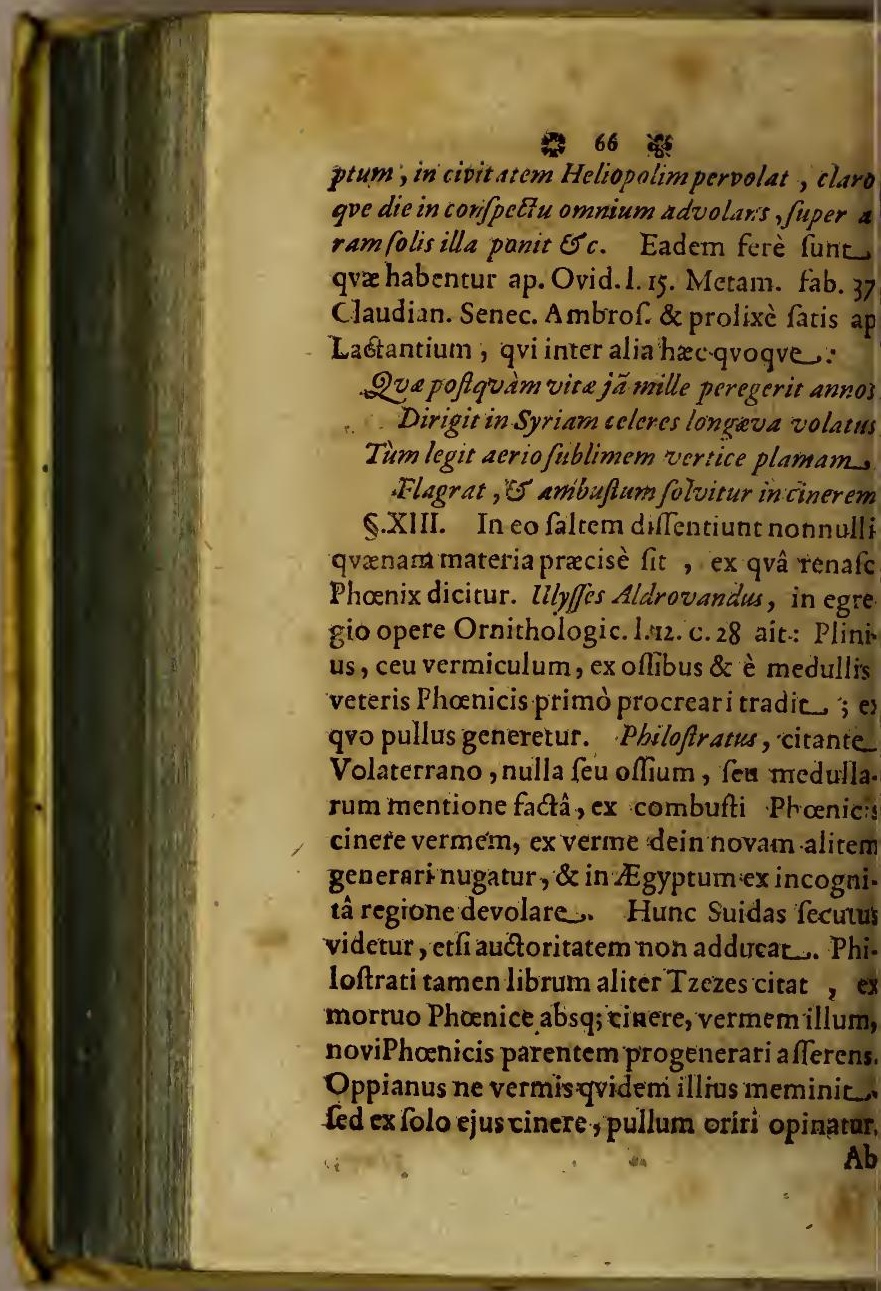




\section{4) 68}

De nutrimento, quod Nectar \& A mbro fiam effe volunt, alii faluberrimum qvendam rorem; Ovid. thurilacrymas \& amomi fuccum \&c. ac cantu, qvetm modulatiflimum \& inimitabilem omnibus effe, ftrenuè nugantur, zcet propemodim narrare plura. Tantem \& mendacia bilem movent.

$\$ \mathrm{XV}$. His tamen non obftantibus, innumeri, qvi pro hiltoricá veritate \& acceperunt hæc, \& pronuntiârunt', extitêre. De Ovid, Claudian. Mantuan. aliisq; Poetis nihil dicam. Eniun verò

$$
\text { - - - Pifforibus atg Poetis }
$$

quodlibet audendi femper fuit eqva poteftas. ExH:ftoricis citari Tacitus, Solinus \& Philofratusfolent. Et Philoftratus quidem, adductus à Conrado Gesnero Tigurino Med. \& Phil. Prof.quondam l.3. de A vibus fol. 692. inquit : Avem $F$ bernicem efe percredimus, que quingentefimo groque anno is Agyptum veriens, banc iffam Irdiam fupervolat. Can. Valerianus, Phonicem devolaviffe in Egyptum tradit ap. Pliniun.Sebaftiantrs Münfterus adducit Epiftolam qvandam. Ethiopir Regis ad Pontificem Romanum. Contenta hæc funt: In terrî meâ eft Pbonix avis, cujus anni vite funt trecenti. HLec propèfiriem vita iàm altè verfus serlum 


\section{69 \%}

lum evolat, ut accendatur â Sole Ere. ExPabus Ecclefix primitivæ, multi , utpote $A m$ ofius, Lactantius, Lyra , Tertull. tefte Fran, I Nicepborus \&c. imponi fibi his paflifunt gamentis.

\$.XVI. Scaligeri hî́c dolendus lapfus effet, ando Exerc.2.33. fcribit : Pbrnicem baud effe nitus fabulofum, lcgimus in commentariis nagationum. In mediterrsneis Indis reperiri: menda vocatur abincolis. Nifi ipfe in fe-, entibus, fidem hiftorix hujus ex parte elere videretur. Ex Recentioribus denuo o Hiftorica veritate, de Phœenice qvæ dintur, pronunciavit, Patricius Junius, Cleentinâ inductus Epiftolâ. Qvæ tamen vel ppofititia eft, juxta nonnullos, notante. eleberr. BOECLERO, vel fi genuina etiam, erhardi Joh.Voffii placet moderatsm, quod betur in Phyfiolog. Chriftian.1.3. c. $99 \cdot j u-$ cium : neceffe non eft credere Clanentem fosfor omia, que facerent ad arcana Puature. e Clemento etiain VIII.Pont.Rom. Cmbden. ribit inHibern.p.783. Hibernis in Reginam Elibetharin rebrllibus, A. 1559.pro magno fo. muere mififfe thornicis plumam. Ridiculè!

CAP.II.

ELENCTICUM ARGUMENTUM. Pbonix nullibi nifi in picturis vifus. Contrari$E_{3}$ antus

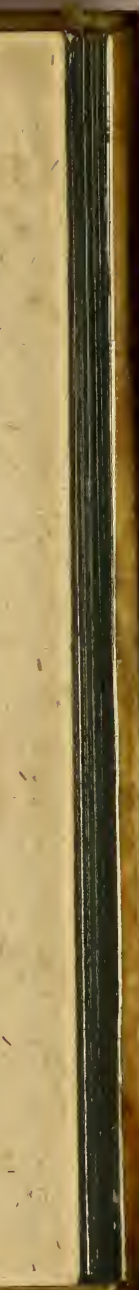




\section{0}

antur Scre S. que de. Phonice rcferuntus

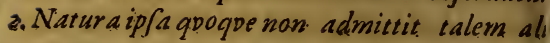
tem. Dantur rationes.

3. Defcribitur Salamandra, Nan vivit in igne cur?

4. Bellarationi fane infert fabulofuss Phanix. s. Ulnde hac, de abfurdo Pbonicescommenta di manarint?

6. Gitatur atque approbatur teflimonium Lan rembergI.

7. An, E quomato ad proverbia \& quospis al os difcursîs adbibendus Pbonix?

S.I. Hxc illa tabulofa, \& non nifi in pietu ris, (ut cum Herodoto logvar) vifa avis. Ns mo hominum eandem, bonâ fíde obfervại Omnes, prater dicunt, inqviunt, narrant crribunt, ajunt, referunt, nihil veri afferunt tefte Gesnero 1. cit. f. 692 . Nos pro impollibi li , abfurdo \& apertè fallo deliramenta repu tamus qvicquid de $P$ hoenice, aliter quàm $æ$ ni gmaticè tradifolet. Injurium quippe cìn in Siripturam S. tüm Naturam, tum dewiqpe ra tionem Sanam, dogma iftud ett. Ibimus pe partes \& probabimus univerfa. Et quidem ex Scripturâ S. liqvet; majculum Ef fumellan in omni animalium genere, condidiffe Creato nem optimum. Hoc enim nomine, genera tienis opus omnibus conceflum erat. Omni 


\section{1 糈}

ous in univerfum dixit idem $:$ Crefcite of muliplicamini.Non hîc excipiendus Phœnix erat. Et ad Noachum, non tantiom ex quadrupedibus.jed Es volatilibus onnibus, ingreffafunt bina ac bin ${ }_{2}$ marculus \& foemina ex immundis: ex mundis verò feptem paria.. Sine dubio ad munda, imò mundisfima omnium, referendus Phonix, fi quis effet. At ubi vcl formina vel mas, vel 7 . ipfa paria?

\$.II. Natura verò feqventia nobis fuppeditat adverfus Phønicis affertores, arma, A privatione, inquit, ad babitum, nullus naturaliter datur regreffis. Semel mortuus Phoenix, totalem fubiit privationem. Hanc enim mors exigit. Natura inquit: 2.generatur , proximè âfibifmiligenexatur. Nullum hîclocum obtinet generatio xqvivoca. Ex vermiculo fi nafcereturPhœnix, generatio xquivoca \& ipfa foret. Natura ait : ex ovisfieriaves, non excineribus. Aves item ovipara animalia effe, non vivipara. Ex cinere galli, nemo expectat gallum, nec ex cinere Phafiani Phafianum. Idem cenfendum de Phonice, Natura docet ifine feminali propagatione ac traduce, nultam conferparifpeciem corparum mixtorum $p o f f e$. Teftatur eadem, nullum ex igne nafci animal, imò ne confervariquidem, in tani copiofis poffe ignibus.

$$
\text { E } 4 \text { S.IIL.Falfum }
$$

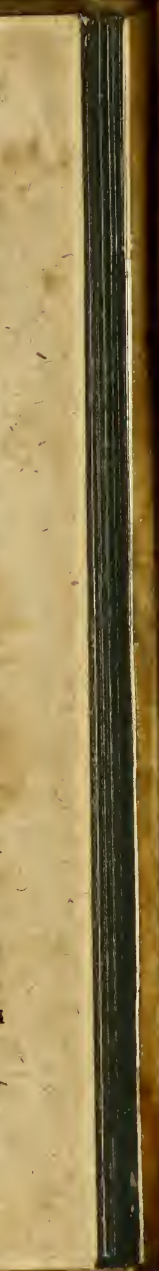




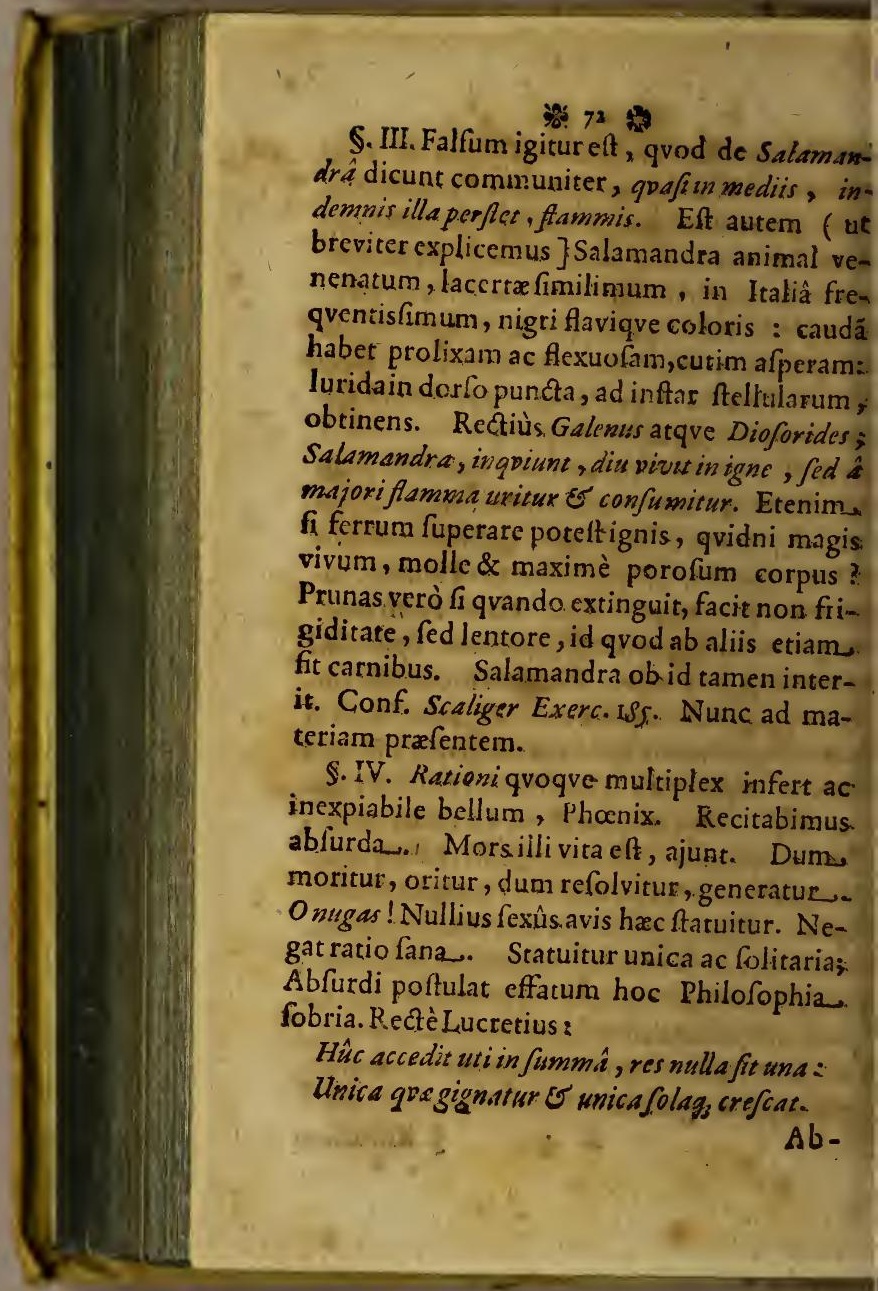




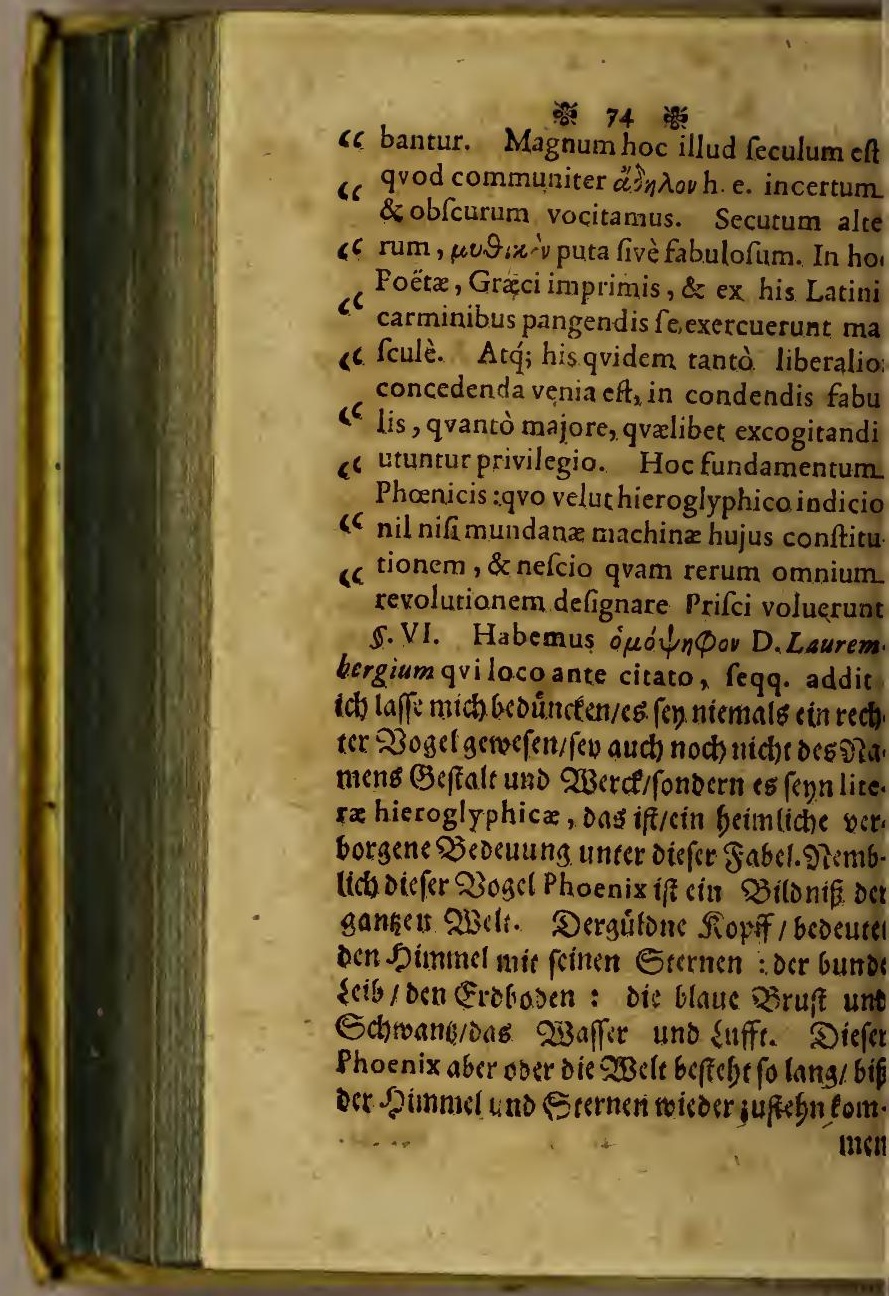




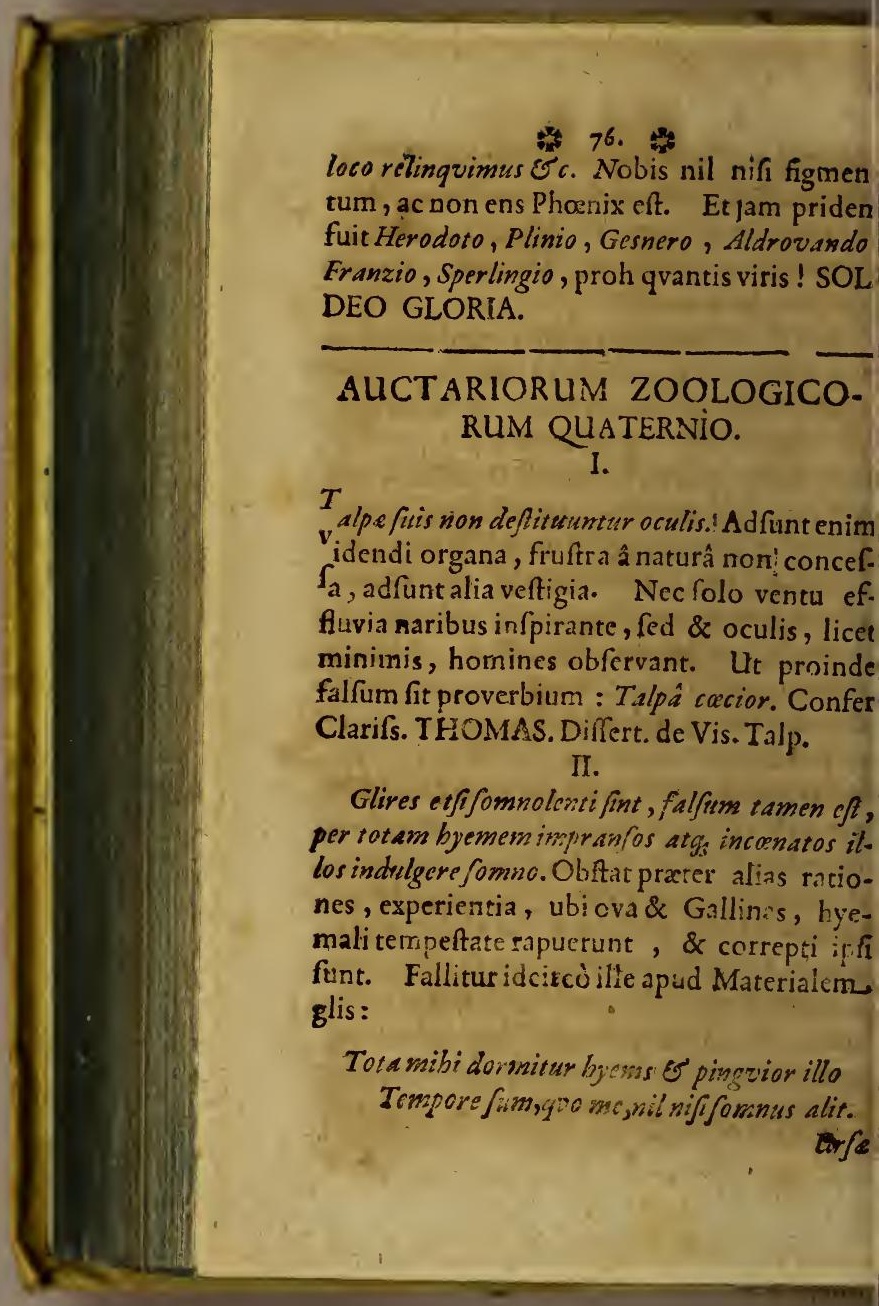




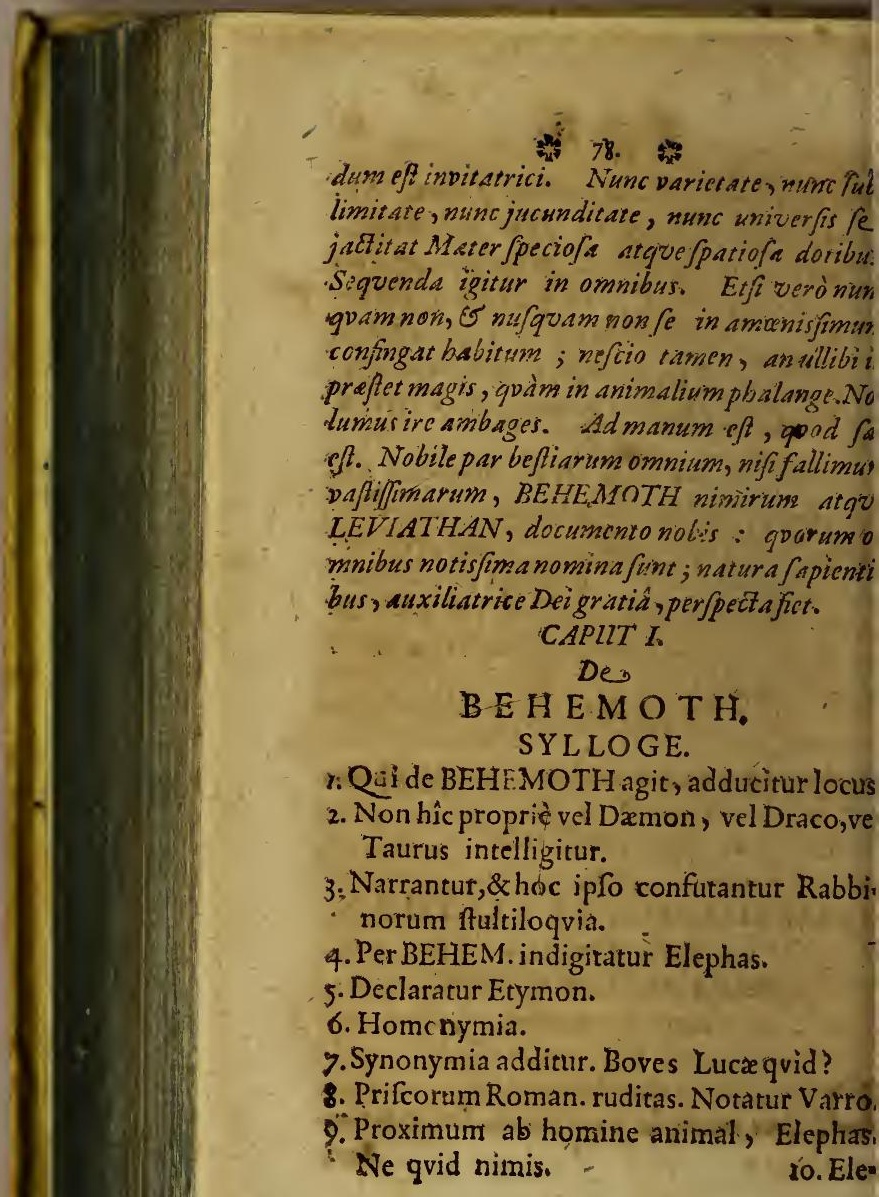


o. Elephanti folertia.

2. Robur admirabile.

3. Aliarum partium configuratio. Flectere crura poteft Barrus.

4. Armatura ejus naturalis.

5. Cibus \& Patria,

6. Potus ejusdem.

7. Captura.

\section{S.I.}

JIOBO, Phyfico in facris literis decanta.

Itisfimo, hiftoriam Behemoth atque Le. riathan deberi, caput XL. \&XLI. qvidem do. cet. Behemoth quid fibi velit, expriori:qvid Leviathan verò, ex pofteriori cognofcemus. Ecce age Bebemoth!(inqvit Natura Autor atqve dem quoque confervator DEUS ) quem feci to. urm, gramen utibos corredit. Ecce age fortitudo ejus, in tumbis ejus, of robur ejus in umbilico ventris ejus. Stringit (feu erigit) caudam fusm veluticedrsim: nervi genitalium ipfous impli. cantur. (vel ramefcunt) ) OJfa ejus fffule ieris, tibie ejus inflar vectis ferrei. Ipje eft Principium oiarum Dei, qoi fecit eum, applicavit gladium. ijus. Huic montes berbas ferunt: omnes beflie agri lufitabunt ibi. Sub umbris recubat in fecreco calami. In luto protegunt eum umbra ivei umbrofa arbufta ] circumsdabunt illum falices cor-

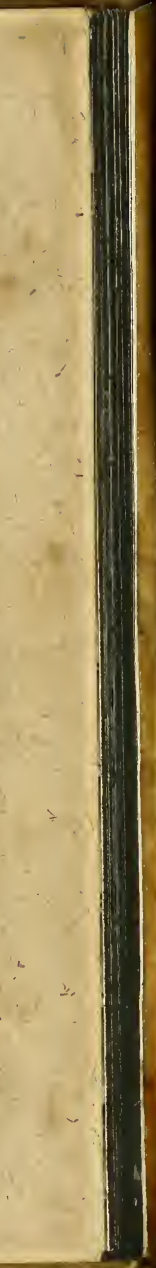




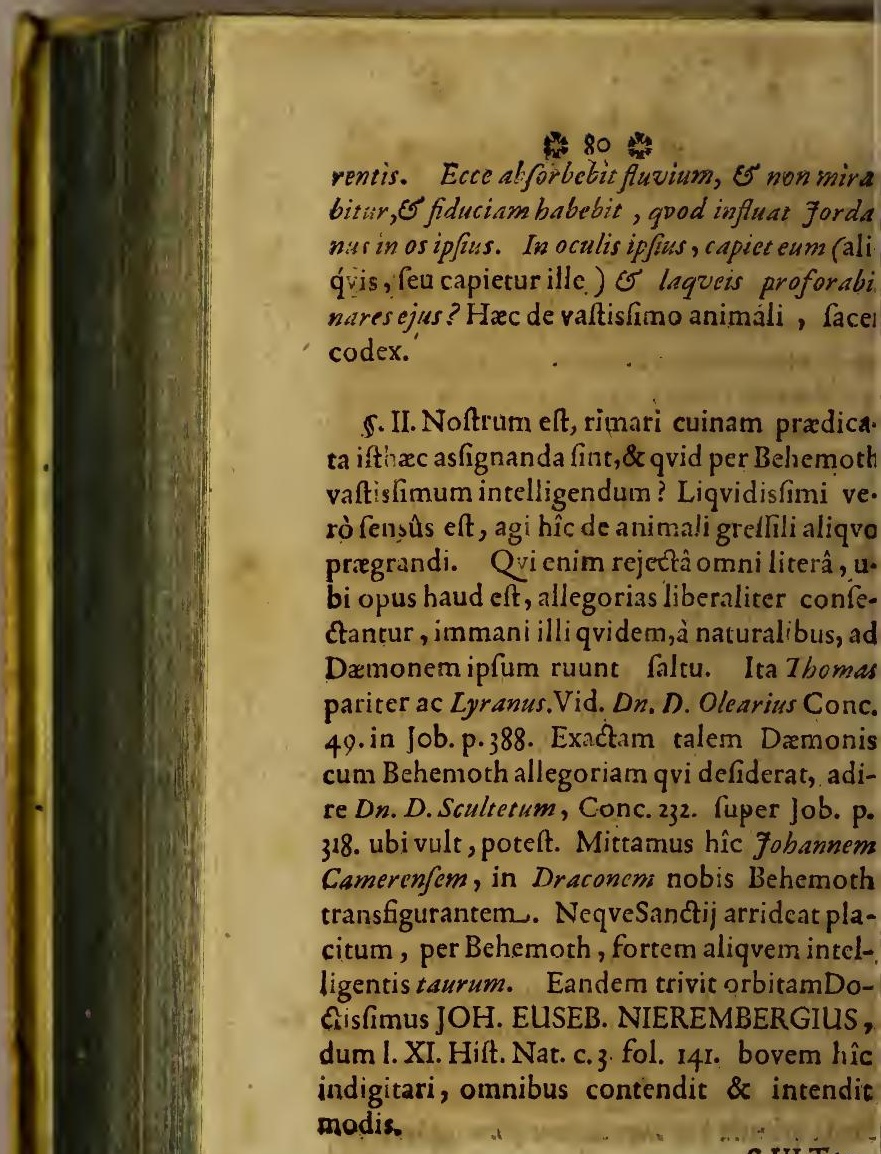




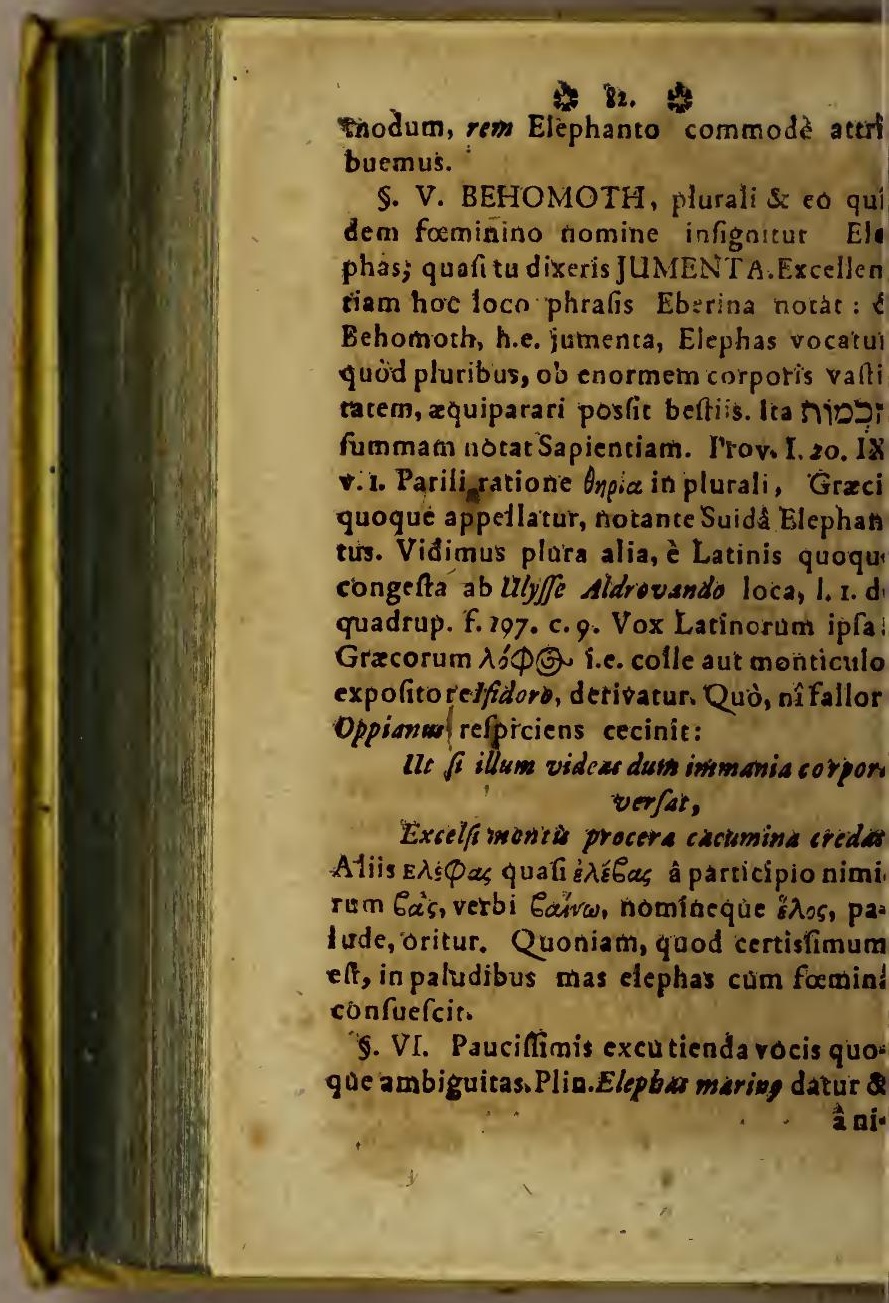




\section{83.}

nimio dentium candore, quin \& magnidine, quâ cưm terreftri Elephanto conveit, fic nomibari folet: Plin. lib. IX. cap. 5 redo, quòd Balænam ita vocitârit. Eft prareà quoddam locufiarum genus, Elephantî omine famigeratum. Plinius audiendus ex b. XXXII. c.11. eft : Elephantilocuftarum geevin nigri.pedibus quaternis bifulc is : preterea racbia dro, binis articulis, fingulisque forpictsodencicalatis.Sed \& quodda m poculorum geus, (tricongium vocant) Elephantum dici, pud Athreneum (!.11. c.5.) legimus. Verfus atinè redditi fic habent:

Idoneum nifi tibi elephastum puer ferat. Quid ef bocper Deos? poculum magnuse, choarum quòd triwin fit capax. Éc.

alibi ap ad eundem c. 16. Epinicus:

\section{-.. Hodie ad Cleplydram}

correntis infuar aurigabor utraque,

- A autem elephas. Elepbantos ntrrabic

grod congios capic duos ..... t.

rbytum

S. VII. Synonyma tangenda paucis. Dis itur hic nofter Behemoth, Latinis pesw In-

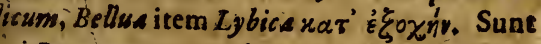
ui Barrums eum, unde proprium Elephantis A, Garritur, vocant. Horatius quarit:

$$
\text { E } 2 \text { Rid }
$$




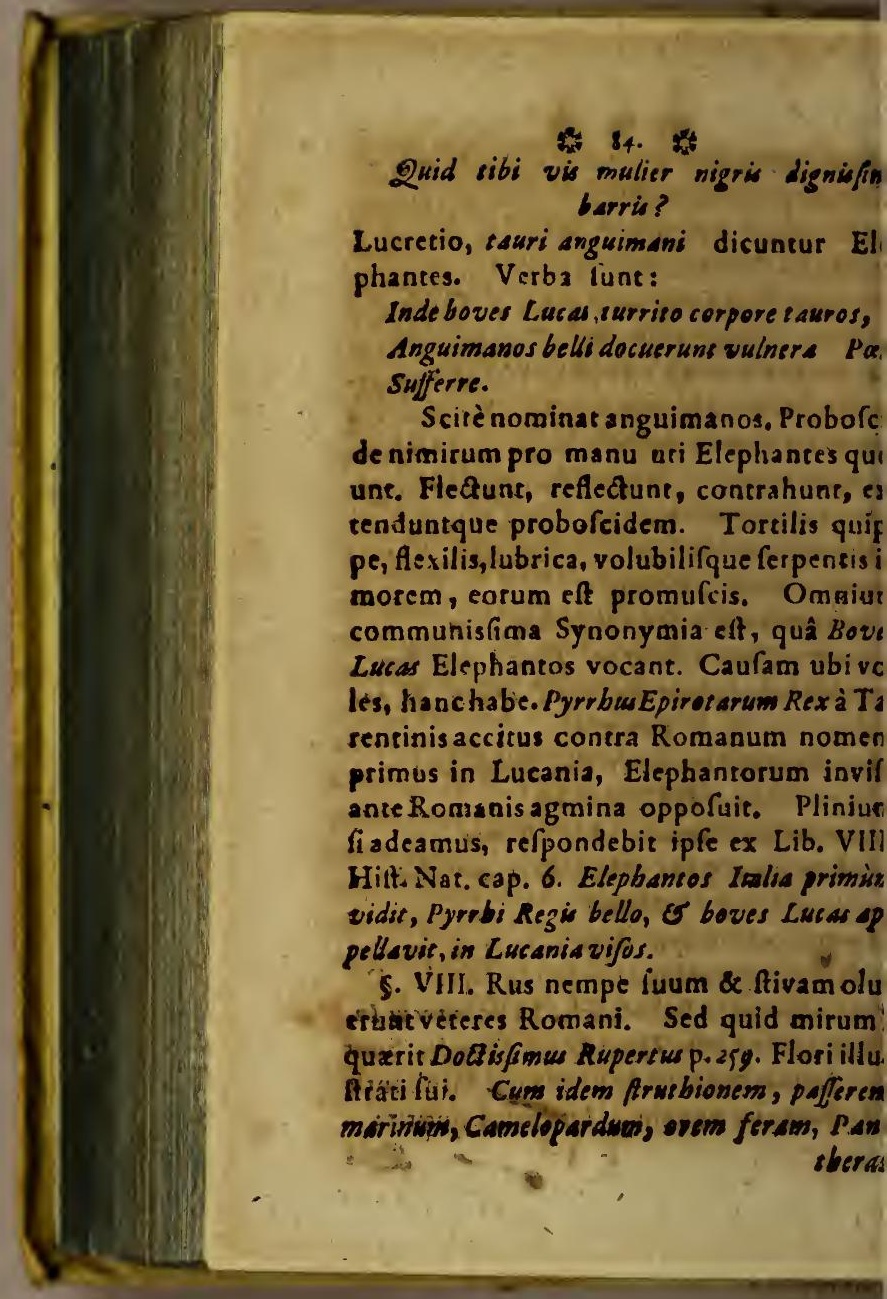




\section{* 35. is}

heras, mures Africanos, Leowes, Livos Numi, icos, appellarint, comparatione femper fatâ aliquầ ad notas \& indigenas a nimanteś. sore rufticorum aut puerorum. Ut Virdunus fuper Flar,l.s. c.18. ex Lipfio 2. Elect.c. 4 . olligit. Quanquam qua de Leone fufpiantur pralaudati Viri, Urrfum Numidicum, uiffe dictum, id folidisfimis refutetur argunentis à Clasdio Salmes. ad Solin. c.16.p.31t. Negaverat è Plınio Lipfius, Africam' habere Iríos. Plinium Lipfiumque Salmafius premit autoritatibus contrariis, Herodoti, StraSonis, Virgilii, Juvenalis, Martialio, Solini, M. Antonii Sabellici \&e. Nos ad boves Lucas reo ditum paramus. Ridec enim M. Varra in oper.de L.L. Lib. VI.\& refellit opinionem ex ilimantium, boves Lucas f. Lucos â Lucanis, ex ingenio Romanorum, dietos fuiffe. Elephantes. Arbisror, inquis, bopes Luces,d Luce potiuss dill as effe, quòd longè reluscbant, propter inaur aros regios cljpe os ; quibus terres elepbancorsm ornabantur. Exculatum it Varso prifcorum Romanorum raditatem. Invitâ fariè veritate. Plinio conçeftatur Lus. Ann. Florm l.1.c.18. Floro Scaligen inappen? dic. ad conject. in Varronem.

ऽ. IX. Expenfo nomine, res fequitur.Subjeaum, Elephantem fecimus. Prodicara or-

dine 


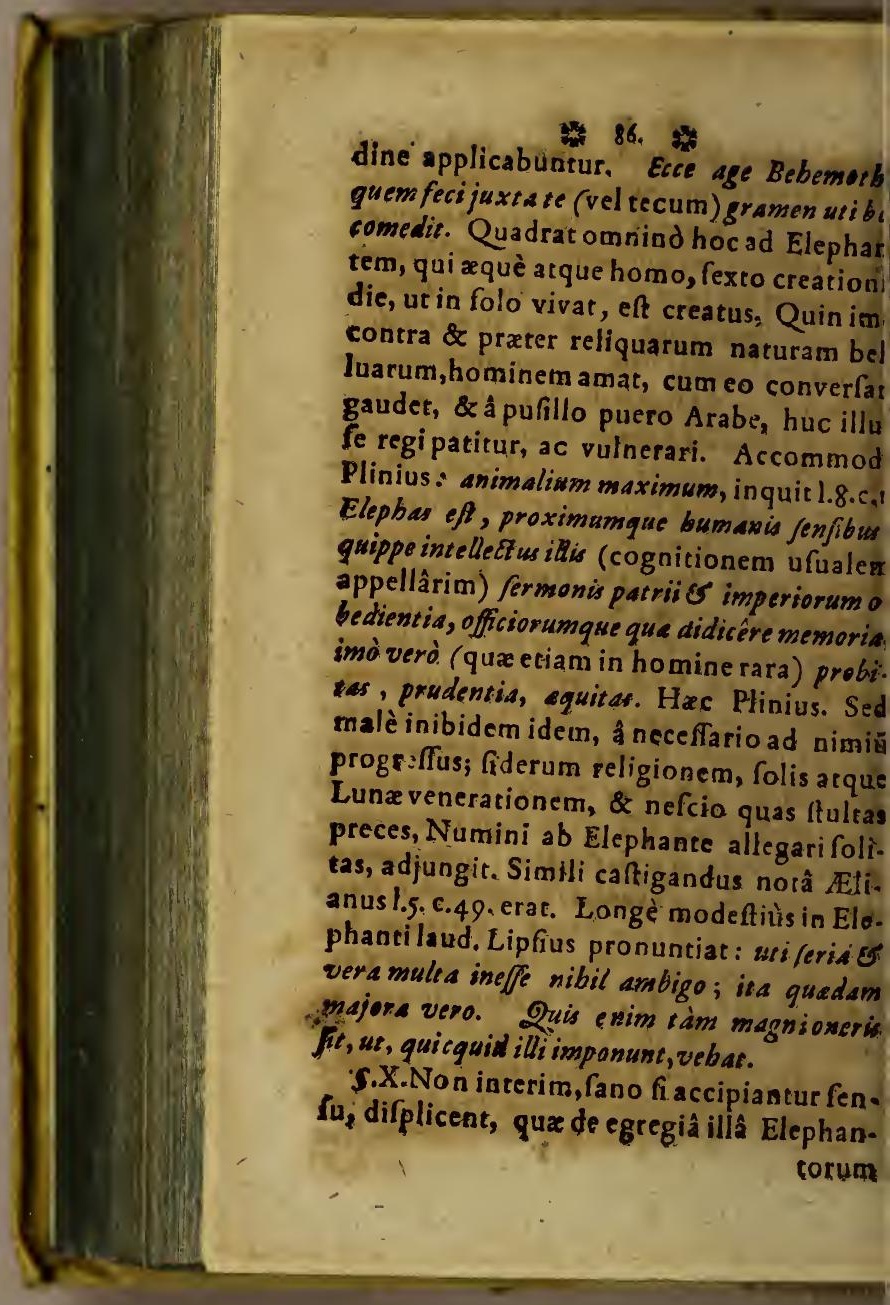




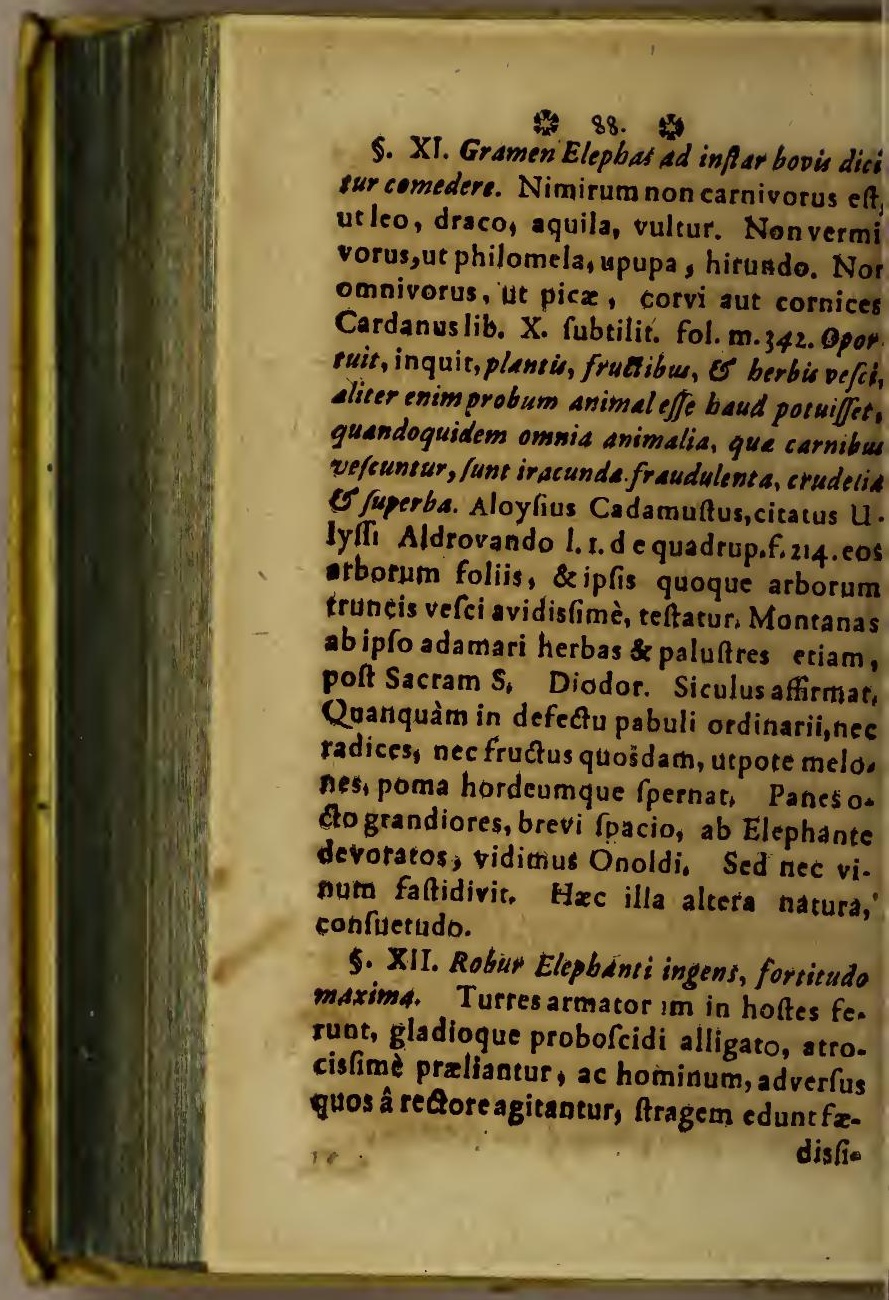




\section{9.}

dis fimam. Cardanus, tantrim, ait, corpori ine/ toboris, wt duo ex bis juncli, navem maximam onu $\{\mathrm{am}$, in terram trabant. Olim \& nunc Indi folent, duabus catenis ferreis circumligatis, fub ventre duas addere clitellas, illisque ligneum fuperimponere caftellum, in quibus feni homines eréti, \& quando que etiam usque ad 14, omni telorum genere ftantpraliantes. Sed quid minora dicimus? 1. Mace cab. VI. v. 37 . locus elegans habeeur, ubi Eles pontifingulj fingulas curres, \& in unaguaque turri, trigints duos armatorum, excepto adbue Aetbiope rectore, porcando fuftinuerunt. Eliano tefte, mania boftium fubvertere Elepbantiolim affolebant. Solâ etian probolci. de, ejectant armatos in fublime. Ctefias ipf: vidit, jubente rectore, Elephantem dentibus fuis palmam, fummá violentiâ, eradicâfre, pedibusque conculsafre. Vide mihi düos en. rundem dentes, $\&$ non ride, 325. pondo $x-$ quant: tefte durd́drin Vartomanno ap.Car. dan.I. X. f. 310. Julius Cafar Scaliger \& ipfo unicum vidit dentem elephantinum, (unde ebur eft] Viro longiorem. Exerc. 204. feeta fe Vidi equidem, inquit, dencem me longè praceriorem. I adici a dhuc majores \& robultiores.

5. XIII. Sequitur partium quarundam lephantinaruma conformatio. Loguendura F 5

ats. 


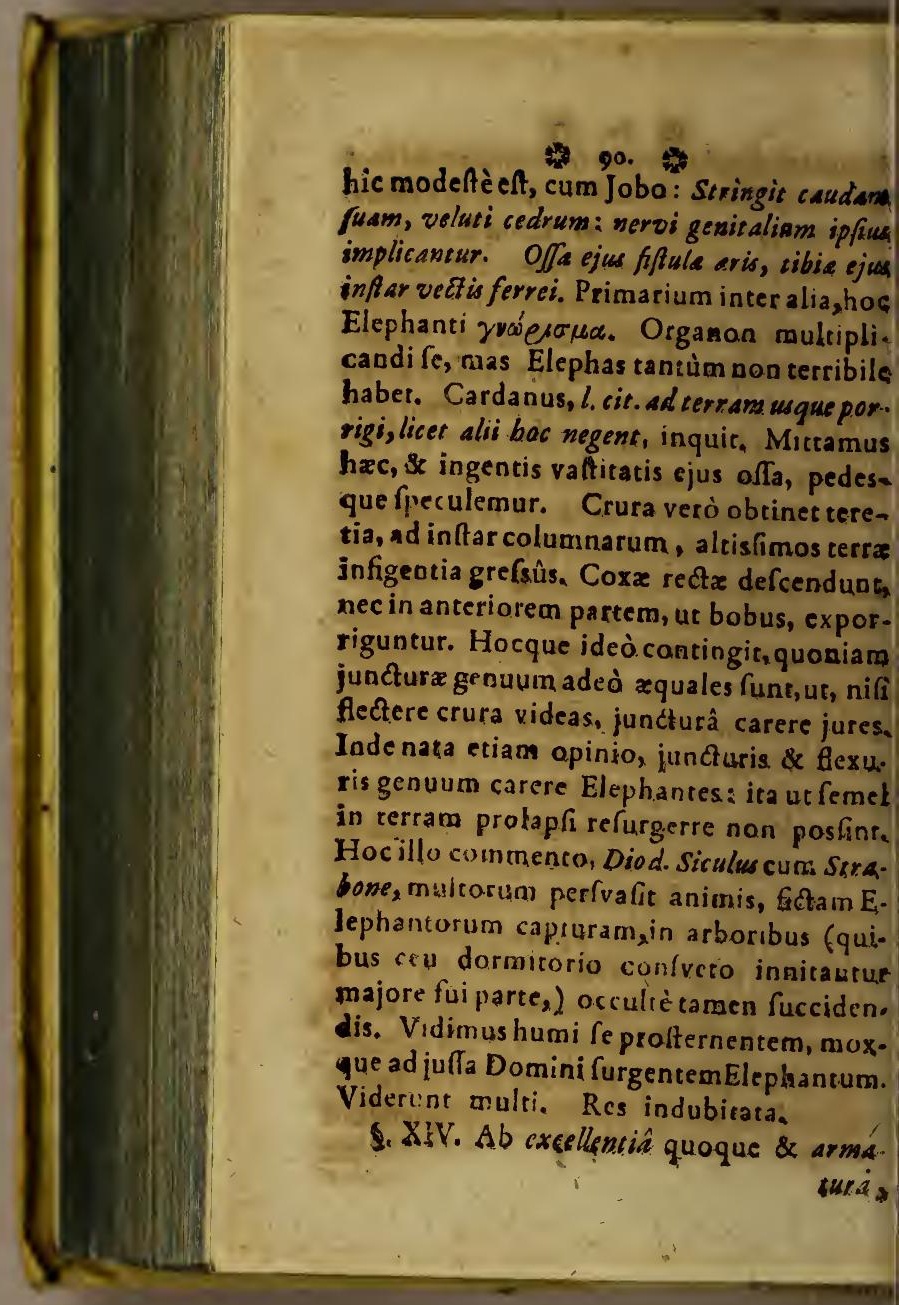


* 91.

tura, notter nobis defcribendus Elephas. $V:$ Dei, opera divina funt. Viarum Domini principium in/ignitur Elephas. Ipter quadru. pedes quippe excellentisfinum, prxcipuum. que, poft hominem, Dei opus. Sed \& primo inter quadrupedes animantes, loco creatus Elephas ftatuitur, a Dn. D. Oleario Canc, 49, Job. p. 388. Quicquid fit, primas, polt ho. minem, elephanto, propter pramedicatas rae tiones, ante Leonem exiam deferre posfis. Quantò enim ad hominem quid viciniùs accedit, tantò xltimandum eft nobilius. Docilem fupra modum Elephantem effe, $\int_{4}$ pra memoravimus. Plinii adhûc adjiciendus locus ex c.3.1.8. Mutianus ter Conful, athe cor eft, aliquem ex bis, $\hat{G}$ literarum duct ûs, Gracorum didicife, Elianus ait: Vidi cgo ipfe quendam in tabula, literes Romanas prossus. (cide/cribentem, recte E noncontortic. 2uis etiam cium fcriberet, oculi ejus cum rigore deje. di in takellam exant; ut planè intentos diceres E fcriptitantes. Nihil tale in Leonem cadit. Solivagum aniraal Leo. Regiâ focie. tate gaudet Elephas. Crudelis heltia $\mathrm{G}_{\mathrm{C}} \mathrm{O}$ Elephas manfvetus fupra fidem. Regem cle mentia decet. Armaturâ regius gaudet Elea phas, Ille, inquit Jobus, quifecit eum, applic an vit gladium ei. Fulmineos puta derites cum prober.
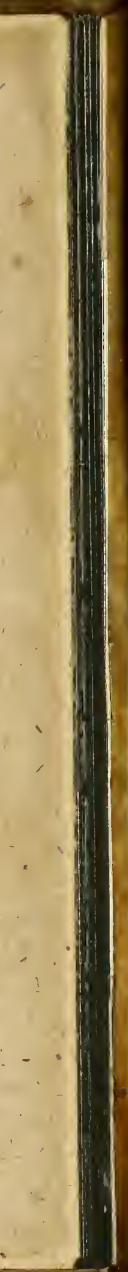


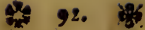

proboleide, quibus velut armis gladioque uritur. Placent Aldrovandi verba; probofcide pro manu usitur, $\mathcal{C}$ extremá ejo parte foc omnis sractat, atque is arebus apprehendendis appli. sat, ut ne minima quidem numismat aip/wm ef. fugiant, queetian jublacâ proboleide rectori infidentitradis. Fluvium aut profundum la. cum trajecturus, per fublatam hanc,in al. tum, probofcidem refpirare, mirabili natu. se prudentia ec providentia folet. Plinius inquit: mandans ore Birant \& bibunt, odoram surque baud impprooric apellacé manu I.\&.c.20.

5. XV. Huic montes berbas ferunt: $\mathcal{G} 0$. mones beflie agrilufsc abant abi. Sub umbris re. cubat in fecreto calami. In tuso eum umbrofa protegnnt arbufia : circumdabunt illum falices correntis. De pabulo ejus fupra dictum. Hîc nunc â manfvecudine ac habitationeBEHE. MOTH defcribitur. Manfvetus ex naturâ fuâ Elephas: \& primo quoque tempore cicurandus. Oppiano aufcultandum;

Ilbi pafous inest animus, dum faltibus errat, is forus; af bomines inter manfuetses be a. ques.

Herbiferic etenim arque umbrofis vallibus olim

Fagos argig oleas es celfa casumina palimes. Seppefola Bravit, firmâ al radice revulfá. Ingensi 


\section{3.}

Ingenti incumbens \& acuto robore dentix: $A \beta$ ubi in bumanis manibus ver/atur, eundem

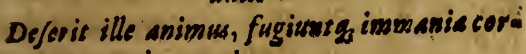
da,

Namig jugum patitur, deirisgig Bat ora twe patis,

Et pueros cergo difcit gefiare magifires. Licet etenim armatus fit, gramine contentus tamen, alia juxta fe animalia fecurè cira cumvagantia, ne imprudens ca conterát, blande fubmovet probolcide,vid.D.Sculsetw L.cit.p.316. Saturi ad loca rolcida paluftriaque revertuntur, \& arundineta, ut cubene ibi, incolunt, Aquas alioqui, nifi coacti, haud intrane, tametfi impendiò delectentut iis. Egerrimè quippe ob pragrandem coro poris valtitatem nataturi.

5. XVI. Esce abforbebit fuvium ES non mi:rabicur, Es fiduciababebit, quod influat fordanius in os ipfiss. Tardè quidem, led diutisfind bibit elephas. Tanta mqque aquarum exhaurit copiam, ac fi integrumexforpturus fluvium effet, Potú tamen nou haurit ance, quàm immisfis aquam conturbâric pedibus. Faciuat idem cameli, atquegenerofiores equi Cognofcunt fcilicet fuas bruta commoditates.

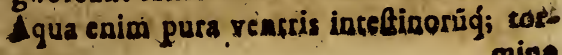
mine 


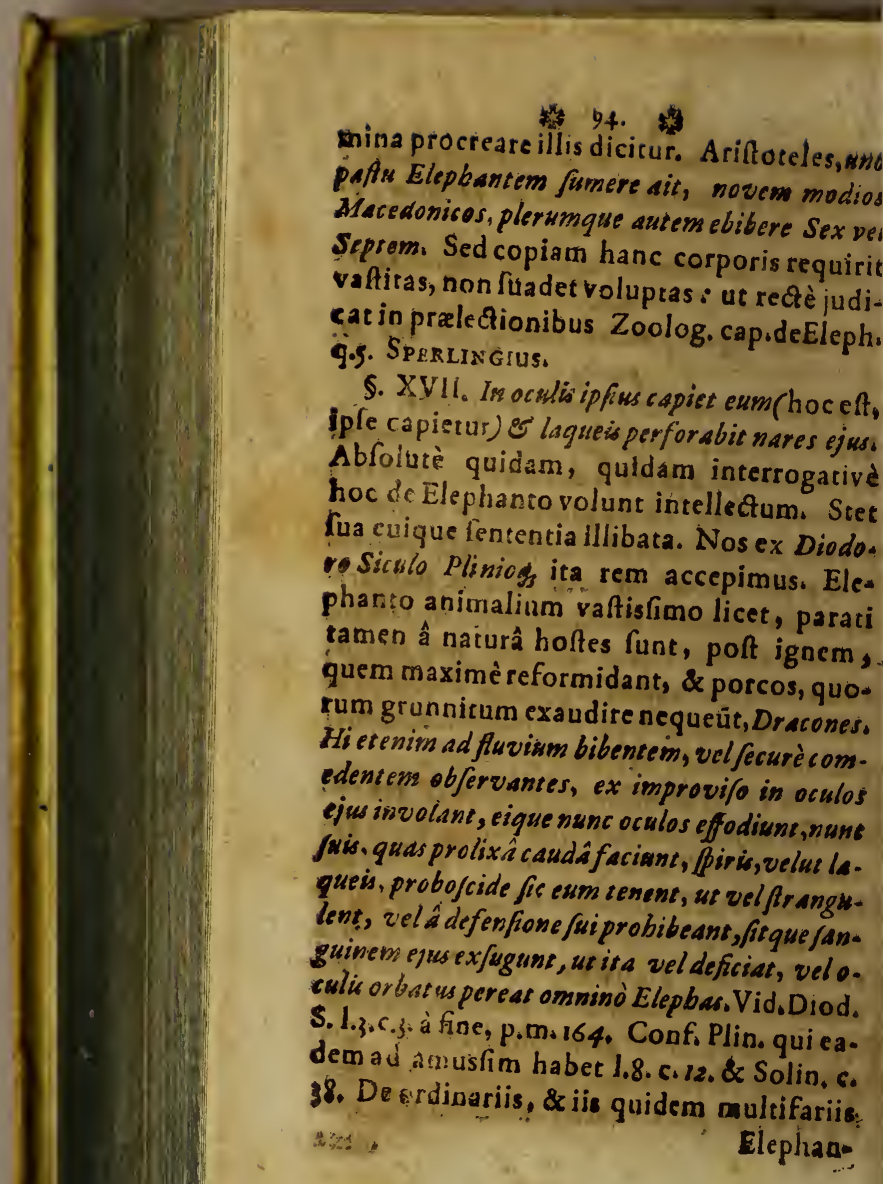




\section{95.}

Elephantorum, ab hominibus capi folitoa rim venationibus, confule poft Aldrovan-

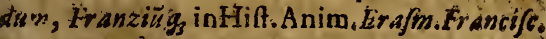

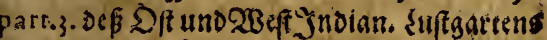
f. $1528 . \&$ reg. Tantum igitur de Elephanto, quantum ad Minoris comprobutionem fue ctat neceffe.

\section{C.AP. $I I$. Des \\ LEVIATHAN. ARGUMENTUM.}

1. Locus de LEVIATTH. adducitur.

Non hîcCacodamon indigatur:nec mon. Atrum aliquod Rabbinicum.

Per LEVIATHAN infinuatur Balzena.

4. Incredibilis valtitas balenze Farrago exemplorum.

- Cofra immanis cujurd. Ceti, Witteberga

8. Captura Balanarum periculofisfima.

7. Continuatur. Indorum capiendi mo dus.

8. Subvertit naves Cetus. Zulus ejus mato rinus.

. Concluditur difcurfus

5. 1.

Igrediendum à valtistino animall terreftri, ad vaftisfimum aquatiles Nome ei $L_{0} \theta_{4}$ , 2 


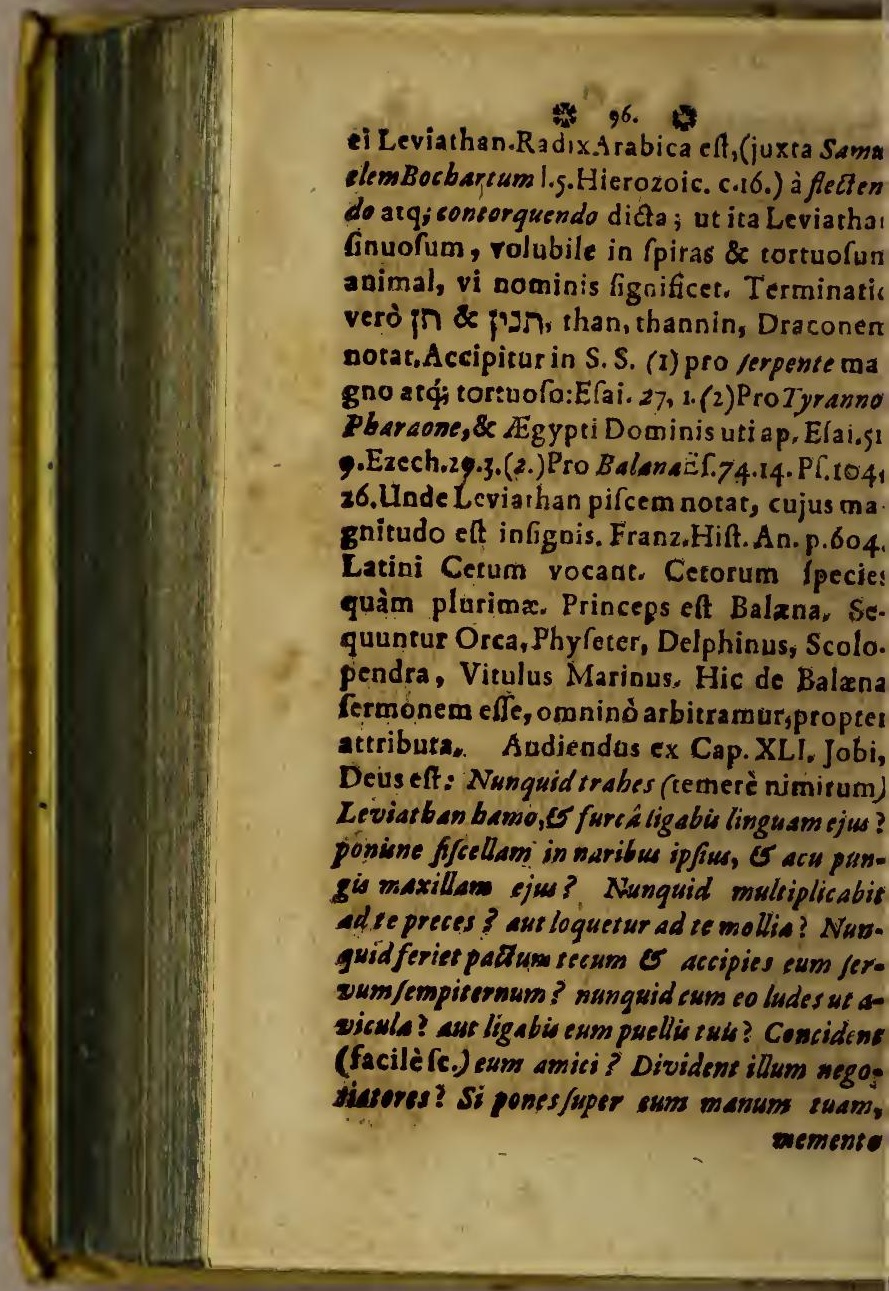




\section{7.}

emento belli, nec ultra addes. Non eff quis. sarris tion ferus, ut cum fufcitet $\mathcal{S} c$.

S. II. Non hîc Tropifias quosdam, qui nil fi $\mathrm{Dxmoné} \mathrm{h.l.propriè} \mathrm{indigitari} \mathrm{puravere.}$ Jmitem, \& R. MenafjebBen.Jfrael, dum I. z. erefurrect. mort.c.19.p.225.per Leviathan, ulumillad, de quo legitur in Bava Batra, uod Deus ifto tempore preparabit illis, qui oimè fanctisfimeque interris vixêre, (quæ ) lu. ai verba funt) infinuarigarrit. Eadem faulatus R. Mo\%. Majmon in More Nebohim part.3.c.23.p.404.perLeviat ban comple. um generale ne, omnium corporalium propri. at u. que diperfe funt in quolibet animali ve. cucce volante, atque ambuläte, denotar.Stulora adhuc in Thalmud part.r.c.16. p. 40.fo. ania, ut qux pro cotidianấLeviathanis efcâ, ifcem crium miltiarium longum, ineptisfimè nxerunt, deprehendas. Conf. Buxterf. in ynag. Jud.i. fupr,cir.

\$. III. Nos his misfis nugamentis, fic raticinamur: Illud proprie bic intelligendum eft er Lêviatían, cui plano frmpliciós fiylo, omnis va de ipfo dicuntur predicata, competunt. Atǵ, oli Ceto predicta cuncta predicat a competunt. Majorem nemo, fi velit etiam, follicitare oterit. Probando minor elt, \& progrediendú rdine. Priùs prefupponendum tanen, de $G$ marinâ 


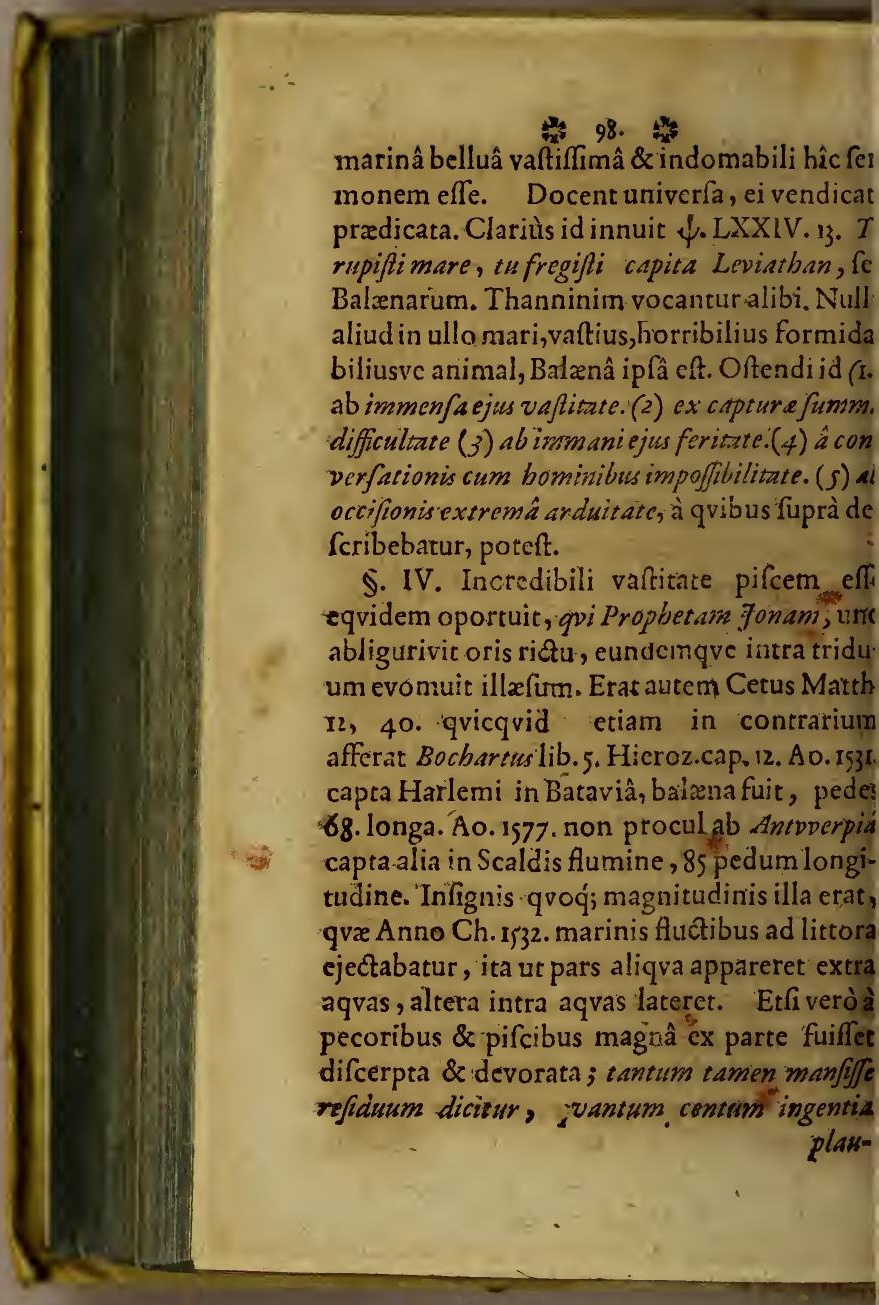


luftra vixpoterant apebere. In longitudine abuit 3o. ulnas. Rictus oris compleatcbatur ex ulnas cum dimidiâ: mandibula 7.eratularum cum dimidiâ : in lateribus habuit 30 oftas, qvarum fingulix longx erant 21 .pedes: ongitudo capitis à principio usq̆; ad riçum ris complectebatur 8 ulnas: lingva 7 ulnarü rat longa. Compendio uti cogimur. Plura irca exemplum hoc reperies Lector, in Epijt? d Polydor. Virgil. que extat apud Franzium art.3. Hift.Anim. c.2. Idem feqvens etiam ha* et: Anno 1545 . in Pomerania Grypbistvaldicaus fuit exigurs gpidam, $\delta$ tamen illius vontrilo reperta efl ingens copia pifcium,nondum aduc concoctorum, $\mathcal{O}$ inter alios, falmo vipus, ule longitudine, ita ut tria dolia, S. conne (pifcim) inde replercntur. Mirabilioris adhuc vaitatis adnotavit balænas, in fuo Itincrario, lieronymus Welfchius Cap. V. de Ital.p. 33Lotich. lib. 3. Commentar.ad Petr. Arbitr.p. 10. quos vide.

5. V. Hæc dum fcribinus, non abs re re ordamur pragrandis illius, in templo adAr$\mathrm{m}$, hîc Wittebergæ, quæ habetur ex Balænâ, ifre. Longa ifta pedum XIV, depofita à Divo xonix Electore, FRIDERICO SAPIENTE, rreâqve parieti alligata catenâ, vifitur. Ad$G_{2}$ jund? 


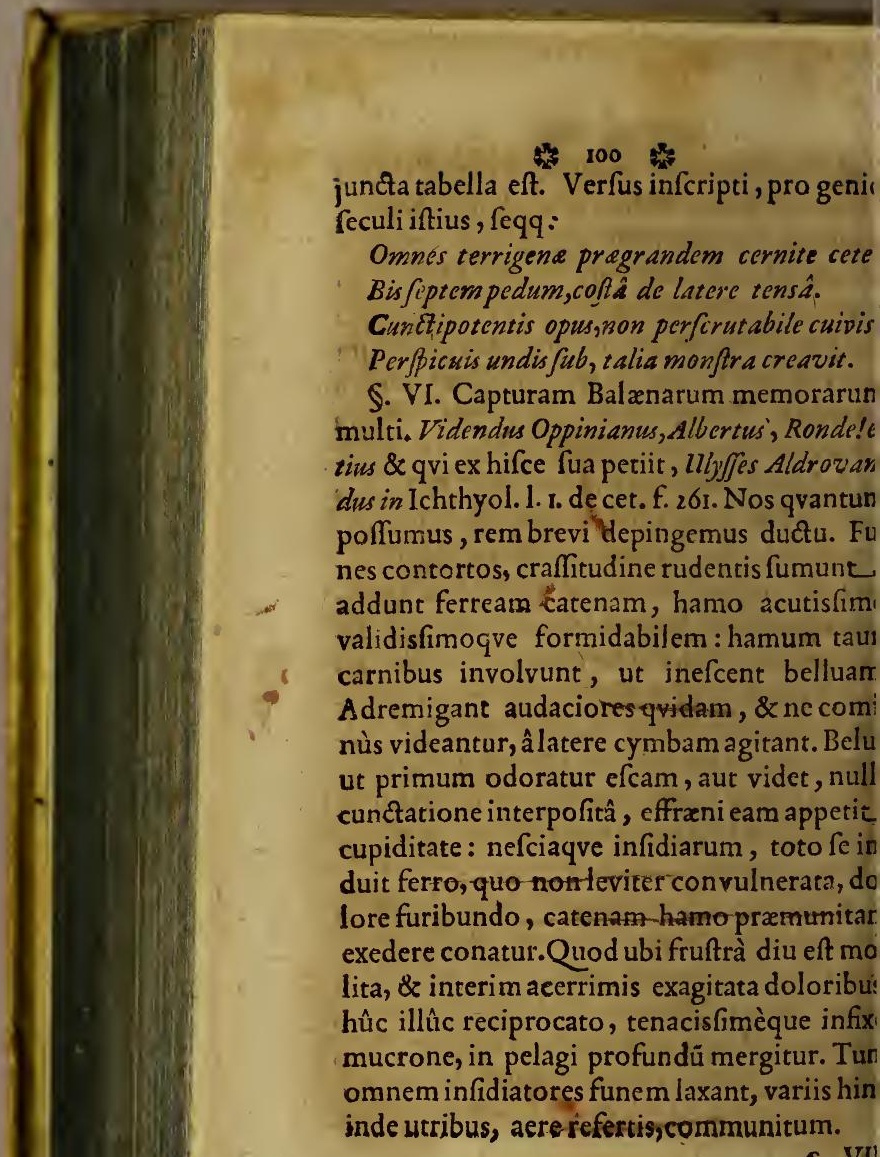

S. VD 


\section{* 10r.}

5. VII. Balæna ad inferiora maris merfa, uiefcit aliquantum; etenim quiefcere cuiturientem, utres non permittunt: aëre Im ad fublimia tnicente. Inftaurat iras bel$1 a$, velutque animalia fibi infefta, utres, ulIcendi anime perfequitur. Fugiunt retrai cum fune utres. Bellua inferiora pro mo. epecit. Hi rurfus fabvolant. Illa cum aibus retracta, horrendum dolet, tantoque evit opere, immanes in fublime jaciendo ucius, we ipfum fubter jurares ftabulari Eoliu. Eacigata diu beftia, \& jam fuis dejecta iribus, vel invita fequitur funem attrahen. es, in proximâ cymbâ illâ, remiges. Tùm gno dato, fuis pifcatores appropinquant avigiis, mutuaque cohortatione, velut in ræfentisfimu armandi pralium,magnis aimis, nec minore tumultu, clamore \& clanore, feram aggrediuntur: illi jaculis, ifti tidentibus bidentibusve, alii falcibus, fecu. ibus, venabulis \& fclopetis ab omnipare circumdare balrnam. Hrc animo impererrito fultinere plagas, \& horrendos fítulá jaculari fluctus. Illi propellere ad littus, liuturnis-vulneribus, non fine vite peicula confodere, obthurare fifulas, novis. imèque penitùs conficere atque inter $\mathrm{fe}$ di. ridere folent Mercatores atque pifcatores focii.

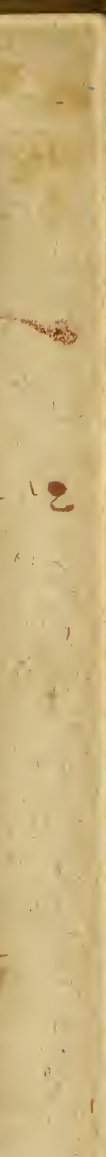




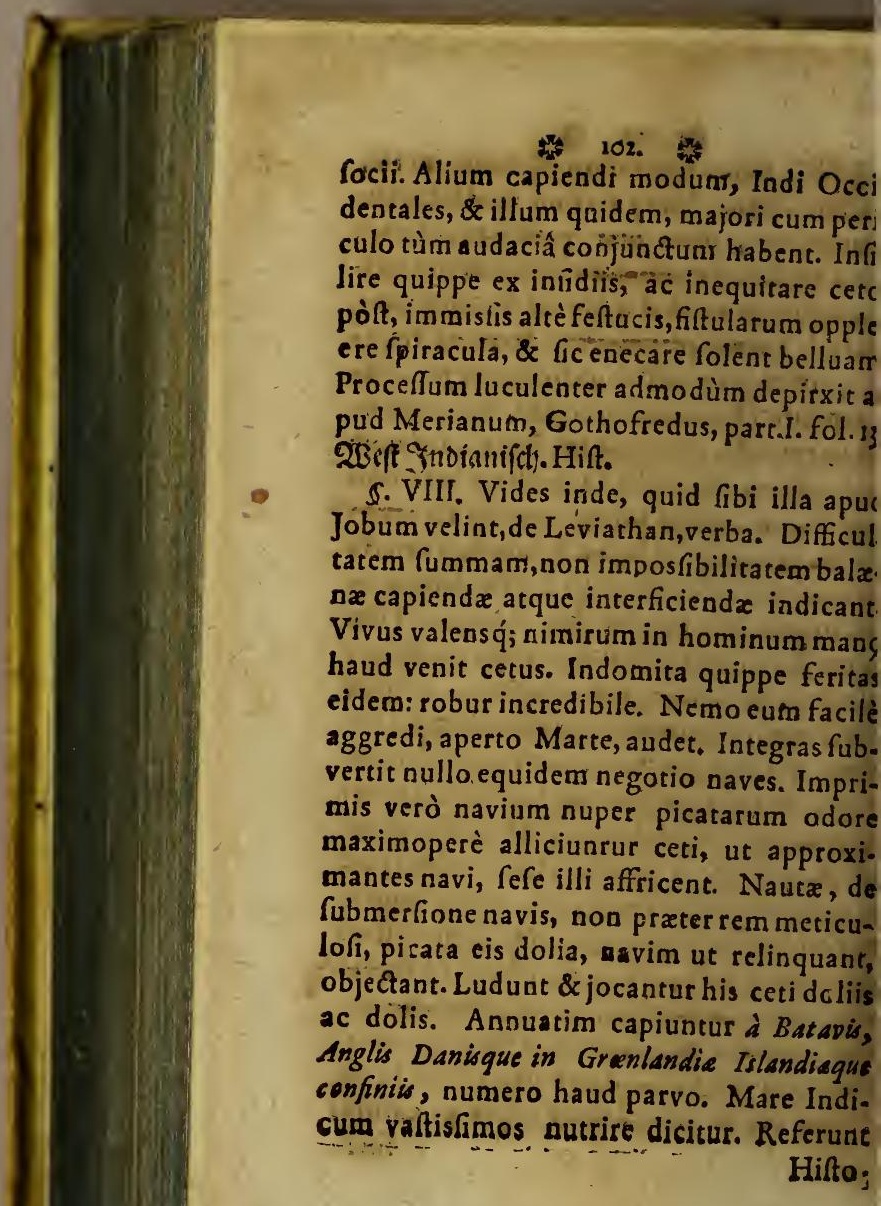


Iiftorici vifas fæpè numerò balænas effe, uaram oculi, ac palpebre fimiles effent randiori militis armati capiti, casfide orato. Et Rondeletius à SPERLiNGIO citaas: vidi, inquit, balænæ mentulam tantam, uæe etiā à procero homine geftata, utrinque, erram contingeret, unde quanta fit, cùm alæax libidine concitatæ ferūtur, conjicee oportet marillla qux A.1618. ad Caletum a. Gallicano tormétus æneis trajęabalæna on fine ltupendo ejulatu fuit, virile memrum cum tefticulis 500. librarum habuiffe icitur à Loticbio cit. aut.loc. Hinc reliquum etiri corpus licer. Exaggerat fuam, inde Iajeftatem, gloriolus Conditor, exemplo lephanti primùm, poftmodò Balænæ. Quis itur, inquit, reffitere meo poteft vultui?

5. IX. Hxc hactenùs de Ceto quoque. 2uem veluti Elephantem, vel ideò prarer lias caufas, non licuit prolixiùs defcribere. c utriusąue tum generationem, tum vivaitatem, (quâ ad CCC. annos ufque, neuter crè deftituirur, ex Zoologorum teftimoniis) ùm alia complura propria adnectere; quciam id duncaxat exincendum nobis fummus, ut per Behemoth, nil nifi Elephanam; per Leviathan verò nihil aliud, nifi etum intelligi oportere, ex Principiis ae -

$$
\mathrm{G}_{4} \text { rationi- }
$$


104. to

rationibus Phyficis demonftraremus. Meli ora docctitem tantum abeft, ut averfemu nos, ut veneremur potit̀s. Manifeßta Dei o pera funt, \& magnifacienda femper.Si tant: in irrationali creatura \& poteftas \& maje ftas; quanta demum in ip fo fuerit Creatore Adumbravir fe in omnibus Numen, nec ul libi reliquit inteftatum. Noftrum eft mira ni, rimari, obfequi \& adorare.

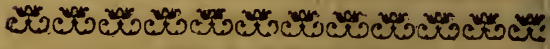
DISPUTATIO $\boldsymbol{V}_{\text {: }}$

$$
\text { De }
$$

\section{DRA C ONE.}

\section{RESPONDE:TE}

ANDREa CHRISTOPHoRo Malletp Wittebergenfi Saxone..

\section{PR AFATIUNCUILA.}

$\mathbf{R}$ Elatum nuper adnos, Romiá, d.XVI. OẼa

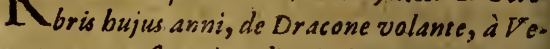
natore, non fine vite difcrimine occifo, bifforis cum documentumeft. Quafitum inter erudicos, de relatione ifthâc, ut que fabule, quàm biforica vicinior videretur, fuit. Res a multi negat a, ab aliis probata, a nonnullis reliez a is fulpenso. Novimus, quid alii, quorum me- 


\section{0\%. \%}

moris in pace, audioritas in falvomaneat, ante nos, bâc de re, ac fi fabulofa effet, judicarint.Dies diem docet. Agende illis quoque gratix, qui tantum, quantum licuit, indagavêre. Intuebimur naturam : rimabimur peritatem. Deus adjutornofter efto!

\section{$C A P U T \quad I$. \\ DE DRACONUM QVIDDITATE ARGLMMENTUM.}

\section{Etymon Draconis varium.}

2. Homonymia extricatur.

3. Cantinuatur eadem.

4. Adducitur Synonymia.

5. Definitur Draco. Ejus, cum bomine, antipathia.

6. Examinantur loca Eliami.

7. Differcntia adducitur. Draconis magnitudo.

8. Reprefentantur exempla.

9. Horribilis Draconum validitas.

10. Anitipatbia cum Elepbanto. Farraga exers plorum.

at. Patria Draconis que?

22. Summus, inter reliquos ferpentes, RexDraco: 3. Venenatus ef: ${ }^{\prime}$ fed non babet mamrias Draco.

5: I. Nomen ut pasfím inculcant Sapien: tes, primitùs enucleandum eft. Draconem G 9

ximet 


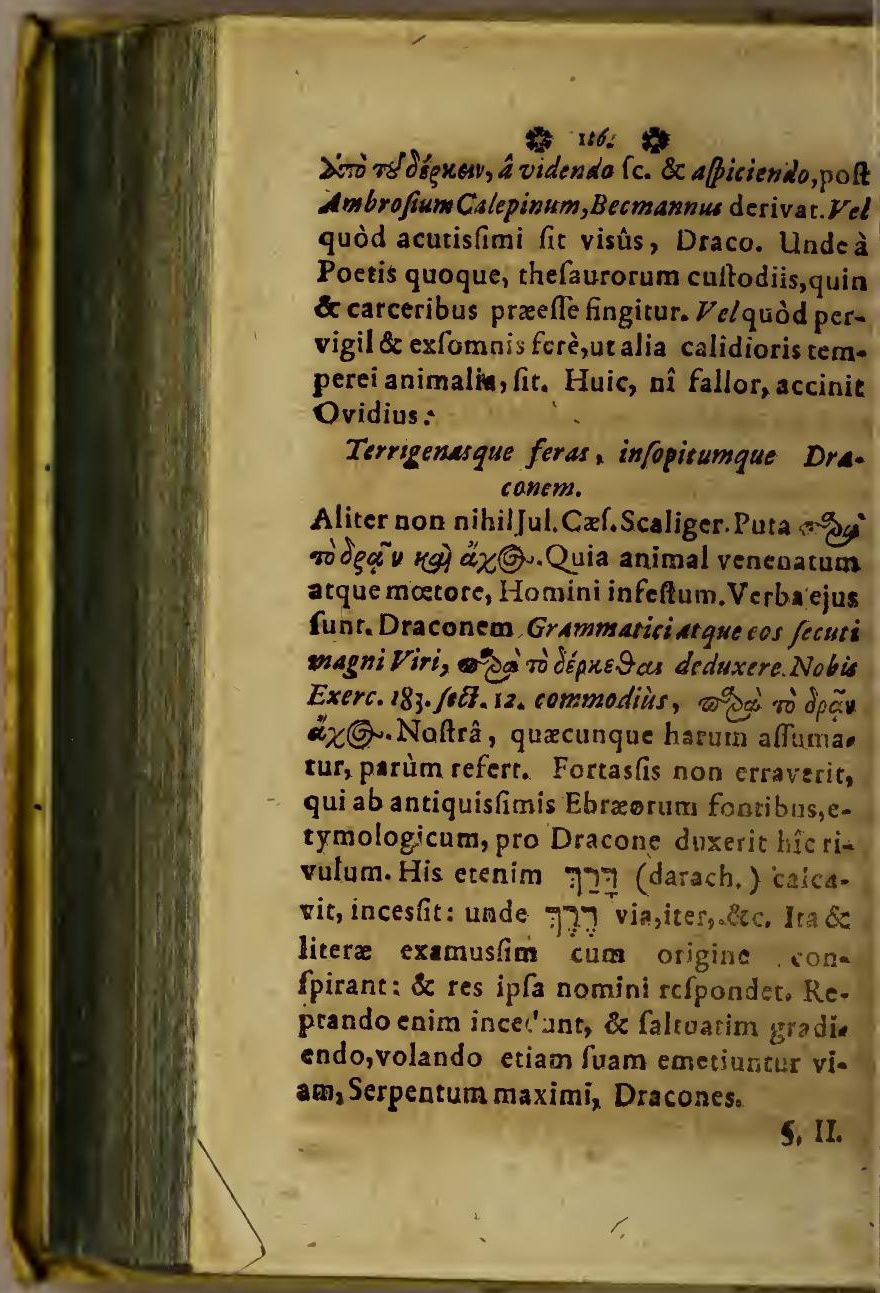




\section{10\%.}

5. II. Voxipfa (ut ad Hamonymiam abeamus) \& bominibus, \& hrut is \& Plantis, fed \& cuidam monti, affigna ri fuevit. Draco vetufisfrmo ille rigorofisfimusque Atbenienfun Legislator, qui non atramento, fed fanguirie, fuas (ut cum Demade, apud Aul. Gellium, lib.18.c.Iz.N.A. \& cum Sralig. Exerc. 112. loquamur, fcripfit leges, à Solone tamen ob nimiam feveritatem abrogatas, latere neninem eruditorum poteft. Fuit \& Dracus quidam Acbearums Dux, ă L. Mumio Romanorum fuperatus duce; Livio nos inform mante, in Epitom. Lib.52. Omniam celeberrimus in toto Orbe, ut quem magno circumnavigavit, fuperiori feculo, ad exitum vergente, conatu, DRACUS, Francifaus ile le, Plimoutbo Britannus, Eques auratus, navali gloria nemini tùn fecundus : plurimarumque gentium leges, fudia, mores, ri = tús aliaque a dmirabilia felicisfimè expert\%\% Inter befiaram lhalanges, Draconis nomi$n e$, marinus quidam venire pifcis folet. An. ab araneo marino, cujus mentionem Plini lib. IX. c.48. facit, a dhue differat?' hariolare $\mathrm{ri}_{2}$ nifi,ipfium confuluerimus. Scaligerum haud posfumy. Werum enimad diftinctionem falfe, fine dubio, eundemScaliger Exerc. 226. (ed7. l3. falutat. Audiamus ipfum.

\$. III. 


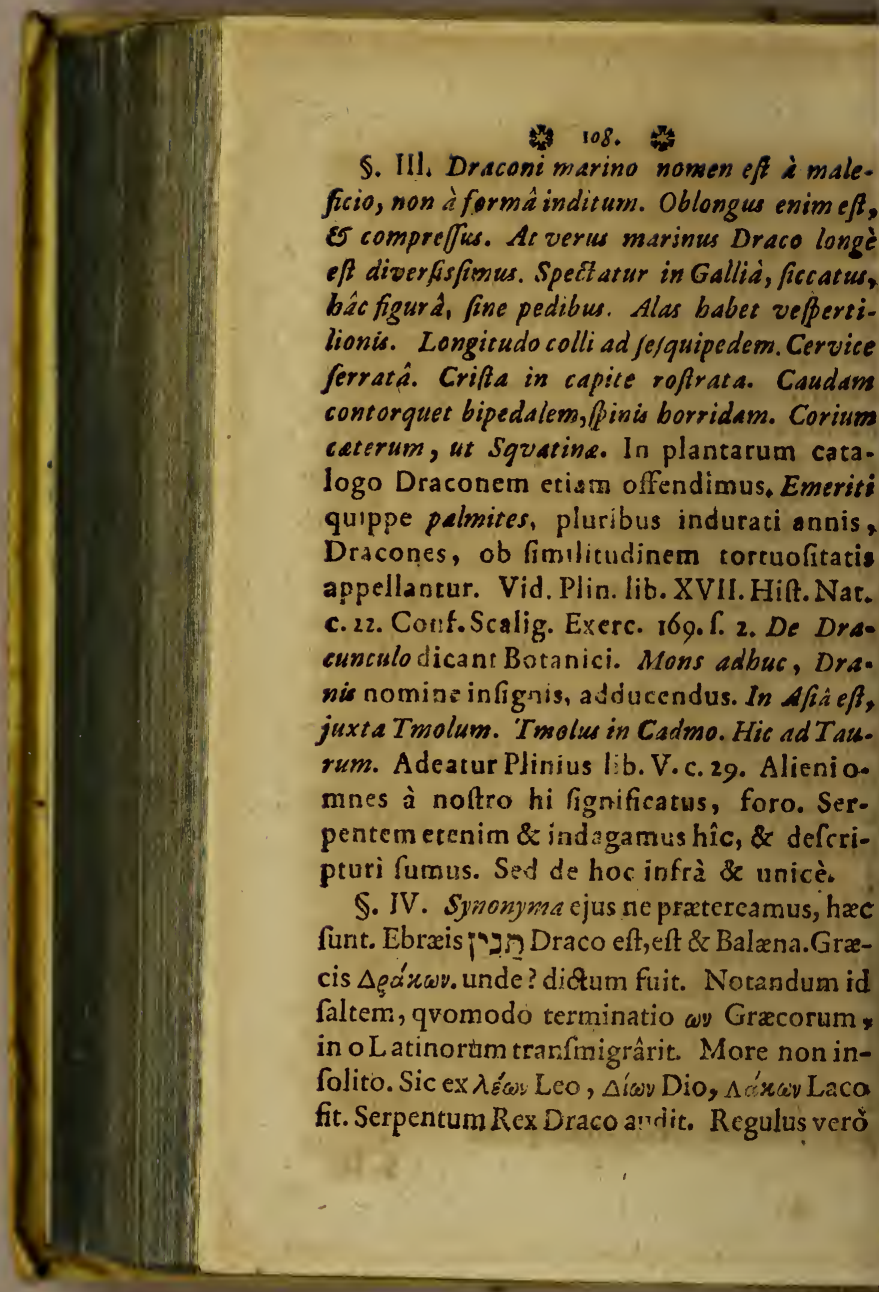




\section{9.}

inter minora reptilium genera, Bafilifcus. Alatum appellari ferpentem ipfum, nec novi quid, nec miri. Dabitur in confecuturis ratio. Annofus ab aliis cognominatur ferpens $\sigma$ pregrandis. Interroganti Franziuspart. 4.c.5. bift. anim. refpond et: Dracones nibil funt aliud,nifi ferpentes valde annofi, $E$ adinodum aucti in qpo. cung genere $\mathbb{E}$ c. Hinc extitit verbum vulgatum; Serpés nifi ferpentem devoraverit, non fit Dra: co.GallisDragon, Dracone Italis: Noftris, rarâ vocum convenientiâ, oer Srache dicitur.

§. V. Nunc res aggrédienda ipfa. Ef nimirum Draco, Serpens maximus, terribilis validitatis, defertorum amans, ferpentum Rex, caude robore imprimisvalens. Qvid mirum, fi accidentium farrago, forma ubi latet, ad diftinctiones rerum affumatur? Gentes animalis hujus, ferpens. Reptile enim calidum, callidum, venenofum \& homini infeftum, Draco qqoqve Hxc primailla, \& hactenus, hominem inter \& ferpentem naturalem etiam, continuata lis inimicitiaqve eft. Et licet ex Eliano aliisque exempla, cujusdam inter Hominem \& Draconem ou $\mu \pi a$ a éas citet $B$. Franzius; id tamen ad? ordinariam non eft trahendum viam. Non magis ideò amicus homini Draco, fi qvando ipfi ab auxilio contra occifores fuit, qvàm Leo, aquila, lupus; animalia rapacitate \& truculentiâ, nưl. 


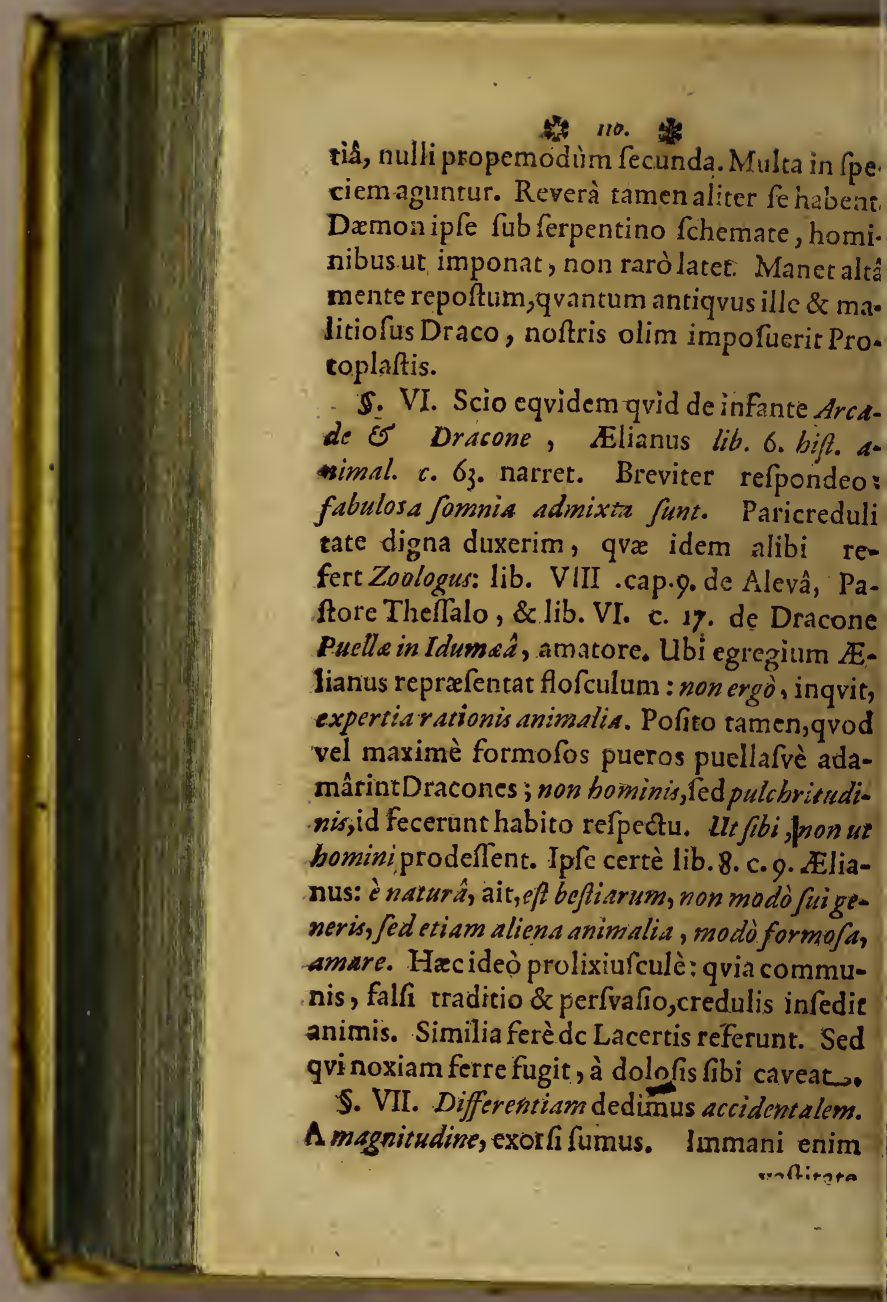


'aftitate gaudet. Nec aliud, molis intuitu, iner ferpenetes, Draco, quàm qvod inter qvadrupedia, Elepbas. Alexander ille, qpem Magni cognoment o, eventuum grandia infgnivêre, civss expetitionem in Indiaim adverfus Porum molireur, mire vafitatis ferpentes, ad XVI. videlice ubitorum longitudinem (Diodor. Sicul.) lib. 17 bibl. bift. n. 90. p. m. 883.offendit. Egypti Rex Ptolemxus, per Venatorum Eqvitumqve agmina, horribilis immanitatis Jaconem, triginta cubitorum longum, non ine \& vitæ difcrimine \& fuorum clade, opugnavit, tandemqve aftu fuperatum, interecit. Prolixè hanc, fuprà citatus Diod. Sicuus 1.3.n.37.p.162. \& feqq. Edit. Rhodomann. liduxit hiftoriam, Qvem fi voles, confer cum ib.3.n. 10.p.143. In India, in tantam adolecunt magnitudinem, Dracones, ut $\delta$ Cervos is Tauros deglutiant. notanta Plinio lib. VIII. uift.nat.c.I4 Paria his vide in Itiner.Ind.Manlesloviano 1.3. P.232. de ingenti voraciflimoğí ferpente qvodam Indico.

5. VIII. Idem Plinius ibidem refert, qvonodo tempore belli Punici ( fecundifcilicet, vermadmodum ex Liv.lib. 30. n. 25. colligere po es) ad flumen Bagradam, (nune Megerada di itur, notante Dalechampio) Atticus Regulus mperator cum univerfo exercitu egreflus, Draconem120. pedum longitudine, oppidi ad inftar 


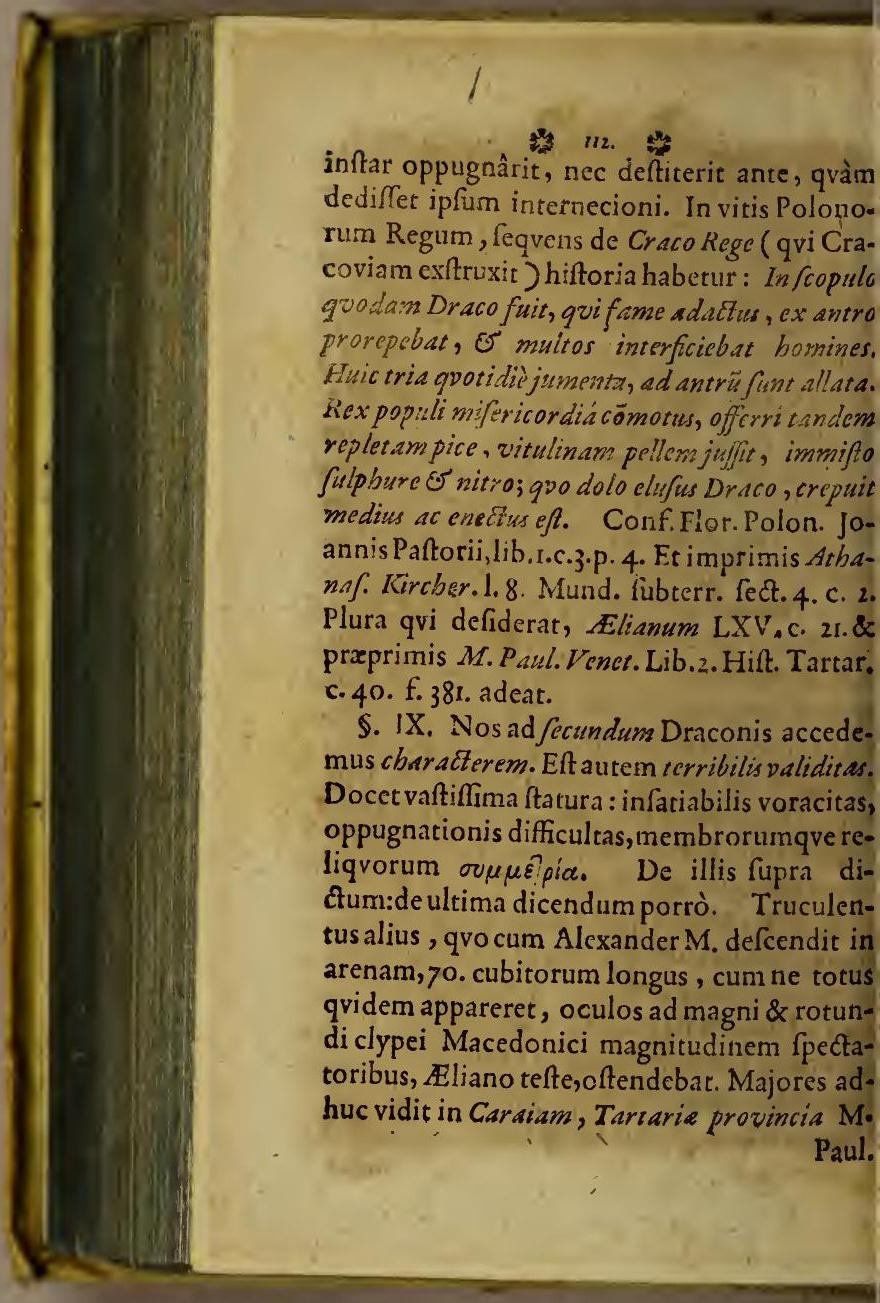




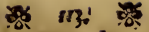

aul. Venetus, prredicto loco. Qvid mirum? am ipfis conflictantur Elephantis, fpirarumre nexu,crura illorum tàm implicant ardiffi$\grave{e}$, ut movere fe nequeant Barri. Arrecto oqque fub probofcidem collo, Elephanti olis obvertunt caput, igneifqve visûs radiîs, nqvam fulgetris (Diodori Siculi hrec funt) cæcatos, ad terram profligant, profligatos Janiant.

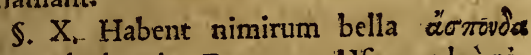
im Elephantis, Dracones. Ulfque, adeò niI tam vaftum, fuperbum, potens, robufum, yod fuum five parem, five inferiorem, quanoquè non experiatur adverfarium, miraili naturze antipathiâ. SicLeoni disfidium am fcorpione eft. Bafilifeo ferpentum veenatisfimo, muftelarum virus, exitio fupre10 cedit .Crocodilus infeftú habetichnev: oné. Ichnevmon củ alpidè, noverçalia geris dia. fcorpjoné ftellio hoftilicer impugnat." apitale odium muribus \& catis. Rara inter eles canesque amicitia. Chamaleonti cum erpentibus, cervis cum acciperere non conenit. Milvum pullus refugit. Ovis luporum aniena : lepus omnium prædæ natus. Cæteum notabis hîc, nobis de Draconum manitudine lo quentibus, non eam a aimo fen. entiam federe, quafi omnes atque finguli, ad 


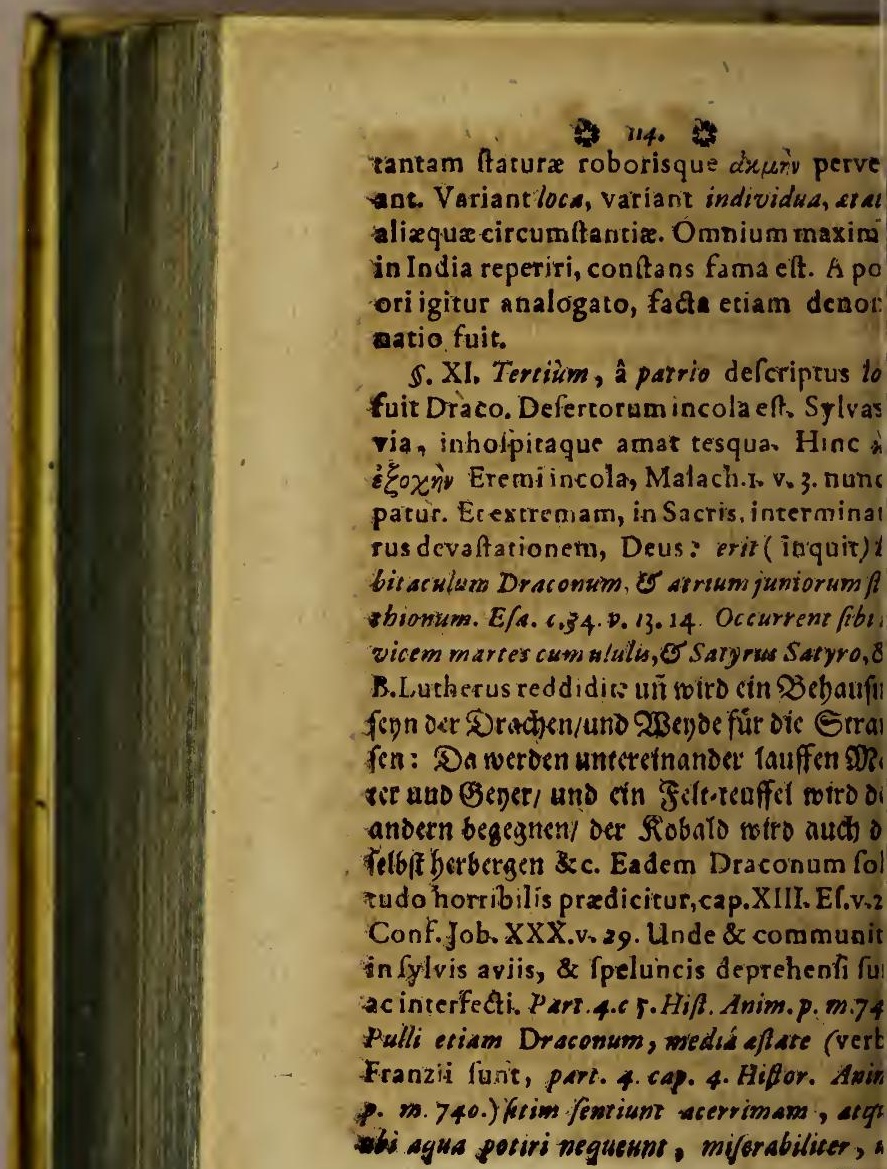

StrA 


\section{खै}

trat bionä pulli lamentantur. In Lybia, LEgytoyArabiâ, Æthiopta, Indià tamen, h.e caliioribus illis regionibus, cómuniter ftabuari beftia fapè dicta foler. Joh. Cyfatus, Heletus lib. de quatuor Helvet fylv.civitat. Criit : nullibi volantium maximè Draconum opiam majorem, quàm in Helyetia comaruiffe.

S. XII. UIteriùs ầ jure (ut ita loquamur) onsinii,quod in reliquos ferpentes habet, de. ribebatur Draco. Inde cum primatum, cia controverfiam obtineat, regio eum nowine criptores affecerunt. Quanquàm \& Bafliffus, ter minorum generum ferpentes Regulus. laximus, fortisfimus, \& formidabilismus ceterorum,Draco. Regia hæc funt aximata. Novisfimì, $\hat{a}$ xaturali armaturâ fû́, deinxirnus Draconem. Caudâ etenim cùm reftet, eâ \&utitur feliciter, \& molis immaisfimæ profternit Elephantos. Sic \& ip?e Eleas probofcide, Leo unguibus, equvs calce, os cornibus, fulmineo dente aper, lupus peore, horrendùm praliantur. Objecta femel mplexa cauda nullum eripere robur valet. nguill $x$ acmediocres faltem ferpentes, fi nfringere brachium humanum poffunt, rid de Draconibus judicandum effe patarimus?

$$
H=\text { S.XIIL }
$$




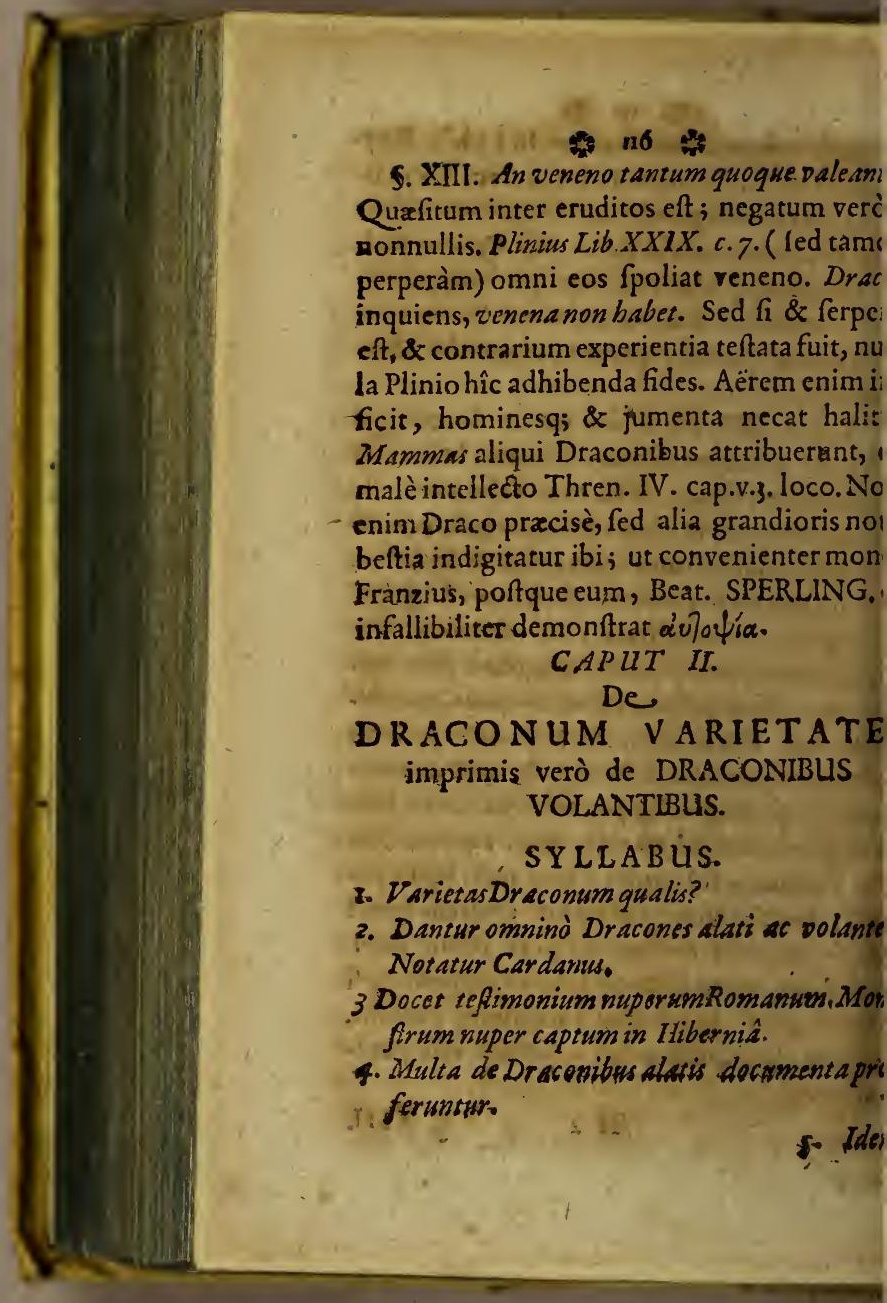




\section{7}

Idem comprobant Parcus, Scaliger, Nierembergius.

Stat pro nobis quoque, poft Franzium, D. T. Bartbolinus, atóg, Athanaf. Kircher. Utrùm ideò ad aves ßectet? Negatur. Dan: tur rationes. Vefpertilio non eft avis. Dantur Volatiles quoǵs pifces,quin \& tefudines. Addusuntur teftimonia.

- Concluditur. Difcurfus.

§. I. Sive accidentalis folummodò, five jecifica \& effentialis Dra conum fit varietas, ec affirmare, nec inficiąri volumg, Neq́; enim ropter vel locorum, vel magnitudinis ipfitus, el coloris etiam varietatem, fpecifica confinenda illicò eft differentia: Canes Anglicani Germani, utcunque \& magnitudine à fe inicem \& loco ; fpecie tamen haudquaquam ifferunt. Dubium movere tantùm poterat, artium quarundam aliena longè configuraio. Quidam enim atis pedibufque jam duous, jam quatuor inftructi : quidam non item. . Franzius ait: quidam funt ruffi, alii nigri, ilii cinerei, alii longi quinque cubitos, alii $X$. aii 39, alii 40. Johann. Eufeb. Nierembergius. ubet, inquit, in alikm or bern redire $E$ intermicere; que Pbilippus Pigafeta defcribit in defcritione Congi. Reperitur ibi amimal bipess,ovis nagnitudine, formâ verò Draconis. Alatum eft, 


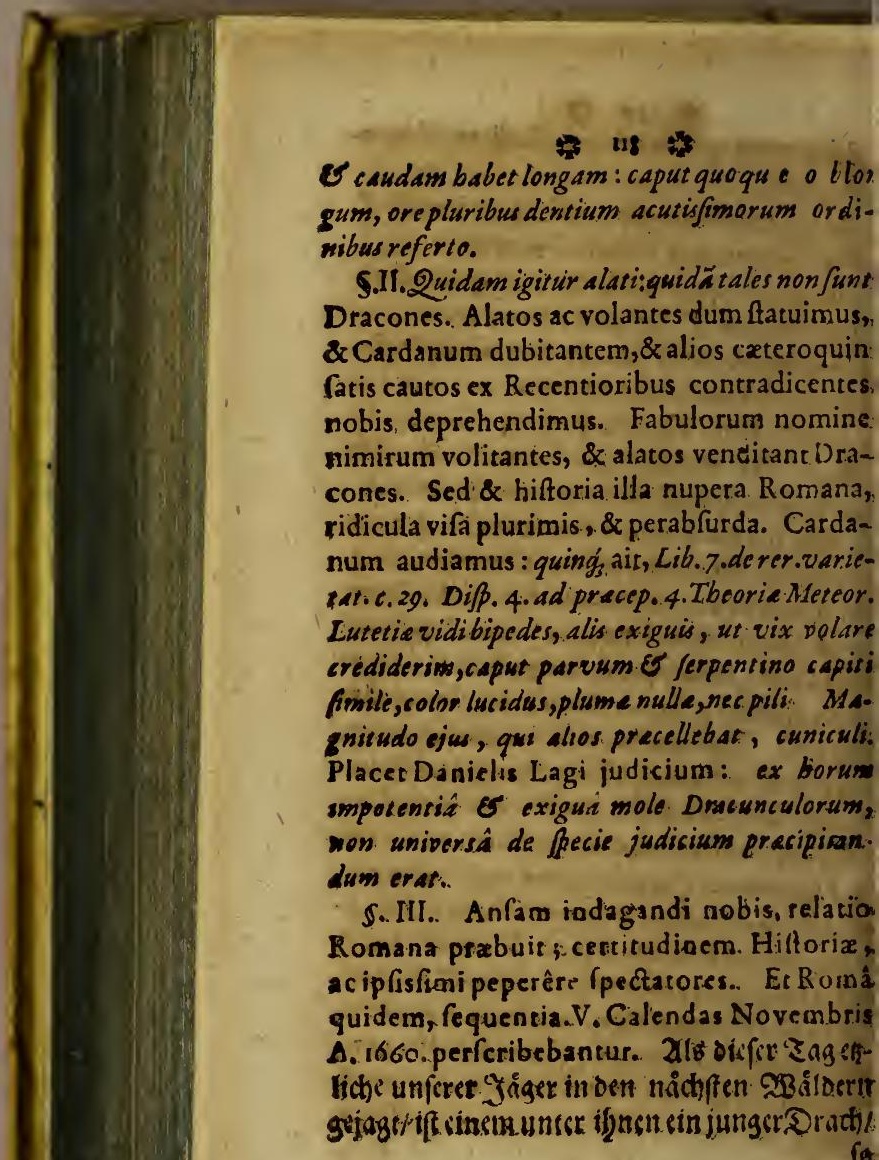




\section{9.}

geos als cin gro|fr Şuno begegnet 1 - octret cinen Fligel gerch affen/ ontauf oer Drach f ign zugetaulfer/er aber entfioben/ unto (5) cenfet betommen / noth sinen $\sigma$ dus su. un ba er ign dunn in oen Nadsen gefthoffen: rnad folych umbgebractst. Venatos tamen mun reverfus, eàdem nocte (veaenifine bio. affiatu) morturs, roto corpore viridis paruit. Confirmat hiftoriam Kircherusl: Mundi fubcerrafect. 4. c. z. qui Draconis us caput in gruféo fuo aftervari memorat: lic five incola, five advena Iraliz fuerit raco? haud follicitabimur. Quanquam ex fricá A Gave advolaffe, per tot milliarium atia, ipfum, ne crediderim, multò minus ffirmarim. Solec enim in noftris quoque uropæorum locis, aliquid ali interdum ponitri Quemadmodum codem anno. - fext Id tús Novembris, in Hiberniâ(ju Šleoe cribrios tin. Elonifichen $2 B$ alo/ uci HagấConims relatum ad nos nuperfuil) (ytuefrim vidam nudves., E. toto corpore hirfutus mas, ruem Sar yon fiom ne. Roer efaluiarunt, vena: ione sinctius est \& inversept us.

\$. LY. If demonftrandum unicè: dari zolatilis Dracones, alatosq̣́; Serpentes. Ala. was inquam feu pinnatos, tametfi non penaros. Lequantur Hiftarici. Apud Matedax Merian, in Hiftor Antipod part i. H 4 E.2ula. 


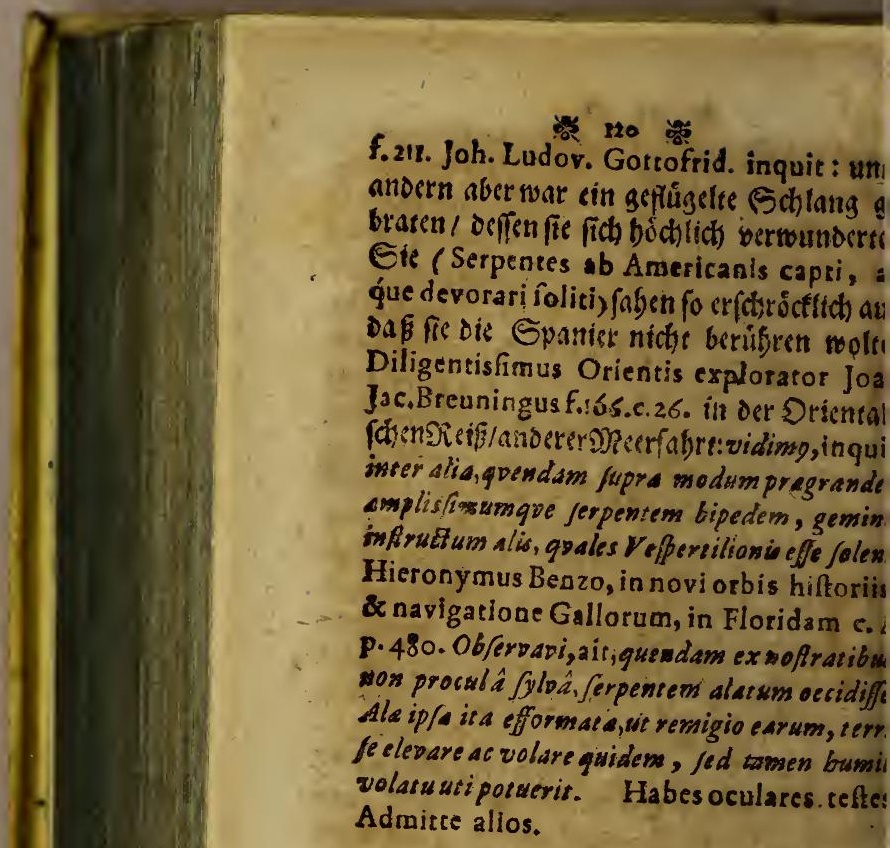

5. V. Ambrofius Paraus, Galliaram Regi guondem primarius \&f Parifenf.Chirurgu 1.1 operum Chirurg. fol. st. ex Plinio refert : it Ethiopiâ longitudinis X. cubitorum, repe. riri Dracones, at in Indiâ centipedales effe, $\int_{w} b$. limeǵs ade ò volare, ue mediis d nubibus, in pre. dam perant abss, Veftigium rei in Scaligero 


\section{然 21}

quoque, exercit, 183. feet. 5. deprehendimus. Vèrba funt: Mows, qui Narfinge regnume dividit âMalabaris, mulas alit feras: inter quas alatos angues, arboribus infidentes. 2uos.ajunt, folo afflatu, vel etiam obtutu, ( hoc.jam byperbólicum) eos, gpi propius accedunt, interficere. Idem nobifcum fentit, caturalium fcientifimus $\xi_{0} b$. Eu/eb. Nierembergius lib. 12. Hiftor. Nat. 5. 36. fol, 282.

S. VI. Sed nee alienus nolter olim Franzius erat, part. 4.Hift. Anim, c. 5. p. m. 74 I. Ait enim: veroram Draconum duc /nst Precio. 2vidam qpibusdam membrane is pinnis fane als ti, quibus fune ale non ex pennis, fed nncm. Lranis, in dor/o, inftar pinsuardm ofc. Tbomas qvoó,i Bartbolinous, magnus magni Parentis flius, in 1 ract. Patavii de unicornu, edito $c$. 7.p.50.vivis, quod a unt, coloribus, \&cicone fimul, ex Tobic Aldini mu/eo, volatilem expreffit Draconem : cujus fceleton Ladopicu XIII. Galliarsy Rex", Cardinali Erancifco Bar. berino, aisnis fuperioribus donaverat. Inde fine dubio, meteorum iftud, quod Draconem volantem; fecundum analogiam, vocita mus, denominationem fuam traxit.Alia \& planè memorabilia de alatis Draconibus exempla Dh. Kircherus in Mundo fubt. Lanted cit.prodidit.

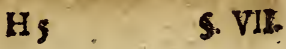




\section{2.}

5. VII. Nec quis mihi hic objiciat: $Q$ vo. Sat, dois eft. Infufficiens quippe propotitio fuerit. Ecquid de Vefpertilione fentiemus? Volatenim. Nectamen evis eft utcungुg id admittat Franzius Hif, anim part. 2.6.20.p. m. s7o. Accipe, fi voles, argumenra: Non enim animal oviparum, fed viviparum. At aves. ová pariunt. Non pennis, fed pinnis poritis, acpilis gaudet. Quin \& mammas habet, lac, \& pulhsidem prabet. Sed nec dentibus. carct. Adde afininas quoque aures, \& acu* minatos dentes. Mintrat etiam Vefpertilio, uti mures alli, Nego igizur illorum vincere fententiam, qui inter aves, vefpersilionem, locant. Adhxc, pifces volantesillos, avium ordini, quod ablurdiffrmum tamen eft , annumerare ob id etiam cogemur.

\$. VIII, Volatiles nimirum pifces dari, omni caret dubitatione, De Staligero, Ex, erc.223 feet. 4. Cardanum caltigante: Volas: sium pifcium cadavera ì te vifalcribis. At: vipi nobir conßpecti jumt Éc.non dican. In mari Veneto, inter Venetias \& Ravennam, duobus, fuprà Qviozam, milliaribus, Anno. Chrifti igso. captus oft pifcis volans, tefte Imbrofio Parao, lib. 24. oper Chirurg. fol. 736. Andreas Tbevenus in Cofmographiâ.fcribit, Gai, dum novum navigando obiiffet orbem , 


\section{器 123}

en, infinitos pifices volantes, fylveftribus: ncolis dictos Bulambacb:, qui ab a quis fublines, quinquaginta pallus volando perre . cunt, fxpisfimeque ad vela, malumque imngenies, efca nautarum evaferunt, appa. iffe. Idem à Jobanne Lerio confirmatum gimus in Hzforia Brafilsanis. Normannis. ace Nicolao. Durentio Villagngno, EguisaMe. enfi, inaumeruns, pilcium volant ium, deehenderune numerum. Vide prolixè hanc: rem, Hiftor. Antip. Johann.' L ùdovic. octofred, apud Matth. Merian fol 318.0et: Beff Ynotanifa. Siftor. Conf: \&el Exa/sm.

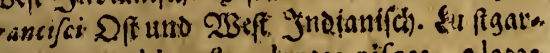
It part.2. ubi polt volantes pifces, alaras iam teftudines in Brafilia, frequenter me m orat p.119.8. \& volâtia iftiusmodi animalsar Atacur a pud Clinenfes fácuiliaria effe, cums lora: Sinenfini Neubof. in defcr. Regni Sin. . 380 .

5. IX. Hos, qvis quasè avium nomine, ,ob, olatum falutaverit pifces? Sola videlicet vom axûs prxéentia, uti ron actutum arguit avem:; a nec abfentia cjusdem, avem effe negat truthiocamelus tametri nec pennis nec alis. cftitutus fit, volare tamen nequit. Avis effer nterim non definit. Hấc ergo ratione, uteunque certo genere volatus, qvidam gaudeane

Draco- 


\section{\% $124 \%$}

Dracones, avium nondum meruére nomen.Sic nec ex natatione exfculpendus illicò pifcis eft.

1. Nam, \& homini \& cani, \& mergulo \& ranx, \& pumici \& pomo, natandi competit facultas. Manent etiañ infectá, vermes, erucæ , cimices \& fic porrò, licet vel maximè qroque repant. Non ex communibus, fed propriis, non aliquibus, fed omnibus, fubjectum judicandum eft, affectionibús. Et tantum de Draconibus.

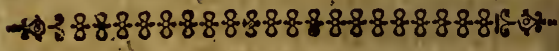

$$
\text { DISPUTATIO VI. }
$$

De

A R A NE A,

Imprimis verò

De

\section{TARANTULIS:}

Refpondente

ANDREA FLACHSIO,

Giefshübelenfi Mifnico.

\section{PREFAMEN.}

Sllbilitatam opifex, Aranea. Fecit folertiffi-

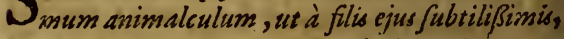
fubtilitatis fluxerit origo. Subtilis Scaliger Exerc.I. Sect.r.de fubtilitate: à filis, ingvit, tenuioribus, originem traxiffe videtur: quain tela benc̀ 


\section{5}

benè textâ, oculorum aciem penè fallunt, unde fignificationis proportio ad alia qvoque fumta fuit. Geometras fuspicimen: : miramur Funambulos; textorer \& textrices colimus. Benè ornnia bec babent. Sed Araneam, ob qpotidjanum $\int u i$, E nemini non obvium conpectum, néc fufpicimus, néc rejpicimus. Ita omnia, admirindis licet inftruct a dotibus, communia fi fint, lefcunt protinus. Erudicorum quoqpe quanto major frequentia, tantò vilius aftimium. Rapiuit jam pridem Salomonem, in adminationem fui. ac indaginern Araneus: geometra, funambinlus, textor. Natus, non factus. Sapiens, fine doctore. Aftutus, fine ductore. Absqpe magiftro, folers. Rimande be fubtilitates funt, Dro laborem for-: cunante.

\section{CAPILTI. \\ DC \\ A R A N A \\ Definitipè Spectatâ.}

\section{ARGUMENTUM.}

1. Aranei laudes varii decantaritye asktorts:

2. Etymon ar anei quale?

3. Eqvivocatio enodatur.

4. Continwatur eidems. s. Synonymik.

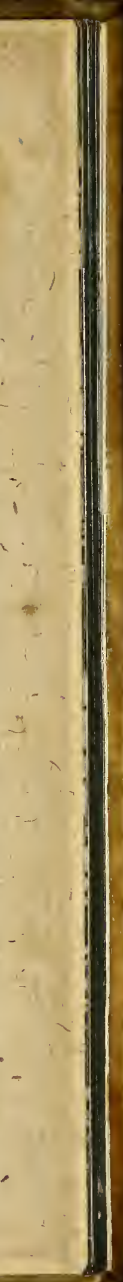




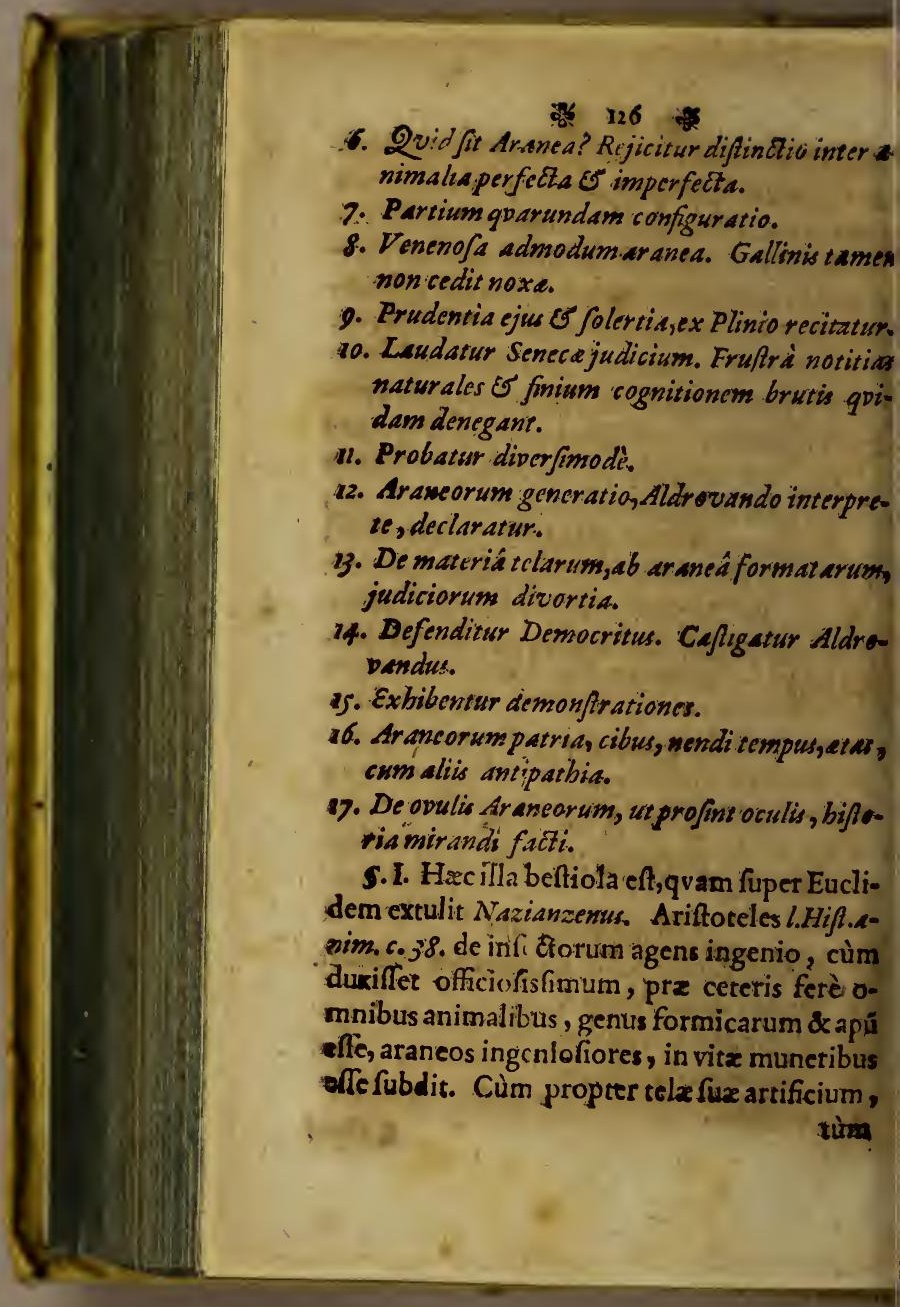




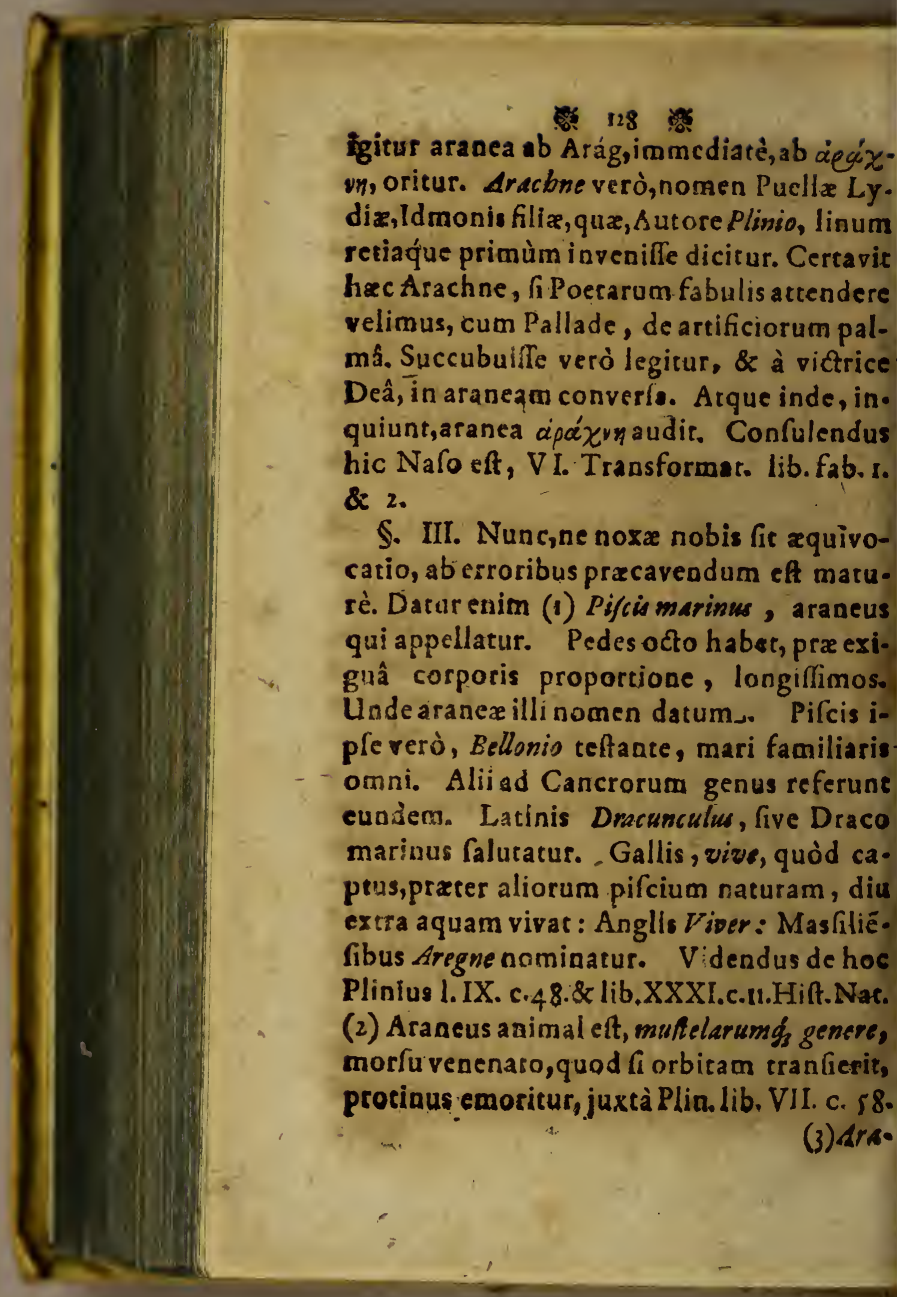




\section{9.}

3) Ar anea,pappus, feu pociùs lanugo eft, qua eperitur in Ialicibus. Plinius I. XXIV. c.9. I. N. inquit : Jalicis fructus, ante maturizaem, in araneam abit.

5. IV. Sed \& (4.) pars Afirolabii que. am, aranea olim vocabatur. Calius numium agens de Gnomone \& Aftrolabii partius 1.12.c.9. Tertia pars, ait, in'ter alia, Dioerice nominatur, vagina contires tympana, in wibus equinodtialis tropicigye defcribuntur: ùm fupra tympanum, que vocatur Amanea, degnatur, in qua Zodiacus Es. Qvin (5) etiam eculiare vitism oliparumgve malumest, aaneus. Erucarum quoddam vel vermiculoum genus efle, colligo exScaligero in Theohraft. 3. de caufis plant. c. 20. fol. m. 2r4* di \& Plin. lib. XVII. H. N. c. 25. Nobis aud licet effe pro!ixioribus.Adde (6) quòd ræter animal, ceucaufam, fapenumerò tesm, feu effectum connotet aranea. Neq; (7) nfolens fermo eft, quo aranearum ticulo, neteoron illud (fila B. Marie vocant) quod ernâ atque autumnali tempettate, ordinaiè circumvolitat in aëre, confalutatur. De Iracbre feu Aranea, proprio puella cujus. lam nomine, cùm fuprà dictum fuerit; non ft ut exiftamus operofiores. Neuter enim ignificatum horumce, ad palatum noltrum; I

fed 


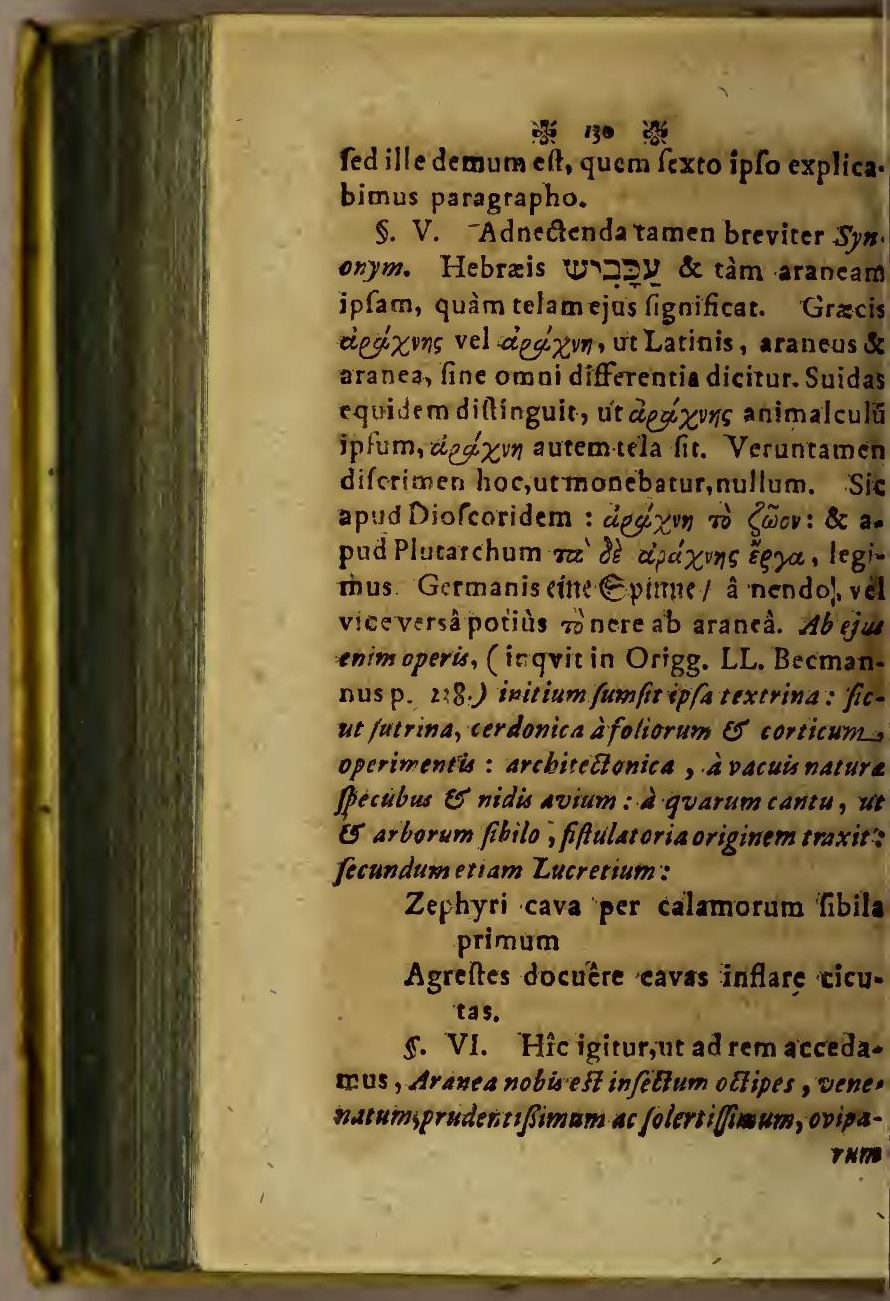




\section{然}

ram, telarum, quas ex ipfo corpore deducit, mirabili indufiris contextarum, fubrilitate de; castasum. Genus conftituimus infectum. Ratio in procinctu. Infecta quippe animalia minora \& infirmiora, commiffuris, certis infignita. Ut apis, mujca, papilio, locufa, vermis, formica, \& hîc etiam araneus. Strictè enim nec ad volatilia, nec repulia nec greffilia, nee natarilia referre valeas infecta. Græ-

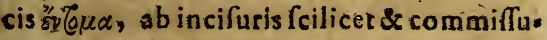
ris, quibus nune in fupinâ, nune pronâ, nunc utraque corporis parte præditæ funt, appellitantur. Nec hîc admittenda diftinato inter animalia perfecta o imperfect a est, dicendumve, ad imperfectorum cenfum fpe. ctare araneam. Nihil imperfectum, qrodea, qux habere debet, habet. Habent infecta, re. quifita fua. Habet apis, habet formica, nee deftituitur araneus. Plura fi haberet, jam non apis ampliùs,' aut formica, aut araneus, fed -liud quid effet. Vidit Deus cuncta que fece. at: É ecce erant omnia valde bona. At quod bonum eft,perfectum eft. Finge bonitarem, \& voca tamen in effentia fua imperfectam, malitiam habebis, non bonitatem: defectū, non effectum. Diftinguatur hîc faltem inter perfectionem abfolutam atque comparatidam: \&uaratur de priori : erit res in vado. In-
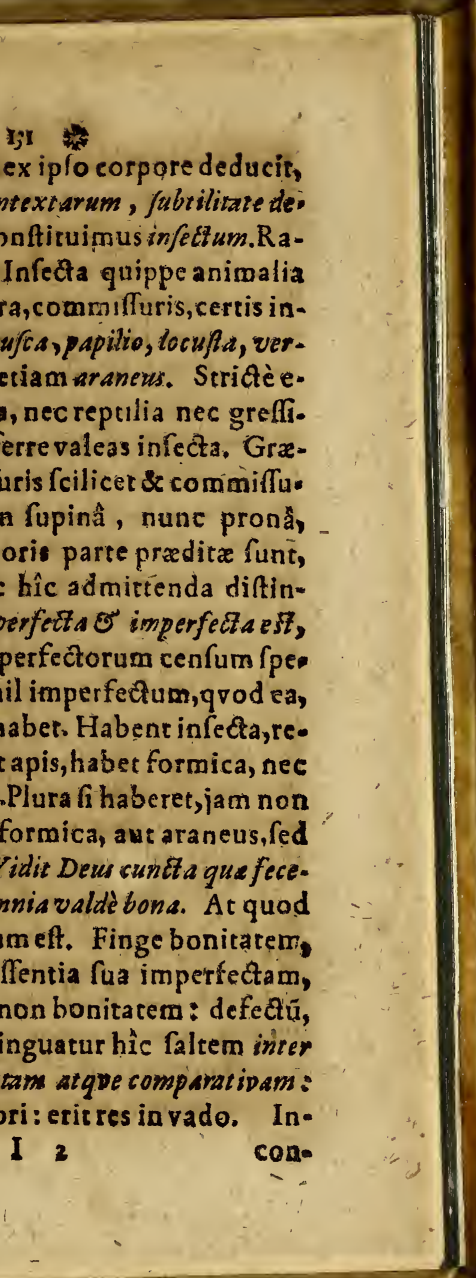


\section{\% $232 \%$}

congrua de pofteriori, quaftio eft, $\&$ ab ea facta denominatio. Ita e. pleræque res dicendx imperfectx forent.

§.VII. Differentia, qualis hîc haberi poterat, accidentalis eft, petitaque (1.) à partium quarundam conffguratione. Octipes quippe araneas, haud fecus atque cancer.Pedes ipfi, longitudinis diverfa, propter diverfas, quas exercent operationes, funt. Qvibusdam eniz (verba Llyylis Aldrovandi lunt ex lib. V. de Inlę, cap. 13. fol. 24I.) fila, gre neverunt, aes tenuant, $\delta$ in longum prosmabunt, aliis eadem in tela deducunt, ac invicem conjunguns, alis denigve per eadem prorepunt, of rum volunt, ex is ceu immobiles fele fußpendunt. Longiores funt anteriores $\&$ pofteriores : minores, medii pedes. Poftremis fila ordinant; \& innectunt, inimitabili artificio. Prioribus, pro manibus utuntur, \& illapfam telis prædam arripiunt; mediis verò adjuvant. Ita nibil â Deo \&natu. râ, fruftrà rebus conceflum deprehendimus.

$\$$. VIII. Sed \& (2) i veneni affectione, nofter deforipius est araneus. Faciunt huc, qva SPERLINGIUS ó pearagirns cap. 6. de Infect. in additam ad Zool. can. 2. habet: ab homine fumptum aranee venenum, feu cum potu, feu cum cibo, miferi afficit, \& affligit corpus. Nunc calorem, nunc rigorem, nunc pruriginem, nunc 


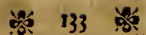

umorem creat agroto. $A$ Gallinis verò aliisgve ivibus, fine periculo aranee comeduntur. Sic con omnibus venenum est, qpod alicui est. Hermultæ noxia nobis, veluti napellus aut cicuta, non item brutis: Porcis excrementa foridisfima, fvaviffimo funt pabulo. Vermibus nocivis aviculx vefcuntur non paucx. Nos aviculis utimur incolumes. Sic non omni peftis eft, quod eft alicui. Catervatim fepè moriuntur homines, illefis beftiis. Et mox bruta, hominibus indemnibus. Infundunt aliàs venena fua aranei, non ictu, ut Scorpii, fed rictu. Unde, qvas novisfimè ceperunt mufcas, pedibus involvunt, mordicant, \&, ut cum Poëta loqvar, vipeream illis animam infpirant, necemqve inferunt protinus, exfucto ante fangvine \& fucco.

5. IX. Prætereà (3.) ab adjuncto prudentic $\int 0-$ lertiag $_{3}$, in contexendâ fubtilisfimè telâ, depinximus araneam. Prudens eqvidem formica atque folers eft ; fed prudentior longè \& folertior araneus. Induftrix admirabilis \& folertiæ, bombyx: bombycem verò multis fupergreditur pasfibus, aranea. Arrident politisfima Plinii verba, ex Hif. Nat. L.XI.cap. 24. tìm moderato ungve, tàm teretifito, É tàm aquali deducit ftamina, ipjo fe pondere ufus. Texere à medio incipit, circinato orbe, fubtegmina

I 3 anne- 


\section{4 涪}

amectens: maculasque partibus femper inter pallis, fed fubinde crefcentibus, ex angufo dilatans, indiffolubili nodo implicat. Qvantâ arte celat pedicas, fcutulata rete graffantes? qpìm. non ad boc videtur pertinere? "vibratspexitas tele, E quaddampoliture axte, ipfaper fe tenax ratio trame? Specus ipfe, quà concameratus architectura, É contra frigarn, quanto villofior? qpàm remotus à medio, aliudque age nti familis. Inclufus verò fic, ut fit, nec ne, intus aliqvis, cerni non poffit? agc firmitas quanta, irrumpeatibus ventis? qpa pulverum mole degrapante? Latitudo tela fepè inter duas arbores, cim exercet artem Es difcit texere: Longitudo fli a culmine, ac nurfus à terra, per illud ipfum, velox reciprocatio : fubitqpe pariter ac fula deducit. Cism verò captura incidit , quam vigilans $\delta$ paratus ad curfum? licet exiremâ bareat plagî, femper in sicdium currit: qpia fos maxime tocum concutiendo, implicat. Sciffa protinus reficit, ad politu ram farciens. Senec. Epift. 21.

S.X. Et appofitisfimè-Romanus Sapiens: Nan vides, quantafubtilitas fit apibus, adfigenda damicilia? qpanta divini laboris obeundiconcordia? Non vides quàm nullimortalium imitabilisfit illa aranei textura: quanti operis fit, fila disponere? alia in rectam immiffa, firmamenti lo6, alia in orbem currentia, ex denfo rara, que 


\section{*135}

vinora animalis, in quorum perniciem ills ten. lentur, velut retibus implicam teneant. Nafciur arsifta,non diffitur. Cedro dignum epihonema hoc. Na/Gitur, inquit, ars ifta, non lifcitur. Vix enim ovulis exclufus fuis, ara, ceolus, aftutisfimum nendi callet fubitqve pificium. Non vidit, non praviis obfervait experimentis. Notitias nimirum à Naurâ inditas, folertisfima hac $\&$ alia posfideut animalcula. Ut proinde fruftra fint, poft Interpretes nonnullos, D. Ereitag. Difp. Anti Sperling. de Orig. Fo rm.th,19, Dn.Zei. Cold in not, ad Jacch.Phy!. lib. 2. c. 10.p. 17.1. \& feqq. ( Conf, ejusdem lib. 1. Infit. punct: 4 pag.144. feqq.\& nuperas, contra Synop/.Sperling. Medinationes.) Mels bior Corneus in Curric. Philof.Tract.2 dub.14 \& Fobarn. Tating hov. cap. 8. qv.I. p. 194. Clav. Phil. Nat. qui neque fines fuos ordinatios cognofcere, neque naturali quả dă fopientiâ, inltructa, effe beftias, conceduat.

5. XI. Nos hic de eo difputabimus, quòd ob finecr.tota, quanta quanta eft, na. tura agat : finis auteas ton operatur, nifi co. gnitus : ignoti quippe, cupirio nulla. Sed neq; de hoc laborabimus, quomodo tota itidem naturs fapienter uniformiterq́; agat, \& bruta ipfa, fini pruportionata expe14 tant

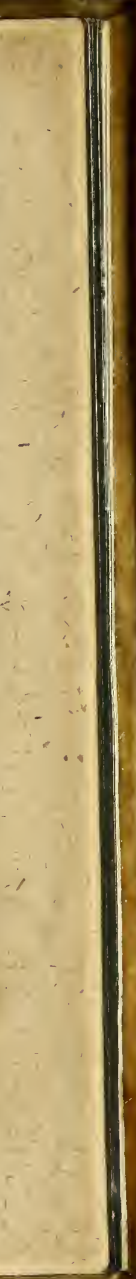




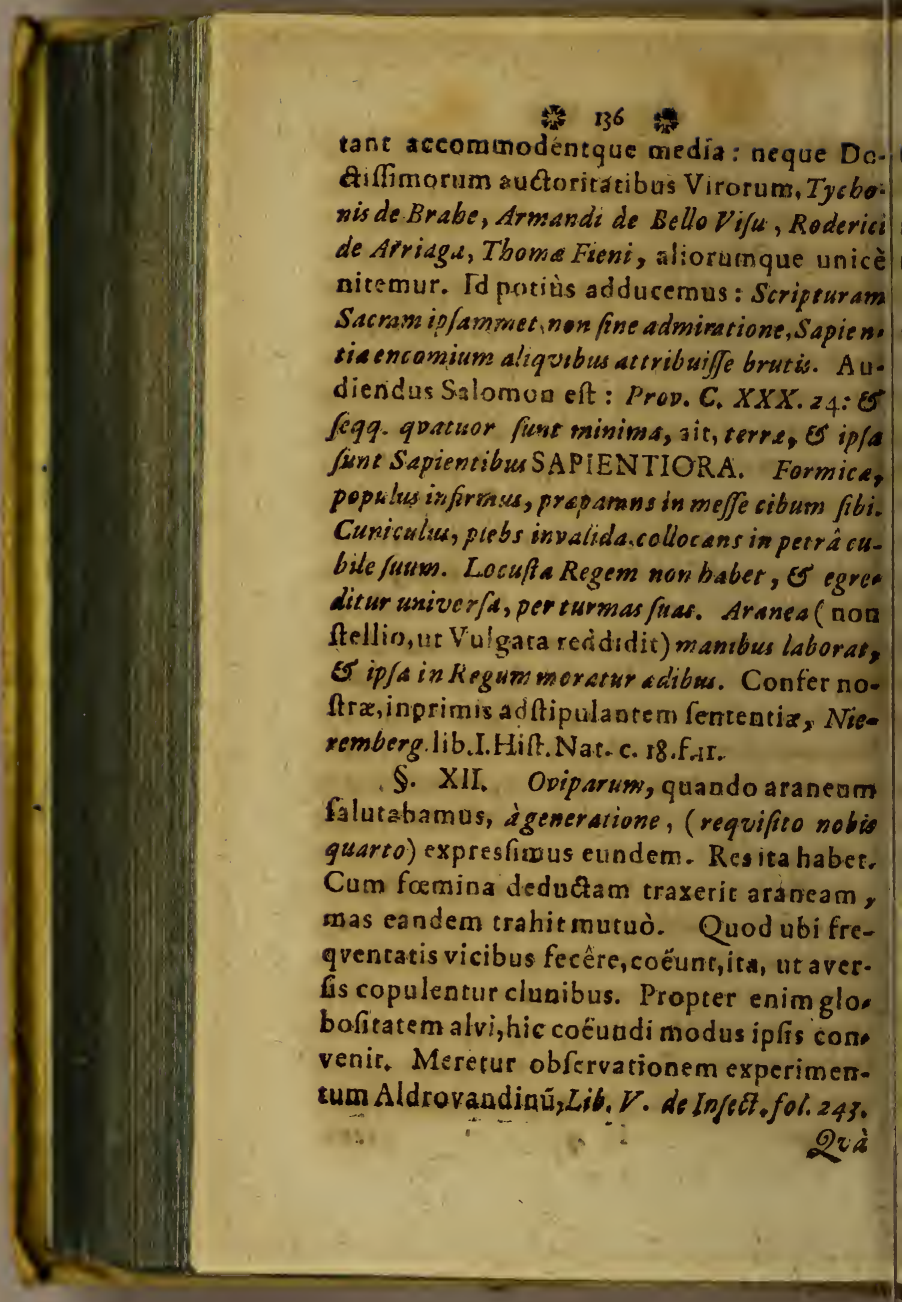




\section{푱' 137 \%}

Ova, ait, aranearsm 'rum aliquando obfervarem, inverieffe mulca, modica, livida, exiguis maculis adperfa, divifa, invicemgde leparaca? molliá \& vifcida, que fi cafu aliqso fuerint perdiscar anea diligenter inquirit, of $/ u$ i ad dit amentis incerioribes, Es roftro ea etism repor. zat. Vidiztem, ex unico opo, multos \& innus. merabiles fetus procreari, ita exigues, ut vix oculis percipi qveant, attamen-qpamprimim odo erant exslue fi, fla deducebant adeo tenuia, ut nibilpoffet effe admirabilius. Ob/ervavi item fub capte ax anee alpe, mingnum ovorum extrus" lum, adeò exiguorum, wt atomis comparare lio เxiffec.

5. XII!. Qvint us aranex character, â materia telarwm texendarum petebatur. Ajo ex ipfus cotporis intrinfecâ vifcofitate, non autem fuperficiariâ la nuginis extremitate, telas, araneas ductitare. Negat hoc Arifoceles, ridet, \& ea nomine Democritum refutat. Statuerat PhilofophusAbderitanus; ex ipfo alvi vifco, certis temporum fpiramentis, nere telas, arancos. Plinius, Hiff, Nat. lib.l.c.23.inquit: Orditur telas, santique operis materis,uterus ipfius fufficis, five ita corrupta alvi natwra, flato tempore, ut Democri. to placet, five est quedam intus ianigera ferti. litas. Ariftoteli contrarius Elianus, $L i b^{\circ}$

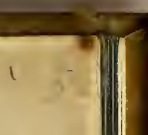




\section{8.}

1.Hift.Anim.c.21. neque aliunde, fcribit, flum afumit, fed ex fuo ventre fromina deducit, \&f irretiendisleviffmis volucribus Venabula contexit, argre in vect iu ßpeciem diffundit. Porrò eodem, guem ad texendum, de ventre fuo de. traxit fucco, ventrem juum fiudiofisfimè alit. Etverisfimè jam olim $\mathrm{Na}$ fo, de tranfrutatione Arachnes, in Araneam cecinit :

Fitque capue minimum, totoque est corpore. parva,

In latere exiles digiti, pro cruribus be. rent,

Catera venter babet, de quocamen ille re. nitcit

Stamina, E contiguas exercet ar anea telas:

S. XIV. Miramur tantum, in re tàm manifeftâ, errorem commifffe Aldrovan. dum, lac. cit. fol: 24t: Meritó astem Demoaxiti, ait, opinionem peflundedit Ariftoteles. Ete. wim arance $\mathcal{B}$ alia iffiusmodi annuloja, parum famunt alimesti, paramgde inutriuntur, propter Janguinio \&s calorio defectum: quare cum ille nos cantum capiant cibi, quin plus continute in telarum texturấ confwers ant, dicendum e flet, majorem fuperfluiditatus excrementersimg pe fore emisfionem, quàm, alissenti sfumtionem, quod abjurduns est fietuere. Alfertio fal $\mathrm{r}_{a}, \mathrm{fe}_{\mathrm{C}}$ quela nulla. Satisfaciemus infra, ac refpon. debimus. 


\section{$1 ; 9$}

debimus. Nunc primùm placet cum Al. drovando Aldrovandum committere. Nea gat de araneis, concedit alibi de bomby cibus, ex ipfo corpore, ferica ipfas nere fila. menta. Et bambyz annulofa eft, \& tantum vix fumere videturalimenti, quantum fericx ex fe fingitielz. Sola, inquit, lib.2. de In/. a.VI. fol.llz. bambyces, mari cantù foliarum ef $u_{3}$ (ericun cexunt. Et mox infra (fol, 14.) Vidam, Poètam Italum, pro fe citat:

...- effundune quefite per avum

famina, ditis opes uteri ....

\$. XV, Sed ecce, cum poft feria nuper quendam natura inftitueremus lufum, araneasque majores, mediocres \& minores, tempareauctnmai venatemur, ex frpè repetita obfervacione deprehendimus, materiam, unde fila torquent, effe lividum, maculofun, gluti * nosum ac tenaciffimum humorem, mafra fubactx \& nigricanti non adeò abfimilem. Exinde per frramen, qvod à clunibus habent, an. guftiffimun, progrediendo femper, fubtilisfin ma protelant frmenta. Die Sept. VII. ex aranea prehenfa, aciculâqve infixâ trabi, ex ipfó corpore, filum 66. pedes, continuâ longum ferie, deduximus. Et fequenti die, ex aila mediocris magnitudinis, cum aliquoties abrumperetur, ftamen, tùm 170 . tamen pedes prolónga-

tum 


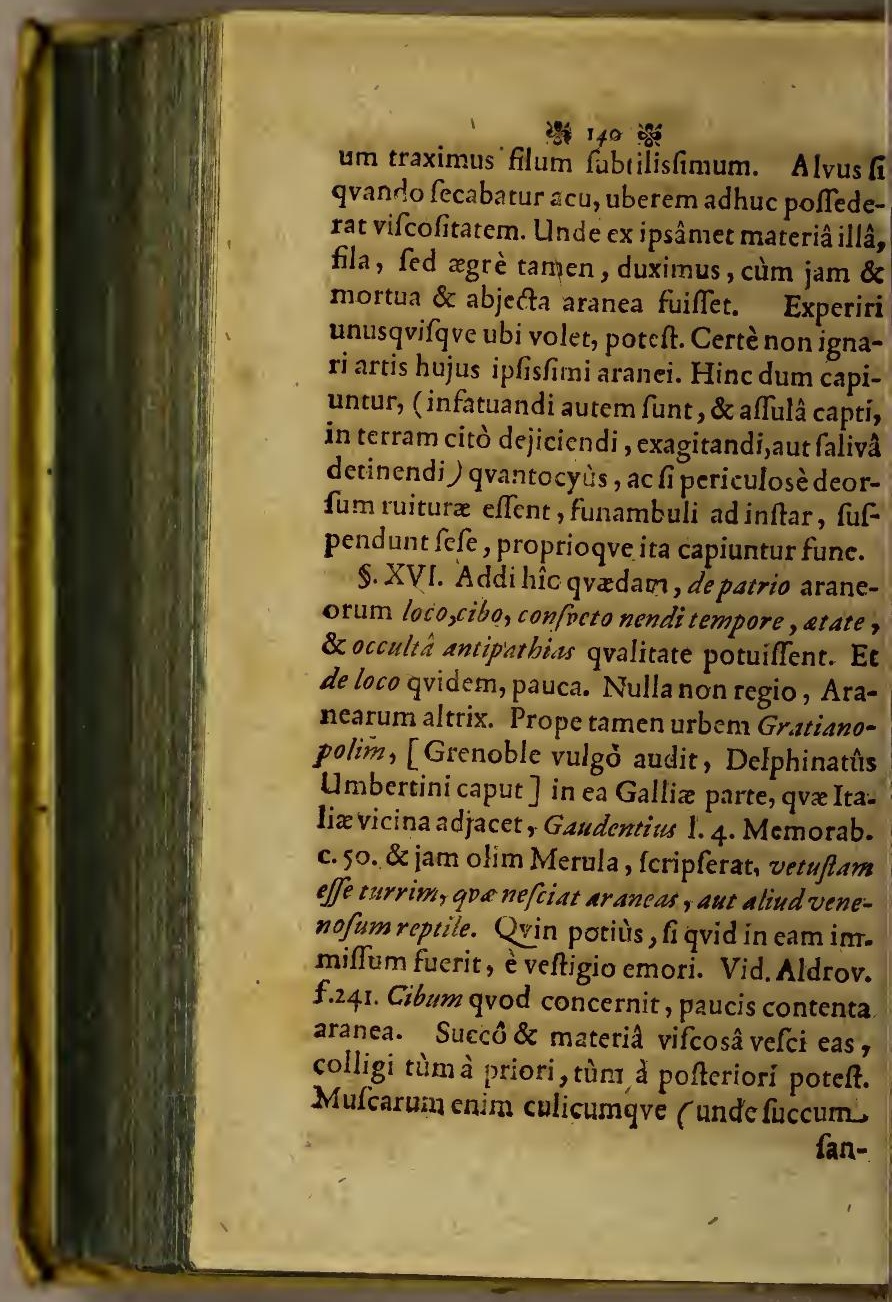




\section{${ }^{-1} 141$ so}

nateriemq́; petunt) venatu vivunt commuaiter. Sed \& alvus vifcofitatis plena. De tem-. ore, hæc habe. Sereno exiftente Jove, rarene er texunt, fed magis nubilo.Inde nubium præagx. Sunt \& ex ea alia auguria. Qvippe incremento amnium futuro, telas fuas tollunt. Iliùs. Annotante Plinio,Lib.XI.Hif.Nat.c.24. Araneorum mufcarumq́; examina infolita, fuuram prenunciare peftem, Autor eft $A t b a n a / 2-$ us Kircberus, in, de pefte, tract.p.r44. Qvin \& ruinas ædium propediem collapfurarum, abitu divinant. Etas illis \& debilis \& brevis. Màturè enim perficiuntur. Qvod citò fit, citò perit. Cæterùm nulli animantium amica aranea. Germani noftri,proverbii occafionem. fumferunt inde: einem Epinnen feino feyn. Qvandoqvidem \& in propriam exitiofa familiam. Singulares tamen, cum fellione, fovere hoftilitates dicitur $a b$ Ariftotele. Odium infuper irreconciliabile cum Bufone gerit. 'Vid. Petr,Lauremb. Cent. 3. Hift. 78. Acerr.Pbil. ubi memorabile, de Monacho Britanno qrodam, adducit exemplum.

5. XVII. Ovula Araneorum mederi oculis, ex hiltoriâ feqventi dilces. In agroCobur-

, genfi ( Slcin Bårnftaot pago alicui no,, men eft:) ante annos abhinc aliqvot famigerata oculorum curâ mulier, Marga-

") retba Wochnera, vixit, qua nullis ufa medica- 


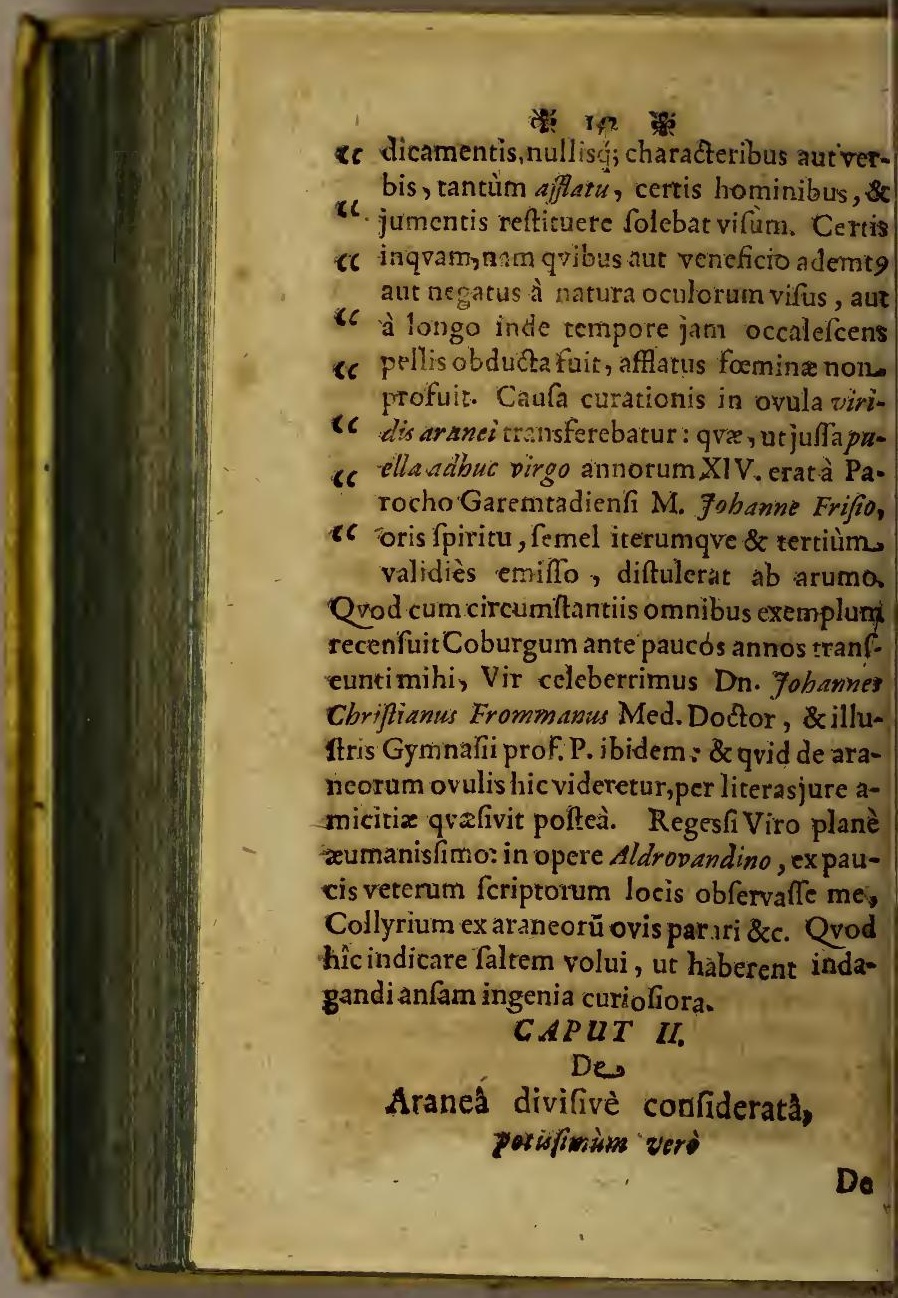




\section{$\rightarrow \cdot$ \\ * 143 \\ De \\ TARANTULIS. \\ - SUIMMARIUM.}

6. Laudatur Petri Bellonii judician.

2. Ar ariearum diffirentic fifuntur.

2. Aranea aquatica. An:Becie differant? Affir. matur de Tarantulis.

3. Pbalangii Tarantuliague Etyman.

4. Definicur Tarancula-Autbores adducuntur.

5. Explicaturporro, E quibus porisfonimo ine fefia Tarantula?

6. Quando imprimis noceat? Quomodo? Quantum? Varii incmirabiles Taranculie effecius.

7. Geftus Er effect us mirsibiles Tarent atorum.

8. Cur Mufich tantoperè afficiantur Tarentati? Mirus Janandi motlus.

9. Aliter procedunt Mauri, SEtbiopes at. Perja.

\$. I. Aranearüm differentix plurima. Differunt enim (1.) rapturâ. Ubi quadam venantur mufcas, quaedam parvulis infidiantur lacertis \& erucis : aliæ vermibus culicibusque retia tendunt. (2.]Tela. Quadam enim fubrilem quadam craffam, quadam mediocrem: \& harum alize nunc nigram, quadam albam adornant telam,Quzdam artificiolas 8 cire 


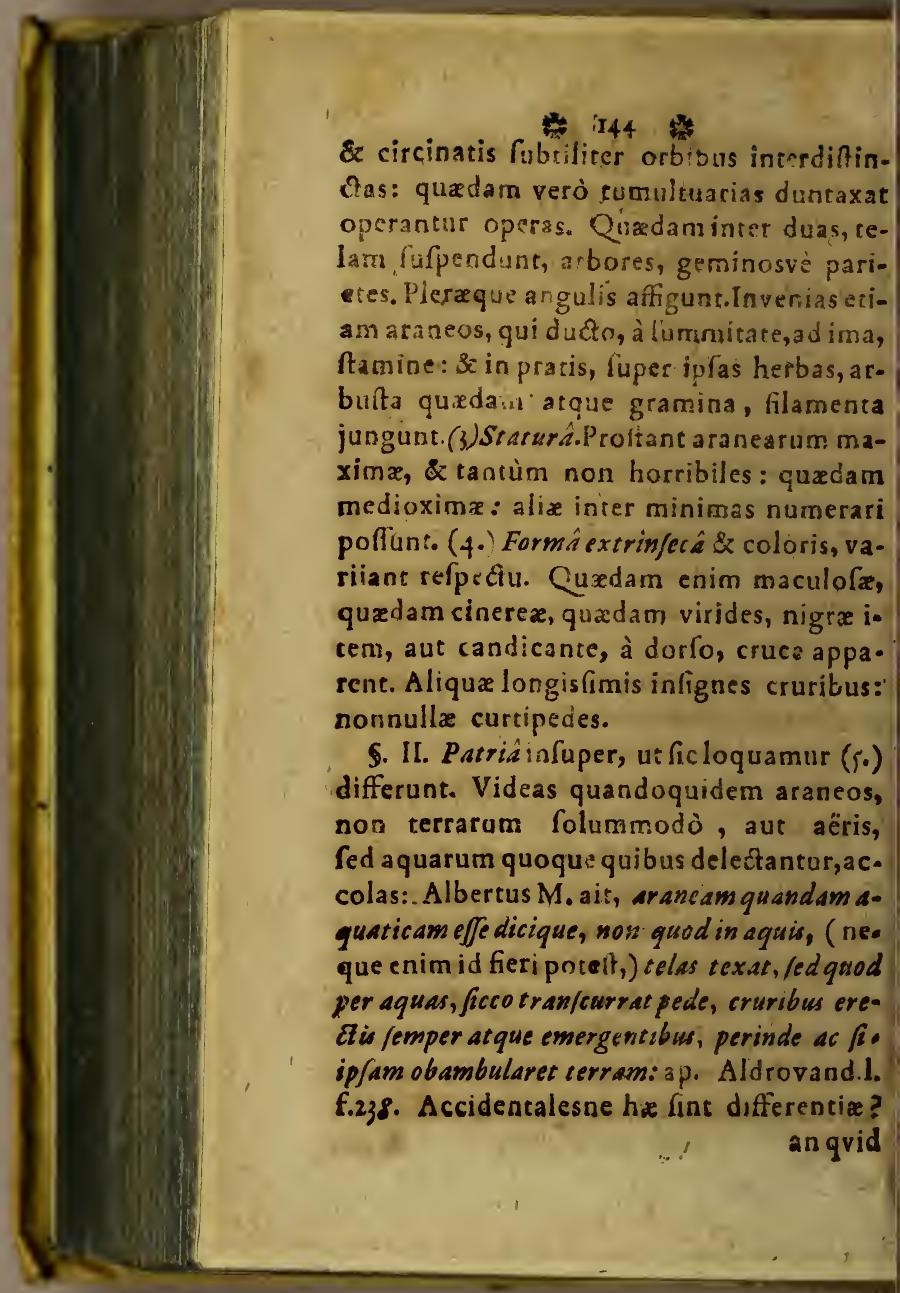




\section{145}

n quidulera fapiant? obfeurum eft deterninatu. Ex folâ vel quantitatis vel tela, vel oloris alteratione, f́pecifica non illicò coningenda diverfitas. Accidentalia hæc funt, * communia magis, quàm propria. Natura omni animalium ordine, fuo fe jactitat ufu. Formas fi perfpectas quadantenùs haeremus, non laborandum in revulgari foet. Miaximè verò veneni ratione differunt aanex. Omniủ aran. atrocisfimi veneni funt arantule, qux uti fpeciem omninò conftiunnt, inter araneas vulgares, peculiarem; ita najoren \& attentionem \& indaginem nunc ibi poftulant.

\$. III. Ut primò Nomen explicemus, diciur etiam Phalangium, (ab internodiis, quourn terna in cruribus obtinet, $\phi a ́ \lambda \alpha \gamma \xi n$. iræcis internodium audit :) communisfimè arontivla, à Tarento dicta potisfimùm. Ahanäfius Kircherusinquit: dicitur Tarantuls civitate Tarcnto, voli flivio Thars, ro quod a boc difiriclu, utpote calidiorbus Es planioribus aputie!locis, ingens carum quotanis propullu. etcopia. Non quod alis quog in locis eedem ion reperiantur, fiquidem $\mathcal{E}^{\circ}$ in Calabriâ, Sicia, quin $\delta$ in campis Romanis, $\alpha \beta$ iv is menfibo, ubinde videntur. Apulisprorfies fimiles, nifi quod insno illo, al faltandum incitativo careans.

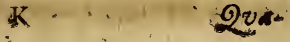




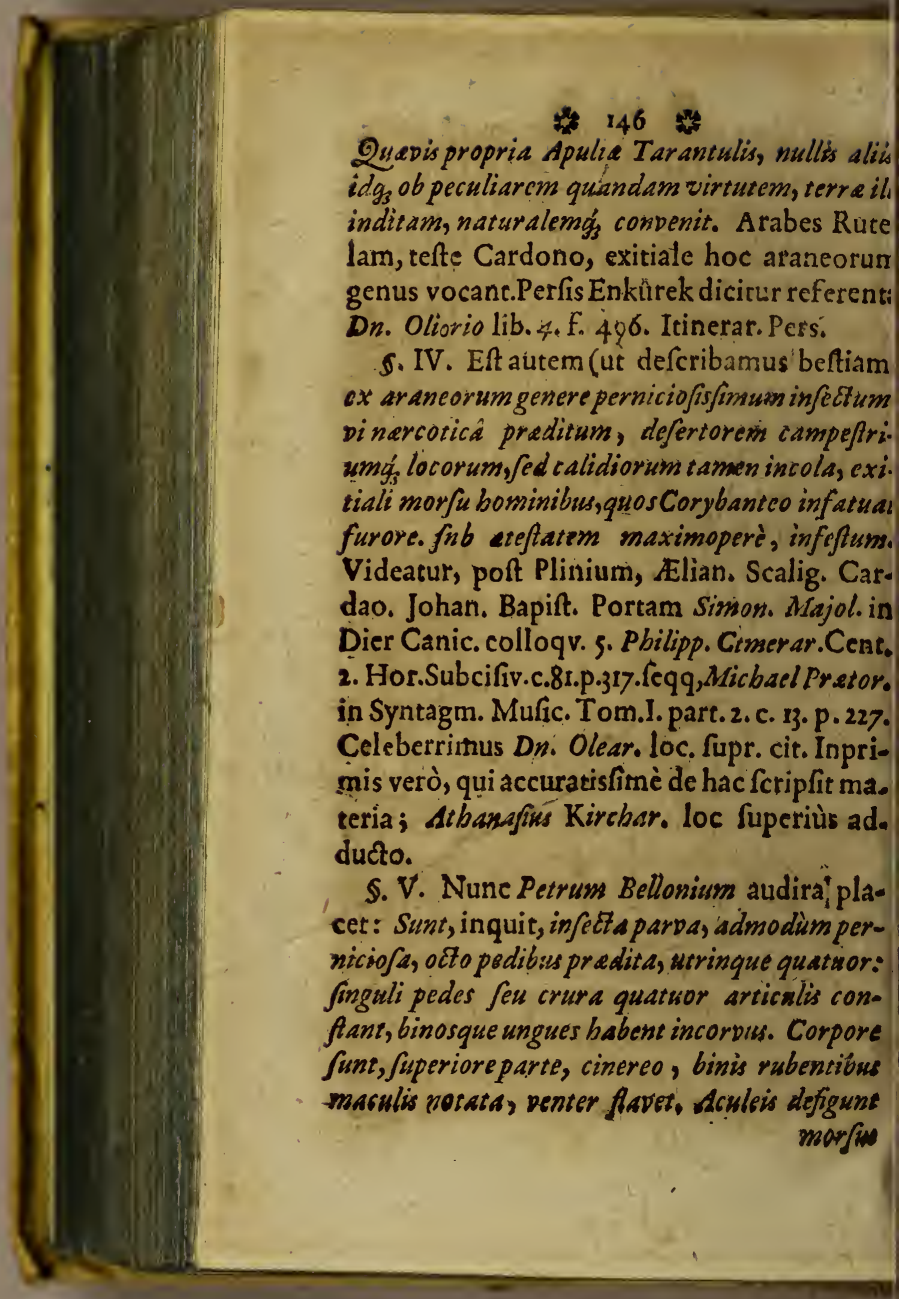




\section{7}

Ébrfus, telas araneorum more textint, mufcisque ic papilionibus vefcuntur. Ove pariunt, ingenti 2umero: E pectori adbercntia fovere folent, tonec excludahtur; $\mathcal{E} c$. Julio Solino quoque, citantê eumi Camerario; Phalangium aranei cenus eft. Sinifusi quaras, nulla diseff, fi potethatem, ictum bominem veneno interficit. Aftivali tempore; inbi Sol fla grantisfimus, Apuliæ Calabriaque totret campos; rúftici communitet incedunt octedti in agris, ut hoc ufi munimento, laboribus. tutiùis vacare queant. Sed alii horum infeftantur puncturis, præprimis Hortulani, meffores; \& paftores, qui necesfitate cỏa citi; fubdio, \& in campeo fribus locis, menfibus maximè calidis \& ficcis, ut]unio, Julio Auge fto, ocreis, \& manicis ton muniti dormire conguntur. Kircherus ex relatione Pasti Nicolleli, in Apudiâ, fefusta, E Job. Baptifle Galliberti, Collegii Tarentini, Symmyf.e lib. 3. Catenx Magnet. part.8.cap. 8redic. Roman. tert:

S. VI. Mirabile imprimis eft, reliquo ando ni tempore, perniciofam minimè aut, exitialé Taranculam effe, imò vix nervorum? ali. quid aut virium obtinere, ad incommodandum, Sole autem, fuum redingrante aftumg tam virulento peltiferum effe morfư ut

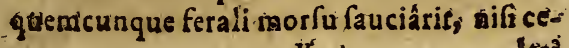




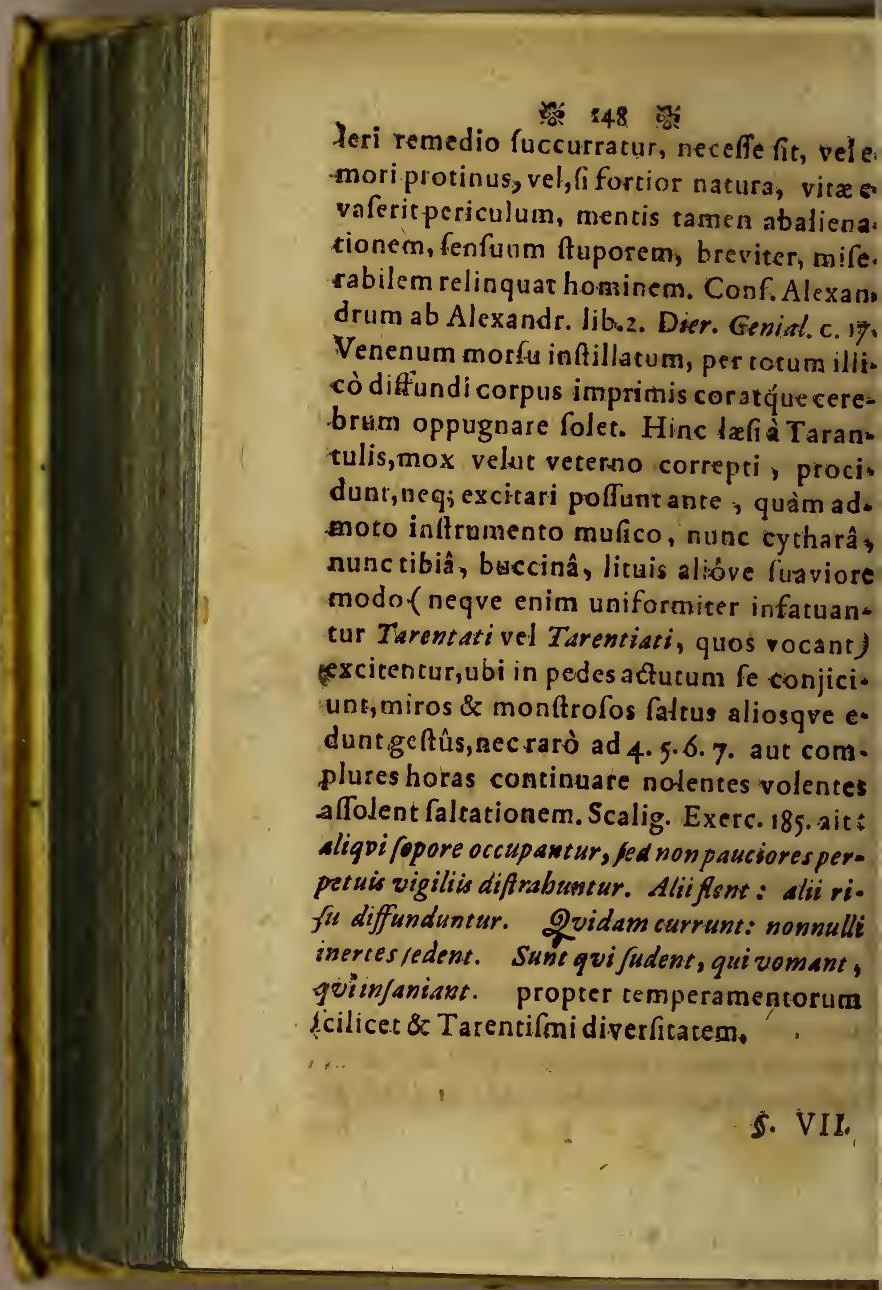




\section{9}

§. VII. Et non minus admirandiTarentatorum geftus pariter $\&$ affectus varii videntur. Alii enim á Phalangio icti perpetuò currunz, rident alii, alii plorant, clamant hi, illi dormiunt, ifti vigilant, plurimi vomitionibus laborant, pleriọ́p faltant, fudant, contremifcunt, quidam \& pavoribus vexantur, alii mala alia, phreneticis lymphatisq́; fumiles experiuntur. Nec ictis hominibus fal tationes iftx proprix; brutis.etiam à Tarantula læfis familiares funt. Vefpam erim \& Gallum ex morfu iftiusmodi faltantes Maximus. Sennertus annotavit 1.2 . Med.Pract. part.2.c.7.\& in concbam refertam aqpâ, ad cytharx modum (quem Tanantellam wocant) faltitantem Athanafius Kixsberus ob. Cervavit L. alleg. p. 599. Jam quid illud fibi vult? quàd diverfis \& proportione veneno re fpondentibus coloribus afficiuntur Tarentati? dum viridem alii, alii rubrum, nonnulli flavum depereunt coiorem. Singulare iftud efr iam exemplun eft, qvod tentavit ipfemet Tarenti Cardinslis Cajetanus, cum Religiofus quicham morfus à phalangio, puspuream epomidem, ipfus tantoperè arderet: Kircher. r.598.

\IIX. Mirabilius verò eft negotin um " quid caufa fubfit, qvòd auditu foni K 3 mufici 


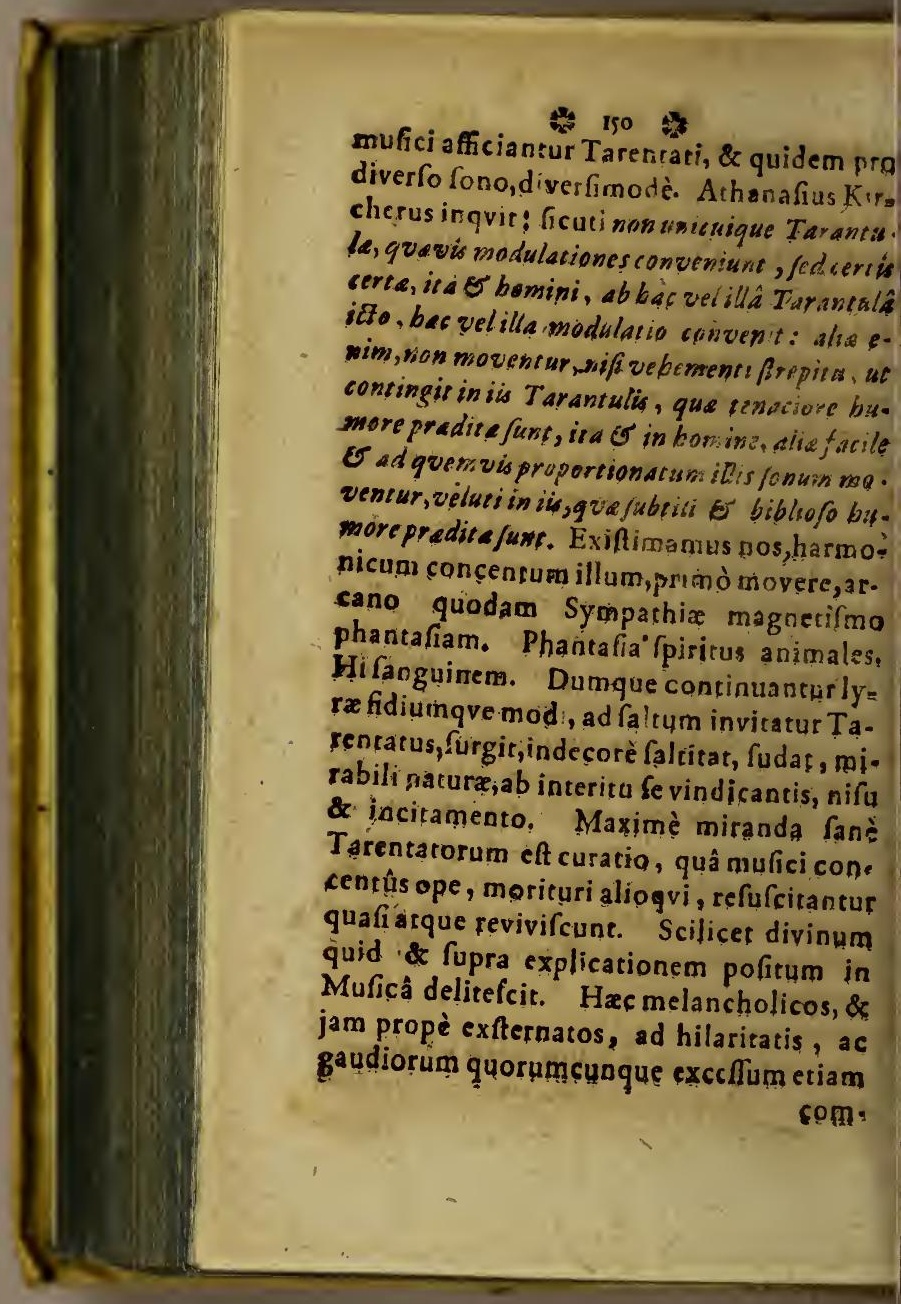


onsponit. Urget imprimis hoc, in Synagmate Mufico Pretorius, donum, idque urat. Scaliger| $E x$ epradicari verbis poffe, as.L. sbore namǵs ac fudore, tum vincitur expellicur vesenurs. Diluta hacLogica qva ex diverfis, imò fubordinatis hic loci, facic oppofita. Unius pofitio en him terius remotio hand eft, Labore ac fudore disfipari pariter ac expeli venenum à Tarantulâpropinatum, infallibiliter verum eft. Vis difperfa inde fit exilior \& débilior; ficut cum unira effet fortior evaferat. Non id fraudi prajudiciòve effé poteft Muficx. Quicquid tamer hic adhibeatur, efficax usque adeò haud eft, quin per temporum ftatutorum fpiramenta, quoddam Tarentifmi pignus cum maximâ fenfuum hebetudine perfentifcant femel loti à Tarantula.

S. X. Mauri, Etbiopes ac Per/a, huic aliter occurrunt malo, Phalangium enim as adhue praftò fit, capiunt, morfulque advenenum extrahendum applicant, prafentisfimo, ut ajunt, remedio. Alter nodus fit per vomitum. Videndus Dn. OLEARIUS 


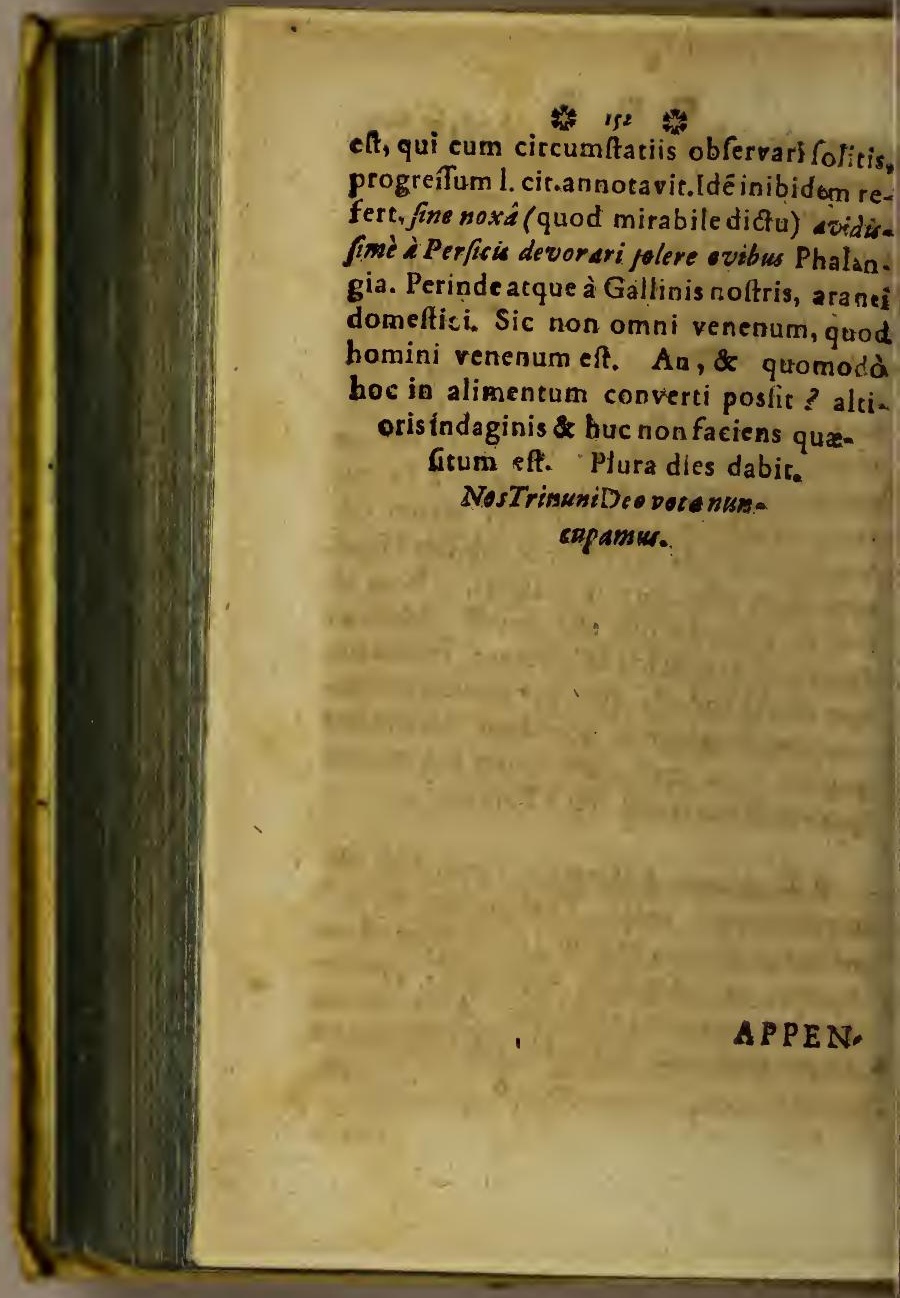


th 153 th

APPENDIX

DC, '

AVE PARADISI,

Give

MANULODIATA.

$C A H U T I$.

Defcriptionem exhibens:

ARGUMENT UM.

Defcribitur Manucodiata. Indigitatur pas tria ipfius.

2. Indorum de eâdem fabulie. Magnitudo. Avis Paradifi, forma extrinfeca item $E$ fo gurat.

3. Utrum coeleftirore, autpuro pivat aëre? negatur in totum of probatur.

4. Anperenni motu gaudeat, $\mathcal{E}$ in aëre continuet volatus fuos? Siffuntur opinionis bujus defenfories.

s. Probatur folide contrarium

\section{I.}

HSt nimirum Manucodiata Orientalis In $\mathcal{H}_{\text {diæ, propenrodùm infra mediocre genus. }}$ avis, pennas elegantisfimas, \& per longiora filamenta amonisfimè productas , caput preffum ac colores ziarios cum fufficiente roftra, babens; qpe vulgò ä $\pi$ \&s of colefti rore pafci. perpetunmeque exercere volatum dicitur. Patri

$\mathrm{K} 5^{\circ}$ inter-

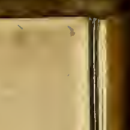




\section{4}

Intervifenda primum, qvæ cùm in Europá ig. noretur, ad Orientalem Indiam nos ducic.. Molucce Infulx potisfimùm, ac far'a major easalit. Qvanquam enim Simon Majolus colloqu, VI. dier. can. de avibus, $f_{\text {. IIz. in orâ }}$ Africe, non longè à Guinea, hanc ftabulari volucrem affirmet; nos tamen cum experientias nautarum,tum alionum etiam fecuti teftimonia, nativum illi locum Orientem fecimg. Audiendus Nobilisfimus $\alpha \cdot \tau^{\prime} \delta^{\prime} \tau \eta s$ ex lib. 3 . Itin. Ind. p.223, Mandesslovius: Gonft findect man audb allbier / (inMoluccis Infulis nim.)

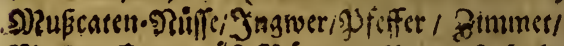

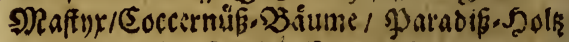
uno Gandel. Zud laffenfich bier am nucifen ofe \$arabies - 30 gel feben/welche ab il fie ecine Súfle baben/in dersuffe fabrocben l und fich mit etlicken Jedern an bie \$iume bett. gen/ete. Confentit poft alios multos, Melchior Guillardinus, deMonte Regio Boruffus. Medicus.

S. II. Moluccarum Infularum Reguli religiosè admodùm ac reverenter hanc habent grem. Hinc Manucodiatas, h. e. ares Dei appellârunt: hâc creduli perfuafione , non. vilneratum iri in pralio eos, etiamfi In primâ qqoque ftent acie, $q$ vi illarum fecum pennas portant. Superioribusgve annis., Reges 


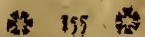

Marmin in Moluccis, animarum immortali. atem inde credere cxpiffe legimus, quod Manucodiatas, pulcherrimas aviculas nunjyam terra, aut cuipiam alii rei infidere, fed exanimes tantummodò in humum decidere confpicerent. Sed cùm perverfisfim: Muhämedani, qui ad illos, cornmerciorum caufsâ, commeabant, Manucodiatas in Paradifo na ci, \& Paradifum , locum animarum i perfuafiffent : Regulos illos ad Máchometis feêtam, pellexerunt neqviter, quàd de hoc animarum loco multa illis ac amplifima spollicerentur. Vid, Llyf. Aldropand, lib. XII. Ornitholog. cap, 3i, f, 400. Convenit de patriâ proinde.

\$. III, Statura nunc \& magnitudo metienda ejus, Avium alia maxime; ut aqvila, Atrue thiocamselus, grus, ciconia, pfittacus, anfer, vultur, corvus \&c.. mediocres alia ; ut colum. ba , pica, turdus, merula \&c. qvarum ordini hîf acçenfemus Manucodiatana, qvæ, licet pennarum amplitudine qvậdam ac prolixitate gaudeat, qvoad corpus tamen, nulla major hirundine, ab Aldrovando deprehenfa fuic: alix verò minims ; ut regulus, philomela , pas rus, curruca \& c, In Javấ nihilominus columie bx magnitudine inveniuntur. Et Scalige Exerç, 228. aliquam picâ non minorem vidìt Teriium def criptam ab extrìnfecâ formâ $\mathcal{E}$ apa 


\section{is6}

natu dedimus eandern. Meruit fcitisfima a. visideò, ut $D c i$, ut Paradifí diceretur volu. cris. Aldrovand. cit. loc. cap.2r. pennarum: inquit, asmbitus difcolor eft, fed admodùm venufus E vifu undique jucundisfimus. Alx cum cauda expanfa, pennæomnibus, filorum inftar tenuisfinx, pavonum ex toto fimiles, nif qvòd oculis déttituantur: omnes tamen, qva vel à ventre, vel dorfo enafcuntur, propter longitudinem caudatæ velut: \& nec dilatari, nec contrahi, pro appetiru animalis poffunt, naturâ eundem femper retinente habiturn. Subjicitque Gvillardinus : avicula eft, corporis magnitudine of penc forma, coturnicifimilis, pennarum ambicu difcolore, fed venuflo adimodum \& decoro, vifuqve jucundisfimo , undiâs. exornata, caput quale birundinis, majufoulum pro corporis amplitudine. Penna fuperior cjus partem, à prima cervicis vertebrâ, ad row firiufque initium exornantes, bredes funt, oraf: $\int_{e}$, dure, $\int_{p i f f e}$, coloris lutei, infigniter fplen. dentes, \& auripurisfimi modo, radiorumvéfolarium inflar fulgentes: cretere, q.pa mentum. contegunt, \& molliores, of tenuiores, atgre $r x$ cyaneo mirè eqvidem virides deprebenduntur, baud planè colore cis diffimiles, qvas in anatum mafculorum capitibus, dum lucidisfime obvcr. custur fideri, conspicimus. confer. Majolus 


\section{(9) 157 है:}

oc. fupr.alleg. fol.II3. Qvartum characterem nobis capitis E roftri exhibet figure. Caput, it Aldropandus, non rotundum, fed preffum, gale hirundinis, nucis juglandis fermè manitudine. Roftrum verò non omnibus $x$ qvè magnum, neq̣ve ejusdem etiam coloris. Gvillardinus addit : roftrum quàm fit birundine orolixius, pedes NLILLI, penne alarum ardeis cormâpares, fed texuiores longioresóg, colore fufco, inter rufun of inigrum fplendentes. Differt tamen habitudo roftri, nune majoris qvippe, nunc minoris: pro annorum fcilicet ac individuorum etiam diverfitate. Vidimus nos Dresdæroftrum, interalia, qqod non minus erat piceo. $7 u l$. Cas. Scaliger Exerc. 228 . fect. 2. Bermardus, Orvefanus, inquit, regix triremi præfectus, ffudiorum meorum. Atudiofisfimus, mifit ad the, hre fcripturientem, Manucodiatam unam, maximâ pica non minorem.s. CAPLIT non rotundum, fed PRESSUM ef, qvale HIRLINDINIS : tam grande, qvanta nux juglans. Cauda longisfima bifurcata. Pluma in capitis parte fuperiore adeò minuta, ut pilo propior, penè vifum fallat. Et viriditas, qva in feris anatibus : fed ita vegeta, ut Smaragdi iplendorem. imitetur. Hacille. Ceterùm an pedibus infruota avis fit ? cùm peculiare ideò feqvatur. 


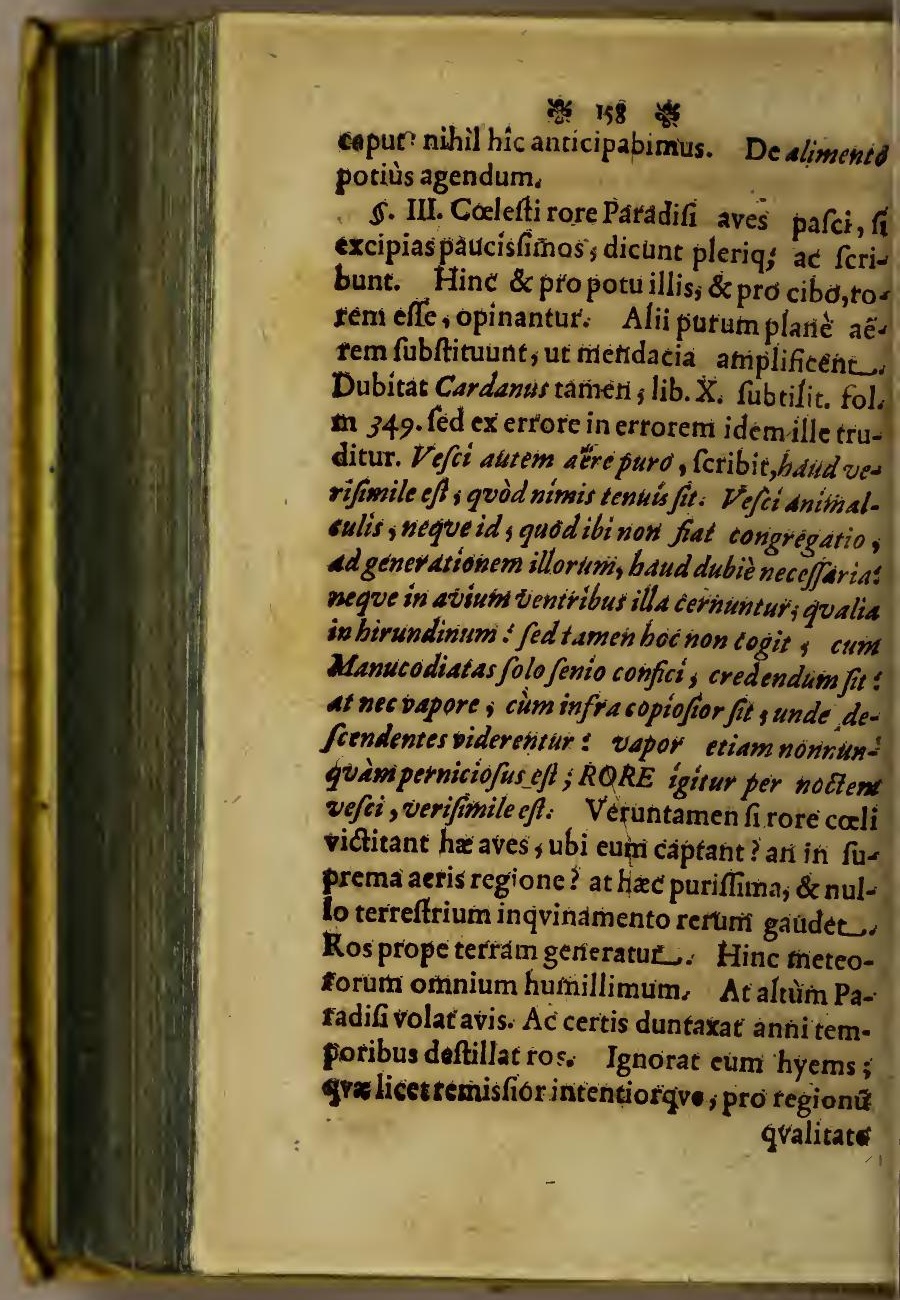




\section{9}

qualitate fit, eft tamen hyems. Qvo tum fae melica avis [ cùm ficci partiter ac calidi temperanenti fit] reficietur pabulo? Q in nec omini vernali aftivalique die, fed fereniore tantùm ros decidit. Adde quòd folo tempore matutino. Miferis itagqve illis natura noverca fuerit, quas deficiente rore emori neceffum eft. Elementa fola nullum antea nutrí te corpus vivim poffunt. Qvid? qvòd occidat potiťs purtus aer, qvàm ut confervet. Rectiùsidcircò Aldropandius; folidiori cibo, infectis fcilicer, tam voluctibus, qvàm apteris', pro cibo illis opus effe, ftatuit. Potum verò Manucodiatarum, fufficienter Catolus defcribit Clufius, ex poftremis Batavorum in In diam navigationibus. Breviter dican : AQVA eft : fed illa tamen limpidifima? \& faluberrima.

5.IV. Nunc denique de motu \& quiete A. vis, folicitos nos effe decet : Majolus : nun quitm ullo loco confidere, femper verò in aere fubfftere, contendit.Id tradidit Maximilianus Tranfylvan, qui addit snungvimm vifam fuifer, nifi mortuam, qvòd tunc, deficiente vitalifpiritu, labatur in terram. Et Guillardinus : cùms enimentic cuneted, quibus cerebrum Suppetit, ex gporum numero of Manucodiata efs, poft diusturnas vigibias, longasgés dies excukiass quiea. 


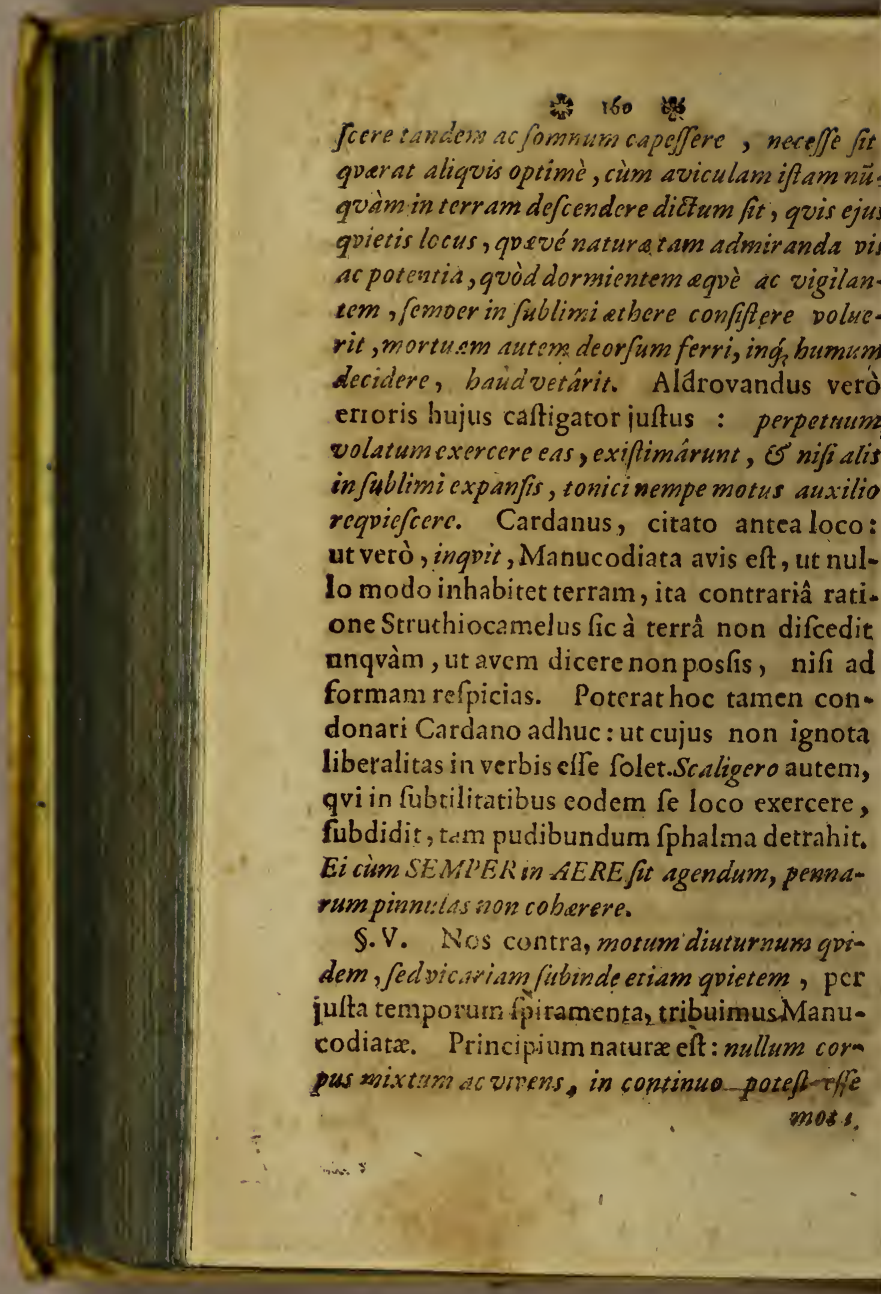




\section{161}

10tu. Detur ratio, detur experientia, cur xcipienda Avis Paradifr? Manet altâ mente epoftum :

Quod caret altçnâ requie, durabile non

$$
\text { eft. }
$$

eceffum etiam, dormireManucodiatas. A nialis enim omnis eft, vigilare \& capeffere omnum poftea. Jam diffonum à fanâ raone eft, fomno intentamavem, in fummo. there pendulam fuftineri.Sed nec infomnem rorfús.vitarn tratiereputandü; cùm hæc maxina omnium videretur carnificina. Eft \& rdeis celfisfimus: falconibus ac milvis veloisfimus: impetuofior aquilis volatus: reqviezune nihilominus per intervalla fua, fubfitunt, dormiunt. Omnis avis famella parit oA : principium natura eft. Finge nunc in aëre, a perenni motu excludi Manucodiatz ova. mnis species generando fe multiplicat. Generat Manucodiata, parit ova, excludit foctum. Jeceffe eft, interqviefcat. Qvid tum, fivilerit nullus? Qvis aqvilam in rupe nidulan$\mathrm{em}$, quis parturientem obfervavit ? Fugiunt 20 fensûs noftros: \& funt intcrim conftaner. Scio, quid excipiant nugivenduli : aviulam banc pre ceteris, acimirabili \& filficiindâprorfus doteNaturam folertisjimam dotafe, ut mas ferminam dormientem excipiat dor 


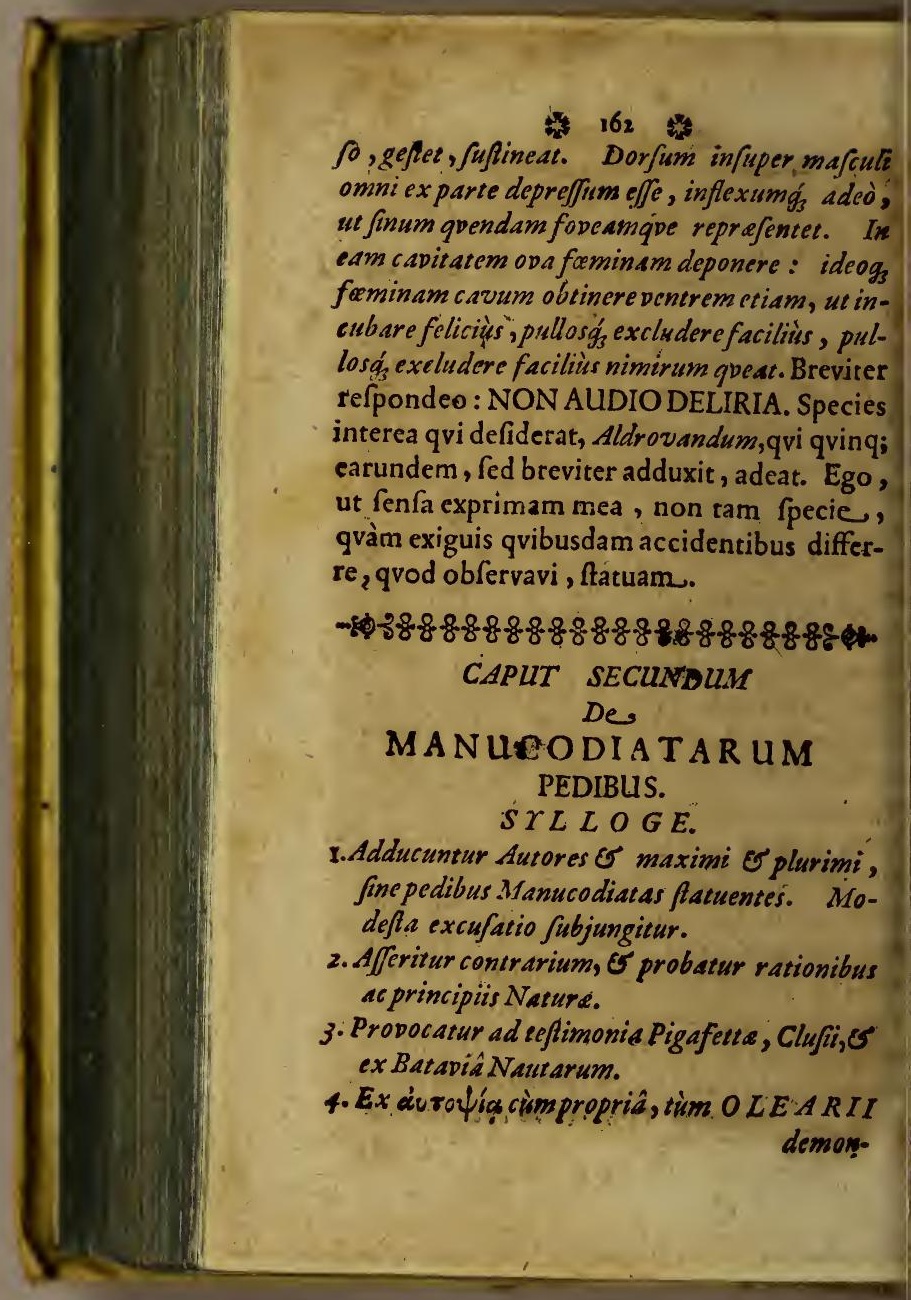




\section{3}

demonfrantur pedes Apis Paradifiace.

5. Openditur anfa É occafio, qpá industa in er rorem tot clarisfima ingenia fucrunt bactenùs.

\section{S.I.}

DEdibus carere Paradifiacam hanc avem. 1 communis omnium ferè fententia eft \& fuit hactenus : adeò ut proter Antonizm Pigafettam, Carolum Clufium, \& in ancipiti verfantem adhuc Cafp. Schostum, tantum non univerfa Literatorum cohors vel incerta nobis, vel contraria apertè videatur. Qvòd enim apodes fint Manucodiatx, ftatuunt (ut No biliores folummodò adducamus breviter ] Cardanus lib. X. fubtil. Scalige" Exerc. 228. fect. 2. Majolus, loco aliqvoties citato. Gcjnerus lib.3. de Avib. Francifc. Lopetz, Grillardinus, Maximilian. Tranfylv. Nierembergius, Pincier in Enigm. fuis, fonfton. in Hift. nat. de Avib. \& quod mirari fubit, ipfe, qvi quingqve tamen earundem vidit, delcripfit, palpavitque Aldropandus, eo nomine caftigans $P_{i}$. gafettam: quibus omnibus accedit etiam Mandeslovius; ut ex verbis ejus priori capite adductis, patet. Poterat hoc omne quidem, quantum eft, vel excufari, vel tolerari qvoque : fi inter minorum gentium auctores prajudicium ftetiffet. Nunc cùm Eruditoium

L 2

Lumina, 


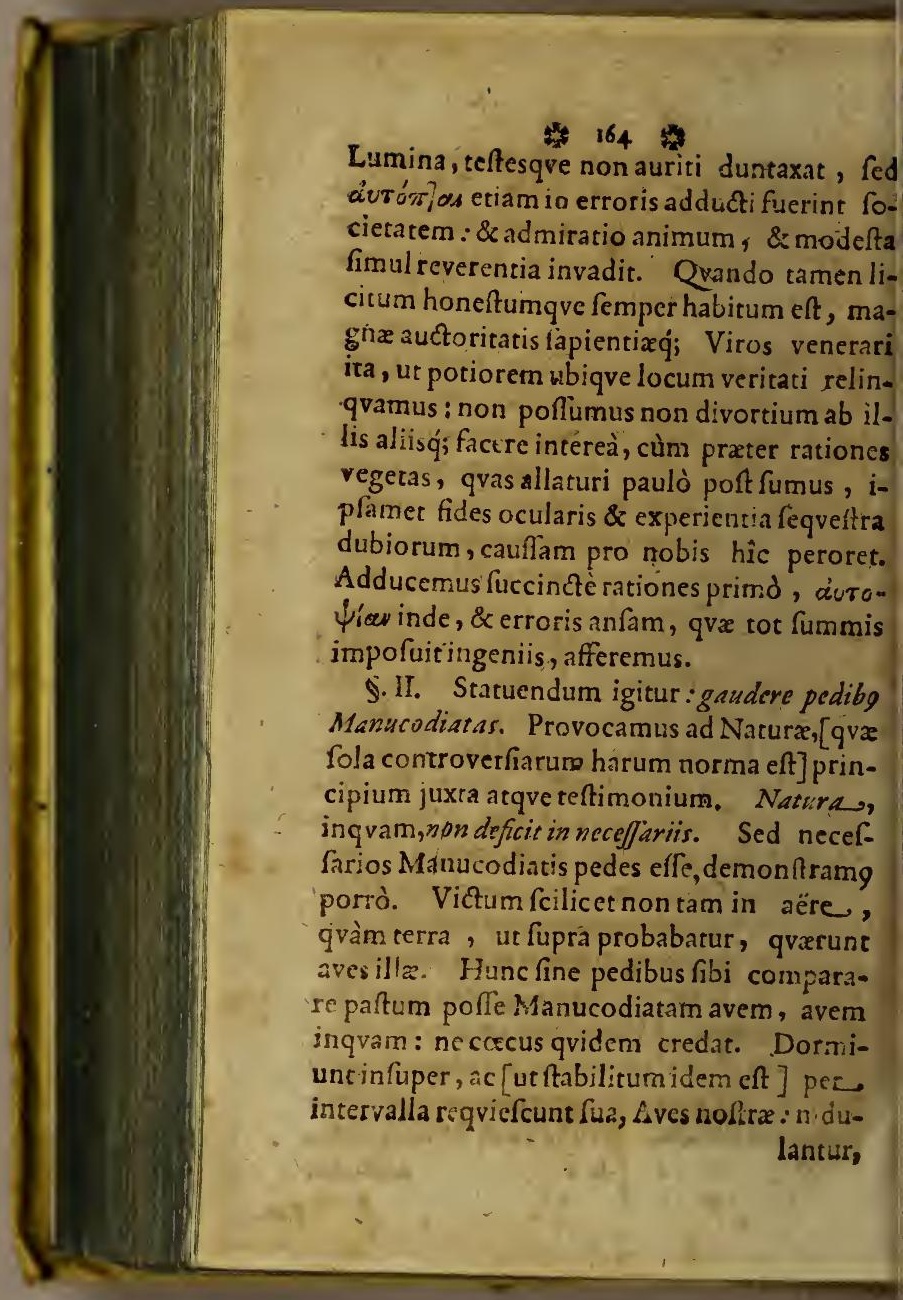




\section{tos 4}

lantur, generant, pariunt ova, excludunt pullos. Pedesaffint, neceffum eft. Principiam nature eft: Deus $\mathcal{E}$ natura nibil faciunt fruftrà. Obtinet Manucodiata fcilicet, ro. suftum fatis, aduncum quodammmodò \& randiufculum qvoddam roltrum? Qvorfum loc verò? ut, inqqvam, pedum benefic: 0 inrimis, victum in terra arboribusq́; fibi comparare poffit. Organa quoque ambulandi \& nervos greffiles inelle circaexteriorem ac primam pedum regionem, docuir anatomia. Breviter dicam : AMBLILANT, STANT.Habent ergo pedes. Qvid clarius?

\$. IlI. Jam cùm hac omnia probanda. d amuffim fint; faxo, ne quid hîc defiderare polfit mens veritatis avida. Nitar verò non olùm Pigafettæ, Clufiicq;; atq; aliorum teftimoniis inprafens; fed ad ocularem demon. trationem potisfimùm recurram. ${ }^{-} A c P_{i-}$ afetta quidem, qui cum Magellano, Victoiâ nave vectus, totum circuivit orbem, \&,3 longinqva navigatione redux, primus 1otitiam Europx de Manucodiatis inculit, , n diario navigationis fux, pedes eis tribuit. Clufues qvoque,qui \&ipfé anteâ conrarium defenderat, cum informaretuc, meliùs ex Batavorum poftremîs in Indiam navigationibus, mutavit fententiam, poft- ")

$$
\text { L. 3. . quàm. }
$$




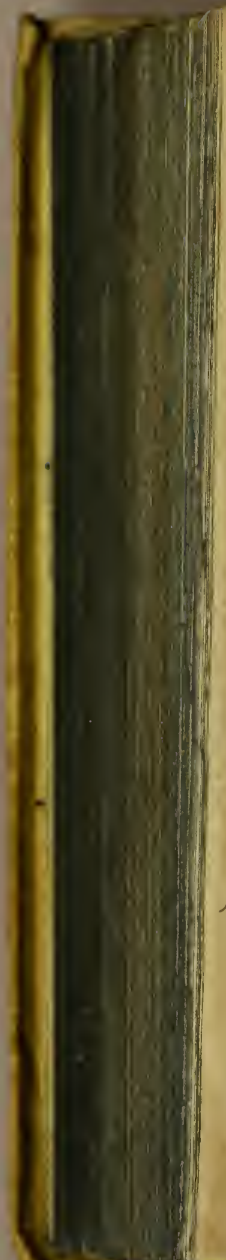

c) quàm Amftelodamum quædam integt: adhuc, crura pedefque retinentes, allat:

- funt à Nautis. Qvæutut infirmiora cru

- ce ra fuerint, crura tamen erant, colorem a trum \& ad caftaneum tendentem obtinen

c6 tia. Sed \&incolx Moluccarum Infula

«c rum, interrogantibus apertè teftabantur omnes pedibus inftructas elle, incedere

(6 volare, verfari in fylvis, incedere non fin

c6 ordine tamen, catervatim : bibere falubriores aquas, capi ab Infulanis, truncaripe.

« dibus, vendiaç diftrahi. Qva, \& plura alia apud Clufium deprehendes.

\$IV. Nete diutiùs nioremur, Lector, plures intusmodi \& Dresde, \& Lipfie \& Spevophordi, cum pedibus fuis, veris, naturalibus, nec parvis adeò Manucodiatas ipfimet obfervavimus, vidimus, tetigimus. Contrarium ne jurantibus credimus amplius. Senfum enim dimittere in iis, qva fenfibus

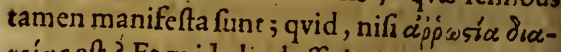
yoías eft ? Et quid aliud efficiunt, qvi, cùm lucium fortè ceperit Pifcator, fyllogifmo ex primæ etiam figuræ modo Barbara, perfuafum illi eunt, non lucium, fed cancrum ab co captum effe. Habemus infuper ó ó $\psi_{\eta} \varphi_{\text {ov }}$, Clariffimum \& virtutè fuâ nobilem DN. OLEARIUM, qqiad notatum fupra locum Mandes: 
eslovianum 1.3. Itiner. Ind. fol.27.hrec addit : Dicfes fatreiber oer von פRandeflo/ nach oer emerinen Ðicoc/muie weld)er cs such) Jonftonus 6. de avib. boilt/nenn er iprict)t: omnibus, c. avibus Paradifi peculiare eft, ut pedibus eaéant, ị aber unrect)t/uno fan nid) $t$ von allin efaget wirdern/Dann wit baben tn oer Botorfficten siunfteammer etliche / noldhe sweee volle ommene 3 tine und Fillfe baben / Dee

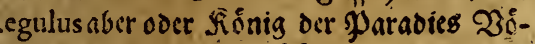
elbae von Ratur Estne Filife I fonbern am Jchroans swolange Strablen / als \$pieroe banr/an derer (Enoe fajóne limbgefrumte grüS Sedern/mit weichen er fich an bie Baiume nbaingen fan. Solum inde Regulum exci-: it, cui analogum qvid interim non denegait Phyfis. Mallemus de Regulo quoque. crutinium exactius, tutius, freqventius. Sed lura dies dabit.

s. V. Paucisfinis adhuc edifferemus, qua ccafio erroris diuturni, penes totfortè fue. it. Narrarunt ipfi exMoluccis Infulani, iuropxis noftris: fe, limul atque ceperunt Manucodiatas, inteftina illis,pedesq́; adi- , nere, abjicere; exponere deinde Soli , ut refcant maturiùs ; refervare aridas, ut xponant venum, aut casfidibus penna- ") um loco aptent. Inde apodes ad nos de- 


\section{* 168}

c latæ diu, ad abfurda adegerunt homines. Accesfit fraus nova Nautarum partim,partim Mercatorum, qua allatas qvandoqve

c6 integras, fine dubio truncarefvafit, ut rei haberetur fides. Qvanqwam non omnes,

cc omnitempore, ccu vidimus, latuerit. Aucc tores alii alios, nune citra indaginem fequuntur : nune turpiter expilant. Sic e. iC undo crefcit rumor, crefcunt mendacia. c6 Nec patrocinium error', errantium parit multitudo. Latet in alto veritas, nec eâoc dem, quâfata eft, luce prodiit. Multa. $\checkmark 6$ polt nos ferus edocebit verper, qvæ cognoa fcere haud potuit aurora. Dexsmagnus.

- E admirabilis, in omnem nos discat scritatem !

E $\quad I N \quad I \quad S$

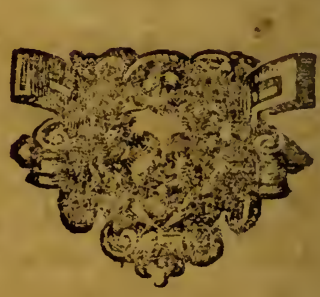




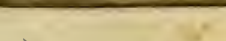

.

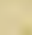
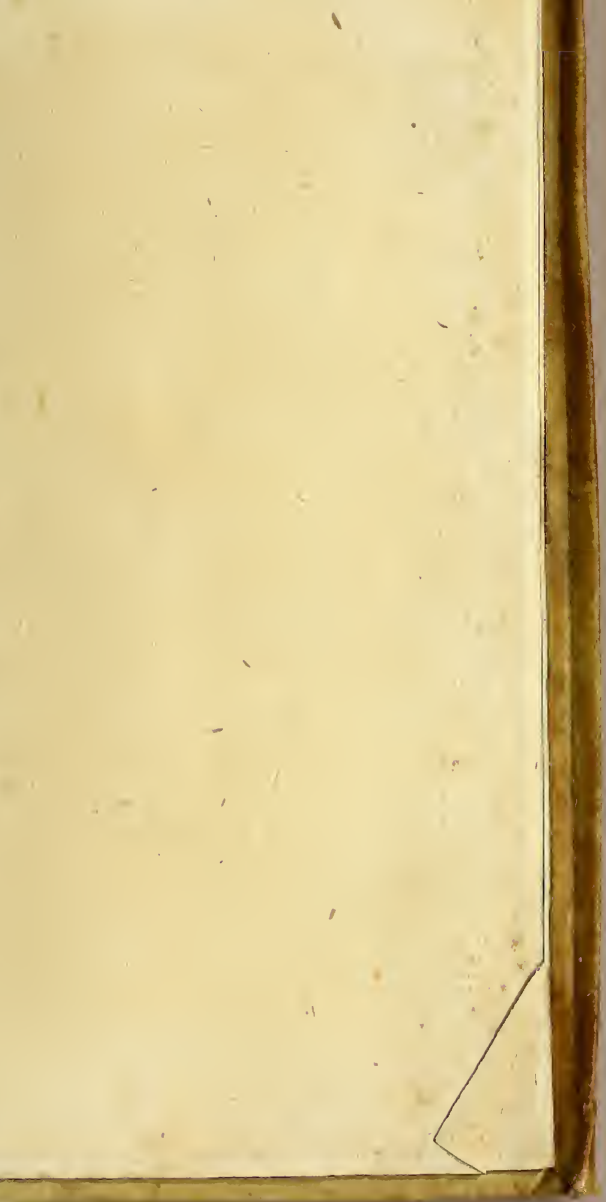


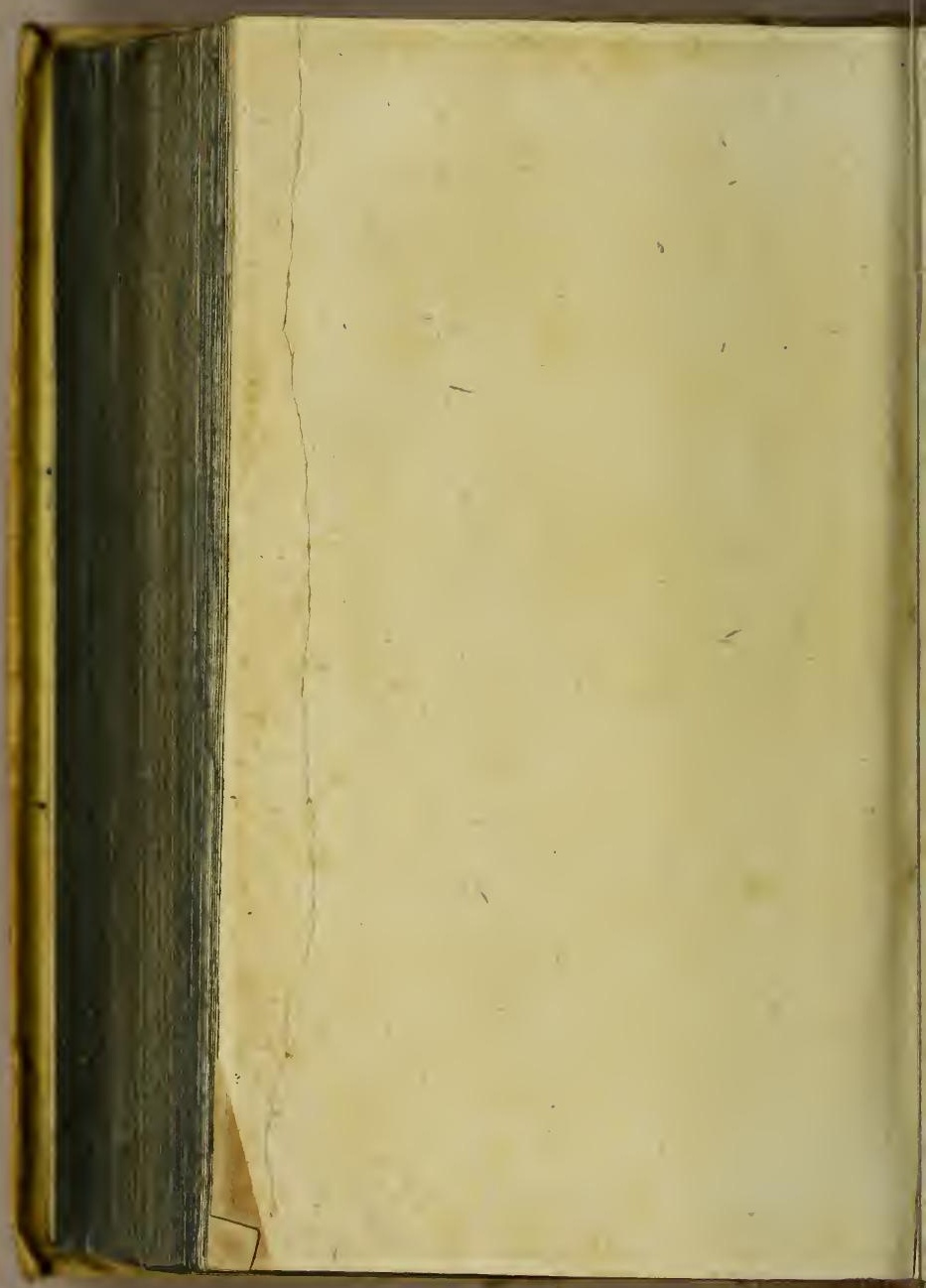




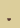

.

.

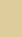

$\nabla$

1

-

$\cdots$

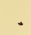

$\checkmark$ 


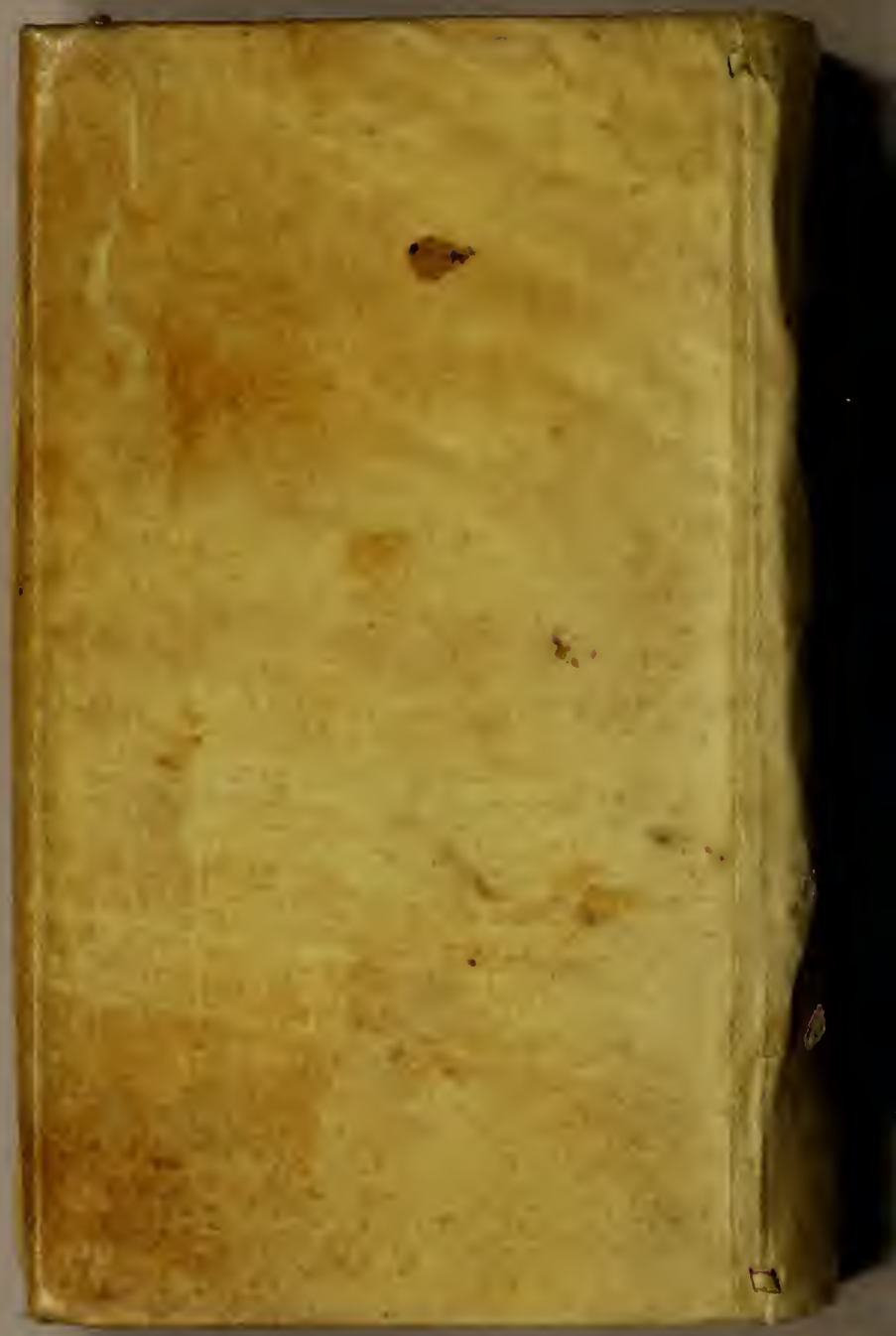

